\title{
Metal-Ligand Multiple Bonds
}

Nitrido and Fluoroimido Complexes of High-Valent Late Transition Metals

\author{
Inaugural-Dissertation \\ to obtain the academic degree \\ Doctor rerum naturalium (Dr. rer. nat.)
}

submitted to the Department of Biology, Chemistry, Pharmacy of Freie Universität Berlin

by

TONY STÜKER

2021 

The work for this dissertation was done in the time period from April 2016 to May 2021 under the supervision of Prof. Dr. Sebastian Hasenstab-Riedel at the Institute of Chemistry and Biochemistry of Freie Universität Berlin.

I hereby declare that the dissertation submitted is my own work. All direct or indirect sources used are acknowledged as references.

$1^{\text {st }}$ Referee: $\quad$ Prof. Dr. Sebastian Hasenstab-Riedel

$2^{\text {nd }}$ Referee: $\quad$ Prof. Dr. Martin Kaupp

Day of Disputation: 19 July 2021 



\section{Acknowledgements}

Throughout the writing of this dissertation I have received a great deal of support and assistance.

I would first like to thank my supervisor, Prof. Dr. Sebastian Hasenstab-Riedel, for the opportunity to conduct my doctoral thesis in his group, for the interesting topic, for his support, and for his encouraging enthusiasm.

Next, I would like to thank Prof. Dr. Martin Kaupp for his time and effort to assess my work as a second referee. Thanks also to the other members of my committee for their time and effort.

I would like to express my sincere gratitude to Dr. habil. Helmut Beckers for proofreading all my manuscripts and whose office door was always open whenever I ran into a trouble spot or had a question about my research or writing. His patience during our countless discussions and insight have steered me through this work.

Thanks to Thomas Hohmann and Xia Xiya for their help while working under my supervision for their internship and Bachelor thesis, respectively.

Many thanks go to the entire working group for the very pleasant working atmosphere, for the many productive discussions and the general helpfulness of everyone. I will especially have fond memories of my colleagues and friends Dr. Li Lin and Dr. Frenio Redeker from the matrix-isolation subgroup.

Finally, I must express my gratitude to my beloved partner Dr. Rita Fernandes, who provided me with unfailing support, proofread this work and the continuous encouragement throughout my years of study. My appreciation also goes out to my dear parents Monika and Gert Stüker, and my dear brother Martin Stüker for their encouragement and support. This accomplishment would not have been possible without them. 



\title{
Metal-Ligand Multiple Bonds \\ Nitrido and Fluoroimido Complexes of High-Valent Late Transition Metals \\ Tony Stüker
}

\begin{abstract}
High-valent group 8 and 9 transition metal complexes bearing nitrogenmetal multiple bonds, such as the fluoroimido difluorides $\mathrm{FNMF}_{2}, \mathrm{M}=\mathrm{Co}, \mathrm{Rh}$, the nitrido trifluorides $\mathrm{NMF}_{3}, \mathrm{M}=\mathrm{Fe}, \mathrm{Ru}, \mathrm{Os}, \mathrm{Rh}, \mathrm{Ir}$, and the binary molecular iridiumnitride $\operatorname{Ir}(\mathrm{N})_{2}$, have been investigated in a joint matrix-isolation infrared and a thorough quantum-chemical study. These novel molecules and their ${ }^{15} \mathrm{~N}$ isotopologues were produced by the reaction of laser-ablated metals with $\mathrm{NF}_{3}$ and $\mathrm{N}_{2}$, and embedded in solid inert gas matrices. An uneven $e^{3}$ occupation of the metal centered, doubly degenerate $\mathrm{HOMO}$ of the group $9 \mathrm{NMF}_{3}(\mathrm{M}=\mathrm{Rh}, \mathrm{Ir})$ in the reference $C_{3 \mathrm{v}}$ configurations leads to their observed Jahn-Teller distorted low-spin doublet ground state, while the even $e^{2}$ HOMO configuration for the group 8 metals suggests an undistorted high-spin ${ }^{3} \mathrm{~A}_{2}$ ground state. However, the latter ground state was only confirmed for $\mathrm{NFeF}_{3}$, while a pseudo-Jahn-Teller distorted low-spin structure of $\mathrm{NRuF}_{3}$, and a magnetic bistability was observed for $\mathrm{NOsF}_{3}$, which exists in two near-degenerate distorted low-spin and high-spin configurations. Since the reasons for their structural distortion is their electronic structure, this has been extensively investigated using multi-configurational calculations. The strongly bent $\mathrm{F}-\mathrm{N}-\mathrm{M}$ units in the group 9 fluoroimido complexes $\mathrm{FNMF}_{2}(\mathrm{M}=\mathrm{Co}, \mathrm{Rh})$ follow from an unusual metal-nitrogen $\sigma$ bond interaction between the $\mathrm{M}\left(d_{\mathrm{z}^{2}}\right)$ and a $\mathrm{N}\left(p_{\mathrm{z}}\right)$ orbital that is perpendicular to the $\mathrm{N}-\mathrm{F}$ bond axis. Comparatively weak $3 d$-metal-nitrogen multiple bonds in $\mathrm{NFeF}_{3}$ and $\mathrm{FNCoF}_{2}$ were attributed to partial ligand oxidations and significant populations of their $\mathrm{M}-\mathrm{N} \sigma^{*}$ and $\pi^{*}$ antibonding orbitals. Spin-densities calculated for $\mathrm{FNCoF}_{2}$ and $\operatorname{Ir}(\mathrm{N})_{2}$ show a considerable nitrogen radical character because of spin-polarization and spin-delocalization, respectively. Hence, the fluoroimido and nitrido ligands in $\mathrm{FNCoF}_{2}, \mathrm{NFeF}_{3}$ and $\operatorname{Ir}(\mathrm{N})_{2}$ must be considered as non-innocent.
\end{abstract}


Zusammenfassung: Hochvalente Gruppe 8 und 9 Übergangsmetallkomplexe, die Stickstoff-Metall Mehrfachbindungen tragen, wie die Fluoroimido-Difluorid $\mathrm{FNMF}_{2}$, $\mathrm{M}=\mathrm{Co}, \mathrm{Rh}$, die Nitrido-Trifluoride $\mathrm{NMF}_{3}, \mathrm{M}=\mathrm{Fe}, \mathrm{Ru}, \mathrm{Os}, \mathrm{Rh}, \mathrm{Ir}$, und das binäre, molekulare Iridiumdinitrid $\operatorname{Ir}(\mathrm{N})_{2}$, wurden in einer Matrix-Isolations Infrarotspektroskopischen, kombiniert mit einer gründlichen quantenchemischen Studie, untersucht. Diese neuartigen Moleküle und ihre ${ }^{15} \mathrm{~N}$-Isotopologe wurden durch die Reaktion von Laser-ablatierten Metallen mit $\mathrm{NF}_{3}$ bzw. $\mathrm{N}_{2}$ dargestellt und in festen Inertgasmatrizen eingebettet. Eine ungerade $e^{3}$-Besetzung des metallzentrierten, doppelt entarteten HOMO der Gruppe $9 \mathrm{NMF}_{3}\left(\mathrm{M}=\mathrm{Rh}\right.$, Ir) in den Referenz- $C_{3 \mathrm{v}}$-Konfigurationen führt zu ihrem beobachteten Jahn-Teller verzerrten, Low-Spin Dublett Grundzustand, während die gerade $e^{2}$ HOMO Konfiguration für die Metalle der Gruppe 8 einen unverzerrten High-Spin ${ }^{3} \mathrm{~A}_{2}$ Grundzustand nahelegt. Der zuletzt Genannte wurde jedoch nur für $\mathrm{NFeF}_{3}$ bestätigt, während für $\mathrm{NRuF}_{3}$ eine pseudo-Jahn-Teller verzerrte Low-Spin Struktur, und für $\mathrm{NOsF}_{3}$ eine magnetische Bistabilität beobachtet wurde, die in zwei nahezu entarteten, verzerrten Low-Spin- und High-Spin Konfigurationen existiert. Da der Grund für ihre strukturelle Verzerrung ihre elektronischen Struktur ist, wurde diese ausgiebig mit Multikonfigurationsrechnungen untersucht. Die stark gewinkelten F-N-M Einheiten in den Gruppe 9 FluoroimidoKomplexen $\mathrm{FNMF}_{2}(\mathrm{M}=\mathrm{Co}, \mathrm{Rh})$ ergeben sich aus einer ungewöhnlichen MetallStickstoff $\sigma$-Bindungswechselwirkung zwischen dem $\mathrm{M}\left(d_{\mathrm{z}^{2}}\right)$ und einem $\mathrm{N}\left(p_{\mathrm{z}}\right)$ Orbital, das senkrecht auf der N-F-Bindungsachse steht. Vergleichsweise schwache $3 d$-MetallStickstoff Mehrfachbindungen in $\mathrm{NFeF}_{3}$ und $\mathrm{FNCoF}_{2}$ wurden auf partielle Ligandenoxidationen und signifikante Populationen ihrer $\mathrm{M}-\mathrm{N} \sigma^{*}$ und $\pi^{*}$ antibindenden Orbitale zurückgeführt. Hervorgerufen von Spin-Polarisation bzw. Spin-Delokalisation zeigen die Spindichten von $\mathrm{FNCoF}_{2}$ und $\operatorname{Ir}(\mathrm{N})_{2}$ einen deutlichen Radikalcharacter am Stickstoff. Daher müssen die Fluoroimido- und Nitrido-Liganden in $\mathrm{FNCoF}_{2}, \mathrm{NFeF}_{3}$ und $\operatorname{Ir}(\mathrm{N})_{2}$ als nicht-unschuldig angesehen werden. 


\section{List of Abbreviations}

B3LYP Becke, 3-parameter, Lee-Yang-Parr

BO bond order

BP86 Becke-Perdew 1986

CASPT2 complete active-space second-order perturbation theory

CASSCF complete active space self-consistent field

CBS complete basis set

CC coupled-cluster

CCSD coupled-cluster singles doubles

$\operatorname{CCSD}(T)$ coupled-cluster singles, doubles and perturbative triples

$\mathrm{Cl}$ configuration interaction

CISD configuration interaction singles doubles

DFT density functional theory

DKH Douglas-Kroll-Hess

DLPNO domain based local pair natural orbital

EBO effective bond order

ECP effective core potential

EN electronegativity

EPR electron paramagnetic resonance

EXAFS extended X-ray absorption fine structure

$\mathrm{FCl}$ full configuration interaction

FTIR Fourier-transform infrared

GGA generalized gradient approximation

HF Hartree-Fock 
HOMO highest occupied molecular orbital

IR infrared

IRPD infrared photodissociation

KS Kohn-Sham

LCAO linear combination of atomic orbitals

LED light-emitting diode

LFS ligand field splitting

LFSE ligand field splitting energy

LIF laser-induced fluorescence

LUMO lowest unoccupied molecular orbital

MO molecular orbital

MP2 Møller-Plesset perturbation theory second order

$\mathrm{MRCI}$ multireference configuration interaction

MRPT multireference perturbation theory

NBO natural bond orbital

Nd:YAG neodymium-doped yttrium aluminum garnet

NEVPT2 n-electron valence state perturbation theory second order

NHC N-heterocyclic carbene

NPA natural population analysis

NR non-relativistic

NRVS nuclear resonant vibrational spectroscopy

OS oxidation state

PES potential energy surface

PO pseudo octahedral

viii 
PTD pseudo tetrahedral

QTAIM quantum theory of atoms in molecules

RR resonance Raman

SOMO singly occupied molecular orbital

SPL square planar

SPY square pyramidal

TBP trigonal bipyramidal

TG tetragonal

TISE time independent Schrödinger equation

TPL trigonal planar

UV/Vis ultraviolet-visible

XAS X-ray absorption spectroscopy

XRD X-ray diffraction

$Z_{\text {eff }}$ effective core charge

ZORA zeroth order regular approximation

\section{List of Ligand Abbrevations}

Ad adamatyl

$\mathrm{Cp}^{*}$ pentamethylcyclopentadiene

cyclam 1,4,8,11-tetraazacyclotetradecane

cyclam-ac 1,4,8,11-tetraazacyclotetradecane-1-acetate

dchypyb 1,2-dichloro-4,5-bis(2-hydroxybenzamido)benzene

Dipp 2,6-diisopropylphenyl

Dmp 2,6-dimesitylphenyl 
dppe 1,2-bis(diphenylphosphino)ethane

Hind indazole

hmds bis(trimethylsilyl)amide

hypyb 1,2-bis(2-hydroxybenzamido)benzene

iPrPDBP 2-[(2,6-diisopropyl-phenyl)imino]methyl-4,6-dibromophenol

$\mathrm{LNO}_{2}$ 2,6-bis(2-hydroxy-2,2-diphenylethyl)pyridine

Me methyl

3,5-Me ${ }_{2} \mathrm{Hpz}$ 3,5-dimethylpyrazole

1-Mebzim 1-methylbenzimidazole

5-MeHpz 5-methylpyrazole

3,4,5-MeO-TPP meso-tetrakis(3,4,5-trimethoxy-phenyl)porphyrinate dianion

$\mathrm{MePy}_{2}$ tacn N-methyl-N,N-bis(2-picolyl)-1,4,7-triazacyclononane

Mes mesityl

3-MPA 3-mercaptopropionate dianion

MTPDPH 5-mesityl-1,9-(2,4,6-triphenylphenyl)dipyrromethene

$\mathrm{NN}_{4}$ 2,6-bis[1,1-di(aminomethyl)ethyl]pyridine

OEP octaethylporphyrinate dianion

OMPG meso-octamethyl-porphyrinogenate tetraanion

$\mathrm{P}_{3}{ }^{\mathrm{B}}$ tris (o-diisopropylphosphinophenyl)borane

PDI pyridine diimine

Ph phenyl

$\mathrm{PhB}\left(\mathrm{CH}_{2} \mathrm{PiPr}\right)_{2}$ tris(diisopropylphosphino)borate

$\mathrm{PhB}(t \text { Bulm })_{3}$ phenyltris(1-tert-butylimidazol-2-ylidene)borate

$\mathrm{PhB}($ Meslm) 3 phenyltris(1-mesityl-imidazol-2-ylidene)borate 
phen 1,10-phenanthroline

PNP bis[2-(di-tert-butylphosphanyl)ethyl]amide

PNP' bis[2-(di-tert-butylphosphanyl)ethenyl]amide

PNPSi 3,9-di-tert-butyl-2,2,5,5,7,7,10,10-octamethyl-6-aza-3,9-diphospha-5,7-disilaundecan-6-ide

salen $N, N^{\prime}$-bis(salicylidene)-o-cyclohexyldiamine dianion

salophen $N, N^{\prime}$-bis(salicylidene)-o-phenylenediamine dianion

sap $N$-salicylidene-2-aminophenolat dianion

tBu tert-Butyl

TIMEN $^{\text {Mes }}$ tris[2-(3-mesityl-imidazol-2-ylide-ne)ethyl]amine

TIMEN $^{X y l}$ tris[2-(3-xylyl-imidazol-2-ylide-ne)ethyl]amine

TMP meso-tetrakis(2,4,6-trimethylphenyl)-porphyrinatre dianion

Tol $p$-tolyl

TPP tetraphenylporphyrinate dianion

TRAP tetrapropylammonium perruthenate

TTPPP 5,10,15,20-tetrakis(2,4,6-triphenylphenyl)porphyrinato

Xyl Xylyl 


\section{Contents}

1. Introduction 1

1.1. The Nature of Metal-Ligand Multiple Bonds . . . . . . . . . . . . 2

1.2. Oxidation States . . . . . . . . . . . . . . . . . 4

1.3. Matrix-Isolation Spectroscopy . . . . . . . . . . . . . . . . 6

1.4. Computational Methods . . . . . . . . . . . . . . . . . . 11

1.5. Nitrido Complexes of the Group 8 and Group 9 Transition Metals . . . 19

1.5.1. Group $8 \ldots \ldots \ldots \ldots$

1.5.2. Group $9 \ldots \ldots \ldots \ldots \ldots \ldots \ldots$

1.5.3. Matrix-Isolation Works . . . . . . . . . . . . . . . . 40

2. Objectives 43

3. Outline 45

3.1. Group 8 Nitrido Fluoride Complexes . . . . . . . . . . . . . . . 46

3.2. Group 9 Nitrido and Imido Complexes . . . . . . . . . . . . . . . . 49

4. Publications 53

4.1. High-Spin Iron(VI), Low-Spin Ruthenium(VI), and Magnetically Bistable of Osmium(VI): Molecular Group 8 Nitrido Trifluorides $\mathrm{NMF}_{3}$. . . . 53

4.2. Fluoro Nitrenoid Complexes $F N=M_{2}(M=C o, R h, I r)$ : Electronic Structure Dichotomy and Formation of Nitrido Fluorides $\mathrm{N} \equiv \mathrm{MF}_{3} \ldots \ldots$. . .

4.3. A Cornucopia of Iridium Nitrogen Compounds Produced from LaserAblated Iridium Atoms and Dinitrogen . . . . . . . . . . . . . . . 71

5. Conclusion and Outlook 83

5.1. Conclusion ......................... 83

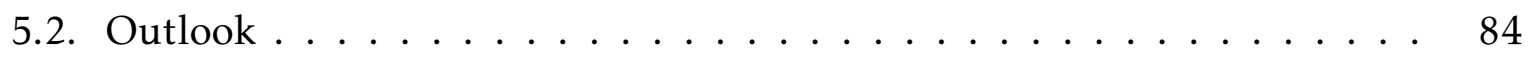

$\begin{array}{ll}\text { 6. References } & 85\end{array}$

$\begin{array}{ll}\text { 7. List of Publications } & 103\end{array}$

A. Supporting Information of Publications 107

A.1. High-Spin Iron(VI), Low-Spin Ruthenium(VI), and Magnetically Bistable of Osmium(VI): Molecular Group 8 Nitrido Trifluorides $\mathrm{NMF}_{3}$. . . . . 107

A.2. Fluoro Nitrenoid Complexes $\mathrm{FN}=\mathrm{MF}_{2}(\mathrm{M}=\mathrm{Co}, \mathrm{Rh}, \mathrm{Ir})$ : Electronic Structure Dichotomy and Formation of Nitrido Fluorides $\mathrm{N} \equiv \mathrm{MF}_{3}$. . . . . . 196 
A.3. A Cornucopia of Iridium Nitrogen Compounds Produced from LaserAblated Iridium Atoms and Dinitrogen . . . . . . . . . . . . . 233 



\section{Introduction}

The metal-ligand multiple bonds represent an ubiquitous feature of early transition metals in high oxidation states (OSs). ${ }^{[1]}$ The carbene $\left(M=C R_{2}\right)$ and carbyne $(M \equiv C R)$ complexes represent a significant class of organometallic chemistry where they play important roles in catalytic reactions, most prominently in alkene and alkyne methathesis. ${ }^{[2-6]}$ Transition metal oxo complexes $\left(\mathrm{M}=\mathrm{O}\right.$ or $\left.\mathrm{M}^{-} \equiv \mathrm{O}^{+}\right)$are omnipresent in oxidation catalysis, ${ }^{[7]}$ most notably in the oxygen evolving complex of photosystem II, responsible for catalyzing the oxidation of water to molecular oxygen in chloroplasts and cyanobacteria. ${ }^{[8,9]}$ Due to their tendency to act as bridging ligands and their instability towards hydrolysis, comparatively few terminal sulphides $(\mathrm{M}=\mathrm{S})$ are known. ${ }^{[10]}$ They are proposed as intermediates in the catalytic cycle of the petroleum desulfurization process. ${ }^{[11]}$

The focus of the this work is on the complexes carrying nitrido $(\mathrm{M} \equiv \mathrm{N})$ and imido $(\mathrm{M}=\mathrm{NR})$ moieties. Nitrido complexes of transition metals have been known for more than 170 years when the synthesis of $\mathrm{OsO}_{3} \mathrm{~N}^{-}$was reported in $1847 .{ }^{[12]}$ Only recently serious efforts have been made to develop their chemistry and to explore fundamental questions regarding their structure and bonding. The $\mathrm{M} \equiv \mathrm{N}$ moiety is isolobal to the $\mathrm{N} \equiv \mathrm{N}$ molecule and therefore comes as no surprise that nitrido complexes are subject of investigations surrounding dinitrogen coordination and activation, including the catalytic formation of ammonia in technology ${ }^{[13-22]}$ and organic synthesis. ${ }^{[23-26]}$ Quite recently, transition metal nitrides emerged as new class of potential anti-cancer and anti-tumor agents. ${ }^{[27-30]}$ Other applications include the catalysis of triple-bond metathesis reactions of alkynes ${ }^{[31,32]}$ and nitriles. ${ }^{[33]}$ Nitrides are examined as potential model compounds in the Haber-Bosch process ${ }^{[34,35]}$ and in the biological nitrogen fixation and activation in the nitrogenase enzyme. ${ }^{[36,37]}$ The chemistry of the imides and nitrides has a lot in common, as they are both often found in the same catalytic cycles. Transition metal imido complexes participate in large number of reactions with direct involvement of the imido ligand, or as stabilizing spectator ligand. ${ }^{[38]}$ Examples of the former type are aminations ${ }^{[39-44]}$ and hydroaminations ${ }^{[45-53]}$ of unsaturated substrates. An outstanding example for the latter type are metathesis reactions of unsaturated hydrocarbons catalyzed by imidocarbene complexes, ${ }^{[54,55]}$ closely related to the above mentioned metathesis reactions of alkenes. 
Despite the many applications of nitrido and imido complexes, the number of known late transition metal complexes lags behind that of early transition metals. This section deals with the nature of metal-ligand multiple bonds in general, and with the theoretical and experimental methods employed in this work. Furthermore, relevant examples of group 8 and group 9 nitrido complexes, as well as group 9 imido complexes are presented. Lastly, a brief overview of matrix-isolation works dealing with relevant nitrido complexes is given.

\subsection{The Nature of Metal-Ligand Multiple Bonds}

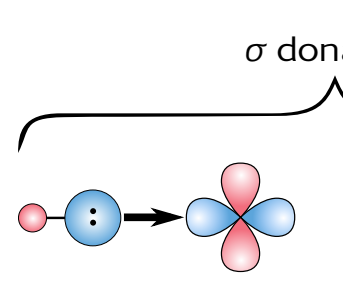

Ligand $\sigma$ to metal $d \sigma$

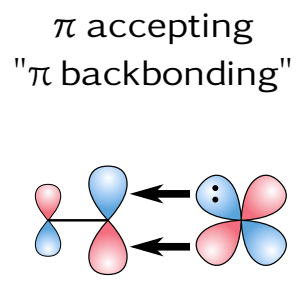

Metal $d \pi$ to ligand $\pi^{*}$

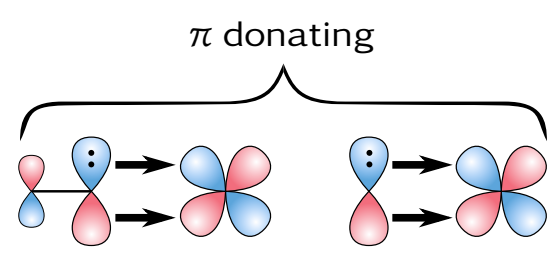

Ligand $\pi^{*}$ to metal $d \pi$
Ligand $p \pi$ to metal $d \pi$

Figure 1.1. Illustration of a few examples of metal-ligand $\sigma$ - and $\pi$-type orbital interactions.

In addition to the $\mathrm{M}-\mathrm{L} \sigma$ bond, overlap between appropriate $\pi$-type ligand binding site orbitals and metal $d \pi$ orbitals must be invoked. While the metal-ligand $\sigma$ bonding is usually ligand-to-metal donating, it is established to distinguish between metal-toligand ( $\pi$ accepting) and ligand-to-metal ( $\pi$ donating) $\pi$ bonding (Figure 1.1). The former is known as $\pi$ backbonding and normally occurs in transition metal complexes of low OSs. The excess charge at the metal center caused by the metal-ligand $\sigma$ bond is compensated by ligands with empty $\pi^{*}$ orbitals which act as $\pi$ acceptor ligands. The resulting interaction between the filled metal $d \pi$ orbital and the low lying lowest unoccupied molecular orbital (LUMO) of the ligand leads to charge transfer from the metal center and a population of the ligands $\pi^{*}$ molecular orbital (MO) and consequentially to a weakening of the corresponding $\pi$ bond within the ligand. Typical $\pi$ acceptor ligands are carbonyl $(\mathrm{CO})$, nitrosyl $\left(\mathrm{NO}^{+}\right)$, cyanido $\left(\mathrm{CN}^{-}\right)$, and to a lesser extend also dinitrogen $\left(\mathrm{N}_{2}\right)$.

Ligand-to-metal $\pi$ bonding is usually found in transition metal complexes of high OSs. It arises when a ligand non- or anti-bonding $\pi$-type orbital combines with an unoccupied metal $d$ orbital of appropriate symmetry. The ligand donates electron density through the resulting $\mathrm{M}-\mathrm{L} \pi$ bond. If the interacting ligand orbital is $\pi^{*}$ antibonding, the $\pi$ bond within the ligand is strengthened. Typical metal-to-ligand multiple bonds are found in oxo- $\left(\mathrm{M}=\mathrm{O}\right.$ or $\left.\mathrm{M}^{-} \equiv \mathrm{O}^{+}\right)$, nitrido- $(\mathrm{M} \equiv \mathrm{N})$, imido- $\left(\mathrm{M}=\mathrm{NR}\right.$ or $\left.\mathrm{M}^{-} \equiv \mathrm{N}^{+} \mathrm{R}\right)$, 

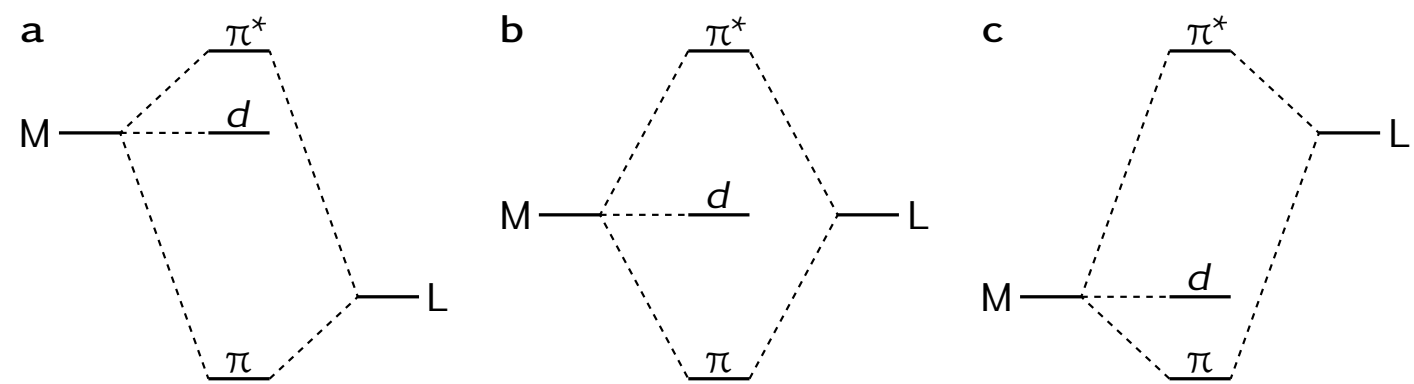

Figure 1.2. Simplified MO diagrams for symmetry-allowed metal-ligand $\pi$ interactions with different relative energies of the interacting orbitals, including nonbonding metal centered $d$ orbitals.

carbene- $\left(\mathrm{M}=\mathrm{CR}_{2}\right)$ and carbyne- $(\mathrm{M} \equiv \mathrm{CR})$ complexes. Due to their higher electronegativity $(\mathrm{EN})$ the $\pi$-type orbitals of nitrogen or oxygen ligands are usually lower in energy than the metal $d \pi$ orbitals (Figure 1.2, case a). It is thus the best way to describe them as closed shell $\mathrm{N}^{3-}, \mathrm{NR}^{2-}$, and $\mathrm{O}^{2-}$ anions. In contrast, the lower EN of carbon sometimes leads to cases $\mathbf{b}$ and $\mathbf{c}$ shown in Figure 1.2. In the latter case the carbyne ligands are best described as $\mathrm{CR}^{+}$. The transition between these extremes depends on the relative energy of the interacting ligand and the metal orbitals. The average energy of the $d$ orbitals decreases as we go from left to right across the transition metals and with increasing metal OS, and decreases in each group from top to bottom. The energy of the ligand based $p$ orbitals decreases on moving from carbon to nitrogen to oxygen. The resulting $\mathrm{M}-\mathrm{L}$ bonding and antibonding $\pi$ MOs determine the ligand reactivity. The ligand reacts nucleophilic in case a in Figure 1.2 when the occupied $\pi$ bonding orbitals are mostly localized on the ligand binding site while the $\pi^{*}$ antibonding combinations have dominant metal $d$ orbital character. As the energy difference between $\mathrm{M}(d)$ and $\mathrm{L}(p)$ decreases to case $\mathbf{b}$, the $\mathrm{M}-\mathrm{L}$ bonding becomes more covalent, whereas a electrophilic reactivity is expected in case $\mathrm{c}$ where the unoccupied $\pi^{*} \mathrm{MO}$ are mostly localized at the ligand.

In the formal ionic representation (Figure 1.2 , case a) $\mathrm{N}^{3-}, \mathrm{NR}^{2-}, \mathrm{O}^{2-}$ and $\mathrm{CR}^{3-}$ are isoelectronic closed-shell anions able to form $\mathrm{M} \equiv \mathrm{L}$ triple bonds with suitable metal centers. ${ }^{[1]}$ This is most commonly assumed for terminal nitrido and oxo ligands, where these donor ligands lead to qualitatively similar metal orbital $d$ splittings in the 4-6 coordinated complexes shown in Figure 1.3. This shows the influence of the coordination geometry on the $d$-orbital splitting and reveals that, for instance, four-fold symmetric (tetragonal (TG), $C_{4 \mathrm{v}}$ ) complexes become increasingly unstable when the $d$-electron count is larger than two. This leads to a population of $\pi^{*}$-antibonding MOs which reduces the formal bond order (BO) of the metal-ligand multiple bond. In this coordination geometry the BO remains unchanged for $d^{0}, d^{1}$ and $d^{2}$ low spin configurations and gradually decreases going from $d^{3}$ to $d^{6}$ from a triple to a single bond. The 


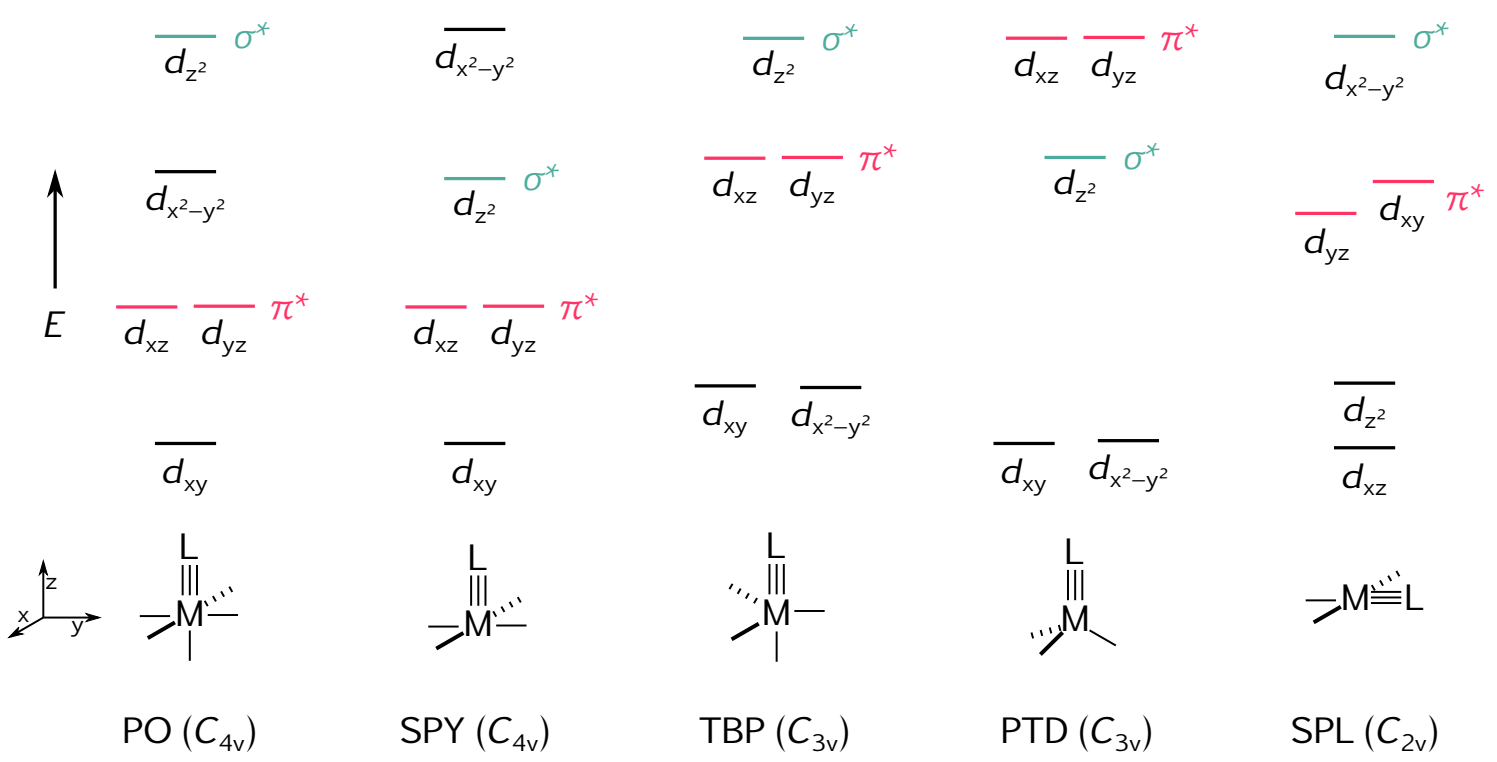

Figure 1.3. Qualitative $d$-orbital splittings for common coordination geometries of two-, three- and fourfold symmetric environments: pseudo octahedral (PO), square pyramidal (SPY), trigonal bipyramidal (TBP), pseudo tetrahedral (PTD) and square planar (SPL). The $\mathrm{M} \equiv \mathrm{L} \sigma^{*}$ and $\pi^{*}$-antibonding orbitals are highlighted. Note that $d_{x^{2}-y^{2}}$ in $C_{4 v}$ symmetric coordinations is $\sigma^{*}$-antibonding with respect to ligands in the equatorial plane.

$d$-electron count of the metal center depends entirely on its position in the periodic table and its OS. The higher oxidation potential and a high $d$-electron count of late transition metals are the reasons for the lower stability of metal-ligand multiple bonds of these metal centers. In the case of oxo complexes, this led to the concept termed oxo wall and describes the rule that oxo ligands can not form multiple bonds to metals beyond group VIII in TG environments (PO and SPY coordination geometries). ${ }^{[56]}$ The same is true for nitrogen and so it is also referred to as the nitrido wall. ${ }^{[24,57]}$ In contrast, the presence of two instead of one non-bonding $d$-orbitals in trigonal and twofold symmetric geometries (Figure 1.3, $C_{3 \mathrm{v}}$ and $C_{2 \mathrm{v}}$ ) allow metal-ligand multiple bonds with a higher $d$-electron count without overcoming, but instead shifting the oxo/nitrido wall further to the right. ${ }^{[58]}$

\subsection{Oxidation States}

The OS of an atom can be used to formally describe the electron count at an atom. A negative OS indicates increased electron count, and a positive OS decreased electron count with respect to the free, neutral atom. Deducted from the linear combination of atomic orbitals (LCAO) model, the bond's electrons are assigned to its main atomic contributor in heteronuclear, and equally in homonuclear bonds. The OS is the hypothetical charge that an atom would have if all heteronuclear bonds were purely 
ionic. However, as a purely formal quantity it correlates poorly with the actual electron alignment or charge distribution. OSs are either positive, neutral or negative and are typically represented in integer values. Exceptions can exist when a (hypothetical) charge is shared between chemically equivalent atoms, such as the oxygen in the superoxid anion $\left(\mathrm{O}_{2}^{-}\right)$which has the $\mathrm{OS}-0.5$. In transition metal complexes the notation $d^{n}$ describes the number of electrons $n$ occupying $d$-type orbitals at the metal center. The OS of the metal center is the difference between $n$ and the number of valence electrons of the neutral metal atom. The highest OS of an element within a chemical compound is generally limited by the number of its valence electrons. The activation of core electrons usually can only be overcome under extreme conditions, for example by applying high pressure. ${ }^{[59]}$

In practice, the assignment of OSs is often straightforward using the appropriate Lewis (resonance) structure of the compound and the EN values of the elements involved. The bond's electrons are assigned to the element with the higher EN. Problematic are compounds for which it is difficult or impossible to create a suitable Lewis structure a priori. In cases where the nature of the bond and therefore the electronic alignment is unclear and a satisfying Lewis structure can not be derived, experimental or theoretical methods can be used to assign an OS. Ambiguity may arise when quantum-chemical calculations results in bond polarities that contradict electron alignments suggested by their EN. In some cases the bond polarities depend on the theoretical method employed and may even differ for $\alpha$ and $\beta$ spin orbitals in spin-unrestricted calculations. ${ }^{[60]}$ The OSs assigned based on the bond multiplicity and EN without considering polarizations of covalent bonds are called formal OSs. ${ }^{[61,62]}$ The highest known formal OS is IX, assigned to the iridiumtetroxide cation, $\left[\mathrm{IrO}_{4}\right]^{+}$, experimentally observed in the gas-phase by infrared (IR) photodissociation spectroscopy. ${ }^{[63]}$ Although IR spectroscopy cannot directly determine oxidation states, vibrational frequencies allow a variety of conclusions to be drawn about the properties of the bond in question. Especially supported by quantum-chemical predictions which are validated by experimentally measured parameters. Most of the experimental methods require theoretically calculated reference values. For example, the effective core charge $\left(Z_{\text {eff }}\right)$ and thus the metal $d^{n}$ configuration can be estimated using K-edge X-ray absorption spectroscopy (XAS) data of the ligands. ${ }^{[64-66]}$ In Mößbauer spectroscopy, it is possible to observe a nearly linear relationship between OS and isomer shift if a series of complexes with similar geometric and electronic structure are used. ${ }^{[67]}$ These spectroscopic OSs may differ from formal OSs. ${ }^{[62]}$

Transition metal OSs are limited by the redox stability of the ligands, since highly oxidized coordination centers are able to oxidize ligands by spontaneous self-reduction. ${ }^{[68]}$ Predominantly closed-shell and redox-stable ligands that permit the evalua- 
tion of the central atom's OS are called innocent. ${ }^{[61,69]}$ Examples that are often considered innocent include $\mathrm{F}^{-}, \mathrm{Cl}^{-}$and $\mathrm{O}^{2-}$, but also $\mathrm{CO}, \mathrm{CN}^{-}$or $\mathrm{NH}_{3} \cdot{ }^{[61]}$ Non-innocent behavior arises when electrons cannot be unequivocally assigned to either the ligand or the central atom. ${ }^{[69]}$ A well-known example of a compound with ambiguous oxidation state due to a non-innocent ligand is the "brown-ring" iron complex $\left[\mathrm{Fe}\left(\mathrm{H}_{2} \mathrm{O}\right)_{5} \mathrm{NO}\right]^{2+}$, for which Griffith et al. ${ }^{[70]}$ in 1958 deducted a quartet electronic ground state and a $\left[\mathrm{Fe}^{\mathrm{I}}\left(\mathrm{H}_{2} \mathrm{O}\right)_{5}\left({ }^{1} \mathrm{NO}^{+}\right)\right]^{2+}$ formulation. Due to the singly occupied $\pi^{*}-\mathrm{MO}$ of $\mathrm{NO}$, it may also occur as anionic $\mathrm{NO}^{-[71]}$ or neutral NO. ${ }^{[72]}$ In the most recent work from 2019 by Monsch and Klüfers ${ }^{[60]}$ however, it was concluded that "there are no mandatory reasons to deprecate the $\mathrm{Fe}^{\mathrm{I}}\left(\mathrm{NO}^{+}\right)$formula in favor of the $\mathrm{Fe}^{\mathrm{II}}\left(\mathrm{NO}^{0}\right)$ or the $\mathrm{Fe}^{\mathrm{III}}\left(\mathrm{NO}^{-}\right)$ formulation". Non-innocent systems may be exploited as redox catalysts in which they participate in the catalytic cycle as electron reservoir, or in formation/breaking of substrate covalent bonds. ${ }^{[73]}$ In these cases they are called redox active or redox noninnocent. ${ }^{[73-76]}$

\subsection{Matrix-Isolation Spectroscopy}

Temperature and concentration are important factors which can be tuned in order to control the rate of any chemical reaction. In chemical kinetics the empirical Arrhenius equation is a formula for the temperature dependence of chemical reaction rates. It states that any chemical reaction that has a reaction barrier can essentially be stopped if the temperature is low enough. In collision theory chemical reactions are rationalized as colliding particles which may lead to a chemical reaction if the collision energy is high enough to overcome the reaction barrier. A higher concentration of reaction partners leads to an increase of the collision rate which in turn leads to a higher reaction rate. This also applies to unimolecular reactions in which the internal energy of the particle needed to overcome the reaction barrier is provided by a collision with a bath particle of the same or different kind.

The matrix-isolation technique, pioneered in its modern form by George C. Pimentel in the 1950s, minimizes temperature and concentration effects and allows trapping reactive or otherwise unstable compounds. ${ }^{[7]}$ This is done by co-depositing an inert host gas at very low temperatures, typically $4 \mathrm{~K}$ to $20 \mathrm{~K}$, with a small amount of sample, usually in the $0.01 \%$ to $1 \%$ range, on a cryogenic matrix support in an evacuated chamber at about $1 \times 10^{-6}$ mbar. The molecules trapped inside the solid, cryogenic matrix are surrounded by chemically inert molecules effectively preventing reaction inducing collisions with other particles. The most typical inert matrix host gases are $\mathrm{Ne}$, Ar and $\mathrm{N}_{2}$, but also $\mathrm{Kr}$, Xe and $\mathrm{CH}_{4}$. Reactive matrix hosts are also being used, such as $\mathrm{F}_{2}$, if the direct formation of higher fluorides is desired. ${ }^{[78,79]}$ The most inert, i.e., 
the least interacting matrix host, is Ne which also often produces highly transparent matrices, followed by Ar.

The most common way to investigate the isolated species is by vibrational or ultraviolet-visible (UV/Vis) spectroscopy, but also electron paramagnetic resonance (EPR) spectroscopy is very well suited for open-shell compounds. The spectroscopic data obtained from matrix-isolation experiments are often rightfully compared to gas-phase data and are often referred to as "pseudo gas-phase" data. An important effect caused by the low temperature and solid state of the matrix is the reduced number of degrees of freedom of the guest molecule by preventing rotational and translational motions. It reduces band broardening effects such as Collision and Doppler broadening as well as rotational transitions. It generally improves the quality of IR spectra and makes matrix-isolation IR spectra easier to interpret compared to spectra obtained using gas-phase experiments. In many cases, however, there are qualitative differences between matrix and gas-phase spectra. Their magnitude depends on the level and nature of the interactions between the guest and host. Especially transition metal ions and other suitable Lewis acids may coordinate matrix host molecules, even noble gas atoms. This can lead to noticeable spectroscopic band shifts and site-splittings with respect to the gas-phase absorption. Matrix-site splittings, i.e., IR band splittings observed under matrix-isolation conditions, can be caused by different orientations of the guest molecules inside the matrix cavity. For example, the IR spectrum of $\mathrm{CO}_{2}$ embedded in Ar shows sharp bands of roughly the same intensity at $663.4 \mathrm{~cm}^{-1}$ and $661.9 \mathrm{~cm}^{-1}$ in the $\mathrm{CO}_{2}$ bending region. Both are attributed to the bending mode $\left(v_{2}\right)$ of monomeric $\mathrm{CO}_{2}$ in different orientations inside the host matrix. ${ }^{[80]}$ Matrix shifts on the other hand are caused by electrostatic or chemical interactions between the matrix guest and the host and have been observed with any matrix gas. They range from rather weak van-der-Waals interactions with matrix shifts of less than $3 \mathrm{~cm}^{-1}$ to the formation of complexes with noble gas atoms with significant matrix shifts, especially when symmetries are lifted, of more than $100 \mathrm{~cm}^{-1}$. [81]

The workflow and instrumental requirements of a matrix-isolation experiment depend on the nature of the guest and the problem at hand. In any case, the guest must be deposited from the gas-phase seeded in excess host gas. The simplest case would be a pure gaseous sample which can be pre-mixed with matrix gas and directly be deposited on the matrix support. For this method, thermally stable samples that can be evaporated without decomposition can be used. For thermally less stable or highly reactive samples a u-tube can be used in front of the matrix chamber, in which the sample is placed into a stream of matrix host gas which carries the guest molecules with it into the matrix chamber and onto the matrix support. The vapor pressure of the sample is then controlled by adjusting the bath temperature around the u-tube. A Knudsen 
cell consists of a quartz tube and a heating element in which a solid sample is exposed to a stream of matrix gas which carries the guest molecules to the matrix support. ${ }^{[82]}$ These methods all have in common that the desired guest molecule is deposited directly, however, it is also possible to study reactions of the precursor molecules directly before or during deposition and to isolate the product molecules. To achieve this a number of methods are available. A gaseous sample can be passed through a heated tube prior deposition to trigger controlled (flash) pyrolysis reactions, or the matrix can be irradiated with visible or UV light to trigger photolysis reactions. ${ }^{[7]}$ Another way is mixing different reactive gases which are allowed to react before or during deposition. For example, radicals, ionic species and excited atoms can be generated in a microwave discharge and co-deposited with a precursor diluted in matrix gas. ${ }^{[83]}$ To react metal atoms with precursor molecules it is possible to evaporate the metal atoms thermally either by directly heating the metal using an electrically heated thin ribbon filament, ${ }^{[84]}$ or by laser-ablation. ${ }^{[85]}$ The latter method has the advantage that even electrically non-conductive material with very low vapor pressure, such as transition metal oxides ${ }^{[86]}$ and alkali halides, ${ }^{[87]}$ can be transferred to the gas-phase.
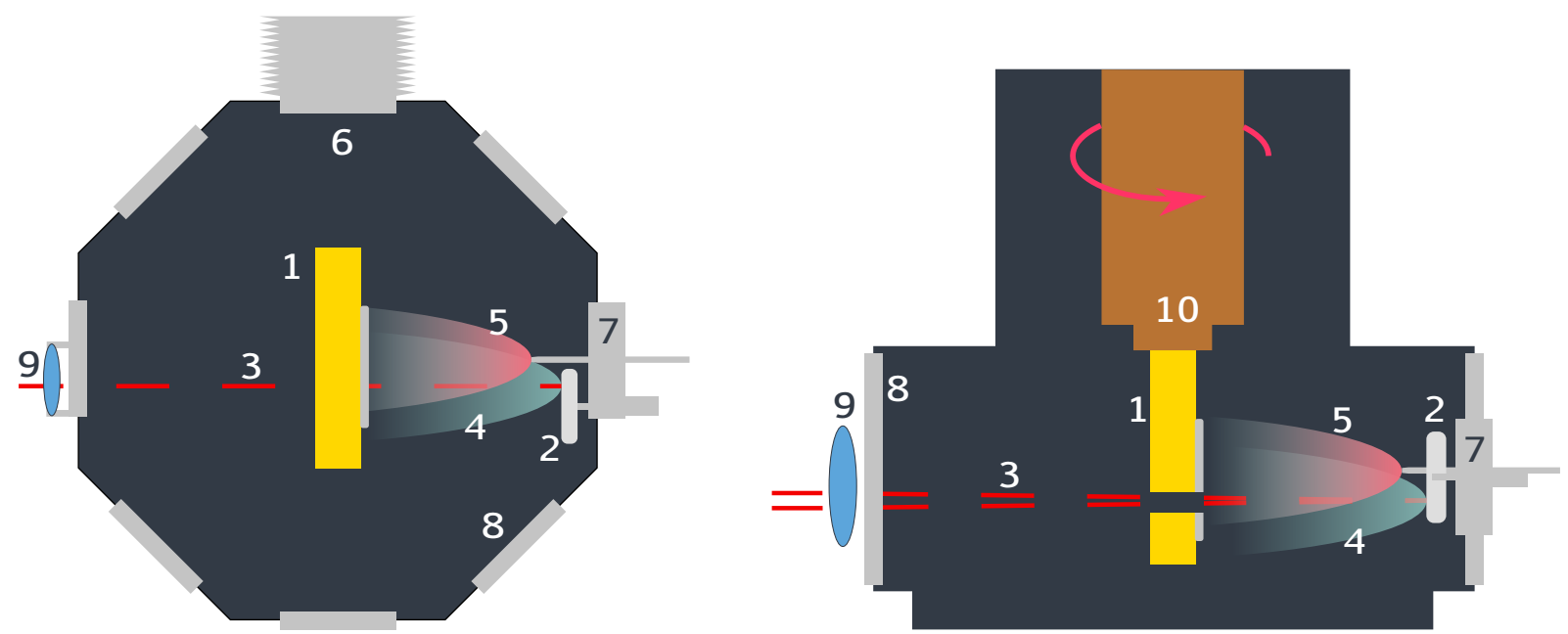

Figure 1.4. Top (left) and side view (right) of an illustration of a matrix chamber for co-depositing precursor gas mixed with laser-ablated material during the laser-ablation process. For measuring operation the matrix support is rotated $90^{\circ}$ counterclockwise, for irradiation experiments $45^{\circ}$ clockwise. 1 cold gold-plated copper matrix support with hole and matrix layer, 2 rotating laser ablation target, 3 pulsed IR laser, 4 plasma plume, 5 precursor gas, $6 \mathrm{Csl}$ window to attached IR spectrometer, 7 gas nozzle and target motor assembly, 8 quartz windows, 9 focusing quartz lens, 10 closed-cycle helium cryostat $\&$ heating element assembly.

Figure 1.4 shows a drawing of an experimental setup that was used in this work. A neodymium-doped yttrium aluminum garnet (Nd:YAG) $(\lambda=1065 \mathrm{~nm})$ laser pulse of about $10 \mathrm{~ns}$ (3) focused by a quartz lens (9) is guided through a hole in the matrix 
support (1) and evaporates material from the rotating ablation target (2). The evaporation process at the surface of the ablation target induced by a pulsed nanosecond laser starts with the expulsion of electrons within femtoseconds. It proceeds by a Coulomb explosion of the cationic material left behind and is followed by thermal evaporation of target material under the influence of the pulse. ${ }^{[87]}$ The vaporized target material in the plasma plume (4) is then mixed with precursor gas (5) inside the vacuum chamber and deposited on the cold gold-plated copper matrix support (1) until a sufficient amount of material is deposited. After about $60 \mathrm{~min}$ to $120 \mathrm{~min}$ when the deposition finished, the matrix support is rotated $90^{\circ}$ and an IR spectrum can be recorded in reflection mode using a transfer optic assembly located in the sample compartment of the IR spectrometer and a CsI window (6) attached at the back of the matrix chamber. The high vacuum of $10^{-6}$ mbar to $10^{-5}$ mbar enables a controlled deposition rate and ensures thermal insulation of the matrix support held at $4 \mathrm{~K}$ to $20 \mathrm{~K}$ from the environment. Pumps able to create and maintain these pressures include turbomolecular and diffusion pumps. Both have in common that they transfer momentum to single gas particles in the direction of the outlet. The turbomolecular pump achieves this by rapidly spinning metal turbine blades. The diffusion pump does not contain any moving parts and uses a gas-jet of silicone oil vapor to direct gas particles to the exhaust. The latter is often found in matrix-isolation laboratories thanks to its low maintenance, robustness and longevity. Abrasive gases and sudden increases of pressure can degrade the silicon oil in diffusion pumps, but can destroy turbomolecular pumps.
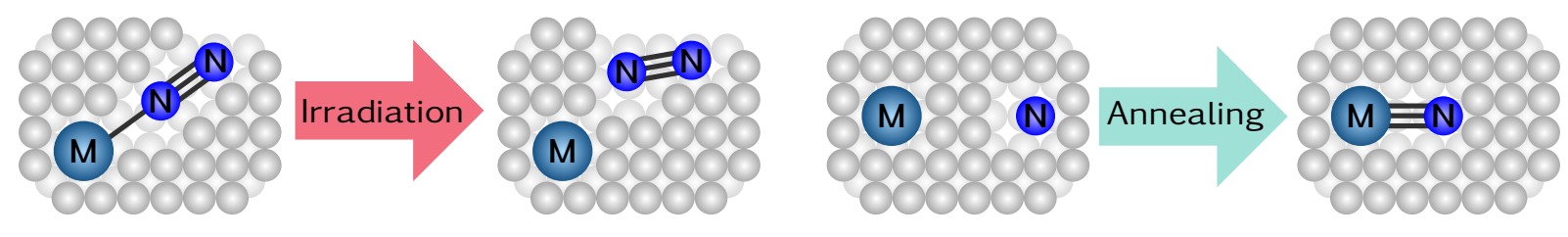

Figure 1.5. Illustration of guest reactions inside the matrix triggered by irradiation (left) and by annealing (right).

After the matrix has been deposited, irradiation and annealing experiments may be conducted. Irradiation experiments can be carried out either by unspecific broadband irradiation using, for example, a high-pressure mercury lamp, or selectively by using optical filters, laser light or light-emitting diode (LED) light with a narrow spectral range around $\lambda_{\max } \pm 10 \mathrm{~nm}$. By using LED or monochromatic laser light it is possible to induce specific unimolecular photochemical reactions, such as rearrangements or dissociation reactions. The irradiation experiment shown in Figure 1.5 illustrates a dissociation reaction of a dinitrogen complex $\left[\mathrm{M}\left(\mathrm{N}_{2}\right)\right]$ to $\mathrm{M}$ and $\mathrm{N}_{2}$. It is worth pointing out that the matrix is exposed to radiation from the laser-ablation process, which could prevent the formation and buildup of photo-sensitive compounds. During irradiation 
experiments diffusion effects are minimal and are usually not observed. In annealing experiments diffusion of lighter atoms through the softened matrix may occur. The right part of Figure 1.5 shows the formation of MN enabled by matrix annealing which initiates the diffusion of nitrogen atoms into the matrix cavity containing the metal atom. The annealing temperature is limited. As a rule of thumb, the maximum annealing temperature is approximately half of the freezing point of the matrix host gas. However, it is advisable to stay a little below that, depending on the host, evaporation can happen very suddenly because the temperature gradient within the matrix support and the solid matrix is often not precisely known. Spectroscopic data obtained in $\mathrm{Ne}$ are usually very close to those obtained in vacuum, since host guest interactions are very small and it offers a high transparency for all spectroscopic methods. Its low freezing point at $25 \mathrm{~K}$ and the resulting low maximum annealing temperature of about $10 \mathrm{~K}$ limits its applications in annealing experiments. The next suitable matrix host is Ar (freezing point: $84 \mathrm{~K}$ ), which allows annealing temperatures of up to about $40 \mathrm{~K}$. However, Ar matrices exhibit stronger host-guest interaction energies and a lower transparency.

Additionally, annealing and irradiation experiments are useful to assign species present in the matrix. As a result of the depletion or the enrichment of certain species, the spectrum looses or gains features. Furthermore, bands associated to the same species form a set of bands that show similar intensity ratios in different experiments. Even small band intensity changes can be made visible with the help of difference spectra. Here, the spectrum of the matrix before treatment is subtracted from the spectrum after treatment. In such a difference spectrum obtained in transmission mode, bands that lost intensity are pointing up, and new bands or bands that gained intensity are pointing down. Varying the host-guest concentration can also facilitate the assignment of unknown bands in the spectrum. When laser ablated atoms are allowed to react with precursor gas molecules, the concentration of the precursor in the matrix gas influences the distributions of different stoichiometries of the reaction products. The isotope effect is a very useful feature for the assignment of unknown bands in an IR spectrum. Isotopologues of precursor material often allow clear assignments of their bands based on their isotopic pattern and associated isotopic shifts, $\Delta \tilde{v}=\tilde{v}-\tilde{v}^{\prime}$, or isotopic ratios $\left(\frac{\tilde{v}}{\tilde{v}^{\prime}}\right)$, with $\tilde{v}$ as the band position of the isotopologue containing the most abundant isotope and $\tilde{v}^{\prime}$ the band position of a different isotopologue in which at least one atom is substitutated by a different isotope. In contrast to computed absolute band positions, predicted isotopic ratios are often much more precise and therefore provide solid evidence for band assignments. 


\subsection{Computational Methods}

What makes the chemistry of transition metal complexes so interesting is also what makes their quantum-chemical description difficult. The reliable prediction of transition metal complex properties is one of the most difficult tasks in quantum-chemistry. ${ }^{[88,89]}$ This is, for the most part, because of the near degeneracies of their electronic states. ${ }^{[88]}$

To theoretically describe chemical bonding in transition metal compounds a number of electronic structure methods are available. For practical reasons, most commonly in electronic structure calculations a MO analysis is employed. ${ }^{[90]}$ Valuable information about the electronic structure can be extracted from the electronic wave function, which makes it the central element for the analysis of the chemical bond. The total wave function of a quantum-mechanical system, such as a molecule, can be obtained by solving the time independent Schrödinger equation (TISE), which depends on electronic and nuclear coordinates. ${ }^{[91]}$ Nuclei move much more slowly than electrons since they are much heavier. For this reason it is assumed within the Born Oppenheimer approximation that electrons are moving in a field of fixed nuclei. In this approximation the total wave function can be expressed as a product of the nuclear and electronic wave function, which depends on the nuclear coordinates only parametrically. Several approximations exist to solve the TISE, of which the Hartree-Fock (HF) method is the simplest. It is based on the expansion of the wave function in a single Slater determinant constructed from spin orbitals.

\section{Wave Function Based Correlation Methods}

In single-reference post-HF methods the HF wave function is the basis, or reference, of more sophisticated calculations in an attempt to recover what is called electron correlation energy. In the framework of the LCAO theory a basis set is composed of the spatial part of atomic orbitals, usually represented by orthogonal gaussian-type functions. The minimum number of functions equals the number of atomic orbitals, while the exact electronic wave function of the respective method is a linear combination of an infinite basis set, in practice only finite basis sets can be used. The number of spin orbitals in the Slater determinant is equal to twice the number of basis functions of the basis set. The full configuration interaction (FCI) approach uses a linear variational method which provides numerically exact solutions to the non-relativistic (NR)-TISE. In this method, all Slater determinants that can be generated by all possible electron excitations into all virtual orbitals are included in the variational space.

The correlation energy is the difference between the HF energy and the FCI energy using a complete basis set. The general term for methods which aim to approximate 
that energy are called correlation methods, which can be divided further into single and multi-reference correlation methods. Figure 1.6 shows Pople's diagram which il-

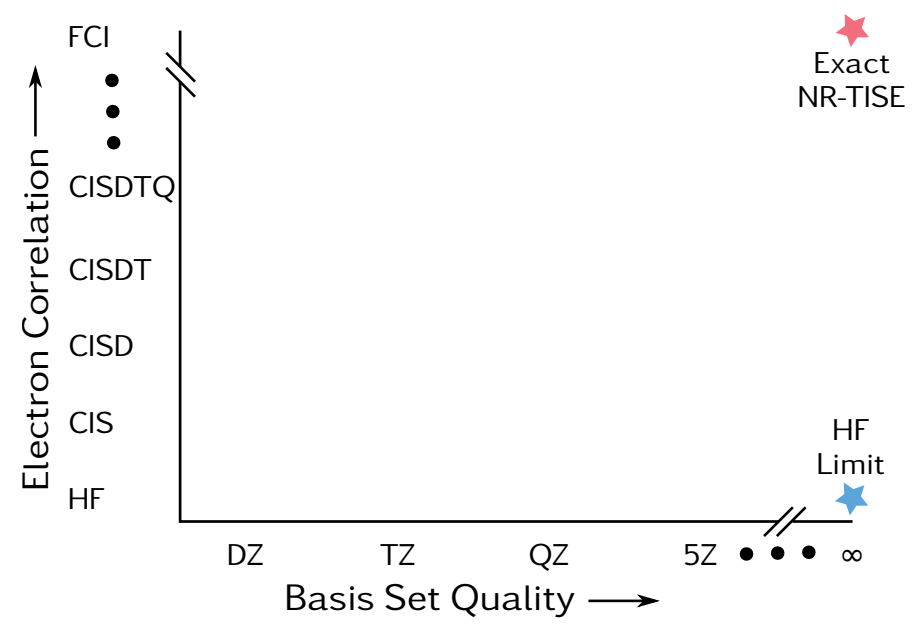

Figure 1.6. Pople's diagram showing the relationship between increasing configuration interaction $(\mathrm{Cl})$ excitation levels. The blue star marks the HF limit and the red star exact solution of the NR-TISE.

lustrates the relationship between basis sets and various correlation methods in computational chemistry. ${ }^{[92]}$ While FCI is a conceptional simple method, the exponential dependence on the number of slater determinants limits its application to small systems. Truncated CI methods exist where, for instance, only single and double excitations are included (configuration interaction singles doubles (CISD)). However, there are significantly more efficient methods available, such as Møller-Plesset perturbation theory second order (MP2), where the electron correlation is treated as perturbation of the unperturbed reference wave function with one and two electron excitations. While this method is established and widely used since decades and available in virtually every quantum-chemistry software, it fails to address the rather large electron correlation often found in transition metal compounds.

The coupled-cluster (CC) method is conceptually similar to the FCI method and provides an exact solution to the NR-TISE, but instead of a linear, it follows an exponential expansion ansatz which comes with a number of advantages. The widely used "gold standard" of quantum-chemistry is coupled-cluster singles, doubles and perturbative triples $(\operatorname{CCSD}(\mathrm{T}))$. It involves a singles and doubles truncated CC ansatz with triple excitations approximated using perturbation theory.

Truncated CI, MP2 and CCSD(T) and all other methods which use one slater determinant (or reference function) are called single-reference correlation methods and are good approximations only when the reference state is properly described by a single slater determinant, i.e., only dynamic electron correlation needs to be considered. For transition metal compounds this approximation often breaks down and additionally 
non-dynamic correlation becomes important when several electronic configurations have similar energies and considerable configuration mixing takes place. The suitability of the single-reference $\operatorname{CCSD}(\mathrm{T})$ ansatz for transition metal compounds can be gauged by the values of the $T_{1}, D_{1}$ and \%TAE diagnostics. ${ }^{[93,94]}$ The complete active space self-consistent field (CASSCF) method ${ }^{[95]}$ allows one to perform an FCI calculation for a limited orbital space. This active space should consist of the most important orbitals and represents the most flexible part of the wave function, i.e., molecular orbitals that are expected to have occupations deviating from 0 and 2, or those that are involved in bond formation/breaking.

The primogenic effect describes the phenomenon and effects of the small and compact nature of the first row transition metal $3 d$ orbitals. ${ }^{[96,97]}$ The absence of radial nodes at $r \neq 0$ for shells of a given angular momentum quantum number $l$ that are first occupied $(1 s, 2 p, 3 d, \ldots)$ leads to the compact nature of these orbitals. The consequence is that the size of the $3 d$ orbitals of first row transition metals is actually comparable to those of the $3 s$ and $3 p$ orbitals. The electrostatic repulsion between the ligand and metal core orbitals prevents a relatively short bond from forming that would be required to maximize the overlap between the metal $3 d$ and ligand orbitals. This leads to attenuated ligand-metal overlap and consequently to low excitation energies and considerable mixing of the ground state with excited states. As an example, in Figure 1.7 an active space for a $\mathrm{NML}_{3} 3 d^{2}(\mathrm{M}=3 d$ metal), which includes the singly occupied, degenerate metal centered $d_{\mathrm{xy}}$ and $d_{\mathrm{x}^{2}-\mathrm{y}^{2}}$ type orbitals $(3 e)$, as well as the $\mathrm{M}-\mathrm{N}$ bonding and anti-bonding $\sigma$ type $\left(1 \mathrm{a}_{1}, 2 \mathrm{a}_{1}\right)$ and $\pi$ type $(2 \mathrm{e}, 4 \mathrm{e})$ MOs. The green area marks the active space allowing the distribution of 8 valence electrons between all configurations that can be constructed from 8 molecular orbitals, or in short $\operatorname{CASSCF}(8,8)$. In this example, the three most contributing configurations contribute in total $75 \%$ to the total electronic CASSCF wave function. The leading configuration determines the electronic state of ${ }^{3} \mathrm{~A}_{2}$ and contributes $60 \%$ to the total CASSCF wave function. The next two largest contributors shown in Figure 1.7 constitute double (10\%) and single excitations ( $5 \%$ ) from the $\mathrm{M}-\mathrm{N} \pi$ bonding (2e) into the $\mathrm{M}-\mathrm{N}$ anti-bonding $\pi^{*}$ orbitals (4e). This form of electron correlation is commonly referred to as non-dynamical correlation. The dynamical electron correlation neglected by excluding the inactive and virtual orbitals can be recovered by taking the CASSCF wave function as a reference for subsequent multireference configuration interaction $(\mathrm{MRCI})^{[98,99]}$ or multireference perturbation theory $(\mathrm{MRPT})^{[100]}$ treatment. The latter in the form of complete active-space second-order perturbation theory (CASPT2) ${ }^{[89,101]}$ or the more advanced n-electron valence state perturbation theory second order (NEVPT2) ${ }^{[102]}$ which coincides with MP2 in the case of a HF reference (or single-reference) wave function.

Recent developments to reduce the computational cost and improve the accuracy 


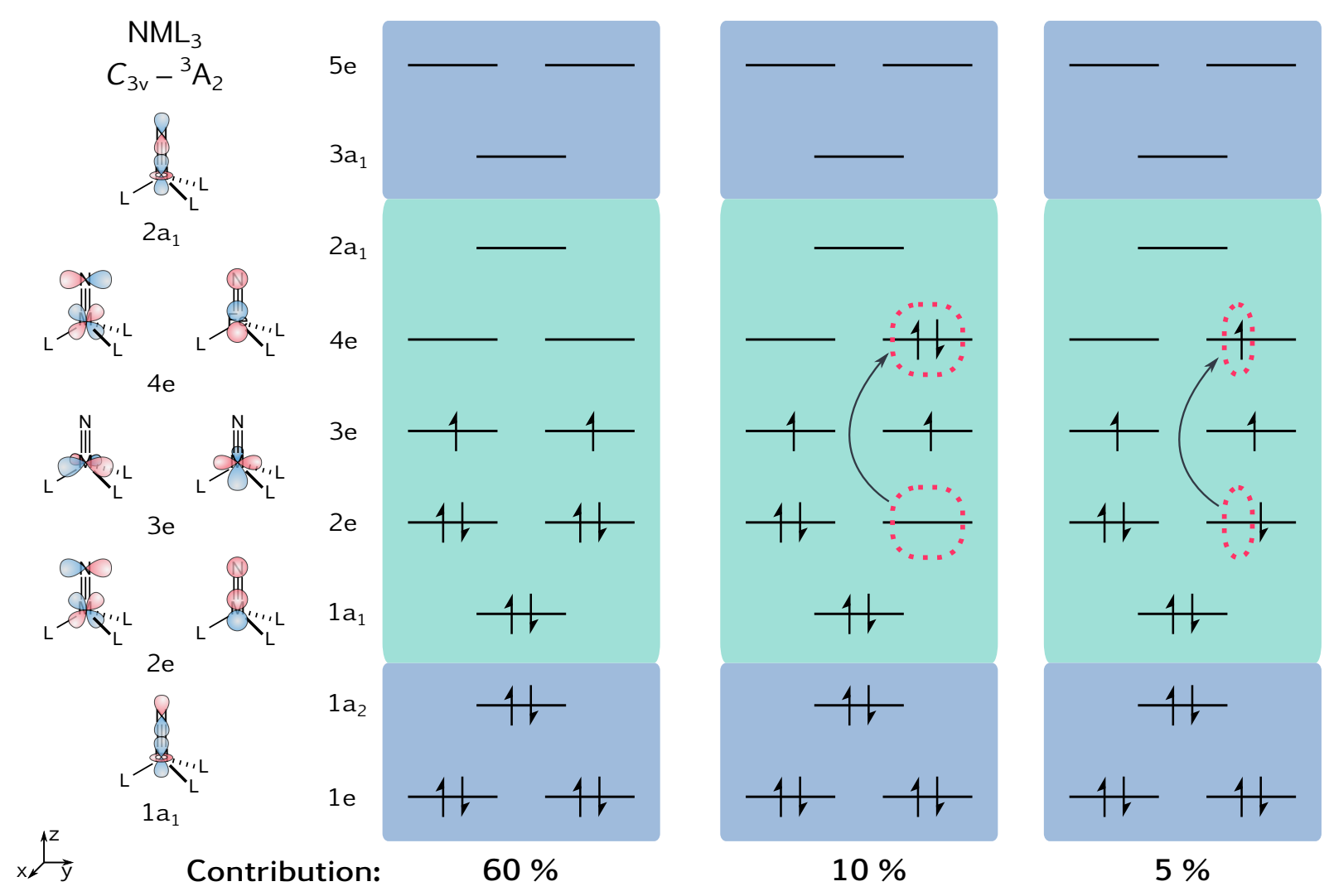

Figure 1.7. The three most contributing electronic configurations to the ${ }^{3} \mathrm{~A}_{2}$ electronic ground state of a $\mathrm{NML}_{3}$ complex in $C_{3 \mathrm{v}}$ point group symmetry. The lower blue area contains the highest three MOs of the inactive orbitals $\left(1 \mathrm{a}_{2}\right.$ and two components of $1 \mathrm{e}$ ) and the top blue area contains the lowest three virtual MOs ( $3 \mathrm{a}_{1}$ and two components of $\left.5 \mathrm{e}\right)$. The green area contains the active space MOs: eight electrons in eight orbitals.

of wave function based correlation methods include explicitly correlated F12 theories (for example CCSD(T)-F12 ${ }^{[103]}$, CASPT2-F12 ${ }^{[104]}$ and MRCI-F12 ${ }^{[104]}$ ) and the linear scaling domain based local pair natural orbital (DLPNO)-CCSD $(T)^{[105]}$ method. Nevertheless, the application of these high-level methods are still limited for geometry optimizations and normal mode analyses of transition metal complexes, in particular for systems larger than six heavy elements, i.e., elements of the second row and beyond.

\section{Density Functional Theory}

The HF and all post-HF methods have in common that all properties of the system are derived from the wave function. A different approach is density functional theory (DFT), where these are completely determined by the electron density of the system. The Hohenberg-Kohn ${ }^{[106]}$ theorem is a proof that important properties such as the energy of a system depend directly on the electron density of the system and is 
thus the basis for modern DFT. The single Slater determinant based Kohn-Sham (KS)DFT framework ${ }^{[107]}$ is the most wide-spread formalism and algorithmically very much alike the HF protocol. It is in fact so wide-spread that in quantum-chemistry KS-DFT is often simply referred to as DFT. Despite the similarities to HF, DFT is surprisingly accurate, even for some degree of static correlation. In fact, it is conceptionally accurate, however, for systems more complex than simple model systems the exchangecorrelation term is unknown and its functional form needs to be approximated. For this purpose different families of exchange-correlation functionals exist with different levels of sophistication and reliance on empirical parameters. ${ }^{[108,109]}$ The most common and almost universally applicable exchange-correlation functionals include the generalized gradient approximation (GGA) type Becke-Perdew 1986 (BP86),[110,111] and the hybrid type Becke, 3-parameter, Lee-Yang-Parr (B3LYP). ${ }^{[12-115]}$ However, more sophisticated functionals exist, ${ }^{[16]}$ including the long-range corrected family of functionals $\omega \mathrm{B} 97^{[117-119]}$ and the highly parameterized M06 ${ }^{[120-123]}$ functionals. Among the latter, the specialized meta-GGA functional M06-L ${ }^{[120]}$ is recommended for systems involving transition metals. ${ }^{[120]}$

The advantage offered by DFT is the relatively high accuracy with relatively low computational cost. However, unlike wave-function based methods, DFT cannot be systematically improved as it can be, for example, by switching from coupled-cluster singles doubles (CCSD) to CCSD(T). Instead, improvements can be achieved by choosing a more accurate exchange-correlation functional, informally classified in Jacob's ladder in which exchange-correlation functionals with similar capabilities are placed at the same rung. ${ }^{[108]}$

\section{Relativistic Methods}

Relativistic effects in the context of quantum-chemistry are all variances between values calculated by models that consider relativity and those which do not. By ignoring the finite speed of light in the NR-TISE, spin-orbit coupling and kinematic (or scalar) relativistic effects are completely neglected. The incorporation of relativistic effects in quantum-chemical calculations becomes more important as the nuclear charge number increases, making it a requirement for forth row elements and improves the accuracy of geometries and energetics involving elements from the third row. ${ }^{[124]}$ The best relativistic method involves the explicit four-component solutions of the Dirac equation, however, even calculations of diatomic systems with a sufficiently large basis set are very expensive and require significant computational resources. ${ }^{[88,125]}$ Approximations of this method involve the separation of scalar relativistic effects from those caused by spin-orbit coupling, or even removing the explicit consideration of rela- 
tivistic effects entirely by using effective core potentials (ECPs). ${ }^{[126]}$ Popular approximations to the Dirac equation used in this work are the Douglas-Kroll-Hess (DKH) Hamiltonian ${ }^{[127,128]}$ and the zeroth order regular approximation (ZORA). ${ }^{[129,130]}$

\section{Basis Sets}

Basis sets are sets of functions which essentially all calculations use to express the unknown MOs by means of a set of known functions. While in principle any type of function might be chosen, in practice, the basis functions should fit the physical problem to be approached and be easy to use in computational algorithms. By weighing these requirements, Gaussian-type functions have emerged as the most used for molecular systems, mainly because they can be implemented most efficiently in computational code. In the LCAO framework, every MO is represented by a linear combination of a finite number of basis functions. For this, there must be at least as many basis functions as there are atomic orbitals of all involved atoms. These minimal basis sets are hardly used in practice because of their bad predictive quality. Split valence basis sets are used much more frequently, in which valence orbitals that are particularly relevant in chemistry are described by more than one basis function. Depending on the number of functions used to describe the valence orbitals, these basis sets are called valence double-, triple-, quadruple- $\zeta$, and so on, basis sets. Functions that can be added to the basis set to improve the description of molecular systems include diffuse and polarization functions. The latter are integrated in most of the popular basis sets by default and the former can be added if systems are prone to dispersion effects, such as anions, or to gain accuracy in systems involving inter- and intramolecular non-covalent bonds.

A popular general purpose polarized split valence basis set, especially suitable for DFT calculations, is the def2 family of basis sets ${ }^{[131-134]}$ of the Karlsruhe group of which the quadruple- $\zeta$ basis set def2-QZVP achieves near basis set limit accuracy for atomization energies at the DFT level of theory. ${ }^{[134]}$ They are all-electron basis sets for elements $\mathrm{H}$ to $\mathrm{Kr}$, and automatically load Stuttgart-Dresden ECPs for elements $\mathrm{Rb}$ to Rn. [133,135-138]

The quasi-standard for wave function based correlation methods is the correlation consistent family of basis sets which come with a number of useful features and variants. The standard variant follows the cc-pVnZ scheme (i.e.: correlation-consistent polarized $n$ valence split, with $n=\mathrm{D}, \mathrm{T}, \mathrm{Q}, 5$ for double-, triple-, quadruple- and $5-\zeta$ qualities, respectively). ${ }^{[139-146]}$ Popular variants incorporate relativistic effects in the form of ECPs (sufix “-PP”) ${ }^{[133,138,147-153]}$ or via the use of a DKH Hamiltonian (sufix "-DK"), ${ }^{[154]}$ augmentations with diffuse functions to better satisfy the long-range part of the wave function of anions ("aug-" prefix), and core-valence correlation (cc- 
pwCVnZ). ${ }^{[139,155,156]}$ These basis sets are designed to systematically converge towards the complete basis set (CBS) limit with increasing cardinal number $n$. A large number of extrapolation schemes that can be used to estimate the CBS limit have been proposed. ${ }^{[157]}$

\section{Wave Function Analysis}

The wave function obtained by solving the electronic TISE determines all information that can be known from a quantum system. Unlike the electron density, which can be easily obtained from the wave function, the wave function itself does not have any physical meaning. A number of analytical methods have been developed to extract useful information from the wave function, such as magnetic properties, MO populations and compositions, as well as BOs and atomic charges. The latter is an important property to categorize reactive sites in molecules as electrophile (positive charge) or nucleophile (negative charge). The most commonly used approaches to assign charges to atoms are based on partitioning the electron density and distributing it to individual atoms based on the electrostatic potential, basis functions or topology. Established partition methods based on basis functions are the Mulliken ${ }^{[158]}$ and the Löwdin ${ }^{[159]}$ methods, which both best perform with small or medium sized basis sets but can lead to odd behavior, especially when used in conjunction with diffuse basis sets. ${ }^{[124]} \mathrm{A}$ more sophisticated method called natural bond orbital (NBO) analysis involves orbital transformations into a (localized) form which allows to analyze the wave function in terms of the classical Lewis structure concept of two-center electron pairs (bonds) and one-center electron pairs (lone pairs). ${ }^{[160]}$

Somewhat physically more justified is to analyze the electron density itself instead of the basis functions representing the wave function. The quantum theory of atoms in molecules (QTAIM) method of R. Bader ${ }^{[161-163]}$ is probably the most accurate way to divide the molecular volume into atomic subspaces containing exactly one nucleus. In this framework, chemical bonding is defined based on the topology of the electron density with stationary points together with the gradient paths that connect and terminate at these points. Among these stationary points are maxima and saddle points. The former usually correspond to the position of the nuclei and are called attractors. One type of the latter is called bond critical points which are usually positioned between two attractors with one positive and two perpendicular negative second derivates. The electron density at a bond critical point $\left(\rho_{\mathrm{bcp}}\right)$ is associated with the bond strength and BO. ${ }^{[163]}$ Based on the topology analysis, the total electron density can be assigned to attractors and its integration within each atomic basin gives atomic charges and electric moments. 
From MO considerations the formal BO of a bond between two atoms is defined by Equation 1.

$$
\mathrm{BO}=\frac{\text { number of bonding } \mathrm{e}^{-}-\text {number of antibonding } \mathrm{e}^{-}}{2}
$$

It is a simple scheme to evaluate the number of electrons $\left(\mathrm{e}^{-}\right)$shared between two atoms, which indicates the stability of the bond. An extension to that is the effective bond order (EBO) which allows fractional numbers and is obtained from natural occupations using the same formula. ${ }^{[164]}$ The EBO is always smaller than the formal BO and the multiplicity of a bond is named according to the next larger integer value. ${ }^{[164]}$

Spin density profiles are obtained by subtracting the electron densities of the spin down $(\beta)$ electrons from the one of the spin up $(\alpha)$ electrons obtained from spinunrestricted calculations. They permit a simple, quick and visualizable probe of ligand non-innocence (see Section 1.2) in transition metal complexes in which positive or negative spin density at the ligand indicate spin delocalization or spin polarization, respectively. ${ }^{[69]}$ 


\subsection{Nitrido Complexes of the Group 8 and Group 9 Transition Metals}

A survey of selected known terminal nitrido complexes of the group 8 (iron, ruthenium and osmium) and group 9 (cobalt, rhodium and iridium) transition metals is presented. Additionally, selected terminal imido complexes are included for group 9 transition metals. The overview focuses on molecular complexes featuring metalnitrogen multiple bonds for which experimental structural or vibrational data are available. In addition, a short overview of relevant matrix-isolation works in which the reaction products of laser-ablated transition metal atoms and dinitrogen, as well as nitrogen trifluoride were investigated is given.

\subsubsection{Group 8}

Transition metals of group 8 have 8 valence electrons and can reach oxidation states of up to VIII ( $\mathrm{Ru}$ and Os). Os(VI) nitrido complexes in tetragonal structures with lowspin $d^{2}$ configurations avoid any population of antibonding $\pi^{*}$ MOs (see Figure 1.3) and facilitate strong $\mathrm{Os} \equiv \mathrm{N}$ triple bonds. Trigonal symmetric structures on the other hand, are able to accommodate up to four electrons in their non-bonding $d$-type MOs (Figure 1.3). Hence, the lowest OS needed to enable triple bonds for these structures is IV.

\section{Iron Nitrido Complexes}

The first terminal nitrido iron complex was reported by Wagner and Nakamoto ${ }^{[165]}$ in 1988. The square planar porphyrin ligand based $\left[(\mathrm{TPP}) \mathrm{Fe}^{\mathrm{V}} \mathrm{N}\right]$ complex (Figure $1.8 \mathrm{~A}$ ) was produced by photolysis of the corresponding azide precursor and its resonance Raman (RR) spectrum was reported. ${ }^{[165]}$ In 1989 the related complexes $\left[(\mathrm{OEP}) \mathrm{Fe}^{\mathrm{V}} \mathrm{N}\right]$ and $\left[(\mathrm{TMP}) \mathrm{Fe}^{\mathrm{V}} \mathrm{N}\right]$ were obtained by the same group using the same method. ${ }^{[166]} \mathrm{Ra}$ man spectra of these complexes show $\mathrm{Fe}-\mathrm{N}$ stretching frequencies at around $875 \mathrm{~cm}^{-1}$ as well as ${ }^{14 / 15} \mathrm{~N}$ isotopic shifts. The claimed $\mathrm{OS}$ of $\mathrm{Fe}(\mathrm{V})$ in the these complexes was questioned by Meyer et al. ${ }^{[168]}$ in view of the non-innocent nature of the employed auxiliary ligands. However, a very recent report of the related $\left[(\mathrm{TTPPP}) \mathrm{Fe}^{\mathrm{V}} \mathrm{N}\right]$ complex by Wang et al. ${ }^{[167]}$ describes a $\mathrm{Fe}(\mathrm{V})$ center with a low-spin $\left(d_{\mathrm{xy}}\right)^{2}\left(d_{\mathrm{xz}}\right)^{1}\left(d_{\mathrm{yz}}\right)^{0}$ configuration $(\mathrm{BO}=2.5)$ and an $\mathrm{Fe}-\mathrm{N}$ stretching frequency of $876 \mathrm{~cm}^{-1}(\mathrm{RR})$, which supports the previously reported data for $\left[(\mathrm{TPP}) \mathrm{Fe}^{\mathrm{V}} \mathrm{N}\right],\left[(\mathrm{OEP}) \mathrm{Fe}^{\mathrm{V}} \mathrm{N}\right]$ and $\left[(\mathrm{TMP}) \mathrm{Fe}^{\mathrm{V}} \mathrm{N}\right]$.

About 10 years later, Meyer et al. ${ }^{[168]}$ and shortly thereafter Grapperhaus et al. ${ }^{[169]}$ presented the first cyclam ligand based pseudo octahedral nitrido complexes [(cyclam) $\left.\left(\mathrm{N}_{3}\right) \mathrm{Fe}^{\mathrm{V}} \mathrm{N}\right]^{+}$and $\left[\left(\text {cyclam-ac) } \mathrm{Fe}^{\mathrm{V}} \mathrm{N}\right]^{+}\right.$(Figure $1.8 \mathrm{~B}$ and $\mathrm{C}$ ), respectively, produced by 


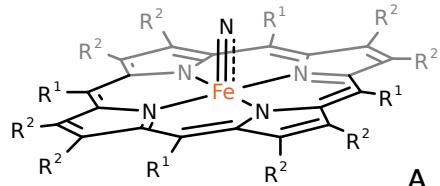

$\left.\left[(\mathrm{TPP}) \mathrm{Fe}^{\mathrm{V}} \mathrm{N}\right)\right] \quad\left(\mathrm{R}^{1}=\right.$ Phenyl, $\left.\mathrm{R}^{2}=\mathrm{H}\right)$ $\left.\left[(\mathrm{OEP}) \mathrm{Fe}^{\vee} \mathrm{N}\right)\right] \quad\left(\mathrm{R}^{1}=\mathrm{H}, \mathrm{R}^{2}=\right.$ Ethyl $)$ $\left.\left[(T M P) F^{\vee} N\right)\right] \quad\left(R^{1}=\right.$ Mesityl, $\left.R^{2}=H\right)$ $\left.\left[\left(T_{T P P P}\right) \mathrm{Fe}^{\vee} \mathrm{N}\right)\right]\left(\mathrm{R}^{1}=\right.$ TPPP, $\left.\mathrm{R}^{2}=\mathrm{H}\right)$

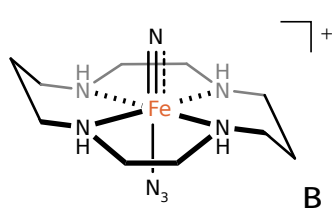

$\left[(\right.$ cyclam $\left.\left.)\left(\mathrm{N}_{3}\right) \mathrm{Fe}^{\vee} \mathrm{N}\right)\right]^{+}$

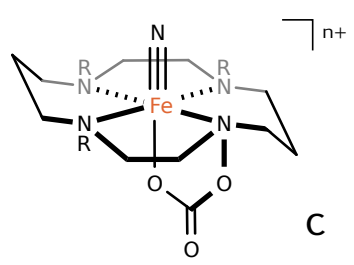

$\left[(\right.$ cyclam-ac $\left.\left.) \mathrm{Fe}^{\vee} \mathrm{N}\right)\right]^{+} \quad(\mathrm{R}=\mathrm{H})$ $\left[\left(\mathrm{Me}_{3}\right.\right.$ cyclam-ac $\left.\left.) \mathrm{Fe}^{\mathrm{V} /} \mathrm{N}\right)\right]^{2+}(\mathrm{R}=$ Methyl $)$

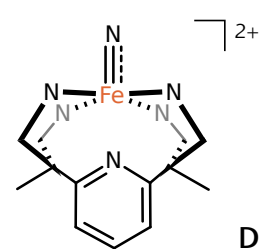

$\left.\left[\left(\mathrm{NN}_{4}\right) \mathrm{Fe}^{\mathrm{V}} \mathrm{N}\right)\right]^{2+}$

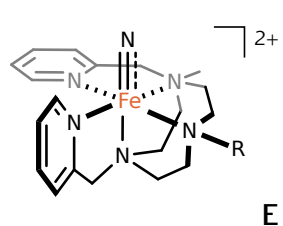

\section{E}

$\left.\left[\left(\mathrm{MePy}_{3} \mathrm{tacn}\right) \mathrm{Fe}^{\mathrm{V}} \mathrm{N}\right)\right]^{2+}(\mathrm{R}=\mathrm{H})$ $\left.\left[\left(\mathrm{Me}_{2} \mathrm{Py}_{3} \mathrm{tacn}\right) \mathrm{Fe}^{\mathrm{V}} \mathrm{N}\right)\right]^{2+}(\mathrm{R}=$ Methyl $)$

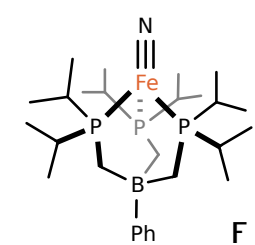

$\left.\left.\left[\left(\mathrm{PhB}\left(\mathrm{PCH}_{2}{ }^{i} \mathrm{Pr}_{2}\right)\right)_{3}\right) \mathrm{Fe}^{\mathrm{IV}} \mathrm{N}\right)\right]$

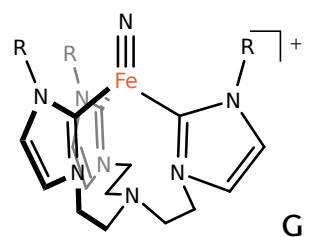

$\left[\left(\right.\right.$ TIMEN $\left.\left.\left.^{\text {Mes }}\right) \mathrm{Fe}^{\mathrm{IV}} \mathrm{N}\right)\right]^{+}(\mathrm{R}=$ Mesityl $)$ $\left[\left(\right.\right.$ TIMEN $\left.\left.\left.^{\mathrm{Xyl}}\right) \mathrm{Fe}^{\mathrm{IV}} \mathrm{N}\right)\right]^{+} \quad(\mathrm{R}=$ Xylyl $)$

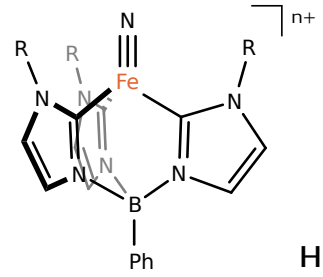

$\mathrm{H}$

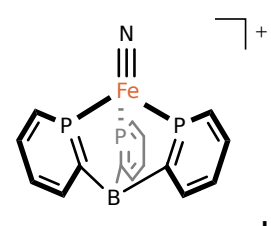

I

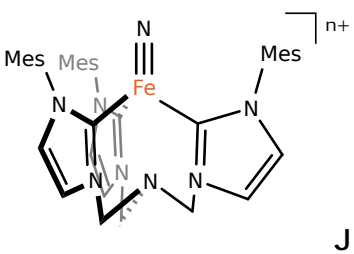

$\left[\left(\right.\right.$ TIMMN $\left.\left.\left.^{\mathrm{Mes}}\right) \mathrm{Fe}^{\mathrm{IV}} \mathrm{N}\right)\right]^{+}$ $\left.\left[\left(\operatorname{TIMMN}^{\mathrm{Mes}}\right) \mathrm{Fe}^{\mathrm{V}} \mathrm{N}\right)\right]^{2+}$

$\left.\left[\left(\mathrm{PhB}(\mathrm{Meslm})_{3}\right) \mathrm{Fe}^{\mathrm{IV}} \mathrm{N}\right)\right] \quad(\mathrm{R}=$ Mesityl $)$

$\left.\left[\left(\mathrm{PhB}\left({ }^{\mathrm{t} B u l m}\right)_{3}\right) \mathrm{Fe}^{\mathrm{IV}} \mathrm{N}\right)\right] \quad\left(\mathrm{R}={ }^{t}\right.$ Butyl $)$

$\left.\left[\left(\mathrm{PhB}\left({ }^{\mathrm{t} B u l m}\right)_{3}\right) \mathrm{Fe}^{\vee} \mathrm{N}\right)\right]+(\mathrm{R}=$ tButyl $)$

$\left.\left[\left(\mathrm{P}_{3}^{\mathrm{B}}\right) \mathrm{Fe}^{\mathrm{IV}} \mathrm{N}\right)\right]^{+}$

Figure 1.8. Selection of known iron nitrido complexes of tetragonal (A, ${ }^{[165-167]}$
$B,{ }^{[168]} C,[67,169]$
$D,{ }^{[170]} E$
$\left.H^{,[15,175,176]}{ }^{\left[{ }^{[37]}\right.} \mathbf{J}^{[177]}\right)$

photolysis of the corresponding azide in a frozen $\mathrm{CH}_{3} \mathrm{CN}$ solution at $77 \mathrm{~K}$ to avoid dimerization. For these complexes, $\mathrm{Fe}(\mathrm{V})$ in $d^{3}$ high-spin configuration was found by Mößbauer and EPR spectroscopy, indicating the occupation pattern $\left(d_{\mathrm{xy}}\right)^{1}\left(d_{\mathrm{xz}}\right)^{1}\left(d_{\mathrm{yz}}\right)^{1}$ and a $\mathrm{BO}$ of 2 . The $\mathrm{Fe}-\mathrm{N}$ stretching mode was not reported, however, $\mathrm{Fe}-\mathrm{N}$ stretching frequencies of $855 \mathrm{~cm}^{-1}$ and $864 \mathrm{~cm}^{-1}$ were later obtained for [(cyclam-ac) $\left.\mathrm{Fe}^{\mathrm{V}} \mathrm{N}\right]^{+}$ using infrared photodissociation (IRPD) spectroscopy ${ }^{[172]}$ and nuclear resonant vibrational spectroscopy (NRVS), ${ }^{[178]}$ respectively. The frequencies of these cationic complexes are somewhat lower than the RR frequencies obtained for the neutral $\mathrm{Fe}(\mathrm{V})$ porphyrinato nitrido complexes (Table 1.1). The oxygenation of $\left[\left(\text { cyclam-ac) } \mathrm{Fe}^{\mathrm{V}} \mathrm{N}\right]^{+}\right.$ lead to an iron nitrosyl complex. ${ }^{[179]}$

Until the report of the dicationic complex $\left[\left(\mathrm{Me}_{3} \text { cyclam-ac }\right) \mathrm{Fe}^{\mathrm{VI}} \mathrm{N}\right]^{2+}$ by Berry et al. ${ }^{[67]}$ in 2006 (Figure $1.8 \mathrm{C}$ ), the ferrate anion $\mathrm{FeO}_{4}{ }^{2-}$ was the only known iron(VI) compound. Like the other cyclam-based complexes it was obtained by photolysis of the 
corresponding azide, but $N$-methylation of the cyclam-ac ligand allowed the oxidation of the precursor to a stable $\mathrm{Fe}(\mathrm{IV})$-azido complex prior photolysis. The $\mathrm{Fe}-\mathrm{N}$ bond length of $157 \mathrm{pm}$ was estimated by fitting extended X-ray absorption fine structure (EXAFS) data. Based on its Mößbauer spectrum and supported by DFT calculations the iron center adopts an OS of VI in a $d^{2}$ low-spin singlet configuration consistent with an occupation pattern of $\left(d_{\mathrm{xy}}\right)^{2}\left(d_{\mathrm{xz}}\right)^{0}\left(d_{\mathrm{yz}}\right)^{0}$ and a genuine $\mathrm{Fe} \equiv \mathrm{N}$ triple bond, for which a computed $\mathrm{Fe} \equiv \mathrm{N}$ stretching frequency of $1064 \mathrm{~cm}^{-1}$ (DFT) was reported.

Other tragonal dicationic nitrido iron complexes based on macrocyclic amine ligands, suchs as $\left[\left(\mathrm{NN}_{4}\right) \mathrm{Fe}^{\mathrm{V}} \mathrm{N}\right]^{2+[170]}$ (Figure $\left.1.8 \mathrm{D}\right),\left[\left(\mathrm{MePy}_{2} \mathrm{tacn}\right) \mathrm{Fe}^{\mathrm{V}} \mathrm{N}\right]^{2+},{ }^{[171]}$ and $\left[\left(\mathrm{Me}_{2}\right.\right.$ $\left.\mathrm{Py}_{2} \mathrm{tacn}_{\text {) }} \mathrm{Fe}^{\mathrm{V}} \mathrm{N}\right]^{2+[172]}$ (Figure $1.8 \mathrm{E}$ ) have been published. The FeN stretching frequencies obtained by IRPD spectroscopy of the latter two complexes are reported to be $855 \mathrm{~cm}^{-1}$ and $867 \mathrm{~cm}^{-1}{ }^{\dagger}$ as well as $866 \mathrm{~cm}^{-1}$, respectively. ${ }^{[172]}$ Thus, reported $\mathrm{Fe}-\mathrm{N}$ stretching frequencies for tetragonal terminal $\mathrm{Fe}^{\mathrm{IV}}$ and $\mathrm{Fe}^{\mathrm{V}}$ nitrido complexes are within $855 \mathrm{~cm}^{-1}$ to $867 \mathrm{~cm}^{-1}$, indicating comparable $\mathrm{Fe}-\mathrm{N}$ bond strengths.

The $\mathrm{Fe}-\mathrm{N}$ stretching frequency of the first reported trigonal symmetric pseudo tetrahedral complex $\left[\left(\mathrm{PhB}\left(\mathrm{CH}_{2} \mathrm{PiPr}_{2}\right)_{3}\right) \mathrm{Fe}^{\mathrm{IV}} \mathrm{N}\right]$ (Figure 1.8 F), published by Betley and Peters ${ }^{[173]}$ in 2004, was recorded in pentane at $1034 \mathrm{~cm}^{-1}$, and is significantly higher than those assigned to the tetragonal symmetric complexes. The MO occupation pattern of $\left(d_{\mathrm{xy}}\right)^{2}\left(d_{\mathrm{x}^{2}-\mathrm{y}^{2}}\right)^{2}\left(d_{\mathrm{yz}}\right)^{0}$ shows a low-spin $d^{4}$ configuration and accordingly a $\mathrm{BO}$ of 3. The short bond length of 153(2) pm obtained by fitting EXAFS data reflects the presence of an $\mathrm{Fe} \equiv \mathrm{N}$ triple bond in accord with the observed $\mathrm{Fe} \equiv \mathrm{N}$ vibrational frequency. ${ }^{[180]}$ In contrast to all other iron nitrido complexes presented here, this complex was not prepared by photolysis of the corresponding azide, but from an iron chloride precursor and the $N$-atom transfer reagent $\mathrm{Li}(\mathrm{dbabh})(\mathrm{dbadh}=2,3: 5,6$ - $\mathrm{di}$ benzo-7-aza bicyclo[2.2.1] hepta-2,5-diene) by liberation of anthracene.

The first crystal structure obtained by X-ray diffraction (XRD) of a terminal iron nitrido complex was published in 2008 by Vogel et al. ${ }^{[174]}$, which yielded bond distances of 152.6(2) pm and 152.7(3) pm for [(TIMEN $\left.\left.{ }^{\mathrm{R}}\right) \mathrm{Fe}^{\mathrm{IV}} \mathrm{N}\right]^{+}(\mathrm{R}=$ Mesityl, Xylyl, see Figure $1.8 \mathrm{G})$. In the same year the crystal structure of $\left[\left(\mathrm{PhB}(t \mathrm{BuIm})_{3}\right) \mathrm{Fe}^{\mathrm{IV}} \mathrm{N}\right]$ with a $\mathrm{Fe}-\mathrm{N}$ bond distance of $151.1(2) \mathrm{pm}$ was reported (Figure $1.8 \mathbf{H}){ }^{[175]}$ It was later shown that this bond distance was influenced by coordinated solvent molecules and that the $\mathrm{Fe}-\mathrm{N}$ bond distance in the solvent-free crystal structure is 153.2(5) pm. ${ }^{[181]}$ The $\mathrm{Fe}-\mathrm{N}$ stretching frequencies for these three complexes of $1008 \mathrm{~cm}^{-1}, 1008 \mathrm{~cm}^{-1}$ and $1029 \mathrm{~cm}^{-1}(\mathrm{RR})$, respectively, which combined with the short $\mathrm{Fe} \equiv \mathrm{N}$ bond distances of about $153 \mathrm{pm}$ indicate strong $\mathrm{Fe} \equiv \mathrm{N}$ triple bonds. An in-depth experimental and computational study of $\left[\left(\mathrm{PhB}(t \mathrm{BuIm})_{3}\right) \mathrm{Fe}^{\mathrm{IV}} \mathrm{N}\right]$ by Bucinsky et al. ${ }^{[181]}$ confirms a singlet ground state and a $d^{4}$ configuration with a $\left(d_{\mathrm{xy}}\right)^{2}\left(d_{\mathrm{x}^{2}-\mathrm{y}^{2}}\right)^{2}\left(d_{\mathrm{yz}}\right)^{0}$ occupation pattern,

\footnotetext{
${ }^{\dagger}$ Signals split due to coupling between the FeN stretching and ligand vibrational modes.
} 
which supports previous results of Betley and Peters ${ }^{[173]}$ on $\left[\left(\mathrm{PhB}\left(\mathrm{CH}_{2} \mathrm{PiPr}_{2}\right)_{3}\right) \mathrm{Fe}^{\mathrm{IV}} \mathrm{N}\right]$. These complexes have shown to undergo nitrogen atom transfer reactions with $\mathrm{CO}$ and $\mathrm{C} \equiv \mathrm{N} t \mathrm{Bu}$, leading to the formation of new $\mathrm{N}-\mathrm{C}$ bonds. ${ }^{[182]} \mathrm{A}$ rather short $\mathrm{Fe}-\mathrm{N}$ bond distance of 150.9(2) pm has been determined by XRD for the neutral complex $\left[\left(\mathrm{PhB}(\mathrm{MesIm})_{3}\right) \mathrm{Fe}^{\mathrm{IV}} \mathrm{N}\right]$ shown in Figure $1.8 \mathbf{H}^{[15,181]}$ while a longer bond distance of 154(2) pm (EXAFS fit) was found for the cationic complex $\left[\left(\mathrm{P}_{3}^{\mathrm{B}}\right) \mathrm{Fe}^{\mathrm{IV}} \mathrm{N}\right]^{+}$(Figure 1.8 I). ${ }^{[37]}$

Interesting observations have been made for $\mathrm{Fe}^{\mathrm{IV}} \equiv \mathrm{N} / \mathrm{Fe}^{\mathrm{V}} \equiv \mathrm{N}$ redox pairs $\left[\left(\mathrm{PhB}(t \mathrm{BuIm})_{3}\right) \mathrm{Fe}^{\mathrm{IV}} \mathrm{N}\right]^{0 /+}$ on one hand, ${ }^{[175,176,181]}$ and $\left[\left(\mathrm{TIMMN}^{\mathrm{Mes}}\right) \mathrm{Fe}^{\mathrm{IV}} \mathrm{N}\right]^{0 /+}$ (Figure $1.8 \mathrm{~J}$ ) on the other. ${ }^{[177]}$ The oxidation should lead to shorter bond distances due to an increased Coulomb attraction between the formal $\mathrm{Fe}^{5+}$ and $\mathrm{N}^{3-}$ ions. However, in case of the former pair, the $\mathrm{Fe}-\mathrm{N}$ bond distance decreases upon oxidation quite considerably from $153.2(5) \mathrm{pm}$ to $150.6(2) \mathrm{pm}$, while this distance increases from about $151.3 \mathrm{pm}$ (average, see Table 1.1) to 152.9(2) pm for the latter. This unexpected observation was attributed to the higher steric flexibility of the TIMMN ${ }^{\mathrm{Mes}}$ chelate ligand, allowing for a larger distortion of the $d^{3}$ metal orbitals. In addition, for both of the trigonal symmetric $\mathrm{Fe}^{\mathrm{V}} \equiv \mathrm{N}$ complexes the $e^{3}$ occupation lead to Jahn-Teller distortions which lift the degeneracy of the $e$-orbital set.

Lastly, the stretching frequency and bond distance of the diatomic FeN was determined to be $871 \mathrm{~cm}^{-1}$ and $158.0 \mathrm{pm}$, respectively, by Aiuchi and Shibuya ${ }^{[183]}$ in 2000. Due to the many low-lying states its electronic ground state was very difficult to determine. ${ }^{[183-186]}$ In the end, a doublet ${ }^{2} \Delta$ ground state was obtained with a $\left(1 \sigma^{2}\right)\left(2 \sigma^{2}\right)\left(1 \pi^{2}\right)\left(1 \delta^{3}\right)\left(3 \sigma^{2}\right)$ configuration, ${ }^{[187]}$ which is consistent with the first prediction by Siegbahn and Blomberg ${ }^{[184]}$ using CASSCF in 1984 . The $3 \sigma(4 s)$ orbital is considered repulsive and this repulsion likely contributes to a low stretching frequency compared to other iron nitrido complexes bearing $\mathrm{Fe} \equiv \mathrm{N}$ triple bonds. ${ }^{[184]}$ In matrixisolation studies, in which the reaction products of laser-ablated iron with dinitrogen were studied and isolated in solid argon, a stretching frequency of diatomic FeN was assigned to a band located at $938 \mathrm{~cm}^{-1}$, significantly larger than the gas-phase value of $871 \mathrm{~cm}^{-1}{ }^{[185]}$ This large frequency shift could be due to an ArFeN complex, but also a different electronic state of matrix-isolated FeN cannot be excluded. ${ }^{[183]}$

While this summary shows the enormous progress that has been made in recent years in the synthesis of molecular iron nitrido complexes, it also shows that with $\left[\left(\mathrm{Me}_{3} \mathrm{cyclam}-\mathrm{ac}\right) \mathrm{Fe}^{\mathrm{VI}} \mathrm{N}\right]^{2+}$ only one experimentally known hexavalent iron nitrido complex exist. Thus, no trigonal symmetric Fe(VI)-nitrido complex has so far been reported. It can be concluded that the influence of the stabilizing macrocyclic and chelating ligands on the electronic structure, the $\mathrm{Fe}-\mathrm{N}$ bond length and the $\mathrm{Fe}-\mathrm{N}$ stretching vibration frequency cannot be neglected. Thus, the available data only allow limited 
conclusions about the electronic structure and the nature of the $\mathrm{Fe}-\mathrm{N}$ bond in nitrido iron(VI) complexes which are not stabilized by bulky substituents.

\section{Ruthenium Nitrido Complexes}

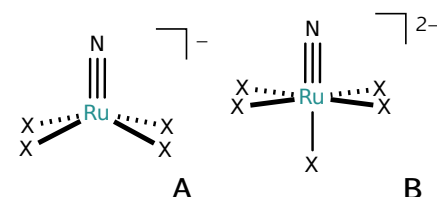

$\left[\mathrm{X}_{4} \mathrm{Ru}^{\mathrm{V} /} \mathrm{N}\right]^{-} \quad\left[\mathrm{X}_{5} \mathrm{Ru}^{\mathrm{V} /} \mathrm{N}\right]^{2-}$ $(\mathrm{X}=\mathrm{Cl}, \mathrm{Br}) \quad(\mathrm{X}=\mathrm{Cl}, \mathrm{Br})$

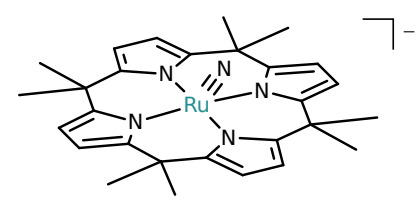

$\mathrm{F}$<smiles>CCCC(NC(=O)CSC)NC(=O)CSC</smiles>

C

$\left[(3-M P A){ }_{2} R u^{V / N} N\right]^{-}$

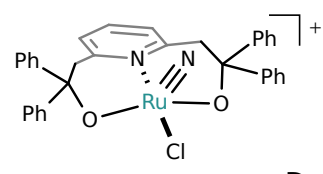

D

$\left[\left(\mathrm{LNO}_{2}\right) \mathrm{Ru}^{\mathrm{V} /} \mathrm{N}\right]^{+}$

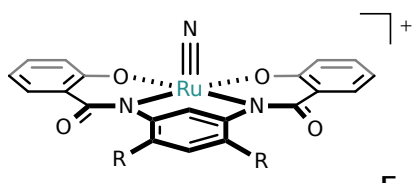

$\left[\left(\text { hypyb)Ru } u^{\vee / N}\right]^{+} \quad(\mathrm{R}=\mathrm{H})\right.$ $\left[\left(\text { dchypyb)Ru } u^{\mathrm{V}} \mathrm{N}\right]^{+}(\mathrm{R}=\mathrm{Cl})\right.$

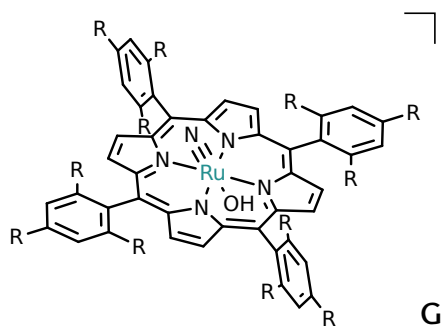

$\left[(\mathrm{TMP}) \mathrm{Ru}^{\mathrm{V}} \mathrm{N}\right]^{-} \quad(\mathrm{R}=$ Methyl $)$ $\left[(\mathrm{MeO}-\mathrm{TPP}) \mathrm{Ru}^{\mathrm{V}} \mathrm{N}\right]^{-}(\mathrm{R}=$ Methoxy $)$

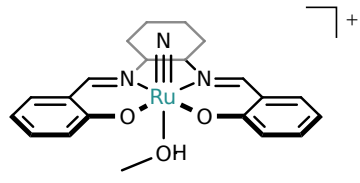

G

$\left[(\text { salen })(\mathrm{MeOH}) \mathrm{Ru}^{\mathrm{V} /} \mathrm{N}\right]^{+}$
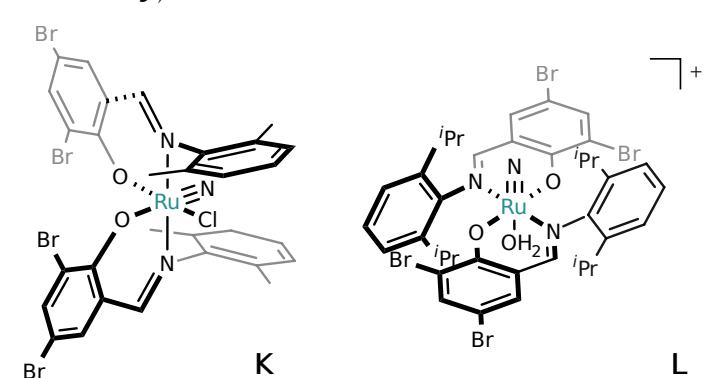

$\left[(i \operatorname{PrPDBP})_{2}(\mathrm{Cl}) \mathrm{Ru}^{\mathrm{V} /} \mathrm{N}\right] \quad\left[(i \operatorname{PrPDBP})_{2}\left(\mathrm{H}_{2} \mathrm{O}\right) \mathrm{Ru}^{\mathrm{V} /} \mathrm{N}\right]^{+}$

$\left[\left(\mathrm{PNP}^{\mathrm{Si}}\right) \mathrm{Ru}^{\mathrm{IV} N}\right]^{+}\left(\mathrm{R}=\mathrm{Si}\left(\mathrm{CH}_{3}\right)_{2}\right) \quad\left[(\mathrm{dPhf})_{4} \mathrm{Ru}^{\mathrm{III}} \mathrm{Ru}^{\mathrm{IV}} \mathrm{N}\right] \quad \mathrm{dPhf}^{-}$ $\left[(\mathrm{PNP}) \mathrm{Ru}^{\mathrm{IV}} \mathrm{N}\right]^{+} \quad\left(\mathrm{R}=\mathrm{CH}_{2}\right)$

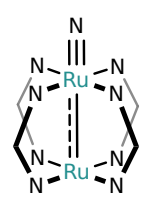

$\sum_{N}^{N}=\underbrace{N_{P h}^{N}}_{P h}-H$

Figure 1.9. Selection of experimentally known terminal ruthenium nitrido complexes:
$A,{ }^{[190]} B,{ }^{[190]} C,{ }^{[191]} D^{[191]} E^{[191]} F^{[192]}$ and L. ${ }^{[197]}$
$\mathbf{G}^{[193]} \mathbf{H},{ }^{[194]} \mathbf{I},{ }^{[17,195]} \mathbf{J},{ }^{[196]} \mathbf{K},{ }^{[197]}$

In 1973 the first terminal ruthenium nitrido complexes, $\left[\left(\mathrm{X}_{4}\right) \mathrm{Ru}^{\mathrm{VI}} \mathrm{N}\right]^{-}$and $\left[\left(\mathrm{X}_{5}\right) \mathrm{Ru}^{\mathrm{VI}} \mathrm{N}\right]^{-}$with $\mathrm{X}=\mathrm{Cl}$ or $\mathrm{Br}$ (Figure $1.9 \mathrm{~A}$ and $\mathbf{B}$, respectively), were published by Griffith and Pawson ${ }^{[190]}$. $\left[\left(\mathrm{Cl}_{4}\right) \mathrm{Ru}^{\mathrm{VI}} \mathrm{N}\right]^{-}$turned out to be particularly useful, as numerous complexes have been derived from it (see below). It features a $\mathrm{Ru}-\mathrm{N}$ bond distance of $157.0(7) \mathrm{pm}^{[198]}$ and a Ru-N stretching frequency of $1090 \mathrm{~cm}^{-1}$, very close to the band at $1088 \mathrm{~cm}^{-1}$ obtained for the bromido congener. As evident from the lower stretching frequency of $1045 \mathrm{~cm}^{-1}$ obtained for $\left[\left(\mathrm{X}_{5}\right) \mathrm{Ru}^{\mathrm{VI}} \mathrm{N}\right]^{-}(\mathrm{X}=\mathrm{Cl}, \mathrm{Br})$ trans coordination weakens the $\mathrm{Ru}-\mathrm{N}$ bond.

Bidentate ligands involving sulfide and amide donors were used by Schwab et al. ${ }^{[199]}$ to obtain $\left[(3-\mathrm{MPA})_{2} \mathrm{Ru}^{\mathrm{VI}} \mathrm{N}\right]^{-}$(Figure $1.9 \mathrm{C}$ ) from $\left[\left(\mathrm{Cl}_{4}\right) \mathrm{Ru}^{\mathrm{VI}} \mathrm{N}\right]^{-}$in 1991 . A Ru-N bond 
Table 1.1: Selection of experimentally known terminal iron nitrido complexes. Reported $\mathrm{Fe}-\mathrm{N}$ bond distances, $d(\mathrm{Fe}-\mathrm{N})$, in $\mathrm{pm}$, and vibrational frequency, $\tilde{v}$, of the iron nitrido stretching mode $[v(\mathrm{Fe}-\mathrm{N})]$ in $\mathrm{cm}^{-1}$ are included.

\begin{tabular}{|c|c|c|c|c|c|}
\hline Complex & Syn ${ }^{a}$ & Geom. ${ }^{b}$ & $d(\mathrm{Fe}-\mathrm{N})$ & $\tilde{v}[v(\mathrm{Fe}-\mathrm{N})]$ & Year $^{[R E F]}$ \\
\hline$\left[(\mathrm{TPP}) \mathrm{Fe}^{\mathrm{V}} \mathrm{N}\right]$ & $\mathrm{P}$ & SPY & - & $876^{c}$ & $1988^{[165]}$ \\
\hline$\left[(\mathrm{OEP}) \mathrm{Fe}^{\mathrm{V}} \mathrm{N}\right]$ & $\mathrm{P}$ & SPY & - & $876^{c}$ & $1989^{[166]}$ \\
\hline$\left[(\mathrm{TMP}) \mathrm{Fe}^{\mathrm{V}} \mathrm{N}\right]$ & $\mathrm{P}$ & SPY & - & $873^{c}$ & $1989^{[166]}$ \\
\hline$\left[(\text { cyclam })\left(\mathrm{N}_{3}\right) \mathrm{Fe}^{\mathrm{V}} \mathrm{N}\right]^{+}$ & $\mathrm{P}$ & $\mathrm{PO}$ & - & - & $1999^{[168]}$ \\
\hline$\left[(\text { cyclam }-\mathrm{ac}) \mathrm{Fe}^{\mathrm{V}} \mathrm{N}\right]^{+}$ & $\mathrm{P}$ & $\mathrm{PO}$ & $161^{d}$ & $855^{e}$ & $2000^{[169]}$ \\
\hline$\left[\left(\mathrm{Me}_{3} \text { cyclam-ac }\right) \mathrm{Fe}^{\mathrm{VI}} \mathrm{N}\right]^{2+}$ & $\mathrm{P}$ & $\mathrm{PO}$ & $157(2)^{f}$ & [1064] & $2006^{[67]}$ \\
\hline$\left[\left(\mathrm{NN}_{4}\right) \mathrm{Fe}^{\mathrm{V}} \mathrm{N}\right]^{2+}$ & $\mathrm{P}$ & $\mathrm{PO}$ & {$[160]$} & - & $2008^{[170]}$ \\
\hline$\left[\left(\mathrm{MePy}_{2} \operatorname{tacn}\right) \mathrm{Fe}^{\mathrm{V}} \mathrm{N}\right]^{2+}$ & $\mathrm{P}$ & $\mathrm{PO}$ & $164^{g}$ & $855,867^{h}$ & $2017^{[171]}$ \\
\hline$\left[\left(\mathrm{Me}_{2} \mathrm{Py}_{2} \text { tacn }\right) \mathrm{Fe}^{\mathrm{V}} \mathrm{N}\right]^{2+}$ & $\mathrm{P}$ & $\mathrm{PO}$ & {$[158-160]$} & 866 & $2018^{[172]}$ \\
\hline$\left[(\mathrm{TTPPP}) \mathrm{Fe}^{\mathrm{V}} \mathrm{N}\right]$ & $\mathrm{P}$ & SPY & [159] & $876^{c}$ & $2021^{[167]}$ \\
\hline$\left[\left(\mathrm{PhB}\left(\mathrm{CH}_{2} \mathrm{PiPr}_{2}\right)_{3}\right) \mathrm{Fe}^{\mathrm{IV}} \mathrm{N}\right]$ & $\mathrm{L}$ & PTD & $153(2)^{i}$ & $1034^{j}$ & $2004^{[173]}$ \\
\hline$\left[\left(\mathrm{TIMEN}^{\mathrm{Mes}}\right) \mathrm{Fe}^{\mathrm{IV}} \mathrm{N}\right]^{+}$ & $\mathrm{P}$ & PTD & $152.6(2)^{k}$ & $1008^{l}$ & $2008^{[174]}$ \\
\hline$\left[\left(\mathrm{TIMEN}^{\mathrm{Xyl}}\right) \mathrm{Fe}^{\mathrm{IV}} \mathrm{N}\right]^{+}$ & $\mathrm{P}$ & PTD & $152.7(3)^{k}$ & $1008^{l}$ & $2008^{[174]}$ \\
\hline$\left[\left(\mathrm{PhB}(t \mathrm{BuIm})_{3}\right) \mathrm{Fe}^{\mathrm{IV}} \mathrm{N}\right]$ & $\mathrm{P}$ & PTD & $153.2(5)^{m}$ & $1028^{c}$ & $2008^{[175]}$ \\
\hline$\left[\left(\mathrm{PhB}(\mathrm{MesIm})_{3}\right) \mathrm{Fe}^{\mathrm{IV}} \mathrm{N}\right]$ & $\mathrm{P}$ & PTD & $150.9(2)^{n}$ & - & $2009^{[15]}$ \\
\hline$\left[\left(\mathrm{PhB}(t \mathrm{BuIm})_{3}\right) \mathrm{Fe}^{\mathrm{V}} \mathrm{N}\right]^{+}$ & $\mathrm{P}$ & PTD & $150.6(2)^{o}$ & - & $2011^{[176]}$ \\
\hline$\left[\left(\mathrm{P}_{3}^{\mathrm{B}}\right) \mathrm{Fe}^{\mathrm{IV}} \mathrm{N}\right]^{+}$ & $\mathrm{P}$ & PTD & $154(2)^{p}$ & - & $2017^{[37]}$ \\
\hline$\left[\left(\mathrm{TIMMN}^{\mathrm{Mes}}\right) \mathrm{Fe}^{\mathrm{IV}} \mathrm{N}\right]^{+}$ & $\mathrm{P}$ & PTD & $150.0(3)^{q}$ & - & $2021^{[177]}$ \\
\hline$\left[\left(\mathrm{TIMMN}^{\mathrm{Mes}}\right) \mathrm{Fe}^{\mathrm{V}} \mathrm{N}\right]^{2+}$ & $\mathrm{P}$ & PTD & $152.9(2)^{r}$ & - & $2021^{[177]}$ \\
\hline$[\mathrm{FeN}]$ & $\mathrm{E}$ & LI & $158.0^{s}$ & $871^{t}$ & $2000^{[183]}$ \\
\hline \multicolumn{6}{|c|}{$\begin{array}{l}{ }^{a} \text { Synthesis; P: Photolysis of corresponding azide; L: Using } N \text {-transfer reagent } \mathrm{Li}(\mathrm{dbabh})(\mathrm{dbadh}= \\
\text { 2,3:5,6-dibenzo-7-aza bicyclo[2.2.1] hepta-2,5-diene) from chlorido precursor; E: From elements } \\
\text { in gas-phase }\end{array}$} \\
\hline \multicolumn{6}{|c|}{${ }^{b}$ Coordination Geometry, see Figure 1.3; LI: Linear } \\
\hline \multicolumn{6}{|c|}{${ }^{c}$ Resonance Raman } \\
\hline \multicolumn{6}{|c|}{${ }^{d}$ EXAFS fit;; ${ }^{[188]}$ DFT: 161 pm ${ }^{[188]}$} \\
\hline \multicolumn{6}{|c|}{${ }^{e}$ From IRPD spectroscopy; ${ }^{[172]}$ NRVS: $864 \mathrm{~cm}^{-1[178]}$ DFT: $937 \mathrm{~cm}^{-1[178,188]}$} \\
\hline \multicolumn{6}{|c|}{$f$ EXAFS fit; DFT: $153 \mathrm{pm}$} \\
\hline \multicolumn{6}{|c|}{$g$ EXAFS fit; DFT: $160 \mathrm{pm}$} \\
\hline \multirow{2}{*}{\multicolumn{6}{|c|}{$\begin{array}{l}{ }^{h} \text { Coupling of the FeN stretching and ligand vibrational modes; From IRPD spectroscopy }{ }^{[172]} \\
{ }^{[} \text {EXAFS fit; }{ }^{[180]} \text { DFT: } 149 \mathrm{pm}^{[173]} 151 \mathrm{pm}^{[189]}\end{array}$}} \\
\hline \multirow{2}{*}{\multicolumn{5}{|c|}{$j$ Pentane solution }} & \\
\hline \multirow{2}{*}{\multicolumn{4}{|c|}{${ }^{k}$ From XRD }} & & \\
\hline \multicolumn{5}{|c|}{${ }^{l} \mathrm{KBr}$ pellet } & \\
\hline \multicolumn{6}{|c|}{${ }^{m}$ From XRD; ${ }^{[181]}$ Original publication solvated $(\mathrm{MeCN}): 151.1(2) \mathrm{pm}^{[175,181]}$} \\
\hline \multicolumn{6}{|c|}{${ }^{n}$ From XRD; ${ }^{[181]}$ Original publication solvated $(\mathrm{MeCN}): 149.9(5) \mathrm{pm}^{[15,181]}$} \\
\hline \multicolumn{6}{|c|}{ From XRD at $35 \mathrm{~K}$ and $150.2(2) \mathrm{pm}$ at $100 \mathrm{~K}$} \\
\hline \multicolumn{6}{|c|}{$p$ EXAFS fit; DFT: $151 \mathrm{pm}$} \\
\hline \multicolumn{6}{|c|}{$\begin{array}{l}9 \text { From XRD; Complex crystallizes in space group } \mathrm{C} 2 / \mathrm{c} \text { with two independent molecules per unit } \\
\text { cell with } \mathrm{Fe}-\mathrm{N} \text { bond distances of } 150.0(3) \mathrm{pm} \text { and } 152.6(3) \mathrm{pm}\end{array}$} \\
\hline${ }^{r}$ From XRD; DFT: $151 \mathrm{pm}$ & & & & & \\
\hline$s$ From laser-induced fluores & ( & & & & \\
\hline
\end{tabular}


distance of $159.5(8) \mathrm{pm}$ and a corresponding stretching frequency of $1094 \mathrm{~cm}^{-1}$ were reported.

In 1998 Ram et al. ${ }^{[200]}$ studied diatomic, neutral RuN by using Fourier-transform infrared (FTIR) emission spectroscopy combined with multi-reference calculations. A doublet ${ }^{2} \Sigma^{+}$ground state with a stretching frequency of $1109 \mathrm{~cm}^{-1}$ and a configuration of $\left(1 \sigma^{2}\right)\left(2 \sigma^{2}\right)\left(1 \pi^{2}\right)\left(1 \delta^{4}\right)\left(3 \sigma^{1}\right)$ was determined. The fully occupied non-bonding, degenerate $1 \delta$ orbital, and a single occupation of the slightly repulsive $3 \sigma[(n-1) d]$ orbital of RuN differs from the ground state configuration of FeN (see above). This study was followed by a second work of Ram and Bernath ${ }^{[201]}$ in 2002 in which a refined equilibrium bond distance $\left(r_{\mathrm{e}}\right)$ of $157.1 \mathrm{pm}$ was determined using Fourier-transform emission spectroscopy, which confirms the theoretical predictions of a strong triple bond from the earlier work and provides a basis for a comparison of terminal $\mathrm{Ru}-\mathrm{N}$ bond distances. ${ }^{[200]}$ On this basis the $\mathrm{Ru}-\mathrm{N}$ bond length and stretching frequencies obtained for the anionic complexes $\left[\left(\mathrm{Cl}_{4}\right) \mathrm{Ru}^{\mathrm{VI}} \mathrm{N}\right]^{-}$and $\left[(3-\mathrm{MPA}){ }_{2} \mathrm{Ru}{ }^{\mathrm{VI}} \mathrm{N}\right]^{-}$are indicative for strong triple bonds and low-spin $d^{2}$ configurations without population of antibonding orbitals (cf. Figure 1.3). It is worth pointing out that the band at $982 \mathrm{~cm}^{-1}$, assigned to RuN isolated in solid argon, also deviates significantly from the one obtained in the gas-phase $\left(1109 \mathrm{~cm}^{-1}\right)$. [202]

Chan et al. ${ }^{[191]}$ in 1998 presented a series of ruthenium(VI) nitrido complexes containing di-, tri- and tetra-anionic ligands, such as $\left[\left(\mathrm{LNO}_{2}\right) \mathrm{Ru}^{\mathrm{VI}} \mathrm{N}\right]^{+},\left[(\text {hypyb }) \mathrm{Ru}^{\mathrm{VI}} \mathrm{N}\right]^{+}$ and $\left[\left(\text { dchypyb) } \mathrm{Ru}^{\mathrm{VI}} \mathrm{N}\right]^{+}\right.$(Figure 1.9, D and E). They were prepared by ligand substitution reactions from $\left[\left(\mathrm{Cl}_{4}\right) \mathrm{Ru}^{\mathrm{VI}} \mathrm{N}\right]^{-}$, and their $\mathrm{Ru}-\mathrm{N}$ bond distances (XRD: 161.5(5) pm, $159.4(4) \mathrm{pm}$ and $160.9(6) \mathrm{pm}$, respectively), and stretching frequencies $\left(1026 \mathrm{~cm}^{-1}\right.$, $1073 \mathrm{~cm}^{-1}$ and $1010 \mathrm{~cm}^{-1}$, respectively) were obtained. The electronic structure and bonding of the nitrido ligand was not discussed, but the $\mathrm{Ru}-\mathrm{N}$ bond distances and vibrational frequencies indicate formal triple bonds, although the frequency of $1010 \mathrm{~cm}^{-1}$ assigned to [(dchypyb) $\left.\mathrm{Ru}^{\mathrm{VI}} \mathrm{N}\right]^{+}$is considered to be on lower end of the spectrum for a $\mathrm{Ru} \equiv \mathrm{N}$ triple bond.

A remarkably short $\mathrm{Ru}-\mathrm{N}$ bond distance of $156.9(6) \mathrm{pm}$ was determined for the anionic, hexavalent porphyrinogen complex $\left[(\mathrm{OMPG}) \mathrm{Ru}^{\mathrm{VI}} \mathrm{N}\right]^{-}$(Figure $1.9 \mathrm{~F}$ ) by Bonomo et al. ${ }^{[192]}$ in 2001, however, no vibrational data were reported. This complex, that was obtained by reacting $\left[(\mathrm{OMPG}) \mathrm{Ru}^{\mathrm{II}}\right]^{2-}$ with diphenyldiazomethane, shows an electrophilic nitrido nitrogen atom, and undergoes a reversible one-electron reduction to a dianionic ruthenium(v) nitrido complex, which is expected to show a longer bond distance due to the occupation of antibonding orbitals. ${ }^{[192]}$

The porphyrin based complexes [(TMP)Ru $\left.{ }^{\mathrm{VI}} \mathrm{N}\right]^{-}$and $\left[(\mathrm{MeO}-\mathrm{TPP}) \mathrm{Ru}^{\mathrm{VI}} \mathrm{N}\right]^{-}$presented by Leung et al. ${ }^{[193]}$ in 2003 and shown in Figure 1.9 G were prepared from the corresponding metal oxo complexes using $\mathrm{HN}=\mathrm{C} t \mathrm{Bu}_{2}$. The $\mathrm{Ru}-\mathrm{N}$ stretching frequency 
of the former was found at $1038 \mathrm{~cm}^{-1}$, while the $\mathrm{Ru}-\mathrm{N}$ bond distance for the structurally closely related latter complex amounts to $165.6(5) \mathrm{pm}$, both values indicate $\mathrm{Ru} \equiv \mathrm{N}$ triple bonds.

Because of the highly electrophilic/oxidizing nature of the complex [(salen) $(\mathrm{MeOH})$ $\left.\mathrm{Ru}^{\mathrm{VI}} \mathrm{N}\right]^{+}$(Figure $1.9 \mathrm{H}$ ), bearing Schiff base salen ligand and published by Man et al. ${ }^{[194]}$ in 2004, a number of reactivity studies have since been published. These include nitrogen atom transfer reactions to alkenes, ${ }^{[203]}$ and the activation of $\mathrm{C}-\mathrm{H}$ bonds. ${ }^{[204,205]}$ It catalyzes the hydrosilylation of ketones and aldehydes, ${ }^{[206]}$ the nitrogenation of alkynes, ${ }^{[207]}$ as well as the oxidation of ascorbic acid, phenols, or hydroquinones. ${ }^{[208-210]}$ This complex, obtained from $\left[\left(\mathrm{Cl}_{4}\right) \mathrm{Ru}^{\mathrm{VI}} \mathrm{N}\right]^{-}$, displays a characteristic $\mathrm{Ru} \equiv \mathrm{N}$ triple bond distance of $159.2(4) \mathrm{pm}$ and a stretching frequency of $1059 \mathrm{~cm}^{-1}$.

The distorted square planar structure of the tetravalent pincer complexes $\left[\left(\mathrm{PNP}^{\mathrm{Si}}\right)\right.$ $\left.\mathrm{Ru}^{\mathrm{IV}} \mathrm{N}\right]^{+[195]}$ and $\left[(\mathrm{PNP}) \mathrm{Ru}^{\mathrm{IV}} \mathrm{N}\right]^{+[17]}$ shown in Figure $1.9 \mathrm{I}$ has been attributed to the preference of the $d^{4}$ configuration to adopt a pseudo tetrahedral geometry to optimize RuN multiple bonding. The $\mathrm{Ru}-\mathrm{N}$ bond distances of these complexes amount to $162.7(2) \mathrm{pm}$ and $165.8 \mathrm{pm}$, respectively. The reactivity and selectivity of the former complex against electrophilic attacks was studied. ${ }^{[211,212]}$ The differences in the $\mathrm{Ru}-\mathrm{N}$ bond distances is also reflected in their $\mathrm{Ru}-\mathrm{N}$ stretching frequencies of $1030 \mathrm{~cm}^{-1}$ and $976 \mathrm{~cm}^{-1}$, respectively. A considerable disorder regarding the nitrido ligand in the molecular structure derived by XRD of the latter complex was solved by applying a split model for the nitrido ligand with $\mathrm{Ru}-\mathrm{N}$ bond lengths of 168.8(3) pm and $162.8(4) \mathrm{pm}$, accompanied by $\mathrm{N}-\mathrm{Ru}-\mathrm{N}$ angular distortions from a square planar structure of $147.3(2)^{\circ}$ and $165.6(3)^{\circ}$, respectively. This observation was rationalized by the flat $\mathrm{N}-\mathrm{Ru}-\mathrm{N}$ bending potential attributed to competitive $\pi$ bonding abilities of the nitrido and amido ligands.

The dinuclear complex $\left[(\mathrm{dPhf})_{4} \mathrm{Ru}^{\mathrm{III}} \mathrm{Ru}^{\mathrm{IV}} \mathrm{N}\right]$ (Figure 1.9 J) reported by Pap et al. ${ }^{[196]}$ demonstrates that a metal-metal multiply bonded complex is capable of binding a terminal ligand with multiple bonds. Despite the long $\mathrm{Ru}-\mathrm{N}$ bond distance of $176 \mathrm{pm}$ obtained by fitting EXAFS data and the low corresponding stretching frequency of $847 \mathrm{~cm}^{-1}$, theoretical calculations confirm a formal $\mathrm{Ru} \equiv \mathrm{N}$ triple bond which lies between the extremes of mononuclear ruthenium(VI) nitrido and a Ru-surface-bound nitrogen atom. This interaction is stabilized by electron delocalization over the second $\mathrm{Ru}$ atom leading to nonbonding $\mathrm{MO}$ combinations that can accommodate the electrons that would otherwise occupy antibonding orbitals in mononuclear species. ${ }^{[196]}$

Lastly, the ruthenium(VI) complex cis-[(iPrPDBP $\left.)_{2}(\mathrm{Cl}) \mathrm{Ru}^{\mathrm{VI}} \mathrm{N}\right]$ presented by $\mathrm{Ng}$ et al. ${ }^{197]}$ and shown in Figure $1.9 \mathrm{~K}$ features sterically bulky bidentate Schiff base ligands. The cationic complex trans- $\left[(i \operatorname{PrPDBP})_{2}\left(\mathrm{H}_{2} \mathrm{O}\right) \mathrm{Ru}^{\mathrm{VI}} \mathrm{N}\right]^{+}$shown in Figure $1.9 \mathrm{~L}$ is obtained after chloride abstraction and undergoes a rearrangement where the ni- 
trido ligand is positioned in a trans position to the aqua ligand. In contrast to [(salen) $\left.(\mathrm{MeOH}) \mathrm{Ru}^{\mathrm{VI}} \mathrm{N}\right]^{+}$, this complex did not react with nucleophiles, demonstrating that electronic and steric factors of the co-ligands influence the stability and reactivity of ruthenium(VI) nitrido complexes.

So far and to the best of my knowledge, no tetrahedral ruthenium nitrido complexes are known. Further, ruthenium complexes with oxidation states beyond VI are rare. They include tetrapropylammonium perruthenate (TRAP), a mild oxidizing agent used in the Ley-Griffith-oxidation reaction to convert primary alcohols into aldehydes, ${ }^{[213]}$ and was proposed as intermediate within the catalytic cycle of the oxidative cyclization of 5,6-dihydroxy alkenes. ${ }^{[214]}$ However, no ruthenium(VII) nitrido species has been reported up to date.

\section{Osmium Nitrido Complexes}

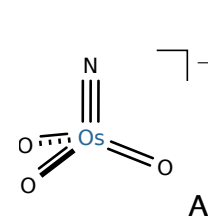

$\left[\mathrm{O}_{3} \mathrm{Os}{ }^{\mathrm{VIII}} \mathrm{N}\right]^{-}$

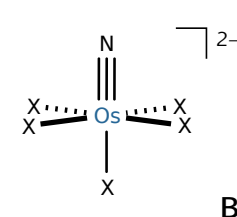

$\left[\mathrm{X}_{5} \mathrm{Os}^{\mathrm{V} / \mathrm{N}}\right]^{2-}(\mathrm{X}=\mathrm{Cl}, \mathrm{Br})$

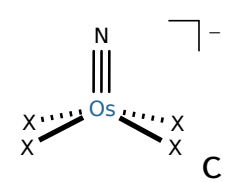

$\left[\mathrm{X}{ }_{4} \mathrm{Os}{ }^{\mathrm{V} /} \mathrm{N}\right]^{-}(\mathrm{X}=\mathrm{Cl}, \mathrm{Br})$

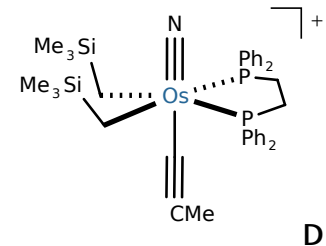

$\left[\left(\mathrm{CH}_{2} \mathrm{SiMe}_{3}\right)_{2}(\mathrm{dppe})(\mathrm{NCMe}) \mathrm{Os}^{\mathrm{V}} \mathrm{N}\right]^{+}$

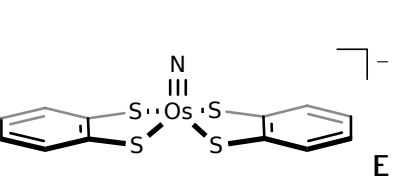

$\left[\left(\mathrm{S}_{2} \mathrm{C}_{6} \mathrm{H}_{4}\right)_{2} \mathrm{Os}^{\mathrm{V} / \mathrm{N}}\right]^{-}$

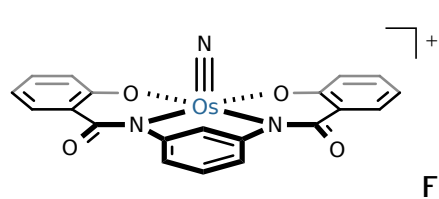

$\left[\left(\text { hypyb)Os } \mathrm{s}^{\mathrm{V}} \mathrm{N}\right]^{+}\right.$

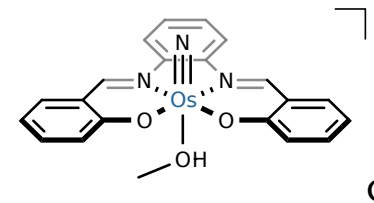

$\left[(\text { salophen })(\mathrm{MeOH}) \mathrm{Os}^{\mathrm{V} /} \mathrm{N}\right]^{+}$

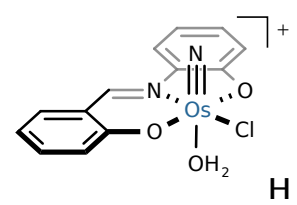

$\left[(\operatorname{sap})\left(\mathrm{OH}_{2}\right) \mathrm{Os}^{\mathrm{V}} \mathrm{N}\right]^{+}$<smiles>N#[R](Cl)(Cl)[Hg]</smiles>

fac $-\left[(\mathrm{Cl})_{3} \mathrm{R}_{2} \mathrm{Os}^{\mathrm{IV}} \mathrm{N}\right]$ $\mathrm{R}=\mathrm{Hind}, 5-\mathrm{MeHpz}$ 3,5-Me ${ }_{2} \mathrm{Hpz}$

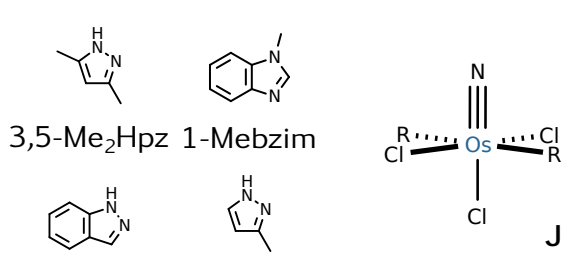

Hind

5-MeHpz

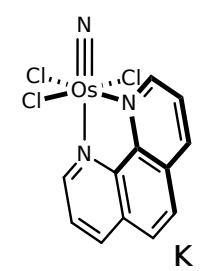

mer- $\left[(\mathrm{Cl})_{3} \mathrm{R}_{2} \mathrm{Os}^{\mathrm{IV}} \mathrm{N}\right.$ $\mathrm{R}=1$-Mebzim

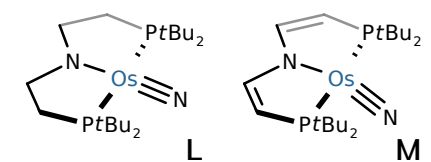

N] $\left[(\mathrm{Cl})_{3}(\right.$ phen $\left.) \mathrm{Os}^{\mathrm{IV} N}\right] \quad\left[(\mathrm{PNP})_{2} \mathrm{Os}{ }^{\mathrm{IV} N}\right] \quad\left[\left(\mathrm{PNP}^{\prime}\right)_{2} \mathrm{Os}^{\mathrm{IV} N}\right]$

Figure 1.10. Selection of experimentally known terminal osmium nitrido complexes:
$A,{ }^{[12]} B,{ }^{[215]} C_{,}^{[190]}$
$L^{,[221]}$ and $\mathbf{M}^{[57]}$
$D^{,[216]} E^{[217]} F,[191] G,[218]$
$\mathbf{H}^{[219]},{ }^{[28]} \mathbf{J},{ }^{[28]} \mathbf{K},{ }^{[220]}$

The first osmium nitrido complex was produced almost 175 years ago when Fritzsche and Struve ${ }^{[12]}$ treated osmium(VIII) tetroxide with ammonia in 1847. However, it took another 50 years until Werner and Dinklage ${ }^{[215]}$ assigned the correct composition of the $\left[(\mathrm{O})_{3} \mathrm{Os}{ }^{\mathrm{VIII}} \mathrm{N}\right]^{-}$complex (Figure $1.10 \mathrm{~A}$ ) in 1901 . Having a $d^{0}$ configuration it repre- 
Table 1.2: Selection of experimentally known ruthenium nitrido complexes. Reported bond lengths, $d(\mathrm{Ru}-\mathrm{N})$, in pm and vibrational frequency, $\tilde{v}$, of the ruthenium nitrido stretching mode $[v(\mathrm{Ru}-\mathrm{N})]$ in $\mathrm{cm}^{-1}$ are included. The $\mathrm{Ru}-\mathrm{N}$ bond distances are obtained from XRD, unless noted otherwise.

\begin{tabular}{|c|c|c|c|c|c|}
\hline Complex & Syn. ${ }^{a}$ & Geom. ${ }^{b}$ & $d(\mathbf{R u}-\mathbf{N})$ & $\tilde{v}[v(\mathbf{R u}-\mathrm{N})]$ & Year $^{[R E F]}$ \\
\hline$\left[\left(\mathrm{Cl}_{4}\right) \mathrm{Ru}^{\mathrm{VI}} \mathrm{N}\right]^{-}$ & $\mathrm{Az}^{c}$ & SPY & $157.0(7)^{[198]}$ & $1090^{d}$ & $1973^{[190]}$ \\
\hline$\left[\left(\mathrm{Br}_{4}\right) \mathrm{Ru}^{\mathrm{VI}} \mathrm{N}\right]^{-}$ & $\mathrm{Az}{ }^{c}$ & SPY & - & $1088^{d}$ & $1973^{[190]}$ \\
\hline$\left[\left(\mathrm{Cl}_{5}\right) \mathrm{Ru}^{\mathrm{VI}} \mathrm{N}\right]^{2-}$ & $\mathrm{Az}^{c}$ & $\mathrm{PO}$ & - & $1045^{d}$ & $1973^{[190]}$ \\
\hline$\left[\left(\mathrm{Br}_{5}\right) \mathrm{Ru}^{\mathrm{VI}} \mathrm{N}\right]^{2-}$ & $\mathrm{Az}^{c}$ & $\mathrm{PO}$ & - & $1045^{d}$ & $1973^{[190]}$ \\
\hline$\left[(3-\mathrm{MPA})_{2} \mathrm{Ru}^{\mathrm{VI}} \mathrm{N}\right]^{-}$ & GP & SPY & $159.5(8)$ & $1094^{e}$ & $1991^{[199]}$ \\
\hline$\left[\left(\mathrm{LNO}_{2}\right) \mathrm{Ru}^{\mathrm{VI}} \mathrm{N}\right]^{+}$ & GP & SPY & $161.5(4)$ & $1025^{f}$ & $1998^{[191]}$ \\
\hline$\left[\left(\text { hypyb) } \mathrm{Ru}^{\mathrm{VI}} \mathrm{N}\right]^{+}\right.$ & GP & SPY & $159.4(4)$ & $1073^{f}$ & $1998^{[191]}$ \\
\hline$\left[(\text { dchypyb }) \mathrm{Ru}^{\mathrm{VI}} \mathrm{N}\right]^{+}$ & GP & SPY & $160.9(6)$ & $1010^{f}$ & $1998^{[191]}$ \\
\hline$\left[\mathrm{Ru}{ }^{\mathrm{III}} \mathrm{N}\right]$ & EL & LI & $157.1^{g}$ & $1109^{g}$ & $1998^{[200]}$ \\
\hline$\left[(\mathrm{OMPG}) \mathrm{Ru}^{\mathrm{VI}} \mathrm{N}\right]^{-}$ & DA & SPY & $156.9(6)$ & - & $2001^{[192]}$ \\
\hline$\left[(\mathrm{TMP}) \mathrm{Ru}^{\mathrm{VI}} \mathrm{N}\right]^{-}$ & $\mathrm{OM}$ & SPY & - & $1038^{d}$ & $2003^{[193]}$ \\
\hline$\left[(\mathrm{MeO}-\mathrm{TPP}) \mathrm{Ru}^{\mathrm{VI}} \mathrm{N}\right]^{-}$ & $\mathrm{OM}$ & SPY & $165.6(5)$ & - & $2003^{[193]}$ \\
\hline$\left[(\text { salen })(\mathrm{MeOH}) \mathrm{Ru}^{\mathrm{VI}} \mathrm{N}\right]^{+}$ & GP & $\mathrm{PO}$ & $159.2(4)$ & $1059^{d}$ & $2004^{[194]}$ \\
\hline$\left[\left(\mathrm{PNP}^{\mathrm{Si}}\right) \mathrm{Ru}^{\mathrm{IV}} \mathrm{N}\right]^{+}$ & $\mathrm{Az}$ & $\mathrm{SPL}^{h}$ & $162.7(2)$ & 1030 & $2005^{[195]}$ \\
\hline$\left[(\mathrm{dPhf})_{4} \mathrm{Ru}^{\mathrm{III}} \mathrm{Ru}^{\mathrm{IV}} \mathrm{N}\right]$ & $\mathrm{Az}$ & $\mathrm{PO}$ & $172^{i}$ & $840^{j}$ & $2008^{[196]}$ \\
\hline$\left[(\mathrm{PNP}) \mathrm{Ru}^{\mathrm{IV}} \mathrm{N}\right]^{+}$ & $\mathrm{Az}$ & $\mathrm{SPL}^{h}$ & $165.8^{k}$ & $976^{f}$ & $2011^{[17]}$ \\
\hline$\left[(i \operatorname{PrPDBP})_{2}(\mathrm{Cl}) \mathrm{Ru}^{\mathrm{VI}} \mathrm{N}\right]$ & GP & $\mathrm{PO}$ & - & 1025 & $2013^{[197]}$ \\
\hline$\left[(i \operatorname{PrPDBP})_{2}\left(\mathrm{H}_{2} \mathrm{O}\right) \mathrm{Ru}^{\mathrm{VI}} \mathrm{N}\right]^{+}$ & GP & $\mathrm{PO}$ & $165.1(6)$ & 1029 & $2013^{[197]}$ \\
\hline
\end{tabular}

${ }^{a}$ Synthesis; Az: From corresponding azide; GP: Starting from $\left[\left(\mathrm{Cl}_{4}\right) \mathrm{Ru}^{\mathrm{VI}} \mathrm{N}\right]^{-}\left(\right.$Griffith and Pawson ${ }^{[190]}$ ); EL: From elements in gas-phase; DA: By reaction with diphenyldiazomethane; OM: Reaction of oxo-metal complexes with an imine compound

${ }^{b}$ Coordination Geometry; See Figure 1.3; LI: Linear

${ }^{c}$ Reacting trans- $\left[\mathrm{RuO}_{2} \mathrm{X}_{2}\right]^{2-}$ with azide and CsX to get $\left[\left(\mathrm{X}_{4}\right) \mathrm{Ru}^{\mathrm{VI}} \mathrm{N}\right]^{-}$; Replacing CsX with $\left[\mathrm{Ph}_{4} \mathrm{As}\right] \mathrm{X}$ or $\left[\mathrm{Bu}_{4} \mathrm{~N}\right] \mathrm{X}$ to get $\left[\left(\mathrm{X}_{5}\right) \mathrm{Ru}^{\mathrm{VI}} \mathrm{N}\right]^{2-}(\mathrm{X}=\mathrm{Cl}, \mathrm{Br})$

${ }^{d}$ From solid

${ }^{e}$ From $\mathrm{KBr}$ pellet

$f$ In Nujol

$g$ From Fourier transform infrared emission spectroscopy; Bond distance from Ref ${ }^{[201]}$

${ }^{h}$ Distorted square planar

${ }^{i}$ From EXAFS fit

j From RR

${ }^{k}$ Average from 168.8(3) pm and 1.628(4) pm obtained by XRD and applying a split model for the nitride ligand because of considerable disorder regarding the nitrido ligand position. 
sents the highest possible OS of osmium of VIII, with a OsN bond distance of $162 \mathrm{pm}$ and a corresponding stretching frequency of $1023 \mathrm{~cm}^{-1} \cdot{ }^{[222-224]}$ This complex reacts with hydrogen halides to $\left[(\mathrm{Cl})_{5} \mathrm{Os}^{\mathrm{VI}} \mathrm{N}\right]^{2-}$ and $\left[(\mathrm{Br})_{5} \mathrm{Os}^{\mathrm{VI}} \mathrm{N}\right]^{2-}$, depicted in Figure 1.10 B. ${ }^{[215,225]}$ For the pentachloride complex, Os $-\mathrm{N}$ stretching frequencies of $1073 \mathrm{~cm}^{-1}$ to $1084 \mathrm{~cm}^{-1}$ (depending on the counter ion) and a bond distance of 161.4(13) pm have been recorded. ${ }^{[24,226]}$ For the pentabromide complex an Os $-\mathrm{N}$ stretching frequency of $1073 \mathrm{~cm}^{-1}$ was reported for the potassium salt, which is $11 \mathrm{~cm}^{-1}$ lower than the one observed for $\mathrm{K}_{2}\left[(\mathrm{Cl})_{5} \mathrm{Os}{ }^{\mathrm{VI}} \mathrm{N}\right] .{ }^{[190]}$ The tetrahalides $\left[(\mathrm{Cl})_{4} \mathrm{Os}{ }^{\mathrm{VI}} \mathrm{N}\right]^{-}$and $\left[(\mathrm{Br})_{4} \mathrm{Os}^{\mathrm{VI}} \mathrm{N}\right]^{-}$ shown in Figure $1.10 \mathrm{C}$ were published in 1973 by Griffith and Pawson ${ }^{[190]}$. For the nitrido bomide an Os-N stretching frequency of $1119 \mathrm{~cm}^{-1}$ was observed, while that of the chloride congener is slightly higher at $1123 \mathrm{~cm}^{-1}$. For the latter a very short Os $-\mathrm{N}$ bond distance of $160.0(11) \mathrm{pm}$ was determined. ${ }^{\text {[227] }}$ To an even greater extent than for the ruthenium congener, the nitrido tetrachloride anion $\left[(\mathrm{Cl})_{4} \mathrm{Os}{ }^{\mathrm{VI}} \mathrm{N}\right]^{-}$ served as starting material for large number of complexes synthesized via ligand substitution reactions. ${ }^{[28,219,220,228-230]}$ Among those, the phosphine osmium(VI) complex $\left[(\text { dppe })\left(\mathrm{CH}_{2} \mathrm{SiMe}_{3}\right)_{2}(\mathrm{NCMe}) \mathrm{Os}^{\mathrm{VI}} \mathrm{N}\right]^{+}$(Figure $\left.1.10 \mathrm{D}\right)$ that features an Os $-\mathrm{N}$ bond distance of $163.8(5) \mathrm{pm},{ }^{[216]}$ as well as the square planar thiolate osmium(VI) complex $\left[\left(\mathrm{S}_{2} \mathrm{C}_{6} \mathrm{H}_{4}\right)_{2} \mathrm{Os}{ }^{\mathrm{VI}} \mathrm{N}\right]^{-}$(Figure $1.10 \mathrm{E}$ ), for which an Os-N bond distance of 164(1) pm and an Os $-\mathrm{N}$ stretching frequency of $1063 \mathrm{~cm}^{-1}$ was obtained. [217]

The cationic complex [(hypyb)Os $\left.{ }^{\mathrm{VI}} \mathrm{N}\right]^{+}$(Figure 1.10, F) allows comparison of $\mathrm{M}-\mathrm{N}$ bond lengths and stretching frequencies with the complex of the lighter ruthenium congener $\left[(\text { hypyb }) \mathrm{Ru}^{\mathrm{VI}} \mathrm{N}\right]^{+}$published in the same work. ${ }^{[191]}$ The Os $-\mathrm{N}$ bond distance is with $161.8(7) \mathrm{pm}$ is about $1.4 \mathrm{pm}$ longer, and the stretching frequency of $1108 \mathrm{~cm}^{-1}$ is $35 \mathrm{~cm}^{-1}$ higher than that of the lighter congener. These values are consistent with the ones obtained for $\left[(\mathrm{Cl})_{4} \mathrm{Os}^{\mathrm{VI}} \mathrm{N}\right]^{-}$and $\left[(\mathrm{Cl})_{4} \mathrm{Ru}^{\mathrm{VI}} \mathrm{N}\right]^{-}$which are $160.0(11) \mathrm{pm}$ and $157.0(7) \mathrm{pm}$, as well as $1123 \mathrm{~cm}^{-1}$ and $1092 \mathrm{~cm}^{-1}$, respectively.

A kinetic investigation of the reaction between the Schiff base complexes [(salophen) $\left.(\mathrm{MeOH}) \mathrm{Os}^{\mathrm{VI}} \mathrm{N}\right]^{+}$(Figure $1.10 \mathrm{G}$ ) and $\left[(\text { salen })(\mathrm{MeOH}) \mathrm{Os}^{\mathrm{VI}} \mathrm{N}\right]^{+}$with $\mathrm{PPh}_{3}$ revealed that the electrophilic reactivity of the nitrido ligand increases with electron-withdrawing substituents at the salophen ligand. ${ }^{[218]}$ A comparatively long Os $-\mathrm{N}$ bond distance of $165.1(7) \mathrm{pm}$ has been determined by XRD of [(salophen) $\left.(\mathrm{MeOH}) \mathrm{Os}{ }^{\mathrm{VI}} \mathrm{N}\right]^{+}$. The OsN stretching frequencies of $1094 \mathrm{~cm}^{-1}$ for the salen substituted, and $1072 \mathrm{~cm}^{-1}$ for the salophen complex, are both well within the expected range for $\mathrm{Os} \equiv \mathrm{N}$ triple bonds and somewhat larger than the frequency obtained for the ruthenium congener [(salen) $\left.(\mathrm{MeOH}) \mathrm{Ru}^{\mathrm{VI}} \mathrm{N}\right]^{+}\left(1059 \mathrm{~cm}^{-1}\right.$, Table 1.2).

Owing to its labile aqua and chloro ligands in trans and cis position to the nitrido ligand, the $\left[(\operatorname{sap})\left(\mathrm{OH}_{2}\right)(\mathrm{Cl}) \mathrm{Os}^{\mathrm{VI}} \mathrm{N}\right]^{+}$complex (Figure $1.10 \mathrm{H}$ ), which makes use of the tridentate Schiff base ligand, displays prominent in vitro and in vivo anti-cancer pro- 
perties. ${ }^{[219]}$ While no structural data of this complex were reported, the Os $-\mathrm{N}$ stretching frequencies of $1092 \mathrm{~cm}^{-1}$ to $1098 \mathrm{~cm}^{-1}$ obtained for these derivates indicate strong $\mathrm{O} s \equiv \mathrm{N}$ triple bonds. A family of eight $\mathrm{Os}^{\mathrm{VI}} \mathrm{N}$ based complexes of the general formula $\left[(\mathrm{Cl})_{3}(\text { Hazole })_{2} \mathrm{Os}^{\mathrm{VI}} \mathrm{N}\right.$ (Hazole $=$ azole heterocycle) show antitumor activity as well. ${ }^{[28]}$ Of these, the molecular structures of the complexes shown in Figure $1.10 \mathrm{I}$ and $\mathbf{J}$ have been determined using XRD. The Os $-\mathrm{N}$ bond distances (and stretching frequencies) amount to $161.9(9) \mathrm{pm}\left(1080 \mathrm{~cm}^{-1}\right), 161.5(5) \mathrm{pm}\left(1060 \mathrm{~cm}^{-1}\right), 164.3(4) \mathrm{pm}\left(1070 \mathrm{~cm}^{-1}\right)$ and $167.5(3) \mathrm{pm}\left(1070 \mathrm{~cm}^{-1}\right)$ for the Hind, 5-MeHpz, 3,5-Me ${ }_{2} \mathrm{Hpz}$ and 1-Mebzim substituted derivates, respectively. These complexes, however, do not display a meaningful relationship between their $\mathrm{Os}-\mathrm{N}$ bond distances and stretching frequencies. The closely related nitrido trichloride complexes bearing bidentate ligands, such as bipy, phen, and derivatives, also show promising anti-cancer properties. ${ }^{[20,230]}$ Especially $\left[(\right.$ phen $\left.)(\mathrm{Cl})_{3} \mathrm{Os}{ }^{\mathrm{VI}} \mathrm{N}\right]$ (Figure $1.10 \mathrm{~K}$ ) has shown promising results, and exhibits selective toxicity for breast cancer stem cell enriched cell populations. ${ }^{[230]}$

The low-valent, square planar $\left[(\mathrm{PNP}) \mathrm{Os}{ }^{\mathrm{VI}} \mathrm{N}\right]$ (Figure $1.10 \mathrm{~L}$ ) recently published by Schendzielorz et al. ${ }^{[21]}$ is a rare example of an osmium(IV) nitrido complex produced by reductive deprotonation of an osmium(VI) hydride. It features a comparatively long Os $-\mathrm{N}$ bond distance of $168.32(18) \mathrm{pm}$ and a stretching frequency of $999 \mathrm{~cm}^{-1}$, which can be attributed to a trans-effect of the imide donor in trans position to the nitrido ligand. In this coordination geometry the $d^{4}$ configuration leads to a singlet configuration with populated non-bonding metal-centered $\left(d_{z^{2}}\right)^{2}\left(d_{y z}\right)^{2}$ orbitals. In reactivity investigations the nitrido ligand shows ambiphilic reactivity, and complete hydrogenolysis of the nitrido ligand to ammonia was observed in high yield. ${ }^{[221]}$ The closely related complex $\left[\left(\mathrm{PNP}^{\prime}\right) \mathrm{Os}{ }^{\mathrm{VI}} \mathrm{N}\right]$ depicted in Figure $1.10 \mathrm{M}$ shows a weakened $\mathrm{Os} \equiv \mathrm{N}$ bond because of the distorted structure with a bent $\mathrm{N}-\mathrm{Os} \equiv \mathrm{N}$ unit. ${ }^{[57]}$ The Os $\equiv \mathrm{N}$ bond distance was determined to be $173.5(2) \mathrm{pm}$, which is exceptionally long for a formal Os $\equiv \mathrm{N}$ triple bond. Surprisingly, the associated stretching frequency of $1025 \mathrm{~cm}^{-1}$ is higher than the one observed for $\left[(\mathrm{PNP}) \mathrm{Os}{ }^{\mathrm{VI}} \mathrm{N}\right]$.

The electronic structure of the group 8 diatomics (MN) was investigated extensively. ${ }^{[183,187,200,201,231]}$ The gas-phase vibrational frequencies decrease from OsN to FeN, $1137 \mathrm{~cm}^{-1}(\mathrm{OsN}), 1109 \mathrm{~cm}^{-1}(\mathrm{RuN})$, and $871 \mathrm{~cm}^{-1}(\mathrm{FeN})$, while the bond distances amount to $161.8 \mathrm{pm}(\mathrm{OsN}), 157.1 \mathrm{pm}(\mathrm{RuN})$ and $158.0 \mathrm{pm}(\mathrm{FeN})$. Interestingly, like FeN, but unlike RuN, OsN adopts a ${ }^{2} \Delta$ electronic ground state. The stretching frequency obtained for diatomic OsN in solid argon is only shifted by $-7 \mathrm{~cm}^{-1}$, [202] a considerable smaller gas-to-matrix shift than those observed for $\operatorname{RuN}\left(-140 \mathrm{~cm}^{-1}\right)$ and $\mathrm{FeN}\left(67 \mathrm{~cm}^{-1}\right)$. In the same matrix-isolation work it was discovered that laser ablated osmium atoms insert into the triple bond of dinitrogen to form bent $\mathrm{Os}(\mathrm{N})_{2}$ under cryogenic conditions. ${ }^{[232]}$ This follows from the observation of only two isotopologues, 
Os $\left({ }^{15} \mathrm{~N}\right)_{2}$ and $\operatorname{Os}\left({ }^{14} \mathrm{~N}\right)_{2}$ upon annealing.

It can be concluded that the osmium nitride chemistry is dominated by osmium(VI) in pseudo octahedral or square pyramidal coordination geometries. Rare exceptions to this include the high-valent pseudo tetrahedral $\left[(\mathrm{O})_{3} \mathrm{Os}{ }^{\mathrm{VIII}} \mathrm{N}\right]^{-}$(Figure $1.10 \mathrm{~A}$ ), and the low-valent distorted square planar $\left[(\mathrm{PNP}) \mathrm{O} \mathrm{s}^{\mathrm{IV}} \mathrm{N}\right]$ and $\left[\left(\mathrm{PNP}^{\prime}\right) \mathrm{Os}^{\mathrm{IV}} \mathrm{N}\right]$ complexes (Figure $1.10 \mathbf{L}$ and $\mathbf{M}$, respectively). 
Table 1.3: Selection of experimentally known osmium nitrido complexes. Reported bond distances, $d(\mathrm{Os}-\mathrm{N})$, in pm and vibrational frequencies, $\tilde{v}$, of the osmium nitrido stretching mode $[v(\mathrm{Os}-\mathrm{N})]$ in $\mathrm{cm}^{-1}$ are included. The $\mathrm{Os}-\mathrm{N}$ bond distances are obtained from XRD, unless noted otherwise.

\begin{tabular}{|c|c|c|c|c|c|}
\hline Complex & Syn. ${ }^{a}$ & Geom. ${ }^{b}$ & $d(\mathrm{Os}-\mathrm{N})$ & $\tilde{v}[v(\mathrm{Os}-\mathrm{N})]$ & Year $^{[R E F]}$ \\
\hline$\left[(\mathrm{O})_{3} \mathrm{Os}^{\mathrm{VIII}} \mathrm{N}\right]^{-}$ & $\mathrm{Ox}$ & PTD & $162^{c}$ & $1023^{d}$ & $1847^{[12]}$ \\
\hline$\left[(\mathrm{Cl})_{5} \mathrm{Os}^{\mathrm{VI}} \mathrm{N}\right]^{2-}$ & $\mathrm{HX}$ & $\mathrm{PO}$ & $161.4(13)$ & $1073^{e}$ & $1901^{[215]}$ \\
\hline$\left[(\mathrm{Br})_{5} \mathrm{Os}^{\mathrm{VI}} \mathrm{N}\right]^{2-}$ & HX & $\mathrm{PO}$ & - & $1073^{f}$ & $1906^{[225]}$ \\
\hline$\left[(\mathrm{Cl})_{4} \mathrm{Os}^{\mathrm{VI}} \mathrm{N}\right]^{-}$ & $\mathrm{Az}$ & SPY & $160.0(11)$ & $1123^{g}$ & $1973^{[190]}$ \\
\hline$\left[(\mathrm{Br})_{4} \mathrm{Os}^{\mathrm{VI}} \mathrm{N}\right]^{-}$ & $\mathrm{Az}$ & SPY & - & $1119^{g}$ & $1973^{[190]}$ \\
\hline$\left[(\mathrm{dppe})\left(\mathrm{L}^{1}\right)_{2}\left(\mathrm{~L}^{2}\right) \mathrm{Os}^{\mathrm{VI}} \mathrm{N}\right]^{+h}$ & GP & $\mathrm{PO}$ & $163.8(5)$ & - & $1994^{[216]}$ \\
\hline$\left[\left(\mathrm{S}_{2} \mathrm{C}_{6} \mathrm{H}_{4}\right)_{2} \mathrm{Os}^{\mathrm{VI}} \mathrm{N}\right]^{-}$ & GP & SPY & $164(1)^{i}$ & $1063^{j}$ & $1997^{[217]}$ \\
\hline$\left[\left(\text { hypyb)Os }{ }^{\mathrm{VI}} \mathrm{N}\right]^{+}\right.$ & GP & SPY & $161.8(7)$ & $1108^{k}$ & $1998^{[191]}$ \\
\hline Os ${ }^{\mathrm{III}} \mathrm{N}$ & EL & LI & $161.8^{l}$ & $1137^{m}$ & $1999^{[231]}$ \\
\hline $\mathrm{Os}(\mathrm{N})_{2}$ & EL & $\mathrm{BE}$ & {$[168.3]^{n}$} & $901^{\circ}$ & $1999^{[232]}$ \\
\hline$\left[(\text { salen })(\mathrm{MeOH}) \mathrm{Os}^{\mathrm{VI}} \mathrm{N}\right]^{+}$ & GP & TG & - & $1094^{j}$ & $1999^{[218]}$ \\
\hline$\left[(\text { salophen })\left(\mathrm{L}^{3}\right) \mathrm{Os}{ }^{\mathrm{VI}} \mathrm{N}\right]^{+h}$ & GP & TG & $165.1(7)$ & $1072^{j}$ & $1999^{[218]}$ \\
\hline$\left[(\operatorname{sap})\left(\mathrm{OH}_{2}\right)(\mathrm{Cl}) \mathrm{Os}^{\mathrm{VI}} \mathrm{N}\right]^{+}$ & GP & TG & - & $1098^{j}$ & $2011^{[219]}$ \\
\hline$\left[(\mathrm{Hind})_{2}(\mathrm{Cl})_{3} \mathrm{Os}^{\mathrm{VI}} \mathrm{N}\right]$ & GP & TG & $161.9(9)$ & $1080^{j}$ & $2012^{[28]}$ \\
\hline$\left[(5-\mathrm{MeHpz})_{2}(\mathrm{Cl})_{3} \mathrm{Os}^{\mathrm{VI}} \mathrm{N}\right]$ & GP & TG & $161.5(5)$ & $1060^{j}$ & $2012^{[28]}$ \\
\hline$\left[\left(3,5-\mathrm{Me}_{2} \mathrm{Hpz}\right)_{2}(\mathrm{Cl})_{3} \mathrm{Os}^{\mathrm{VI}} \mathrm{N}\right]$ & GP & TG & $164.3(4)$ & $1070^{j}$ & $2012^{[28]}$ \\
\hline$\left[(1-\mathrm{Mebzim})_{2}(\mathrm{Cl})_{3} \mathrm{Os}^{\mathrm{VI}} \mathrm{N}\right]$ & GP & TG & $167.5(3)$ & $1070^{j}$ & $2012^{[28]}$ \\
\hline$\left[(\right.$ phen $\left.)(\mathrm{Cl})_{3} \mathrm{Os}^{\mathrm{VI}} \mathrm{N}\right]$ & GP & TG & - & $1080^{j}$ & $2013^{[220]}$ \\
\hline$\left[(\mathrm{PNP}) \mathrm{Os}^{\mathrm{IV}} \mathrm{N}\right]$ & $\mathrm{Az}$ & SQ & $168.32(18)$ & $999^{j}$ & $2016^{[221]}$ \\
\hline$\left[\left(\mathrm{PNP}^{\prime}\right) \mathrm{Os}^{\mathrm{IV}} \mathrm{N}\right]$ & $\mathrm{Az}$ & SQ & $173.5(2)$ & $1025^{k}$ & $2017^{[57]}$ \\
\hline
\end{tabular}

a Synthesis; Ox: From $\mathrm{OsO}_{4}$ and $\mathrm{NH}_{3}$; HX: From $(\mathrm{O})_{3} \mathrm{OsN}$ and corresponding hydrogen halide; Az: From corresponding azide; GP: Starting from $\left[\left(\mathrm{Cl}_{4}\right) \mathrm{Os}^{\mathrm{VI}} \mathrm{N}\right]^{-}$(Griffith and Pawson ${ }^{[190]}$ ); EL: From elements in gas-phase

${ }^{b}$ Geometry; See Figure 1.3, LI = Linear, BE = Bent, SQ: Distorted square planar

c XRD ${ }^{[222,223]}$

${ }^{d}$ Nujol ${ }^{[224]}$

e Potassium salt in nujol ${ }^{[224]}$

$f$ From solid ${ }^{[190]}$

$g$ From Raman spectroscopy

${ }^{h} \mathrm{~L}^{1}: \mathrm{CH}_{2} \mathrm{SiMe}_{3} ; \mathrm{L}^{2}$ : $\mathrm{NCMe} ; \mathrm{L}^{3}: \mathrm{MeOH}$

$i$ Two independent molecules in the asymmetric unit with 164(1) pm and 166(1) pm, respectively

j $\mathrm{KBr}$ pellet

$k$ In nujol

${ }^{l} r_{e}$ from Fourier transform emission spectroscopy

${ }^{m}$ Gas phase; In solid argon: $1130 \mathrm{~cm}^{-1[232]}$

${ }^{n}$ From DFT calculation

$o$ In solid argon 


\subsubsection{Group 9}

The 9 valence electrons of the group 9 transition metals, in principle, facilitate OSs up to IX. However, the iridium tetroxide cation $\left[\mathrm{IrO}_{4}\right]^{+}$is the only compound with OS IX that has been reported to date. ${ }^{[63]}$ In contrast to earlier transition metals, significantly fewer terminal group 9 nitrido and imido complexes exist.

\section{Cobalt Imido and Nitrido Complexes}
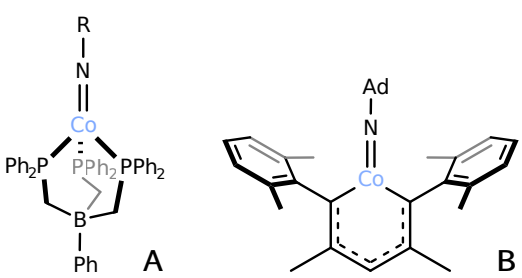

$\left[\left(\mathrm{PhBP}_{3}\right) \mathrm{Co}^{\prime \prime \prime}(\mathrm{NR})\right] \quad\left[\left(\mathrm{Me}_{2} \mathrm{NN}\right) \mathrm{Co}^{\prime \prime \prime}(\mathrm{NAd})\right]$ $(\mathrm{R}=\mathrm{Tol}, \mathrm{Ph}, \mathrm{tBu})$

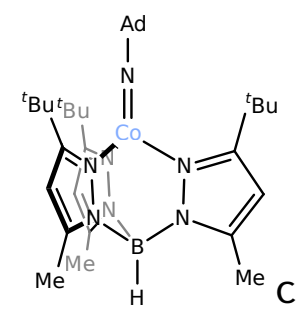

$\left[\left(\mathrm{Tp}^{\mathrm{tBu}, \mathrm{Me}}\right) \mathrm{Co} \mathrm{O}^{\prime \prime \prime}(\mathrm{NAd})\right]$
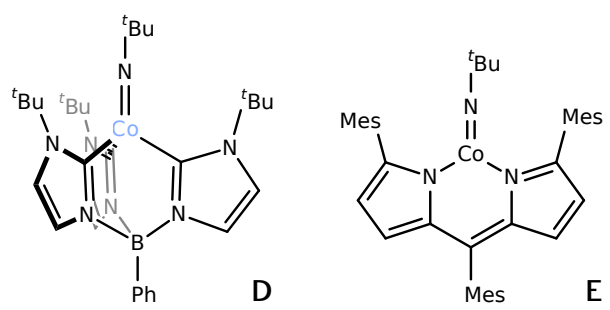

$\left.\left[(\mathrm{PhB})(t \mathrm{Bulm})_{3}\right) \mathrm{Co}^{\prime \prime \prime}(\mathrm{N} t \mathrm{Bu})\right]\left[(\mathrm{MTPDP}) \mathrm{Co}^{\prime \prime \prime}(\mathrm{N} t \mathrm{Bu})\right]$

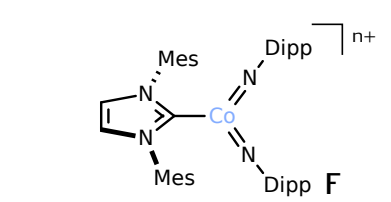

$\left[(\right.$ IMes $\left.) \mathrm{Co}^{\mathrm{IV}}(\mathrm{NDipp})_{2}\right] \quad(\mathrm{n}=0)$ $\left[(\text { IMes }) \mathrm{Co}^{\vee}(\mathrm{NDipp})_{2}\right]^{+}(\mathrm{n}=1)$

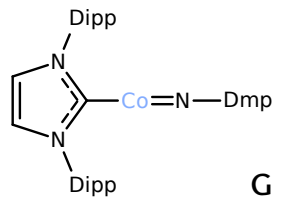

$\left[(\operatorname{IPr}) \mathrm{Co}^{\|}(\mathrm{NDmp})\right]$

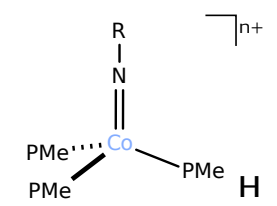

$\left[(\mathrm{PMe})_{3} \mathrm{Co}\right.$ (NDipp) $]$ $\left[(\mathrm{PMe})_{3} \mathrm{Co}^{\prime \prime \prime}(\mathrm{NDmp})\right]^{+}$

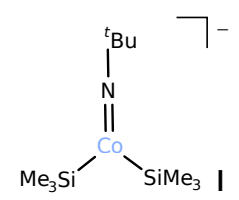

$\left[(\text { hmds })_{2} \mathrm{Co}^{\prime \prime \prime}(\mathrm{NtBu})\right]^{-}$

Figure 1.11. Selection of experimentally known terminal cobalt imido complexes: $A,{ }^{[233,234]} \mathrm{B},{ }^{[235]} \mathrm{C},{ }^{[236]} \mathrm{D},{ }^{[237]} \mathrm{E}^{[238]} \mathrm{F},{ }^{[239]} \mathrm{G},{ }^{[240]} \mathrm{H},{ }^{[241]}$ and I. ${ }^{[242]}$

For a very long time cobalt with multiply bonded, strong $\pi$-donor ligands were unknown and to this day diatomic $\mathrm{Co}^{\mathrm{III}} \mathrm{N}$ is the only known nitrido complex. It has been isolated in solid argon in 1998. ${ }^{[243]}$ An experimental equilibrium bond length $\left(r_{\mathrm{e}}\right.$, estimated from $\left.B_{\text {eff }}\right)$ of $157.5 \mathrm{pm}$ was reported in a theoretical study by Yamaki et al. ${ }^{[244]}$ in 2003 from gas-phase LIF excitation spectra of CoN, carried out by Aiuchi and Shibuya (private communication). ${ }^{[244]}$ Reminiscent of the iron congener (see Section 1.5.1), the determination of the electronic ground state of CoN has been subject to controversial discussions. Theoretical investigations ${ }^{[244,245]}$ predict a ${ }^{1} \Sigma^{+}$electronic ground state based on rigorous multi-configurational studies by Gobbo and Borin ${ }^{\text {[245] }}$ in 2006, while former DFT calculations carried out by Andrews et al. ${ }^{[243]}$, and MRCI + $\mathrm{Q}$ calculations of Yamaki et al. ${ }^{[244]}$ erroneously lead to ${ }^{5} \Delta$ electronic ground state. The $X^{1} \Sigma^{+}$state corresponds to a leading configuration of $7 \sigma^{2} 8 \sigma^{2} 9 \sigma^{2} 3 \pi^{4} 1 \delta^{4} 4 \pi^{0}$, where the $7 \sigma, 9 \sigma$ and $1 \delta$ orbitals correspond to the $\mathrm{N}$ centered $2 \mathrm{~s}$, Co centered $4 \mathrm{~s}$ and $3 d_{\mathrm{xy}, \mathrm{x}^{2}-\mathrm{y}^{2}}$ orbitals, respectively. The bonding and antibonding orbitals are represented by $8 \sigma$, 
$3 \pi$ and $4 \pi^{*}$, respectively. Computed CoN bond distances of $156.1 \mathrm{pm}$ (MRCI) and $157.3 \mathrm{pm}$ (CASPT2) are in very good agreement with the experimental gas-phase value of 157.5 pm estimated from $B_{\text {eff. }}{ }^{[244]}$ The computed vibrational frequencies of $914 \mathrm{~cm}^{-1}$ (MRCI) and $888 \mathrm{~cm}^{-1}$ (CASPT2) are, however, significantly higher than the experimental value of $827 \mathrm{~cm}^{-1}$ obtained in solid argon. ${ }^{[243]}$

The strong $\pi$-donating character of the $\mathrm{N}^{3-}$ ligand combined with the inability of cobalt to achieve higher OSs than $\mathrm{V}$ and the associated high $d$-electron counts make cobalt nitrido complexes appear unfavorable. In contrast, the imido ligand $\left(\mathrm{RN}^{2-}\right)$ is able to act as four or six electron donor ${ }^{[246]}$ and a number of imido complexes have been synthesized since the first example, namely $\left[\left(\mathrm{PhBP}_{3}\right) \mathrm{Co}^{\mathrm{III}}(\mathrm{Ntol})\right]$ (Figure 1.11 A), was published in 2002. [233] With only one exception, the complexes shown in Figure 1.11 were prepared by oxidative addition of organic nitrenes (NR), obtained by $\mathrm{N}_{2}$ elimination from organic azides $\mathrm{RN}_{3}$, while $\left[\left(\mathrm{PhB}(t \mathrm{BuIm})_{3}\right) \mathrm{Co}^{\mathrm{III}}(\mathrm{N} t \mathrm{Bu})\right]$ (Figure 1.11 D) was prepared by deprotonation of $\left[\left(\mathrm{PhB}(t \mathrm{BuIm})_{3}\right) \mathrm{Co}^{\mathrm{II}}(\mathrm{NH} t \mathrm{Bu})\right]$. The OSs of cobalt in these imido complexes range from $\mathrm{II}^{[240,241]}$ to $\mathrm{V}^{[239]}$, with OS III being the most prominent (see Table 1.5).

Strikingly, there are no examples of cobalt imido complexes with tetragonal coordination geometry. This circumstance can easily be rationalized by the fact that $d$ electron counts lower than four have not yet been realized. A $d$-electron count $d^{\mathrm{n}}$, with $\mathrm{n}>2$ in a tetragonal coordination (i.e., PO and SPY coordination geometries in Figure 1.3) would lead to a significant destabilization due to the occupation of antibonding orbitals (nitrido wall, see Section 1.1). A coordination geometry commonly found in cobalt nitrido complexes is pseudo tetrahedral with Co in the OSs of III. $\mathrm{Co}-\mathrm{N}$ bond distances in these complexes range from 163.3(2) pm to 167.5(2) pm (Table 1.5 and Figure 1.11 A, C, D, and $\mathbf{H}$ ). Low-spin configurations are dominant, and $\left[\left(\mathrm{Tp}^{t \mathrm{Bu}, \mathrm{Me}}\right) \mathrm{Co}^{\mathrm{III}}(\mathrm{NAd})\right]$ shown in Figure $1.11 \mathrm{C}$ is the only example that shows a highspin configuration in pseudo tetrahedral geometry. ${ }^{[241]}$ In linear $\mathrm{R}-\mathrm{N}-\mathrm{Co}$ coordination the $d$-orbital splitting caused by the imido ligand is similar to that of the nitrido ligand $\mathrm{N}^{3-}$, however, the antibonding $d_{\mathrm{z}^{2}}$ is surprisingly stable because of significant symmetry allowed cobalt $3 d_{\mathrm{z}}$ and $4 p_{\mathrm{z}}$ orbital mixing, which mitigates antibonding character of this orbital. ${ }^{[238,246]}$ In this splitting scheme, the Co ${ }^{\text {III }}$ center adopts idealized $\left(d_{\mathrm{xy}, \mathrm{x}^{2}-\mathrm{y}^{2}}\right)^{4}\left(d_{\mathrm{z}^{2}}\right)^{2}\left(d_{\mathrm{xz}, \mathrm{yz}}\right)^{0}$ low-spin ${ }^{[233,234,237,241,247]}$ and $\left(d_{\mathrm{xy}, \mathrm{x}^{2}-\mathrm{y}^{2}}\right)^{4}\left(d_{\mathrm{z}^{2}}\right)^{1}\left(d_{\mathrm{xz}, \mathrm{yz}}\right)^{1}$ high-spin ${ }^{[236]}$ ground-state electron configurations. The only compound featuring a $\mathrm{Co}^{\mathrm{II}}$ ion in this coordination geometry is $\left[(\mathrm{PMe}){ }_{3} \mathrm{Co}^{\mathrm{II}}(\mathrm{NDipp})\right]$ (Figure $\left.1.11 \mathbf{H}\right)$, which comprises a significantly elongated $\mathrm{Co}-\mathrm{N}$ bond length of $170.89(15) \mathrm{pm}$ compared to $165.40(17) \mathrm{pm}$ of the analogous $\mathrm{Co}^{\mathrm{III}}$ cation $\left[(\mathrm{PMe}){ }_{3} \mathrm{Co}^{\mathrm{III}}(\mathrm{NDmp})\right]^{+}$. The elongated bond length of the $\mathrm{Co}^{\mathrm{II}}$ complex is consistent with a low-spin ground state electron configuration of $\left(d_{\mathrm{xy}, \mathrm{x}^{2}-\mathrm{y}^{2}}\right)^{4}\left(d_{\mathrm{z}^{2}}\right)^{2}\left(d_{\mathrm{xz}, \mathrm{yz}}\right)^{1}$ and a reduced formal BO of 1.5. ${ }^{\text {[241] }}$ 
Another reported coordination geometry of cobalt imido complexes is trigonal planar (TPL). Examples shown in Figure 1.11 include $\mathrm{Co}^{\mathrm{III}}(\mathbf{B}, \mathbf{E}$ and $\mathbf{I})$, as well as $\mathrm{Co}^{\mathrm{IV}}$ and $\mathrm{Co}^{\mathrm{V}}(\mathbf{F})$ centers with $\mathrm{Co}-\mathrm{N}$ bond distances ranging from $162.1(3) \mathrm{pm}$ to $170.67(12) \mathrm{pm}$ (Table 1.5). For these three-coordinate species, the $d_{\mathrm{xz}, \mathrm{yz}}$ set is no longer degenerate, as $d_{\mathrm{xy}}$ bears antibonding character with respect to the ancillary ligands, whereas $d_{\mathrm{yz}}$ does not. The splitting and, consequently, the preferred spin-state depends on the nature of the imido substituent. ${ }^{[238]}$ Low-spin configurations have been attributed to [( $\left.\mathrm{Me}_{2} \mathrm{NN}\right)$ $\left.\mathrm{Co}^{\mathrm{III}}(\mathrm{NAd})\right]$ (Figure $1.11 \mathrm{~B}$ ) and [(giso)Co $\left.{ }^{\mathrm{III}}(\mathrm{NAd})\right]$ (Table 1.5), with similar valence configurations to those of the four-fold coordinated low-spin complexes described above. ${ }^{[235,248]}$ Complexes bearing weak-field ancillary ligands have shown to stabilize high-spin complexes, such as $\left[(\mathrm{MTPDP}) \mathrm{Co}^{\mathrm{III}}(\mathrm{N} t \mathrm{Bu})\right]$ and $\left[(\mathrm{hmds})_{2} \mathrm{Co}^{\mathrm{III}}(\mathrm{N} t \mathrm{Bu})\right]^{-}$(Figure $1.11 \mathrm{E}$ and $\mathbf{I}$, respectively). ${ }^{[238,242]}$ The former undergoes a thermally induced spin crossover from a singlet ground state to the quintet state electron configuration $\left(d_{\mathrm{xy}, \mathrm{x}^{2}-\mathrm{y}^{2}}\right)^{3}\left(d_{\mathrm{z}^{2}}\right)^{1}\left(d_{\mathrm{yz}}\right)^{1}\left(d_{\mathrm{xz}}\right)^{1}$ according to DFT calculations and in accord with the observed elongation of all Co-N bonds. ${ }^{[238]}$ The bis imido complexes shown in Figure $1.11 \mathrm{~F}$ possess a delocalized $\mathrm{N}-\mathrm{Co}-\mathrm{N} \pi$ electron system evident by the contraction of the $\mathrm{N}-\mathrm{Co}-\mathrm{N}$ bonds upon oxidation. According to a joint DFT and EPR study, the unpaired electron in the neutral $\mathrm{Co}^{\mathrm{IV}}$ complex is removed upon oxidation to the $\mathrm{Co}^{\mathrm{V}}$ complex from a singly occupied, delocalized $\pi^{*}$ orbital. ${ }^{[239]}$

Furthermore, a $N$-heterocyclic carbene (NHC) stabilized high-spin cobalt(II) imido complex with linear coordination at the cobalt center has been reported (Figure 1.11 G) which accommodates two unpaired electrons in the $\pi^{*}$ antibonding $d_{\mathrm{xz}, \mathrm{yz}}$ orbitals and one in a non-bonding $d_{\mathrm{x}^{2}-\mathrm{y}^{2}} \mathrm{MO}$, resulting in a quartet ground state. ${ }^{[240]}$ The Co-N bond distance and the $\mathrm{Co}-\mathrm{N}-\mathrm{C}$ angle amount to $169.1(6) \mathrm{pm}$ and $173.0(3)^{\circ}$, respectively.

Table 1.4: Vibrational frequencies $\left(\mathrm{cm}^{-1}\right)$ of ${ }^{14 / 15} \mathrm{~N}$ isotopologues of cobalt nitrido and imido complexes. Only modes with significant nitrido or imido nitrogen contributions are listed.

\begin{tabular}{lccc}
\hline Complex & ${ }^{14} \mathbf{N}$ & ${ }^{15} \mathbf{N}$ & Year $^{[\mathrm{REF}]}$ \\
\hline $\mathrm{Co}^{\mathrm{III}} \mathrm{N}$ & 827 & 804 & $1998^{[243]}$ \\
{$\left[\left(\mathrm{PhBP}_{3}\right) \mathrm{Co}^{\mathrm{III}}(\mathrm{NtBu})\right]$} & $577,1103,1238$ & $578,1084,-^{a}$ & $2006^{[234]}$ \\
{$\left[\left(\mathrm{PhBP}_{3}\right) \mathrm{Co}^{\mathrm{III}}(\mathrm{NPh})\right]$} & $956,995,1307,1332$ & $944,992,1295,1313$ & $2006^{[234]}$ \\
\hline
\end{tabular}

a Band corresponding to $1238 \mathrm{~cm}^{-1}$ obscured in spectrum

Vibrational data for the complexes shown in Figure 1.11 and listed in Table 1.5 are scarce. With one exception, ${ }^{[234]}{ }^{14 / 15} \mathrm{~N}$ isotopic substitution experiments are lacking, which makes it impossible to identify modes involving the imido group. Raman 
experiments with ${ }^{15} \mathrm{~N}$ and $\mathrm{D}$ substituted samples of $\left[\left(\mathrm{PhBP}_{3}\right) \mathrm{Co}^{\mathrm{III}}(\mathrm{N} t \mathrm{Bu})\right]$ conducted by Mehn et al. ${ }^{[234]}$ lead to an assignment of bands at $1103 \mathrm{~cm}^{-1}$ and $1238 \mathrm{~cm}^{-1}$ to primarily $\mathrm{Co}-\mathrm{N}$ and $\mathrm{N}-\mathrm{C}$ stretching modes, respectively. The first band shows a ${ }^{14 / 15} \mathrm{~N}$ isotopic shifts of about $-20 \mathrm{~cm}^{-1}$, while the band associated to the ${ }^{15} \mathrm{~N}$ isotopologue of the second band is obscured ${ }^{+}$in the spectrum. Isotopic ${ }^{15} \mathrm{~N}$ subsitution of $\left[\left(\mathrm{PhBP}_{3}\right) \mathrm{Co}^{\mathrm{III}}(\mathrm{NPh})\right]$ revealed a high degree of coupling of the modes involving the imido group with the aryl ring vibrational modes. Vibrational data of these complexes are summarized in Table 1.4.

Lastly, it is worth pointing out that all known cobalt imido complexes adopt a linear (or nearly linear) $\mathrm{Co}-\mathrm{N}-\mathrm{R}$ geometry and the substituents are limited to organic, electron donating groups.

Table 1.5: Selection of published terminal cobalt nitrido and imido complexes. Including, where available, $\mathrm{Co}-\mathrm{N}$ bond distances, $d(\mathrm{Co}-\mathrm{N})(\mathrm{pm})$ and $(\mathrm{Co}=\mathrm{N}-\mathrm{R})$ bond angle $\left({ }^{\circ}\right)$. All structural data obtained from XRD, unless indicated otherwise. All imido complexes were obtained from the corresponding azides, unless indicated otherwise.

\begin{tabular}{|c|c|c|c|c|}
\hline Complex & Geom. ${ }^{a}$ & $d(\mathrm{Co}-\mathrm{N})$ & $\measuredangle(\mathrm{Co}=\mathrm{N}-\mathrm{R})$ & Year $^{[R E F]}$ \\
\hline $\mathrm{Co}^{\mathrm{III}} \mathrm{N}^{b}$ & LI & $157.5^{c}$ & - & $1998^{[243]}$ \\
\hline$\left[\left(\mathrm{PhBP}_{3}\right) \mathrm{Co}^{\mathrm{III}}(\mathrm{Ntol})\right]$ & PTD & $165.8(2)$ & $169.51(2)$ & $2002^{[233]}$ \\
\hline$\left[\left(\mathrm{PhBP}_{3}\right) \mathrm{Co}^{\mathrm{III}}(\mathrm{N} t \mathrm{Bu})\right]$ & PTD & 163.3(2) & $176.9(1)$ & $2006^{[234]}$ \\
\hline$\left[\left(\mathrm{Me}_{2} \mathrm{NN}\right) \mathrm{Co}^{\mathrm{III}}(\mathrm{NAd})\right]$ & TPL & $162.4(4)$ & $161.5(3)$ & $2004^{[235]}$ \\
\hline$\left[\left(\mathrm{TIMEN}^{\mathrm{Mes}}\right) \mathrm{Co}^{\mathrm{III}}(\mathrm{NMes})\right]$ & PTD & 167.5(2) & $168.6(2)$ & $2004^{[247]}$ \\
\hline$\left[\left(\mathrm{Tp}^{t \mathrm{Bu}, \mathrm{Me}}\right) \mathrm{Co}^{\mathrm{III}}(\mathrm{NAd})\right]$ & PTD & $165.5(2)$ & $178.3(2)$ & $2005^{[236]}$ \\
\hline$\left[\left(\mathrm{PhB}(t \mathrm{BuIm})_{3}\right) \mathrm{Co}^{\mathrm{III}}(\mathrm{N} t \mathrm{Bu})\right]^{d}$ & PTD & $166.0(3)$ & $179.7(3)$ & $2007^{[237]}$ \\
\hline$\left[(\right.$ giso $\left.) \mathrm{Co}^{\mathrm{III}}(\mathrm{NAd})\right]$ & TPL & $162.1(3)$ & $172.1(3)$ & $2009^{[248]}$ \\
\hline$\left[(\mathrm{MTPDP}) \mathrm{Co}^{\mathrm{III}}(\mathrm{N} t \mathrm{Bu})\right]$ & TPL & $160.9(3)^{e}$ & $177.5(3)^{e}$ & $2012^{[238]}$ \\
\hline$\left[(\mathrm{IMes}) \mathrm{Co}^{\mathrm{IV}}(\mathrm{NDipp})_{2}\right]$ & TPL & $166.5(3)$ & $173.0(3)$ & $2014^{[239]}$ \\
\hline$\left[(\mathrm{IMes}) \mathrm{Co}^{\mathrm{V}}(\mathrm{NDipp})_{2}\right]^{+}$ & TPL & $164.1(3)^{f}$ & $174.2(3)^{f}$ & $2014^{[239]}$ \\
\hline$\left[(\mathrm{IPr}) \mathrm{Co}^{\mathrm{II}}(\mathrm{NDmp})\right]$ & LI & $169.1(6)$ & $173.0(3)$ & $2015^{[240]}$ \\
\hline$\left[(\mathrm{PMe})_{3} \mathrm{Co}^{\mathrm{II}}(\mathrm{NDipp})\right]$ & PTD & $170.89(15)$ & $177.85(14)$ & $2017^{[241]}$ \\
\hline$\left[(\mathrm{PMe})_{3} \mathrm{Co}^{\mathrm{III}}(\mathrm{NDmp})\right]^{+}$ & PTD & $165.40(17)$ & $166.99(15)$ & $2017^{[241]}$ \\
\hline$\left[(\mathrm{hmds})_{2} \mathrm{Co}^{\mathrm{III}}(\mathrm{N} t \mathrm{Bu})\right]^{-}$ & TPL & $170.67(12)$ & $160.78(12)$ & $2020^{[242]}$ \\
\hline
\end{tabular}

${ }^{a}$ Geometry; See Figure 1.3; LI: Linear

${ }^{b}$ By reacting laser-ablated cobalt atoms with $\mathrm{N}_{2}$

${ }^{c}$ Equilibrium bond distance $\left(r_{\mathrm{e}}\right)$ evaluated from rotational constant $B_{\text {eff }}{ }^{[244]}$

${ }^{d}$ By deprotonation of $\left[\left(\mathrm{PhB}(t \mathrm{BuIm})_{3}\right) \mathrm{Co}^{\mathrm{II}}(\mathrm{NH} t \mathrm{Bu})\right]$ obtained from reacting corresponding chloride with $\mathrm{LiNH} t \mathrm{Bu}$.

$e$ At $150 \mathrm{~K}$, at $300 \mathrm{~K}: 163.2(3) \mathrm{pm}$ and $178.2(3)^{\circ}$

$f$ Average; $d(\mathrm{Co}-\mathrm{N})=164.0(3) \mathrm{pm}$ and $164.2(3) \mathrm{pm} ; \measuredangle(\mathrm{Co}=\mathrm{N}-\mathrm{R})=173.7(3)^{\circ}$ and $174.7(3)^{\circ}$

\footnotetext{
${ }^{\dagger}$ The corresponding band of the iron congener shows an isotopic shift of $-5 \mathrm{~cm}^{-1}$.
} 


\section{Rhodium Imido and Nitrido Complexes}

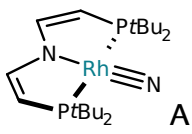

$\left[\left(P N P^{\prime}\right) \operatorname{Rh}^{I V} N\right]$

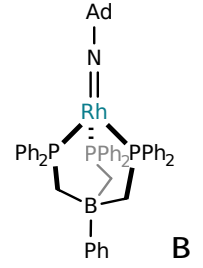

$\left[\left(\mathrm{PhBP}_{3}\right) \mathrm{Rh}^{\text {III}}(\mathrm{NAd})\right]$

Figure 1.12. Literature known non-binary terminal rhodium nitrido $(A)^{[249]}$ and rhodium-imido complexes (B). ${ }^{[250]}$

Despite the numerous cobalt imido complexes, the number of related rhodium complexes is remarkably low. The first rhodium-nitrogen multiple bond was realized in 1998 in the diatomic $\mathrm{Rh}^{\mathrm{III}} \mathrm{N} .{ }^{[251]}$ The electronic ground state was predicted to be ${ }^{1} \Sigma^{+}$ using all-electron $a b$ initio methods with a corresponding configuration of $10 \sigma^{2} 11 \sigma^{2}$ $12 \sigma^{2} 5 \pi^{4} 2 \delta^{4} 4 \pi^{0}$, which is isoelectronic to CoN. ${ }^{[252,253]}$ Shortly after that it was first produced in the gas-phase, ${ }^{[251]}$ and later isolated in solid argon. ${ }^{[254]}$ In solid argon, a $\mathrm{Rh}-\mathrm{N}$ stretching frequency of $895 \mathrm{~cm}^{-1}$ was obtained, ${ }^{[254]}$ which is very close to gas-phase values of $897 \mathrm{~cm}^{-1}$ and $900 \mathrm{~cm}^{-1}$ found in LIF excitation, and dispersed fluorescence spectra, respectively. ${ }^{[255]} \mathrm{The} \mathrm{Rh}-\mathrm{N}$ equilibrium bond distance was estimated to $164.1 \mathrm{pm} .{ }^{[255]}$ Additionally, in cryogenic matrices of the reaction products of laser-ablated rhodium and dinitrogen diluted in argon a band at $822.8 \mathrm{~cm}^{-1}$ has been assigned to bent $\mathrm{Rh}(\mathrm{N})_{2}$, for which an electronic ground state of ${ }^{2} \mathrm{~B}_{1}$ was claimed, however, no further investigation of the nature of the bonding was undertaken. ${ }^{[254]}$

Recently, the $\mathrm{Rh}^{\mathrm{IV}}$ pincer complex shown in Figure $1.12 \mathrm{~A}$ was successfully isolated. ${ }^{[249]}$ It was produced by irradiating the corresponding azide at $20 \mathrm{~K}$ and characterized by its EPR spectrum. IR spectra were taken from a $\mathrm{KBr}$ pellet containing the azide that was irradiated for a short time. The stretching frequency was observed at $874 \mathrm{~cm}^{-1}$, which is close to the stretching frequency assigned to diatomic RhN. The EPR data are consistent with DFT calculations that predict a $d^{5}$ configuration with a singly occupied molecular orbital (SOMO) of $\pi^{*}$ character and a $\mathrm{Rh}-\mathrm{N}$ bond distance of $168 \mathrm{pm}$. Due to the high degree of covalency of the $\mathrm{Rh} \equiv \mathrm{N} \pi$ system, the spin-density is delocalized over this unit, which results in a formal $\mathrm{BO}$ of 2.5. [249]

A significantly longer bond distance of $178.0(2) \mathrm{pm}$ associated with a nearly linear $\mathrm{Rh}=\mathrm{N}-\mathrm{C}$ bond angle of $177.5(2)^{\circ}$ was found in the thermally stable, pseudotetrahedral rhodium imido complex $\left[\left(\mathrm{PhBP}_{3}\right) \mathrm{Rh}^{\mathrm{III}}(\mathrm{NAd})\right]$, shown in Figure $1.12 \mathbf{B}$, using XRD. ${ }^{[250]}$ Additionally, the related $\left[\left(\mathrm{PhBP}_{3}\right) \mathrm{Rh}^{\mathrm{III}}(\mathrm{NR})\right]\left(\mathrm{R}=2,6-i \mathrm{Pr}_{2} \mathrm{C}_{6} \mathrm{H}_{6}\right.$ and $\mathrm{C}_{6} \mathrm{~F}_{5}$ ) were successfully synthesized, but no crystals suitable for a crystal structure analysis could be obtained. ${ }^{[250]}$ Theoretical calculation at DFT level revealed closed- 
shell $d^{6}$ configurations for these complexes, consistent with $\mathrm{Rh}=\mathrm{N}$ double bonds.

The experimentally isolated rhodium-imido and -nitrido complexes are summarized in Table 1.6.

Table 1.6: All published terminal rhodium-nitrido and rhodium-imido complexes. Including, where available, Rh-N bond lengths ( $d$ in $\mathrm{pm}$ ) and $\mathrm{Rh}-\mathrm{N}$ stretching frequencies $\left(\tilde{v}\right.$ in $\left.\mathrm{cm}^{-1}\right)$. All structural data obtained from XRD or DFT (square brackets).

\begin{tabular}{lcccc}
\hline Complex & Geometry $^{a}$ & $d(\mathbf{R h}-\mathbf{N})$ & $\tilde{v}[\boldsymbol{v}(\mathbf{R h}-\mathbf{N})]$ & Year $^{[\mathrm{REF}]}$ \\
\hline $\mathrm{Rh}^{\mathrm{III}} \mathrm{N}$ & $\mathrm{LI}$ & $164.1^{b}$ & $895-900^{c}$ & $1998^{[251]}$ \\
$\mathrm{Rh}(\mathrm{N})_{2}$ & $\mathrm{BE}$ & {$[173]$} & $823^{d}$ & $1999^{[254]}$ \\
{$\left[\left(\mathrm{PNP}^{\prime}\right) \mathrm{Rh}^{\mathrm{IV}} \mathrm{N}\right]$} & $\mathrm{SPL}$ & {$[168]$} & $874^{e}$ & $2013^{[249]}$ \\
{$\left[\left(\mathrm{PhBP}_{3}\right) \mathrm{Rh}^{\mathrm{III}}(\mathrm{NAd})\right]$} & $\mathrm{PTD}$ & $178.0(2)$ & - & $2014^{[250]}$ \\
\hline
\end{tabular}

${ }^{a}$ See Figure 1.3; LI: Linear, BE: Bent

$b$ Equilibrium bond distance $\left(r_{\mathrm{e}}\right)$ evaluated from rotational constant $B_{\text {eff }}{ }^{[255]}$

$c$ Values from solid argon and gas-phase (see text) ${ }^{[254,255]}$

$d$ Solid argon

e $\mathrm{KBr}$ pellet

Iridium Imido and Nitrido Complexes

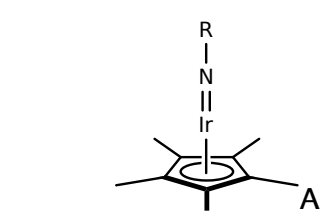

$\left[\left(\mathrm{Cp}^{*}\right) \mid r^{\mathrm{IV}}(\mathrm{NR})\right]$

$\mathrm{R}=t \mathrm{Bu}, \mathrm{SiMe}_{2} t \mathrm{Bu}, \mathrm{Xyl}$, Dipp

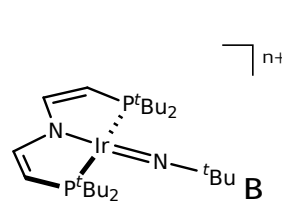

$\left.[(\mathrm{PNP})) r^{\prime \prime \prime}(\mathrm{N} t \mathrm{Bu})\right] \quad(\mathrm{n}=0)$

$\left.[(\mathrm{PNP})) \operatorname{rr}^{\mathrm{IV}}(\mathrm{N} t \mathrm{Bu})\right]^{+}(\mathrm{n}=1)$

$\left[\left(\mathrm{PNP}^{\prime}\right) \operatorname{Ir}^{\mathrm{V}}(\mathrm{N} t \mathrm{Bu})\right]^{2+}(\mathrm{n}=2)$

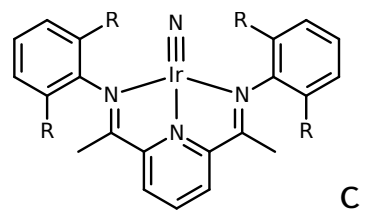

$\left[\left(i \mathrm{Pr}_{4} \mathrm{PDI}\right) \mid \mathrm{r}^{\mathrm{V}} \mathrm{N}\right](\mathrm{R}=i \mathrm{Pr})$

$\left[\left(\mathrm{Cl}_{4} \mathrm{PDI}\right) \mathrm{Ir}^{\vee} \mathrm{N}\right] \quad(\mathrm{R}=\mathrm{Cl})$

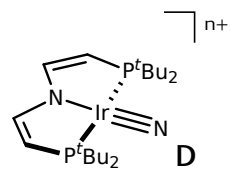

$\left[\left(\mathrm{PNP}^{\prime}\right) \mid r^{\mathrm{IV}} \mathrm{N}\right] \quad(\mathrm{n}=0)$ $\left[\left(P^{\prime} N P^{\prime}\right) \mid r^{\vee} N\right]^{+}(n=1)$

Figure 1.13. Literature known non-binary terminal iridium imido $\left(\mathrm{A}^{[256,257]}\right.$ and $\left.\mathbf{B}^{[258]}\right)$ and iridium nitrido complexes $\left(\mathrm{C}^{[259,260]}\right.$ and $\left.\mathrm{D}^{[261]}\right)$.

As with rhodium, isolated iridium nitrido and imido complexes are scarce. Imido complexes were produced by treating the precursor complexes with lithium amides (LiNHR) in salt metathesis reactions, characterized as linear $\mathrm{Cp}^{*}$ and square planar PNP' complexes. ${ }^{[256-258]}$ The former, shown in Figure 1.13 A, comes with iridium in OS III and was crystallized, showing terminal imido ligands and with $\mathrm{Ir}-\mathrm{N}$ bond distances ranging from $171.2(7) \mathrm{cm}^{-1}$ to $175.0(7) \mathrm{cm}^{-1} \cdot{ }^{[256,257]}$ Due to the absence of ligands in the xy plane, the $d$-orbital splitting of these complexes feature two metal centered fully occupied non-bonding $\left(d_{x y}\right)^{2}\left(d_{x^{2}-y^{2}}\right)^{2}$ orbitals, along with $\left(d_{z^{2}}\right)^{2}$ which only weakly interacts with the $\mathrm{Cp}^{*}$ orbitals. ${ }^{[257]}$ Very recently, the square planar PNP pincer com- 
plexes shown in Figure 1.13 B with iridium OSs from III to V were investigated. [258] For the complexes with iridium in formal OSs III and IV crystal structures with very long $\mathrm{Ir}-\mathrm{N}$ bond distances of 180.5(2) pm $\left(\mathrm{Ir}^{\mathrm{IV}}\right)$ and 186.8(2) pm ( $\left.\mathrm{Ir}^{\mathrm{III}}\right)$ were recorded. This is consistent with a $d^{5}$ triplet configurations of the $\operatorname{Ir}^{\mathrm{IV}}$ complex, in which one electron is accomodated in the $\pi^{*}$ LUMO (c.f. Figure 1.3, SPL), resulting in $\operatorname{Ir}-\mathrm{N}$ bond elongation, reduced $\mathrm{BO}$ and an triplet electronic ground state. The $\mathrm{Ir}=\mathrm{N}$ bond in $\left[\left(\mathrm{PNP}^{\prime}\right) \operatorname{Ir}^{\mathrm{IV}}(\mathrm{N} t \mathrm{Bu})\right]^{+}$was characterized by EPR spectroscopy. It is highly covalent and the imido ligand shows non-innocent character, evident by cylindrical spin density delocalization around the $\mathrm{Ir}=\mathrm{N}$ bond attributed to orbital mixing of the near degenerate, perpendicular $\pi^{*}$-antibonding SOMO and LUMO. ${ }^{[258]}$ Furthermore, the corresponding $\mathrm{Fe}^{\mathrm{V}}$ dicationic complex was synthesized as well. As expected, its electronic ground state is a singlet state, however, no XRD analysis and no theoretical structural predictions were reported.

The equilibrium bond distance $\left(r_{\mathrm{e}}\right)$ of diatomic $\operatorname{Ir}^{\mathrm{III}} \mathrm{N}$ was evaluated from the experimental rotational constant to $160.7 \mathrm{pm} .{ }^{[262]}$ Like CoN and $\mathrm{RhN}$ (see above) the electronic ground state is a ${ }^{1} \Sigma^{+}$state. ${ }^{[262]}$ A number of additional investigations of the ground- and excited states of IrN have been conducted experimentally and theoretica1ly. ${ }^{[263-265]}$ The first terminal iridium nitrido complex characterized by XRD, shown in Figure 1.13 C $(\mathrm{R}=i \mathrm{Pr})$, exhibits a $\mathrm{Ir}-\mathrm{N}$ bond distance of $164.6(9) \mathrm{pm} .{ }^{[259]}$ The authors refrain from assigning an OS, but suggest a $d^{6}$ electron configuration based on multireference calculations, while a formal OS of $\mathrm{V}$ with a $d^{4}$ electron configuration would be assigned in the ionic approximation, based on the neutral total charge of the complex and ligand charges of $\mathrm{PDI}^{2-}$ and $\mathrm{N}^{3-}$. This corresponds to a singlet ground state with fully occupied set of non-bonding $\left(d_{x y}, x^{2}-y^{2}\right)$ orbitals and empty anti-bonding $\sigma^{*}$ and $\pi^{*}$ MOs, resulting in an $\mathrm{Ir} \equiv \mathrm{N}$ BO of three. It has been demonstrated that the nitrido ligand in this complex displays both electrophilic and nucleophilic properties, depending on the substrate employed. ${ }^{[266,267]}$ Investigations focused on C-H activation reactivity and dimerization lead to the synthesis of the analog in which the $i \mathrm{Pr}-$ groups are substituted by chlorine (Figure $1.13 \mathrm{C}$ ) to hamper intramolecular $\mathrm{C}-\mathrm{H}$ activation. ${ }^{[260,268]}$ Both of these complexes show very similar $\mathrm{Ir}-\mathrm{N}$ stretching frequencies of $958 \mathrm{~cm}^{-1}\left(\mathrm{R}=i \mathrm{Pr}\right.$, Raman shift) and $955 \mathrm{~cm}^{-1}(\mathrm{R}=\mathrm{Cl})$.

The square planar closed and open-shell PNP pincer iridium nitrido complexes shown in Figure 1.13 D are closely related to the corresponding imido complexes presented above (Figure 1.10 B). ${ }^{[261]}$ This becomes clear from the comparable covalent nature of the $\pi$-bonding and $\pi^{*}$-antibinding MOs. The formal OSs of IV and V are not consistent with the observed reactivity of the cationic complex, which exhibited electrophilic reactivity. This lead to a revised assignment of an effective OS of III for the cationic complex. The SOMO of the neutral complex is a $\pi^{*}$-antibonding 
orbital and the covalent character of this orbital leads to a distribution of the spindensity over the $\mathrm{Ir}-\mathrm{N}$ moiety and to a non-innocent character of the nitrido ligand. The Ir $-\mathrm{N}$ bond length of $167.8(4) \mathrm{pm}(172 \mathrm{pm}$, DFT) and $\mathrm{Ir}-\mathrm{N}$ stretching frequencies of $999 \mathrm{~cm}^{-1}\left(901 \mathrm{~cm}^{-1}\right)$ of the cationic (neutral) species are consistent with these findings. The nitrido ligands of these complexes can be oxidatively coupled to yield dinitrogen. ${ }^{[269]}$

It is worth point out that, so far, no matrix isolatation experiments of laser-ablated iridium and dinitrogen gas have been conducted. In addition to the potential formation of $\operatorname{Ir}(\mathrm{N})_{2}$, this experiment may produce $\operatorname{Ir}(\mathrm{N})_{3}$ with a formal iridium OS of IX. Furthermore, iridium complexes with terminal nitrido ligands and formal OSs beyond five were proposed very recently, but not yet characterized. [270]

Table 1.7: Known terminal iridium nitrido and iridium-imido complexes with reported $\operatorname{Ir}-\mathrm{N}$ bond lengths $(d$ in $\mathrm{pm})$ and $\mathrm{Ir}-\mathrm{N}$ stretching frequencies $\left(\tilde{v}\right.$ in $\left.\mathrm{cm}^{-1}\right)$. Structural data obtained from XRD or DFT calculations (in square brackets).

\begin{tabular}{|c|c|c|c|c|}
\hline Complex & Geometry $^{a}$ & $d(\mathbf{I r}-\mathbf{N})$ & $\tilde{v}[v(\mathbf{I r}-\mathbf{N})]$ & Year $^{[R E F]}$ \\
\hline$\left[\left(\mathrm{Cp}^{*}\right) \operatorname{Ir}^{\mathrm{III}}(\mathrm{N} t \mathrm{Bu})\right]$ & LI & $171.2(7)$ & - & $1989^{[256]}$ \\
\hline$\left[\left(\mathrm{Cp}^{*}\right) \operatorname{Ir}{ }^{\mathrm{III}}\left(\mathrm{NSiMe}_{2} t \mathrm{Bu}\right)\right]$ & LI & $175.0(7)$ & - & $1991^{[257]}$ \\
\hline$\left[\left(\mathrm{Cp}^{*}\right) \operatorname{Ir}^{\mathrm{III}}(\mathrm{NXyl})\right]$ & LI & $172.9(7)$ & - & $1991^{[257]}$ \\
\hline$\left[\left(\mathrm{Cp}^{*}\right) \mathrm{Ir}^{\mathrm{III}}(\mathrm{NDipp})\right]$ & LI & $174.9(7)$ & - & $1991^{[257]}$ \\
\hline $\mathrm{Ir}^{\mathrm{III}} \mathrm{N}$ & LI & $160.7^{b}$ & 1114 & $1999^{[262]}$ \\
\hline$\left[\left(i \mathrm{Pr}_{4} \mathrm{PDI}\right) \mathrm{Ir}^{\mathrm{V}} \mathrm{N}\right]$ & SPL & $164.6(9)$ & $958^{c}$ & $2009^{[259]}$ \\
\hline$\left[\left(\mathrm{Cl}_{4} \mathrm{PDI}\right) \mathrm{Ir}^{\mathrm{V}} \mathrm{N}\right]$ & SPL & [169] & $955^{d}$ & $2011^{[260]}$ \\
\hline$\left[\left(\mathrm{PNP}^{\prime}\right) \mathrm{Ir}^{\mathrm{V}} \mathrm{N}\right]^{+}$ & SPL & $167.8(4)$ & $999^{e}$ & $2012^{[261]}$ \\
\hline$\left[\left(\mathrm{PNP}^{\prime}\right) \mathrm{Ir}^{\mathrm{IV}} \mathrm{N}\right]$ & SPL & {$[172]$} & $901^{e}$ & $2012^{[261]}$ \\
\hline$\left[\left(\mathrm{PNP}^{\prime}\right) \operatorname{Ir}^{\mathrm{III}}(\mathrm{N} t \mathrm{Bu})\right]$ & SPL & $186.8(2)$ & - & $2018^{[258]}$ \\
\hline$\left[\left(\mathrm{PNP}^{\prime}\right) \operatorname{Ir}^{\mathrm{IV}}(\mathrm{N} t \mathrm{Bu})\right]^{+}$ & SPL & $180.5(2)$ & - & $2018^{[258]}$ \\
\hline
\end{tabular}

${ }^{a}$ See Figure 1.3; LI: Linear

${ }^{b}$ Equilibrium bond distance $\left(r_{\mathrm{e}}\right)$ evaluated from rotational constant

${ }^{c}$ Raman shift

${ }^{d} \mathrm{KBr}$ pellet

${ }^{e}$ Nujol

\subsubsection{Matrix-Isolation Works}

Works in which group 8 and 9 metal nitrido complexes were studied using matrixisolation spectroscopy are limited to reactions of laser-ablated metal atoms and dinitrogen (Table $1.8, \mathrm{M}+\mathrm{N}_{2}$ ). ${ }^{[185,202,232,243,254]}$ The exception is iridium, for which no nitrido complexes were investigated in matrix-isolation experiments to this date. In 
these works, mononuclear nitrido $(\mathrm{MN})$ and dinitrido complexes $\left(\mathrm{M}(\mathrm{N})_{2}\right)$ were observed, except for cobalt, where only CoN was detected. The reaction products of laserablated transition metal atoms and nitrogen trifluoride were investigated for group 4, 6, and 11 elements (Table 1.8, $\mathrm{M}+\mathrm{NF}_{3}$ ). These products consist of triplet nitrene trifluorides (group 4), ${ }^{[271]}$ nitrido trifluorides (group 6), ${ }^{[272]}$ as well as difluoroimino fluoride and fluoroimido difluoride complexes (group 11). ${ }^{[273]}$ Metal fluorido complexes were investigated in matrix-isolation experiments of the group 8 and 9 elements iron, ${ }^{[78,274]}$ ruthenium, ${ }^{[275,276]}$, osmium, ${ }^{[277]}$ cobalt, ${ }^{[278]}$ rhodium, ${ }^{[275]}$ and iridium. ${ }^{[277]}$

Table 1.8: Vibrational frequencies $\tilde{v}\left(\mathrm{~cm}^{-1}\right)$ obtained from matrix-isolation IR spectroscopic investigations of product molecules embedded in dinitrogen, argon or neon. These include nitrido complexes from reactions of laser-ablated group 8 and 9 metals and $\mathrm{N}_{2}$, as well as laser-ablated group 4 and 6 metals and $\mathrm{NF}_{3}$. Additionally included are fluoroimido and difluoroimino complexes from the reaction of laser-ablated group 11 metals and $\mathrm{NF}_{3}$.

\begin{tabular}{|c|c|c|c|c|}
\hline Complex & $\tilde{v}\left(\mathrm{~N}_{2}\right)$ & $\tilde{v}(\mathbf{A r})$ & $\tilde{v}(\mathrm{Ne})$ & [REF] \\
\hline \multicolumn{5}{|l|}{$\mathbf{M}+\mathbf{N}_{2}$} \\
\hline $\mathrm{FeN}$ & 934.8 & 938.0 & - & {$[185]$} \\
\hline $\mathrm{Fe}(\mathrm{N})_{2}$ & $903.6^{a}$ & $903.4^{a}$ & - & [185] \\
\hline $\mathrm{RuN}$ & 981.5 & 984.0 & - & {$[202,232]$} \\
\hline $\mathrm{Ru}(\mathrm{N})_{2}$ & $831.5^{a}$ & $831.9^{a}$ & - & {$[202,232]$} \\
\hline OsN & 1049.6 & 1130.3 & - & {$[202,232]$} \\
\hline $\mathrm{Os}(\mathrm{N})_{2}$ & $901.1^{a}$ & $900.4^{a}$ & - & {$[202,232]$} \\
\hline $\mathrm{CoN}$ & - & 826.5 & - & [243] \\
\hline $\mathrm{RhN}$ & - & 894.9 & - & {$[254]$} \\
\hline $\operatorname{Rh}(\mathrm{N})_{2}$ & $830.9^{a}$ & $822.8^{a}$ & - & {$[254]$} \\
\hline \multicolumn{5}{|l|}{$\mathbf{M}+\mathrm{NF}_{3}$} \\
\hline $\mathrm{NTiF}_{3}$ & - & $596.7,782.1,705.1^{b}$ & 一 & {$[271]$} \\
\hline $\mathrm{NZrF}_{3}$ & - & $553.1,667.4,658.2^{b}$ & 一 & {$[271]$} \\
\hline $\mathrm{NHfF}_{3}$ & - & $548.1,666.7,643.9^{b}$ & - & {$[271]$} \\
\hline $\mathrm{NCrF}_{3}$ & - & $1015,792,705^{b}$ & $1020,798,709^{b}$ & {$[272]$} \\
\hline $\mathrm{NMoF}_{3}$ & - & $1075,704,682^{b}$ & $1080,708,688^{b}$ & {$[272]$} \\
\hline $\mathrm{NWF}_{3}$ & - & $1091,693,699^{b}$ & $1096,704,699^{b}$ & {$[272]$} \\
\hline $\mathrm{FNCuF}_{2}$ & - & $1139.6,736.2^{c}$ & - & {$[273]$} \\
\hline $\mathrm{F}_{2} \mathrm{NCuF}$ & - & $1090.5,985.0,678.5,597.5^{d}$ & $1094.3,988.2,-,-^{d}$ & {$[273]$} \\
\hline $\mathrm{F}_{2} \mathrm{NAgF}$ & - & $1099.2,1006.2,529.6,--^{d}$ & $1102.4,1010.8,-,-^{d}$ & [273] \\
\hline $\mathrm{F}_{2} \mathrm{NAuF}$ & - & $1089.7,1006.3,-,-^{d}$ & $1095.3,-,-,-^{d}$ & {$[273]$} \\
\hline
\end{tabular}

a Antisymmetric stretching mode

${ }^{b} \mathrm{a}_{1}[v(\mathrm{MN})], \mathrm{e}[v(\mathrm{MF})], \mathrm{a}_{1}[v(\mathrm{MF})]$ (notation based on $C_{3 \mathrm{v}}$ point group symmetry)

c $v(\mathrm{NF}), v_{\mathrm{as}}(\mathrm{FCuF})$

$d v_{\mathrm{s}}(\mathrm{FNF}), v_{\mathrm{as}}(\mathrm{FNF}), v(\mathrm{MF}), \delta(\mathrm{FNF})$ 



\section{Objectives}

The chemistry of high-valent late transition metal complexes is more intricate and convoluted than a simple MO picture based on the isoelectronegativity principle would suggest. In other words, the oxidation of a known nitrido metal complex in a low metal oxidation state, especially those of late transition metals, can often not simply be represented as removing of electrons from the metal center, as one might assume based on a simplified MO model. This widespread view completely neglects more recent developments in the chemistry of very high-valent metal complexes, such as the concept of non-innocent oxo and nitrido ligands, ${ }^{[75,76]}$ the concept of an inverted ligand field, ${ }^{[279]}$ as well as the enhanced primogenic repulsion in high-valent $1^{\text {st }}$ row transition metal complexes, ${ }^{[96,97]}$ and the near-degeneracy of excited electronic states in high-valent complexes. Also an appropriate quantum chemical description of such high-valent compounds is difficult and intricate. ${ }^{[62,125]}$ Therefore, the spectroscopic characterization of reactive species bearing metals in their highest possible oxidation states and which currently cannot be synthesized using conventional methods is highly desired.

Although structural and vibrational data of a considerable number of terminal nitrido complexes of group 8 and 9 were already reported, only one nitrido compound of iron in the formal OS of VI has so far been described and for cobalt the diatomic CoN is, as far as I know, the only experimentally known example of a nitrido cobalt compound. As this work relies on a systematic experimental and computational study of high-valent late transition metal nitrido complexes it should be emphasized, that even in those cases where reliable XRD data are available, the electronic properties and the strength of the metal nitrido ligand multiple bond seems to be significantly influenced by the supporting complex ligands, especially in the presence of donor ligands or solvent molecules in a trans-position to the nitrido ligand. These data seems to be only of limited use for a systematic and rigorous computational investigation of high-valent late transition metal nitrido compounds. A much better experimental basis for such an investigation, on the other hand, is provided by vibrational data of closely related and more simple metal nitrido compounds using innocent auxiliary ligands that support and enable a rigorous computational investigation.

The aim of this work was therefore to use the matrix-isolation technique to prepare such high-valent late transition metal complexes with metal-nitrogen multiple bonds. These encompass metal-nitrido and metal-imido bonding with emphasis on high metal oxidation states as well as exploring the limits of attainable oxidation states in binary metal-nitrido complexes without supporting auxiliary ligands. In particular, this was achieved by reacting laser-ablated group 8 and 9 transition metal atoms with nitrido trifluoride, and laser-ablated iridium atoms with dinitrogen. For the former 
reaction, products were expected to include $\mathrm{NMF}_{3}$ and $\mathrm{FNMF}_{2}$ compounds that either feature a metal-nitrido triple bond with high-valent metal centers, or the uncommon fluoro-substituated fluoroimido ligand, both stabilized by innocent fluorido $\left(\mathrm{F}^{-}\right)$auxiliary ligands. The latter experiment with iridium atoms was aimed to explore the oxidation state limit that can be achieved in binary iridium nitrido complexes. Since iridium is able to reach formal oxidation states of up to IX, the goal was to generate and characterize molecular trinitrido iridium(IX), $\operatorname{Ir}(\mathrm{N})_{3}$.

The results of this work are briefly outlined in the next section, followed by the corresponding articles in Section 4 and their Supporting Information in the Appendix. 


\section{Outline}

The reaction of laser-ablated group 8 and 9 late transition metal atoms with nitrogen trifluoride diluted in inert gas provides access to products formed by metal insertion into one of the $\mathrm{N}-\mathrm{F}$ bonds and subsequent rearrangement reactions shown in Reactions 1-3.

$$
\begin{aligned}
& \mathrm{NF}_{3}+\mathrm{M} \longrightarrow \mathrm{F}_{2} \mathrm{~N}-\mathrm{MF} \\
& \mathrm{F}_{2} \mathrm{~N}-\mathrm{MF} \longrightarrow \mathrm{FN}=\mathrm{MF}_{2} \\
& \mathrm{FN}=\mathrm{MF}_{2} \longrightarrow \mathrm{N} \equiv \mathrm{MF}_{3}
\end{aligned}
$$

Because the $\mathrm{N}-\mathrm{F}$ bond can be expected to be much weaker than the corresponding $\mathrm{M}-\mathrm{F}$ bonds and the barrier for an exothermic fluorine migration from nitrogen to the metal center is usually low, it should lead, in most cases, to the nitrido metal trifluorides with the metal in the OS of VI. Indeed, nitrido fluorides, $\mathrm{N} \equiv \mathrm{MF}_{3}$, were obtained for $\mathrm{M}=\mathrm{Fe}, \mathrm{Ru}, \mathrm{Os}, \mathrm{Rh}$, Ir, while only for $\mathrm{M}=\mathrm{Co}$ and $\mathrm{Rh}$ fluoroimido complexes, $\mathrm{FN}=\mathrm{MF}_{2}$, were observed. These products were deposited on a cryogenic matrix support trapped in solid inert gas.

The laser-ablation of iridium atoms in the presence of dinitrogen gas should not only lead to its dinitrogen complexes. Iridium atoms may also insert into the $\mathrm{N} \equiv \mathrm{N}$ bond of $\mathrm{N}_{2}$ to yield NIrN, but also $\mathrm{N}$ atoms will be generated by photo-decomposition of $\mathrm{N}_{2}$, which is exposed to the broadband radiation emitted by the plasma plume. Reactions of nitrogen radicals with iridium atoms may lead to the formation of $\operatorname{IrN}, \operatorname{Ir}(\mathrm{N})_{2}$ and $\operatorname{Ir}(\mathrm{N})_{3}$ product molecules with formal iridium OSs of up to IX. The product molecules are then rigorously investigated using IR spectroscopy in conjunction with quantumchemical calculations. Of particular interest in these studies is the nature of the metalnitrogen multiple bond to the group 8 and 9 metal centers in high OS facilitated by either innocent fluorido spectator ligands or additional nitrido ligands. 


\subsection{Group 8 Nitrido Fluoride Complexes}

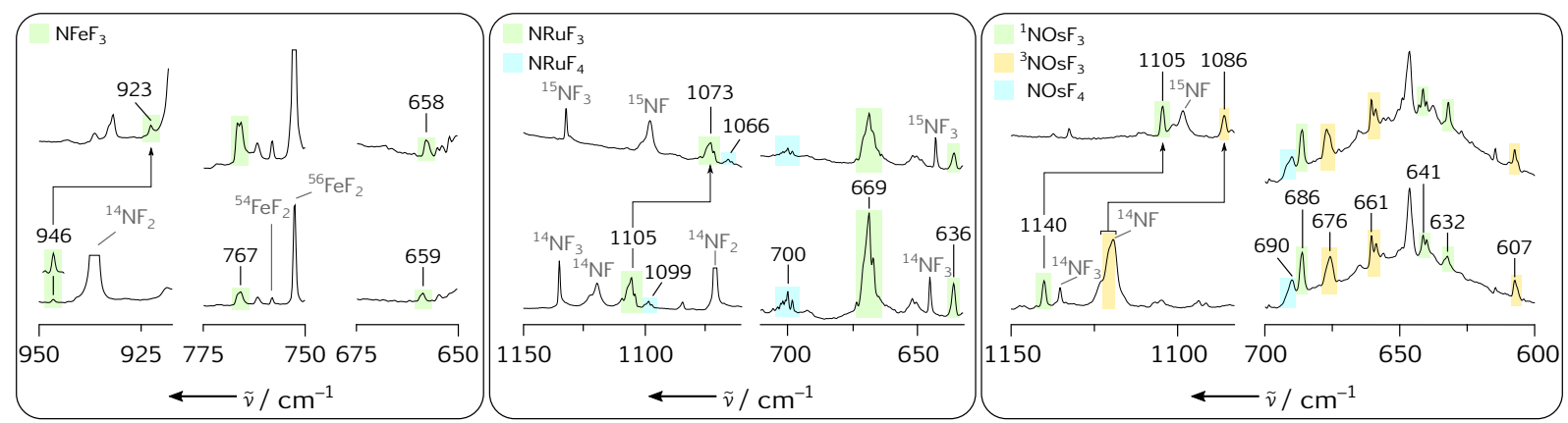

Figure 3.1. IR absorption spectra obtained from co-deposition of laser ablated group 8 metals iron (left), ruthenium (center) and osmium (right) with ${ }^{15} \mathrm{NF}_{3}$ (top) and ${ }^{14} \mathrm{NF}_{3}$ (bottom) in solid neon. For clarity, vibrational frequencies for just one isotopologue are given only when no ${ }^{14 / 15} \mathrm{~N}$ isotopic shift was detected. For more details see Section 4.1.

The main reaction product of excited laser-ablated group 8 atoms with nitrogen trifluoride $\left(\mathrm{NF}_{3}\right)$ is nitrido metal(VI) trifluoride $\left(\mathrm{NM}^{\mathrm{VI}} \mathrm{F}_{3}, \mathrm{M}=\mathrm{Fe}, \mathrm{Ru}, \mathrm{Os}\right)$, with weaker signals of nitrido metal(VII) tetrafluorides $\left(\mathrm{NM}^{\mathrm{VII}} \mathrm{F}_{4}, \mathrm{M}=\mathrm{Ru}, \mathrm{Os}\right) . \mathrm{All} \mathrm{NMF}_{3}$ and $\mathrm{NMF}_{4}$ product formations are calculated to be considerably exothermic at the DFT level of theory. Excerpts from the IR spectra of the product molecules depicted in Figure 3.1 show all assigned product bands and their isotopic shifts caused by substituting the ${ }^{14} \mathrm{NF}_{3}$ reactant with ${ }^{15} \mathrm{NF}_{3}$. The assignment of the product molecules was facilitated by distinct ${ }^{14 / 15} \mathrm{~N}$ isotopic shifts of vibrational frequencies of modes that involve nitrogen displacements and sophisticated quantum-chemical calculations. The latter allowed thorough investigations of the electronic and geometric structure of the main products. An overview of these results is presented in Figure 3.2.

As outlined in Section 1.5.1, the dicationic $\left[\left(\mathrm{Me}_{3} \text { cyclam-ac }\right) \mathrm{Fe}^{\mathrm{VI}} \mathrm{N}\right]^{2+}$ complex in pseudo octahedral (PO) coordination geometry is the only iron(VI) nitrido complex known to this date. ${ }^{[67]}$ In accordance with the $d$-orbital splitting scheme (see Figure 1.3) for this coordination geometry, a singlet ground state was determined for this complex featuring a $\mathrm{Fe} \equiv \mathrm{N}$ triple bond with a bond distance of 157(2) pm obtained by fitting EXAFS data. ${ }^{[67]}$ Complexes in pseudo tetrahedral (PTD) geometries with $\mathrm{Fe}^{\mathrm{IV}}$ and $\mathrm{Fe}^{\mathrm{V}}$ centers have been successfully characterized as well, with $\mathrm{Fe}-\mathrm{N}$ bond distances determined by XRD of $150.0(3) \mathrm{cm}^{-1}$ to $153.2(5) \mathrm{cm}^{-1},[15,174-177]$ and $\mathrm{Fe}-\mathrm{N}$ vibrational frequencies of $1008 \mathrm{~cm}^{-1}$ to $1034 \mathrm{~cm}^{-1} \cdot{ }^{[173-175]}$ The hexavalent, three-fold symmetric $\mathrm{NFe}^{\mathrm{VI}} \mathrm{F}_{3}$ complex presented in this work features a $d^{2}$ high-spin ground state electronic configuration (Figure 3.2). The band position at $946 \mathrm{~cm}^{-1}$ assigned to the $\mathrm{Fe}-\mathrm{N}$ stretching mode of the highly symmetric pseudo tetrahedral (PTD) complex with $C_{3 \mathrm{v}}$ point group symmetry is consistent with a weakened $\mathrm{Fe} \equiv \mathrm{N}$ triple bond 

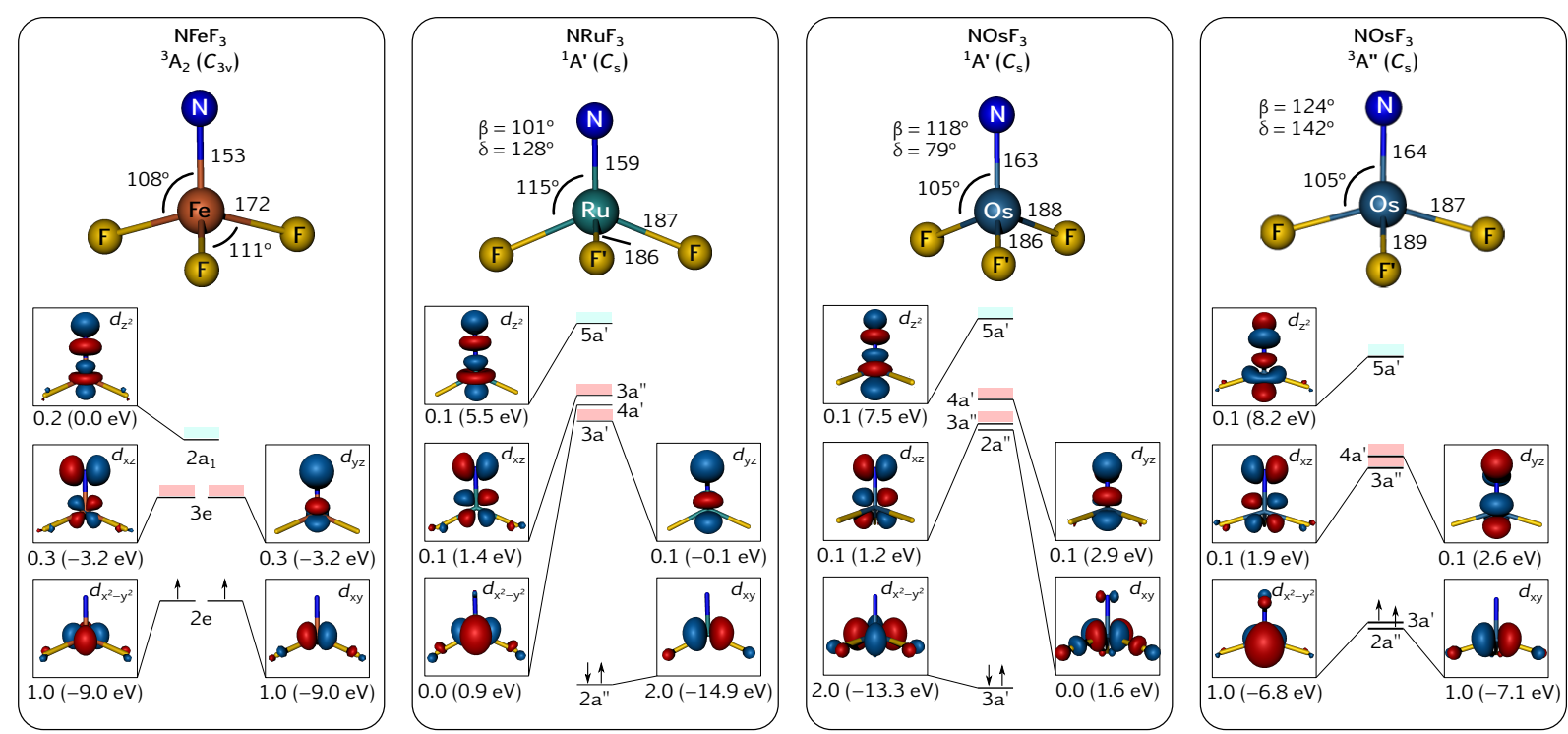

Figure 3.2. Calculated geometric structures and $d$-orbital splitting schemes, including occupation numbers and orbital energies, of the identified $\mathrm{NMF}_{3}$ species. Antibonding $\sigma^{*}$ and $\pi^{*} \mathrm{MOs}$ are highlighted in pink and light cyan, respectively. For more details see Section 4.1.

caused by configuration mixing evident by the increasing population of $\mathrm{Fe}-\mathrm{N}$ antibonding $3 e$ and $2 \mathrm{a}_{1}$ natural MOs shown in Figure 3.2. This results in an effective bond order $(\mathrm{EBO})$ of 2.2 for the $\mathrm{Fe} \equiv \mathrm{N}$ triple bond.

The bands assigned to the heavier ruthenium congener $\mathrm{NRu}^{\mathrm{VI}} \mathrm{F}_{3}$ are consistent with a distorted PTD coordination geometry, the first terminal ruthenium nitrido complex in PTD coordination geometry. The band at $1105 \mathrm{~cm}^{-1}$ assigned to the $\mathrm{Ru}-\mathrm{N}$ stretching vibration is indicative for a strong $\mathrm{Ru} \equiv \mathrm{N}$ triple bond close to the frequency obtained for diatomic RuN at $1109 \mathrm{~cm}^{-1}$ (see Table 1.2). This observation is consistent with the computational results for $\mathrm{NRu}^{\mathrm{VI}} \mathrm{F}_{3}$ which show a singlet electronic ground state. Analysis of the CASSCF wave function reveals low populations of the antibonding $\sigma^{*}$-type $\left(5 a^{\prime}\right)$ and $\pi^{*}$-type $\left(3 a^{\prime}, 3 a^{\prime \prime}\right)$ natural MOs and an EBO of 2.7. Calculations at the $\operatorname{CCSD}(\mathrm{T}) / \mathrm{CBS}$ level of theory locate the $C_{3 \mathrm{v}}$ symmetric ${ }^{3} \mathrm{~A}_{2}$ triplet state only $5 \mathrm{~kJ} \mathrm{~mol}^{-1}$ above the distorted singlet ${ }^{1} \mathrm{~A}^{\prime}$ electronic ground state. In the singlet configuration, the electrons are paired in one of the metal centered degenerate $e$-type MOs (c.f. 2e of $\mathrm{NFeF}_{3}$ ), namely $d_{\mathrm{xy}}$, which leads to the distorted ground state structure. In addition, bands at $1099 \mathrm{~cm}^{-1}$ and $700 \mathrm{~cm}^{-1}$ are assigned to $\mathrm{NRuF}_{4}$ in $C_{4 \mathrm{v}}$ point group symmetry. It adopts a ${ }^{2} \mathrm{~B}_{1}$ doublet ground state and is the first heptavalent ruthenium nitrido complex (for details see Section 4.1).

The first osmium nitrido complex, $\left[(\mathrm{O})_{3} \mathrm{Os}^{\mathrm{VIII}} \mathrm{N}\right]^{-}$, published in 1847 is not only the one with the highest OS, but also the only example in PTD coordination geometry (see Table 1.3). ${ }^{[12]}$ The $d^{0}$ configuration of this complex, which was synthesized 
from $\mathrm{OsO}_{4}$ and $\mathrm{NH}_{3}$, is consistent with its undistorted $C_{3 \mathrm{v}}$ structure, an Os $-\mathrm{N}$ bond distance of $162 \mathrm{pm}$, and with a stretching frequency of $1023 \mathrm{~cm}^{-1} .^{[222-224]}$ Quantumchemical calculations at the $\mathrm{CCSD}(\mathrm{T}) / \mathrm{CBS}$ level for the pseudo-tetrahedral $\mathrm{NOsF}_{3}$, on the other hand, predict quasi degenerate, distorted structures in singlet ${ }^{1} \mathrm{~A}^{\prime}$ and triplet ${ }^{3} \mathrm{~A}$ " electronic states with an energy gap of $-1.3 \mathrm{~kJ} \mathrm{~mol}^{-1}$ in favor of the triplet state. In fact, the spectra clearly show the formation of at least two different osmium nitrido species in good agreement with the predicted vibrational data (see Section 4.1). Consequently, the bands (Figure 3.1) were assigned to $\mathrm{NOsF}_{3}$ molecules in two different electronic states, which are depicted in Figure 3.2. The Os $-\mathrm{N}$ stretching frequencies of $1140 \mathrm{~cm}^{-1}\left({ }^{1} \mathrm{~A}^{\prime}\right)$ and $1086 \mathrm{~cm}^{-1}\left(\mathrm{Os}-{ }^{15} \mathrm{~N},{ }^{3} \mathrm{~A}^{\prime \prime}\right)$ and the calculated bond distances of $163 \mathrm{pm}\left({ }^{1} \mathrm{~A}^{\prime}\right)$ and $164 \mathrm{pm}\left({ }^{3} \mathrm{~A}^{\prime \prime}\right)$ indicate strong $\mathrm{Os} \equiv \mathrm{N}$ triple bonds. Furthermore, the band at $690 \mathrm{~cm}^{-1}$ provides evidence for the formation of $\mathrm{NOs}^{\mathrm{VII}} \mathrm{F}_{4}$.

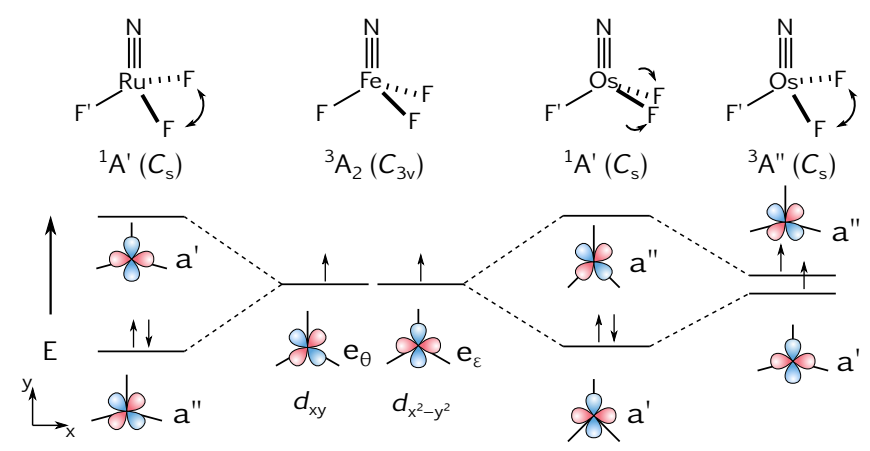

Figure 3.3. Hidden-pseudo-Jahn-Teller distortions and different $d^{2}$ electronic configurations of characterized group 8 nitrido metal fluorides $\mathrm{NMF}_{3}$.

Interestingly, all four $\mathrm{NMF}_{3}$ have different geometric and electronic structures. A high symmetry $C_{3 \mathrm{v}}$ ground state was only verified for $\mathrm{NFeF}_{3}$, albeit predicted by Hund's rule for two electrons in two-fold degenerate MOs. Figure 3.3 summarizes the metal centered $e$ orbital occupations and correlates them to the distortions of the different $d^{2}$ $\mathrm{NMF}_{3}$ species. Exhaustive potential energy surface (PES) scans of all electronic states arising from the $e^{2}$ configurations provides evidence that the origin of the ground state distortions are due to pseudo-Jahn-Teller effects "hidden" in the excited states. ${ }^{\text {[280-282] }}$ For details see Section 4.1. 


\subsection{Group 9 Nitrido and Imido Complexes}
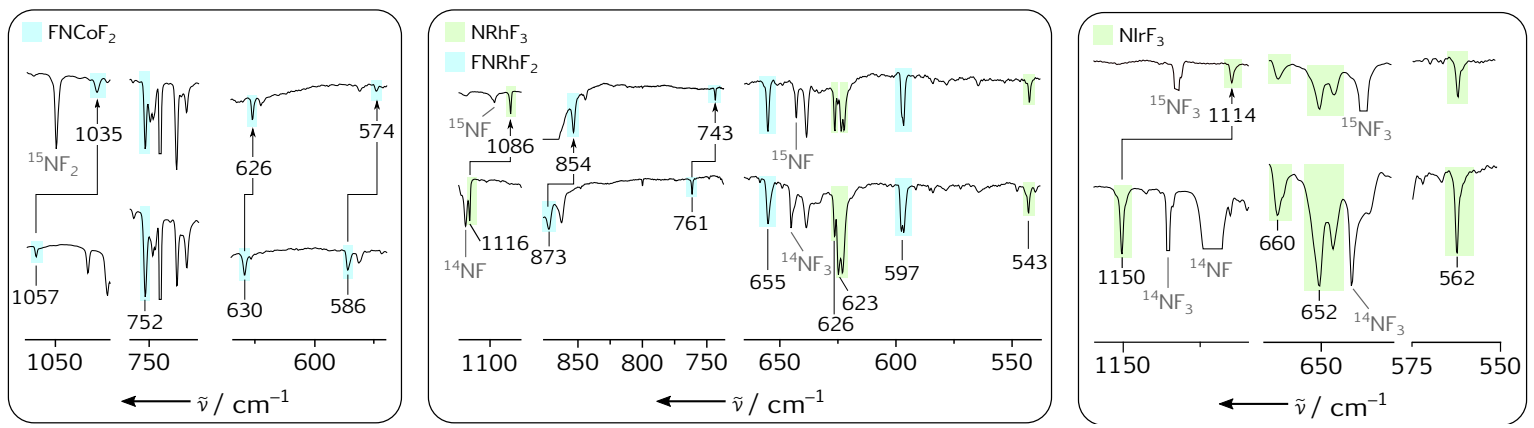

Figure 3.4. IR transmission spectra obtained from co-deposition of laser ablated group 9 metals cobalt (left), rhodium (center) and iridium (right) with ${ }^{15} \mathrm{NF}_{3}$ (top) and ${ }^{14} \mathrm{NF}_{3}$ (bottom) in solid neon. For clarity, vibrational frequencies for only one isotopologue are shown when no isotopic shift was detected. For more details see Section 4.2.

The most stable structural isomers obtained from $\mathrm{NF}_{3}+\mathrm{M}(\mathrm{M}=\mathrm{Co}, \mathrm{Rh}, \mathrm{Ir})$ and predicted by DFT calculations are $\mathrm{FNCoF}_{2}, \mathrm{NRhF}_{3}$ and $\mathrm{NIrF}_{3}$, which corroborates the assignments of the IR transmission spectra shown in Figure 3.4. Additional bands in the rhodium spectrum exhibit distinct ${ }^{14 / 15} \mathrm{~N}$ isotopic shifts that lead to the assignment of $\mathrm{FNRhF}_{2}$ which is only $12 \mathrm{~kJ} \mathrm{~mol}^{-1}$ higher in energy than the structural isomer $\mathrm{NRhF}_{3}$. The metal-nitrogen bond found in the fluoroimido complexes of cobalt and rhodium is very different to the ones described in Section 1.5.2 for $\mathrm{N}-\mathrm{CR}$ imido ligands. In the latter complexes bearing organic imido ligands the bonding is facilitated by $\pi$ interactions of $\mathrm{N}\left(p_{\mathrm{x}, \mathrm{y}}\right)$ and $\mathrm{M}\left(d_{\mathrm{xz}, \mathrm{yz}}\right)$ orbitals and a linear or nearly linear coordination. The $d$-orbital interactions depicted in Figure 3.5 show that in $\mathrm{FNCoF}_{2}$ and $\mathrm{FNRhF}_{2}$ the metal-nitrogen bond is formed by a $\sigma$-type interaction of the $\mathrm{M}\left(d_{\mathrm{z}^{2}}\right)$ and $\mathrm{N}\left(p_{\mathrm{z}}\right)$ orbitals (Figure 3.5, 4a' MO corresponds to the $\sigma^{*}$ antibonding $\mathrm{MO}$ ) that is perpendicular to the $\mathrm{N}-\mathrm{F}$ bond, resulting in a strongly bent structure with a $\mathrm{M}-\mathrm{N}-\mathrm{F}$ bond angle of $113^{\circ}$ for both $\mathrm{FNMF}_{2}$ complexes. Additionally, a $\pi$-type bond is provided by the interaction of $\mathrm{M}\left(d_{\mathrm{xz}}\right)$ and $\mathrm{N}\left(p_{\mathrm{x}}\right)$ orbitals. The corresponding $\pi^{*}$ antibonding orbital is labeled $3 \mathrm{a}^{\prime \prime}$ in Figure 3.5. The highest occupied molecular orbital (HOMO) of the dianionic fluoroimido ligand $\mathrm{NF}^{2-}$ (HOMO not shown in Figure 3.5 ) has mainly $\pi^{*} \mathrm{~F}-\mathrm{N}$ antibonding character and is strongly polarized towards the $\mathrm{N}$ atom. Any electron density donated from this ligand orbitals into a metal-centered orbital results in a strengthening of the $\mathrm{N}-\mathrm{F}$ bond. A low EBO of 1.1 for the $\mathrm{N}-\mathrm{Co}$ bond follows from the high natural occupation numbers of the antibonding orbitals of $\mathrm{FNCoF}_{2}$ ( $3 \mathrm{a}^{\prime \prime}$ and $4 \mathrm{a}^{\prime} \mathrm{MO}$ in Figure 3.5), which results in a very long $\mathrm{N}-\mathrm{Co}$ bond distance of $177 \mathrm{pm}$ and a weak $\mathrm{N}-\mathrm{Co}$ bond. This is in very good agreement with the band positions assigned to primarily $\mathrm{N}-\mathrm{Co}$ and $\mathrm{N}-\mathrm{F}$ stretching modes. The former is surprisingly low at $586 \mathrm{~cm}^{-1}$, confirming 

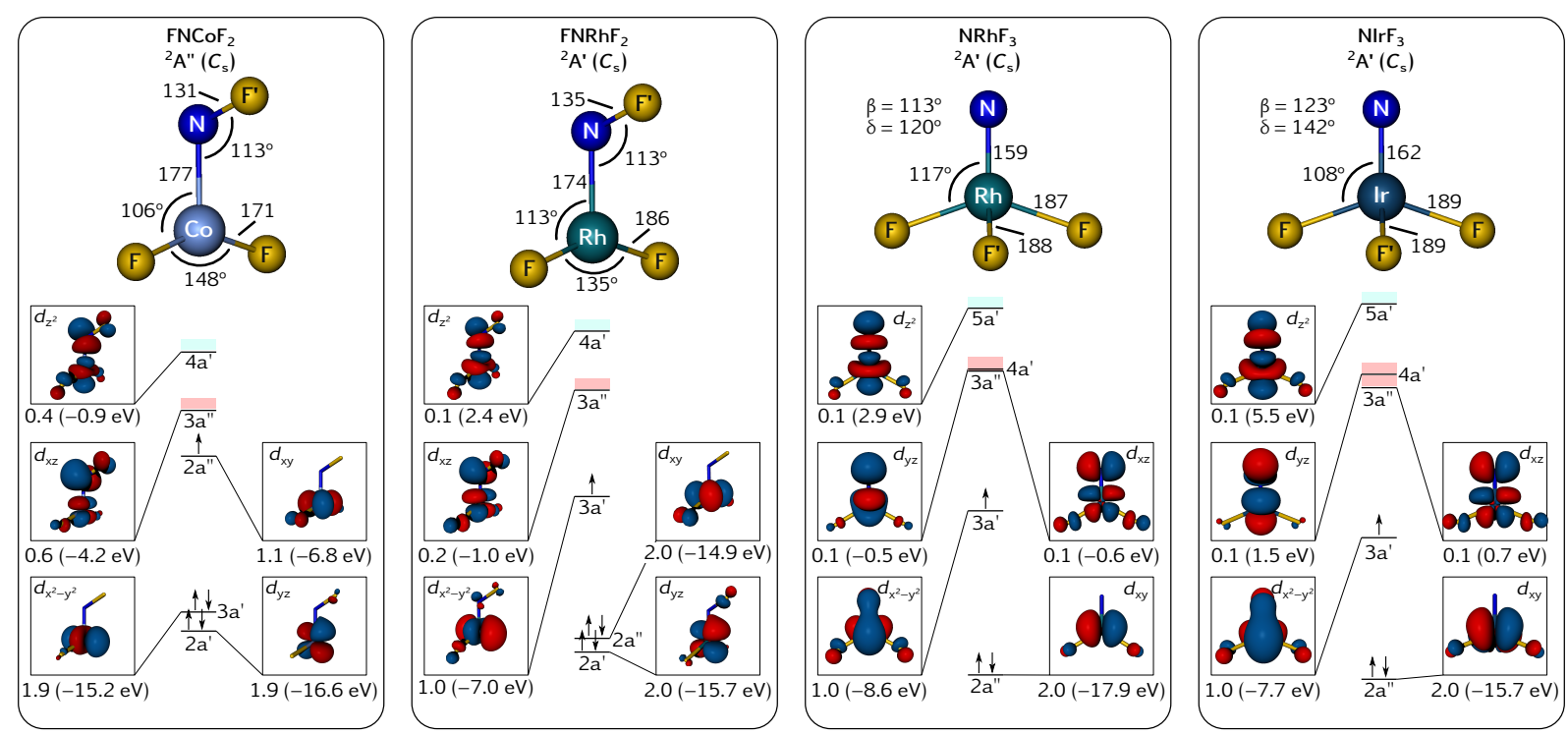

Figure 3.5. Calculated geometric structures and $d$-orbital splitting schemes, including occupation numbers and orbital energies, of the identified $\mathrm{NMF}_{3}$ species. Antibonding $\sigma^{*}$ and $\pi^{*}$ MOs are highlighted in pink and light cyan, respectively. For more details see Section 4.2 .

the weak Co-N bond strength. The latter is located at $1057 \mathrm{~cm}^{-1}$, only red-shifted by $63 \mathrm{~cm}^{-1}$ from that of free, neutral NF in solid neon at $1119 \mathrm{~cm}^{-1}$, which indicates a considerable oxidation of the formally dianionic $\mathrm{FN}^{2-}$ ligand. The non-innocent behavior of the $\mathrm{NF}^{2-}$ ligand in $\mathrm{FNCoF}_{2}$ is further supported by the considerable spin populations of -0.46 and 1.46 at the nitrogen and cobalt atom, respectively, obtained by CASSCF calculations. In line with, according to natural population analysis (NPA) and QTAIM analyses, an almost uncharged NF ligand (instead of the formal dianionic $\mathrm{FN}^{2-}$ ), the NF ligand features considerable imidyl/nitrene radical character. It is worth pointing out that this effect is even stronger pronounced in the FN stretching frequency of $\mathrm{FNCuF}_{2}$ in solid argon. ${ }^{[273]}$ It was assigned to a band at $1140 \mathrm{~cm}^{-1}$, significantly higher than that of free NF in solid argon at $1115 \mathrm{~cm}^{-1}$, hinting at a formal $\mathrm{NF}^{2-}$ ligand oxidation beyond neutral NF. ${ }^{273]}$ In contrast, the bands of $\mathrm{FNRhF}_{2}$ assigned to these modes are located at $873 \mathrm{~cm}^{-1}$ and $761 \mathrm{~cm}^{-1}$, indicating a stronger $\mathrm{Rh}-\mathrm{N}$, and a weaker $\mathrm{N}-\mathrm{F}$ bond. This observation is in full agreement with the calculated stretching frequencies $\left(872 \mathrm{~cm}^{-1}\right.$ and $\left.707 \mathrm{~cm}^{-1}\right)$, a higher $\mathrm{Rh}=\mathrm{N}$ EBO of 1.7 , and negative NPA and QTAIM total charge of the NF ligand (NPA: -0.13, QTAIM: -0.20 ). For details see Section 4.2.

The electronic and geometric structures of $\mathrm{NRhF}_{3}$ and $\mathrm{NIrF}_{3}$ are very similar. They both show Jahn-Teller distortions of the high-symmetry $C_{3 \mathrm{v}}$ reference structure caused by an uneven occupation of the two-fold degenerate $e$ orbital with three electrons. This leads to a widening of the $\mathrm{F}-\mathrm{M}-\mathrm{F}$ angle and a lifting of the degeneracy of the $e^{3}$ orbital 
into $\left(2 \mathrm{a}^{\prime \prime}\right)^{2}\left(3 \mathrm{a}^{\prime}\right)^{1}$ (Figure 3.5). In fact, the geometric structures of these complexes are very similar to that of $\mathrm{NRuF}_{3}$ whose ${ }^{1} \mathrm{~A}^{\prime}$ electronic ground state configuration corresponds to that determined for $\mathrm{NRhF}_{3}$ and $\mathrm{NIrF}_{3}$, with the outermost electron removed from the 3a' orbital. The band positions of the symmetric and antisymmetric $\mathrm{F}-\mathrm{M}-\mathrm{F}$ stretching mode are red-shifted by about $45 \mathrm{~cm}^{-1}$ for $\mathrm{M}=\mathrm{Rh}$ compared to that of $\mathrm{M}=$ $\mathrm{Ru}$, which can be attributed to a weak F-M-F antibonding character of the $3 \mathrm{a}^{\prime} \mathrm{MO}$. At $1150.4 \mathrm{~cm}^{-1}$, the $\mathrm{Ir}-\mathrm{N}$ stretching frequency of $\mathrm{NIrF}_{3}$ is the highest value determined so far for any metal-nitrogen bond. For details see Section 4.2.

While the diatomic IrN has been thoroughly investigated, ${ }^{[262-265,283]}$ higher binary nitrido complexes have not been characterized so far. This is especially intriguing as it has been shown that molecular $\mathrm{M}(\mathrm{N})_{2}$ species were formed by the reaction of nitrogen atoms with diatomic $\mathrm{MN}$ molecules isolated in noble gas matrices upon annealing. ${ }^{[185]}$ Given the ability of iridium to achieve OSs of up to IX, this opens up the possibility to produce $\operatorname{Ir}(\mathrm{N})_{3}$, a neutral complex with formal iridium OS of IX. The IR absorption of diatomic $\mathrm{Ir} \equiv \mathrm{N}$ in solid neon was assigned to a band at $1111 \mathrm{~cm}^{-1}$, in very good agreement with the gas-phase value of $1114 \mathrm{~cm}^{-1}$. ${ }^{[262]}$ The antisymmetric $\mathrm{N}-\mathrm{Ir}-\mathrm{N}$ stretching mode of $\operatorname{Ir}\left(\mathrm{N}_{2}\right)$ in solid neon was assigned to a band located at $853 \mathrm{~cm}^{-1}$. The ${ }^{14 / 15} \mathrm{~N}$ isotopic pattern for this mode showed no band corresponding to the $\operatorname{Ir}\left({ }^{14} \mathrm{~N}\right)\left({ }^{15} \mathrm{~N}\right)$ isotopologue when the spectrum was recorded using a 1:1 mixture of ${ }^{14} \mathrm{~N}_{2}$ and ${ }^{15} \mathrm{~N}_{2}$ diluted in neon. However, when the spectrum is recorded in a pure 1:1 mixture of ${ }^{14} \mathrm{~N}_{2}$ and ${ }^{15} \mathrm{~N}_{2}$ an intensity pattern of approximately 1:2:1 is observed. This shows a formation of $\operatorname{Ir}(\mathrm{N})_{2}$ in two different ways. Diluted in neon the reaction takes place by insertion of an iridium atom in the $\mathrm{N} \equiv \mathrm{N}$ bond of dinitrogen, while in pure nitrogen it takes place by addition of a nitrogen atom to molecular IrN (Reaction 4 and 5, respectively).

$$
\begin{aligned}
\mathrm{Ir}+\mathrm{N}_{2} & \longrightarrow \operatorname{Ir}(\mathrm{N})_{2} \\
\mathrm{IrN}+\mathrm{N} & \longrightarrow \operatorname{Ir}(\mathrm{N})_{2}
\end{aligned}
$$

Although nitrogen atom mobility in cryogenic noble gas matrices was observed and the addition of a nitrogen atom to $\operatorname{Ir}(\mathrm{N})_{2}$ is predicted to be considerably exothermic, no band could be assigned to $\operatorname{Ir}(\mathrm{N})_{3}$. Since the formation of $\operatorname{Ir}(\mathrm{N})_{3}$ through the insertion of IrN into the $\mathrm{N} \equiv \mathrm{N}$ bond of $\mathrm{N}_{2}$ has a high barrier and, on the other hand, its formation starting from $\operatorname{Ir}(\mathrm{N})_{2}+\mathrm{N}$ already requires a larger amount of $\operatorname{Ir}(\mathrm{N})_{2}$, the yield of $\operatorname{Ir}(\mathrm{N})_{3}$, if any, is expected to be very low. In addition, the calculated intensity of the IR active stretching band of $\operatorname{Ir}(N)_{3}$ is much lower than that of $\operatorname{Ir}(\mathrm{N})_{2}$, which renders the detection of this band in the IR spectrum very unlikely.

The SOMO of the ${ }^{2} \mathrm{~B}_{1}$ doublet electronic ground state of $\operatorname{Ir}(\mathrm{N})_{2}$ determined by quan- 
tum-chemical calculations corresponds to a delocalized out of plane $\pi^{*}$-type MO. As a consequence, the spin density is well delocalized and the determination of an integer OS is not possible. The nitrido ligands in this case must be considered non-innocent and possess partial nitridyl $\left(\mathrm{N}^{2-\bullet}\right)$ character. The iridium $\mathrm{OS}$ in $\operatorname{Ir}(\mathrm{N})_{2}$ is between $\mathrm{V}$ and VI. In the case of the $C_{3 \mathrm{v}}$ point group symmetric $\operatorname{Ir}(\mathrm{N})_{3}$, a ${ }^{1} \mathrm{~A}_{1}{ }^{\prime}$ electronic ground state was calculated. The HOMO corresponds to a doubly occupied, non-bonding metal centered $d_{\mathrm{Z}^{2}}$ orbital which indicates an iridium OS of VII associated with a partially oxidized nitrido ligands with an average OSs of -2.3 , as well as an considerable nitridyl $\left(\mathrm{N}^{2-\bullet}\right)$ radical character. For details see Section 4.3. 


\section{Publications}

\subsection{High-Spin Iron(VI), Low-Spin Ruthenium(VI), and Magnetically Bistable of Osmium(VI): Molecular Group 8 Nitrido Trifluorides $\mathrm{NMF}_{3}$}

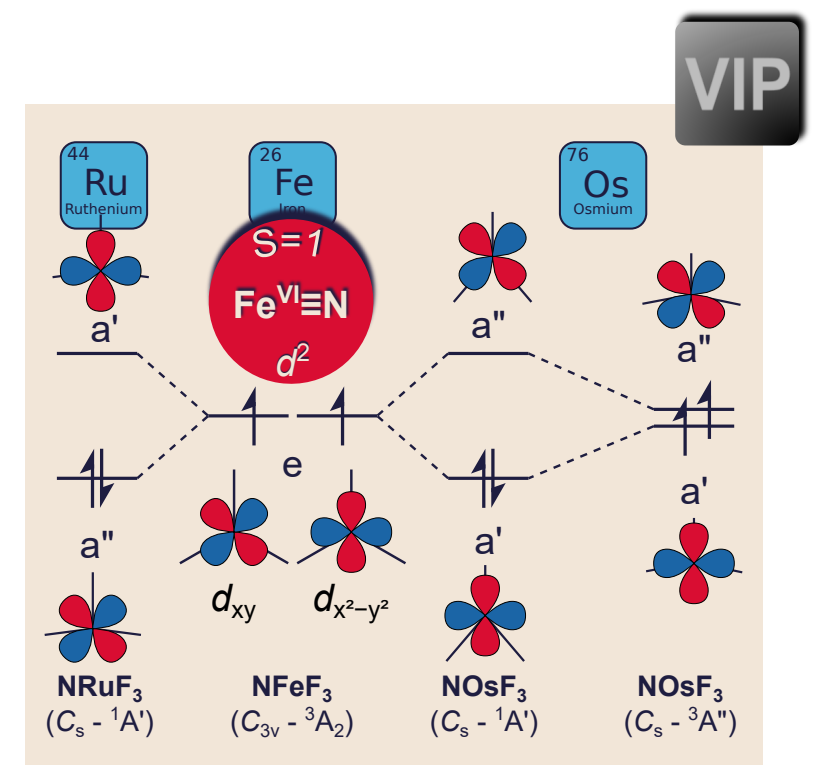

Tony Stüker, Xiya Xia, Helmut Beckers and Sebastian Riedel ${ }^{*}$

Chemistry - A European Journal, 2021, Advance online publication.

DOI: $10.1002 /$ chem. 202101404

(C) 2021 The Authors. Published by Wiley-VCH GmbH

For the Supporting Information see Appendix A.1.

\section{Author Contribution}

Tony Stüker did all calculations, wrote the manuscript and supervised the experiments. Tony Stüker and Xiya Xia carried out the experiments. Helmut Beckers and Sebastian Riedel managed the project and revised the manuscript. 


\title{
High-Spin Iron(VI), Low-Spin Ruthenium(VI), and Magnetically Bistable Osmium(VI) in Molecular Group 8 Nitrido Trifluorides $\mathrm{NMF}_{3}$
}

\author{
Tony Stüker, ${ }^{[a]}$ Xiya Xia, ${ }^{[a]}$ Helmut Beckers, ${ }^{[a]}$ and Sebastian Riedel ${ }^{*[a]}$
}

\begin{abstract}
Pseudo-tetrahedral nitrido trifluorides $\mathrm{N}_{\mathrm{MF}_{3}}(\mathrm{M}=$ $\mathrm{Fe}, \mathrm{Ru}, \mathrm{Os}$ ) and square pyramidal nitrido tetrafluorides $\mathrm{N} \equiv \mathrm{MF}_{4}$ $(\mathrm{M}=\mathrm{Ru}, \mathrm{Os})$ were formed by free-metal-atom reactions with $\mathrm{NF}_{3}$ and subsequently isolated in solid neon at $5 \mathrm{~K}$. Their IR spectra were recorded and analyzed aided by quantumchemical calculations. For a $d^{2}$ electron configuration of the $\mathrm{N} \equiv \mathrm{MF}_{3}$ compounds in $C_{3 \mathrm{v}}$ symmetry, Hund's rule predict a high-spin ${ }^{3} \mathrm{~A}_{2}$ ground state with two parallel spin electrons and two degenerate metal $d(\delta)$-orbitals. The corresponding
\end{abstract}

\section{Introduction}

The group 8 transition metals have eight electrons in their valence shell, but in addition to the well-known strong oxidizers $\mathrm{RuO}_{4}$ and $\mathrm{OsO}_{4}$, only Os has a variety of different complexes in oxidation state VIII. ${ }^{[1]}$ While the oxidation state $\mathrm{VI}$ is abundant for ruthenium and osmium, the complex anion $\left[\mathrm{FeO}_{4}\right]^{2-}$ was the only known $\mathrm{Fe}^{\mathrm{vl}}$ compound for a long time. ${ }^{[2]}$ In 2007 the neutral, dioxo $\mathrm{Fe}^{\mathrm{vl}}$ peroxide $\mathrm{O}_{2} \mathrm{Fe}\left(\eta^{2}-\mathrm{O}_{2}\right)$ was reported to be formed from molecular $\mathrm{FeO}_{2}$ and $\mathrm{O}_{2}$ under cryogenic conditions. ${ }^{[3]}$ Tetrahedral $\mathrm{Fe}^{\mathrm{VIII}} \mathrm{O}_{4}$ was shown to be metastable with respect to $\mathrm{O}_{2} \mathrm{Fe}^{\mathrm{v}}\left(\eta^{2}-\mathrm{O}_{2}\right)$ in the gas phase, ${ }^{[4]}$ and the oxidation state $\mathrm{VII}$ is so far the highest oxidation state of iron observed experimentally for the tetrahedral tetroxide anion $\mathrm{FeO}_{4}{ }^{-} \cdot{ }^{[5]}$ In addition to oxygen, nitrogen ligands are also able to stabilize high oxidation states of iron. Such terminal iron-nitrido complexes have already been the subject of several up-to-date reviews. ${ }^{[6]}$ We restrict ourselves to some representative examples such as the square-pyramidal $\left[(\mathrm{TPP}) \mathrm{Fe}^{\mathrm{v}} \mathrm{N}\right]\left(\mathrm{TPP}^{2-}=\right.$ tetraphenylporphyrinate dianion), characterized by Raman spectroscopy ${ }_{1}^{[7]}$ the tetragonal nitrido $\mathrm{Fe}^{\mathrm{Vl}}$ dication [( $\left.\mathrm{Me}_{3} \mathrm{Cyac}\right)$ $\mathrm{FeN}^{2+} \quad\left(\left[\mathrm{Me}_{3} \mathrm{Cyac}\right]^{-}=\mathrm{N}, \mathrm{N}, \mathrm{N}\right.$-tri-methyl-1,4,8,11-tetraazacyclotetra-decane-1-acetate), confirmed by Mössbauer and X-ray spectroscopy ${ }_{1}^{[8]}$ the pseudo-tetrahedral $\left[\left(\mathrm{PhB}_{(}\left(\mathrm{PCH}_{2} \mathrm{PiPr}_{2}\right)_{3}\right) \mathrm{Fe}^{\mathrm{IV} N} \mathrm{~N}\right]$

[a] T. Stüker, X. Xia, Dr. H. Beckers, Prof. S. Riedel

Institut für Chemie und Biochemie, Anorganische Chemie

Freie Universität Berlin

Fabeckstr. 34/36, 14195 Berlin (Germany)

E-mail: s.riedel@fu-berlin.de

$\square$ Supporting information for this article is available on the WWW under https://doi.org/10.1002/chem.202101404

of $\odot 2021$ The Authors. Chemistry - A European Journal published by Wiley$\mathrm{VCH} \mathrm{GmbH}$. This is an open access article under the terms of the Creative Commons Attribution License, which permits use, distribution and reproduction in any medium, provided the original work is properly cited. high-spin ${ }^{3} \mathrm{~A}_{2}$ ground state was, however, only found for $\mathrm{N} \equiv \mathrm{FeF}_{3}$, the first experimentally verified neutral nitrido $\mathrm{Fe}^{\mathrm{vl}}$ species. The valence-isoelectronic $\mathrm{N} \equiv \mathrm{RuF}_{3}$ and $\mathrm{N} \equiv \mathrm{OsF}_{3}$ adopt different angular distorted singlet structures. For $\mathrm{N} \equiv \mathrm{RuF}_{3}$, the triplet ${ }^{3} \mathrm{~A}_{2}$ state is only $5 \mathrm{~kJ} \mathrm{~mol}^{-1}$ higher in energy than the singlet ${ }^{1} A^{\prime}$ ground state, and the magnetically bistable molecular $\mathrm{N} \equiv \mathrm{OsF}_{3}$ with two distorted near degenerate ${ }^{1} \mathrm{~A}^{\prime}$ and ${ }^{3} \mathrm{~A}^{\prime}$ electronic states were experimentally detected at $5 \mathrm{~K}$ in solid neon.
$\left(\mathrm{PhB}\left(\mathrm{PCH}_{2} \mathrm{PiPr}_{2}\right)_{3}=\right.$ tris(diisopropylphosphinophenyl)borane) ${ }_{1}^{[9]}$ and, very recently, the crystal structure of a thermally stable four-coordinate $\mathrm{Fe}^{\mathrm{VI}}$ bis(imido) cation, $\left[\left(\mathrm{H}_{2} \mathrm{~B}(\text { Meslm })_{2}\right) \mathrm{Fe}(=\right.$ NMes $\left.)_{2}\right]^{+}\left(\left[\mathrm{H}_{2} \mathrm{~B}[\text { MesIm }]_{2}\right]^{-}=\right.$dihydrobis-[1-(2,4,6-trimethylphenyl) imidazol-2-ylidene]borato). ${ }^{[10]}$

Nitrido iron complexes play an important role in a number of chemical and biological processes, for example in the catalytic cycle of cytochrome P450, ${ }^{[1]}$ in the FeMo cofactor of the nitrogenase enzyme ${ }^{[6 a]}$ and in the Haber-Bosch process. ${ }^{[12]}$ In analogy to the active iron surface nitride in the Haber-Bosch process, ammonia synthesis has also successfully achieved under mild conditions using the ruthenium pincer nitrido complex [(PNP)RuN] $\left.\left(\mathrm{PNP}^{-}=\left[\mathrm{N}\left(\mathrm{CH}_{2} \mathrm{CH}_{2} \mathrm{P}^{\mathrm{t}} \mathrm{Bu}_{2}\right)_{2}\right)\right]^{-}\right){ }^{[13]}$ Quite recently osmium( $\mathrm{VI})$ nitrides have emerged as a new class of potential anticancer and antitumor agents. ${ }^{[14]}$ Examples include $\left[(\text { bipy }) \mathrm{Cl}_{3} \mathrm{Os}^{\mathrm{VI}} \mathrm{N}\right]^{[15]} \quad\left(\text { bipy }=2,2^{\prime} \text {-bipyridine }\right)^{[16]}$ and $[($ sap $)($ py) $\left.\mathrm{ClOs}^{\mathrm{VI}} \mathrm{N}\right] \quad\left(\right.$ sap $=$ deprotonated $\mathrm{N}$-salicylidene-2-aminophenol). ${ }^{[17]}$ The wide field of possible applications of group 8 nitrido complexes underline the importance of a deeper understanding of the properties of this class of compounds. Especially the nitrido metal-ligand multiple bond and the valency of the metal are key factors for the reactivity and structure of these compounds.

In particular, there has been a tremendous progress in the synthesis and the chemistry of molecular $\mathrm{Fe}^{\mathrm{IV}}$ and $\mathrm{Fe}^{\mathrm{V}}$ nitrido compounds in the recent years that have been described in detail in several review articles. $^{[6]}$ They are supported by sterically encumbered macrocyclic or chelating ligands involving nitrogen or $\mathrm{N}$-heterocyclic carbene donors based on, for example porphyrin or nitrogen- and boron-anchored tri- and tetrapodal chelates to protect the reactive $\mathrm{Fe}=\mathrm{N}$ moiety (see Scheme 1 for representative examples). The most common route to these nitrido compounds is the photolysis of an iron azido precursor and concomitant $\mathrm{N}_{2}$ evolution, whereby the 


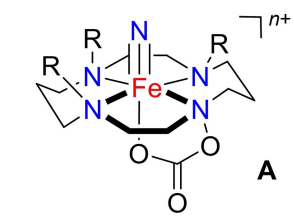

$\mathrm{R}=\mathrm{Me}:\left[\left(\mathrm{Me}_{3} \text { cyclam-ac }\right) \mathrm{Fe}^{\mathrm{V} /} \mathrm{N}\right]^{2+}$ $\mathrm{R}=\mathrm{H}:\left[\left(\text { cyclam-ac) } \mathrm{Fe}^{\mathrm{V}} \mathrm{N}\right]^{+}\right.$

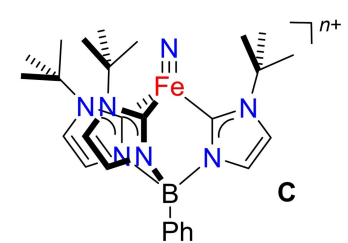

$\left[\mathrm{PhB}(\text { tBulm })_{3} \mathrm{Fe}^{\mathrm{IV}} \mathrm{N}\right]$ $\left[\mathrm{PhB}(\text { tBulm })_{3} \mathrm{Fe}^{\mathrm{V}} \mathrm{N}\right]^{+}$

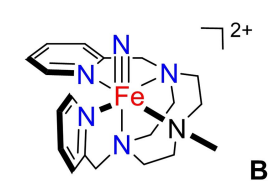

$\left[\left(\mathrm{MePy}_{2} \text { tacn }\right) \mathrm{Fe}^{\mathrm{V}} \mathrm{N}\right]^{2+}$

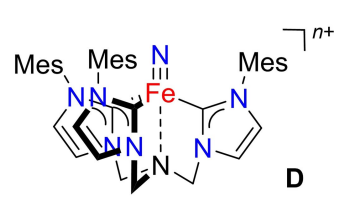

$\left[\left(T_{I M M N}{ }^{M e s}\right) \mathrm{Fe}^{I V} \mathrm{~N}\right]^{+}$ $\left[\left(\text { TIMMN }^{\mathrm{Mes}}\right) \mathrm{Fe}^{\mathrm{V}} \mathrm{N}\right]^{2+}$
Scheme 1. Representative examples of ligand-supported tetragonal $\left(\mathbf{A}^{[8,22]}\right.$ and $\left.\mathbf{B}^{[19 d]}\right)$ and trigonal ( $\mathbf{C}^{[19 a]}$ and $\mathbf{D}^{[19 b]}$ ) coordinated high-valent iron nitrido complexes.

one-electron oxidation of the $\mathrm{Fe}^{\mathrm{IV}}$ nitrido complexes often represents an alternative route to $\mathrm{Fe}^{\mathrm{V}}$ nitrido complexes. ${ }^{[6 a, b]}$

The reactivity of these high-valent nitrido iron compounds in chemical transformations have been thoroughly explored, ${ }^{[6,18]}$ their structures, and their electronic properties have been investigated in detail using a variety of experimental and quantum mechanical methods. ${ }^{[19]}$ While these studies contributed greatly to the understanding of the iron nitride bonding motif, our knowledge about the behavior, the nature, and bond-strengths of the $\mathrm{Fe}=\mathrm{N}$ triple bond in high valent iron compounds upon iron oxidization is, however, still very limited and contradictory. Two questions arise here: Is there a nitrido wall $^{[20]}$ from which the nitrido ligand gives up its innocent behavior, ${ }^{[21]}$ and does the $\mathrm{Fe} \equiv \mathrm{N}$ bond become stronger and stronger through oxidation of the iron center?

It should be emphasized that the known iron nitrido species can be divided into trigonal (pseudo-tetrahedral) and tetragonal (pseudo-octahedral) complexes (Scheme 1), since these two groups show different ligand field splitting of the $\mathrm{Fe}(3 \mathrm{~d})$ orbitals. ${ }^{[9,23]}$ In a trigonal $C_{3 v}$ ligand field there are two purely $\mathrm{Fe}=\mathrm{N}$ nonbonding e-type orbitals $\left(\mathrm{d}_{x y, x^{2}-y^{2}}\right)$, which allow the accommodation of up to four electrons energetically below the antibonding $\mathrm{Fe}=\mathrm{N}$ orbitals. ${ }^{[6 a, c, 9,23]}$ This results in a relatively strong $\mathrm{Fe}=\mathrm{N}$ triple bonds, for example, low spin $\mathrm{Fe}^{\mathrm{IV}}$ derivatives, for which very short experimental $\mathrm{Fe}-\mathrm{N}$ distances (Table $\mathrm{S} 1$ in the Supporting Information) and $\mathrm{Fe}-\mathrm{N}$ stretching vibrations at $1008-1034 \mathrm{~cm}^{-1}$ were found..$^{[9,24]}$

Conversely, in the tetragonal $C_{4 v}$ ligand field there is only one purely nonbonding $\left(d_{x y}\right)$ orbital with respect to the $\mathrm{Fe} \equiv \mathrm{N}$ bond energetically below the $\pi^{*}$-antibonding $\left(d_{x z, y z}\right)$ MOs. ${ }^{[6 a, c]} A$ d-electron count larger than two results here in the occupation of $\pi^{*}(\mathrm{Fe}=\mathrm{N})$ orbitals, and, accordingly, $\mathrm{Fe}^{\mathrm{IV}}\left(\mathrm{d}^{4}\right)$ and $\mathrm{Fe}^{\mathrm{V}}\left(\mathrm{d}^{3}\right)$ nitrido complexes in tetragonal symmetry are generally thermally less stable and more reactive..$^{[6 b, 18 a, c]}$ Note that the $d^{3}$ ground-state electron configuration of $\mathrm{Fe}^{v}$ nitrido complexes is subject to a Jahn-Teller distortion. ${ }^{[19 b, c]}$ To overcome the thermal instability and high reactivity of such tetragonal $\mathrm{Fe}^{\mathrm{v}}$ nitride complexes their $\mathrm{Fe}=\mathrm{N}$ distances and stretching frequencies were obtained by a variety of spectroscopic methods either at cryogenic temperatures or at the gas phase (for representative examples, see Table S1). As expected, the experimental Fe-N distances for the two tetragonal complexes $\left[\mathrm{Fe}^{\mathrm{v}-}\right.$ (N) $\left(\mathrm{MePy}_{2} \text { tacn) }\right]^{2+}$ (Scheme 1, 3d $\mathrm{d}^{4}$ configuration, $\mathrm{Fe}-\mathrm{N}$ : 164(1) $\mathrm{pm})^{[19 \mathrm{~d}]}$ and $\left[\mathrm{Fe}^{\mathrm{V}}(\mathrm{N}) \quad(\text { cyclam-ac })\right]^{+} \quad($ Scheme 1 , cyclam-ac $=$ 1,4,8,11-tetraazacyclotetradecane-1-acetato, $\mathrm{Fe}-\mathrm{N}$ : 161(1) $\mathrm{pm}),{ }^{[22]}$ estimated from extended $\mathrm{X}$-ray absorption fine structure (EXAFS) analysis, were found to be longer than the $\mathrm{Fe}-\mathrm{N}$ distance of the analogous $\mathrm{Fe}^{\mathrm{VI}}$ dication $\left[\mathrm{Fe}^{\mathrm{Vl}}(\mathrm{N})\left(\mathrm{Me}_{3} \mathrm{Cyclam}-\mathrm{ac}\right)\right]^{2+}$ (Scheme 1, 157(2) pm) with a singlet $3 \mathrm{~d}^{2}$ configuration. ${ }^{[8]}$

In contrast, the formal $\mathrm{Fe}=\mathrm{N}$ bond order in trigonal $\mathrm{Fe}-$ nitrido complexes does not change by increasing the iron oxidation state from singlet $\mathrm{Fe}^{\mathrm{IV}}$ to triplet $\mathrm{Fe}^{\mathrm{V}}$, making predictions about the bond lengths less intuitive as other factors such as the geometry and the nature of the ligands come to the fore. X-ray structure analysis of the $\mathrm{Fe}^{\mathrm{IV}} \mathrm{N} / \mathrm{Fe}^{\mathrm{V}} \mathrm{N}$ derivatives of the two redox pairs $\left[\mathrm{PhB}(t \mathrm{Bulm})_{3} \mathrm{FeN}\right]^{0 /+}$ (Scheme 1) $^{[19 a, 24 b]}$ and $\left[\left(\right.\right.$ TIMMN $\left.^{\text {MES }}\right) \mathrm{FeN}^{+/ 2+}(\text { Scheme } 1)^{[196]}$ show different trends. While the Fe-N length decreases slightly from 151.2(1) $\mathrm{pm}$ to $150.6(2) \mathrm{pm}$ for the former, it increases from 151.3(3) pm to 152.9(1) pm for the latter. The different trend in these $\mathrm{Fe}=\mathrm{N}$ distances during oxidation of $\mathrm{Fe}^{\mathrm{IV}}$ to $\mathrm{Fe}^{\mathrm{V}}$ was attributed to a possibly stronger interaction between the ligand $\mathrm{N}$ anchor with the more electrophilic $\mathrm{Fe}^{\mathrm{v}}$ center in [Fe$(\mathrm{N})\left(\right.$ TIMMN $\left.\left.^{\mathrm{MES}}\right)\right]^{2+} \quad$ (Scheme 1). ${ }^{[19 \mathrm{~b}]}$ On the other hand, also coordinated solvent molecules can make it difficult to compare the $\mathrm{Fe} \equiv \mathrm{N}$ distances of different complexes, since this leads to shortened experimental $\mathrm{Fe}=\mathrm{N}$ distances. ${ }^{[19 \mathrm{e}]}$

In this work, we describe the preparation of the molecular, neutral nitrido trifluorides $\mathrm{NM}^{\mathrm{V}} \mathrm{F}_{3}$ of the group 8 metals $\mathrm{M}=\mathrm{Fe}$, $\mathrm{Ru}$, Os from IR laser ablated metal atoms and gaseous $\mathrm{NF}_{3}$ and their IR-spectroscopic characterization under cryogenic conditions in a noble gas matrix. These trigonal nitrido trifluorides bear genuine $\mathrm{M} \equiv \mathrm{N}$ triple bonds, unsupported by sterically encumbered electron donor substituents with the innocent fluoride ligand. The $\mathrm{M} \equiv \mathrm{N}$ stretching vibration of theses derivatives is energetically sufficiently isolated from other fundamentals. Hence, it is considered to be a reliable experimental signature for $\mathrm{M}-\mathrm{N}$ bond strength and $\mathrm{M}-\mathrm{N}$ bond length in these nitrido complexes. This analysis overcomes the difficulties described above and also has the advantage that the experimental results can be supported and analyzed by reliable and accurate quantum mechanical calculations of these molecular, neutral compounds. Furthermore, this analysis enables a direct comparison of experimental $M \equiv N$ stretching frequencies of $\mathrm{M}=\mathrm{Fe}^{\mathrm{Vl}}$ and its heavier group 8 congeners with those of the analogous nitrido trifluorides $\mathrm{N}_{\mathrm{MF}_{3}}$ of group $6(\mathrm{M}=\mathrm{Cr}$, Mo, $\mathrm{W})^{[25]}$ and group $9(\mathrm{Co}, \mathrm{Rh}, \mathrm{Ir})^{[26]}$ transition metals which have been studied previously. To the best of our knowledge, $\mathrm{N} \equiv \mathrm{Fe}^{\mathrm{V}} \mathrm{F}_{3}$ is the first experimentally verified neutral, nitrido iron(VI) complex. In addition, we have evidence for the formation of $\mathrm{NM}^{\mathrm{VII}} \mathrm{F}_{4}(\mathrm{M}=\mathrm{Ru}, \mathrm{Os})$. 
For an electronic metal $d^{2}$ configuration of these $\mathrm{N} \equiv \mathrm{MF}_{3}$ compounds in $C_{3 v}$ symmetry Hund's rule predict that two parallel spin electrons occupy the degenerate $M\left(d_{x y, x^{2}-y^{2}}\right)$ orbitals of e-type symmetry resulting in a non-degenerate highspin ${ }^{3} \mathrm{~A}_{2}$ ground state. Although this ${ }^{3} \mathrm{~A}_{2}$ state is not Jahn-Teller (JT) active, an electronic $\mathrm{e}^{2}$ configuration can generally lead to a Jahn-Teller distorted ground state as a result of a strong pseudo-Jahn-Teller (PJT) mixing of two excited singlet electronic states. ${ }^{[27]}$ This is because an electronic $\mathrm{e}^{2}$ configuration in $C_{3 v}$ symmetry, in addition to the ${ }^{3} A_{2}$ state, is generally associated with two electronic singlet states ${ }^{1} A_{1}$ and ${ }^{1} E$. These electronic states are reminiscent of the well-known singlet excited states of molecular oxygen. ${ }^{[28]}$

It has been noted that the JT stabilization energy of the excited ${ }^{1} \mathrm{E}$ state is usually much weaker than the PJT stabilization resulting from mixing of the two excited ${ }^{1} \mathrm{~A}_{1}$ and ${ }^{1} \mathrm{E}$ states. The stabilization energy of this PJT interaction can be so large that the lower of these excited states crosses the ${ }^{3} \mathrm{~A}_{2}$ potential energy surfaces and become the distorted global minimum configuration. ${ }^{[27,31]}$ We observed such a "hidden" PJT distortion for $\mathrm{N} \equiv \mathrm{RuF}_{3}$ and $\mathrm{N} \equiv \mathrm{OsF}_{3}$ but not for $\mathrm{NFe}=\mathrm{F}_{3}$. Note that this distortion is also associated with a PJT-induced triplet-singlet spin crossover. ${ }^{[27 a]}$

\section{Results}

\section{Vibrational wavenumbers of group 8 nitrido trifluorides} $\mathrm{NM}^{\mathrm{V} I} \mathrm{~F}_{3}$ and tetrafluorides $\mathrm{NM}^{\mathrm{VII}} \mathrm{F}_{4}$

The IR spectra of the novel group 8 metal nitrido trifluorides, $\mathrm{N} \equiv \mathrm{MF}_{3} \quad(\mathrm{M}=\mathrm{Fe}$, $\mathrm{Ru}, \mathrm{Os})$ were recorded from the products obtained from laser-ablated free metal atoms with $\mathrm{NF}_{3}$ seeded in a 1:1000 excess of neon after their deposition at $5 \mathrm{~K}$ on a gold-plated copper mirror (for experimental details see the Supporting Information). According to density functional theory calculations, the direct insertion of the metal atoms into an $\mathrm{F}-\mathrm{N}$ bond of $\mathrm{NF}_{3}$ to yield $\mathrm{F}_{2} \mathrm{~N}-\mathrm{MF}$, and the subsequent fluorine migration from nitrogen to the metal center to $\mathrm{FN}=\mathrm{MF}_{2}$ is highly exothermic for all three metals (Figure 1, Table S2).

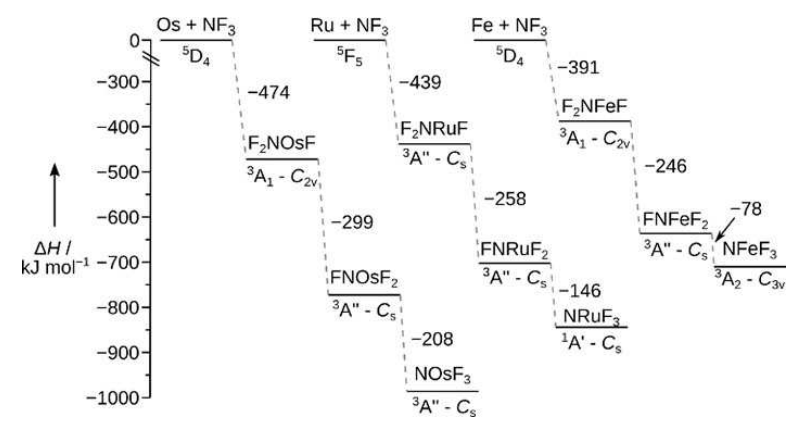

Figure 1. Stationary points on the reaction coordinate obtained at the BP86 level of theory for the formation of the nitrido metal complexes $\mathrm{N} \equiv \mathrm{MF}_{3}$ starting from the free metal atoms $M$ and $\mathrm{NF}_{3}\left(C_{3 v}-{ }^{1} A_{1}\right)$. See Table S2 for more details.
The rearrangement of the fluorimido complexes to the hexavalent nitrido trifluorides $\mathrm{N} \equiv \mathrm{MF}_{3}$ is found to be considerably exothermic for osmium $\left(-208 \mathrm{~kJ} \mathrm{~mol}^{-1}\right)$, ruthenium $\left(-146 \mathrm{~kJ} \mathrm{~mol}^{-1}\right)$, and iron $\left(-78 \mathrm{~kJ} \mathrm{~mol}^{-1}\right)$ at the BP86/def2QZVP $^{[32]}$ level of theory (details see the Supporting Information). Experimental IR spectra are shown from the deposits obtained in solid neon for the iron (Figures 2 and S1), ruthenium (Figures 3 and S2), and the osmium experiments (Figures 4 and S3), respectively. Experimental band positions are compared

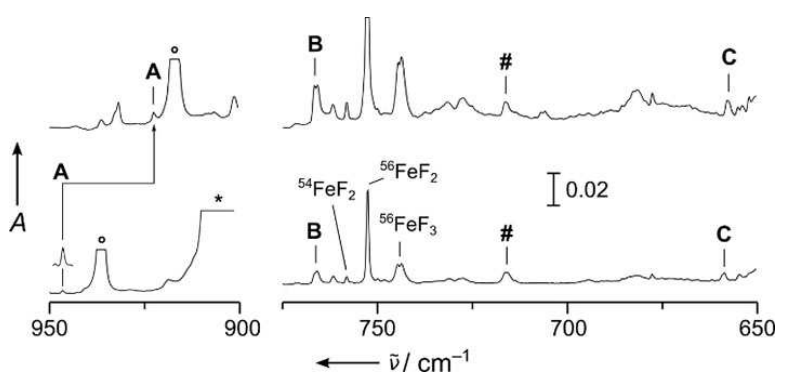

Figure 2. IR absorption spectra obtained from co-deposition of laser-ablated iron with $0.1 \%{ }^{14} \mathrm{NF}_{3}$ (bottom) and $0.1 \%{ }^{15} \mathrm{NF}_{3}$ (top) in solid Ne. Bands labeled with $\mathrm{A}, \mathrm{B}$ and $\mathrm{C}$ are assigned to $\mathrm{NFeF}_{3}$ (Table 1). Band $\mathbf{A}$ is enhanced by a factor of five. Known bands of binary iron fluorides ${ }^{[29]}$ are labeled, and an unassigned band showing no ${ }^{14 / 15} \mathrm{~N}$ isotopic shift is labeled with a hash mark. The bands associated with $\mathrm{NF}_{2}$ and $\mathrm{NF}_{3}$ are marked with circles and asterisks, respectively. ${ }^{[30]}$ For more details, see Figure $\mathrm{S} 1$.
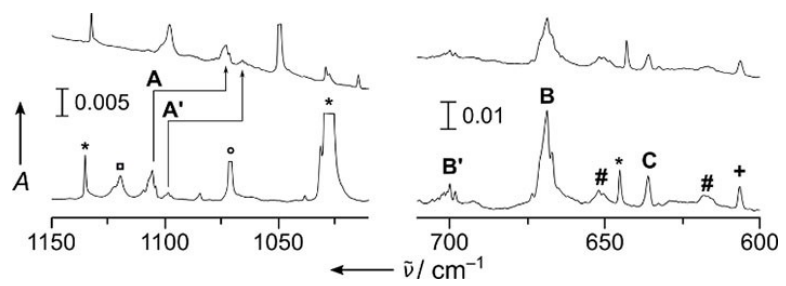

Figure 3. IR absorption spectra obtained from co-deposition of laser ablated ruthenium with $0.1 \%{ }^{14} \mathrm{NF}_{3}$ (bottom), and ${ }^{15} \mathrm{NF}_{3}$ (top) in solid Ne, respectively. Bands labeled $\mathbf{A}-\mathbf{C}$ are attributed to $\mathrm{NRuF}_{3}$ and $\mathbf{A}^{\prime}$ and $\mathbf{B}^{\prime}$ are due to $\mathrm{NRuF}_{4}$. Unknown bands are labeled by a pound and a plus sign, respectively. The bands associated with ${ }^{14} \mathrm{NF}^{14} \mathrm{NF}_{2}$ and ${ }^{14} \mathrm{NF}_{3}$ are marked with squares, circles, and asterisks, respectively. ${ }^{[30]}$ For more details, see Figure $\mathrm{S} 2$.

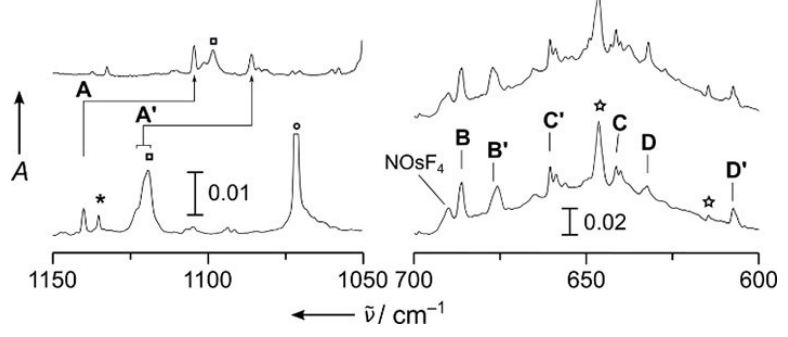

Figure 4. IR absorption spectra of laser ablated osmium co-deposited with $0.1 \%{ }^{14} \mathrm{NF}_{3}$ in solid $\mathrm{Ne}$ (bottom), with $0.1 \%{ }^{15} \mathrm{NF}_{3}$ in $\mathrm{Ne}$ (top). Bands labeled A-D are attributed to $\operatorname{NOsF}_{3}\left({ }^{\prime} A^{\prime}\right)$ and $A^{\prime}-D^{\prime}$ to $\operatorname{NOsF}_{3}\left({ }^{3} A^{\prime \prime}\right)$. The bands marked with a pentagram sign are binary osmium fluorides. The bands associated with $\mathrm{NF}, \mathrm{NF}_{2}$ and $\mathrm{NF}_{3}$ are marked with squares, circles and asterisks, respectively. ${ }^{[30]}$ For more details see Figure S3. 


\subsection{High-Spin Iron(VI), Low-Spin Ruthenium(VI), and Magnetically Bistable of Osmium(VI): Molecular Group 8 Nitrido Trifluorides $\mathrm{NMF}_{3}$}

Full Paper

doi.org/10.1002/chem.202101404

Chemistry

Europe

European Chemical
Societies Publishing with predicted ones from quantum-chemical calculations in Tables 1 and S4 (for a detailed band assignment refer to the Supporting Information). The formation of molecular $\mathrm{NFeF}_{3}\left(C_{3 \mathrm{v}}\right)$ is clearly proved by the assignment of all its stretching vibrations marked A $\left(v(\mathrm{NFe}): \quad 946.4 \mathrm{~cm}^{-1}\right), \quad$ B $\quad\left(v_{\text {as }}\left(\mathrm{FeF}_{3}\right)\right.$ : $\left.766.8 \mathrm{~cm}^{-1}\right)$, and $\mathrm{C}\left(v_{\mathrm{s}}\left(\mathrm{FeF}_{3}\right): 658.8 \mathrm{~cm}^{-1}\right)$ in Figure 2 (Table 1). Bands at $743.6 / 744.7,752.6$ and $785.1 \mathrm{~cm}^{-1}$ were assigned to the known molecular binary iron fluorides ${ }^{56} \mathrm{FeF}_{3},{ }^{56} \mathrm{FeF}_{2}$ and ${ }^{54} \mathrm{FeF}_{2}$, respectively. ${ }^{[29]}$ Their high intensity and the high yield of these binary fluorides compared to the $\mathrm{NFeF}_{3}$ product bands indicate the lower stability of $\mathrm{NFeF}_{3}$ under the harsh conditions of the laser ablation process. The spectra recorded in the ruthenium experiment (Figure 3), clearly revealed the presence of two different nitrido ruthenium complexes, finally assigned to $\mathrm{NRuF}_{3}\left(C_{\mathrm{s}}\right)$ and $\mathrm{NRuF}_{4}\left(C_{4 \mathrm{v}}\right)$. The characteristic $\mathrm{Ru} \equiv \mathrm{N}$ stretching bands of $\mathrm{NRuF}_{3}\left(C_{\mathrm{s}}\right)$ and $\mathrm{NRuF}_{4}\left(C_{4 \mathrm{v}}\right)$ are labeled $\mathbf{A}\left(1105.4 \mathrm{~cm}^{-1}\right.$, $\left.\mathrm{NRuF}_{3}\right)$ and $\mathbf{A}^{\prime}\left(1098.5 \mathrm{~cm}^{-1}, \mathrm{NRuF}_{4}\right)$ in Figure 3. The $\mathrm{RuF}_{3}$ stretching modes of $C_{5}$ symmetric $\mathrm{NRuF}_{3}$ split into three modes. The strong antisymmetric $\mathrm{F}-\mathrm{Ru}-\mathrm{F}$ appears at $668.5 \mathrm{~cm}^{-1}$ (labeled B in Figure 3) and likely overlaps with the nearby weaker $\mathrm{F}^{\prime}-\mathrm{Ru}$ band. The symmetric $\mathrm{F}-\mathrm{Ru}-\mathrm{F}$ mode is attributed to the band labeled $\mathrm{C}$ in Figure 3 at $635.8 \mathrm{~cm}^{-1}$ (Table 1).

Table 1. Calculated and experimental vibrational wavenumbers $\left(v\left({ }^{14} \mathrm{~N}\right)\right.$ in $\mathrm{cm}^{-1}$ ) and ${ }^{14 / 15} \mathrm{~N}$ isotopic shifts ( $\Delta v$ in parentheses) for $\mathrm{NFeF}_{3}, \mathrm{NRuF}_{3}, \mathrm{NRuF}_{4}$ $\mathrm{NOsF}_{3}$ and $\mathrm{NOsF}_{4}$.

\begin{tabular}{|c|c|c|}
\hline $\operatorname{Exp}^{[a]}$ & $\operatorname{CCSD}(T)^{[\mathrm{b}]}$ & Assignment \\
\hline \multicolumn{3}{|l|}{$\mathrm{NFeF}_{3}\left(C_{3 \mathrm{v},}{ }^{3} \mathrm{~A}_{2}\right)^{[\mathrm{c}]}$} \\
\hline $946.4(-23.7)^{[\mathrm{d}]}$ & $1028(-26)^{[e, f]}$ & NFe str., $a_{1}$ \\
\hline 766.8/766.7 (0) & $737(0)^{[f]}$ & $\mathrm{FeF}_{3}$ str., e \\
\hline $658.8(-1.1)$ & $689(-2)^{[f]}$ & $\mathrm{FeF}_{3}$ str., $\mathrm{a}_{1}$ \\
\hline \multicolumn{3}{|l|}{$\mathrm{N}^{102} \mathrm{RuF}_{3}\left(C_{\mathrm{s}},{ }^{1} \mathrm{~A}^{\prime}\right)^{[\mathrm{g}]}$} \\
\hline $1105.4(-32.7)$ & $1085(-32)$ & NRu str., a' \\
\hline$-{ }^{[\mathrm{h}]}$ & $682(0)$ & 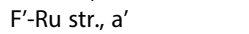 \\
\hline $668.5(0)$ & $678(0)$ & antisym. F-Ru-F str., a" \\
\hline \multicolumn{3}{|l|}{$\mathrm{N}^{102} \mathrm{RuF}_{4}\left(C_{4 \mathrm{v},}{ }^{2} \mathrm{~B}_{1}\right)^{[\mathrm{g}]}$} \\
\hline $1098.5(-32.5)$ & $1080(-32)$ & NRu str., $a_{1}$ \\
\hline $700.1(0)$ & $711(0)$ & $\mathrm{RuF}_{4}$ stretch, e \\
\hline$-^{[\mathrm{h}]}$ & $681(0)$ & RuF $_{4}$ stretch, $a_{1}$ \\
\hline$-\left[\begin{array}{ll}{[j]} \\
n\end{array}\right.$ & $598(0)$ & $\mathrm{RuF}_{4}$ stretch, $b_{2}$ \\
\hline \multicolumn{3}{|l|}{$\mathrm{NOsF}_{3}\left(C_{s^{\prime}}{ }^{1} \mathrm{~A}^{\prime}\right)$} \\
\hline $1140.1(-35.5)$ & $1152(-36)$ & NOs str., a' \\
\hline 686.0/686.6 (0) & $689(0)$ & $\mathrm{OsF}_{2}$ sym. str., $\mathrm{a}^{\prime}$ \\
\hline $641.3 / 640.0(0)$ & $664(0)$ & OsF' sym. str., a' \\
\hline $632.3(0)$ & $652(0)$ & $\mathrm{OsF}_{2}$ antisym. str., a" \\
\hline \multicolumn{3}{|l|}{$\mathrm{NOsF}_{3}\left(C s,{ }^{3} A^{\prime \prime}\right)$} \\
\hline $1086.0(-)^{[i]}$ & $1095(-36)^{[i]}$ & ${ }^{15} \mathrm{NOs}$ str, $\mathrm{a}^{\prime}$ \\
\hline $675.8 / 677.0$ & $675(0)$ & $\mathrm{OsF}_{2}$ antisym. str., a" \\
\hline $660.5 / 658.9(0)$ & $668(0)$ & $\mathrm{OsF}_{2}$ sym. str., $\mathrm{a}^{\prime}$ \\
\hline $607.4(0.0)$ & $614(0)$ & OsF' sym. str., a' \\
\hline \multicolumn{3}{|l|}{$\mathrm{NOsF}_{4}\left(C_{4 \mathrm{v}},{ }^{2} \mathrm{~B}_{1}\right)$} \\
\hline$-^{[k]}$ & $1145(-36)$ & NOs str., $a_{1}$ \\
\hline$--^{[k]}$ & $706(0)$ & $\mathrm{OsF}_{4}$ stretch, $\mathrm{a}_{1}$ \\
\hline $689.9(0)$ & $693(0)$ & $\mathrm{OsF}_{4}$ stretch, e \\
\hline$-[j]$ & $635(0)$ & $\mathrm{OsF}_{4}$ stretch, $\mathrm{b}_{2}$ \\
\hline
\end{tabular}

[a] Neon matrix; matrix sites are separated by a slash. [b] Intensities from DFT calculations available in Table S4. [c] M06-L/def2-QZVP: $785 \mathrm{a}_{1}(-11)$ [12], 703 e (0) [200], $617 \mathrm{a}_{1}(-1)$ [40]. [d] ${ }^{14 / 15} \mathrm{~N}$ isotopic ratio: 1.0256 . [e] ${ }^{14 /}$ ${ }^{15} \mathrm{~N}$ isotopic ratio: 1.0257. [f] NEVPT2/aug-cc-pwCVTZ-DK. [g] For the experimentally observed $\mathrm{Ru}$ isotope splitting see Tables S5-S7 and Figures S4 and S5). [h] Band is likely hidden by the stronger antisymmetric F-Ru-F stretching mode $\left(\mathrm{a}^{\prime \prime}\right)$. [i] $v\left({ }^{15} \mathrm{~N}-\mathrm{Os}\right)$ in $\mathrm{cm}^{-1}$, see text. [j] Not IR active. [k] Too weak or overlapped.
For $\mathrm{NRuF}_{4}$ only the strongest $\mathrm{RuF}_{4}$ stretching band, the degenerate $e$-type mode could safely be assigned to the band labeled $\mathbf{B}^{\prime}$ in Figure 3 centered at $700.0 \mathrm{~cm}^{-1}$.

In the spectra obtained from the reaction of osmium atoms with isotopic labeled ${ }^{15} \mathrm{NF}_{3}$ two $\mathrm{Os} \equiv \mathrm{N}$ stretching bands appeared at 1104.6 and $1086 \mathrm{~cm}^{-1}$, which are labeled $\mathbf{A}$ and $\mathbf{A}^{\prime}$, respectively, in Figure 4, and which are finally assigned to different "spinisomers" of $\mathrm{NOsF}_{3}$ in near-degenerate singlet ${ }^{1} \mathrm{~A}$ ' and triplet ${ }^{3} \mathrm{~A}$ " electronic states (Table 1). In the ${ }^{14} \mathrm{NF}_{3}$ experiment $\mathbf{A}$ is observed at $1140 \mathrm{~cm}^{-1}$ (Figure 4), while $A^{\prime}$ is overlapped by a stronger band due to the ${ }^{14} \mathrm{NF}$ radical at $1120.8 \mathrm{~cm}^{-1} \cdot{ }^{[30 \mathrm{~b}]}$ All three Os-F stretching bands of singlet $\mathrm{NOsF}_{3}\left({ }^{1} \mathrm{~A}^{\prime}\right)$ are assigned (Table 1) and labeled $\mathbf{B}$ $\left(v_{s}\left(\mathrm{OsF}_{2}\right): 686.0 \mathrm{~cm}^{-1}\right), \mathrm{C}\left(v\left(\mathrm{OsF}^{\prime}\right): 641.3 \mathrm{~cm}^{-1}\right)$, and $\mathbf{D}\left(v_{\text {as }}\left(\mathrm{OsF}_{2}\right)\right.$ : $632.3 \mathrm{~cm}^{-1}$ ) in Figure 4, respectively. Bands labeled $\mathbf{B}^{\prime}, \mathbf{C}^{\prime}$ and $\mathbf{D}^{\prime}$ at $675.8 \mathrm{~cm}^{-1}, 660.5 \mathrm{~cm}^{-1}$ and $607.4 \mathrm{~cm}^{-1}$, respectively, are assigned to the three Os-F stretching modes of triplet $\mathrm{NOsF}_{3}\left({ }^{3} \mathrm{~A}^{\prime \prime}\right.$, Table 1). Finally, a band at $689.6 \mathrm{~cm}^{-1}$ in Figure 4 is tentatively assigned to the strongest vibrational mode of $\mathrm{NOsF}_{4}\left(C_{4 v}\right.$, Table 1$)$. The tetrafluorides $N \equiv M F_{4}$ ( $M=R u$, Os) are likely formed by the exothermic addition of a fluorine atom to $\mathrm{N} \equiv \mathrm{MF}_{3}$ (Table S2).

\section{Pseudo-Jahn-Teller distortion of molecular group 8 nitrido fluorides $\mathrm{NM}^{\mathrm{V} \mathrm{I}} \mathrm{F}_{3}$}

The group 8 nitrido fluorides $\mathrm{NM}^{\mathrm{v}} \mathrm{F}_{3}$ adopt metal $d^{2}$ configurations, for which Hund's rule predicts a high-spin ${ }^{3} \mathrm{~A}_{2}$ ground state in an undistorted $C_{3 v}$ symmetry and two parallel spin electrons in the twofold degenerate $e\left(\mathrm{~d}_{x y, x^{2}-y^{2}}\right)$-orbital $\left(\left|e_{\varepsilon} \uparrow ; e_{\theta} \uparrow\right\rangle\right)$, labeled $9 \mathrm{e}$ for $\mathrm{NFeF}_{3}$ in the Supporting Information Figure $\mathrm{S} 6$. Three $e^{2}$ terms (four states) can be formed, ${ }^{3} \mathrm{~A}_{2}\left(\left|e_{\varepsilon} \uparrow ; e_{\theta} \uparrow\right\rangle\right),{ }^{1} \mathrm{~A}_{1}(\sqrt{ }$ $\left.1 / 2\left[\left|e_{\varepsilon} \uparrow ; e_{\varepsilon} \downarrow\right\rangle+\left|e_{\theta} \uparrow ; e_{\theta} \downarrow\right\rangle\right]\right),{ }^{1} \mathrm{E}_{\theta}\left(\sqrt{ } 1 / 2\left[\left|e_{\varepsilon} \uparrow ; e_{\varepsilon} \downarrow\right\rangle-\left|e_{\theta} \uparrow ; e_{\theta} \downarrow\right\rangle\right]\right)$ and ${ }^{1} \mathrm{E}_{\varepsilon}$ $\left(\sqrt{ } 1 / 2\left[\left|e_{\theta} \uparrow ; e_{\varepsilon} \downarrow\right\rangle+\left|e_{\theta} \downarrow ; e_{\varepsilon} \uparrow\right\rangle\right]\right)$. Due to the nondegenerate nature and totally symmetric charge distribution of the ${ }^{3} \mathrm{~A}_{2}$ state no Jahn-Teller distortion is expected. ${ }^{[3]}$ Other distributions of the electrons, as outlined above, result in configurations with lower spin and the absence of low-lying triplet excited states rule out obvious ground state pseudo-Jahn-Teller distortions.

Nevertheless, as shown in Figure 5 and in agreement with experimental vibrational assignments, all four $\mathrm{NMF}_{3}$ species possess surprisingly different structures and the $C_{3 \mathrm{v}}$ symmetric ground state was only verified for $\mathrm{NFeF}_{3}$. In case of $\mathrm{NRuF}_{3}$, extensive $\operatorname{CCSD}(\mathrm{T}) / \mathrm{CBS}$ calculations (Table S10) find the high symmetric ${ }^{3} \mathrm{~A}_{2}$ is just about $5 \mathrm{~kJ} \mathrm{~mol}^{-1}$ higher than the distorted ${ }^{1} \mathrm{~A}^{\prime}$ ground state. According to our experimental data, $\mathrm{NOsF}_{3}$ features two quasi-degenerate, distorted structures in ${ }^{1} \mathrm{~A}^{\prime}$ and ${ }^{3} \mathrm{~A}^{\prime}$ electronic states, separated by only $\Delta E_{\mathrm{T}-\mathrm{S}}=-1.3 \mathrm{~kJ} \mathrm{~mol}^{-1}$ (CCSD(T)/CBS, Table S11).

To elucidate these findings, adiabatic potential energy surface (APES) scans were carried out using state-averaged complete active space self-consistent field calculations by distributing eight electrons in the eight molecular orbits formed by the metal ( $\mathrm{n}-1) d$ and $\mathrm{N}(2 p)$ orbitals (SA-CASSCF $(8,8)$ ) with subsequent NEVPT2 treatment to recover dynamic correlation. Shown in Figure $6 \mathrm{a}-\mathrm{c}$ are cross sections along a distortion coordinate $(D)$ that connects the two stationary points of the 

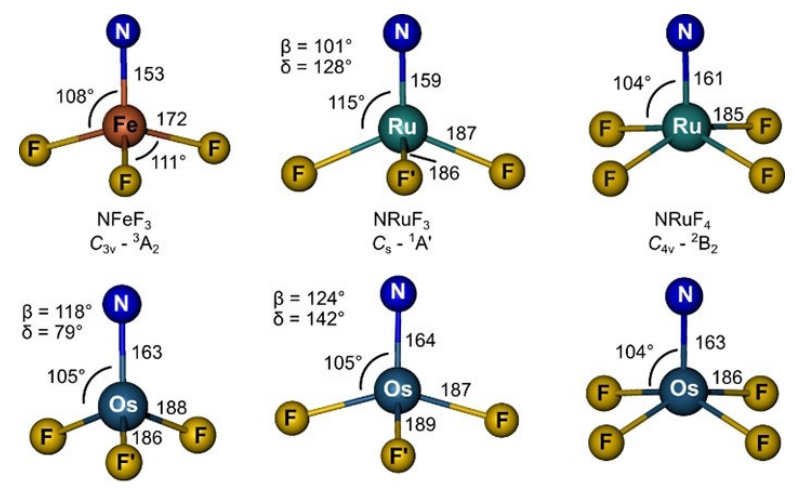

$\mathrm{NOsF}_{3}$

$\mathrm{NOsF}_{3}$

$\mathrm{NOsF}_{4}$

Figure 5. Ground-state structures of $\mathrm{NMF}_{3}$ and $\mathrm{NMF}_{4}$ calculated at the CCSD (T)/aVTZ (M=Ru, Os, M: aVTZ-PP) and the NEVPT2/aVTZ-DK $\left(\mathrm{NFeF}_{3}, \mathrm{Fe}\right.$ : awCVTZ-DK) levels of theory. Bond lengths are given in pm and angles in degrees. $\beta$ denotes the $\mathrm{N}-\mathrm{M}-\mathrm{F}^{\prime}$ and $\delta$ the $\mathrm{F}-\mathrm{M}-\mathrm{F}$ angle for structures with $C_{\mathrm{s}}$ symmetry.

${ }^{1} \mathrm{~A}^{\prime}$ surface, at $D=-1$ and 1 , respectively, via the high-symmetry $C_{3 v}$ stationary point at $D=0$.

The distortions take place along one component of the lowest $\left(\mathrm{NFeF}_{3}, \mathrm{NRuF}_{3}\right)$ or imaginary $\left(\mathrm{NOsF}_{3}\right)$ degenerate $e$ normal mode in the high-symmetry $C_{3 v}$ configuration. Therefore, mainly bond angle distortions are involved, in particular the dihedral angle
$\mathrm{F}^{\prime}-\mathrm{M}-\mathrm{N}-\mathrm{F}\left(\alpha\right.$, Figure S9), and the valence angles $\mathrm{N}-\mathrm{M}-\mathrm{F}^{\prime}(\beta$, Figure 5), and $\mathrm{N}-\mathrm{M}-\mathrm{F}(\gamma)$. The sign of the distortion $D$ in Figure 6 indicates a widening (positive) or closing (negative) of $\alpha$. Differences in these angles and in the three nonequivalent bond distances between two localized stationary points in $C_{S}$ symmetry were divided into equal incremental steps and used as intermediate internal coordinates in the APES calculation for each step (Tables S14-S17). In the case of Figure $6 \mathrm{~d}$ the distortion in the positive direction was carried out using the $\mathrm{NOsF}_{3}{ }^{3} \mathrm{~A}^{\prime \prime}$ minimum structure at $D=1$. The graphs shown in Figure $6 a-d$ represent the energies of the terms arising from the electronic $e^{2}$ configuration, as outlined above. They demonstrate the propensity of trigonal group 8 nitrido complexes in the oxidation state $\mathrm{VI}$ to be subject to a PJT distortion. Other trigonal systems displaying a $(A+E) \otimes e$ Pseudo-Jahn-Teller effect (PJTE) that is "hidden" in excited states (h-PJTE) have already been described. ${ }^{[27 a, 31]}$ The condition for a distorted ground state minimum structure caused by the h-PTJE is that the PJT stabilization energy of an excited state $\left(E_{\mathrm{PJT}}\right)$ is larger than the energy gap $\Delta_{0}$ between the ground state in the highsymmetry configuration and the PJT active excited state $\left(E_{\mathrm{PJT}}>\Delta_{0}\right.$, see Figure $6, \mathrm{a}-\mathrm{c}) .^{[27 \mathrm{a}]}$ The global minimum of the APES of $\mathrm{NFeF}_{3}$ shown in Figure $6 a$ is located at the high-symmetry point. The stationary points on the ${ }^{1} A^{\prime}$ (blue line) surface are a local minimum $(D=1)$ and a first-order saddle point $(D=-1)$ without surface crossings in between. Consistent with the experimental vibrational data the global minimum is the high symmetry configuration. The h-PJTE in the ${ }^{1} E$ state is not strong enough to distort the high-
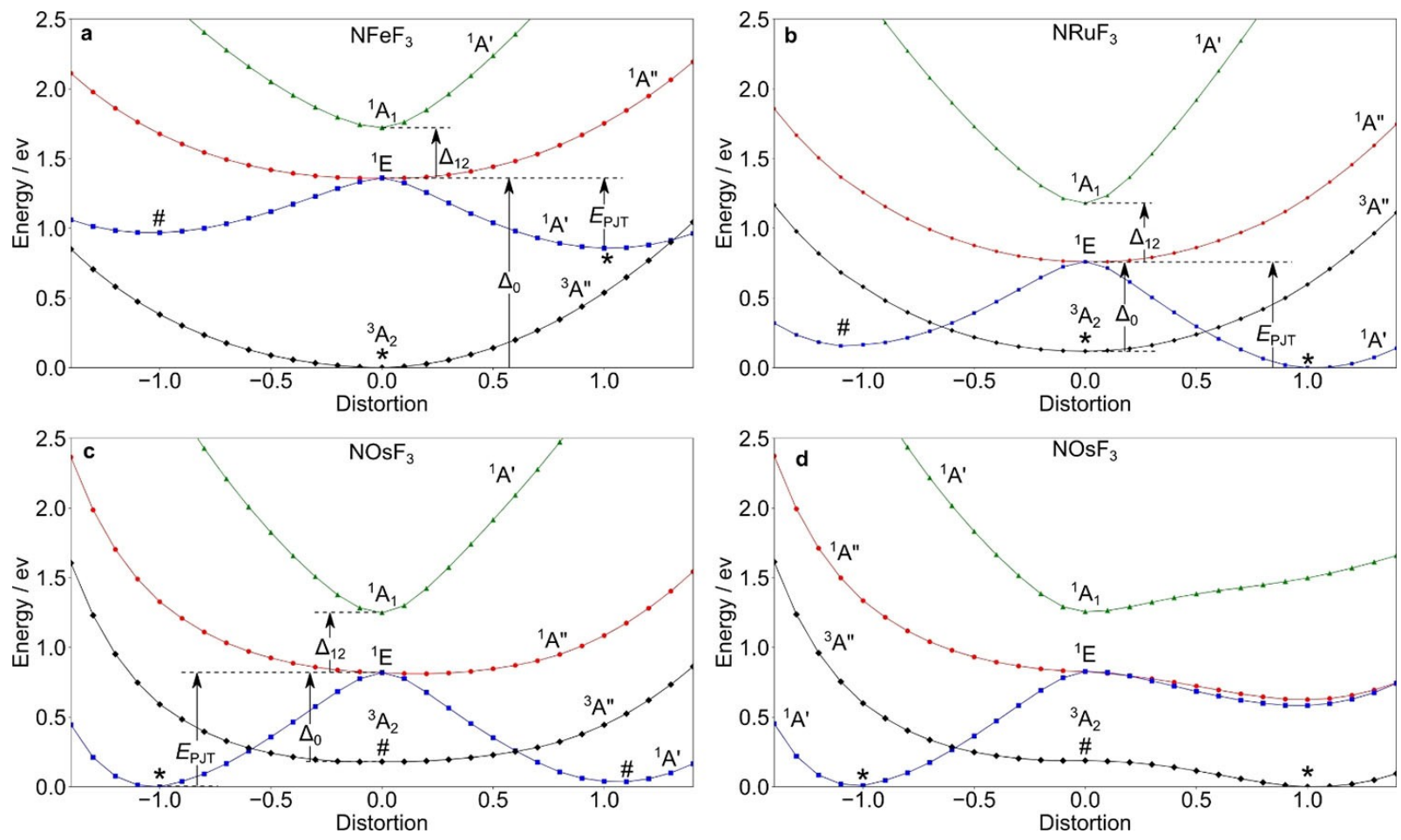

Figure 6. Cross section of the APES for the terms arising from the electronic $e^{2}$ configurations of a) NFeF ${ }_{3}$, b) $\left.\mathrm{NRuF}_{3}, \mathrm{C}\right)$, d) $\mathrm{NOsF}_{3}$ along the distortion coordinate $(D)$ connecting stationary points located at $D=1,0$ and -1 , respectively, on the ${ }^{1} A^{\prime}$ (blue line) and the ${ }^{3} A_{2}\left({ }^{3} A^{\prime \prime}\right.$, black line) surfaces. Minimum points are marked with an asterisk, and first-order saddle points with a hash mark. The PJT stabilization energy $\left(E_{\mathrm{PJT}}\right)$ of the lowest excited state, its excitation energy at $C_{3 v}$ symmetry $\left(\Delta_{0}\right)$, and the ${ }^{1} E-{ }^{1} A_{1}$ energy gap $\left(\Delta_{12}\right)$ are indicated in (a)-(c). 


\subsection{High-Spin Iron(VI), Low-Spin Ruthenium(VI), and Magnetically Bistable of Osmium(VI): Molecular Group 8 Nitrido Trifluorides $\mathrm{NMF}_{3}$}

symmetry configuration. The PJT stabilization energy, $E_{\mathrm{PJJ}}$, is about $0.39 \mathrm{eV}$ and smaller than the ${ }^{1} \mathrm{E}-{ }^{3} \mathrm{~A}_{2}$ energy gap $\Delta_{0}=1.36 \mathrm{eV}$. The ${ }^{1} A^{\prime}$ minima, which features a $\left(\left|e_{\theta} \uparrow ; e_{\theta} \downarrow\right\rangle\right)$ electronic configuration, and the ${ }^{3} \mathrm{~A}_{2}$ minima are separated by about $0.86 \mathrm{eV}$. The angular distortion from $D=-1$ to $D=1$ at the ${ }^{1} \mathrm{~A}^{\prime}$ surface extends from about $101-132(\alpha), 100-120(\beta)$, and $112-104(\gamma)$.

The cross section of the APES of $\mathrm{NRuF}_{3}$ along the distortion coordinate from $D=0$ to $D=1$ illustrated in Figure $6 \mathbf{b}$ shows that one of the components of the ${ }^{1} E$ term is stabilized by the strong PJT coupling with the excited ${ }^{1} \mathrm{~A}_{1}$ state. It crosses the ${ }^{3} \mathrm{~A}_{2}$ ground state of the undistorted high-symmetry configuration to produce the global minimum with a distorted structure. The triplet-singlet spin crossover is associated with an orbital disproportionation, ${ }^{[27]}$ because in the distorted structure the electrons are paired in one $e_{\theta}$ orbital $\left(\left|e_{\theta} \uparrow ; e_{\theta} \downarrow\right\rangle\right)$ instead of the symmetric distribution $\left(\left|e_{\varepsilon} \uparrow ; e_{\theta} \uparrow\right\rangle\right)$ in the undistorted configuration. Accordingly, we find that $E_{\mathrm{PJT}}=0.76 \mathrm{eV}$ is larger than $\Delta_{0}=$ $0.64 \mathrm{eV}$. The high-spin ${ }^{3} \mathrm{~A}$ " state is higher in energy by only $\sim 0.12 \mathrm{eV}$ and it has an energy barrier of $\sim 0.25 \mathrm{eV}$ to the point of spin crossover with the low-spin ${ }^{1} \mathrm{~A}$ ' state.

Figures $6 c$ and $d$ exhibit four relevant low-lying stationary points on the ${ }^{1} A^{\prime}$ and ${ }^{3} A^{\prime \prime}$ APES of $\mathrm{NOsF}_{3}$. The h-PJTE in this case produces a minimum with a distorted ${ }^{1} \mathrm{~A}$ ' structure at $D=-1$ and accordingly, the orbital disproportionation and spin crossover leads to a $\left(\left|e_{\varepsilon} \uparrow ; e_{\varepsilon} \downarrow\right\rangle\right)$ configuration with $E_{\mathrm{PJT}}=0.82 \mathrm{eV}$ and $\Delta_{0}=0.60 \mathrm{eV}$. Unlike the former two cases, the ${ }^{3} \mathrm{~A}_{2}$ highsymmetry configuration of $\mathrm{NOSF}_{3}$ does not represent a minimum point, but a first order saddle point. Following the $\varepsilon$ component of the imaginary e mode in Figure $6 \mathrm{~d}$ we find - in accordance with the $\operatorname{CCSD}(\mathrm{T}) / \mathrm{CBS}$ results - an energetically quasi-degenerate distorted ${ }^{3} \mathrm{~A}$ " minimum that shows orbital disproportionation, but no spin crossover about $0.1 \mathrm{eV}$ (or $0.7 \mathrm{~kJ} \mathrm{~mol}^{-1}$ ) lower than the ${ }^{1} \mathrm{~A}^{\prime}$ state. The energy barrier of the spin crossover point is $\sim 0.27 \mathrm{eV}(\mathrm{CCSD}(\mathrm{T}) / \mathrm{VTZ}-\mathrm{PP}: 0.24 \mathrm{eV}$, Table S12), a significant barrier connecting both stationary points at the experimental cryogenic conditions. These findings support the observation of two different species in the experimental infrared spectra which correspond to species in different ${ }^{1} \mathrm{~A}^{\prime}$ and ${ }^{3} \mathrm{~A}^{\prime}$ electronic states. We did not analyze the source of the distortion of the high-spin minimum $\left({ }^{3} \mathrm{~A}^{\prime \prime}\right)$. But, under the premise that PJTE is the only source for symmetry breaking of non-degenerate high-symmetry states, ${ }^{[27 b, 31]}$ the source is most likely an interacting triplet ${ }^{3} \mathrm{E}$ excited state.

\section{Discussion}

All metal specific bands showing a ${ }^{14 / 15} \mathrm{~N}$ isotopic shift were successfully assigned. Bands due to binary fluorides are always present in experiments using IR laser ablation of metals in the presence of molecular fluorides as precursors. They are likely formed by recombination of metal atoms and atomic fluorine radicals formed by thermal or photolytic decomposition of the fluoride precursor in the hot plasma plume region or by the decomposition of metal fluoride product molecules. However, the very strong $\mathrm{NF}_{3}$ precursor bands and comparatively weak $\mathrm{NF}$ and $\mathrm{NF}_{2}$ bands in all spectra suggest that the formation of the $\mathrm{NMF}_{3}$ title product can be attributed to the reaction of $\mathrm{M}_{\text {and }} \mathrm{NF}_{3}$. Lower nitrido fluorides NMF or $\mathrm{NMF}_{2}$ could in principle also be formed through the cleavage of a metal-fluorine bond or by the reaction of metal atoms with $\mathrm{NF}$ or $\mathrm{NF}_{2}$, but have so far not been identified. ${ }^{[25,26,30 c, 33]}$ The addition of fluorine to NMF and $\mathrm{NMF}_{2}$ to yield $\mathrm{NMF}_{3}$ and also the formation of $\mathrm{NMF}_{4}$ for $\mathrm{M}=\mathrm{Ru}$ and $\mathrm{Os}$ are calculated to be exothermic (Table S2).

As shown here, all the trigonal $\mathrm{NMF}_{3}$ species possess two equilibrium configurations with different spin multiplicities, while those of $\mathrm{NRuF}_{3}$ and $\mathrm{NOsF}_{3}$ are close in energy. Such a magnetic and structural PJT induced bistability may also be possible for ligand-stabilized trigonal nitrido $\mathrm{d}^{2}$ metal complexes. Such compounds are of interest for molecular switching, especially when symmetry breaking is involved (as for $\mathrm{NFeF}_{3}$ and $\left.\mathrm{NRuF}_{3}\right)^{[34]}$

The different stationary structures that were obtained for the group $8 \mathrm{NMF}_{3}$ molecules shown in Figure 5 possess surprisingly different electronic configurations, as outlined above and summarized in Figure 7 (for molecular orbital plots, see Figures $\mathrm{S} 6$ and S8). The different ${ }^{1} \mathrm{~A}$ ' electronic ground states of $\mathrm{NRuF}_{3}$ and $\mathrm{NOsF}_{3}$ arise from the pairing of two unpaired electrons in different orbitals, which are associated with two different structural distortions. The $\mathrm{HOMO}$ of $\mathrm{NRuF}_{3}\left({ }^{1} A^{\prime}\right)$ is of a" symmetry, which is consistent with a widening of the $\mathrm{F}-\mathrm{M}-\mathrm{F}$ angle, whereas the $\mathrm{HOMO}$ of $\mathrm{NOsF}_{3}\left({ }^{1} \mathrm{~A}^{\prime}\right)$ is of a' symmetry, which shows a reduction in the $\mathrm{F}-\mathrm{M}-\mathrm{F}$ angle bisected by the $\sigma$ plane in $C_{s}$ symmetry (Figure 5). The $d^{1}$ metal configuration for the heptavalent tetrafluorides $\mathrm{NRu}^{\mathrm{VII}} \mathrm{F}_{4}$ and $\mathrm{NOs}^{\mathrm{VI}} \mathrm{F}_{4}\left(C_{4 \mathrm{v}}\right)$ give rise to a ${ }^{2} \mathrm{~B}_{2}$ electronic ground state (see Figure $\mathrm{S7}$ for the singly occupied $\mathrm{MO}$ ).

The effective bond orders ${ }^{[35]}$ (EBOs) for $\mathrm{NOsF}_{3}, \mathrm{NRuF}_{3}$ and $\mathrm{NFeF}_{3}$ are 2.8, 2.7 and 2.2, respectively, which in fact corresponds to triple bonds for all these $\mathrm{M}-\mathrm{N}$ bonds. The computed $\mathrm{M}-\mathrm{N}$ bond lengths for the novel nitrido compounds (153 pm (FeN), $159 \mathrm{pm}$ (RuN), 163-164 pm (OsN), Figure 7) are close to our published triple bond additive covalent radii: $156 \mathrm{pm}$ (FeN), $157 \mathrm{pm}(\mathrm{RuN})$ and $163 \mathrm{pm}(\mathrm{OsN}){ }_{1}^{[36]}$ and also the experimental $\mathrm{N}-\mathrm{M}$ stretching frequencies (Table 1) support the presence of strong $\mathrm{M} \equiv \mathrm{N}$ triple bonds in the novel hexavalent nitrido complexes $\mathrm{NM}^{\mathrm{V}} \mathrm{F}_{3}$. We note that the experimental $v(\mathrm{Fe}=\mathrm{N})$ frequency of $\mathrm{NFe}^{\mathrm{v}} \mathrm{F}_{3}$ of $946 \mathrm{~cm}^{-1}$ (Table 1) is not well reproduced by calculations at DFT or $\operatorname{CCSD}(\mathrm{T})$ levels (Table S3) and is also

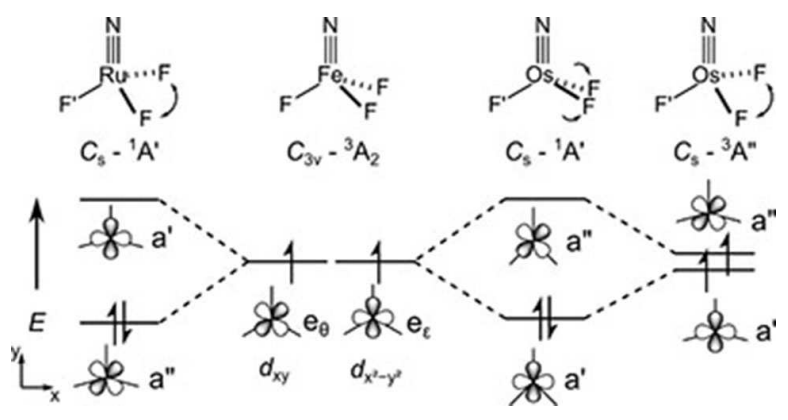

Figure 7. Comparison of the different $d^{2}$ electron configurations of the $\mathrm{NMF}_{3}$ species ( $\mathrm{M}=\mathrm{Fe}, \mathrm{Ru}, \mathrm{Os})$. The metal centered $\mathrm{a}^{\prime}$ and $\mathrm{a}^{\prime \prime}-\mathrm{MOs}$ are dominantly $M\left(d_{x^{2}-y^{2}}\right)$ and $M\left(d_{x y}\right)$ atomic orbitals, respectively. 
overestimated by the more sophisticated NEVPT2 multi-reference approach $\left(v(\mathrm{Fe}=\mathrm{N})=1027 \mathrm{~cm}^{-1}\right.$, Table S3). On the other hand, its comparison with experimental $\mathrm{Fe}=\mathrm{N}$ stretching frequencies for pseudo-tetrahedral $\mathrm{N}^{\mathrm{IV}} \mathrm{FeL}_{3}$ complexes, previously reported at 1008 $\left(\left[\mathrm{Fe}^{\mathrm{IV}}(\mathrm{N})\left(\mathrm{TIMEN}^{\mathrm{Mes}}\right)\right]^{+}\right)_{{ }^{[24 \mathrm{c}]}} 1028 \quad\left(\left[\mathrm{Fe}^{\mathrm{IV}}(\mathrm{N})\left(\mathrm{PhB}\left({ }^{\mathrm{H}} \mathrm{Bulm}\right)_{3}\right]\right)\right)^{[24 \mathrm{~b}]}$ and

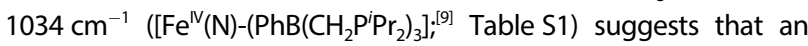
increase in the iron oxidation state beyond $\mathrm{V}$ does not necessarily lead to a stronger $\mathrm{Fe}=\mathrm{N}$ bond.

Table 2 shows experimental $\mathrm{M}-\mathrm{N}$ stretching frequencies of molecular $\mathrm{NMF}_{3}$ species formed by the reaction of $\mathrm{NF}_{3}$ with laserablated transition metals. For the $\mathrm{d}^{0}$ configurations of all group 4 and group 6 nitrido trifluorides the ideal pseudo-tetrahedral $C_{3 \mathrm{v}}$ symmetric arrangement was experimentally verified, since there are no electrons in the nonbonding $e\left(\mathrm{~d}_{x y, x^{2}-y^{2}}\right)$ orbitals that could cause distortions. ${ }^{[25,33]}$ The $e^{3}$ configuration of $\mathrm{NRhF}_{3}$ and $\mathrm{NlrF}_{3}$ leads to Jahn-Teller distorted spin doublet ground states in $C_{s}$ symmetry. ${ }^{[6]}$ So far, no experimental data are available for the group 10 derivatives, and for the group 11 analogues only the initial metal insertion products $\mathrm{F}_{2} \mathrm{~N}-\mathrm{M}^{\mathrm{N}} \mathrm{F}$ were detected after matrix deposition (irradiation of $\mathrm{F}_{2} \mathrm{NCuF}$ led to rearrangement to metastable $\left.\mathrm{FN}=\mathrm{CuF}_{2}\right){ }^{[30 \mathrm{cc}]}$

The $\mathrm{M}-\mathrm{N}$ stretching normal mode of the terminally bond nitrogen ligands of the nitrido trifluorides can regarded to be a good approximation as an almost pure and uncoupled metalnitrogen stretching mode that can be used as a measure of the $\mathrm{M}-\mathrm{N}$ bond strength. The $\mathrm{NM}^{\mathrm{IV}} \mathrm{F}_{3}$ derivatives of the group 4 metals possess a singly bonded triplet nitrene $\left({ }^{3} \mathrm{~N}^{-}\right)$ligand, since the ligand cannot oxidize the $d^{0}$ metal center any further. The two unpaired electrons in the $N(2 p)$ orbitals are reported to be involved in weak degenerate $\pi$ bonding interactions for $\mathrm{M}=\mathrm{Ti} \gg$ $\mathrm{Zr}, \mathrm{Hf}^{[33]}$ In contrast, the group 6, 8 and $9 \mathrm{NM}^{\mathrm{V}} \mathrm{F}_{3}$ molecules show a $\mathrm{N} \equiv \mathrm{M}$ triple bond with one $\sigma$ and two $\pi$ bonds to the terminal nitrido $\left(\mathrm{N}^{3-}\right)$ ligand. The strength and overlap of these bonds increases going down the groups likely due to an improved $M(\pi d)-N(\pi p)$ orbital overlap as a result of an increasing relativistic expansion ${ }^{[37]}$ of the $4 \mathrm{~d}$ and $5 \mathrm{~d}$ orbitals and the absence of metal core/ligand repulsion proposed in first-row transition metal compounds. ${ }^{[38]}$ The general trend of increasing $\mathrm{N}-\mathrm{M}$ bond strength moving along the rows culminates in the highest observed $\mathrm{M}-\mathrm{N}$ stretching frequency for $\mathrm{NIrF}_{3}$. Unexpectedly, this trend does not apply to $\mathrm{NFeF}_{3}$ which shows a lower $\mathrm{M}-\mathrm{N}$ stretching frequency than the group 6 homologue $(\mathrm{M}=\mathrm{Cr})$. The lower stability of high-valent first row late transition metals is well known. ${ }^{[1,39]}$ In the series of $3 \mathrm{~d} \mathrm{NM}^{\mathrm{V}} \mathrm{F}_{3}$ compounds, for $\mathrm{M}=\mathrm{Fe}$ it seems we have reached the limit of stability. $\mathrm{NCo}^{\mathrm{v}} \mathrm{F}_{3}$ is not a stable compound and only $\mathrm{FNCoF}_{2}$ has been observed experimentally. ${ }^{[26]}$ For the $4 d$ element $\mathrm{Rh}$ it was found that the rearrangement of the fluoro nitrene complex $\mathrm{FNRhF}_{2}$ into $\mathrm{N} \models \mathrm{Rh}^{\mathrm{V}} \mathrm{F}_{3}$ is only slightly exothermic $\left(\Delta H^{0}=-12 \mathrm{~kJ} \mathrm{~mol}^{-1}, \operatorname{CCSD}(\mathrm{T})\right)$, which enables the observation of both rearrangement products. ${ }^{[26]}$

Within the atoms in molecules (AIM) scheme ${ }^{[00]}$ the partial negative charge at the nitrido ligand in $\mathrm{NM}^{\mathrm{V}} \mathrm{F}_{3}$ increases from $\mathrm{M}=$ Fe to Os (Tables S9 and S13), which indicates a decreasing electron withdrawing effect of the $M^{\mathrm{V}} \mathrm{F}_{3}$ fragment within this group. For $\mathrm{M}=\mathrm{Fe}$ and $\mathrm{Ru}$ the negative charge at the nitrogen atom also decreases from $\mathrm{NMF}_{2}(\mathrm{M}=\mathrm{Fe}:-0.35, \mathrm{Ru}:-0.40)$ to $\mathrm{NMF}_{3}(\mathrm{M}=\mathrm{Fe}$ : $-0.25, \mathrm{Ru}:-0.35)$, while for $\mathrm{M}=\mathrm{Os}$ it remains unchanged $\left(\mathrm{NOsF}_{2}\right.$ : $-0.50, \mathrm{NOsF}_{3}:-0.49$ ). As expected, fluorination of $\mathrm{NMF}_{3}$ further decreases the atomic charge of the nitrido ligand in $\mathrm{NMF}_{4}(\mathrm{M}=\mathrm{Ru}$ : -0.25 , Os: -0.40 , Table S9). The high oxidation potential of $\mathrm{Fe}^{\mathrm{vl}}$ in $\mathrm{NFeF}_{3}$ leads to relatively high $\sigma^{*}$ and $\pi^{*}$ occupation numbers $(0.2$ and 0.3 electrons, respectively; Figure S6). These indicates a weakened covalent $\mathrm{N}-\mathrm{Fe}$ bond, for which the formal $\mathrm{N}^{3-}$ nitride notations seems to be a very poor approximation. The occupation of formally antibonding MOs also indicates an oxidation, and thus the onset of a redox non-innocent behavior of the nitrido ligand.

\section{Conclusion}

The nitrido complexes $\mathrm{NFeF}_{3}, \mathrm{NRuF}_{3}, \mathrm{NRuF}_{4}, \mathrm{NOsF}_{3}\left({ }^{1} A^{\prime}\right)$, $\operatorname{NOsF}_{3}\left({ }^{3} A^{\prime \prime}\right)$, and $\mathrm{NOsF}_{4}$ were shown to be formed by the reaction of free group 8 metal atoms with $\mathrm{NF}_{3}$ and established by their characteristic IR spectra recorded in solid neon matrices. Their assignment is supported by observed ${ }^{14 / 15} \mathrm{~N}$ isotope shifts and quantum-chemical predictions. All stretching fundamentals of the $\mathrm{NM}^{\mathrm{V}} \mathrm{F}_{3}$ complexes were confidently assigned. For the $C_{4 v}$ symmetric $\mathrm{NRuF}_{4}$ two distinct bands were confidently assigned, whereas for $\mathrm{NOsF}_{4}$ only the strongest band was tentatively assigned. Based on the joint experimental $\mathbb{I R}$ and quantum-chemical analysis the half-filled $e^{2}$ configuration of $\mathrm{NFeF}_{3}$ can be assigned to an undistorted $C_{3 \mathrm{v}}$ structure in a non-degenerate ${ }^{3} \mathrm{~A}_{2}$ electronic ground state. $\mathrm{NFeF}_{3}$ features an unprecedented low $\mathrm{Fe}=\mathrm{N}$ triple-bond frequency of $946.7\left({ }^{14} \mathrm{~N}=\mathrm{Fe}\right)$ and $922.7 \mathrm{~cm}^{-1}\left({ }^{15} \mathrm{~N} \equiv \mathrm{Fe}\right)$. The heavier group $8 \mathrm{NMF}_{3}$ homologues are subject to symmetry lowering and spin-crossover caused by a pseudo Jahn-Teller effect "hidden" in the excited states. While the electronic ground state of $\mathrm{NRuF}_{3}$ is a structurally distorted singlet ${ }^{1} A^{\prime}$ state $\left(C_{S}\right.$ symmetry), for molecular $\mathrm{NOsF}_{3}$ two coexisting distorted $C_{S}$ structures with high-spin and low-spin $d^{2}$ configurations (magnetic bistability) were detected at $5 \mathrm{~K}$ in solid neon. To the best of our knowledge, apart from $\mathrm{O}_{2} \mathrm{Fe}\left(\eta^{2}-\mathrm{O}_{2}\right),{ }^{[3-5]}$ no other neutral $\mathrm{Fe}^{\mathrm{VI}}$ complexes or molecular neutral complexes of $\mathrm{Ru}^{\mathrm{VII}}$ have yet been reported, and after $\mathrm{OsOF}_{5}{ }^{[1]} \mathrm{NOsF}_{4}$ is the second known monomeric Os ${ }^{\mathrm{VII}}$ compound.

\begin{tabular}{|c|c|c|c|c|c|}
\hline Row & Group $4^{[a]}$ & Group $6^{[\mathrm{b}]}$ & Group $8^{[c]}$ & Group $9^{[d]}$ & Group $11^{[30 c]}$ \\
\hline $3 d$ & $596.7\left(\mathrm{Ti}, \mathrm{C}_{3 \mathrm{v},}{ }^{3} \mathrm{~A}_{1}\right)$ & $1015\left(\mathrm{Cr}, \mathrm{C}_{3 \mathrm{v}},{ }^{1} \mathrm{~A}_{1}\right)$ & $946.4\left(\mathrm{Fe}, C_{3 v},{ }^{3} \mathrm{~A}_{2}\right)$ & $\mathrm{FN}=\mathrm{CoF}_{2}$ only & $\mathrm{F}_{2} \mathrm{~N}-\mathrm{CuF}, \mathrm{FN}=\mathrm{CuF}_{2}$ \\
\hline $4 d$ & $553.1\left(\mathrm{Zr}, C_{3 \mathrm{v},}{ }^{3} \mathrm{~A}_{1}\right)$ & $1075\left(\mathrm{Mo}, \mathrm{C}_{3 \mathrm{v}},{ }^{1} \mathrm{~A}_{1}\right)$ & $1098.5\left(\mathrm{Ru}, \mathrm{C}_{\mathrm{s}^{\prime}}{ }^{1} \mathrm{~A}^{\prime}\right)$ & $\begin{array}{l}1116.1\left(\mathrm{Rh}, \mathrm{C}_{\mathrm{s}^{\prime}}{ }^{2} \mathrm{~A}^{\prime}\right)[\mathrm{Ne}] \\
1112.5[\mathrm{Rh}, \mathrm{Ar}]^{\text {[e] }}\end{array}$ & $\mathrm{F}_{2} \mathrm{~N}-\mathrm{AgF}$ only \\
\hline $5 d$ & $548.1\left(\mathrm{Hf}, \mathrm{C}_{3 \mathrm{v}},{ }^{3} \mathrm{~A}_{1}\right)$ & $1091\left(\mathrm{~W}, \mathrm{C}_{3 \mathrm{v}},{ }^{1} \mathrm{~A}_{1}\right)$ & $\begin{array}{l}1140.1\left(\mathrm{Os}, \mathrm{C}_{\mathrm{s}}{ }^{1} \mathrm{~A}^{\prime}\right) \\
1086.0\left(\mathrm{Os}, \mathrm{C}_{\mathrm{s}}{ }^{3} \mathrm{~A}^{\prime \prime}\right)\end{array}$ & $\begin{array}{l}1150.4\left(\mathrm{Ir}, \mathrm{C}_{\mathrm{s}^{\prime}}{ }^{2} \mathrm{~A}^{\prime}\right)[\mathrm{Ne}] \\
1144.6[\mathrm{lr}, \mathrm{Ar}]\end{array}$ & $\mathrm{F}_{2} \mathrm{~N}-\mathrm{AuF}$ only \\
\hline
\end{tabular}




\section{Acknowledgements}

We gratefully acknowledge the Zentraleinrichtung für Datenverarbeitung (ZEDAT) of the Freie Universität Berlin for the allocation of computing resources. ${ }^{[41]}$ We thank the ERC Project HighPotOx as well as the CRC 1349 (SFB 1349) Fluorine Specific Interactions - Project-ID 387284271 - for continuous support. Open access funding enabled and organized by Projekt DEAL.

\section{Conflict of Interest}

The authors declare no conflict of interest.

Keywords: ab initio calculations $\cdot$ high oxidation states $\cdot$ matrix isolation $\cdot \mathrm{N}$ ligands $\cdot$ transition metals

[1] a) S. Riedel, M. Kaupp, Coord. Chem. Rev. 2009, 253, 606-624; b) O. Ruff, E. Vidic, Z. Anorg. Allg. Chem. 1924, 136, 49-61; c) W. J. Casteel Jr, D. A Dixon, H. P. A. Mercier, G. J. Schrobilgen, Inorg. Chem. 1996, 35, 43104322; d) A. O. Chong, K. Oshima, K. B. Sharpless, J. Am. Chem. Soc. 1977, 99, 3420-3426; e) K. Muniz, Chem. Soc. Rev. 2004, 33, 166-174; f) H. Shorafa, K. Seppelt, Inorg. Chem. 2006, 45, 7929-7934.

[2] H. Schmidbaur, Z. Anorg. Allg. Chem. 2018, 644, 536-559.

[3] Y. Gong, M. Zhou, L. Andrews, J. Phys. Chem. A 2007, 111, 12001-12006.

[4] W. Huang, D.-H. Xing, J.-B. Lu, B. Long, Schwarz, W. H. Eugen, J. Li, J. Chem. Theory Comput. 2016, 12, 1525-1533.

[5] J.-B. Lu, J. Jian, W. Huang, H. Lin, J. Li, M. Zhou, Phys. Chem. Chem. Phys. 2016, 18, 31125-31131.

[6] a) J. Hohenberger, K. Ray, K. Meyer, Nat. Commun. 2012, 3, 720; b) J. M. Smith, D. Subedi, Dalton Trans. 2012, 41, 1423-1429; c) B. Mondal, L. Roy, F. Neese, S. Ye, Isr. J. Chem. 2016, 56, 763-772.

[7] W. D. Wagner, K. Nakamoto, J. Am. Chem. Soc. 1988, 110, 4044-4045.

[8] J. F. Berry, E. Bill, E. Bothe, S. D. George, B. Mienert, F. Neese, K. Wieghardt, Science 2006, 312, 1937-1941.

[9] T. A. Betley, J. C. Peters, J. Am. Chem. Soc. 2004, 126, 6252-6254.

[10] J. L. Martinez, S. A. Lutz, H. Yang, J. Xie, J. Telser, B. M. Hoffman, V. Carta M. Pink, Y. Losovyj, J. M. Smith, Science 2020, 370, 356-359.

[11] E. W. Svastits, J. H. Dawson, R. Breslow, S. H. Gellman, J. Am. Chem. Soc $1985,107,6427-6428$.

[12] a) T. Kandemir, M. E. Schuster, A. Senyshyn, M. Behrens, R. Schlögl, Angew. Chem. Int. Ed. 2013, 52, 12723-12726; Angew. Chem. 2013, 125, 12955-12959; b) G. Ertl, Chem. Rec. 2001, 1, 33-45.

[13] a) B. Askevold, J. T. Nieto, S. Tussupbayev, M. Diefenbach, E. Herdtweck, M. C. Holthausen, S. Schneider, Nat. Chem. 2011, 3, 532-537; b) B. M. Lindley, Q. J. Bruch, P. S. White, F. Hasanayn, A. J. M Miller, J. Am. Chem. Soc. 2017, 139, 5305-5308.

[14] a) W.-X. Ni, W.-L. Man, M. T.-W. Cheung, R. W.-Y. Sun, Y.-L. Shu, Y.-W. Lam, C.-M. Che, T.-C. Lau, Chem. Commun. 2011, 47, 2140-2142; b) W.-X. Ni, W.-L. Man, S.-M. Yiu, M. Ho, M. T.-W. Cheung, C.-C. Ko, C.-M. Che, Y.W. Lam, T.-C. Lau, Chem. Sci. 2012, 3, 1582.

[15] K. Suntharalingam, T. C. Johnstone, P. M. Bruno, W. Lin, M. T. Hemann, S. J. Lippard, J. Am. Chem. Soc. 2013, 135, 14060-14063.

[16] K. Suntharalingam, W. Lin, T. C. Johnstone, P. M. Bruno, Y.-R. Zheng, M. T. Hemann, S. J. Lippard, J. Am. Chem. Soc. 2014, 136, 14413-14416.

[17] W.-X. Ni, W.-L. Man, W.-Q. Huang, C.-X. Wang, T. Liu, Z.-X. Li, C. Pan, Y.-Z. Chen, X. Lian, Dalton Trans. 2020, 49, 17173-17182.

[18] a) H.-X. Wang, L. Wu, B. Zheng, L. Du, W.-P. To, C.-H. Ko, D. L. Phillips, C.M. Che, Angew. Chem. Int. Ed. 2021, 60, 4796-4803; Angew. Chem. 2021 133, 4846-4853; b) N. B. Thompson, M. T. Green, J. C. Peters, J. Am. Chem. Soc. 2017, 139, 15312-15315; c) P. Vöhringer, Dalton Trans. 2020 $49,256-266$.

[19] a) J. J. Scepaniak, C. S. Vogel, M. M. Khusniyarov, F. W. Heinemann, K. Meyer, J. M. Smith, Science 2011, 331, 1049-1052; b) M. Keilwerth, L. Grunwald, W. Mao, F. W. Heinemann, J. Sutter, E. Bill, K. Meyer, J. Am.
Chem. Soc. 2021, 143, 1458-1465; c) G. E. Cutsail, B. W. Stein, D. Subedi, J. M. Smith, M. L. Kirk, B. M. Hoffman, J. Am. Chem. Soc. 2014, 136, 12323-12336; d) G. Sabenya, L. Lázaro, I. Gamba, V. Martin-Diaconescu, E. Andris, T. Weyhermüller, F. Neese, J. Roithova, E. Bill, J. Lloret-Fillol, M. Costas, J. Am. Chem. Soc. 2017, 139, 9168-9177; e) L. Bucinsky, M. Breza, W.-T. Lee, A. K. Hickey, D. A. Dickie, I. Nieto, J. A. DeGayner, T. D. Harris, K. Meyer, J. Krzystek, A. Ozarowski, J. Nehrkorn, A. Schnegg, K. Holldack, R. H. Herber, J. Telser, J. M. Smith, Inorg. Chem. 2017, 56, 4752-4769.

[20] The "oxo wall" concept for terminal tetragonal oxo complexes is associated with d-orbital occupations beyond 5 and the resulting population of all metal-oxo $\mathrm{pi}^{*}$ antibonding orbitals. Here, we refer to the concept of non-innocent ligands, which is of general importance in transition-metal chemistry and is not restricted to tetragonal complexes or to the occupation of antibonding MOs, but to the more general concepts of covalency and ligand field inversion. See ref. [22] and: L. Li, H. Beckers, T. Stüker, T. Lindič, T. Schlöder, D. Andrae, S. Riedel, Inorg. Chem. Front. 2021, 8, 1215-1228.

[21] a) W. Kaim, Eur. J. Inorg. Chem. 2012, 2012, 343-348; b) R. Hoffmann, S. Alvarez, C. Mealli, A. Falceto, T. J. Cahill, T. Zeng, G. Manca, Chem. Rev. 2016, 116, 8173-8192.

[22] N. Aliaga-Alcalde, S. DeBeer George, B. Mienert, E. Bill, K. Wieghardt, F. Neese, Angew. Chem. Int. Ed. 2005, 44, 2908-2912; Angew. Chem. 2005, 117, 2968-2972.

[23] M. P. Hendrich, W. Gunderson, R. K. Behan, M. T. Green, M. P. Mehn, T. A. Betley, C. C. Lu, J. C. Peters, Proc. Natl. Acad. Sci. USA 2006, 103, 1710717112.

[24] a) J.-U. Rohde, T. A. Betley, T. A. Jackson, C. T. Saouma, J. C. Peters, Q. Lawrence Jr, Inorg. Chem. 2007, 46, 5720-5726; b) J. J. Scepaniak, M. D. Fulton, R. P. Bontchev, E. N. Duesler, M. L. Kirk, J. M. Smith, J. Am. Chem. Soc. 2008, 130, 10515-10517; c) C. Vogel, F. W. Heinemann, J. Sutter, C. Anthon, K. Meyer, Angew. Chem. Int. Ed. 2008, 47, 2681-2684; Angew. Chem. 2008, 120, 2721-2724.

[25] X. Wang, L. Andrews, R. Lindh, V. Veryazov, B. O. Roos, J. Phys. Chem. A 2008, 112, 8030-8037.

[26] T. Stüker, T. Hohmann, H. Beckers, S. Riedel, Angew. Chem. Int. Ed. 2020, 59, 23174-23179; Angew. Chem. 2020, 132, 23374-23379.

[27] a) P. Garcia-Fernandez, I. B. Bersuker, J. E. Boggs, J. Chem. Phys. 2006, 125, 104102; b) I. B. Bersuker, Chem. Rev. 2021, 121, 1463-1512.

[28] M. Laing, J. Chem. Educ. 1989, 66, 453.

[29] T. Schlöder, T. Vent-Schmidt, S. Riedel, Angew. Chem. Int. Ed. 2012, 51, 12063-12067; Angew. Chem. 2012, 124, 12229-12233.

[30] a) M. E. Jacox, J. Phys. Chem. Ref. Data 1998, 27, 115-393; b) D. E. Milligan, M. E. Jacox, J. Chem. Phys. 1964, 40, 2461-2466; c) Y. Gong, L. Andrews, Inorg. Chem. 2012, 51, 667-673.

[31] I. B. Bersuker, Chem. Rev. 2013,113, 1351-1390.

[32] a) A. D. Becke, Phys. Rev. A 1988, 38, 3098-3100; b) J.P. Perdew, Phys. Rev. B 1986, 33, 8822-8824; c) F. Weigend, F. Furche, R. Ahlrichs, J. Chem. Phys. 2003, 119, 12753-12762; d) F. Weigend, R. Ahlrichs, Phys. Chem. Chem. Phys. 2005, 7, 3297-3305; e) D. Andrae, U. Huermann, M. Dolg, H. Stoll, H. Preu, Theor. Chim. Acta 1990, 77, 123-141.

[33] X. Wang, J. T. Lyon, L. Andrews, Inorg. Chem. 2009, 48, 6297-6302.

[34] P. Garcia-Fernandez, I. B. Bersuker, Phys. Rev. Lett. 2011, 106, 246406.

[35] B. O. Roos, A. C. Borin, L. Gagliardi, Angew. Chem. Int. Ed. 2007, 46, 1469-1472; Angew. Chem. 2007, 119, 1491-1494.

[36] P. Pyykkö, S. Riedel, M. Patzschke, Chem. Eur. J. 2005, 11, 3511-3520.

[37] P. Pyykkö, Chem. Rev. 1988, 88, 563-594.

[38] M. Kaupp, J. Comput. Chem. 2007, 28, 320-325.

[39] S. X. Hu, W. L. Li, J. B. Lu, J. L. Bao, H. S. Yu, D. G. Truhlar, J. K. Gibson, J. Marçalo, M. Zhou, S. Riedel, Schwarz, W. H. Eugen, J. Li, Angew. Chem. Int. Ed. 2018, 57, 3242-3245; Angew. Chem. 2018, 130, 3297-3300.

[40] R. F.W. Bader, Atoms in Molecules: A Quantum Theory, Clarendon, Oxford, 1994.

[41] L. Bennett, B. Melchers, B. Proppe, Curta: A General-Purpose HighPerformance Computer at ZEDAT, Freie Universität Berlin; Freie Universität Berlin, 2020.

Manuscript received: April 19, 2021

Accepted manuscript online: May 27, 2021

Version of record online: 


\section{FULL PAPER}

In different states: Molecular hexavalent group 8 nitrido fluorides feature different electronic ground-state $d^{2}$ configurations in solid Ne matrices. While $\mathrm{NFeF}_{3}$ adopts a high symmetry structure, the heavier homologues are subject to symmetry lowering and spin-crossover caused by a pseudo Jahn-Teller effect "hidden" in the excited states. For $\mathrm{NOsF}_{3}$ two coexisting high- and low-spin structures show triplet-singlet spin crossover and magnetic bistability. A weakened covalent $\mathrm{N}-\mathrm{Fe}$ bond in $\mathrm{NFe}^{\mathrm{Vl}} \mathrm{F}_{3}$ indicates the non-innocent character of the nitrido ligand.

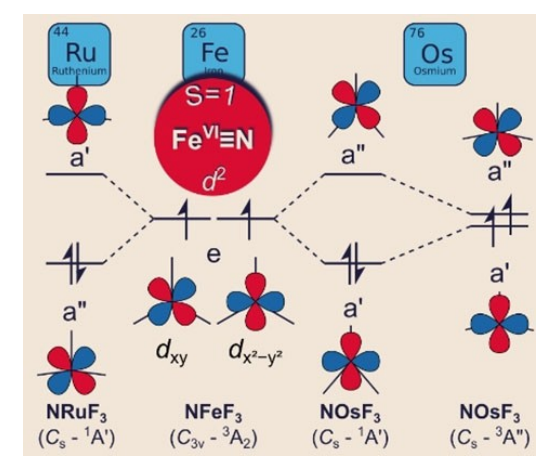

T. Stüker, X. Xia, Dr. H. Beckers, Prof. S. Riedel*

$1-9$

High-Spin Iron(VI), Low-Spin Ruthenium(VI), and Magnetically Bistable Osmium(VI) in Molecular Group 8 Nitrido Trifluorides $\mathrm{NMF}_{3}$ 


\subsection{Fluoro Nitrenoid Complexes $\mathrm{FN}=\mathrm{MF}_{2}(\mathrm{M}=\mathrm{Co}, \mathrm{Rh}, \mathrm{Ir})$ : Electronic Structure Dichotomy and Formation of Nitrido Fluorides $\mathrm{N} \equiv \mathrm{MF}_{3}$}

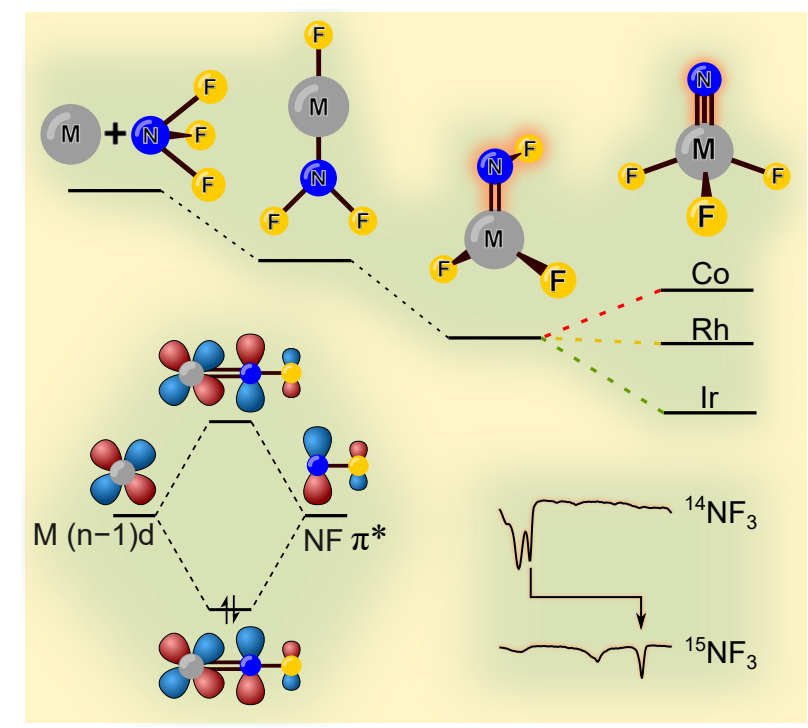

Tony Stüker, Thomas Hohmann, Helmut Beckers and Sebastian Riedel ${ }^{*}$ Angewandte Chemie International Edition 2020, 59, 23174-23179;

Angewandte Chemie 2020, 132, 23374-23379.

DOI: 10.1002/anie.202010950; 10.1002/ange. 202010950

(C) 2020 The Authors. Published by Wiley-VCH GmbH

For the Supporting Information see Appendix A.2.

\section{Author Contribution}

Tony Stüker did all calculations, wrote the manuscript and supervised the experiments and precursor synthesis. Tony Stüker and Thomas Hohmann carried out the experiments and the precursor synthesis. Helmut Beckers and Sebastian Riedel managed the project and revised the manuscript. 
Fluorine Chemistry

How to cite: Angew. Chem. Int. Ed. 2020, 59, 23174-23179

International Edition: doi.org/10.1002/anie.202010950

German Edition:

doi.org/10.1002/ange.202010950

\title{
Fluoro Nitrenoid Complexes $\mathbf{F N}=\mathbf{M F}_{2}(\mathbf{M}=\mathbf{C o}$, $\mathbf{R h}$, Ir): Electronic Structure Dichotomy and Formation of Nitrido Fluorides $\mathbf{N} \equiv \mathbf{M F}_{\mathbf{3}}$
}

\author{
Tony Stüker, Thomas Hohmann, Helmut Beckers, and Sebastian Riedel*
}

\begin{abstract}
The fluoronitrenoid metal complexes $\mathrm{FNCoF}_{2}$ and $\mathrm{FNRhF}_{2}$ as well as the first ternary $R h^{V I}$ and $I^{V I}$ complexes $\mathrm{NIrF}_{3}$ and $\mathrm{NRhF}_{3}$ are described. They were obtained by the reaction of excited Group-9 metal atoms with $\mathrm{NF}_{3}$ and their IR spectra, isolated in solid rare gases (neon and argon), were recorded. Aided by the observed ${ }^{14 / 15} \mathrm{~N}$ isotope shifts and quantum-chemical predictions, all four stretching fundamentals of the novel complexes were safely assigned. The $F-N$ stretching frequencies of the fluoronitrenoid complexes $F_{N C o F_{2}}\left(1056.8 \mathrm{~cm}^{-1}\right)$ and $F N R h F_{2}\left(872.6 \mathrm{~cm}^{-1}\right)$ are very different and their $\mathrm{N}-\mathrm{M}$ bonds vary greatly. In $\mathrm{FNCoF}_{2}$, the FN ligand is singly bonded to Co and bears considerable iminyl/nitrene radical character, while the $N-R h$ bond in $F_{N R h F_{2}}$ is a strong double bond with comparatively strong $\sigma$ and $\pi$-bonds. The anticipated rearrangement of $\mathrm{FNCoF}_{2}$ to the nitrido $\mathrm{Co}^{V I}$ complex is predicted to be endothermic and was not observed.
\end{abstract}

\section{Introduction}

Fluoronitrenoid metal complexes are underexplored compounds as only two examples have been reported so far, $\mathrm{FNReF}_{5}$ and $\mathrm{FNCuF}_{2}{ }^{[2]}$ This is most likely due to the fact that they bear a reactive FN function and are not readily available. In general, late transition-metal-nitrogen multiple bonds have attracted particular interest after having been found to enable the conversion of ubiquitous $\mathrm{C}-\mathrm{H}$ and $\mathrm{C}-\mathrm{C}$ bonds into valuable $\mathrm{C}-\mathrm{N}$ bonds as either catalysts or intermediates. ${ }^{[3,4-6]}$ Detailed knowledge of the geometry and electronic structure of such compounds are vital to elucidate the nature and mechanism of these reactions. ${ }^{[4]}$ While nitrido complexes usually feature a $\mathrm{M} \equiv \mathrm{N}$ triple bond, ${ }^{[4,7]}$ the imido ligand $\mathrm{NR}^{2-}$ exhibits a $\mathrm{M}=\mathrm{N}$ double bond in complexes with a bent $\mathrm{M}=\mathrm{N}-$ $\mathrm{R}$ linkage (Scheme 1) ${ }^{[4]}$ However, it has been mentioned that the energy required to change the $\mathrm{M}=\mathrm{N}-\mathrm{R}$ angle from bent to linearity is often small, and indeed, transition metal imido complexes bearing sterically encumbered ligands to protect the reactive metal-nitrogen multiple bond often feature short

[*] M. Sc. T. Stüker, M. Sc. T. Hohmann, Dr. H. Beckers, Prof. S. Riedel Anorganische Chemie, Institut für Chemie und Biochemie, Freie Universität Berlin

14195 Berlin (Germany)

E-mail: s.riedel@fu-berlin.de (2) Supporting information and the ORCID identification number(s) for

(iD) https://doi.org/10.1002/anie.202010950.

of (c) 2020 The Authors. Published by Wiley-VCH GmbH. This is an open access article under the terms of the Creative Commons Attribution License, which permits use, distribution and reproduction in any medium, provided the original work is properly cited.
$\mathrm{M}-\mathrm{N}$ bond lengths and nearly linear angles about the $\mathrm{M}-\mathrm{N}-$ R linkage (Scheme 1) ${ }^{[4,5]}$

In this bonding Scheme the anionic $\mathrm{NR}^{2-}$ imido ligand is expected to bear a nucleophilic character in its reactions. The polarities of both the $\sigma$ and $\pi$ bonds are important factors that govern the reactivity of imido complexes. ${ }^{[4,5]}$ As one moves from early to late transition metals, the binding energy of the metal d-electrons increases, and an imido ligand becomes less nucleophilic. This applies in particular to late transition metals in higher oxidation states. In fact, the imido ligands in late $3 \mathrm{~d}$ transition metal complexes are often so electrophilic that these complexes can be better described as metal-nitrene complexes (Scheme 1). Formally, an imido complex differs from a nitrene complex in the formal charge of the ligand and thus in the oxidation state of the metal (Scheme 1). An imido species suggests a dianionic imido ligand $\left(\mathrm{NR}^{2-}\right)$, whereas a neutral nitrene ligand is usually the result of a predominantly covalent nitrogen-metal bond. In the case of neutral, covalently bound ligands, no polarization of bonding electrons towards the ligand and no or only little charge transfer from the metal to the ligand is generally to be expected. Additionally, not long-ago a few examples were reported where an iminyl radical $\left({ }^{2} \mathrm{NR} \cdot\right)$ is coordinated to a transition metal. ${ }^{[8]}$ Metal-imido cores containing iminyl radical ligands are proposed as reactive intermediates in a number of metal

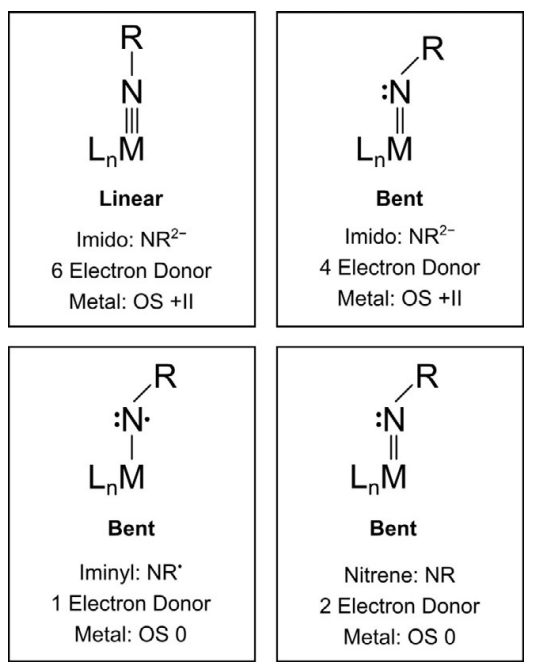

Scheme 1. Simplified scheme ${ }^{[1]}$ for the interactions of a metal center and an anionic imido (formal $\mathrm{NR}^{2-}$, top) and a neutral nitrene (bottom) ligand, respectively, in linear and bent nitrenoid complexes. The charge of the NR ligand in the ionic $\left(\mathrm{NR}^{2-}\right)$ and neutral (NR) approximation and the corresponding formal metal oxidation states are indicated below for uncharged donor ligands $\mathrm{L}$. 
catalyzed aziridination and amination reactions. ${ }^{[5]}$ These and further possible interpretations of the electronic structures of terminal metal nitrenoid complexes (e.g., imido, $\mathrm{M}\left(\mathrm{RN}^{2-}\right)$; iminyl, $\mathrm{M}\left({ }^{2} \mathrm{RN}^{*}\right)$; nitrene, $\mathrm{M}(\mathrm{RN})$; and triplet nitrene $\left({ }^{3} \mathrm{RN}^{*}\right)^{[9]}$ demonstrate the diversity of the metal-nitrogen bond in $\mathrm{M}-\mathrm{N}-\mathrm{R}$ complexes.

We became interested in fluoronitrenoid complexes of the group 9 metal difluorides, $\mathrm{F}-\mathrm{N}=\mathrm{MF}_{2}, \mathrm{M}=\mathrm{Co}, \mathrm{Rh}$, Ir. These simple nitrene complexes should allow a rigorous experimental and quantum-chemical comparison of the electronic properties of the $\mathrm{Co}^{\mathrm{IV}}$ complex with those of its heavier congeners. Fluoronitrenoid-metal complexes show more complex nitrenoid-metal binding modes and new reactivities. The fluoronitrene ligand shares some similarities with the oxygen molecule, since the nitrogen $2 p$ electrons involved in metal-nitrogen bonding are accommodated in a degenerate pair of $\pi^{*}(\mathrm{~F}-\mathrm{N})$ orbitals. Hence any metal-to-ligand charge transfer in a fluoronitrene complex will increase the occupancy of these $\pi^{*}(\mathrm{~F}-\mathrm{N})$ orbital, rendering the $\mathrm{N}-\mathrm{F}$ stretching frequency a highly sensitive probe for the polarity and the strength of the $\mathrm{N}=\mathrm{M}$ bond: a weak nitrogen-metal bond in a metal-nitrene complex result in a strong fluorine-nitrogen bond and vice versa. Utilizing the $\mathrm{F}-\mathrm{N}$ functionality and relying upon a high metal-fluorine bond energy we have targeted the synthesis of high-valent nitridometal trifluorides $\mathrm{N} \equiv \mathrm{MF}_{3}$, starting from the fluoronitrene complexes by an oxidative $\mathrm{F}-\mathrm{N}$ to $\mathrm{M}-\mathrm{F}$ fluorine migration, by which the formal metal oxidation state will be increased by two units. As far as we know, molecular nitridometal trifluorides, $\mathrm{NMF}_{3}$, are known only for the early transition metals of group IV $\left(\mathrm{M}=\mathrm{Ti}, \mathrm{Zr}, \mathrm{Hf}^{[10]}\right)$ and $\mathrm{VI}\left(\mathrm{Cr}, \mathrm{Mo}, \mathrm{W}^{[11]}\right)$. Notably, the formal metal oxidation state VI in $\mathrm{N} \equiv \mathrm{MF}_{3}(\mathrm{M}=\mathrm{Co}, \mathrm{Rh}, \mathrm{Ir})$ is rare, with $\operatorname{IrO}_{3}, \operatorname{Ir}\left(\eta_{2}-\mathrm{O}_{2}\right) \mathrm{O}_{2}, \operatorname{IrF}_{6}, \operatorname{Rh}\left(\eta_{2}-\mathrm{O}_{2}\right) \mathrm{O}_{2}$ and $\mathrm{RhF}_{6}$ as the only examples. ${ }^{[12]}$ Terminal nitrido complexes of very high formal oxidation states have been predicted very recently, ${ }^{[13]}$ however, such high-valent group 9 metals are still unknown. They would be of particular interest for cobalt, since the highest oxidation state reported for any molecular complex of cobalt is $\mathrm{V}$, for example, the well-known $\left[\mathrm{Co}(1 \text {-norbornyl })_{4}\right]^{+}$ or in the tricoordinated cationic bis(nitrene) cobalt complex [(IMes)Co(NDipp $\left.)_{2}\right]^{+} \cdot{ }^{[6,14]}$ The latter low-coordinated cationic complex is supported by the strongly electron-donating and sterically demanding $N$-heterocyclic carbene ligand IMes, and has been obtained by oxidation of the corresponding neutral bis(nitrene) $\mathrm{Co}^{\mathrm{IV}}$ complex. Interestingly, theoretical calculations indicated that the frontier molecular orbitals of these bis(nitrene) complexes have near-equal contributions from both the cobalt center and the nitrene ligand orbitals, indicating that the spectroscopic oxidation states for these cobalt centers are likely to be lower than IV and V, respectively. Apart from these bis(nitrene) complexes, the majority of the known cobalt nitrenoid complexes have low spin $\mathrm{Co}^{\mathrm{III}}$ centers which are supported, for example, by bulky ancillary tripodal or bidentate ligands to achieve kinetic stabilization. ${ }^{[15]}$ To the contrary, terminal nitrido complexes of cobalt still remain elusive. ${ }^{[16]}$

\section{Results and Discussion}

To obtain the group 9 metal difluorides, $\mathrm{F}-\mathrm{N}=\mathrm{MF}_{2}(\mathrm{M}=$ $\mathrm{Co}, \mathrm{Rh}, \mathrm{Ir})$, we have studied the gas-phase reaction of the laser-ablated free metal atoms with $\mathrm{NF}_{3}$ seeded in a 1:1000 excess of neon or argon. The reaction products were deposited on a gold-plated copper mirror cooled to 5 and $12 \mathrm{~K}$ and IR-spectroscopically investigated (for experimental details see the Supporting Information). According to preliminary calculations at the DFT-B3LYP and BP86 levels of theory the direct insertion of the excited metal atoms into the $\mathrm{F}-\mathrm{N}$ bond of $\mathrm{NF}_{3}$ to $\mathrm{F}_{2} \mathrm{~N}-\mathrm{MF}$, and the subsequent fluorine migration from nitrogen to the metal center to yield the desired $\mathrm{FN}=\mathrm{MF}_{2}$ is highly exothermic for all three metals (Figure 1, Table S1). However, the expected rearrangement of the fluoronitrene to a high-valent nitrido trifluoride $\mathrm{N} \equiv$ $\mathrm{MF}_{3}$ is found to be endothermic for the cobalt complex, rendering $\mathrm{FN}=\mathrm{CoF}_{2}$ the most stable $\mathrm{CoF}_{3} \mathrm{~N}$ isomer. To the contrary, this rearrangement is slightly exothermic for the rhodium nitrene complex $\left(\Delta H^{0}=-12 \mathrm{~kJ} \mathrm{~mol}^{-1}, \mathrm{CCSD}(\mathrm{T})\right)$, and becomes strongly exothermic for the iridium congener $\left(\Delta H^{0}=-98 \mathrm{~kJ} \mathrm{~mol}^{-1}, \operatorname{CCSD}(\mathrm{T})\right.$, Table $\left.\mathrm{S} 1\right)$, which rendered the detection of the iridium nitrene complex difficult if not impossible.

These predictions were fully supported by the analysis of the experimental IR spectra of the deposits in solid neon shown for cobalt (Figure 2), rhodium (Figure 3) and iridium (Figure 4). Complementary argon spectra for the experiments using rhodium and iridium have also been recorded and shown in the supporting information, Figures S1-S3. These spectra are dominated by strong bands of the $\mathrm{NF}_{3}$ precursor (Figure S4, Table S2 and Ref. [17]) and its plasma radiation induced decomposition products $\mathrm{NF}$ and $\mathrm{NF}_{2}{ }^{[18]}$ However, the assignment of IR bands associated with the targeted nitrene and nitrido complexes is facilitated by a characteristic ${ }^{14 / 15} \mathrm{~N}$ isotope shift exhibited by all modes in which the nitrogen atom is significantly involved. These isotope shifts are indicated in the experimental spectra shown in the Figures 2-4. They were obtained in experiments using ${ }^{15} \mathrm{NF}_{3}$, which was synthesized from ${ }^{15} \mathrm{~N}_{2}$ and $\mathrm{F}_{2}$ mixtures in an electric
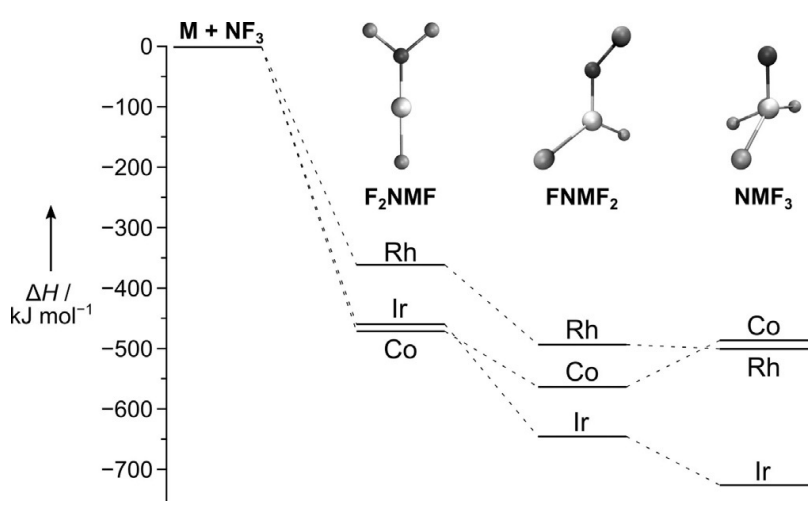

Figure 1. Stationary points on the reaction coordinate obtained at the B3LYP level of theory for the formation of the nitrido complexes $\mathrm{N} \equiv$ $\mathrm{MF}_{3}\left(\mathrm{M}=\mathrm{Co}, \mathrm{Rh}\right.$, and Ir) from the free metal atoms $\mathrm{M}$ and $\mathrm{NF}_{3}$. See Table S1 for more details. 


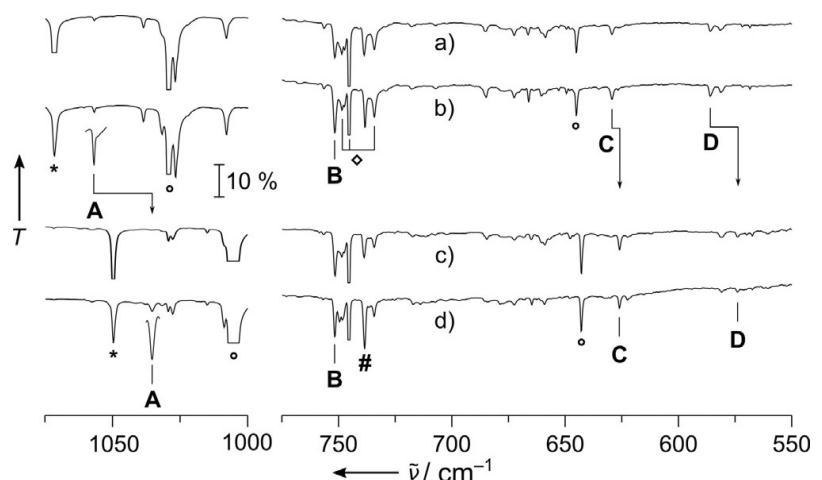

Figure 2. Infrared transmission spectra obtained after co-depositing laser-ablated cobalt atoms with $0.1 \%{ }^{14} \mathrm{NF}_{3}$ in neon (a), with ${ }^{14} \mathrm{NF}_{3}$ after annealing to $10 \mathrm{~K}$ (b) as well as with ${ }^{15} \mathrm{NF}_{3}$ (c), with subsequent annealing to $10 \mathrm{~K}$ (d). Bands attributed to $\mathrm{FNCoF}_{2}$ are labeled A-D, and their ${ }^{14 / 15} \mathrm{~N}$ isotope shift is indicated. The cutout band labeled $\mathbf{A}$ is enhanced by factor 5 . Further assignments are $\mathrm{NF}_{2}$ (asterisk), $\mathrm{NF}_{3}$ (circle) and $\mathrm{CoF}_{n}$ (square). The pound sign marks an unassigned product band.

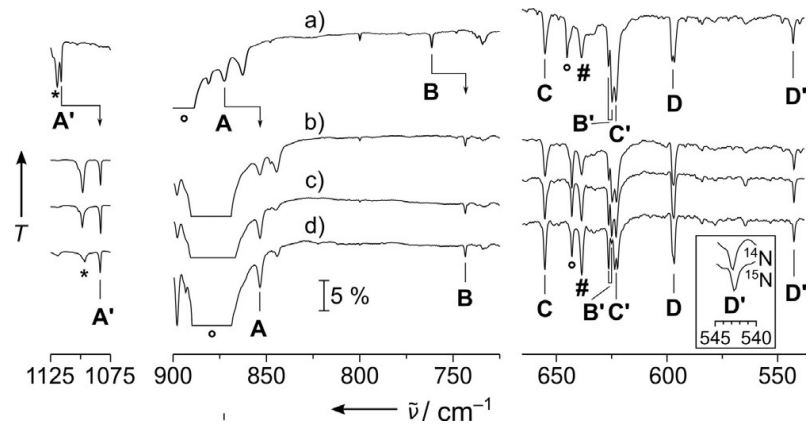

Figure 3. Infrared transmission spectra in the $1125-1075 \mathrm{~cm}^{-1}$ (left), $900-725 \mathrm{~cm}^{-1}$ (center) and $675-525 \mathrm{~cm}^{-1}$ (right) region from codepositing laser-ablated rhodium atoms with $0.1 \%{ }^{14} \mathrm{NF}_{3}$ in neon (a), and co-depositing rhodium with ${ }^{15} \mathrm{NF}_{3}$ in neon (b) with subsequent full-arc photolysis (c) and annealing to $12 \mathrm{~K}$ (d). Bands attributed to $\mathrm{FNRhF}_{2}$ are labeled $\mathrm{A}-\mathrm{D}$ and those assigned to $\mathrm{NRhF}_{3}$ are marked by $A^{\prime}-D^{\prime}$. Their ${ }^{14 / 15} \mathrm{~N}$ isotope shift is indicated. The enhanced inset shows the small ${ }^{14 / 15} \mathrm{~N}$ isotopic shift of $\mathbf{D}^{\prime}$. Further assignments are NF (asterisk) and $\mathrm{NF}_{3}$ (circle). The pound sign marks an unassigned product band which is the only band that gains intensity upon annealing.

discharge. ${ }^{[19]}$ While a detailed report about the spectral assignment is given in the Supporting Information, it should be mentioned here, that bands due to binary metal fluorides $\mathrm{MF}_{n}$ also appeared in these spectra, however these were safely assigned in nitrogen-free experiments, in which $\mathrm{NF}_{3}$ was replaced by elemental fluorine. In these experiments none of the bands assigned to a nitrogen-containing species appeared. Furthermore, by comparing spectra of experiments using different group 9 metals, the desired metal dependent bands were identified. A list of all observed IR bands associated with the target compound is shown in Table 1 together with their approximate assignment and supporting predictions from quantum-chemical calculations.

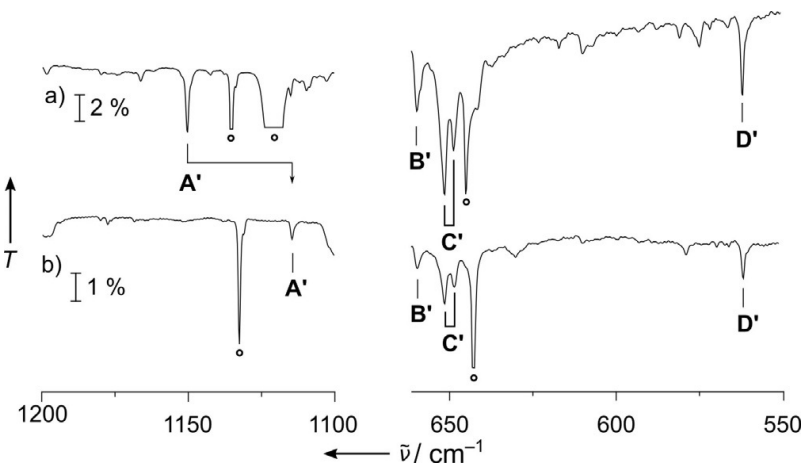

Figure 4. Infrared transmission spectra in the $1200-1100 \mathrm{~cm}^{-1}$ (left) and $630-550 \mathrm{~cm}^{-1}$ (right) region from co-deposition of laser-ablated iridium atoms with $0.1 \%{ }^{14} \mathrm{NF}_{3}$ (a) and $0.1 \%{ }^{15} \mathrm{NF}_{3}$ (b) in neon. Bands attributed to $\mathrm{NIrF}_{3}$ are labeled $\mathbf{A}^{\prime}-\mathbf{D}^{\prime}$, and their ${ }^{14 / 15} \mathrm{~N}$ isotope schift is indicated. Bands associated with $\mathrm{NF}_{3}$ are marked by a circle.

In the experiment using laser-ablated $\mathrm{Co}$ atoms and $\mathrm{NF}_{3}$ four IR bands were obtained that displayed a characteristic ${ }^{14 /}$ ${ }^{15} \mathrm{~N}$ isotope shift (labeled $\mathbf{A}-\mathbf{D}$ in Figure 2) and their assignment to the targeted fluoronitrene complex $\mathrm{FNCoF}_{2}$ is well supported by prediction on the CASPT2/cc-pVTZ-DK level of theory (Table 1 ). The values obtained using single reference correlation methods did either not converge (CCSD $(T))$, or did not yield qualitatively consistent results (B3LYP and BP86). Bands associated to the desired nitrido complex $\mathrm{NCoF}_{3}$ were not detected, which is consistent with the significant higher energy of this isomer. On the other side, in the spectra obtained from laser-ablated $\mathrm{Ir}$ atoms and $\mathrm{NF}_{3}$ our search for bands due to $\mathrm{FNIrF}_{2}$ was unsuccessful and only the nitrido complex $\mathrm{NIrF}_{3}$ was formed. Again, this reflects the lower stability of the former species, which exothermically rearranged to the lowest energy isomer. Here, too, four bands were assigned to $\mathrm{NIrF}_{3}$ (marked with $\mathbf{A}^{\prime}-\mathbf{D}^{\prime}$ in Figure 4), of which only two revealed a ${ }^{14 / 15} \mathrm{~N}$ isotope shift. Quantumchemical calculations (Table 1) performed at the DFT (BP86, $\mathrm{B} 3 \mathrm{LYP})$ and $\operatorname{CCSD}(\mathrm{T})$ levels of theory fully support these assignments. The $\mathrm{IrF}_{3}$ stretching modes are split into three components due to a first order Jahn-Teller distortion for the anticipated $5 d^{3}$ configuration, which reduced the full $C_{3 v}$ point group symmetry to $C_{\mathrm{s}}$ symmetry (for structures see Figures 5 , $\mathrm{S} 5$, and Table S3). All three $\mathrm{Ir}-\mathrm{F}$ stretching modes were observed, but only the band associated with the Ir- $\mathrm{F}^{\prime}$ bond, which resides in the mirror plane together with the $\mathrm{N}-\mathrm{Ir}$ bond, show a small ${ }^{14 / 15} \mathrm{~N}$ isotope shift.

The assignment of the IR spectra obtained after codepositing evaporated rhodium and diluted $\mathrm{NF}_{3}$ (Figure 3) was more puzzling. In these experiments both the anticipated compounds are finally detected in the solid matrices and for each all four stretching bands were successfully assigned (Table 1). As described above for the corresponding Iridium compound also for $\mathrm{NRhF}_{3}$ a ${ }^{14 / 15} \mathrm{~N}$ isotope shift was observed for the $\mathrm{N}-\mathrm{Rh}$ and the $\mathrm{Rh}-\mathrm{F}^{\prime}$ stretching modes (Figure 3, $\mathbf{A}^{\prime}$ and $\mathbf{D}^{\prime}$, respectively). Our $\operatorname{CCSD}(\mathrm{T})$ calculations for this species yield two imaginary frequencies which likely are caused by a close-lying excited electronic state which interferes with the calculation of displaced steps during the 
Table 1: Comparison of infrared band positions $\left(\mathrm{cm}^{-1}\right)$ and isotopic shifts $\left(\mathrm{cm}^{-1}\right.$, in parenthesis) observed in solid neon and argon with calculated values [intensities in $\mathrm{km} \mathrm{mol}^{-1}$ in brackets] and their assignment in terms of an approximate description of the vibrational modes. ${ }^{[a]}$

\begin{tabular}{|c|c|c|c|c|c|}
\hline Neon & Argon & BP86 & B3LYP & $\operatorname{CCSD}(\mathrm{T})$ & Assignment \\
\hline \multicolumn{6}{|l|}{$\mathrm{FNCoF}_{2}$} \\
\hline $1056.8(-21.4)$ & $-^{[b]}$ & 870 (-19) [220] & $1080(-20)[293]$ & $1152(-22)[-]^{[c]}$ & $\mathrm{F}-\mathrm{N}$ str. $\left[\mathrm{a}^{\prime}\right]$ \\
\hline $751.7(-0.1)$ & $-[b]$ & $732(0)[123]$ & 764 (0) $[171]$ & $859(-0.3)[-]^{[c]}$ & antisym. F-Co-F str. $\left[\mathrm{a}^{\prime \prime}\right]$ \\
\hline $629.6(-3.5)$ & $-^{[b]}$ & $627(-1)[63]$ & 611 (0) [60] & $651(-1)[-]^{[c]}$ & sym. $\mathrm{F}-\mathrm{Co}-\mathrm{F}$ str. $\left[\mathrm{a}^{\prime}\right]$ \\
\hline $586.1(-12.1)$ & $-^{[b]}$ & $765(-17)[37]$ & $442(-13)[12]$ & $609(-16)[-]^{[c]}$ & $\mathrm{N}-$ Co str. $\left[\mathrm{a}^{\prime}\right]$ \\
\hline \multicolumn{6}{|l|}{$\mathrm{NRhF}_{3}$} \\
\hline $1116.1(-33.0)$ & $1112.56(-33)$ & $1087(-32)[48]$ & $1113(-33)[55]$ & - & $\mathrm{N}-\mathrm{Rh}$ str. $\left[\mathrm{a}^{\prime}\right]$ \\
\hline $626.2 / 624.8(0)^{[\mathrm{d}]}$ & 612.0 & $603(0)[96]$ & $625(0)[118]$ & - & antisym. F-Rh-F str. $\left[a^{\prime \prime}\right]$ \\
\hline $622.2 / 622.8(0)^{[\mathrm{d}]}$ & 610.5 & 601 (0) [48] & 618 (0) $[63]$ & - & sym. $\mathrm{F}-\mathrm{Rh}-\mathrm{F}$ str. $\left[\mathrm{a}^{\prime}\right]$ \\
\hline $542.5(-0.4)$ & $539.9(-0.5)$ & $562(0)[45]$ & $581(0)[52]$ & - & $\mathrm{Rh}-\mathrm{F}^{\prime}$ str. $\left[\mathrm{a}^{\prime}\right]$ \\
\hline \multicolumn{6}{|l|}{$\mathrm{FNRhF}_{2}{ }^{[\mathrm{e}]}$} \\
\hline $872.6(-18.9)$ & $-^{[b]}$ & $850(-24)[103]$ & $935(-24)[168]$ & $872(-16)[-]$ & $\mathrm{F}-\mathrm{N}$ str. $\left[\mathrm{a}^{\prime}\right]$ \\
\hline $761.4(-18.0)$ & $760.1(-19.6)$ & $721(-12)[181]$ & $786(-16)[117]$ & $707(-19)[-]$ & $\mathrm{N}-\mathrm{Rh}$ str. $\left[\mathrm{a}^{\prime}\right]$ \\
\hline $655.1(0)$ & $638.9(0)$ & $625(0)[132]$ & $641(0)[150]$ & $652(0)[-]$ & antisym. F-Rh-F str. $\left[\mathrm{a}^{\prime \prime}\right]$ \\
\hline $596.7(0)$ & $585.9(-0.5)$ & $572(-0.3)[101]$ & $594(-0.3)[75]$ & $580(-2)[-]$ & sym. $\mathrm{F}-\mathrm{Rh}-\mathrm{F}$ str. $\left[\mathrm{a}^{\prime}\right]$ \\
\hline \multicolumn{6}{|l|}{$\mathrm{NIrF}_{3}$} \\
\hline $1150.4(-36.0)$ & $1144.6(-35.8)^{[f]}$ & $1121(-35)[22]$ & $1158(-36)[23]$ & $1126(-36)[-]$ & $\mathrm{N}-$ Ir str. $\left[\mathrm{a}^{\prime}\right]$ \\
\hline $659.8(0)$ & $\_^{[g]}$ & $618(0)[34]$ & $635(0)[43]$ & $653(0)[-]$ & sym. F-Ir-F str. $\left[a^{\prime}\right]$ \\
\hline $651.6 / 648.9(0)^{[c]}$ & $\__{[\mathrm{g}]}$ & $618(0)[132]$ & $634(0)[147]$ & $650(0)[-]$ & antisym. F-Ir-F str. [a"] \\
\hline $562.1(-0.2)$ & $560.1(-0.5)^{[f]}$ & $562(0)[36]$ & 581 (0) $[40]$ & $607(0)[-]$ & Ir-F $\mathrm{F}^{\prime}$ str. $\left[\mathrm{a}^{\prime}\right]$ \\
\hline
\end{tabular}

[a] Only normal modes predicted in the experimentally observable range $\left(\tilde{v}>400 \mathrm{~cm}^{-1}\right)$ are listed. A full list of computed frequencies is presented in the Supporting Information. For CASPT2 and CCSD(T) no intensities are available; [b] Bands not observed, or too weak. [c] Wavenumbers (isotopic shifts) obtained at the CASPT2/cc-pVTZ-DK level; [d] Two matrix sites; [e] Wavenumbers (isotopic shifts, in $\mathrm{cm}^{-1}$ ) obtained using CASPT2/cc-pVTZDK: 981 (-19.5), $756(-20.4), 672(0), 623(-0.5)$; [f] Weak bands tentatively assigned. [g] Too weak or overlapped by broad and strong NF ${ }_{3}$ bands in this area.

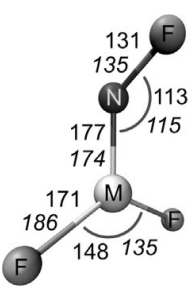

${ }^{2} A "{ }^{2} A '$

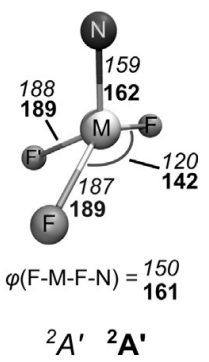

Figure 5. Electronic ground state structures of $F N M F_{2}$ for $M=C o\left({ }^{2} A^{\prime \prime}\right.$, regular) and $\mathrm{Rh}\left({ }^{2} \mathrm{~A}^{\prime}\right.$, italic) calculated at the CASPT2/cc-pVTZ-DK level and of $\mathrm{NMF}_{3}$ for $\mathrm{M}=\mathrm{Rh}\left({ }^{2} \mathrm{~A}^{\prime}\right.$, italic) and $\operatorname{Ir}\left({ }^{2} \mathrm{~A}^{\prime}\right.$, bold $)$ obtained the $\operatorname{CCSD}(T)$ /aug-cc-pVTZ(-PP) level of theory. Bond lengths are given in $\mathrm{pm}$ and angles in degree ( $\varphi$ denotes the dihedral angle of F-M-F-N).

numerical hessian calculation where the symmetry is lowered to $C_{1}$. However, the structure obtained at the B3LYP level of theory is close to the one obtained at the $\operatorname{CCSD}(\mathrm{T})$ level (Figures 5 and S5) and the good agreement of the B3LYP results for $\mathrm{NIrF}_{3}$ with the experimental frequencies suggest a good performance also for the $\mathrm{NRhF}_{3}$ species. The ${ }^{14 / 15} \mathrm{~N}$ isotope shift observed for the nitrene complex $\mathrm{FNRhF}_{2}$ is well distributed between the $\mathrm{F}-\mathrm{N}$ and the $\mathrm{N}-\mathrm{Rh}$ stretching bands (Figure 3, bands $\mathbf{A}$ and $\mathbf{B}$, respectively) indicating a strong vibrational coupling between these two modes. Analyzing the $\mathrm{N}-\mathrm{M}$ and $\mathrm{F}-\mathrm{N}$ stretching frequencies of $\mathrm{FNCoF}_{2}$ and $\mathrm{FNRhF}_{2}$ we found surprisingly large differences in the bonding of the fluoronitrene ligand. In general, the two singly occupied anti bonding $\pi^{*}(\mathrm{~F}-\mathrm{N})$-orbitals of the $\mathrm{FN}$ ligand form a $\sigma$ and a $\pi$ bond to these metal centers, as depicted in the qualitative molecular orbital (MO) interaction diagram shown in Figure 6. The F-N mode of $\mathrm{FNCoF}_{2}\left(1056.8 \mathrm{~cm}^{-1}\right)$ appeared red-shifted by $62.6 \mathrm{~cm}^{-1}$ from the absorption of free, neutral FN $\left(1119.4 \mathrm{~cm}^{-1}\right),{ }^{[11]}$ indicating the presence of an almost neutral nitrene ligand, while the corresponding mode of $\mathrm{FNRhF}_{2}\left(872.6 \mathrm{~cm}^{-1}\right)$ is much stronger red-shifted by $246.8 \mathrm{~cm}^{-1}$.

On the other side, the low $\mathrm{N}-\mathrm{Co}$ stretching frequency of $\mathrm{FNCoF}_{2}\left(586.1 \mathrm{~cm}^{-1}\right)$ is most likely associated with a $\mathrm{N}-\mathrm{Co}$ single bond, while the $\mathrm{N}-\mathrm{Rh}$ frequency of $\mathrm{FNRhF}_{2}$

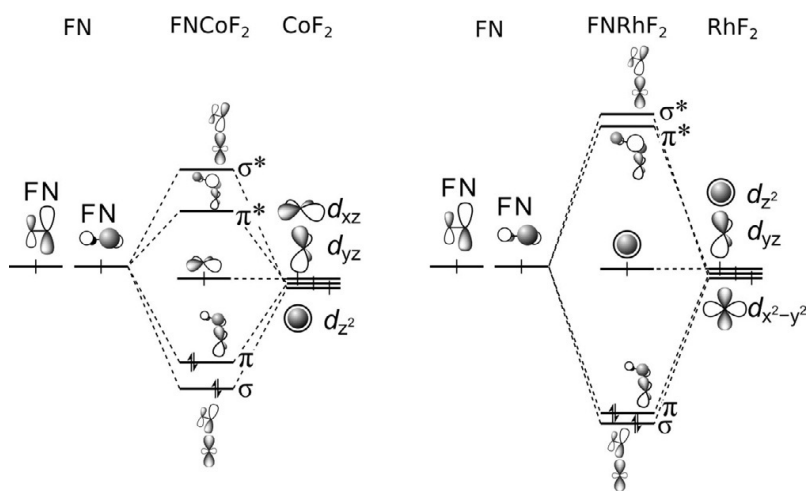

Figure 6. Simplified MO diagrams for the leading electronic configurations of the 4-electron-3-center F-N-M bond of $\mathrm{FNCoF}_{2}$ (left) and $\mathrm{FNRhF}_{2}$ (right). The low-energy $\mathrm{F}-\mathrm{N}$ bonding orbitals are not shown. 
$\left(761.4 \mathrm{~cm}^{-1}\right)$ can be attributed to a $\mathrm{N}=\mathrm{Rh}$ double bond. These experimental observations are consistent with calculated atomic charges for the $\mathrm{FN}$ fragment in $\mathrm{FNCoF}_{2}$ (NPA: 0.02, AIM: -0.02) and $\mathrm{FNRhF}_{2}$ (NPA: -0.25 , AIM: -0.20$)$, as well as Mayer and Wiberg bond orders for the $\mathrm{N}-\mathrm{M}$ bonds listed in Table 2, and the calculated $\mathrm{N}-\mathrm{M}$ bond lengths $(\mathrm{M}=\mathrm{Co}$ : $177 \mathrm{pm}, \mathrm{Rh}: 174 \mathrm{pm}$, Figure 5). To shed light on these striking bonding differences non-dynamical electron-correlation effects were taken into account. The results of CASSCF calculations revealed that the leading configuration $\left(\sigma^{2} \pi^{2} \delta^{1}\right.$ $\left.\pi^{*^{0}} \sigma^{* 0}\right)$ associated with the qualitative MO Scheme shown in Figure 6 contributes only $48 \%$ to the ${ }^{2} \mathrm{~A}^{\prime \prime}$ ground state of $\mathrm{FNCoF}_{2}$, followed by states with significant weights which contain single and double $\pi \rightarrow \pi^{*}$ excitations (Table S4). For $\mathrm{FNRhF}_{2}$ a much smaller extend of non-dynamic correlation was determined, since the most dominant configuration as depicted in Figure 6 contributes to $84 \%$ to its ${ }^{2} \mathrm{~A}^{\prime}$ electronic ground state. As a consequence of these correlation effects significant higher $\sigma^{*}$ and $\pi^{*}$ populations $(0.37$ and 0.61 , Figure S6) were found for $\mathrm{FNCoF}_{2}$ compared to $\mathrm{FNRhF}_{2}\left(\sigma^{*}\right.$ : $\left.0.11, \pi^{*}: 0.18\right)$. The effective bond orders $(\mathrm{EBO})^{[20]}$ derived from the natural orbitals obtained at the CASSCF level are 1.1 for the $\mathrm{Co}-\mathrm{N}$ and 1.7 for the $\mathrm{Rh}=\mathrm{N}$ bond. We also note a considerable amount of minority spin population at the $\mathrm{N}$ atom $(-0.46)$ in $\mathrm{FNCoF}_{2}$ (Table 2 and Figure S7) antiferromagnetically coupled to the majority spin at the Co center (1.46). The latter spin density can mainly be attributed to the singly occupied nonbonding $\delta$-MO of a" symmetry (Figures 6 and S6). Taking these effects into account, the FN unit in $\mathrm{FNCoF}_{2}$ has at least a considerable fraction of iminyl/nitrene radical character, which explains the shortened single bond. The disparities in the metal-nitrogen bonds of these nitrene

Table 2: NPA and AIM charges, spin populations, as well as Mayer and Wiberg bond orders obtained from electronic ground state wavefunctions calculated at the $\operatorname{CASSCF}(9,7) /$ cc-pVTZ-DK levels of theory. All units in atomic units.

\begin{tabular}{|c|c|c|c|}
\hline Property & & $\mathrm{F}^{\prime} \mathrm{NCoF}_{2}\left({ }^{2} \mathrm{~A}^{\prime \prime}, \mathrm{C}_{\mathrm{s}}\right)$ & $\mathrm{F}^{\prime} \mathrm{NRhF}_{2}\left({ }^{2} \mathrm{~A}^{\prime}, \mathrm{C}_{\mathrm{s}}\right)$ \\
\hline NPA & $\mathrm{F}^{\prime}$ & -0.2342 & -0.2508 \\
\hline \multirow[t]{3}{*}{ Charge } & $\mathrm{N}$ & 0.2552 & 0.1196 \\
\hline & M & 1.6134 & 1.6264 \\
\hline & $F$ & -0.8172 & -0.7476 \\
\hline AIM & $\mathrm{F}^{\prime}$ & -0.3780 & -0.3932 \\
\hline \multirow[t]{3}{*}{ Charge } & $\mathrm{N}$ & 0.3576 & 0.1916 \\
\hline & M & 1.6158 & 1.6929 \\
\hline & $\mathrm{F}$ & -0.7977 & -0.7457 \\
\hline Spin & $\mathrm{F}^{\prime}$ & -0.0239 & -0.0006 \\
\hline \multirow[t]{3}{*}{ Population } & $\mathrm{N}$ & -0.4639 & -0.1149 \\
\hline & M & 1.4593 & 1.0627 \\
\hline & $\mathrm{F}$ & 0.0143 & 0.0264 \\
\hline \multirow[t]{3}{*}{ Mayer Bond Order } & $F^{\prime}-N$ & 0.976 & 0.909 \\
\hline & N-M & 0.561 & 1.395 \\
\hline & $M-F$ & 0.647 & 0.647 \\
\hline \multirow[t]{3}{*}{ Wiberg Bond Order } & $\mathrm{F}^{\prime}-\mathrm{N}$ & 1.429 & 1.337 \\
\hline & $\mathrm{N}-\mathrm{M}$ & 1.246 & 2.156 \\
\hline & $M-F$ & 1.180 & 1.167 \\
\hline
\end{tabular}

complexes can likely be attributed to the peculiarity of bonding of the strongly correlated first-row transition metalligand bonds. Especially the close internuclear distance required for an optimum orbital overlap for $\pi$ bonding is likely hindered due to Pauli repulsion of the Co $3 \mathrm{~s}, 3 \mathrm{p}$ coreshell and the nitrogen ligand orbitals. ${ }^{[21]}$

For the nitrido complexes $\mathrm{NRhF}_{3}$ and $\mathrm{NIrF}_{3}$ the computed bond length (162 pm ( $\mathrm{IrN}), 159(\mathrm{RhN})$; for comparison: triple-bond additive covalent radii: $160 \mathrm{pm}(\mathrm{IrN})$ and $160 \mathrm{pm}$ $(\mathrm{RhN}),{ }^{[22]}$ Figure 5) and the experimental stretching frequencies (Table 1 ) indicate strong $\mathrm{N} \equiv \mathrm{M}$ triple bonds. An analysis of the CASSCF $(9,8)$ natural molecular orbitals (Figure S8) reveals $\mathrm{EBO}$ of 2.7 and 2.8 for $\mathrm{N} \equiv \mathrm{Rh}$ and $\mathrm{N} \equiv \mathrm{Ir}$, respectively. Consistent with the assignment of oxidation state + VI for both metal centers, a $d^{3}$ configuration and a Jahn-Teller distorted ${ }^{2} \mathrm{~A}^{\prime}$ electronic ground state was determined for both species. The $\mathrm{N}-\mathrm{Ir}$ stretching frequency in neon of $1150.4 \mathrm{~cm}^{-1}$ is moderately higher than that observed for diatomic IrN embedded in solid neon $\left(1111.1 \mathrm{~cm}^{-1}\right) \cdot{ }^{[23]}$ However, in case of rhodium a significant blue-shift of the $\mathrm{N}-\mathrm{Rh}$ stretching mode $\left(1112.6 \mathrm{~cm}^{-1}\right)$ of $221.2 \mathrm{~cm}^{-1}$ occurred compared to diatomic $\mathrm{RhN}$ embedded in argon $\left(891.4 \mathrm{~cm}^{-1}\right){ }^{[24]}$ The increased force constant of $920 \mathrm{Nm}^{-1}$ in $\mathrm{NRhF}_{3}$ from $580 \mathrm{Nm}^{-1}$ in $\mathrm{RhN}$ indicates a significant strengthening of the nitrogen-metal bond induced by the fluorine ligands. This fluorine effect is less pronounced for the already strong triple bond in $\mathrm{IrN}$, where force constants increase from 950 to $1020 \mathrm{~N} \mathrm{~m}^{-1}$ for IrN and $\mathrm{NIrF}_{3}$, respectively.

\section{Conclusion}

In summary, we described the exothermic formation of the fluoronitrenoid complexes $\mathrm{FNCoF}_{2}$ and $\mathrm{FNRhF}_{2}$ and of the nitrido complexes $\mathrm{NRhF}_{3}$ and $\mathrm{NIrF}_{3}$ by the reaction of the free group 9 metal atoms with $\mathrm{NF}_{3}$. The IR spectra of these compounds isolated in solid rare gases (neon and argon) were recorded and, aided by the observed ${ }^{14 / 15} \mathrm{~N}$ isotope shifts and quantum-chemical predictions, all four stretching fundamentals of these complexes were safely assigned. Neither nitrido nor other ternary complexes of $\mathrm{Rh}^{\mathrm{VI}}$ and $\mathrm{Ir}^{\mathrm{VI}}$ have yet been reported. The anticipated rearrangement of $\mathrm{FNCoF}_{2}$ to the nitrido $\mathrm{Co}^{\mathrm{VI}}$ complex was not observed, because this reaction is endotherm. The covalently bound FN ligand in these highvalent metal complexes is almost neutrally charged, and the formal picture of an $\mathrm{FN}^{2-}$ ligand bound to a $\mathrm{MF}_{2}$ fragment is a rather coarse approximation for these fluoronitrenoid complexes. However, the bonding of the $\mathrm{FN}$ ligand in $\mathrm{FNCoF}_{2}$ and $\mathrm{FNRhF}_{2}$ was found to be strikingly different. In $\mathrm{FNCoF}_{2}$ the FN ligand is singly bonded to $\mathrm{Co}$ and bears considerable iminyl/nitrene radical character, while the $\mathrm{N}=\mathrm{Rh}$ double bond in $\mathrm{FNRhF}_{2}$ shows comparatively strong $\sigma$ - and $\pi$-bonds. The stretched $\mathrm{N}-\mathrm{Co}$ bond and the poor overlap especially between the ligand $\pi$ - and the metal 3d-orbitals can likely be attributed to a repulsion between the ligand orbitals and the outermost core $3 \mathrm{~s}, 3 \mathrm{p}$ shell of cobalt. 


\section{Acknowledgements}

We gratefully acknowledge the Zentraleinrichtung für Datenverarbeitung (ZEDAT) of the Freie Universität Berlin for the allocation of computing resources. We thank the ERC Project HighPotOx as well as the CRC 1349 (SFB 1349) Fluorine Specific Interactions-Project-ID 387284271-for continuous support. We also thank Prof. Ralf Haiges for fruitful discussions. Open access funding enabled and organized by Projekt DEAL.

\section{Conflict of interest}

The authors declare no conflict of interest.

Keywords: ab-initio calculations - high oxidation states . matrix isolation $\cdot \mathrm{N}$ ligands $\cdot$ transition metals

[1] Note that the dash $(-)$ between two bonded atoms will depict a two-electron "iono-covalent" bond. It will generally not distinguish between an ionic bond to an Imido ligand or a covalent bond to a neutral NR ligand (see P. Karen, P. McArdle, J. Takats, Pure Appl. Chem. 2014, 86, 1017).

[2] a) J. Fawcett, R. D. Peacock, D. R. Russell, Dalton Trans. 1987, 567; b) K. Dehnicke, J. Straehle, Chem. Rev. 1993, 93, 981; c) Y. Gong, L. Andrews, Inorg. Chem. 2012, 51, 667.

[3] a) A. I. Olivos Suarez, V. Lyaskovskyy, J. N. H. Reek, J. I. van der Vlugt, B. de Bruin, Angew. Chem. 2013, 125, 12740 b) Y. Park, Y. Kim, S. Chang, Chem. Rev. 2017, 117, 9247; c) M. Kinauer, M. Diefenbach, H. Bamberger, S. Demeshko, E. J. Reijerse, C. Volkmann, C. Würtele, J. van Slageren, B. de Bruin, M. C. Holthausen et al., Chem. Sci. 2018, 9, 4325; d) H. M. L. Davies, J. R. Manning, Nature 2008, 451, 417; e) Y. Liu, J. Du, L. Deng, Inorg. Chem. 2017, 56, 8278; f) T. A. Ramirez, B. Zhao, Y. Shi, Chem. Soc. Rev. 2012, 41, 931; g) A. Reckziegel, C. Pietzonka, F. Kraus, C. G. Werncke, Angew. Chem. Int. Ed 2020, 59, 8527; Angew. Chem. 2020, 132, 8605; h) J. L. Roizen, M. E. Harvey, J. Du Bois, Acc. Chem. Res. 2012, 45, 911; i) J. Schöffel, A. Y. Rogachev, S. DeBeer George, P. Burger, Angew. Chem. Int. Ed. 2009, 48, 4734; Angew. Chem. 2009, 121, 4828; j) J. Schöffel, N. Šušnjar, S. Nückel, D. Sieh, P. Burger, Eur. J. Inorg. Chem. 2010, 4911; k) T. Xiong, Q. Zhang, Chem. Soc. Rev. 2016, 45, 3069; 1) A. I. Olivos Suarez, V. Lyaskovskyy, J. N. H. Reek, J. I. van der Vlugt, B. de Bruin, Angew. Chem. Int. Ed. 2013, 52, 12510; Angew. Chem. 2013, 125, 12740; m) F. Collet, R. H. Dodd, P. Dauban, Chem. Commun. 2009, 5061; n) P. F. Kuijpers, J. I. van der Vlugt, S. Schneider, B. de Bruin, Chem. Eur. J. 2017, 23, 13819.

[4] J. F. Berry, Comments Inorg. Chem. 2009, 30, 28.

[5] K. Ray, F. Heims, F. F. Pfaff, Eur. J. Inorg. Chem. 2013, 3784.

[6] L. Zhang, Y. Liu, L. Deng, J. Am. Chem. Soc. 2014, 136, 15525.

[7] J. M. Smith in Progress in Inorganic Chemistry (Ed.: K. D. Karlin), Wiley, Hoboken, 2014, pp. 417-470.

[8] a) C. C. Lu, S. DeBeer George, T. Weyhermüller, E. Bill, E. Bothe, K. Wieghardt, Angew. Chem. Int. Ed. 2008, 47, 6384; Angew. Chem. 2008, 120, 6484; b) A. N. Walstrom, B. C. Fullmer H. Fan, M. Pink, D. T. Buschhorn, K. G. Caulton, Inorg. Chem.
2008, 47, 9002; c) A. Takaoka, L. C. H. Gerber, J. C. Peters, Angew. Chem. Int. Ed. 2010, 49, 4088; Angew. Chem. 2010, 122, 4182 ; d) A. C. Bowman, C. Milsmann, E. Bill, Z. R. Turner, E. Lobkovsky, S. DeBeer, K. Wieghardt, P. J. Chirik, J. Am. Chem. Soc. 2011, 133, 17353; e) S. P. Heins, W. D. Morris, P. T. Wolczanski, E. B. Lobkovsky, T. R. Cundari, Angew. Chem. Int. Ed. 2015, 54, 14407; Angew. Chem. 2015, 127, 14615; f) E. Kogut, H. L. Wiencko, L. Zhang, D. E. Cordeau, T. H. Warren, $J$. Am. Chem. Soc. 2005, 127, 11248; g) Y. Dong, J. T. Lukens, R. M. Clarke, S.-L. Zheng, K. M. Lancaster, T. A. Betley, Chem. Sci. 2020, 11, 1260; h) M. J. T. Wilding, D. A. Iovan, A. T. Wrobel, J. T. Lukens, S. N. MacMillan, K. M. Lancaster, T. A. Betley, J. Am. Chem. Soc. 2017, 139, 14757.

[9] K. M. Carsch, I. M. DiMucci, D. A. Iovan, A. Li, S.-L. Zheng, C. J. Titus, S. J. Lee, K. D. Irwin, D. Nordlund, K. M. Lancaster et al., Science 2019, 365, 1138.

[10] X. Wang, J. T. Lyon, L. Andrews, Inorg. Chem. 2009, 48, 6297.

[11] X. Wang, L. Andrews, R. Lindh, V. Veryazov, B. O. Roos, J. Phys. Chem. A 2008, 112, 8030.

[12] a) H. C. Mattraw, N. J. Hawkins, D. R. Carpenter, W. W. Sabol, J. Chem. Phys. 1955, 23, 985; b) A. Citra, L. Andrews, J. Phys. Chem. A 1999, 103, 4182; c) Y. Gong, M. Zhou, M. Kaupp, S. Riedel, Angew. Chem. Int. Ed. 2009, 48, 7879; Angew. Chem. 2009, 121, 8019; d) A. Citra, L. Andrews, J. Phys. Chem. A 1999, 103, 4845; e) C. L. Chernick, H. H. Claassen, B. Weinstock, J. Am. Chem. Soc. 1961, 83, 3165.

[13] a) M. Domański, Ł. Wolański, P. Szarek, W. Grochala, J. Mol. Model. 2020, 26, 1; b) Ł. Wolański, M. Domański, W. Grochala, P. Szarek, Chem. Eur. J. 2019, 25, 10290.

[14] E. K. Byrne, K. H. Theopold, J. Am. Chem. Soc. 1989, 111, 3887.

[15] a) C. Jones, C. Schulten, R. P. Rose, A. Stasch, S. Aldridge, W. D. Woodul, K. S. Murray, B. Moubaraki, M. Brynda, G. La Macchia et al., Angew. Chem. Int. Ed. 2009, 48, 7406; Angew. Chem. 2009, 121, 7542; b) M. P. Mehn, S. D. Brown, D. M. Jenkins, J. C. Peters, L. Que, Inorg. Chem. 2006, 45, 7417; c) T. A. Betley, J. C. Peters, J. Am. Chem. Soc. 2003, 125, 10782; d) X. Dai, P. Kapoor, T. H. Warren, J. Am. Chem. Soc. 2004, 126, 4798; e) X. Hu, K. Meyer, J. Am. Chem. Soc. 2004, 126,16322; f) R. E. Cowley, R. P. Bontchev, J. Sorrell, O. Sarracino, Y. Feng, H. Wang, J. M. Smith, J. Am. Chem. Soc. 2007, 129, 2424.

[16] a) D. Sengupta, C. Sandoval-Pauker, E. Schueller, A. M. Encerrado-Manriquez, A. Metta-Magaña, W.-Y. Lee, R. Seshadri, B. Pinter, S. Fortier, J. Am. Chem. Soc. 2020, 142, 8233; b) E. M. Zolnhofer, M. Käß, M. M. Khusniyarov, F. W. Heinemann, L. Maron, M. van Gastel, E. Bill, K. Meyer, J. Am. Chem. Soc. 2014, 136, 15072; c) C. C. Hojilla Atienza, A. C. Bowman, E. Lobkovsky, P. J. Chirik, J. Am. Chem. Soc. 2010, 132, 16343.

[17] M. K. Wilson, S. R. Polo, J. Chem. Phys. 1952, 20, 1716.

[18] M. E. Jacox, J. Phys. Chem. Ref. Data 1998, 27, 115.

[19] W. Maya, Inorg. Chem. 1964, 3, 1063.

[20] B. O. Roos, A. C. Borin, L. Gagliardi, Angew. Chem. Int. Ed. 2007, 46, 1469; Angew. Chem. 2007, 119, 1491.

[21] M. Kaupp, J. Comput. Chem. 2007, 28, 320.

[22] P. Pyykkö, S. Riedel, M. Patzschke, Chem. Eur. J. 2005, 11, 3511.

[23] T. Stüker, H. Beckers, S. Riedel, Chem. Eur. J. 2020, 26, 7384.

[24] A. Citra, L. Andrews, J. Phys. Chem. A 1999, 103, 3410.

Manuscript received: August 12, 2020

Revised manuscript received: August 30, 2020

Accepted manuscript online: September 4, 2020

Version of record online: October 15, 2020 



\subsection{A Cornucopia of Iridium Nitrogen Compounds Produced from Laser-Ablated Iridium Atoms and Dinitrogen}

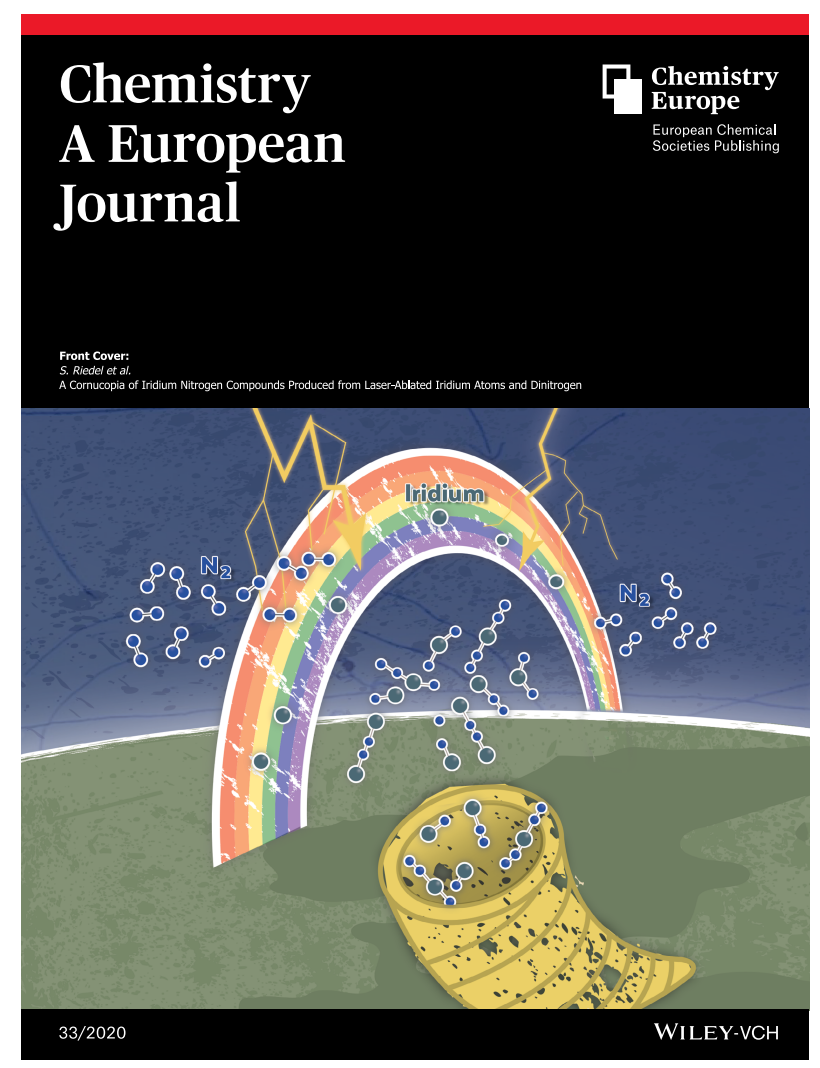

Tony Stüker, Helmut Beckers and Sebastian Riedel ${ }^{\star}$

Chemistry - A European Journal 2020, 26, 7384-7394.

DOI: $10.1002 /$ chem.201905514

(C) 2020 The Authors. Published by Wiley-VCH GmbH

For the Supporting Information see Appendix A.3.

\section{Author Contribution}

Tony Stüker did all calculations, carried out all experiments and wrote the manuscript. Sebastian Riedel and Helmut Beckers managed the project and revised the manuscript. 


\title{
Iridium Compounds |Hot Paper|
}

\section{(4) A Cornucopia of Iridium Nitrogen Compounds Produced from Laser-Ablated Iridium Atoms and Dinitrogen}

\author{
Tony Stüker, Helmut Beckers, and Sebastian Riedel*[a]
}

\begin{abstract}
The reaction of laser-ablated iridium atoms with dinitrogen molecules and nitrogen atoms yield several neutral and ionic iridium dinitrogen complexes such as $\operatorname{Ir}\left(\mathrm{N}_{2}\right)$, $\operatorname{Ir}\left(\mathrm{N}_{2}\right)^{+}, \operatorname{Ir}\left(\mathrm{N}_{2}\right)_{2}, \operatorname{Ir}\left(\mathrm{N}_{2}\right)_{2}{ }^{-}, \operatorname{IrNN} I r$, as well as the nitrido complexes $\operatorname{IrN}, \operatorname{Ir}(\mathrm{N})_{2}$ and $\operatorname{Ir} \mid r N$. These reaction products were deposited in solid neon, argon and nitrogen matrices and characterized by their infrared spectra. Assignments of vibrational bands are supported by ab initio and first principle calcu-
\end{abstract}

lations as well as ${ }^{14 / 15} \mathrm{~N}$ isotope substitution experiments. The structural and electronic properties of the new dinitrogen and nitrido iridium complexes are discussed. While the formation of the elusive dinitrido complex $\operatorname{Ir}(\mathrm{N})_{2}$ was observed in a subsequent reaction of $\operatorname{IrN}$ with $\mathrm{N}$ atoms within the cryogenic solid matrices, the threefold coordinated iridium trinitride $\operatorname{Ir}(\mathrm{N})_{3}$ could not be observed so far.

\section{Introduction}

Molecular complexes combining nitrogen and platinum group metals (PGM), such as dinitrogen complexes $L_{m} M\left(N_{2}\right)_{n}$ and polynitrido metal complexes $L_{m} M(N)_{n}$ have recently attracted much attention. ${ }^{[1]}$ Molecular dinitrogen complexes are of vivid interest in nitrogen fixation and reduction since 1966, when the first iridium dinitrogen complex was published, shortly after the first transition metal dinitrogen complexes $\left[\mathrm{Ru}\left(\mathrm{NH}_{3}\right)_{5} \mathrm{~N}_{2}\right] \mathrm{X}_{2}$ with $\mathrm{X}=\mathrm{Br}^{-}$, $\mathrm{I}^{-}$and $\mathrm{BF}_{4}^{-}$were reported in $1965 .^{[2]}$ The activation and weakening of the strong triple bond in the $\mathrm{N}_{2}$ molecule is facilitated by $\pi$-back-bonding from orthogonal $d_{x z}$ and $d_{y z}$ or even $p$ orbitals into the antibonding $\pi^{*}$-orbitals of the $\mathrm{N}_{2}$ ligand. $^{[1 a, 2 c, 3]}$ This effect is readily observable spectroscopically by a red-shift of the $\mathrm{N}-\mathrm{N}$ stretching mode compared to free dinitrogen in the IR spectra. All binary PGM dinitrogen complexes, except those of iridium, were investigated experimentally using matrix isolation techniques, where metal atoms are generated by thermal evaporation or laser ablation for $\mathrm{Ru}_{1}{ }^{[4]} \mathrm{Rh}_{1}{ }^{[5]} \mathrm{Pd}_{1}^{[6]} \mathrm{Re}^{[7]} \mathrm{Os}^{\left[{ }^{[4]}\right.}$ and $\mathrm{Pt}^{\left[{ }^{[6 b, 8]}\right.}$ By these methods homoleptic dinitrogen complexes $M\left(N_{2}\right)_{n}$ can be prepared, which allow the investigation of metal-nitrogen bonding interactions independent of the influence of other li-

[a] T. Stüker, Dr. H. Beckers, Prof. S. Riedel

Institut für Chemie und Biochemie, Anorganische Chemie

Freie Universität Berlin, Fabeckstr. 34/36, 14195 Berlin (Germany)

E-mail: s.riedel@fu-berlin.de

$\square$ Supporting information and the ORCID identification number(s) for the

iD auth author(s) of this article can be found under: https://doi.org/10.1002/chem.201905514.

[0 (c) 2020 The Authors. Published by Wiley-VCH Verlag GmbH \& Co. KGaA This is an open access article under the terms of the Creative Commons Attribution License, which permits use, distribution and reproduction in any medium, provided the original work is properly cited. gands and thus give important insight into the bonding properties and mechanisms of dinitrogen activation.

Polynitrido metal complexes have recently attracted attention as the nitrido ligand facilitates high oxidation states. Examples are the group 6 complexes $\mathrm{NM}^{+\mathrm{V}^{2}} \mathrm{~F}_{3}$ (with $\mathrm{M}=\mathrm{Cr}$, Mo and $\mathrm{W})^{[9]}$ and the more recently predicted but so far unknown

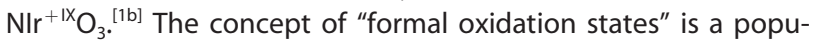
lar and important method of counting and assigning electrons to chemical elements in molecular and solid-state structures. ${ }^{[0]}$ In recent years the range of compounds in high and unusual formal oxidation states has been expanded experimentally as well as theoretically. The so far highest experimentally attained formal oxidation state across all chemical elements is + IX of iridium in the $\left[\mathrm{IrO}_{4}\right]^{+}$cation. ${ }^{[11]}$ It was generated in the gas phase and detected using infrared photodissociation spectroscopy after it was predicted theoretically. ${ }^{[12]}$ But also compounds with iridium in the oxidation states of $+\mathrm{VI}$ and $+\mathrm{VIII}$

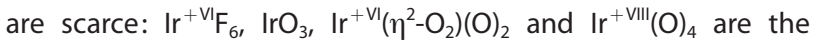
only experimentally known examples. ${ }^{[13]}$ Nitrogen is the third most electronegative element and with a formal oxidation number of -3 it can increase the formal oxidation state of the metal center by three units, while occupying only a single coordination site. The problem associated with the $\mathrm{N}^{3-}$ ligand is that, compared to $\mathrm{F}^{-}$and $\mathrm{O}^{2-}$, it is more easily oxidized by strong oxidizing metal centers, especially in complexes bearing metals in high oxidation states. Several binary transition metal nitrides were previously prepared by the reaction of laser-ablated metal atoms with pure dinitrogen or dinitrogen diluted in rare gases, and subsequent deposition on a cold matrix support. Although this method mainly yields metal dinitrogen complexes, also molecular mono- and dinitrides of the platinum group metals, such as $\mathrm{RuN}$ and $\mathrm{Ru}(\mathrm{N})_{2},{ }^{[4]} \mathrm{RhN}$ and $\mathrm{Rh}(\mathrm{N})_{2},{ }^{[5 b]} \mathrm{OsN}$ and $\mathrm{Os}(\mathrm{N})_{2}{ }^{[4]}$ and $\mathrm{PtN}^{[8 c]}$ were formed as well. So far, the only known binary molecular iridium nitrogen compound is the IrN molecule, first produced by laser ablation of 
iridium atoms in the presence of $\mathrm{NH}_{3}$ and characterized by optical/Stark spectroscopy. ${ }^{[14]}$ Subsequently, its spectral and bonding properties were studied further experimentally and theoretically. ${ }^{[15]}$ Furthermore, high-pressure materials of the composition $\operatorname{Ir}_{2} \mathrm{~N}, \operatorname{Ir}(\mathrm{N})_{2}$ and $\operatorname{Ir}(\mathrm{N})_{3}$, respectively, are potentially (super) hard materials and their structural, electronic and mechanical properties were previously investigated theoretically ${ }^{[16]}$ and experimentally. ${ }^{[17]}$ These materials however contain quasi-molecu$\operatorname{lar} \mathrm{N}_{2}{ }^{2-}$ or $\mathrm{N}_{2}{ }^{4-}$ units rather than $\mathrm{N}^{3-} \cdot{ }^{[18]}$

We have carried out reactions of laser-ablated iridium atoms with dinitrogen molecules and studied the reaction products by matrix-isolation IR spectroscopy. The photodecomposition of $\mathrm{N}_{2}$ molecules and the formation of $\mathrm{N}$ atoms induced by plasma radiation in the laser-ablation process should also facilitate the formation of molecular binary iridium nitrides up to $\operatorname{Ir}^{+I X}(N)_{3}$. These molecular binary iridium nitrides will allow to gauge the ability of the $\mathrm{N}$ atom to oxidize the iridium metal center and to investigate the nature of the chemical bonding independent of the influence of other ligands.

\section{Experimental and Computational Methods}

\section{Matrix-isolation experiments}

${ }^{14} \mathrm{~N}_{2}$ (99.999\%, Linde) and ${ }^{15} \mathrm{~N}_{2}$ (98+ atom \%, Campro) were premixed with neon or argon (both $99.999 \%$, Linde) in a stainlesssteel cylinder. The mixing vessel was connected to a stainless-steel vacuum line connected to a self-made matrix chamber by a stainless-steel capillary. The gas mixture was then co-deposited with laser-ablated iridium atoms onto a CsI window (argon and dinitrogen matrices) or onto a gold plated copper mirror (neon matrices) and cooled to $4 \mathrm{~K}$ by using a closed-cycle helium cryostat (Sumitomo Heavy Industries, RDK-205D) inside the vacuum chamber. For the laser-ablation, the $1064 \mathrm{~nm}$ fundamental of a Nd:YAG laser (Continuum, Minilite $\mathrm{Il}, 10 \mathrm{~Hz}$ repetition rate, $35-50 \mathrm{~mJ}$ pulse ${ }^{-1}$ ) was focused onto a rotating iridium metal target through a hole in the cold window. Infrared spectra were recorded on a Bruker Vertex 70 spectrometer purged with dry air (argon and dinitrogen matrices) or a Bruker Vertex $80 \mathrm{v}$ with evacuated optical path (neon matrices) at $0.5 \mathrm{~cm}^{-1}$ resolution in the region $4000-430 \mathrm{~cm}^{-1}$ by using a liquid-nitrogen-cooled mercury cadmium telluride (MCT) detector. Far-IR (FIR) spectra were recorded at a resolution of $0.5 \mathrm{~cm}^{-1}$ at the Bruker Vertex $80 \mathrm{v}$ equipped with a FIR multilayer mylar beam-splitter $\left(680-30 \mathrm{~cm}^{-1}\right)$, a Csl window $\left(>180 \mathrm{~cm}^{-1}\right)$, and a liquid helium cooled bolometer. The matrix samples were irradiated by a mercury arc streetlamp (Osram HQL 250) with the outer globe removed. Wavelength selective irradiations in the visible spectrum were realized with OSRAM LEDs with typical powers between 5 and 10 watts.

\section{Electronic-structure calculations}

Density functional theory (DFT) calculations were performed using the TURBOMOLE 7.0.1 program package ${ }^{[19]}$ employing the GGA exchange-correlation density functional $\mathrm{BP}^{2} 6^{[20]}$ with the polarized quadruple- $\xi$ basis set def2-QZVP ${ }^{[21]}$ which applies the StuttgartDresden effective core potential for iridium. ${ }^{[22]}$ All Coupled Cluster Single Double and perturbative Triple excitations (CCSD(T)) combined with Dunning's augmented correlation consistent polarized triple- $\xi$ basis sets aug-cc-pVTZ for nitrogen, ${ }^{[23]}$ and aug-cc-pVTZ-PP combined with the ECP60MDF effective core potential for iridi- um $^{[24]}$ were performed using the CFOUR 2.00beta software. ${ }^{[2]}$ State-averaged complete active space self-consistent field (SACASSCF) calculations combined with Dunning's correlation consistent polarized valence triple- $\xi$ basis sets $c c-p V T Z^{[26]}$ and cc-pVTZ$\mathrm{PP}^{[24]}$ for nitrogen and iridium and the effective core potential (ECP60MDF) for iridium were carried out for iridium dinitride using the Molpro 2019 software. ${ }^{[27]}$ The active space was chosen to consist of the molecular orbitals formed by the $2 p(N), 5 d(I r)$ and $6 s(I r)$ atomic orbitals, yielding 15 electrons in 12 molecular orbitals. One calculation for each spin multiplicity, doublet, quartet and sextet was carried out employing the state-averaging formalism in $C_{2 v}$ point group symmetry, including two states of each state symmetry $\left(A_{1}, B_{1}, B_{2}\right.$ and $\left.A_{2}\right)$, resulting in eight states with equal weights of 0.125 . Harmonic vibrational frequency calculations were carried out for all optimized structures analytically (BP86) or numerically $(\mathrm{CCSD}(\mathrm{T}))$. The decomposition pathways of $\operatorname{Ir}(\mathrm{N})_{2}$ and $\operatorname{Ir}(\mathrm{N})_{3}$ were analyzed by optimizing the geometries of the nitrides, the complexes formed by the rearrangement, and the transition states connecting both minima using the BP86 exchange-correlation density functional with the application of the zeroth-order regular relativistic approximation (ZORA) ${ }^{[28]}$ combined with the adapted version of the def2 basis set ZORA-def2-TZVPP for nitrogen and the segmented all-electron relativistic contracted SARC-ZORA-TZVPP for iridi$u^{[29]}$ as implemented in ORCA 4.1.2. ${ }^{[30]}$ Additionally, the meta-GGA M06-L exchange correlation density functional ${ }^{[31]}$ was used for calculating the energy barriers associated with the decompositions of $\operatorname{Ir}(\mathrm{N})_{2}$ and $\operatorname{Ir}(\mathrm{N})_{3}$. The NBO and AIM analyses were carried out using wavefunctions obtained at the BP86/def2-QZVP level of theory using NBO $7.0^{[31]}$ and Multiwfn $3.5^{[33]}$ respectively. Because of the multitudes of combinations and the rapidly increasing computational challenges, compounds of the formula $\operatorname{Ir}_{x} \mathrm{~N}_{y}$ with $y$ and $x$ greater than two are not explicitly considered.

\section{Results and Discussion}

Laser-ablated iridium atoms were reacted with diluted dinitrogen in a vacuum chamber and the reaction products were subsequently deposited on a matrix support under cryogenic conditions and studied using IR spectroscopy. The experimental details are presented in the experimental section. The obtained products can be separated in two different sets: dinitrogen and nitrido complexes. The $\mathrm{N}-\mathrm{N}$ stretching vibrations of the dinitrogen complexes occur in the region from $2350-1850 \mathrm{~cm}^{-1}$, and the $\mathrm{I}-\mathrm{N}$ stretching vibrations of dinitrogen and nitrido complexes in the region below $1150 \mathrm{~cm}^{-1}$ (Table 1). The main absorptions that appeared in the $\mathrm{N}-\mathrm{N}$ stretching region of the IR spectra are located at 2270.3, 2241.6, 2154.0, 2097.4, $1956.4 \mathrm{~cm}^{-1}$. They are assigned and labeled in Figures 1 and 2 to the dinitrogen complexes $\left[\operatorname{Ir}\left(\mathrm{N}_{2}\right)\right]^{+}, \operatorname{Nir}\left(\mathrm{N}_{2}\right), \operatorname{Ir}\left(\mathrm{N}_{2}\right)_{2}, \operatorname{Ir}\left(\mathrm{N}_{2}\right)$ and $\left[\operatorname{Ir}\left(\mathrm{N}_{2}\right)_{2}\right]^{-}$, respectively. In the $\mathrm{Ir}-\mathrm{N}$ stretching region of these spectra absorptions of $\operatorname{IrN}, \operatorname{Ir} \mid r N, \operatorname{Ir}(\mathrm{N})_{2}$ and IrNNIr were detected. These are indicated in Figures 3, 4 and 5 to bands at 1111.1, 1004.4, 853.5 and $786.5 \mathrm{~cm}^{-1}$, respectively. Additional bands were observed when the reaction products are deposited in neat nitrogen matrices (Table 2 and Figure 2, trace d). In the ${ }^{14} \mathrm{~N}_{2}$ matrices a band appeared at $2221.7 \mathrm{~cm}^{-1}$, accompanied by a matrix site at $2214.3 \mathrm{~cm}^{-1}$ (Figure 2), which is probably associated with clusters of $\operatorname{Ir}_{x}\left(\mathrm{~N}_{2}\right)_{y}$

Complementary spectra were also recorded in solid argon (Figures S1 and S2), and in the FIR region using neon as matrix 


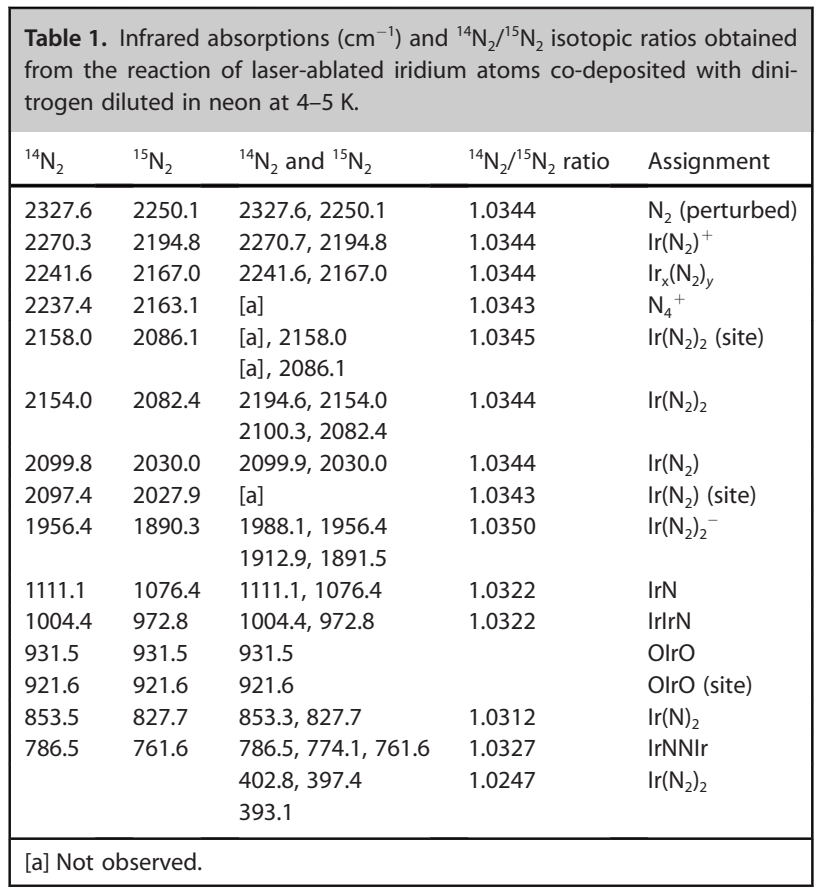

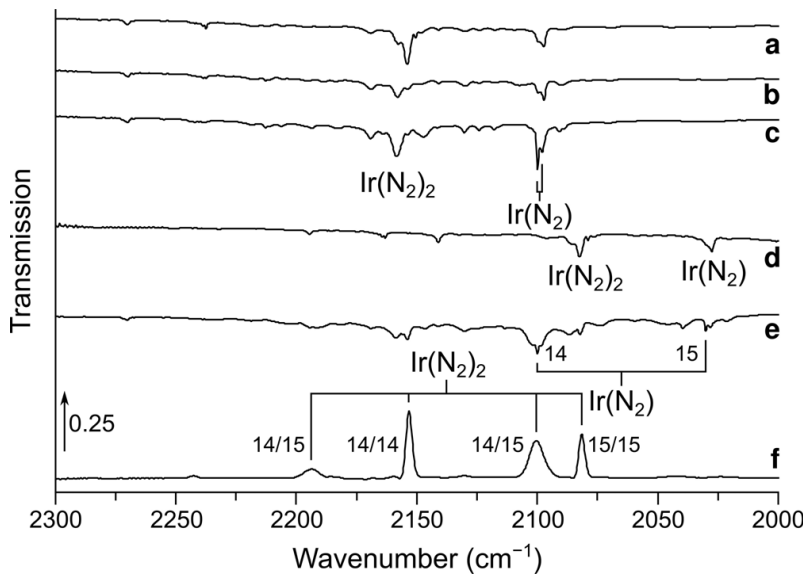

Figure 1. Infrared spectra in the $2000-2350 \mathrm{~cm}^{-1}$ region of the reaction products of laser-ablated iridium atoms with $0.5 \%{ }^{14} \mathrm{~N}_{2}$ in neon after deposition (a), 10 min broadband irradiation (b), annealing to $T=10 \mathrm{~K}$ (c), with $0.5 \%{ }^{15} \mathrm{~N}_{2}$ in neon after deposition (d), with $0.5 \%$ of a 1:1 mixture of ${ }^{14} \mathrm{~N}_{2}$ and ${ }^{15} \mathrm{~N}_{2}$ in neon after $10 \mathrm{~min}$ of broadband irradiation and subsequent annealing of $T=10 \mathrm{~K}$ (e) and with $10 \%$ of a 1:1 mixture of ${ }^{14} \mathrm{~N}_{2}$ and ${ }^{15} \mathrm{~N}_{2}$ in neon after $10 \mathrm{~min}$ of irradiation with LED light $\lambda=455 \mathrm{~nm}$ (f). Bands due to iridium nitrogen compounds and some selected ${ }^{14 / 15} \mathrm{~N}$ isotope patterns are indicated.

host (Figure S3). A full list of absorptions found in argon matrices are given in Table 3. The bands centered at 2144.7, 2110.6, 2087.6, 1004.1, $848.2 \mathrm{~cm}^{-1}$ were assigned and marked in the Figures $\mathrm{S} 1$ and $\mathrm{S} 2$ to $\operatorname{Ir}\left(\mathrm{N}_{2}\right)_{2}, \operatorname{Ir}\left(\mathrm{N}_{2}\right), \operatorname{Ir}\left(\mathrm{N}_{2}\right), \operatorname{Ir} \mid r N$ and $\operatorname{Ir}(\mathrm{N})_{2}$, respectively. Bands obtained in the FIR region are shown in Figure S3. They are due to the three ${ }^{14 / 15} \mathrm{~N}$ isotopologues of $\operatorname{Ir}\left(\mathrm{N}_{2}\right)_{2}$ embedded in solid neon and located at 402.8, 397.4 and $393.1 \mathrm{~cm}^{-1}$, respectively. Optimized structures of the above-

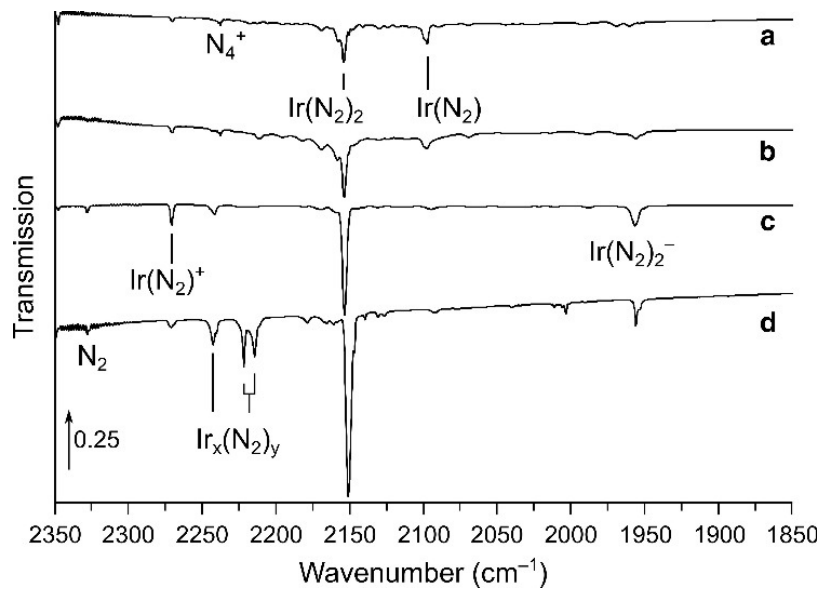

Figure 2. Infrared spectra in the $1850-2350 \mathrm{~cm}^{-1}$ region of the reaction products of laser-ablated iridium atoms with $0.5 \%$ (a), $3 \%$ (b), $10 \%$ (c) ${ }^{14} \mathrm{~N}_{2}$ in neon, and neat ${ }^{14} \mathrm{~N}_{2}$ (d). Bands due to iridium nitrogen compounds are indicated.

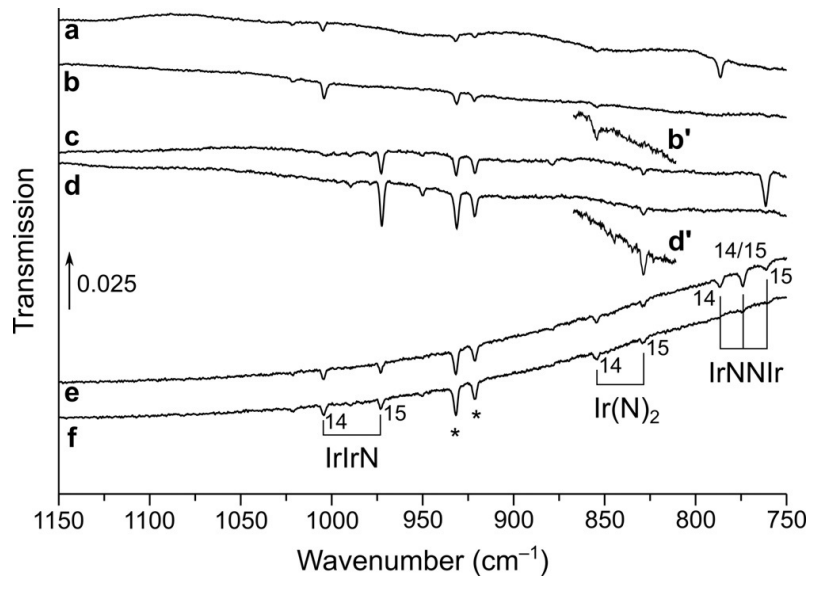

Figure 3. Infrared spectra in the $1150-750 \mathrm{~cm}^{-1}$ region of the reaction products of laser-ablated iridium atoms in neon doped with $10 \%{ }^{14} \mathrm{~N}_{2}$ after depo sition (a), after $10 \mathrm{~min}$ of $455 \mathrm{~nm}$ irradiation (b), with $10 \%{ }^{15} \mathrm{~N}_{2}$ in neon after deposition (c) after irradiation with $455 \mathrm{~nm}$ (d), as well as with $10 \%$ of a 1:1 mixture of ${ }^{14} \mathrm{~N}_{2}$ and ${ }^{15} \mathrm{~N}_{2}$ in neon after deposition (e), and 10 min of irradiation with $455 \mathrm{~nm}(\mathrm{f})$. Bands due to iridium nitrogen compounds and some selected ${ }^{14 / 15} \mathrm{~N}$ isotope patterns are indicated. The sections showing the $\operatorname{Ir}(\mathrm{N})_{2}$ absorption in the spectra $\mathrm{b}$ and $\mathrm{d}$ are enhanced by a factor of 5 and tagged with $b^{\prime}$ and $d^{\prime}$.

mentioned dinitrogen and nitrido complexes of iridium were obtained at the DFT and $\operatorname{CCSD}(\mathrm{T})$ levels of theory and depicted in Figure 6. Computed harmonic frequencies of the reaction products are summarized in Table S1, and computed reaction enthalpies related to the formation of the observed reaction products are listed in Table 4. In the following the infrared spectra and the annealing and photolysis behavior of the reaction products, as well as our computational results are discussed, starting with the dinitrogen iridium complexes. 


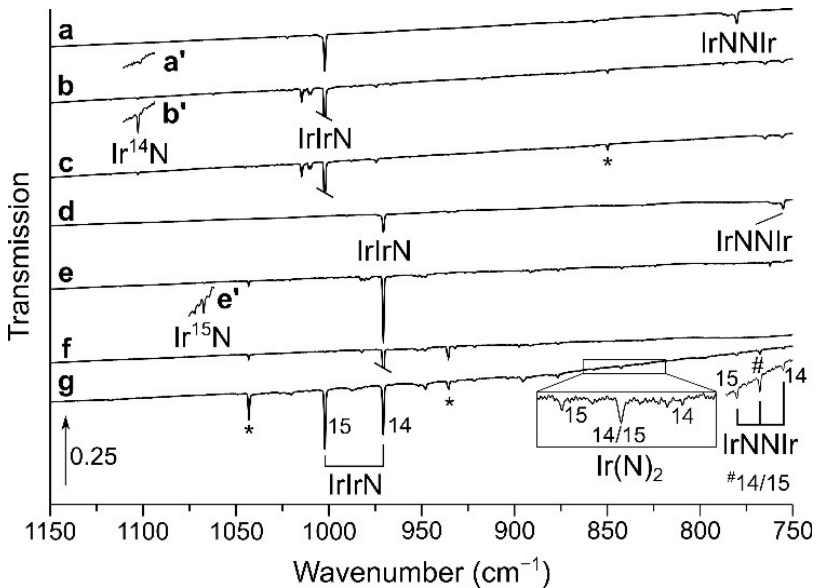

Figure 4. Infrared spectra in the $1150-750 \mathrm{~cm}^{-1}$ region of the reaction products of laser-ablated iridium atoms with ${ }^{14} \mathrm{~N}_{2}$ after deposition (a), annealing to $35 \mathrm{~K}$ (b) and broadband irradiation (c), as well as with ${ }^{15} \mathrm{~N}_{2}$ after deposition (d), annealing to $35 \mathrm{~K}$ (e), broadband irradiation ( $\mathrm{f}$ ) and finally after deposition with a 1:1 mixture of ${ }^{14} \mathrm{~N}_{2}$ and ${ }^{15} \mathrm{~N}_{2}$ (g). Bands due to iridium nitrogen compounds and some selected ${ }^{14 / 15} \mathrm{~N}$ isotope patterns are indicated. Bands marked by an asterisk exhibit no isotopic shift and remained unassigned. The transmission of the bands shown in the sections $\mathrm{a}^{\prime}, \mathrm{b}^{\prime}$ and $\mathrm{e}^{\prime}$ are enhanced by a factor of 10,10 , and 15 , respectively.

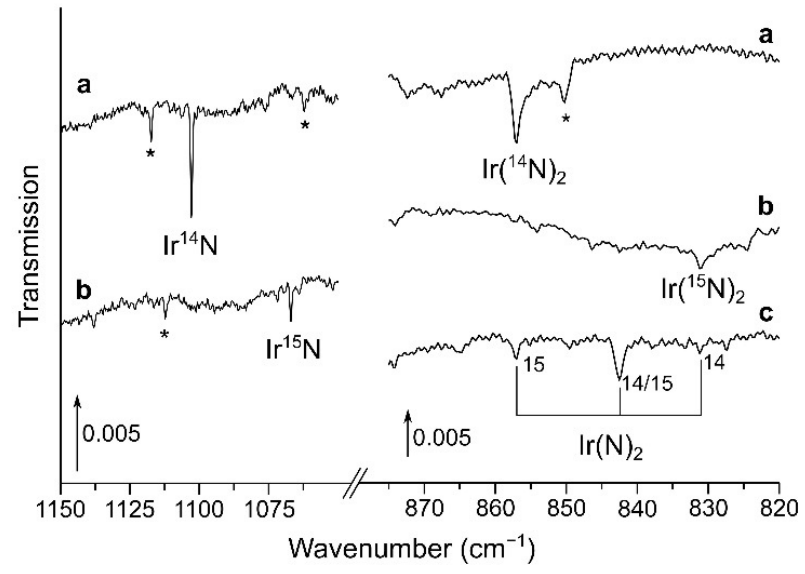

Figure 5. Infrared spectra in the $1150-1050 \mathrm{~cm}^{-1}$ and $875-820 \mathrm{~cm}^{-1}$ regions of the reaction products of laser-ablated iridium atoms with ${ }^{14} \mathrm{~N}_{2}(\mathrm{a}),{ }^{15} \mathrm{~N}_{2}$ (b) as well as a 1:1 mixture of ${ }^{14} \mathrm{~N}_{2}$ and ${ }^{15} \mathrm{~N}_{2}$ (c). Bands due to iridium nitrogen compounds and some selected ${ }^{14 / 15} \mathrm{~N}$ isotope patterns are indicated. Bands marked with an asterisk exhibit no isotopic shift and remained unassigned.

$\operatorname{Ir}\left(\mathbf{N}_{2}\right)$

The band observed at $2097.4 \mathrm{~cm}^{-1}$ in neon doped with $0.5 \%$ ${ }^{14} \mathrm{~N}_{2}$ with a weaker matrix site at $2099.8 \mathrm{~cm}^{-1}$ is assigned to the $\operatorname{Ir}\left(\mathrm{N}_{2}\right)$ complex (Figure 1). This band is unaffected by broadband irradiation and grows upon annealing, while the sharp matrix site at $2099.8 \mathrm{~cm}^{-1}$ overtakes the initially stronger band at $2097.4 \mathrm{~cm}^{-1}$. The ${ }^{15} \mathrm{~N}$ counterpart exhibits the same behavior upon irradiation and is located at 2027.6 and $2030.0 \mathrm{~cm}^{-1}$, giving an isotopic frequency ratio of 1.0344 typical for $\mathrm{N}-\mathrm{N}$ stretching modes. In the mixed ${ }^{14} \mathrm{~N}_{2}$ and ${ }^{15} \mathrm{~N}_{2}$ isotopic experiment the band at $2097.4 \mathrm{~cm}^{-1}$ is interfered by a stronger band

\begin{tabular}{|c|c|c|c|c|}
\hline${ }^{14} \mathrm{~N}_{2}$ & ${ }^{15} \mathrm{~N}_{2}$ & ${ }^{14} \mathrm{~N}_{2}$ and ${ }^{15} \mathrm{~N}_{2}$ & ${ }^{14} \mathrm{~N}_{2} /{ }^{15} \mathrm{~N}_{2}$ ratio & Assignment \\
\hline 2327.9 & 2249.9 & $2327.9,2249.9$ & 1.0347 & $\mathrm{~N}_{2}$ (perturbed) \\
\hline 2271.3 & 2195.2 & [a] & 1.0347 & $\operatorname{Ir}\left(\mathrm{N}_{2}\right)^{+}$ \\
\hline 2242.8 & 2168.2 & {$[b]$} & 1.0344 & $\operatorname{lr}_{x}\left(N_{2}\right)_{y}$ \\
\hline 2221.7 & 2147.6 & {$[b]$} & 1.0345 & $\operatorname{lr}_{\mathrm{x}}\left(\mathrm{N}_{2}\right)$ \\
\hline 2217.5 & 2143.5 & [b] & 1.0345 & $\operatorname{lr}_{x}\left(\mathrm{~N}_{2}\right)_{y}$ \\
\hline 2214.3 & 2140.5 & [b] & 1.0345 & $\operatorname{lr}_{x}\left(\mathrm{~N}_{2}\right)_{y}$ \\
\hline 2151.1 & 2079.5 & $\begin{array}{l}2196.4,2189.6 \\
2151.1,2101.8 \\
2094.8,2079.5\end{array}$ & 1.0344 & $\operatorname{lr}(\mathrm{NN})_{2}$ \\
\hline 2150.0 & 2078.3 & [a] & 1.0345 & $\operatorname{Ir}(\mathrm{NN})_{2}$ (site) \\
\hline 2003.2 & 1937.6 & $\begin{array}{l}2003.3,1992.8 \\
1948.7,1937.5\end{array}$ & 1.0339 & $\mathrm{~N}_{3}^{-}$ \\
\hline 1955.8 & 1890.7 & $\begin{array}{l}1955.8,1912.4 \\
1890.7\end{array}$ & 1.0344 & $\operatorname{Ir}\left(\mathrm{N}_{2}\right)_{2}^{-}$ \\
\hline 1657.5 & 1603.3 & $\begin{array}{l}1657.6,1649.2 \\
1612.9,1603.3\end{array}$ & 1.0338 & $\mathrm{~N}_{3}$ \\
\hline 1652.4 & 1597.6 & [a] & 1.0343 & $\mathrm{~N}_{3}$ (site) \\
\hline 1102.8 & 1066.9 & [a] & 1.0336 & IrN \\
\hline 1002.2 & 970.7 & $1002.2,970.7$ & 1.0325 & IrlrN \\
\hline 857.1 & 831.2 & $\begin{array}{l}857.1,842.6 \\
831.2\end{array}$ & 1.0312 & $\operatorname{Ir}(\mathrm{N})_{2}$ \\
\hline 780.2 & 755.2 & $\begin{array}{l}780.2,767.7 \\
755.2\end{array}$ & 1.0331 & IrNNIr \\
\hline
\end{tabular}

Table 3. Infrared absorptions $\left(\mathrm{cm}^{-1}\right)$ and ${ }^{14} \mathrm{~N}_{2} /{ }^{15} \mathrm{~N}_{2}$ isotopic ratios obtained from the reaction of laser-ablated iridium atoms co-deposited with dinitrogen diluted in argon at $4-5 \mathrm{~K}$.

\begin{tabular}{lllll|}
${ }^{14} \mathrm{~N}_{2}$ & ${ }^{15} \mathrm{~N}_{2}$ & ${ }^{14} \mathrm{~N}_{2}$ and ${ }^{15} \mathrm{~N}_{2}$ & ${ }^{14} \mathrm{~N}_{2} /{ }^{15} \mathrm{~N}_{2}$ ratio & Assignment \\
\hline 2327.1 & 2249.2 & & 1.0346 & $\mathrm{~N}_{2}$ (perturbed) \\
2144.7 & 2073.7 & $\begin{array}{l}2187.5,2144.7 \\
\end{array}$ & 1.0342 & $\operatorname{Ir}\left(\mathrm{N}_{2}\right)_{2}$ \\
2138.5 & 2138.5 & & & \\
2110.6 & 2040.1 & $2110.6,2040.1$ & 1.0346 & $\mathrm{CO}$ \\
2087.6 & 2018.2 & 2018.2 & 1.0344 & $\operatorname{Ir}\left(\mathrm{N}_{2}\right)$ \\
1004.1 & 972.7 & $1004.1,972.7$ & 1.0323 & $\operatorname{Ir}\left(\mathrm{N}_{2}\right)$ \\
848.2 & & & & $\operatorname{Ir}(\mathrm{N})_{2}$ \\
\hline
\end{tabular}

associated with $\operatorname{Ir}\left({ }^{14} \mathrm{~N}_{2}\right)\left({ }^{15} \mathrm{~N}_{2}\right)$. However, due to the sharp, distinctive band shape of the matrix site at $2099.8 \mathrm{~cm}^{-1}$ after annealing, the weaker $\operatorname{Ir}\left(\mathrm{N}_{2}\right)$ band clearly stands out (Figure $1 \mathrm{e}$ ). The spectrum does not show any band related to a scrambled ${ }^{14} \mathrm{~N} /{ }^{15} \mathrm{~N}$ species in the mixed ${ }^{14} \mathrm{~N}_{2}+{ }^{15} \mathrm{~N}_{2}$ experiment, thus, the characteristic doublet isotope pattern indicates a carrier bearing a single $\mathrm{N}_{2}$ unit. The corresponding absorption in the argon matrix is red-shifted by $9.8 \mathrm{~cm}^{-1}$ relative to neon and the same isotopic ratio is found (Figure S1). Due to the formation of the higher coordinated species $\operatorname{Ir}\left(\mathrm{N}_{2}\right)_{2}$, the intensity of the $\operatorname{Ir}\left(\mathrm{N}_{2}\right)$ absorption band decreases with increasing amount of $\mathrm{N}_{2}$ and is absent in the neat dinitrogen spectrum. The assignments are supported by harmonic frequency calculations at the DFT and $\operatorname{CCSD}(\mathrm{T})$ level of theory. In analogy with RhNN, DFT and $\operatorname{CCSD}(\mathrm{T})$ calculations on $\operatorname{Ir}\left(\mathrm{N}_{2}\right)$ result in a linear $C_{\infty \mathrm{v}}$ point group symmetry (Figure 6 ) for the ${ }^{2} \Delta$ electronic ground 


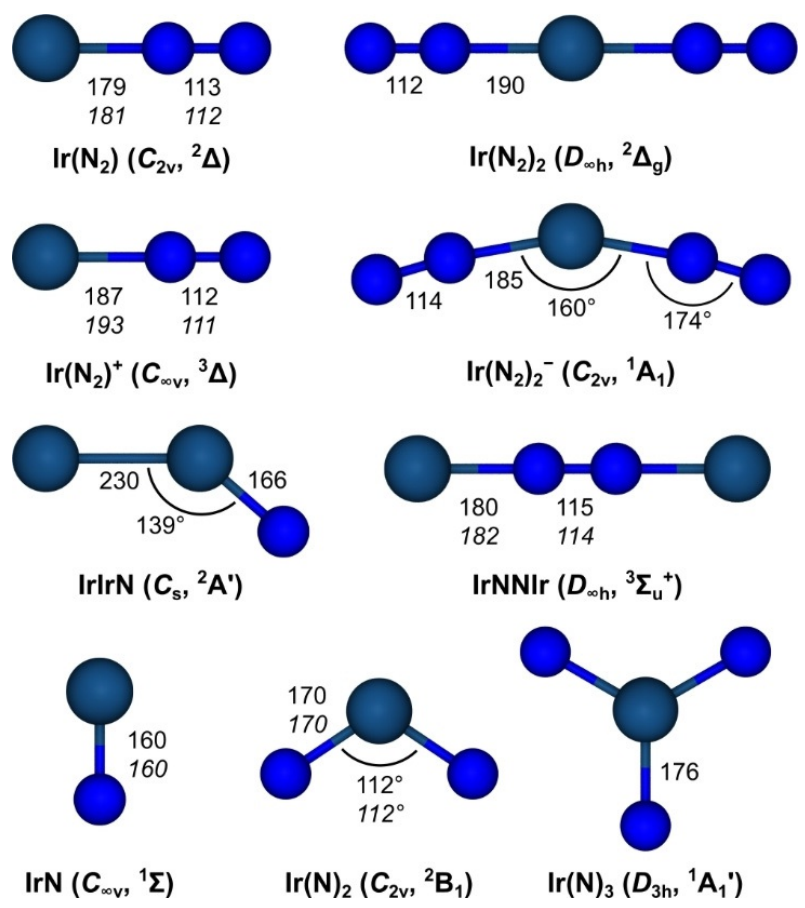

Figure 6. Structures, point group symmetries and electronic ground states calculated and optimized at the BP86/def2-QZVP (regular font) and CCSD(T)/ aVTZ(-PP) (italic font) levels of theory.

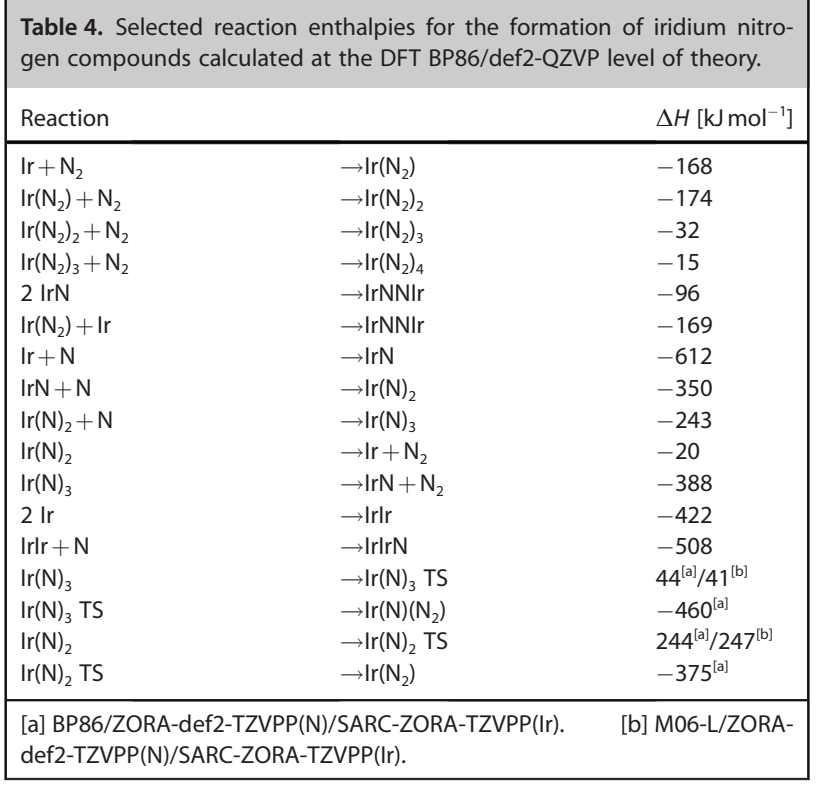

state bearing an unpaired electron in an iridium centered degenerate $\delta$ molecular orbital, originating from $d_{x^{2}-y^{2}}$ and $d_{x y}$ iridium atomic orbitals. The lowest quartet state $\left({ }^{4} A^{\prime}\right)$ is $104 \mathrm{~kJ} \mathrm{~mol}^{-1}$ higher in energy (Table S1). The deviations between the experimental $\mathrm{N}_{2}$ band position of $\operatorname{Ir}\left(\mathrm{N}_{2}\right)$ embedded in $\mathrm{Ne}$ and the computed values are 22 and $43 \mathrm{~cm}^{-1}$ for DFT and $\operatorname{CCSD}(\mathrm{T})$, respectively. The larger deviation of the superior
$\operatorname{CCSD}(\mathrm{T})$ method is due to the fact that no harmonic contributions are considered, while the apparently better DFT value benefits from fortunate error cancelation. The NN stretching isotopic ratios $\tilde{v}\left({ }^{14} \mathrm{~N}^{14} \mathrm{~N}\right) / \tilde{v}\left({ }^{15} \mathrm{~N}^{15} \mathrm{~N}\right)$ obtained by both, the DFT and $\operatorname{CCSD}(\mathrm{T})$ levels of theory are 1.0350, which is in good agreement with the experimental value of 1.0343 .

$\operatorname{Ir}\left(\mathrm{N}_{2}\right)^{+}$

The $\mathrm{N}-\mathrm{N}$ stretching band of the cationic species $\operatorname{Ir}\left(\mathrm{N}_{2}\right)^{+}$appeared red-shifted by 172 at $2270.3 \mathrm{~cm}^{-1}$ and is observed in all experiments using $\mathrm{N}_{2} / \mathrm{Ne}$ mixtures as well as in neat $\mathrm{N}_{2}$, in which the band is blue-shifted by $1.0 \mathrm{~cm}^{-1}$ (Figure 1). Selective irradiations using LED light sources of $\lambda=656,455,405$ and $365 \mathrm{~nm}$ did not affect the absorption intensity. However, full arc irradiation depleted, and annealing of the dinitrogen matrix to $30 \mathrm{~K}$, destroyed the band entirely. The $\mathrm{N}-\mathrm{N}$ stretch of the $\operatorname{Ir}\left({ }^{15} \mathrm{~N}_{2}\right)^{+}$isotopologue is located at $2194.8 \mathrm{~cm}^{-1}$, resulting in an isotopic ratio of 1.0344 , typical for modes involving two nitrogen atoms. As for the neutral species, no additional bands could be assigned to this species in the $1: 1{ }^{14} \mathrm{~N}_{2} /{ }^{15} \mathrm{~N}_{2}$ mixed isotope experiment, implying the presence of a single dinitrogen unit. Computational results at the DFT and $\operatorname{CCSD}(T)$ levels of theory support the assignment further. The calculated harmonic frequencies are at 2212 and $2286 \mathrm{~cm}^{-1}$, respectively. For $\left[\operatorname{lr}\left(\mathrm{N}_{2}\right)\right]^{+}$a ${ }^{3} \Delta$ electronic ground state was found with one electron removed from a non-bonding $\sigma$ type molecular orbital. Compared to the neutral species the electronic ground state of the cation was computed to be $848 \mathrm{~kJ} \mathrm{~mol}^{-1}$ higher in energy.

$\operatorname{Ir}\left(\mathrm{N}_{2}\right)_{2}$

The band centered at $2154.0 \mathrm{~cm}^{-1}$ with a matrix site at $2158.0 \mathrm{~cm}^{-1}$ obtained in solid neon doped with $0.5 \%{ }^{14} \mathrm{~N}_{2}$ and shown in Figure 2 remained unaffected by annealing but decreased dramatically upon irradiation with LED light of $\lambda=$ $455 \mathrm{~nm}$. Annealing after photolysis increased the intensity of the initially weaker matrix site at $2158.0 \mathrm{~cm}^{-1}$. The ${ }^{15} \mathrm{~N}$ counterparts at 2082.4 and $2086.1 \mathrm{~cm}^{-1}$ result in an isotopic ratio of 1.0344. Increasing the amount of $\mathrm{N}_{2}$ in the solid Ne matrices strongly increases the intensity of the band and it is red-shifted by $4.0 \mathrm{~cm}^{-1}$ in neat $\mathrm{N}_{2}$ (Figure 2). The mixed ${ }^{14} \mathrm{~N}_{2}$ and ${ }^{15} \mathrm{~N}_{2}$ spectrum displays a characteristic pattern for linear $\operatorname{Ir}\left(\mathrm{N}_{2}\right)_{2}$ consisting of the three antisymmetric $\mathrm{N}-\mathrm{N}$ stretching modes of $\left({ }^{14} \mathrm{~N}_{2}\right) \operatorname{Ir}\left({ }^{14} \mathrm{~N}_{2}\right),\left({ }^{14} \mathrm{~N}_{2}\right) \operatorname{Ir}\left({ }^{15} \mathrm{~N}_{2}\right)$ and $\left({ }^{15} \mathrm{~N}_{2}\right) \operatorname{lr}\left({ }^{15} \mathrm{~N}_{2}\right)$ at $2154.0,2100.3$ and $2082.4 \mathrm{~cm}^{-1}$, respectively. Additionally, the symmetric $\mathrm{N}-\mathrm{N}$ stretching mode of the $\left({ }^{14} \mathrm{~N}_{2}\right) \operatorname{lr}\left({ }^{15} \mathrm{~N}_{2}\right)$ species becomes IR active due to lower point group symmetry $C_{\infty v}$ and is found at $2194.6 \mathrm{~cm}^{-1}$. Figure $1 \mathrm{f}$ shows the ${ }^{14} \mathrm{~N} /{ }^{15} \mathrm{~N}$ isotope pattern of $\operatorname{Ir}\left(\mathrm{N}_{2}\right)_{2}$ arising from a 1:1 mixture of ${ }^{14} \mathrm{~N}_{2}$ and ${ }^{14} \mathrm{~N}_{2}(10 \%$ in $\mathrm{Ne})$, shown in a difference spectrum obtained by subtracting the spectra after and prior to selective photolysis with LED light of $\lambda=455 \mathrm{~nm}$. In the FIR spectrum shown in Figure S3 a 1:2:1 triplet ${ }^{14 / 15} \mathrm{~N}_{2}$ isotope pattern of $\operatorname{Ir}\left(\mathrm{N}_{2}\right)_{2}$ was also observed at $402.8,397.4$ and $393.1 \mathrm{~cm}^{-1}$ originating from a $1: 1$ mixture of ${ }^{14} \mathrm{~N}_{2}$ and ${ }^{14} \mathrm{~N}_{2}$ in solid neon which results in an isotopic ratio 
of 1.0247. Comparing our assignments to the frequencies calculated at the DFT level of theory there is a very good agreement for the antisymmetric $\mathrm{N}-\mathrm{N}$ stretching mode at $2149 \mathrm{~cm}^{-1}$ and an isotopic ratio of 1.0349 . The symmetric $\mathrm{N}-\mathrm{N}$ stretching mode in $\operatorname{Ir}\left({ }^{14} \mathrm{~N}_{2}\right)\left({ }^{15} \mathrm{~N}_{2}\right)$ is calculated to be centered at $2182 \mathrm{~cm}^{-1}$ and the position of the antisymmetric $\mathrm{Ir}-\mathrm{N}$ stretching mode at $439 \mathrm{~cm}^{-1}$, leading to an isotopic ratio of 1.0267 . In analogy to the $\operatorname{Ir}\left(\mathrm{N}_{2}\right)$ complex, DFT and $\operatorname{CCSD}(\mathrm{T})$ calculations on $\operatorname{Ir}\left(\mathrm{N}_{2}\right)_{2}$ find a ${ }^{2} \Delta_{\mathrm{g}}$ ground state ( $D_{\infty \mathrm{h}}$ point group symmetry) having an unpaired electron located in a degenerate $\delta_{\mathrm{g}}$ molecular orbital. The HOMO $\rightarrow$ LUMO $\left(1 \delta_{\mathrm{g}} \rightarrow 2 \pi_{\mathrm{u}}\right)$ excitation gives rise to the lowest quartet state ${ }^{4} \Pi_{u}$, which is $246 \mathrm{~kJ} \mathrm{~mol}^{-1}$ higher in energy than the electronic ground state.

$\operatorname{Ir}\left(\mathrm{N}_{2}\right)_{2}^{-}$

A strong band observed at $1955.8 \mathrm{~cm}^{-1}$ in neat ${ }^{14} \mathrm{~N}_{2}$ shown in Figures 2 and $\mathrm{S} 7$ decreases completely on annealing and is unaffected by broadband irradiation. The corresponding absorption in solid neon doped with $10 \%{ }^{14} \mathrm{~N}_{2}$ at $1956.4 \mathrm{~cm}^{-1}$ lead to a related ${ }^{15} \mathrm{~N}$ isotopologue absorption at $1890.3 \mathrm{~cm}^{-1}$ (Figure S7). Together with a stronger band at 1912.9 and a weak band at $1988.1 \mathrm{~cm}^{-1}$ which appeared in the $1: 1{ }^{14} \mathrm{~N}_{2} /{ }^{15} \mathrm{~N}_{2}$ spectrum a ${ }^{14 / 15} \mathrm{~N}$ isotope pattern similar to that of $\operatorname{Ir}\left(\mathrm{N}_{2}\right)_{2}$ is observed. Therefore, the band is assigned to the anionic complex $\operatorname{Ir}\left(\mathrm{N}_{2}\right)_{2}{ }^{-}$. The assignment is supported by DFT calculations, which predict a ${ }^{1} A_{1}$ singlet ground state of $C_{2 v}$ point group symmetry and infrared absorptions at 1988, 1940 and $1921 \mathrm{~cm}^{-1}$ for the antisymmetric $\mathrm{N}-\mathrm{N}$ stretching modes of $\operatorname{Ir}\left(\left(^{14} \mathrm{~N}_{2}\right)\left({ }^{14} \mathrm{~N}_{2}\right)^{-}, \operatorname{Ir}\left({ }^{14} \mathrm{~N}_{2}\right)\left({ }^{15} \mathrm{~N}_{2}\right)^{-}\right.$and $\operatorname{Ir}\left({ }^{15} \mathrm{~N}_{2}\right)\left({ }^{15} \mathrm{~N}_{2}\right)^{-}$. The experimental and calculated isotopic ratios are 1.0344 (in neat $\mathrm{N}_{2}$ ), 1.0350 (in solid $\mathrm{Ne}$ ) and 1.0349 (DFT calc.) and are in very good agreement for the less interacting neon matrix. For a bent structure of $\operatorname{Ir}(\mathrm{NN})_{2}{ }^{-}$and unlike the case of a linear $\operatorname{Ir}\left(\mathrm{N}_{2}\right)_{2}$, the symmetric $\mathrm{N}-\mathrm{N}$ stretching mode is IR active. However, this band is not observed in the experiment, probably because of its low intensity, which is calculated to be 50 times lower than that of the antisymmetric mode. In the $\operatorname{Ir}\left({ }^{14} \mathrm{~N}_{2}\right)\left({ }^{15} \mathrm{~N}_{2}\right)^{-}$isotopologue the intensity ratio of the symmetric and antisymmetric modes change to $1: 4$, and hence, the symmetric $\mathrm{N}-\mathrm{N}$ stretching combination can be observed at $2031 \mathrm{~cm}^{-1}$ in the neat $1: 1{ }^{14} \mathrm{~N}_{2} /$ ${ }^{15} \mathrm{~N}_{2}$ spectrum. Compared to the neutral complex the anion $\operatorname{Ir}(\mathrm{NN})_{2}^{-}$is $224 \mathrm{~kJ} \mathrm{~mol}^{-1}$ lower in energy at the DFT level of theory, which corresponds to the adiabatic electron affinity of $\operatorname{lr}\left(\mathrm{N}_{2}\right)_{2}$.

\section{IrNNIr}

Laser-ablated iridium atoms co-deposited with $10 \%{ }^{14} \mathrm{~N}_{2}$ in neon give raise to a band at $786.5 \mathrm{~cm}^{-1}$ which is unaffected by annealing to $12 \mathrm{~K}$ and vanishes after $10 \mathrm{~min}$ of irradiation with $\lambda=455 \mathrm{~nm}$ (Figure 4). The same response was observed for a band at $761.6 \mathrm{~cm}^{-1}$ under the same conditions using ${ }^{15} \mathrm{~N}_{2}$. The isotopic triplet observed at 786.5, 774.1 and $761.6 \mathrm{~cm}^{-1}$ in a 1:1 mixture of ${ }^{14} \mathrm{~N}_{2}$ and ${ }^{15} \mathrm{~N}_{2}$ indicates an Ir-N stretching mode involving two equivalent nitrogen atoms. The intensity pattern of $1: 2: 1$ suggests the presence of the isotopologue containing both isotopes, ${ }^{14} \mathrm{~N}$ and ${ }^{15} \mathrm{~N}$ Based on the very good agreement of the band positions, isotopic pattern and isotopic ratio of the antisymmetric Ir-N stretching mode obtained by our quantum-chemical calculations, the band was assigned to IrNNIr. This dimer could probably be formed by an oxidative coupling of two IrN molecules (Equation 1):

$2 \mathrm{IrN} \rightarrow \operatorname{IrNNIr} \quad \Delta H=-96 \mathrm{~kJ} \mathrm{~mol}^{-1}$

The observed isotopic ratios in solid neon and solid dinitrogen are 1.0327 and 1.0331, which are in very good agreement with the calculated DFT value of 1.0324. The calculated absorptions are 782, 769 and $757 \mathrm{~cm}^{-1}$ for the $1 \mathrm{Ir}^{14} \mathrm{~N}^{14} \mathrm{NIr}, \mathrm{Ir}^{14} \mathrm{~N}^{15} \mathrm{NIr}$ and $\mid r^{15} \mathrm{~N}^{15} \mathrm{NIr}$ isotopologues, respectively. The electronic ground state is found to be a triplet ${ }^{3} \Sigma_{\mathrm{u}}{ }^{+}$, with the two unpaired electrons located at each of the metal centers in degenerated molecular orbitals of $d_{x^{2}-y^{2}}$ and $d_{x y}$-character, reminiscent of the $\operatorname{Ir}\left(\mathrm{N}_{2}\right)$ complex. The $\mathrm{N}-\mathrm{N}$ stretching mode is IR inactive and calculated to be centered at $2081 \mathrm{~cm}^{-1}$ at the DFT level of theory.

\section{IrN}

A very weak band at $1102.8 \mathrm{~cm}^{-1}$ which was not observed in the initially formed solid ${ }^{14} \mathrm{~N}_{2}$ deposit but grew in upon annealing to $35 \mathrm{~K}$ and was destroyed by broadband irradiation, returned on subsequent annealing to $35 \mathrm{~K}$ (Figure 4). The corresponding absorption in ${ }^{14} \mathrm{~N}_{2}$ doped neon is blue-shifted to $1111.1 \mathrm{~cm}^{-1}$ and the ${ }^{15} \mathrm{~N}$ counterparts were found at 1076.4 and $1066.9 \mathrm{~cm}^{-1}$ in neon and ${ }^{15} \mathrm{~N}_{2}$, respectively, while no band due to a mixed ${ }^{14 / 15} \mathrm{~N}$ isotopologue occurred in experiments using a 1:1 mixture of ${ }^{14} \mathrm{~N}_{2}$ and ${ }^{15} \mathrm{~N}_{2}$ (Figure 5). The assignment of this band to IrN is supported by a previous Fourier transform emission spectroscopic study of Ram and Bernath, ${ }^{[15 a]}$ in which a ground-state fundamental Ir-N stretching frequency of $1113.6 \mathrm{~cm}^{-1}$ for ${ }^{193} \mathrm{Ir}^{14} \mathrm{~N}$ was reported, revealing reasonable matrix shifts of -2.5 and $-10.8 \mathrm{~cm}^{-1}$ for neon and solid dinitrogen. For the sake of completeness, DFT and CCSD(T) calculations were carried out and the results are listed in Table S1. The annealing behavior of IrN suggests a temperature induced mobility of $\mathrm{N}$ radicals reacting with iridium atoms to $\operatorname{IrN}(\Delta H=$ $-612 \mathrm{~kJ} \mathrm{~mol}^{-1}$ ).

\section{IrIrN}

An intense band at $1002.2 \mathrm{~cm}^{-1}$ in solid ${ }^{14} \mathrm{~N}_{2}$ matrices and their ${ }^{15} \mathrm{~N}$ counterparts at $970.7 \mathrm{~cm}^{-1}$ grow in upon annealing to $35 \mathrm{~K}$ and remains unaffected by broadband irradiation (Figure 4). The much weaker bands located at 1004.4 and $972.8 \mathrm{~cm}^{-1}$ in solid neon doped with $10 \% \mathrm{~N}_{2}$ depicted in Figure 3 show the same behavior and in experiments using a ${ }^{14} \mathrm{~N}_{2} /{ }^{15} \mathrm{~N}_{2}$ mixture no additional band due to a mixed ${ }^{14 / 15} \mathrm{~N}$ isotopologue occurred, suggesting an $\mathrm{I}-\mathrm{N}$ stretching mode with a single nitrogen atom involved. With IrN already assigned to a band centered about $100 \mathrm{~cm}^{-1}$ blue-shifted, the carrier of this unknown band could be $\operatorname{Ir}(\mathrm{N})\left(\mathrm{N}_{2}\right)$, a dinitrogen complex of IrN, or IrIrN. Calculations at the DFT level of theory predict a fairly strong $\mathrm{N} \equiv \mathrm{N}$ stretching mode for $\operatorname{Ir}(\mathrm{N})\left(\mathrm{N}_{2}\right)$ at $2110 \mathrm{~cm}^{-1}$, much higher than 
the $\mathrm{Ir} \equiv \mathrm{N}$ stretching mode at $1085 \mathrm{~cm}^{-1}$, however, no such $\mathrm{N} \equiv$ $\mathrm{N}$ band could be identified in the spectrum and hence, ruled out an assignment to $\operatorname{Ir}(\mathrm{N})\left(\mathrm{N}_{2}\right)$. On the other side, infrared absorptions computed at the DFT level of theory support the assignment of the band at 1004.4 in solid neon to IrlrN, with calculated harmonic frequencies of 1054 and $1021 \mathrm{~cm}^{-1}$ for $\operatorname{Irlr}^{14} \mathrm{~N}$ and $\operatorname{|r} \mid r^{15} \mathrm{~N}$, respectively, accounting for an isotopic ratio of 1.0323 , which is very close to the experimental ones of 1.0325 in solid dinitrogen and neon. In analogy to IrN, the observed behavior upon annealing suggests a formation by mobilizing nitrogen radicals which react with $\mid r_{2}$ units present in the matrix. This is further supported by a computed reaction enthalpy for the formation of IrIrN from $\mathrm{N}$ atoms and the iridium dimer obtained at the DFT level of theory of $\Delta H=$ $-508 \mathrm{~kJ} \mathrm{~mol}^{-1}$ (Table 4). The electronic ground state of the bent IrlrN structure in the $C_{\mathrm{s}}$ point group symmetry is a doublet ${ }^{2} \mathrm{~A}^{\prime}$ state.

$\operatorname{Ir}(\mathrm{N})_{2}$

A very weak band, located at $853.5 \mathrm{~cm}^{-1}$ in solid neon doped with $0.5 \%{ }^{14} \mathrm{~N}_{2}$ and unaffected by broadband irradiations, presents a doublet pattern in neon doped with $0.5 \%$ of a 1:1 mixture of ${ }^{14} \mathrm{~N}_{2}$ and ${ }^{15} \mathrm{~N}_{2}$ at 853.5 and $827.7 \mathrm{~cm}^{-1}$ (Figure 3). The picture changes when pure dinitrogen is used as matrix host: besides a slight blue-shift of these bands to 857.1 and $831.2 \mathrm{~cm}^{-1}$, an intermediate band at $842.6 \mathrm{~cm}^{-1}$ appears, yielding a triplet pattern with an intensity ratio of about 1:2:1 (Figure 5). The observed triplet pattern is consistent with the involvement of two equivalent nitrogen atoms in an antisymmetric Ir $-\mathrm{N}$ stretching mode, such as in iridium dinitride, $\operatorname{Ir}(\mathrm{N})_{2}$. This assignment is supported by the fact that the intermediate band belonging to the ${ }^{14} \mathrm{NIr}^{15} \mathrm{~N}$ isotopologue is red-shifted $1.6 \mathrm{~cm}^{-1}$ from the center, indicating a coupling between the symmetric and the anti-symmetric Ir-N stretching modes, which in the lower point group symmetry $C_{s}$ have the same $a^{\prime}$ symmetry. The different patterns observed in solid neon and pure dinitrogen matrices can be explained by different reaction mechanisms leading to $\operatorname{Ir}(\mathrm{N})_{2}$ : While a direct insertion of iridium atoms into a dinitrogen bond is proposed in nitrogen doped neon mixtures (Equation 2a), the reaction of IrN with $\mathrm{N}$ atoms preferentially occurred in solid dinitrogen matrices (Equation 2b).

$$
\begin{array}{ll}
\operatorname{Ir}+\mathrm{N}_{2} \rightarrow \operatorname{Ir}(\mathrm{N})_{2} & \Delta H=+20 \mathrm{~kJ} \mathrm{~mol}^{-1} \\
\operatorname{IrN}+\mathrm{N} \rightarrow \operatorname{Ir}(\mathrm{N})_{2} & \Delta H=-612 \mathrm{~kJ} \mathrm{~mol}^{-1}
\end{array}
$$

While the reaction enthalpy of the direct insertion is slightly positive on the DFT level of theory, the high temperature of laser ablated iridium atoms can overcome this barrier and cryogenic conditions prevent the spontaneous elimination of a $\mathrm{N}_{2}$ unit. In contrast to osmium, spontaneous insertion into the NN triple bond at cryogenic conditions is not observed..$^{[4]}$ Harmonic frequencies obtained by calculations on the DFT level of theory are in very good agreement, resulting in antisymmetric $b_{2}$ stretching frequencies of 869,853 and $842 \mathrm{~cm}^{-1}$ for $\operatorname{Ir}\left({ }^{14} \mathrm{~N}\right)_{2}$,
$\operatorname{Ir}\left({ }^{14} \mathrm{~N}\right)\left({ }^{15} \mathrm{~N}\right)$ and $\operatorname{Ir}\left({ }^{15} \mathrm{~N}\right)_{2}$. The symmetric $\mathrm{a}_{1} \operatorname{Ir}-{ }^{14} \mathrm{~N}$ stretching mode was not observed and calculated to be located at $1027 \mathrm{~cm}^{-1}$ having an intensity less than $4 \%$ of the antisymmetric one. From the band positions of the antisymmetric stretching modes in the isotope substitution experiment an estimate of the upper limit of the N-Ir-N bond angle can be estimated to $130^{\circ},{ }^{[34]}$ which is in agreement with the calculated angle of $112^{\circ}$ for the $C_{2 v}\left({ }^{2} B_{1}\right)$ electronic ground state geometry.

\section{$\operatorname{Ir}(\mathrm{N})_{3}$}

No band could be assigned to iridium trinitride, although we observed nitrogen atom mobility in the formation of $\operatorname{Ir}(\mathrm{N})_{2}$, and the third addition of a nitrogen atom was calculated to be exothermic $\left(\Delta H=-243 \mathrm{~kJ} \mathrm{~mol}^{-1}\right.$, Table 4). However, Table S1 shows that the integrated intensity of the IR active Ir-N stretching absorption in the observable region, the degenerate $\mathrm{e}^{\prime}$ mode, is calculated to be $1.4 \mathrm{~km} \mathrm{~mol}^{-1}$, which is about $3 \%$ of the calculated integrated intensity of the corresponding very weak band assigned to $\operatorname{Ir}(\mathrm{N})_{2}$. The amount of iridium trinitride formed according to that mechanism would certainly be very low.

\section{Bonding considerations}

\section{Dinitrogen complexes of iridium}

The nature of the metal nitrogen bond in selected product molecules and in $\operatorname{Ir}(\mathrm{N})_{3}$ will be discussed in terms of the relevant vibrational stretching modes as well as by analysis of the wavefunctions obtained at the BP86/def2-QZVP level of theory. The coordination chemistry of the dinitrogen molecule is limited because it is a comparatively poor $\sigma$-donor, weak $\pi$-acceptor and its lack of dipole moment. ${ }^{[35]}$ The $\pi$-donation of the iridium center into the $\pi^{*}$ molecular orbitals of the dinitrogen unit results in a weakening, or activation of the dinitrogen triple bond. The weakening of the $\mathrm{N}-\mathrm{N}$ bond in dinitrogen complexes can be quantified experimentally by the red-shift of the $\mathrm{N}-\mathrm{N}$ stretching mode in the IR spectrum, comparing the $\mathrm{N}-\mathrm{N}$ bond distances and, theoretically, by extracting information from the wavefunction. Several neutral PGM dinitrogen complexes have previously been studied by matrix isolation spectroscopy. ${ }^{[4]}$ Their experimental $\mathrm{N}-\mathrm{N}$ stretching frequencies embedded in argon are given in Table S2 and provide a solid basis for discussing the nature of bonding in such homoleptic dinitrogen complexes. The red-shift of the $\mathrm{N}-\mathrm{N}$ stretching mode of $\operatorname{Ir}\left(\mathrm{N}_{2}\right)$ relative to that in free dinitrogen (2327.1 $\mathrm{cm}^{-1}$, Table 3) is $240.3 \mathrm{~cm}^{-1}$, which is less than the one for the group 8 metal dinitride $\mathrm{Os}\left(\mathrm{N}_{2}\right)$ and greater than that for the group 10 analogue $\operatorname{Pt}\left(\mathrm{N}_{2}\right)$. This trend is consistent with a decreasing ability of late transition metals to donate electron density into the $\pi^{*}$ orbitals of the coordinated $\mathrm{N}_{2}$ moiety due to less MO overlap caused by larger bond distances and decreasing $d$-orbital energies. The same trend is observed with the corresponding first row transition metals. ${ }^{[1]]}$

The electron density at the bond critical point $\left(\rho_{\mathrm{b}}\right)$ in a molecule can be taken as measure of the character of a bond and its bond order. ${ }^{[36]}$ The data presented in Table S3 shows a sig- 
nificant decrease of $\rho_{\mathrm{b}}(\mathrm{NN})$ going from $\operatorname{Ir}\left(\mathrm{N}_{2}\right)$ (0.622) over $\operatorname{Ir}\left(\mathrm{N}_{2}\right)_{2}$ (0.592) down to IrNNIr (0.579), indicating a weakening of the corresponding $\mathrm{N}-\mathrm{N}$ bond of the dinitrogen ligand within this series. This is also evident in the minimum structures shown in Figure 6, where the longest $\mathrm{N}-\mathrm{N}$ bond lengths within this series of $115 \mathrm{pm}$ is exhibited in the binuclear complex IrNNIr. In contrast to the electron density at the bond critical point $\left(\rho_{\mathrm{b}}\right)$, which seems to be mainly affected by $\sigma$ donation from the $\mathrm{N}_{2}$ ligand to the iridium center, the slightly longer $\mathrm{N}-\mathrm{N}$ bond length in $\operatorname{Ir}\left(\mathrm{N}_{2}\right)$ (113 pm) compared to $\operatorname{Ir}\left(\mathrm{N}_{2}\right)_{2}(112 \mathrm{pm})$, is consistent with an increasing experimental $\mathrm{N}-\mathrm{N}$ stretching frequency from $\operatorname{Ir}\left(\mathrm{N}_{2}\right)\left(2087.6 \mathrm{~cm}^{-1}\right)$ to $\operatorname{Ir}\left(\mathrm{N}_{2}\right)_{2}\left(2144.7 \mathrm{~cm}^{-1}\right)$, and can most likely be rationalized by a stronger $\pi$ backdonation from the iridium center to the $\mathrm{N}_{2}$ ligand bonding in the $\operatorname{Ir}\left(\mathrm{N}_{2}\right)$ complex. Weakly activated $\mathrm{N}-\mathrm{N}$ bond lengths are typically less than $112 \mathrm{pm},{ }^{[35]}$ placing $\operatorname{Ir}\left(\mathrm{N}_{2}\right)$ and $\operatorname{Ir}\left(\mathrm{N}_{2}\right)_{2}$ at the upper end of the scale for what is considered weakly activated. The slightly stronger $\mathrm{N}_{2}$ activation in $\operatorname{Ir}\left(\mathrm{N}_{2}\right)$ compared to $\operatorname{Ir}\left(\mathrm{N}_{2}\right)_{2}$ is also supported by an NBO analysis, which results in NPA bond orders for the $\mathrm{N}-\mathrm{N}$ bonds in $\operatorname{Ir}\left(\mathrm{N}_{2}\right), \operatorname{Ir}\left(\mathrm{N}_{2}\right)_{2}$, and IrNNIr of 2.56, 2.64 and 2.51, respectively, as well as by the shorter calculated Ir-N bond distance in $\operatorname{Ir}\left(\mathrm{N}_{2}\right)$ of $179 \mathrm{pm}$ compared to $190 \mathrm{pm}$ in $\operatorname{Ir}\left(\mathrm{N}_{2}\right)_{2}$ (Table S3).

Comparing the $\mathrm{N}-\mathrm{N}$ stretching modes of the ions $\left[\operatorname{Ir}\left(\mathrm{N}_{2}\right)\right]^{+}$ and $\left[\operatorname{lr}\left(\mathrm{N}_{2}\right)_{2}\right]^{-}$with those of their neutral counterparts, a blueshift for the cation and a red-shift for the anion is observed, which is consistent with the calculated changes in the corresponding $\mathrm{N}-\mathrm{N}$ bond lengths (Table S3, Figure 6) and with the notion that oxidation of the metal center leads to a lower ability of $\pi$-back-donation, while reduction leads to an increase. ${ }^{[2 c]}$ In both cases, the addition or subtraction of an electron does not change the occupation number of the $\pi$-system, but leads to an oxidation or reduction of the iridium center. Compared to a shift for the $\mathrm{C}-\mathrm{O}$ stretching frequency in $\operatorname{Ir}(\mathrm{CO})^{+}$and $\operatorname{Ir}(\mathrm{CO})_{2}{ }^{-}$with respect to neutral $\operatorname{Ir}(\mathrm{CO})$ of +132 and $-29 \mathrm{~cm}^{-1}$, respectively, ${ }^{[37]}$ the frequency shift for the isoelectronic dinitrogen complexes is with +170 and $-198 \mathrm{~cm}^{-1}$ significantly larger. The higher sensitivity of the $\mathrm{N}-\mathrm{N}$ stretching frequency upon oxidation or reduction of the metal center compared to the $\mathrm{C}-\mathrm{O}$ frequency is another indication for the importance of $\pi$-back-bonding as the most significant contribution to the Ir$\mathrm{N}$ bond strength. ${ }^{[2]}$ On the other side, the red-shift of the $\mathrm{N}-\mathrm{N}$ and $\mathrm{C}-\mathrm{O}$ stretching frequencies in the neutral $\operatorname{Ir}\left(\mathrm{N}_{2}\right)$ and $\operatorname{Ir}(\mathrm{CO})$ complexes with respect to the free ligands is with $170 \mathrm{~cm}^{-1}$ (9.8\%) higher in $\operatorname{Ir}\left(\mathrm{N}_{2}\right)$ compared to $132 \mathrm{~cm}^{-1}(5.4 \%)$ in $\operatorname{Ir}(\mathrm{CO})$. As pointed out by Pelikán and Boča, ${ }^{[2]}$ the larger red-shift for the $\mathrm{N}-\mathrm{N}$ stretch does not indicate a stronger $\pi$-back-donation in the $\operatorname{Ir}\left(\mathrm{N}_{2}\right)$ complex, since both interactions, $\sigma$-donation and $\pi$-acceptance lead to a weakening of the $\mathrm{N}-\mathrm{N}$ bond, while in the $\operatorname{Ir}(\mathrm{CO})$ complex $\sigma$-donation leads to an increase and $\pi$ back-donation to a decrease in the $\mathrm{C}-\mathrm{O}$ bond strength. Taking the better $\sigma$-donor ability of $\mathrm{CO}$ compared to $\mathrm{NN}$ into account $^{[38]} \mathrm{CO}$ must be considered a stronger $\pi$-acceptor than the $\mathrm{N}_{2}$ ligand.

In Figure 7 the frontier molecular orbitals of the $\pi$-system are shown for the neutral, linear dinitrogen complexes $\operatorname{Ir}\left(\mathrm{N}_{2}\right)$, $\operatorname{Ir}\left(\mathrm{N}_{2}\right)_{2}$, and IrNNIr. Each of them is comprised of the degenerate

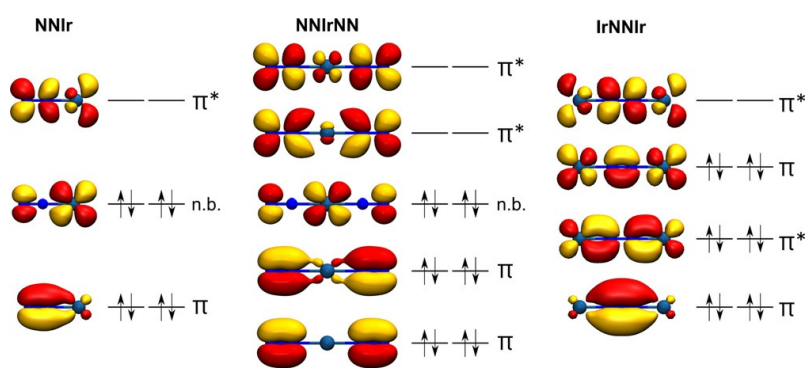

Figure 7. $\operatorname{Ir}\left(\mathrm{N}_{2}\right)$, IrNNIr and $\operatorname{Ir}\left(\mathrm{N}_{2}\right)_{2}$ Kohn-Sham molecular orbitals of their $\pi$ system with an iso surface value of $0.04 \AA^{-1}$ obtained at the BP86/def2QZVP level of theory.

$2 p_{y}$ and $2 p_{z}$ atomic orbitals of the nitrogen atoms and the $3 d_{x y}$ and $3 d_{x z}$ atomic orbitals of the iridium atoms involved. For IrNNIr with $12 \pi$-electrons the first three of four pairs of the molecular $\pi$-orbitals are fully occupied (Figure 7 , right). The first pair essentially forms the $\pi$-bonds of the $N N$ unit, the second pair contains the corresponding $\mathrm{N}-\mathrm{N}$ anti-bonding molecular orbitals of the first set, and the third pair of the $\pi$-bonding orbitals are $\mathrm{Ir}-\mathrm{N}$ anti-bonding and $\mathrm{N}-\mathrm{N}$ bonding. The electronic ground state of ${ }^{3} \Sigma_{\mathrm{u}}{ }^{+}$arises from two unpaired electrons residing in non-bonding molecular orbitals, essentially formed by the non-bonding iridium $3 \mathrm{~d}_{\mathrm{yz}}$ atomic orbitals (not shown in Figure 7). From isotopic triplet observed in a 1:1 mixture of ${ }^{14} \mathrm{~N}_{2}$ and ${ }^{15} \mathrm{~N}_{2}$ for the Ir-N stretching vibration in the IR spectrum it has been concluded that IrNNIr is likely formed during matrix deposition by the coupling of two IrN units. A very similar behavior was reported for the $\left[\mathrm{N}_{2}\{\operatorname{lr}(\mathrm{PNP})\}_{2}\right] \quad(\mathrm{PNP}=$ $\left.\mathrm{N}(\mathrm{CHCHPtBu})_{2}\right)$ pincer complex, holding the same 12 electron IrNNIr $\pi$-system, which was observed to be formed in solution at room temperature by coupling of two terminal [IrN(PNP)] nitrido complexes. ${ }^{[1]]}$ This coupling reaction can be viewed as the reverse of splitting a bridging dinitrogen ligand into separate nitrido complexes, which recently was investigated for $[\mathrm{NIr}(\mathrm{PNP})]_{2}{ }^{n+}(n=0,1,2){ }^{[39]}$ For these complexes reaction enthalpies of the coupling reaction of $2[\mathrm{~N} \operatorname{lr}(\mathrm{PNP})]^{n+}$, with $2 n=0$, 1 , and 2, are exotherm and calculated to $\Delta H=-510,-425$ and $-382 \mathrm{~kJ} \mathrm{~mol}^{-1}$ (D3BJ-PBE0(Cosmo (THF))/def2-TZVP//D3BJ$\mathrm{PBE}$ /def2-SVP) respectively. ${ }^{[39]}$ In contrast to these results coupling of two IrN complexes, bare of any additional ligands and under solvent-free conditions in an argon matrix, is significantly less exothermic with $\Delta H=-96 \mathrm{~kJ} \mathrm{~mol}^{-1}$. The lower reaction enthalpy for the latter coupling reaction can be explained by the formation of two strong triple bonds in the $\mathrm{Ir} \equiv \mathrm{N}$ units.

\section{Nitrido complexes of iridium}

The diatomic iridium nitride, IrN, was investigated extensively using emission ${ }^{[14,15 a, b]}$ and optical Zeeman ${ }^{[15 e]}$ spectroscopy as well as high level ab initio methods. ${ }^{[15 b]}$ It has a closed shell ${ }^{1} \Sigma^{+}$ground state comprising an $\operatorname{Ir} \equiv \mathrm{N}$ triple bond. Our AIM analysis assign charges of 0.278 to iridium and -0.278 to nitrogen (Table S3), while NBO analysis shows NPA charges of -0.032 and 0.032 for iridium and nitrogen, respectively, and 
an NPA bond order of 2.82. The NPA charge close to zero and the low AIM charges imply that the bond nature is mostly covalent.

The calculated Ir-N bond lengths of iridium dinitride, $\operatorname{Ir}(\mathrm{N})_{2}$, in its ${ }^{2} B_{1}$ electronic ground state of $170 \mathrm{pm}$ is considerably larger than the expected ones for a triple bond judged on the calculated bond lengths in iridium mononitride of $160 \mathrm{pm}$, which also corresponds well to the sum of the triple-bond covalent radii of iridium and nitrogen of $160 \mathrm{pm} \cdot{ }^{[40]}$ From the sum of reported double- ${ }^{[41]}$ and triple-bond covalent radii of iridium and nitrogen of 160 and $175 \mathrm{pm}$, respectively, the bond order in $\operatorname{Ir}(\mathrm{N})_{2}$ can be estimated to be between a triple and a double bond, while the computed NPA bond order is 2.06. The NPA (AIM) charges are significantly higher compared to diatomic $\mathrm{Ir} \equiv \mathrm{N}$, amounting to $0.588(0.896)$ and $-0.294(-0.448)$ for iridium and nitrogen, respectively. The higher charges and lower covalent bond order of the dinitride compared to the mononitride suggest an $\mathrm{I}=\mathrm{N}$ double bond in the former one, which is shortened due to a higher ionic character. The valence molecular orbitals and occupation numbers obtained from SACASSCF $(15,12)$ /cc-pVTZ(-PP) calculations (for details see Computational Details) for the ${ }^{2} \mathrm{~B}_{1}$ electronic ground state are depicted in Figure S4. These calculations reveal a lone pair $\left(5 a_{1}\right)$ at the iridium center, two $\sigma$-bonding orbitals $\left(6 a_{1}\right.$ and $\left.4 b_{2}\right)$, two $\pi$-bonding orbitals $\left(2 b_{1}\right.$ and $\left.1 a_{2}\right)$, and their anti-bonding $\sigma^{*}$ $\left(8 a_{1}\right.$ and $\left.6 b_{2}\right)$ and $\pi^{*}$ counterparts $\left(3 b_{1}\right.$ and $\left.2 a_{2}\right)$. We note that one unpaired electron resides in the $3 b_{1} \pi^{*}$ orbital. Additionally, two essentially doubly occupied non-bonding orbitals ( $7 \mathrm{a}_{1}$ and $5 b_{2}$ ) remain at the nitrogen ligands, and finally, there is a high-lying, low-occupied non-bonding orbital $\left(9 a_{1}\right)$ with contributions from the $\operatorname{Ir}(6 s), \operatorname{Ir}\left(5 \mathrm{~d}_{\left.\mathrm{x}^{2}-\mathrm{y}^{2}\right)}\right), \operatorname{Ir}\left(6 \mathrm{p}_{z}\right)$ and $N\left(2 \mathrm{p}_{z}\right)$ atomic orbitals (Figure S4). An effective bond order (EBO) of 1.56 can be estimated for the Ir-N bond by counting the occupation numbers of the bonding- and anti-bonding molecular orbitals, neglecting the slightly bonding characters of the nonbonding orbitals $7 a_{1}$ and $5 b_{2}$. For the ${ }^{2} B_{1}$ electronic ground state the presence of nitrogen-centered unpaired electrons can be ruled out, however, an estimation of low-lying electronic states using SA$\operatorname{CASSCF}(15,12) / c c-p V T Z(-P P)$ calculations show that the lowest lying quartet state is $84 \mathrm{~kJ} \mathrm{~mol}^{-1}$ and the lowest lying sextet state $252 \mathrm{~kJ} \mathrm{~mol}^{-1}$ higher in energy than the electronic ground state (Figure $\mathrm{S} 5$ and Table S4). The most dominant configuration of the electronic ground state is $a_{1}{ }^{6} b_{1}{ }^{3} b_{2}{ }^{4} a_{2}{ }^{2}$ with a weight of $0.86(74 \%)$. Other contributions are small and distributed over the whole expansion space. This electron configuration can be described by the resonance Lewis structure shown in Scheme 1, in which an integral formal oxidation state cannot be assigned to the iridium center a priori.

If we resort to MO theory and wavefunction analysis, spin populations can give insight into which extend the unpaired electron is localized either on iridium, or at the nitrido ligands. Mulliken and Loewdin population analysis yield spin populations of 0.40 and 0.47 at the iridium center, which means the ligands do not allow the definition of a clear-cut integral oxidation state. The formal oxidation state lies between $+\mathrm{V}$ and $+\mathrm{VI}$, with slightly more weight on the side of $+\mathrm{V}$. The nitrido ligands must be considered as non-innocent. ${ }^{[42]}$

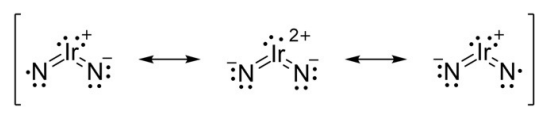

Scheme 1. Lewis structure for the homoleptic diinitrido iridium.

Iridium trinitride is an intriguing compound since iridium would formally be considered in the oxidation state +IX, which so far was experimentally realized only for the cation $\left[\mathrm{IrO}_{4}\right]^{+}$, and more recently claimed for the experimentally unknown nitrido compound $\mathrm{NIrO}_{3}$. Another candidate for the oxidation state $+\mathrm{IX}$ could be $\operatorname{Ir}(\mathrm{N})_{3}$, provided that all $5 \mathrm{~d}$ electrons from the valence shell of iridium can be formally assigned to the nitrogen ligands and no lone pair remains on the iridium atom. We have investigated $\operatorname{Ir}(\mathrm{N})_{3}$ at the BP86/def2-QZVP level of theory and found a regular $D_{3 h}$ structure with an Ir-N bond length of $176 \mathrm{pm}$ in the ${ }^{1} \mathrm{~A}_{1}{ }^{\prime}$ ground electronic state (Figure 6). We have further analyzed the occupied molecular orbitals at the R-BP86/ZORA-def2-TZVPP(N)/SARC-ZORA-TZVPP(Ir) level of theory and depicted the valence molecular orbitals in Figure S6. These calculation reveals a degenerate pair of $\sigma$-bonding orbitals (4e') as well as a degenerate pair of $\pi$-bonding orbitals $\left(1 \mathrm{e}^{\prime \prime}\right)$. In addition, seven ligand-centered lone pairs $\left(4 \mathrm{a}_{1}{ }^{\prime}\right.$, $2 \mathrm{a}_{2}{ }^{\prime \prime}, 2 \times 5 \mathrm{e}^{\prime}, \mathrm{MO}^{\prime} \mathrm{s}$ arising from the $\mathrm{N}(2 \mathrm{~s})$ orbitals are not shown in Figure S6) can be assigned and a metal centered d-orbital is attributed to the highest occupied $\mathrm{MO}\left(\mathrm{HOMO}, 5 \mathrm{a}_{1}{ }^{\prime}\right)$. We note that the lowest unoccupied MO (LUMO, $1 \mathrm{a}_{2}{ }^{\prime}$ ) is a nonbonding ligand-centered MO. Thus, our analysis shows that the nitrido ligands in $\operatorname{Ir}(\mathrm{N})_{3}$ behave as non-innocent ligands as well, ${ }^{[42]}$ meaning that an essentially non-bonding iridium $\left(\mathrm{d}_{z^{2}}\right)$ orbital $\left(5 \mathrm{a}_{1}{ }^{\prime}\right)$ is filled by two electrons at the expense of a ligand delocalized nonbonding LUMO $\left(1 \mathrm{a}_{2}{ }^{\prime}\right)$. This bonding situation, which is consistent with a formal oxidation state of $+\mathrm{VII}$ rather than $+\mathrm{IX}$ for the iridium atom in $\operatorname{Ir}(\mathrm{N})_{3}$, can be approximately described by the resonance Lewis structures shown in Scheme 2 .

This electronic description is supported by the calculated AIM and NPA charges shown in Table S3. While the nitrogen atoms in $\operatorname{Ir}(\mathrm{N})_{3}$ adopt a charge, which is very close to the one found in $\operatorname{Ir}(\mathrm{N})_{2}$, the charge at the iridium center raised to about $3 / 2$ of those in $\operatorname{Ir}(\mathrm{N})_{2}$.

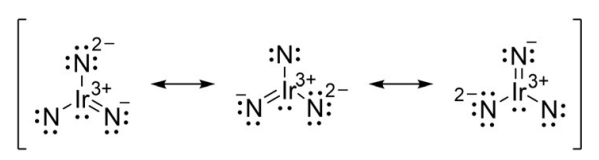

Scheme 2. Lewis resonance structure for the homoleptic trinitrido iridium(VII) complex $\operatorname{Ir}(\mathrm{N})_{3}$.

The most favored decomposition pathway for doublet $\operatorname{Ir}(\mathrm{N})_{2}$ and singlet $\operatorname{Ir}(\mathrm{N})_{3}$ is found to be the elimination of dinitrogen, which is exothermic by $\Delta H=-20$ and $-388 \mathrm{~kJ} \mathrm{~mol}^{-1}$ for $\operatorname{Ir}(\mathrm{N})_{2}$ and $\operatorname{Ir}(\mathrm{N})_{3}$, respectively. According to our all-electron R-BP86/ ZORA-def2-TZVPP(N)/SARC-ZORA-TZVPP(Ir) calculation the lowest energy pathway for dinitrogen elimination proceed by cleavage of an $\mathrm{I}-\mathrm{N}$ bond and formation a dinitrogen complex (Figure 8). The nitrido complexes are separated from their dini- 

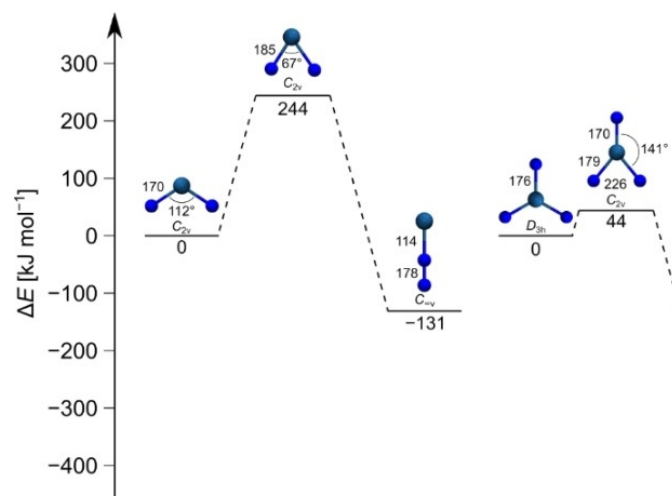

Figure 8. Stationary points on the doublet (singlet) potential energy surface of the decomposition pathways of $\operatorname{Ir}(\mathrm{N})_{2}\left(\operatorname{Ir}(\mathrm{N})_{3}\right)$ leading to elimination and complexation of $\mathrm{N}_{2}$ calculated at the BP86/ZORA-def2-TZVPP(N)/SARC-ZORATZVPP(Ir) level of theory.

trogen coordinated isomers by a barrier of 244 and $44 \mathrm{~kJ} \mathrm{~mol}^{-1}$ for $\operatorname{Ir}(\mathrm{N})_{2}$ and $\operatorname{Ir}(\mathrm{N})_{3}$, respectively. The corresponding transition states on the quartet and triplet surfaces of $\operatorname{Ir}(\mathrm{N})_{2}$ and $\operatorname{Ir}(\mathrm{N})_{3}$, respectively, have also been investigated, and found to be higher in energy with 257 and $114 \mathrm{~kJ} \mathrm{~mol}^{-1}$ above the respective minimum structures. According to these results the kinetic stability with respect to dinitrogen elimination of $\operatorname{lr}(\mathrm{N})_{3}$ is rather low, while $\operatorname{Ir}(\mathrm{N})_{2}$ is kinetically stable and the isomeric dinitrogen complex $\operatorname{Ir}\left(\mathrm{N}_{2}\right)$ has indeed been detected in the present study.

\section{Conclusions}

Laser-ablated iridium atoms were allowed to react with dinitrogen and nitrogen atoms formed from $\mathrm{N}_{2}$ molecules by plasma radiation and the products were isolated in solid neon, argon and nitrogen matrices and identified by their infrared spectra. The assignments are supported by ab initio and first principle calculations as well as ${ }^{14 / 15} \mathrm{~N}$ isotope substitution experiments. The neutral and ionic iridium dinitrogen complexes $\operatorname{Ir}\left(\mathrm{N}_{2}\right)$, $\operatorname{Ir}\left(\mathrm{N}_{2}\right)^{+}, \operatorname{Ir}\left(\mathrm{N}_{2}\right)_{2}, \operatorname{Ir}\left(\mathrm{N}_{2}\right)_{2}{ }^{-}, \operatorname{IrNN} I r$ were formed and assigned by their characteristic $\mathrm{N}-\mathrm{N}$ stretching frequencies at 2097.4, $2270.3,2154.0,1956.4$ and $786.5 \mathrm{~cm}^{-1}$, respectively. In addition, the nitrido complexes $\operatorname{IrN}, \operatorname{Ir}(\mathrm{N})_{2}$ and $\operatorname{Ir} \mid \mathrm{rN}$ were observed and assigned to $\mathrm{Ir}-\mathrm{N}$ stretching bands centered at 1111.1, 853.5 and $1004.4 \mathrm{~cm}^{-1}$, respectively. While $\operatorname{Ir}(\mathrm{N})_{2}$ can be formed by a photo-rearrangement of the corresponding dinitrogen complex $\operatorname{Ir}\left(\mathrm{N}_{2}\right)$ or from $\mathrm{N}$ atoms and $\operatorname{IrN}$, the latter process was deduced from ${ }^{14 / 15} \mathrm{~N}$ isotopic experiments. The threefold coordinated iridium trinitride complex $\operatorname{Ir}(\mathrm{N})_{3}$ was not be observed. The structural and electronic properties of the dinitrogen ligand in the $\mathrm{N}_{2}$ complexes are discussed with respect to dinitrogen activation upon complexation. The largest dinitrogen activation was observed in the neutral, linear binuclear IrNNIr complex and in the anionic $\operatorname{Ir}\left(\mathrm{N}_{2}\right)_{2}{ }^{-}$. Also, the electronic structures of the nitrido complexes $\operatorname{Ir}(\mathrm{N})_{2}$ and $\operatorname{Ir}(\mathrm{N})_{3}$ were investigated by DFT and ab initio calculations. The dinitride $\operatorname{Ir}(\mathrm{N})_{2}$ adopts a bent structure in a ${ }^{2} \mathrm{~B}_{1}$ electronic ground state with one unpaired electron in a delocalized $\pi^{*}$ molecular orbital $\left(3 b_{1}\right)$ and an additional lone pair on the iridium center. $\operatorname{Ir}(\mathrm{N})_{3}$ has a $D_{3 h}$ structure in the lowest energy electronic state in which a lone pair can be attributed to a nonbonding iridium centered $5 d_{z} 2$ orbital $\left(5 \mathrm{a}_{1}{ }^{\prime}\right)$ and a formal oxidation state for iridium of $+\mathrm{VII}$ rather than + IX can be deduced. The lowest energy decomposition pathway of these nitrido complexes has been found computationally to proceed via a rearrangement to the isomeric dinitrogen complexes.

\section{Acknowledgements}

Computing resources and support were granted by the Zentraleinrichtung für Datenverarbeitung (ZEDAT) of the Freie Universität Berlin. Furthermore, we thank the DFG (HA 5639/10) for financial support.

\section{Conflict of interest}

The authors declare no conflict of interest.

Keywords: density functional calculations - high oxidation states $\cdot$ matrix isolation $\cdot$ nitrogen fixation $\cdot$ transition metals

[1] a) H.-J. Himmel, M. Reiher, Angew. Chem. Int. Ed. 2006, 45, 6264-6288; Angew. Chem. 2006, 118, 6412-6437; b) Ł. Wolański, M. Domański, W. Grochala, P. Szarek, Chem. Eur. J. 2019, 25, 10290-10293; c) M. G. Scheibel, B. Askevold, F. W. Heinemann, E. J. Reijerse, B. de Bruin, S. Schneider, Nat. Chem. 2012, 4, 552-558.

[2] a) A. D. Allen, C. V. Senoff, Chem. Commun. (London) 1965, 621; b) J. P. Collman, M. Kubota, F. D. Vastine, J. Y. Sun, J. W. Kang, J. Am. Chem. Soc. 1968, 90, 5430-5437; c) P. Pelikán, R. Boča, Coord. Chem. Rev. 1984, 55, $55-112$.

[3] M.-A. Légaré, G. Bélanger-Chabot, R. D. Dewhurst, E. Welz, I. Krummenacher, B. Engels, H. Braunschweig, Science 2018, 359, 896-900.

[4] a) A. Citra, L. Andrews, J. Am. Chem. Soc. 1999, 121, 11567-11568; b) A. Citra, L. Andrews, J. Phys. Chem. A 2000, 104, 1152-1161.

[5] a) G. A. Ozin, A. V. Voet, Can. J. Chem. 1973, 51, 3332-3343; b) A. Citra, L. Andrews, J. Phys. Chem. A 1999, 103, 3410-3417; c) X. Wang, L. Andrews, J. Phys. Chem. A 2002, 106, 2457-2464.

[6] a) H. Huber, E. P. Kuendig, M. Moskovits, G. A. Ozin, J. Am. Chem. Soc. 1973, 95, 332-344; b) W. Klotzbuecher, G. A. Ozin, J. Am. Chem. Soc. 1975, 97, 2672-2675; c) W. Schrittenlacher, W. Schroeder, H. H. Rotermund, H. Wiggenhauser, R. Grinter, D. M. Kolb, J. Chem. Phys. 1986, 85, $1348-1354$; d) G. A. Ozin, J. G. Prieto, J. Phys. Chem. 1988, 92, 325-337.

[7] M. Zhou, L. Andrews, J. Phys. Chem. A 1998, 102, $9061-9071$.

[8] a) D. W. Green, J. Thomas, D. M. Gruen, J. Chem. Phys. 1973, 58, 5453 5463 ; b) E. P. Kündig, M. Moskovits, G. A. Ozin, Can. J. Chem. 1973, 51, 2710-2721; c) A. Citra, X. Wang, W. D. Bare, L. Andrews, J. Phys. Chem. A 2001, 105, 7799-7811.

[9] X. Wang, L. Andrews, R. Lindh, V. Veryazov, B. O. Roos, J. Phys. Chem. A 2008, 112, 8030-8037.

[10] a) C. K. Jørgensen, Oxidation Numbers and Oxidation States, Springer, New York, 1969; b) S. Riedel, M. Kaupp, Coord. Chem. Rev. 2009, 253, $606-624$; c) S. X. Hu, W. L. Li, J. B. Lu, J. L. Bao, H. S. Yu, D. G. Truhlar, J. K. Gibson, J. Marçalo, M. Zhou, S. Riedel, W. H. E. Schwarz, J. Li, Angew. Chem. Int. Ed. 2018, 57, 3242-3245; Angew. Chem. 2018, 130, $3297-$ 3300 .

[11] G. Wang, M. Zhou, J. T. Goettel, G. J. Schrobilgen, J. Su, J. Li, T. Schlöder, S. Riedel, Nature 2014, 514, 475-477.

[12] D. Himmel, C. Knapp, M. Patzschke, S. Riedel, ChemPhysChem 2010, 11, $865-869$.

[13] a) H. C. Mattraw, N. J. Hawkins, D. R. Carpenter, W. W. Sabol, J. Chem. Phys. 1955, 23, 985-986; b) A. Citra, L. Andrews, J. Phys. Chem. A 1999, 
103, 4182-4190; c) Y. Gong, M. Zhou, M. Kaupp, S. Riedel, Angew. Chem. Int. Ed. 2009, 48, 7879-7883; Angew. Chem. 2009, 121, 8019-8023.

[14] A. J. Marr, M. E. Flores, T. C. Steimle, J. Chem. Phys. 1996, 104, $8183-$ 8196.

[15] a) R. S. Ram, P. F. Bernath, J. Mol. Spectrosc. 1999, 193, 363-375; b) R. S. Ram, J. Liévin, P. F. Bernath, J. Mol. Spectrosc. 1999, 197, 133-146; c) B. Hong, L. Cheng, M. Y. Wang, Z. J. Wu, Mol. Phys. 2010, 108, 25-33 d) H. F. Pang, A. S. C. Cheung, Chin. J. Chem. Phys. 2009, 22, 157-161; e) T. C. Steimle, A. J. Marr, S. A. Beaton, J. M. Brown, J. Chem. Phys. 1997, 106, 2073-2077.

[16] a) R. Yu, Q. Zhan, L. C. de Jonghe, Angew. Chem. Int. Ed. 2007, 46, $1136-$ 1140; Angew. Chem. 2007, 119, 1154-1158; b) R. Yu, X. F. Zhang, Phys. Rev. B 2005, 72, 054103; c) Z.-j. Wu, E.-j. Zhao, H.-p. Xiang, X.-f. Hao, X.-j. Liu, J. Meng, Phys. Rev. B 2007, 76, 054115.

[17] a) J. C. Crowhurst, A. F. Goncharov, B. Sadigh, C. L. Evans, P. G. Morrall, J. L. Ferreira, A. J. Nelson, Science 2006, 311, 1275-1278; b) A. F. Young, C. Sanloup, E. Gregoryanz, S. Scandolo, R. J. Hemley, H.-k. Mao, Phys. Rev. Lett. 2006, 96, 155501.

[18] M. Wessel, R. Dronskowski, J. Am. Chem. Soc. 2010, 132, 2421 -2429.

[19] TURBOMOLE GmbH, TURBOMOLE V7.0.1, 2015.

[20] a) A. D. Becke, Phys. Rev. A 1988, 38, 3098-3100; b) J. P. Perdew, Phys. Rev. $B$ 1986, 33, 8822-8824.

[21] a) F. Weigend, F. Furche, R. Ahlrichs, J. Chem. Phys. 2003, 119, $12753-$ 12762; b) F. Weigend, R. Ahlrichs, Phys. Chem. Chem. Phys. 2005, 7, $3297-3305$.

[22] D. Andrae, U. Huermann, M. Dolg, H. Stoll, H. Preu, Theor. Chim. Acta 1990, 77, 123-141.

[23] R. A. Kendall, T. H. Dunning, R. J. Harrison, J. Chem. Phys. 1992, 96, 6796-6806.

[24] D. Figgen, K. A. Peterson, M. Dolg, H. Stoll, J. Chem. Phys. 2009, 130, 164108.

[25] J. F. Stanton, J. Gauss, L. Cheng, M. E. Harding, D. A. Matthews, P. G. Szalay, CFOUR, Coupled-Cluster techniques for Computational Chemistry, a quantum-chemical program package.

[26] T. H. Dunning, J. Chem. Phys. 1989, 90, 1007-1023.

[27] H.-J. Werner, P. J. Knowles, G. Knizia, F. R. Manby, M. Schütz, P. Celani, W. Györffy, D. Kats, T. Korona, R. Lindh, A. Mitrushenkov, G. Rauhut, K. R. Shamasundar, T. B. Adler, R. D. Amos, S. J. Bennie, A. Bernhardsson, A.
Berning, D. L. Cooper, M. J. O. Deegan, A. J. Dobbyn, F. Eckert, E. Goll, C. Hampel, A. Hesselmann, G. Hetzer, T. Hrenar, G. Jansen, C. Köppl, S. J. R. Lee, Y. Liu, A. W. Lloyd, Q. Ma, R. A. Mata, A. J. May, S. J. McNicholas, W. Meyer, T. F. Miller III, M. E. Mura, A. Nicklass, D. P. O'Neill, P. Palmieri, D. Peng, K. Pflüger, R. Pitzer, M. Reiher, T. Shiozaki, H. Stoll, A. J. Stone, R. Tarroni, T. Thorsteinsson, M. Wang, M. Welborn, MOLPRO, version 2019.1, a package of ab initio programs.

[28] a) E. van Lenthe, E. J. Baerends, J. G. Snijders, J. Chem. Phys. 1993, 99, 4597-4610; b) C. van Wüllen, J. Chem. Phys. 1998, 109, 392-399.

[29] D. A. Pantazis, X.-Y. Chen, C. R. Landis, F. Neese, J. Chem. Theory Comput. 2008, 4, 908-919.

[30] a) F. Neese, WIREs Comput. Mol. Sci. 2012, 2, 73-78; b) F. Neese, WIREs Comput. Mol. Sci. 2018, 8, e1327.

[31] Y. Zhao, D. G. Truhlar, J. Chem. Phys. 2006, 125, 194101.

[32] E. D. Glendening, J. K. Badenhoop, A. E. Reed, J. E. Carpenter, J. A. Bohmann, C. M. Morales, P. Karafiloglou, C. R. Landis, F. Weinhold, NBO 7.0; Theoretical Chemistry Institute, University of Wisconsin, Madison, WI, 2018.

[33] T. Lu, F. Chen, J. Comput. Chem. 2012, 33, 580-592.

[34] M. Allavena, R. Rysnik, D. White, V. Calder, D. E. Mann, J. Chem. Phys. $1969,50,3399-3410$.

[35] M. D. Fryzuk, S. A. Johnson, Coord. Chem. Rev. 2000, 200-202, 379-409.

[36] a) P. Popelier, Atoms in Molecules: An introduction, Prentice Hall, Harlow, 2000; b) The Chemical Bond (Eds.: G. Frenking, S. Shaik), Wiley-VCH, Weinheim, 2014.

[37] M. Zhou, L. Andrews, J. Phys. Chem. A 1999, 103, 7773-7784.

[38] H. H. Jaffé, M. Orchin, Tetrahedron 1960, 10, 212-214.

[39] J. Abbenseth, M. Finger, C. Würtele, M. Kasanmascheff, S. Schneider, Inorg. Chem. Front. 2016, 3, 469-477.

[40] P. Pyykkö, S. Riedel, M. Patzschke, Chem. Eur. J. 2005, 11, 3511-3520.

[41] P. Pyykkö, M. Atsumi, Chem. Eur. J. 2009, 15, 12770-12779.

[42] C. K. Jørgensen, Coord. Chem. Rev. 1966, 1, 164-178.

Manuscript received: December 6, 2019

Accepted manuscript online: January 17, 2020

Version of record online: April 30, 2020 


\section{Conclusion and Outlook}

\subsection{Conclusion}

The reaction products of laser-ablated late transition metals of groups 8 and 9 with $\mathrm{NF}_{3}$ comprise the fluoroimido difluorides $\mathrm{FNMF}_{2}, \mathrm{M}=\mathrm{Co}$, and $\mathrm{Rh}$, the nitrido trifluorides $\mathrm{NMF}_{3}, \mathrm{M}=\mathrm{Fe}, \mathrm{Ru}, \mathrm{Rh}, \mathrm{Os}$, Ir, and the nitrido tetrafluorides $\mathrm{NMF}_{4}, \mathrm{M}=\mathrm{Ru}$ and Os. By reacting laser-ablated iridium atoms with $\mathrm{N}_{2}$ the binary iridium nitrido complexes $\mathrm{IrN}$ and $\operatorname{Ir}(\mathrm{N})_{2}$ along with the dinuclear $\operatorname{IrIrN}$ and dinitrogen complexes of iridium were obtained, while $\operatorname{Ir}(\mathrm{N})_{3}$ was not observed. The product molecules embedded in solid inert gas matrices were characterized by IR spectroscopy, accompanied by thorough quantum-chemical calculations.

The unusual $\sigma$ and $\pi$ metal-nitrogen bonds in $\operatorname{FNMF}_{2}(\mathrm{M}=\mathrm{Co}, \mathrm{Rh})$ are formed by the interaction of $\mathrm{M}\left(d_{\mathrm{z}^{2}, \mathrm{xz}}\right)$-orbitals with the $\mathrm{N}\left(p_{\mathrm{z}, \mathrm{x}}\right)$-orbitals leading to strongly bent $\mathrm{F}-\mathrm{N}-\mathrm{M}$ units. Compared to $\mathrm{FNRhF}_{2}$, the metal-nitrogen bond in $\mathrm{FNCoF}_{2}$ is significantly weakened and bears imidyl/nitrene character, evident by the considerable nitrogen centered spin density.

Formal metal oxidation state of $\mathrm{VI}$ and $\mathrm{M} \equiv \mathrm{N}$ bond orders of 3 were determined for all $\mathrm{NMF}_{3}$ compounds. With the exception of $\mathrm{NFeF}_{3}$ and the magnetically bistable $\mathrm{NOsF}_{3}$, all characterized $\mathrm{NMF}_{3}$ species possess low-spin configurations. Except for the iron congener, all $\mathrm{NMF}_{3}$ complexes exhibit a (pseudo) Jahn-Teller distorted structure with $d^{2}$ (group 8 metals) and $d^{3}$ (group 9 metals) configurations. Compared to the group 6 nitrido trifluorides, the stretching frequencies of the metal-nitrogen triple bond are slightly increased in the group 8 and $9 \mathrm{NMF}_{3}$ compounds, with $\mathrm{NFeF}_{3}$ again being an exception, due to the partial oxidation of its nitrido ligand.

IR spectroscopic evidence for the formation of the $C_{4 \mathrm{v}}$ symmetric spin doublet $\mathrm{NM}^{\mathrm{VII}} \mathrm{F}_{4}(\mathrm{M}=\mathrm{Ru}, \mathrm{Os})$ species is presented. The electron configuration of these complexes corresponds to those of the known $\mathrm{NRuCl}_{4}^{-}$and $\mathrm{NOsCl}_{4}^{-}$anions with one electron removed from the doubly occupied metal centered $d_{\mathrm{x}^{2}-\mathrm{y}^{2}}$ orbital.

The novel rhodium(VI) and iridium(VI) nitrido trifluorides represent rare examples of terminal group 9 nitrido complexes in the unprecedented formal oxidation state VI. Moreover, it has been shown that the metal-nitrogen multiple bonds in $\mathrm{NFeF}_{3}, \mathrm{FNCoF}_{2}$ and $\operatorname{Ir}\left(\mathrm{N}_{2}\right)$ cannot be well described by an oxidation state formalism in which the more electronegative nitrogen atom adopts an OS of -III. The calculated spin densities of $\mathrm{FNCoF}_{2}$ and $\operatorname{Ir}\left(\mathrm{N}_{2}\right)$ clearly show significant ligand radical character by means of spin polarization and spin delocalization, respectively. Molecular $\operatorname{Ir}(\mathrm{N})_{3}$ was found not to contain $\operatorname{Ir}(\mathrm{IX})$, but rather $\operatorname{Ir}(\mathrm{VII})$ with a metal localized $\left(d_{\mathrm{z}^{2}}\right)^{2}$ configuration. 


\subsection{Outlook}

While the reaction of laser-ablated cobalt atoms and $\mathrm{NF}_{3}$ did not lead to the $\mathrm{NCoF}_{3}$ species, lower nitrido fluorides might be stable. The reaction of cobalt with NF could lead to $\mathrm{NCoF}$, an elusive terminal cobalt-nitrido species.

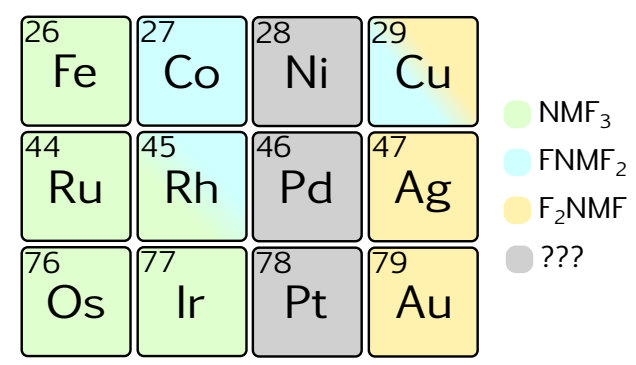

Figure 5.1. Reaction products obtained from $\mathrm{NF}_{3}$ and laser-ablated group 8 (this work), group 9 (this work) as well as group 11 atoms. ${ }^{[272]}$

Figure 5.1 clearly shows that the obvious missing link in the series of known molecular compounds with $\mathrm{F}_{3} \mathrm{MN}$ stoichiometry are the group 10 metals. Imido and nitrido group 10 complexes are very rare. From Figure 5.1 it can be speculated that the $\mathrm{F}_{3} \mathrm{MN}$ molecules of group 10 could include all possible products of the reaction cascade shown in Reaction 6.

$$
\mathrm{M}+\mathrm{NF}_{3} \longrightarrow \mathrm{F}_{2} \mathrm{NMF} \longrightarrow \mathrm{FNMF}_{2} \longrightarrow \mathrm{NMF}_{3}
$$




\section{References}

[1] W. A. Nugent, J. M. Mayer, Metal-Ligand Multiple Bonds: The Chemistry of Transition Metal Complexes Containing Oxo, Nitrido, Imido, Alkylidene, or Alkylidyne Ligands, Wiley, New York, 1988.

[2] R. R. Schrock, D. N. Clark, J. Sancho, J. H. Wengrovius, S. M. Rocklage, S. F. Pedersen, Organometallics 1982, 1, 1645-1651, DOI 10.1021/om00072a018.

[3] S. T. Nguyen, L. K. Johnson, R. H. Grubbs, J. W. Ziller, J. Am. Chem. Soc. 1992, 114, 3974-3975, DOI 10.1021/ ja00036a053.

[4] P. Schwab, M. B. France, J. W. Ziller, R. H. Grubbs, Angew. Chem. Int. Ed. 1995, 34, 2039-2041, DOI 10.1002/anie .199520391; Angew. Chem. 1995, 107, 2179_ 2181, DOI 10.1002/ange. 19951071818.

[5] P. Schwab, R. H. Grubbs, J. W. Ziller, J. Am. Chem. Soc. 1996, 118, 100-110, DOI 10. $1021 /$ ja952676d.

[6] M. Scholl, S. Ding, C. W. Lee, R. H. Grubbs, Org. Lett. 1999, 1, 953-956, DOI 10. 1021/o1990909q.

[7] B. Meunier, Metal-Oxo and Metal-Peroxo Species in Catalytic Oxidations, Vol. 97, Springer, 2003.

[8] J. Raymond, R. E. Blankenship, Coord. Chem. Rev. 2008, 252, 377-383, DOI $10.1016 /$ j .ccr. 2007.08 .026 .

[9] R. B. King, Encyclopedia of Inorganic Chemistry, Vol. 4, John Wiley \& Sons, Inc., 1994.

[10] P. J. Blower, J. R. Dilworth, J. P. Hutchinson, T. Nicholson, J. Zubieta, J. Chem. Soc. Dalton Trans. 1986, 1339, DOI 10.1039/dt9860001339.

[11] R. J. Angelici, Acc. Chem. Res. 1988, 21, 387-394, DOI 10.1021/ar00155a001.

[12] J. Fritzsche, H. Struve, J. prakt. Chem. 1847, 41, 97-113, DOI 10 . 1002 / prac . 18470410113.

[13] D. V. Yandulov, R. R. Schrock, Science 2003, 301, 76-78, DOI 10.1126/science. 1085326.

[14] R. R. Schrock, Acc. Chem. Res. 2005, 38, 955-962, DOI 10.1021/ar0501121.

[15] J. J. Scepaniak, J. A. Young, R. P. Bontchev, J. M. Smith, Angew. Chem. Int. Ed. 2009, 48, 3158-3160, DOI 10.1002/anie.200900381; Angew. Chem. 2009, 121, 3204-3206, DOI 10.1002/ange. 200900381.

[16] K. Arashiba, Y. Miyake, Y. Nishibayashi, Nat. Chem. 2011, 3, 120-125, DOI 10. 1038 /nchem. 906. 
[17] B. Askevold, J. T. Nieto, S. Tussupbayev, M. Diefenbach, E. Herdtweck, M. C. Holthausen, S. Schneider, Nat. Chem. 2011, 3, 532-537, DOI 10.1038/nchem. 1051.

[18] B. M. Lindley, Q. J. Bruch, P. S. White, F. Hasanayn, A. J. M. Miller, J. Am. Chem. Soc. 2017, 139, 5305-5308, DOI 10.1021/ jacs.7b01323.

[19] Y. Nishibayashi, Nat. Chem. 2011, 3, 502-504, DOI 10.1038/nchem. 1077.

[20] K. Nakajima, H. Toda, K. Sakata, Y. Nishibayashi, Nat. Chem. 2019, 11, 702709, DOI 10.1038/s41557-019-0293-y.

[21] J. Fajardo, J. C. Peters, J. Am. Chem. Soc. 2017, 139, 16105-16108, DOI 10 . $1021 /$ jacs. 7b 10204.

[22] S. J. K. Forrest, B. Schluschaß, E. Y. Yuzik-Klimova, S. Schneider, Chem. Rev. 2021, DOI 10.1021/acs . chemrev.0c00958.

[23] J. J. Curley, E. L. Sceats, C. C. Cummins, J. Am. Chem. Soc. 2006, 128, 1403614037, DOI 10.1021/ ja066090a.

[24] M. J. Bezdek, P. J. Chirik, Angew. Chem. Int. Ed. 2016, 55, 7892-7896, DOI 10. 1002 / anie . 201603142; Angew. Chem. 2016, 128, 8022-8026, DOI 10 . 1002 / ange. 201603142.

[25] I. Klopsch, M. Kinauer, M. Finger, C. Würtele, S. Schneider, Angew. Chem. Int. Ed. 2016, 55, 4786-4789, DOI 10. 1002 / anie.201600790; Angew. Chem. 2016, 128, 4864-4867, DOI 10.1002/ange.201600790.

[26] Z.-J. Lv, J. Wei, W.-X. Zhang, P. Chen, D. Deng, Z.-J. Shi, Z. Xi, Natl. Sci. Rev. 2020, 7, 1564-1583, DOI 10.1093/nsr/nwaa142.

[27] M. Ting-WaiáCheung, R. Wai-YináSun, et al., Chem. Commun. 2011, 47, 2140 2142.

[28] W.-X. Ni, W.-L. Man, S.-M. Yiu, M. Ho, M. T.-W. Cheung, C.-C. Ko, C.-M. Che, Y.-W. Lam, T.-C. Lau, Chem. Sci. 2012, 3, 1582-1588, DOI 10 . 1039 / C2SC01031C.

[29] W.-Q. Huang, C.-X. Wang, T. Liu, Z.-X. Li, C. Pan, Y.-Z. Chen, X. Lian, W.-L. Man, W.-X. Ni, Dalton Trans. 2020, 49, 17173-17182, DOI 10. 1039/D0DT02715D.

[30] M. Hanif, M. V. Babak, C. G. Hartinger, Drug Discov. Today 2014, 19, 16401648, DOI 10.1016/j.drudis.2014.06.016.

[31] R. L. Gdula, M. J. A. Johnson, J. Am. Chem. Soc. 2006, 128, 9614-9615, DOI 10. $1021 /$ ja058036k. 
[32] E. S. Wiedner, K. J. Gallagher, M. J. A. Johnson, J. W. Kampf, Inorg. Chem. 2011, 50, 5936-5945, DOI 10.1021/ic1024247.

[33] M. H. Chisholm, E. E. Delbridge, A. R. Kidwell, K. B. Quinlan, Chem. Commun. 2003, 0, 126-127, DOI 10.1039/B210286B.

[34] G. Ertl, Chem. Rec. 2001, 1, 33-45, DOI 10. 1002/1528-0691(2001) 1: 1<33: : AID-TCR6>3.0.C0;2-V.

[35] T. Kandemir, M. E. Schuster, A. Senyshyn, M. Behrens, R. Schlögl, Angew. Chem. Int. Ed. 2013, 52, 12723-12726, DOI 10.1002/anie.201305812; Angew. Chem. 2013, 125, 12955-12959, DOI 10.1002/ange.201305812.

[36] M. Georgiadis, H. Komiya, P. Chakrabarti, D. Woo, J. Kornuc, D. Rees, Science 1992, 257, 1653-1659, DOI 10.1126/science. 1529353.

[37] N. B. Thompson, M. T. Green, J. C. Peters, J. Am. Chem. Soc. 2017, 139, 1531215315, DOI $10.1021 /$ jacs.7b09364.

[38] D. N. Zarubin, N. A. Ustynyuk, Russ. Chem. Rev. 2006, 75, 671, DOI 10. 1070 / RC2006v075n08ABEH003595.

[39] E. R. King, E. T. Hennessy, T. A. Betley, J. Am. Chem. Soc. 2011, 133, 4917-4923, DOI $10.1021 /$ ja110066 j.

[40] T. A. Ramirez, B. Zhao, Y. Shi, Chem. Soc. Rev. 2012, 41, 931-942, DOI 10.1039/ C1CS15104E.

[41] D. A. Iovan, T. A. Betley, J. Am. Chem. Soc. 2016, 138, 1983-1993, DOI 10. $1021 /$ jacs. 5b 12582.

[42] Y. Baek, T. A. Betley, J. Am. Chem. Soc. 2019, 141, 7797-7806, DOI 10 . 1021/ jacs.9b01262.

[43] Y. Baek, A. Das, S.-L. Zheng, J. H. Reibenspies, D. C. Powers, T. A. Betley, J. Am. Chem. Soc. 2020, 142, 11232-11243, DOI 10.1021/ jacs.0c04252.

[44] G. Coin, R. Patra, S. Rana, J. P. Biswas, P. Dubourdeaux, M. Clémancey, S. P. de Visser, D. Maiti, P. Maldivi, J.-M. Latour, ACS Catal. 2020, 10, 10010-10020, DOI $10.1021 /$ acscatal.0c01427.

[45] P. J. Walsh, A. M. Baranger, R. G. Bergman, J. Am. Chem. Soc. 1992, 114, 17081719, DOI 10.1021/ ja00031a026.

[46] P. L. McGrane, M. Jensen, T. Livinghouse, J. Am. Chem. Soc. 1992, 114, 54595460, DOI 10.1021/ ja00039a087. 
[47] M. Nobis, B. Drießen-Hölscher, Angew. Chem. Int. Ed. 2001, 40, 3983-3985, DOI 10.1002/1521-3773(20011105) 40:21<3983: :AID-ANIE3983>3.0.C0;28; M. Nobis, B. Drießen-Hölscher, Angew. Chem. 2001, 113, 4105-4108, DOI 10. 1002/1521-3757(20011105) 113:21<4105: :AID-ANGE4105>3 . 0 . C0;2-0.

[48] T.-G. Ong, G. P. A. Yap, D. S. Richeson, J. Am. Chem. Soc. 2003, 125, 8100-8101, DOI $10.1021 /$ ja035716 j.

[49] L. L. Anderson, J. Arnold, R. G. Bergman, Org. Lett. 2004, 6, 2519-2522, DOI 10. $1021 / 010492851$.

[50] C. Lorber, R. Choukroun, L. Vendier, Organometallics 2004, 23, 1845-1850, DOI 10. $1021 /$ om0342762.

[51] Y. Li, Y. Shi, A. L. Odom, J. Am. Chem. Soc. 2004, 126, 1794-1803, DOI 10. $1021 /$ ja038320g.

[52] R. Severin, S. Doye, Chem. Soc. Rev. 2007, 36, 1407-1420, DOI 10. 1039/B600981F.

[53] L. Xu, W.-X. Zhang, Z. Xi, Organometallics 2015, 34, 1787-1801, DOI 10.1021/ acs.organomet. $5 \mathrm{~b} 00251$.

[54] R. R. Schrock, A. H. Hoveyda, Angew. Chem. Int. Ed. 2003, 42, 4592-4633, DOI 10. 1002/anie.200300576; Angew. Chem. 2003, 115, 4740-4782, DOI 10. 1002 / ange .200300576.

[55] R. R. Schrock, J. Mol. Catal. Chem., The 15th. International Symposium on Olefin Metathesis and Related Chemistry 2004, 213, 21-30, DOI 10 . 1016 / j.molcata.2003.10.060.

[56] J. R. Winkler, H. B. Gray in Molecular Electronic Structures of Transition Metal Complexes I, Springer Berlin Heidelberg, 2011, pp. 17-28, DOI 10 . 1007 / 430_ 2011_55.

[57] J. Abbenseth, S. C. Bete, M. Finger, C. Volkmann, C. Würtele, S. Schneider, Organometallics 2017, 37, 802-811, DOI 10.1021/acs.organomet.7b00707.

[58] H. B. Gray, J. R. Winkler, Acc. Chem. Res. 2018, 51, 1850-1857, DOI 10.1021/ acs.accounts. $8 \mathrm{~b} 00245$.

[59] M. Miao, Y. Sun, E. Zurek, H. Lin, Nat. Rev. Chem. 2020, 4, 508-527, DOI 10. $1038 / \mathrm{s} 41570-020-0213-0$.

[60] G. Monsch, P. Klüfers, Angew. Chem. Int. Ed. 2019, 58, 8566-8571, DOI 10 . 1002 / anie . 201902374; Angew. Chem. 2019, 131, 8654-8659, DOI 10 . 1002 / ange. 201902374.

[61] C. K. Jørgensen in Structure And Bonding, Springer, Berlin, Heidelberg, 1966, pp. 234-248, DOI 10.1007/BFb0119554. 
[62] S. Riedel, M. Kaupp, Coord. Chem. Rev. 2009, 253, 606-624, DOI 10. 1016 / j . ccr.2008.07.014.

[63] G. Wang, M. Zhou, J. T. Goettel, G. J. Schrobilgen, J. Su, J. Li, T. Schlöder, S. Riedel, Nature 2014, 514, 475-477, DOI 10.1038/nature13795.

[64] S. P. Cramer, K. O. Hodgson in Prog. Inorg. Chem. John Wiley \& Sons, Inc., 1979, pp. 1-39, DOI 10.1002/9780470166260.ch1.

[65] E. I. Solomon, B. Hedman, K. O. Hodgson, A. Dey, R. K. Szilagyi, Coord. Chem. Rev. 2005, 249, 97-129, DOI 10.1016/ j .ccr.2004.03.020.

[66] S. Sproules, K. Wieghardt, Coord. Chem. Rev. 2011, 255, 837-860, DOI 10 . $1016 /$ j .ccr.2010.12.006.

[67] J. F. Berry, E. Bill, E. Bothe, S. D. George, B. Mienert, F. Neese, K. Wieghardt, Science 2006, 312, 1937-1941, DOI 10.1126/science. 1128506.

[68] S.-X. Hu, W.-L. Li, J.-B. Lu, J. L. Bao, H. S. Yu, D. G. Truhlar, J. K. Gibson, J. Marçalo, M. Zhou, S. Riedel, W. H. E. Schwarz, J. Li, Angew. Chem. Int. Ed. 2018, 57, 3242-3245, DOI 10. 1002/anie.201711450; Angew. Chem. 2018, 130, 3297-3300, DOI 10.1002/ange.201711450.

[69] S. Ganguly, A. Ghosh, Acc. Chem. Res. 2019, 52, 2003-2014, DOI 10. 1021/acs. accounts.9b00115.

[70] W. P. Griffith, J. Lewis, G. Wilkinson, J. Chem. Soc. 1958, 3993-3998, DOI 10. 1039 / JR9580003993.

[71] A. Wanat, T. Schneppensieper, G. Stochel, R. van Eldik, E. Bill, K. Wieghardt, Inorg. Chem. 2002, 41, 4-10, DOI 10.1021/ ic010628q.

[72] H.-Y. Cheng, S. Chang, P.-Y. Tsai, J. Phys. Chem. A 2004, 108, 358-361, DOI 10. $1021 /$ jp031136x.

[73] V. Lyaskovskyy, B. de Bruin, ACS Catal. 2012, 2, 270-279, DOI 10 . 1021 / cs200660v.

[74] P. J. Chirik, Inorg. Chem. 2011, 50, 9737-9740, DOI 10. 1021/ ic201881k.

[75] W. Kaim, Eur. J. Inorg. Chem. 2012, 2012, 343-348, DOI 10. 1002 / e j ic . 201101359.

[76] A. I. Olivos Suarez, V. Lyaskovskyy, J. N. H. Reek, J. I. van der Vlugt, B. de Bruin, Angew. Chem. Int. Ed. 2013, 52, 12510-12529, DOI 10 . 1002 / anie . 201301487; Angew. Chem. 2013, 125, 12740-12760, DOI 10. 1002 / ange . 201301487.

[77] E. Whittle, D. A. Dows, G. C. Pimentel, J. Chem. Phys. 1954, 22, 1943-1943, DOI $10.1063 / 1.1739957$. 
[78] T. Schlöder, T. Vent-Schmidt, S. Riedel, Angew. Chem. Int. Ed. 2012, 51, 1206312067, DOI 10. 1002/anie.201206464; Angew. Chem. 2012, 124, 12229-12233, DOI 10.1002 / ange. 201206464.

[79] F. Brosi, T. Vent-Schmidt, S. Kieninger, T. Schlöder, H. Beckers, S. Riedel, Chem. - Eur. J. 2015, 21, 16455-16462, DOI 10.1002/chem. 201502849.

[80] L. Fredin, B. Nelander, G. Ribbegård, J. Mol. Spectrosc. 1974, 53, 410-416, DOI 10. 1016/0022-2852(74)90077-0.

[81] O. M. Wilkin, N. Harris, J. F. Rooms, E. L. Dixon, A. J. Bridgeman, N. A. Young, J. Phys. Chem. A 2018, 122, 1994-2029, DOI 10.1021/acs. jpca.7b09734.

[82] M. J. Linevsky, A Method for the Observation of the Infrared Spectrum of High Temperature Vapors by Matrix Isolation. I. The Infrared Spectrum of Lithium Fluoride, General Electric Co. Missile and Space Vehicle Dept., Philadelphia, 1960.

[83] C. A. Wight, B. S. Ault, L. Andrews, J. Chem. Phys. 1976, 65, 1244-1249, DOI $10.1063 / 1.433233$.

[84] P. L. Timms, J. Chem. Soc. D 1969, 1033a-1033a, DOI 10. 1039/C2969001033A.

[85] T. R. Burkholder, L. Andrews, J. Chem. Phys. 1991, 95, 8697-8709, DOI 10. $1063 / 1.461814$.

[86] L. Shao, L. Zhang, M. Chen, H. Lu, M. Zhou, Chem. Phys. Lett. 2001, 343, 178184, DOI 10.1016/S0009-2614(01)00675-3.

[87] F. A. Redeker, Dissertation, Freie Universität Berlin, 2020, DOI 10 . 17169 / REFUBIUM-26725.

[88] M. Reiher, A. Wolf, Relativistic Quantum Chemistry, John Wiley \& Sons, Inc., 2009.

[89] K. Pierloot, Int. J. Quantum Chem. 2011, 111, 3291-3301, DOI 10. 1002 / qua . 23029.

[90] G. Frenking, S. Shaik, The Chemical Bond: Chemical Bonding Across the Periodic Table, Vol. 2, John Wiley \& Sons, 2014.

[91] A. Szabo, N. S. Ostlund, Modern Quantum Chemistry: Introduction to Advanced Electronic Structure Theory, Dover, 1996.

[92] M. Karplus, J. Phys. Chem. 1990, 94, 5435-5436, DOI 10. 1021/ j 100377a002.

[93] W. Jiang, N. J. DeYonker, A. K. Wilson, J. Chem. Theory Comput. 2012, 8, 460468, DOI $10.1021 /$ ct2006852. 
[94] J. Wang, S. Manivasagam, A. K. Wilson, J. Chem. Theory Comput. 2015, 11, 5865-5872, DOI 10.1021/acs. jctc.5b00861.

[95] B. O. Roos in Advances in Chemical Physics, (Ed.: K. P. Lawley), John Wiley \& Sons, Inc., Hoboken, NJ, USA, 2007, pp. 399-445, DOI 10. $1002 / 9780470142943$. ch7.

[96] M. Kaupp, J. Comput. Chem. 2006, 28, 320-325, DOI 10. 1002 / jcc. 20522.

[97] P. Pyykkö, Phys. Scr. 1979, 20, 647-651, DOI 10. 1088/0031-8949/20/5-6/016.

[98] H.-J. Werner, P. J. Knowles, J. Chem. Phys. 1988, 89, 5803-5814, DOI 10.1063/ 1.455556 .

[99] P. J. Knowles, H.-J. Werner, Chem. Phys. Lett. 1988, 145, 514-522, DOI 10 . 1016/0009-2614 ( 88 ) 87412-8.

[100] P. Celani, H.-J. Werner, J. Chem. Phys. 2000, 112, 5546-5557, DOI 10.1063/1. 481132.

[101] K. Andersson, P.-Å. Malmqvist, B. O. Roos, J. Chem. Phys. 1992, 96, 1218-1226, DOI $10.1063 / 1.462209$.

[102] C. Angeli, R. Cimiraglia, S. Evangelisti, T. Leininger, J.-P. Malrieu, J. Chem. Phys. 2001, 114, 10252-10264, DOI 10.1063/1.1361246.

[103] G. Knizia, T. B. Adler, H.-J. Werner, J. Chem. Phys. 2009, 130, 054104, DOI 10. $1063 / 1.3054300$.

[104] T. Shiozaki, H.-J. Werner, Mol. Phys. 2013, 111, 607-630, DOI 10. 1080/00268976. 2013. 779393.

[105] C. Riplinger, P. Pinski, U. Becker, E. F. Valeev, F. Neese, J. Chem. Phys. 2016, 144, 024109, DOI 10.1063/1.4939030.

[106] P. Hohenberg, W. Kohn, Phys. Rev. 1964, 136, B864-B871, DOI 10.1103/PhysRev . 136. B864.

[107] W. Kohn, L. J. Sham, Phys. Rev. 1965, 140, A1133-A1138, DOI 10 . 1103 / PhysRev. 140.A1133.

[108] J. P. Perdew, K. Schmidt, AIP Conf. Proc. 2001, 577, 1-20, DOI 10 . 1063 / 1. 1390175.

[109] J. P. Perdew, MRS Bull. 2013, 38, 743-750, DOI 10.1557/mrs .2013. 178.

[110] A. D. Becke, Phys. Rev. A 1988, 38, 3098-3100, DOI 10 . $1103 /$ PhysRevA . 38. 3098.

[111] J. P. Perdew, Phys. Rev. B 1986, 33, 8822-8824, DOI 10.1103/PhysRevB . 33. 8822. 
[112] A. D. Becke, J. Chem. Phys. 1993, 98, 5648-5652, DOI 10.1063/1.464913.

[113] C. Lee, W. Yang, R. G. Parr, Phys. Rev. B 1988, 37, 785-789, DOI 10 . 1103 / PhysRevB.37.785.

[114] P. J. Stephens, F. J. Devlin, C. F. Chabalowski, M. J. Frisch, J. Phys. Chem. 1994, 98, 11623-11627, DOI 10.1021/ j100096a001.

[115] S. H. Vosko, L. Wilk, M. Nusair, Can. J. Phys. 1980, DOI 10.1139/p80-159.

[116] P. Verma, D. G. Truhlar, Trends Chem. 2020, 2, 302-318, DOI 10 . 1016 / j . trechm.2020.02.005.

[117] J.-D. Chai, M. Head-Gordon, J. Chem. Phys. 2008, 128, 084106, DOI 10.1063/ 1.2834918 .

[118] J.-D. Chai, M. Head-Gordon, Phys. Chem. Chem. Phys. 2008, 10, 6615-6620, DOI 10.1039/B810189B.

[119] J.-D. Chai, M. Head-Gordon, J. Chem. Phys. 2009, 131, 174105, DOI 10. 1063 / 1.3244209 .

[120] Y. Zhao, D. G. Truhlar, J. Phys. Chem. A 2006, 110, 13126-13130, DOI 10. 1021 / jp066479k.

[121] Y. Zhao, D. G. Truhlar, J. Chem. Phys. 2006, 125, 194101, DOI 10 . 1063 / 1. 2370993.

[122] Y. Wang, X. Jin, H. S. Yu, D. G. Truhlar, X. He, Proc. Natl. Acad. Sci. 2017, 114, 8487-8492, DOI 10.1073/pnas. 1705670114.

[123] Y. Zhao, D. G. Truhlar, Theor. Chem. Acc. 2007, 120, 215-241, DOI 10. 1007 / s00214-007-0310-x.

[124] F. Jensen, Introduction to Computational Chemistry, 2nd ed., John Wiley \& Sons, Inc., 2007.

[125] M. Reiher, Chimia 2009, 63, 140-145, DOI 10.2533/chimia.2009.140.

[126] M. Dolg in Theoretical and Computational Chemistry, Elsevier, 2002, pp. 793862, DOI 10.1016/s1380-7323(02)80040-1.

[127] M. Douglas, N. M. Kroll, Ann. Phys. 1974, 82, 89-155, DOI 10 . 1016 / 0003 4916(74)90333-9.

[128] B. A. Hess, Phys. Rev. A 1986, 33, 3742-3748, DOI 10. 1103 / PhysRevA . 33. 3742.

[129] E. van Lenthe, E. J. Baerends, J. G. Snijders, J. Chem. Phys. 1993, 99, 4597-4610, DOI 10.1063/1.466059. 
[130] E. van Lenthe, E. J. Baerends, J. G. Snijders, J. Chem. Phys. 1994, 101, 97839792, DOI $10.1063 / 1.467943$.

[131] X. Cao, M. Dolg, J. Chem. Phys. 2001, 115, 7348-7355, DOI 10 . 1063 / 1. 1406535.

[132] R. Gulde, P. Pollak, F. Weigend, J. Chem. Theory Comput. 2012, 8, 4062-4068, DOI $10.1021 / \operatorname{ct} 300302 u$.

[133] K. A. Peterson, D. Figgen, E. Goll, H. Stoll, M. Dolg, J. Chem. Phys. 2003, 119, 11113-11123, DOI 10.1063/1.1622924.

[134] F. Weigend, R. Ahlrichs, Phys. Chem. Chem. Phys. 2005, 7, 3297-3305, DOI 10. $1039 /$ B508541A.

[135] D. Andrae, U. Häußermann, M. Dolg, H. Stoll, H. Preuß, Theoret. Chim. Acta 1990, 77, 123-141, DOI 10.1007/BF 01114537.

[136] M. Kaupp, P. v. R. Schleyer, H. Stoll, H. Preuss, J. Chem. Phys. 1991, 94, 13601366, DOI 10.1063/1.459993.

[137] T. Leininger, A. Nicklass, W. Küchle, H. Stoll, M. Dolg, A. Bergner, Chem. Phys. Lett. 1996, 255, 274-280, DOI 10.1016/0009-2614(96)00382-X.

[138] B. Metz, H. Stoll, M. Dolg, J. Chem. Phys. 2000, 113, 2563-2569, DOI 10. 1063 / 1.1305880 .

[139] N. B. Balabanov, K. A. Peterson, J. Chem. Phys. 2005, 123, 064107, DOI 10. $1063 / 1.1998907$.

[140] N. B. Balabanov, K. A. Peterson, J. Chem. Phys. 2006, 125, 074110, DOI 10 . $1063 / 1.2335444$.

[141] T. H. Dunning, J. Chem. Phys. 1989, 90, 1007-1023, DOI 10.1063/1.456153.

[142] J. Koput, K. A. Peterson, J. Phys. Chem. A 2002, 106, 9595-9599, DOI 10.1021/ jp026283u.

[143] B. P. Prascher, D. E. Woon, K. A. Peterson, T. H. Dunning, A. K. Wilson, Theor. Chem. Acc. 2011, 128, 69-82, DOI 10.1007/s00214-010-0764-0.

[144] A. K. Wilson, D. E. Woon, K. A. Peterson, T. H. Dunning, J. Chem. Phys. 1999, 110, 7667-7676, DOI 10.1063/1.478678.

[145] D. E. Woon, T. H. Dunning, J. Chem. Phys. 1993, 98, 1358-1371, DOI 10.1063/ 1.464303.

[146] D. E. Woon, T. H. Dunning, J. Chem. Phys. 1994, 100, 2975-2988, DOI 10.1063/ 1.466439 . 
[147] D. Figgen, G. Rauhut, M. Dolg, H. Stoll, Chem. Phys., Relativistic Effects in Heavy-Element Chemistry and Physics. In Memoriam Bernd A. Hess (1954-2004) 2005, 311, 227-244, DOI 10.1016/ j . chemphys.2004.10.005.

[148] D. Figgen, K. A. Peterson, M. Dolg, H. Stoll, J. Chem. Phys. 2009, 130, 164108, DOI $10.1063 / 1.3119665$.

[149] B. Metz, M. Schweizer, H. Stoll, M. Dolg, W. Liu, Theor. Chem. Acc. 2000, 104, 22-28, DOI 10.1007/s002149900101.

[150] K. A. Peterson, J. Chem. Phys. 2003, 119, 11099-11112, DOI 10 . 1063 / 1. 1622923.

[151] K. A. Peterson, C. Puzzarini, Theor. Chem. Acc. 2005, 114, 283-296, DOI 10. 1007 / s00214-005-0681-9.

[152] K. A. Peterson, B. C. Shepler, D. Figgen, H. Stoll, J. Phys. Chem. A 2006, 110, 13877-13883, DOI 10.1021/ jp0658871.

[153] K. A. Peterson, D. Figgen, M. Dolg, H. Stoll, J. Chem. Phys. 2007, 126, 124101, DOI $10.1063 / 1.2647019$.

[154] W. A. de Jong, R. J. Harrison, D. A. Dixon, J. Chem. Phys. 2001, 114, 48, DOI $10.1063 / 1.1329891$.

[155] K. A. Peterson, T. H. Dunning, J. Chem. Phys. 2002, 117, 10548-10560, DOI $10.1063 / 1.1520138$.

[156] K. A. Peterson, K. E. Yousaf, J. Chem. Phys. 2010, 133, 174116, DOI 10.1063/ 1.3503659 .

[157] D. Feller, K. A. Peterson, J. Grant Hill, J. Chem. Phys. 2011, 135, 044102, DOI $10.1063 / 1.3613639$.

[158] R. S. Mulliken, J. Chem. Phys. 1962, 36, 3428-3439, DOI 10.1063/1. 1732476.

[159] P.-O. Löwdin in Advances in Quantum Chemistry, Vol. 5, (Ed.: P.-O. Löwdin), Academic Press, 1970, pp. 185-199, DOI 10.1016/S0065-3276 (08)60339-1.

[160] F. Weinhold, C. R. Landis, Discovering Chemistry with Natural Bond Orbitals, 1. ed, Wiley, Hoboken, NJ, 2012.

[161] R. F. W. Bader, Chem. Rev. 1991, 91, 893-928, DOI 10.1021/cr00005a013.

[162] R. F. W. Bader, Atoms in Molecules: A Quantum Theory, Oxford University Press, Oxford, New York, 1994.

[163] P. Popelier, Atoms In Molecules: An Introduction, Prentice Hall, Harlow, 2000. 
[164] B. O. Roos, A. C. Borin, L. Gagliardi, Angew. Chem. Int. Ed. 2007, 46, 14691472, DOI 10. 1002 / anie . 200603600; Angew. Chem. 2007, 119, 1491-1494, DOI 10.1002 / ange. 200603600 .

[165] W. D. Wagner, K. Nakamoto, J. Am. Chem. Soc. 1988, 110, 4044-4045, DOI 10. $1021 /$ ja00220a057.

[166] W. D. Wagner, K. Nakamoto, J. Am. Chem. Soc. 1989, 111, 1590-1598, DOI 10. $1021 /$ ja00187a010.

[167] H.-X. Wang, L. Wu, B. Zheng, L. Du, W.-P. To, C.-H. Ko, D. L. Phillips, C.-M. Che, Angew. Chem. Int. Ed. 2021, 60, 4796-4803, DOI 10.1002/ ani e.202014191; Angew. Chem. 2021, 133, 4846-4853, DOI 10.1002/ange. 202014191.

[168] K. Meyer, E. Bill, B. Mienert, T. Weyhermüller, K. Wieghardt, J. Am. Chem. Soc. 1999, 121, 4859-4876, DOI 10.1021/ ja983454t.

[169] C. A. Grapperhaus, B. Mienert, E. Bill, T. Weyhermüller, K. Wieghardt, Inorg. Chem. 2000, 39, 5306-5317, DOI 10.1021/ic0005238.

[170] M. Schlangen, J. Neugebauer, M. Reiher, D. Schröder, J. P. López, M. Haryono, F. W. Heinemann, A. Grohmann, H. Schwarz, J. Am. Chem. Soc. 2008, 130, 4285-4294, DOI 10.1021/ ja075617w.

[171] G. Sabenya, L. Lázaro, I. Gamba, V. Martin-Diaconescu, E. Andris, T. Weyhermüller, F. Neese, J. Roithova, E. Bill, J. Lloret-Fillol, M. Costas, J. Am. Chem. Soc. 2017, 139, 9168-9177, DOI 10.1021/ jacs.7b00429.

[172] E. Andris, R. Navrátil, J. Jašík, G. Sabenya, M. Costas, M. Srnec, J. Roithová, Chem. - Eur. J. 2018, 24, 5078-5081, DOI 10.1002/chem. 201705307.

[173] T. A. Betley, J. C. Peters, J. Am. Chem. Soc. 2004, 126, 6252-6254, DOI 10. $1021 /$ ja048713v.

[174] C. Vogel, F. W. Heinemann, J. Sutter, C. Anthon, K. Meyer, Angew. Chem. Int. Ed. 2008, 47, 2681-2684, DOI 10. 1002 / anie.200800600; Angew. Chem. 2008, 120, 2721-2724, DOI 10.1002/ ange.200800600.

[175] J. J. Scepaniak, M. D. Fulton, R. P. Bontchev, E. N. Duesler, M. L. Kirk, J. M. Smith, J. Am. Chem. Soc. 2008, 130, 10515-10517, DOI $10.1021 /$ ja8027372.

[176] J. J. Scepaniak, C. S. Vogel, M. M. Khusniyarov, F. W. Heinemann, K. Meyer, J. M. Smith, Science 2011, 331, 1049-1052, DOI 10.1126/ science. 1198315.

[177] M. Keilwerth, L. Grunwald, W. Mao, F. W. Heinemann, J. Sutter, E. Bill, K. Meyer, J. Am. Chem. Soc. 2021, 143, 1458-1465, DOI 10.1021/ jacs.0c11141. 
[178] T. Petrenko, S. DeBeer George, N. Aliaga-Alcalde, E. Bill, B. Mienert, Y. Xiao, Y. Guo, W. Sturhahn, S. P. Cramer, K. Wieghardt, F. Neese, J. Am. Chem. Soc. 2007, 129, 11053-11060, DOI 10.1021/ ja070792y.

[179] H.-C. Chang, Y.-H. Lin, C. Werlé, F. Neese, W.-Z. Lee, E. Bill, S. Ye, Angew. Chem. Int. Ed. 2019, 58, 17589-17593, DOI 10.1002/anie.201908689; Angew. Chem. 2019, 131, 17753-17757, DOI 10.1002/ange.201908689.

[180] J.-U. Rohde, T. A. Betley, T. A. Jackson, C. T. Saouma, J. C. Peters, L. Que, Inorg. Chem. 2007, 46, 5720-5726, DOI 10.1021/ ic700818q.

[181] L. Bucinsky, M. Breza, W.-T. Lee, A. K. Hickey, D. A. Dickie, I. Nieto, J. A. DeGayner, T. D. Harris, K. Meyer, J. Krzystek, A. Ozarowski, J. Nehrkorn, A. Schnegg, K. Holldack, R. H. Herber, J. Telser, J. M. Smith, Inorg. Chem. 2017, 56, 4751-4768, DOI 10.1021/acs.inorgchem.7b00512.

[182] J. J. Scepaniak, R. P. Bontchev, D. L. Johnson, J. M. Smith, Angew. Chem. Int. Ed. 2011, 50, 6630-6633, DOI 10. 1002/ anie.201102028; Angew. Chem. 2011, 123, 6760-6763, DOI 10.1002/ ange.201102028.

[183] K. Aiuchi, K. Shibuya, J. Mol. Spectrosc. 2000, 204, 235-261, DOI 10 . 1006 / jmsp. 2000.8226.

[184] P. E. M. Siegbahn, M. R. A. Blomberg, Chem. Phys. 1984, 87, 189-201, DOI 10. 1016/0301-0104(84)85045-4.

[185] G. V. Chertihin, L. Andrews, M. Neurock, J. Phys. Chem. 1996, 100, 1460914617, DOI 10.1021/ jp961423 j.

[186] A. Fiedler, S. Iwata, Chem. Phys. Lett. 1997, 271, 143-151, DOI 10.1016/S00092614 ( 97 ) 00444-2.

[187] P. M. Sheridan, L. M. Ziurys, T. Hirano, Astrophys. J. 2003, 593, L141-L144, DOI $10.1086 / 378177$.

[188] N. Aliaga-Alcalde, S. D. George, B. Mienert, E. Bill, K. Wieghardt, F. Neese, Angew. Chem. Int. Ed. 2005, 44, 2908-2912, DOI 10.1002/anie .200462368; N. Aliaga-Alcalde, S. D. George, B. Mienert, E. Bill, K. Wieghardt, F. Neese, Angew. Chem. 2005, 117, 2968-2972, DOI 10.1002/ange.200462368.

[189] M. P. Hendrich, W. Gunderson, R. K. Behan, M. T. Green, M. P. Mehn, T. A. Betley, C. C. Lu, J. C. Peters, Proc. Natl. Acad. Sci. 2006, 103, 17107-17112, DOI 10. $1073 /$ pnas. 0604402103 .

[190] W. P. Griffith, D. Pawson, J. Chem. Soc. Dalton Trans. 1973, 1315-1320, DOI 10. $1039 /$ DT9730001315. 
[191] P.-M. Chan, W.-Y. Yu, C.-M. Che, K.-K. Cheung, J. Chem. Soc. Dalton Trans. 1998, 0, 3183-3190, DOI 10. 1039/A804204G.

[192] L. Bonomo, E. Solari, R. Scopelliti, C. Floriani, Angew. Chem. Int. Ed. 2001, 40, 2529-2531, DOI 10 . 1002 / $1521-3773$ (20010702) $40: 13<2529::$ AID ANIE2529>3 .0.C0;2-B; Angew. Chem. 2001, 113, 2597-2599, DOI 10.1002 / 1521-3757 (20010702) 113:13<2597: :AID-ANGE2597>3 . 0 . C0 ;2-H.

[193] S. K.-Y. Leung, J.-S. Huang, J.-L. Liang, C.-M. Che, Z.-Y. Zhou, Angew. Chem. Int. Ed. 2003, 42, 340-343, DOI 10.1002/anie.200390111; Angew. Chem. 2003, 115, 354-357, DOI 10.1002/ange. 200390079.

[194] W.-L. Man, T.-M. Tang, T.-W. Wong, T.-C. Lau, S.-M. Peng, W.-T. Wong, J. Am. Chem. Soc. 2004, 126, 478-479, DOI 10.1021/ ja037899f.

[195] A. Walstrom, M. Pink, X. Yang, J. Tomaszewski, M.-H. Baik, K. G. Caulton, J. Am. Chem. Soc. 2005, 127, 5330-5331, DOI 10.1021/ ja050361k.

[196] J. S. Pap, S. DeBeer George, J. F. Berry, Angew. Chem. Int. Ed. 2008, 47, 1010210105, DOI 10.1002/anie.200804397; Angew. Chem. 2008, 120, 10256-10259, DOI 10.1002 / ange. 200804397.

[197] H.-Y. Ng, N.-M. Lam, M. Yang, X.-Y. Yi, I. D. Williams, W.-H. Leung, Inorganica Chim. Acta 2013, 394, 171-175, DOI 10.1016/ j . ica.2012.07.025.

[198] F. L. Phillips, A. C. Skapski, Acta Crystallogr. B 1975, 31, 2667-2670, DOI 10. $1107 /$ S0567740875008424.

[199] J. J. Schwab, E. C. Wilkinson, S. R. Wilson, P. A. Shapley, J. Am. Chem. Soc. 1991, 113, 6124-6129, DOI 10.1021/ ja00016a031.

[200] R. S. Ram, J. Liévin, P. F. Bernath, J. Chem. Phys. 1998, 109, 6329-6337, DOI $10.1063 / 1.477275$.

[201] R. S. Ram, P. F. Bernath, J. Mol. Spectrosc. 2002, 213, 170-178, DOI 10. 1006 / jmsp.2002.8565.

[202] A. Citra, L. Andrews, J. Phys. Chem. A 2000, 104, 1152-1161, DOI $10.1021 /$ jp993338s.

[203] W.-L. Man, W. W. Y. Lam, S.-M. Yiu, T.-C. Lau, S.-M. Peng, J. Am. Chem. Soc. 2004, 126, 15336-15337, DOI 10.1021/ ja045845f.

[204] W.-L. Man, W. W. Y. Lam, H.-K. Kwong, S.-M. Peng, W.-T. Wong, T.-C. Lau, Inorg. Chem. 2010, 49, 73-81, DOI 10.1021/ic901374f.

[205] W.-L. Man, W. W. Y. Lam, H.-K. Kwong, S.-M. Yiu, T.-C. Lau, Angew. Chem. Int. Ed. 2012, 51, 9101-9104, DOI 10.1002/anie.201204136; Angew. Chem. 2012, 124, 9235-9238, DOI 10.1002/ ange.201204136. 
[206] T. V. Truong, E. A. Kastl, G. Du, Tetrahedron Lett. 2011, 52, 1670-1672, DOI 10.1016/ j.tetlet.2011.01.139.

[207] W.-L. Man, J. Xie, P.-K. Lo, W. W. Y. Lam, S.-M. Yiu, K.-C. Lau, T.-C. Lau, Angew. Chem. Int. Ed. 2014, 53, 8463-8466, DOI 10 . 1002 / anie . 201404421; Angew. Chem. 2014, 126, 8603-8606, DOI 10.1002/ange.201404421.

[208] Q. Wang, W.-L. Man, W. W. Y. Lam, T.-C. Lau, Chem. Commun. 2014, 50, 1579915802, DOI 10.1039/C4CC07568D.

[209] J. Xie, W.-L. Man, C.-Y. Wong, X. Chang, C.-M. Che, T.-C. Lau, J. Am. Chem. Soc. 2016, 138, 5817-5820, DOI 10.1021/ jacs.6b02923.

[210] J. Xie, P.-K. Lo, W. W. Y. Lam, W.-L. Man, L. Ma, S.-M. Yiu, K.-C. Lau, T.-C. Lau, Chem. Commun. 2016, 52, 11430-11433, DOI 10.1039/C6CC06231H.

[211] A. Walstrom, M. Pink, H. Fan, J. Tomaszewski, K. G. Caulton, Inorg. Chem. 2007, 46, 7704-7706, DOI 10.1021/ic700789y.

[212] A. Walstrom, H. Fan, M. Pink, K. G. Caulton, Inorganica Chim. Acta, Protagonist in Chemistry: Paul S. Pregosin 2010, 363, 633-636, DOI 10.1016/ j . ica. 2008. 11.010 .

[213] S. V. Ley, J. Norman, W. P. Griffith, S. P. Marsden, Synthesis 1994, 1994, 639666, DOI 10.1055/s-1994-25538.

[214] H. Cheng, C. B. W. Stark, Angew. Chem. Int. Ed. 2010, 49, 1587-1590, DOI 10. 1002 / anie . 200903090; Angew. Chem. 2010, 122, 1632-1635, DOI 10.1002 / ange. 200903090.

[215] A. Werner, K. Dinklage, Berichte Dtsch. Chem. Ges. 1901, 34, 2698-2703, DOI 10. 1002 / cber. 190103402220.

[216] P. A. Shapley, R. M. Marshman, J. M. Shusta, Z. Gebeyehu, S. R. Wilson, Inorg. Chem. 1994, 33, 498-502, DOI 10.1021/ic00081a017.

[217] D. Sellmann, M. W. Wemple, W. Donaubauer, F. W. Heinemann, Inorg. Chem. 1997, 36, 1397-1402, DOI 10.1021/ic961240b.

[218] T.-W. Wong, T.-C. Lau, W.-T. Wong, Inorg. Chem. 1999, 38, 6181-6186, DOI 10.1021/ic9814571.

[219] W.-X. Ni, W.-L. Man, M. T.-W. Cheung, R. W.-Y. Sun, Y.-L. Shu, Y.-W. Lam, C.-M. Che, T.-C. Lau, Chem. Commun. 2011, 47, 2140-2142, DOI 10 . 1039 / c0CC04515B.

[220] K. Suntharalingam, T. C. Johnstone, P. M. Bruno, W. Lin, M. T. Hemann, S. J. Lippard, J. Am. Chem. Soc. 2013, 135, 14060-14063, DOI 10.1021/ ja4075375. 
[221] F. S. Schendzielorz, M. Finger, C. Volkmann, C. Würtele, S. Schneider, Angew. Chem. Int. Ed. 2016, 55, 11417-11420, DOI 10.1002/anie.201604917; Angew. Chem. 2016, 128, 11589-11592, DOI 10.1002/ange. 201604917.

[222] F. M. Jaeger, J. E. Zanstra, Proc. R. Neth. Acad. Arts Sci. 1932, 35, 610-624.

[223] F. M. Jaeger, J. E. Zanstra, Recl. Trav. Chim. Pays-Bas 1932, 51, 1013-1053, DOI 10. 1002 / recl. 19320511106.

[224] J. Lewis, G. Wilkinson, J. Inorg. Nucl. Chem. 1958, 6, 12-13, DOI 10 . 1016 / 0022-1902 (58)80094-9.

[225] A. Werner, K. Dinklage, Berichte Dtsch. Chem. Ges. 1906, 39, 499-503, DOI 10. 1002 / cber. 19060390181.

[226] D. Bright, J. A. Ibers, Inorg. Chem. 1969, 8, 709-716, DOI 10.1021/ ic50074a002.

[227] S. R. Fletcher, W. P. Griffith, D. Pawson, F. L. Phillips, A. C. Skapski, Inorg. Nucl. Chem. Lett. 1973, 9, 1117-1120, DOI 10.1016/0020-1650(73)80016-9.

[228] D. W. Pipes, M. Bakir, S. E. Vitols, D. J. Hodgson, T. J. Meyer, J. Am. Chem. Soc. 1990, 112, 5507-5514, DOI 10.1021/ ja00170a014.

[229] R. Eikey, Coord. Chem. Rev. 2003, 243, 83-124, DOI 10.1016/S0010-8545(03) 00048-1.

[230] K. Suntharalingam, W. Lin, T. C. Johnstone, P. M. Bruno, Y.-R. Zheng, M. T. Hemann, S. J. Lippard, J. Am. Chem. Soc. 2014, 136, 14413-14416, DOI 10 . 1021/ ja508808v.

[231] R. S. Ram, J. Liévin, P. F. Bernath, J. Chem. Phys. 1999, 111, 3449-3456, DOI $10.1063 / 1.479630$.

[232] A. Citra, L. Andrews, J. Am. Chem. Soc. 1999, 121, 11567-11568, DOI 10.1021/ ja993211g.

[233] D. M. Jenkins, T. A. Betley, J. C. Peters, J. Am. Chem. Soc. 2002, 124, 1123811239, DOI 10.1021/ ja026852b.

[234] M. P. Mehn, S. D. Brown, D. M. Jenkins, J. C. Peters, L. Que, Inorg. Chem. 2006, 45, 7417-7427, DOI 10.1021/ic060670r.

[235] X. Dai, P. Kapoor, T. H. Warren, J. Am. Chem. Soc. 2004, 126, 4798-4799, DOI 10. $1021 /$ ja036308i.

[236] D. T. Shay, G. P. A. Yap, L. N. Zakharov, A. L. Rheingold, K. H. Theopold, Angew. Chem. Int. Ed. 2005, 44, 1508-1510, DOI 10 . 1002 / ani e . 200462529; Angew. Chem. 2005, 117, 1532-1534, DOI 10.1002/ange. 200462529. 
[237] R. E. Cowley, R. P. Bontchev, J. Sorrell, O. Sarracino, Y. Feng, H. Wang, J. M. Smith, J. Am. Chem. Soc. 2007, 129, 2424-2425, DOI 10.1021/ ja066899n.

[238] E. R. King, G. T. Sazama, T. A. Betley, J. Am. Chem. Soc. 2012, 134, 1785817861, DOI 10.1021/ ja307699u.

[239] L. Zhang, Y. Liu, L. Deng, J. Am. Chem. Soc. 2014, 136, 15525-15528, DOI 10. $1021 /$ ja509731z.

[240] J. Du, L. Wang, M. Xie, L. Deng, Angew. Chem. Int. Ed. 2015, 54, 12640-12644, DOI 10.1002/anie.201505937; Angew. Chem. 2015, 127, 12831-12835, DOI 10.1002 / ange .201505937.

[241] Y. Liu, J. Du, L. Deng, Inorg. Chem. 2017, 56, 8278-8286, DOI 10.1021/acs . inorgchem. 7b00941.

[242] A. Reckziegel, C. Pietzonka, F. Kraus, C. G. Werncke, Angew. Chem. Int. Ed. 2020, 59, 8527-8531, DOI 10.1002/anie.201914718; Angew. Chem. 2020, 132, 8605-8609, DOI 10.1002/ange.201914718.

[243] L. Andrews, A. Citra, G. V. Chertihin, W. D. Bare, M. Neurock, J. Phys. Chem. A 1998, 102, 2561-2571, DOI 10.1021/jp9802836.

[244] T. Yamaki, M. Sekiya, K. Tanaka, Chem. Phys. Lett. 2003, 376, 487-492, DOI 10.1016/S0009-2614(03)01035-2.

[245] J. P. Gobbo, A. C. Borin, J. Phys. Chem. A 2006, 110, 13966-13973, DOI 10 . $1021 /$ jp065005i.

[246] J. F. Berry, Comments Inorg. Chem. 2009, 30, 28-66, DOI 10. 1080/02603590902768875.

[247] X. Hu, K. Meyer, J. Am. Chem. Soc. 2004, 126, 16322-16323, DOI 10 . 1021 / ja044271b.

[248] C. Jones, C. Schulten, R. P. Rose, A. Stasch, S. Aldridge, W. D. Woodul, K. S. Murray, B. Moubaraki, M. Brynda, G. La Macchia, L. Gagliardi, Angew. Chem. Int. Ed. 2009, 48, 7406-7410, DOI 10. 1002 / anie .200900780; Angew. Chem. 2009, 121, 7542-7546, DOI 10.1002/ange. 200900780.

[249] M. G. Scheibel, Y. Wu, A. C. Stückl, L. Krause, E. Carl, D. Stalke, B. de Bruin, S. Schneider, J. Am. Chem. Soc. 2013, 135, 17719-17722, DOI 10. $1021 /$ ja409764 j.

[250] A. M. Geer, C. Tejel, J. A. López, M. A. Ciriano, Angew. Chem. Int. Ed. 2014, 53, 5614-5618, DOI 10. 1002 / anie . 201400023; Angew. Chem. 2014, 126, 57205724, DOI 10.1002/ange.201400023.

[251] X. Li, L.-S. Wang, J. Chem. Phys. 1998, 109, 5264-5268, DOI 10 . 1063 / 1. 477143. 
[252] I. Shim, K. Mandix, K. A. Gingerich, J. Mol. Struct. THEOCHEM 1997, 393, 127139, DOI $10.1016 /$ S0166-1280(96)04802-6.

[253] R. Du, B. Suo, H. Han, Y. Lei, G. Zhai, Int. J. Quantum Chem. 2013, 113, 24642470, DOI 10.1002/qua.24484.

[254] A. Citra, L. Andrews, J. Phys. Chem. A 1999, 103, 3410-3417, DOI 10 . 1021 / jp9846274.

[255] S. G. Fougère, W. J. Balfour, J. Cao, C. X. W. Qian, J. Mol. Spectrosc. 2000, 199, 18-25, DOI 10.1006/ jmsp. 1999.7972.

[256] D. S. Glueck, F. J. Hollander, R. G. Bergman, J. Am. Chem. Soc. 1989, 111, 27192721, DOI 10.1021/ ja00189a059.

[257] D. S. Glueck, J. Wu, F. J. Hollander, R. G. Bergman, J. Am. Chem. Soc. 1991, 113, 2041-2054, DOI 10.1021/ ja00006a026.

[258] M. Kinauer, M. Diefenbach, H. Bamberger, S. Demeshko, E. J. Reijerse, C. Volkmann, C. Würtele, J. van Slageren, B. de Bruin, M. C. Holthausen, S. Schneider, Chem. Sci. 2018, 9, 4325-4332, DOI 10.1039/C8SC01113C.

[259] J. Schöffel, A. Y. Rogachev, S. DeBeer George, P. Burger, Angew. Chem. Int. Ed. 2009, 48, 4734-4738, DOI 10.1002/anie.200901494; Angew. Chem. 2009, 121, 4828-4832, DOI 10.1002/ange.200901494.

[260] D. Sieh, J. Schöffel, P. Burger, Dalton Trans. 2011, 40, 9512-9524, DOI 10. 1039/ C1DT10886G.

[261] M. G. Scheibel, B. Askevold, F. W. Heinemann, E. J. Reijerse, B. de Bruin, S. Schneider, Nat. Chem. 2012, 4, 552-558, DOI 10.1038/nchem. 1368.

[262] R. S. Ram, P. F. Bernath, J. Mol. Spectrosc. 1999, 193, 363-375, DOI 10. 1006 / jmsp. 1998.7753.

[263] R. S. Ram, J. Liévin, P. F. Bernath, J. Mol. Spectrosc. 1999, 197, 133-146, DOI 10. $1006 /$ jmsp. 1999.7911.

[264] H. F. Pang, A. S. C. Cheung, Chin. J. Chem. Phys. 2009, 22, 157-161, DOI 10 . 1088/1674-0068/22/02/157-161.

[265] Q.-C. Fan, W.-G. Sun, H.-D. Li, H. Feng, Chinese Phys. B 2012, 21, 023301, DOI 10. 1088/1674-1056/21/2/023301.

[266] D. Sieh, P. Burger, J. Am. Chem. Soc. 2013, 135, 3971-3982, DOI 10 . 1021 / ja311905h.

[267] D. Sieh, P. Burger, Z. Anorg. Allg. Chem. 2015, 641, 52-55, DOI 10.1002/zaac. 201400235. 
[268] J. Schöffel, N. Šušnjar, S. Nückel, D. Sieh, P. Burger, Eur. J. Inorg. Chem. 2010, 2010,4911-4915, DOI 10.1002/ e jic.201000899.

[269] J. Abbenseth, M. Finger, C. Würtele, M. Kasanmascheff, S. Schneider, Inorg. Chem. Front. 2016, 3, 469-477, DOI 10.1039/C5QI00267B.

[270] Ł. Wolański, M. Domański, W. Grochala, P. Szarek, Chem. - Eur. J. 2019, 25, 10290-10293, DOI 10.1002/chem. 201902142.

[271] X. Wang, J. T. Lyon, L. Andrews, Inorg. Chem. 2009, 48, 6297-6302, DOI 10. 1021/ic900633k.

[272] X. Wang, L. Andrews, R. Lindh, V. Veryazov, B. O. Roos, J. Phys. Chem. A 2008, 112, 8030-8037, DOI 10.1021/ jp804469a.

[273] Y. Gong, L. Andrews, Inorg. Chem. 2012, 51, 667-673, DOI 10. 1021/ ic2021758.

[274] S. B. Osin, D. I. Davliasthin, J. S. Ogden, J. Fluor. Chem. 1996, 76, 187-192, DOI 10. 1016/0022-1139(95)03371-8.

[275] A. K. Brisdon, P. J. Jones, W. Levason, J. S. Ogden, J. H. Holloway, E. G. Hope, G. Stanger, J. Chem. Soc. Dalton Trans. 1990, 715-718, DOI 10 . 1039 /DT9900000715.

[276] S. B. Osin, D. I. Davlyatshin, D. S. Ogden, Russ. J. Phys. Chem. A 2001, 75, $1312-$ 1318.

[277] J. H. Holloway, G. Stanger, E. G. Hope, W. Levason, J. Steven Ogden, J. Chem. Soc. Dalton Trans. 1988, 0, 1341-1345, DOI 10.1039/DT9880001341.

[278] J. V. Rau, S. Nunziante Cesaro, N. S. Chilingarov, G. Balducci, Inorg. Chem. 1999, 38, 5695-5697, DOI 10.1021/ic990294t.

[279] R. Hoffmann, S. Alvarez, C. Mealli, A. Falceto, T. J. Cahill, T. Zeng, G. Manca, Chem. Rev. 2016, 116, 8173-8192, DOI 10.1021/acs . chemrev. 6 b00251.

[280] I. B. Bersuker, Chem. Rev. 2013, 113, 1351-1390, DOI 10.1021/cr300279n.

[281] P. Garcia-Fernandez, I. B. Bersuker, Phys. Rev. Lett. 2011, 106, 246406, DOI 10.1103/PhysRevLett . 106.246406.

[282] P. Garcia-Fernandez, I. B. Bersuker, J. E. Boggs, J. Chem. Phys. 2006, 125, 104102, DOI $10.1063 / 1.2346682$.

[283] V. Kalamse, S. Gaikwad, A. Chaudhari, Bull. Mater. Sci. 2010, 33, 233-238, DOI 10. 1007/s12034-010-0036-6. 


\section{List of Publications}

\section{Articles}

[1] Tony Stüker, Xiya Xia, Helmut Beckers, and Sebastian Riedel, "High-Spin Iron(VI), Low-Spin Ruthenium(VI), and Magnetically Bistable Osmium(VI) in Molecular Group 8 Nitrido Trifluorides $\mathrm{NMF}_{3}$ ", Chem. Eur. J., 2021, Advance online publication

https: / / doi.org/10.1002/chem. 202101404

[2] Lin Li, Helmut Beckers, Tony Stüker, Tilen Lindič, Tobias Schlöder, Dirk Andrae, and Sebastian Riedel, "Molecular Oxofluorides $\mathrm{OMF}_{\mathrm{n}}$ of Nickel, Palladium and Platinum: Oxyl Radicals with Moderate Ligand Field Inversion", Inorg. Chem. Front., 2021, 8, 1215-1228

https://doi.org/10.1039/D0QI01151G

[3] Tony Stüker, Thomas Hohmann, Helmut Beckers, and Sebastian Riedel, "Fluoro Nitrenoid Complexes FN= $\mathrm{MF}_{2}(\mathrm{M}=\mathrm{Co}, \mathrm{Rh}, \mathrm{Ir})$ : Electronic Structure Dichotomy and Formation of Nitrido Fluorides $\mathrm{N} \equiv \mathrm{MF}_{3}{ }^{\prime \prime}$, Angew. Chem. Int. Ed., 2020, 59, 23174-23179; Angew. Chem., 2020, 132, 23374-23379

https: / / doi.org/10.1002/anie.202010950

https: / / doi.org/10.1002/ange. 202010950

[4] Tony Stüker, Helmut Beckers, and Sebastian Riedel, "A Cornucopia of Iridium Nitrogen Compounds Produced from Laser-Ablated Iridium Atoms and Dinitrogen”, Chem. Eur. J., 2020, 26, 7384-7394

https://doi.org/10.1002/chem. 201905514

[5] Hongmin Li, Helmut Beckers, Lin Li, Günther Thiele, Tony Stüker and Sebastian Riedel, "Reactions of Titanium, Zirconium and Hafnium Atoms with Hydrogen Selenide: A Matrix-Isolation Study", Chem. Phys. Let., 2020, 740, 137063 https://doi.org/10.1016/ j.cplett.2019.137063

[6] Jan H. Nissen, Lucas Wickemeyer, Tony Stüker, Simon Steinhauer, Helmut Beckers, and Sebastian Riedel, "From Hypochlorites to Perfluorinated Dialkyl Peroxides", J. Fluor. Chem., 2020, 230, 109416

https://doi.org/10.1016/ j.jfluchem.2019.109416 
[7] Lin Li, ${ }^{+}$Tony Stüker, ${ }^{+}$Lester Andrews, Helmut Beckers, and Sebastian Riedel, "Infrared Spectra of the HAnX and $\mathrm{H}_{2} \mathrm{AnX}_{2}$ Molecules $(\mathrm{An}=\mathrm{Th}$ and $\mathrm{U}, \mathrm{X}=\mathrm{Cl}$ and $\mathrm{Br}$ ) in Argon Matrices Supported by Electronic Structure Calculations", Chem. Eur. J., 2019, 25, 1795-1805 https://doi.org/10.1002/chem. 201805372

$\left.{ }^{+}\right]$Lin Li and Tony Stüker contributed equally to this work.

[8] Jan H. Nissen, Tony Stüker, Thomas Drews, Simon Steinhauer, Helmut Beckers, and Sebastian Riedel, "No Fear of Perfluorinated Peroxides: Syntheses and SolidState Structures of Surprisingly Inert Perfluoroalkyl Peroxides", Angew. Chem. Int. Ed., 2019, 58, 3584-3588; Angew. Chem., 2019, 131, 3622-3626 https://doi.org/10.1002/anie.201814417 https://doi.org/10.1002/ange. 201814417

[9] Lin Li, Tony Stüker, Stefanie Kieninger, Dirk Andrae, Tobias Schlöder, Yu Gong, Lester Andrews, Helmut Beckers, and Sebastian Riedel, "Oxygen radical character in group 11 oxygen fluorides", Nat. Commun., 2018, 9, 1267 https: / / doi .org/10.1038/s41467-018-03630-0

[10] Klaus Banert, Madhu Chityala, Manfred Hagedorn, Helmut Beckers, Tony Stüker, Sebastian Riedel, Tobias Rüffer, and Heinrich Lang, "Tricyanomethane and Its Ketenimine Tautomer: Generation from Different Precursors and Analysis in Solution, Argon Matrix, and as a Single Crystal", Angew. Chem. Int. Ed., 2017, 56, 9582-9586; Angew. Chem., 2017, 129, 9710-9714

https://doi .org/10.1002/anie.201704561

https://doi.org/10.1002/ange. 201704561 


\section{Conference Contributions - Poster Presentations}

[1] Tony Stüker, Helmut Beckers, Sebastian Riedel, "Reaction of Laser-Ablated Iridium with Dinitrogen: Infrared Spectra of Matrix Isolated Iridium Nitrides, Dinitrogen-Complexes, and Anions", Chemistry and Physics at Low Temperatures, 2016, Biarritz, France

[2] Tony Stüker, Helmut Beckers, Sebastian Riedel, "Reaction of Laser-Ablated Iridium with Dinitrogen: Infrared Spectra of Matrix Isolated Iridium Nitrides, Dinitrogen-Complexes, and Anions", GDCh Wissenschaftsforum Chemie, 2017, Berlin, Germany 

Appendix A Supporting Information of Publications

A.1 High-Spin Iron(VI), Low-Spin Ruthenium(VI), and Magnetically Bistable of Osmium(VI): Molecular Group 8 Nitrido Trifluorides $\mathrm{NMF}_{3}$ 


\section{Table of Contents}

Experimental and Computational Details ........................................................ 2

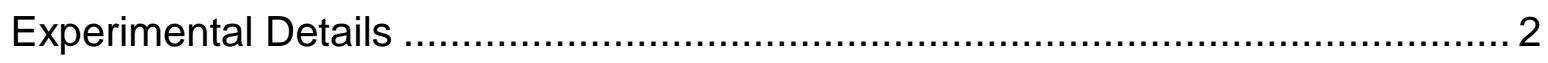

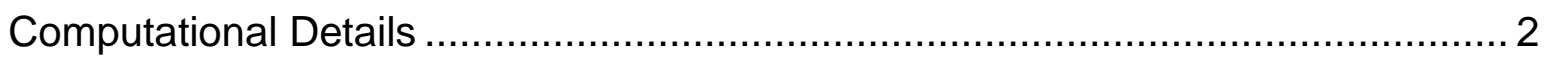

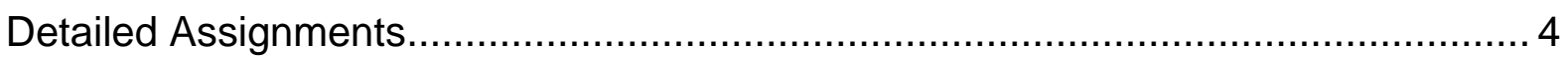

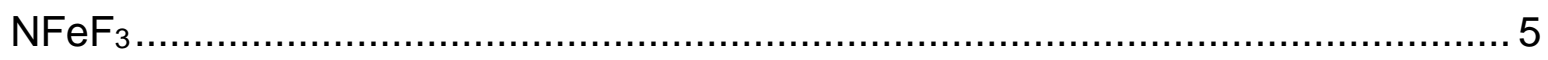

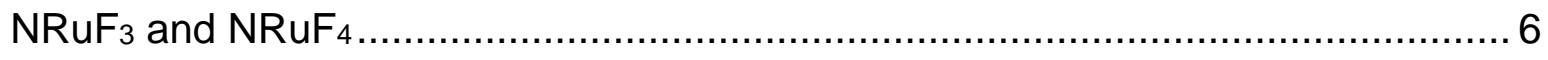

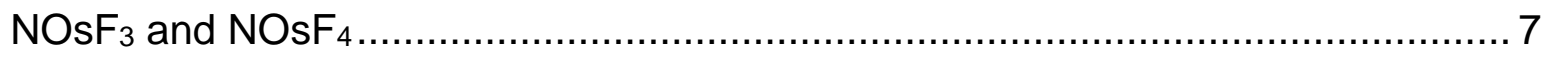

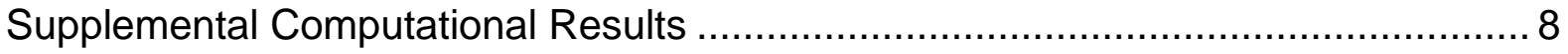

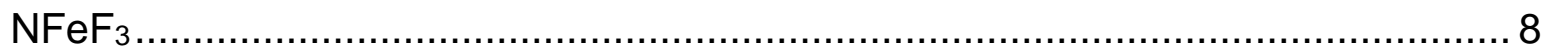

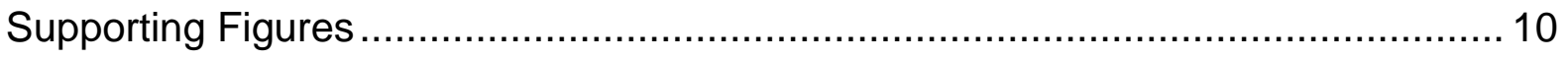

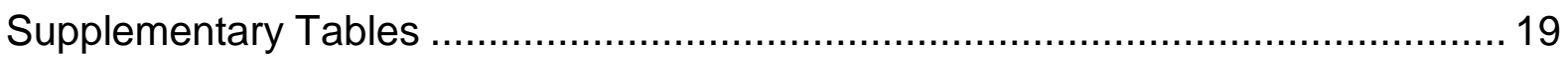

Calculated molecular structures and vibrational data ............................................ 35

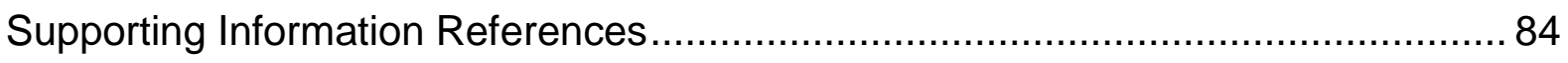




\section{Experimental and Computational Details}

\section{Experimental Details}

${ }^{14} \mathrm{NF}_{3}$ and ${ }^{15} \mathrm{NF}_{3}$ (synthesis described elsewhere ${ }^{[1]}$ ) were premixed 1:1000 with neon (99.999\%, Linde) in a stainless-steel cylinder. The mixing vessel was connected to a stainless-steel vacuum line connected to a self-made matrix chamber by a stainlesssteel capillary. The gas mixture was then co-deposited for 100 min with laser-ablated iron, ruthenium or osmium atoms onto a gold plated copper mirror and cooled to $5 \mathrm{~K}$ by using a closed-cycle helium cryostat (Sumitomo Heavy Industries, RDK-205D) inside the vacuum chamber. For the laser-ablation, the $1064 \mathrm{~nm}$ fundamental of a Nd:YAG laser (Continuum, Minilite II, $10 \mathrm{~Hz}$ repetition rate, 35-50 mJ pulse ${ }^{-1}$ ) was focused onto a rotating metal target. Infrared spectra were recorded on a Bruker Vertex $80 \mathrm{v}$ with evacuated optical path at 0.1 or $0.5 \mathrm{~cm}^{-1}$ resolution in the region $4000-$ $430 \mathrm{~cm}^{-1}$ by using a liquid-nitrogen-cooled mercury cadmium telluride (MCT) detector.

\section{Computational Details}

Density functional theory (DFT) calculations are performed using the TURBOMOLE 7.0.1 program package ${ }^{[2]}$ employing the GGA, meta-GGA or hybrid exchangecorrelation density functionals BP86, ${ }^{[3]} \mathrm{M} 06-\mathrm{L}^{[4]}$ and B3LYP, ${ }^{[5]}$ respectively, with the polarized quadruple- $\xi$ basis set def2-QZVP ${ }^{[6]}$ which applies the Stuttgart-Dresden effective core potential for ruthenium and osmium. ${ }^{[7]}$ The Coupled Cluster Single Double and perturbative Triple excitations $(\operatorname{CCSD}(T))$ calculations are carried out in the spin unrestricted ROHF-UCCSD(T) open-shell coupled cluster formalism ${ }^{[8]}$ using default frozen core settings as implemented in the Molpro 2019 software package. ${ }^{[9]}$ The same software was used for all complete active space self-consistent field $(\mathrm{CASSCF})^{[10]}$ and n-electron valence state perturbation theory (NEVPT2) ${ }^{[11]}$ 
calculations. Unless stated otherwise, all $\operatorname{CCSD}(T)$ calculations were combined with the augmented triple- $\xi$ basis sets aug-cc-pVTZ (for short: aVTZ) for nitrogen, fluorine, iron $^{[12]}$ and aug-cc-pVTZ-PP (for short: aVTZ-PP) for ruthenium and osmium. ${ }^{[13]}$ Only the valence electrons $[N, F: 2 p 2 s, M:(n-1) d n s]$ are correlated in the $\operatorname{CCSD}(T)$ and NEVPT2 dynamic correlation procedure when the (aug)-cc-pVNZ(-PP/-DK) ${ }^{[12 a, 12 c, 13]}$ [for short: (a)VNZ(-PP/-DK)] basis sets are used. Whereas the metal based $(n-1) \mathrm{s}(n-$ 1)p orbitals were included when the aug-cc-pwCVNZ(-PP/-DK) ${ }^{[12 a, 12 c, 13]}$ [for short: awCVNZ(-PP/-DK), $N$ = cardinal number D, T, $\mathrm{Q}$ or 5] basis sets are used. The active space for the state-specific complete active-space (SS-CASSCF) reference wavefunctions is chosen to consist of 8 electrons in 8 orbitals covering the Fe=N three bonding, three antibonding and the two metal centered molecular orbitals. Larger active spaces including the $\mathrm{Fe}(4 \mathrm{~s})$ or $\mathrm{Fe}-\mathrm{F}$ bonding molecular orbitals of $(8,9)(14,11)$ and $(14,12)$ were also applied. However, the larger active space did either not improve the wavefunction $[(8,9)]$, or the optimization process led to wavefunctions which did not contain the desired molecular orbitals in the active space $[(14,11),(14,12)]$. NEVPT2 calculations for $\mathrm{NFeF}_{3}$ were carried out with relativistic corrections using the second order Douglas-Kroll-Hess Hamiltonian. ${ }^{[14]}$ Three diagnostic criteria, $T_{1}, D_{1}$ and the $\% \operatorname{TAE}_{e}[(\mathrm{~T})]$ from $\mathrm{CCSD}(\mathrm{T})$ calculations were examined for all $\mathrm{NMF}_{3}$ compounds under consideration. Except $\mathrm{NFeF}_{3}$, all values shown in Table $\mathrm{S} 7$ are well within the limits of $T_{1} \leq 0.05, D_{1} \leq 0.15$ and $\% \mathrm{TAE} \leq 10$ for $3 \mathrm{~d}$ transition metal (TM) containing species $^{[15]}$ and $T_{1}<0.045, D_{1}<0.120$ and $\%$ TAE $<10$ for $4 d$ TM containing species. ${ }^{[16]}$ The $\mathrm{NOsF}_{3}{ }^{1} \mathrm{~A}^{\prime} /{ }^{3} \mathrm{~A}$ " minimum energy crossing point (MECP) was calculated at the UB3LYP/def2-TZVP[6b] and UHF-UCCSD(T)/cc-pVTZ(Os: cc-pVTZ-PP) level of theory using SurfCrossOpt as implemented in ORCA 4.2.0.[17] Harmonic vibrational frequency calculations were carried out for optimized structures analytically (BP86, 
B3LYP, M06-L) or numerically (CCSD $(T)$ and NEVPT2, step size of numerical differentiation: 0.01 a.u.) The $\mathrm{NFeF}_{3}, \mathrm{NRuF}_{3}$ and $\mathrm{NOsF}_{3}$ APES scans were carried out with the same active space as described above in $C_{\text {s }}$ point group symmetry. For $\mathrm{NFeF}_{3}$ 9 electronic states $\left(3 \times{ }^{1} A^{\prime}, 2 \times{ }^{1} A ", 2 \times{ }^{3} A^{\prime}\right.$ and $\left.2 \times{ }^{3} A^{\prime \prime}\right)$, for $\mathrm{NRuF}_{3}$ and $\mathrm{NOsF}_{3} 8$ electronic states $\left(2 \times{ }^{1} A^{\prime}, 1 \times{ }^{2} A^{\prime \prime}, 2 \times{ }^{3} A^{\prime}\right.$ and $\left.3 \times{ }^{3} A^{\prime \prime}\right)$ were averaged with equal weights with subsequent NEVPT2 treatment of all states individually. The Atoms in Molecules (AIM) charges ${ }^{[18]}$ (Tables S8 and S12) were calculated using Multiwfn 3.6. ${ }^{[19]}$ The NLMO/NPA Bond Orders, ${ }^{[20]}$ Natural Charges $(\text { NPA })^{[20]}$ and Wiberg Bond Indices ${ }^{[21]}$ (Tables S8 and S12) were calculated using the NBO 7.0 software. ${ }^{[22]}$ All rendered figures showing molecular structures and orbitals were obtained using the vmd 1.9.2 program. ${ }^{[23]}$

\section{Detailed Assignments}

By comparing spectra of the reaction products of different metal targets, metal dependent bands were identified. Further simplification was achieved by taking into account band positions of molecular binary fluorides $\mathrm{MF}_{\mathrm{n}}$, which were obtained by recording complementary spectra of the reaction products of metal atoms with elementary fluorine under the same conditions described above for the reaction with $\mathrm{NF}_{3}$. For each experiment those bands were selected which are absent in the spectra obtained with other metal targets and which could not be assigned to the binary metal fluorides NFn. Only this set of selected bands can be considered for the assignment of any novel species formed in this particular experiment. Their further assignment is based on the observed ${ }^{14 / 15} \mathrm{~N}$ isotope shift and on their similar behavior in different experiments, such as e.g. in annealing or photolysis experiments. Only a few bands 
from this selected set of bands could not be assigned to a $\operatorname{NMF}_{n}(n=3,4)$ species. They remained unassigned and were labelled e.g. with a diamond in each spectrum.

Photolysis experiments were conducted using LED light of $\lambda=730,656,617,590$, 528, 470, 455 and $273 \mathrm{~nm}$ and subsequently ArF excimer laser light of $\lambda=193 \mathrm{~nm}$.

\section{$\mathrm{NFeF}_{3}$}

The formation of molecular $\mathrm{NFeF}_{3}\left(C_{3 \mathrm{v}}\right)$ is proved by the assignment of all stretching vibrations marked A, B and $\mathbf{C}$ at $946.4,766.8$ and $658.8 \mathrm{~cm}^{-1}$ in the IR spectrum obtained after co-depositing laser-ablated iron and $\mathrm{NF}_{3}$ in excess neon shown in Figure S1 (see also Table S3). The FeF3 stretching modes split into a degenerate e and an a component at 766.8 and $658.8 \mathrm{~cm}^{-1}$, respectively. The latter shows a small ${ }^{14 / 15} \mathrm{~N}$ isotopic shift of $-1.1 \mathrm{~cm}^{-1}$. The corresponding bands for the group $6 \mathrm{NCrF}_{3}$ congener of $C_{3 v}$ point group symmetry $\left(798 \mathrm{~cm}^{-1}(\mathrm{e}), 709 \mathrm{~cm}^{-1}\left(\mathrm{a}_{1}\right)\right)^{[24]}$ are located about $30 \mathrm{~cm}^{-1}$ and $50 \mathrm{~cm}^{-1}$, respectively, higher than those assigned to $\mathrm{NFeF}_{3}$. This redshift is the result of a weakening of the M-F bonds due to the partial $e^{2}$ occupation of the Fe centered orbitals that are slightly antibonding with respect to these bonds. This is further supported by the computed, slightly elongated Fe-F bond distances (Cr-F: 170 pm, Fe-F: 172 pm). The vibrational e-type mode of $\mathrm{NFeF}_{3}$ exhibits a small splitting in two components $\left(766.8 \mathrm{~cm}^{-1}\right.$ and $\left.766.7 \mathrm{~cm}^{-1}\right)$ with different intensities, which indicates that the degeneracy is moderately lifted, most likely due to different orientations of the $\mathrm{NFeF}_{3}$ molecule within the matrix cavity. The $\mathrm{Fe}-\mathrm{N}$ stretch at $946.4 \mathrm{~cm}^{-1}$, marked $\mathbf{A}$ in Figure S1, shows a ${ }^{14 / 15} \mathrm{~N}$ isotopic shift of $-23.7 \mathrm{~cm}^{-1}$ (isotopic ratio of 1.0257). The band position of the previously reported cationic complex $\left[\left(\mathrm{TIMEN}^{\mathrm{R}}\right) \mathrm{Fe}^{\mathrm{IV}}(\mathrm{N})\right] \mathrm{BPh}_{4}\left(\mathrm{R}=\mathrm{xylyl}\right.$, mesityl) ${ }^{[25]}$ is with $1008 \mathrm{~cm}^{-1}$ higher, but (within given precision) exhibits the same isotopic ratio. Quantum-chemical calculations at the NEVPT2 level overestimate the N-Fe band position, but the predicted isotopic ratio of 
A.1. High-Spin Iron(VI), Low-Spin Ruthenium(VI), and Magnetically Bistable of Osmium(VI): Molecular Group 8 Nitrido Trifluorides $\mathrm{NMF}_{3}$

1.0256 is very close to the experimentally observed value of 1.0257 . Known bands at $744.7 / 744.7,752.6$ and $785.1 \mathrm{~cm}^{-1}$ were assigned to the molecular binary iron fluorides ${ }^{56} \mathrm{FeF}_{3},{ }^{56} \mathrm{FeF}_{2}$ and ${ }^{54} \mathrm{FeF}_{2}$, respectively. ${ }^{[26]}$

\section{$\mathrm{NRuF}_{3}$ and $\mathrm{NRuF}_{4}$}

The spectra recorded after co-depositing laser-ablated ruthenium and $\mathrm{NF}_{3}$ in excess of neon (Figure S2), clearly revealed the presence of two different nitrido ruthenium complexes, finally assigned to $\mathrm{NRuF}_{3}\left(C_{\mathrm{s}}\right)$ and $\mathrm{NRuF}_{4}\left(C_{4 \mathrm{v}}\right)$. Their characteristic $\mathrm{Ru}=\mathrm{N}$ stretching bands are labeled $\mathbf{A}\left(1105.4 \mathrm{~cm}^{-1}, \mathrm{NRuF}_{3}\right)$ and $\mathbf{A}^{\prime}\left(1098.5 \mathrm{~cm}^{-1}, \mathrm{NRuF}_{4}\right)$ in Figure S2. These bands show the same ${ }^{14 / 15} \mathrm{~N}$ isotopic ratio of 1.0305 (Table S3). Their isotopic pattern due to seven naturally occurring, stable ruthenium isotopes obtained from spectra recorded at $0.1 \mathrm{~cm}^{-1}$ are listed in Table S4 and compared in Figure S4 with the predicted pattern. For the $\mathbf{A}^{\prime}$ band the ${ }^{96 / 104} \mathrm{Ru}$ isotopic ratio were not experimentally determined, because of a low natural abundance (5.52\%) of the $\mathrm{N}^{96} \mathrm{RuF}_{4}$ isotopologue. $\mathrm{NRuF}_{4}$ is likely formed by the exothermic addition of a fluorine atom to $\mathrm{NRuF}_{3}$ (see Table S1).

The $\mathrm{RuF}_{3}$ stretching modes of $C_{\text {s }}$ symmetric $\mathrm{NRuF}_{3}$ split into three modes. The strong antisymmetric F-Ru-F appears at $668.5 \mathrm{~cm}^{-1}$ (labeled B in Figure S2) and likely overlaps with the nearby weaker F'-Ru band. A control experiment in which laserablated $\mathrm{Ru}$ was deposited with $\mathrm{F}_{2}$ instead of $\mathrm{NF}_{3}$ revealed that also a band associated with a ruthenium fluoride might contribute to the strong $\mathbf{B}$ absorption. The symmetric $\mathrm{F}-\mathrm{Ru}-\mathrm{F}$ mode is attributed to the band labelled $\mathbf{C}$ at $635.8 \mathrm{~cm}^{-1}$. From the RuF4 stretching modes of $\mathrm{NRuF}_{4}$ only the strongest band, the degenerate e-type mode could safely be assigned to the band labeled B' in Figure S2 centered at $700.0 \mathrm{~cm}^{-1}$. The much weaker predicted $\mathrm{RuF}_{4} \mathrm{a}_{1}$ band was not detected, probably because it is either too weak or overlapped by another band. The high-resolution spectrum shown 
in Figure S5 reveals a distinct ruthenium isotopic pattern for all these three assigned $\mathrm{Ru}-\mathrm{F}$ stretching modes (Tables S5 and S6). The band positions and isotopic pattern observed for $\mathrm{NRuF}_{4}$ can be compared well with those reported for $\mathrm{ORuF}_{4}$ isolated in solid nitrogen. ${ }^{[27]}$ The reported ${ }^{102} \mathrm{Ru} \equiv \mathrm{O}$ stretching mode $\left(1059.5 \mathrm{~cm}^{-1}\right)$ is red-shifted by about $39 \mathrm{~cm}^{-1}$ with respect to $v\left({ }^{102} \mathrm{Ru} \equiv \mathrm{N}\right)\left(1098.5 \mathrm{~cm}^{-1}\right.$, Table S3), while the $\mathrm{RuF}_{4}$ e-type mode is blue-shifted by about $10 \mathrm{~cm}^{-1}$. Considering the greater mass of oxygen and the more interacting nitrogen matrix, the small red-shift suggests very similar bonding in both species. In fact, the bond order of $\mathrm{Ru} \equiv \mathrm{O}$ in $\mathrm{ORuF}_{4}$ is predicted to be three as well.[28]

A few $\mathrm{Ru}-\mathrm{F}$ stretching bands remained unassigned. The ${ }^{96 / 104} \mathrm{Ru}$ isotopic ratio of the band labeled by a plus sign at $651.9 \mathrm{~cm}^{-1}$ in Figure $\mathrm{S} 2$ exhibits a characteristic ruthenium isotopic pattern expected for a mononuclear Ru complex, and the two bands labeled with a pound sign at 606.5 and $616.5 \mathrm{~cm}^{-1}$ show a different isotopic pattern, probably caused by a Ru dimer complex.

\section{$\mathrm{NOsF}_{3}$ and $\mathrm{NOsF}_{4}$}

The metal-nitrogen stretching region of the spectra obtained by co-depositing of laserablated osmium and ${ }^{14} \mathrm{NF}_{3}$ contains one band labeled $\mathbf{A}$ in Figure $\mathrm{S} 3$ at $1140.1 \mathrm{~cm}^{-1}$, while the spectra obtained using isotopic label ${ }^{15} \mathrm{NF}_{3}$ contains two $\mathrm{N}-\mathrm{O}$ s stretching bands. The first band at $1104.6 \mathrm{~cm}^{-1}$ is caused by the ${ }^{15} \mathrm{~N}$ isotopologue of $A$ and shows a ${ }^{14 / 15} \mathrm{~N}$ isotopic shift of $-35.5 \mathrm{~cm}^{-1}$ and a ${ }^{14 / 15} \mathrm{~N}$ isotopic ratio of 1.03214 . By applying the isotopic ratio obtained for $\mathbf{A}$ to the second band at $1086.0 \mathrm{~cm}^{-1}$, we obtain $1120.9 \mathrm{~cm}^{-1}$ as an estimated value for the ${ }^{14} \mathrm{~N}$ isotopologue of the second band labeled $\mathbf{A}^{\prime}$ in Figure S3. This band is overlapped by the stronger band associated with the ${ }^{14} \mathrm{NF}$ radical. Both bands are assigned to $\mathrm{NOsF}_{3}$ in two electronic states. Band $\mathbf{A}$ 
is assigned to the Os=N stretching mode of $\mathrm{NOsF}_{3}$ in the ${ }^{1} \mathrm{~A}^{\prime}$ ground state, and band A' to $\mathrm{NOsF}_{3}$ in a near-by excited ${ }^{3} \mathrm{~A}$ " electronic state. The Os-F stretching bands assigned to $\mathrm{NOsF}_{3}\left({ }^{1} \mathrm{~A}^{\prime}\right)$ are labeled $\mathbf{B}, \mathbf{C}$ and $\mathbf{D}$ in Figure S3 and are at 686.0, with a matrix site at $686.6 \mathrm{~cm}^{-1}$, at 641.3 with a weaker matrix site at $640.1 \mathrm{~cm}^{-1}$ and at $632.3 \mathrm{~cm}^{-1}$, respectively. Bands $\mathbf{B}$ and $\mathbf{D}$ are assigned to the symmetric and antisymmetric F-Os-F stretching mode, respectively, and $\mathbf{C}$ to the $\mathrm{F}^{\prime}-\mathrm{O}$ s stretching mode. Bands labeled B', C' and D' at $675.8 \mathrm{~cm}^{-1}$ (with a matrix site at $677.0 \mathrm{~cm}^{-1}$ ), $660.5 \mathrm{~cm}^{-1}$ (matrix site at $658.9 \mathrm{~cm}^{-1}$ ), and $607.4 \mathrm{~cm}^{-1}$, respectively, are assigned to $\mathrm{NOsF}_{3}\left({ }^{3} \mathrm{~A}\right)$. Finally, the band labeled $\mathbf{A}$ " at $689.6 \mathrm{~cm}^{-1}$ is tentatively assigned to the $\mathrm{OsF}_{4}$ e-type mode of $\mathrm{NOsF}_{4}$ in $\mathrm{C}_{4 v}$ symmetry. The $\mathrm{N}-\mathrm{Os}$ stretching band and the remaining Os-F stretching bands of $\mathrm{NOsF}_{4}$ are predicted with significantly lower intensity and were not detected. The intensity of the bands assigned to $\mathrm{NOsF}_{3}$ and $\mathrm{NOsF}_{4}$ did not change in annealing and photolysis experiments. All assignments and isotopic shifts are in excellent agreement with values obtained at the $\operatorname{CCSD}(T)$ level of theory summarized in Table S3.

\section{Supplemental Computational Results}

\section{$\mathrm{NFeF}_{\mathbf{3}}$}

The B3LYP hybrid functional was found to perform worst when comparing the $\mathrm{Fe}-\mathrm{N}$ bond length and stretching frequency with results from other single-reference methods (DFT and $\operatorname{CCSD}(\mathrm{T})$ ) or multi-reference NEVPT2 calculations (Table S2). To obtain reliable structural and vibrational data for $\mathrm{NFeF}_{3}$ by taking dynamical, non-dynamical and core-valence correlation effects, as well as scalar relativistic effects into account the NEVPT2/CASSCF(8,8)/aVTZ-DK(Fe: awCVTZ-DK) method was employed. The 
rearrangement of the iron fluoroimino intermediate, $\mathrm{FN}=\mathrm{FeF}_{2}$, to the high-valent iron nitrido trifluoride $\mathrm{N}=\mathrm{FeF}_{3}$ is predicted to be exothermic by only $-7 \mathrm{~kJ} \mathrm{~mol}^{-1}$ at the B3LYP level (Table S1), while the GGA and meta-GGA functionals BP86 and M06-L predict more exothermic reaction enthalpies of -78 and $-74 \mathrm{~kJ} \mathrm{~mol}^{-1}$, respectively. The latter predictions agree better with the NEVPT2 results (Table S2). CASSCF $(8,8)$ calculations reveal that the leading configuration of $\mathrm{NFeF}_{3}$ is $\sigma^{2} \pi^{2} \pi^{2} \delta^{1} \delta^{1} \pi^{\star 0} \pi^{\star 0} \sigma^{\star 0}$, which contributes only $60 \%$ to the ${ }^{3} \mathrm{~A}_{2}$ ground state. The small ligand field splitting, $\mathrm{i}$. e. the low energy gap between the non-bonding $3 d(\mathrm{Fe}, \delta)-\mathrm{MOs}$ and the antibonding MOs indicates a poor overlap between the $3 d(\mathrm{Fe})$ orbitals with the $\mathrm{N}^{3-}$ ligand orbitals, ${ }^{[29]}$ and leads to a significant population of $\mathrm{Fe}=\mathrm{N}$ antibonding $\pi^{\star}$ and $\sigma^{*}$ orbitals (Figure S6). The effective bond order ${ }^{[30]}(\mathrm{EBO})$ of the individual bonds is $0.8(\sigma)$ and $0.7(\pi)$, a total of 2.2 , or an integer BO of 3 . The NLMO bond order of 2.30 and the Wiberg bond index of 2.52 obtained from analyzing the DFT wavefunction (Table S8) further support the assignment of a Fe $=\mathrm{N}$ triple bond. The short calculated $\mathrm{Fe} \equiv \mathrm{N}$ bond length of $153 \mathrm{pm}$ is within the range of reported crystallographic data for iron complexes with triply bonded nitride ligands of $153 \mathrm{pm}\left(\left[\left(\operatorname{TIMEN}^{\mathrm{R}}\right) \mathrm{Fe}^{\mathrm{IV}}(\mathrm{N})\right] \mathrm{BPh} 4, \mathrm{R}=\right.$ xylyl, mesityl), ${ }^{[25]} \quad 151 \mathrm{pm} \quad\left(\left[\mathrm{PhB}\left({ }^{\mathrm{t} B u l m}\right){ }_{3} \mathrm{Fe}^{\mathrm{IV}}(\mathrm{N})\right]\right)^{[31]}$ and $150-151 \mathrm{pm}$ $\left(\left[\mathrm{PhB}\left({ }^{\mathrm{t} B u l m}\right)_{3} \mathrm{Fe}^{\mathrm{V}}(\mathrm{N})\right] \mathrm{BarF}_{24}\right)^{[31]}$, or $157 \mathrm{pm}\left(\left[\left(\mathrm{Me}_{3} \mathrm{cyac}\right) \mathrm{Fe}^{\mathrm{Vl}}(\mathrm{N})\right]\left(\mathrm{PF}_{6}\right)_{2}\right.$, derived from EXAFS data) ${ }^{[32] .}$ 


\section{Supporting Figures}

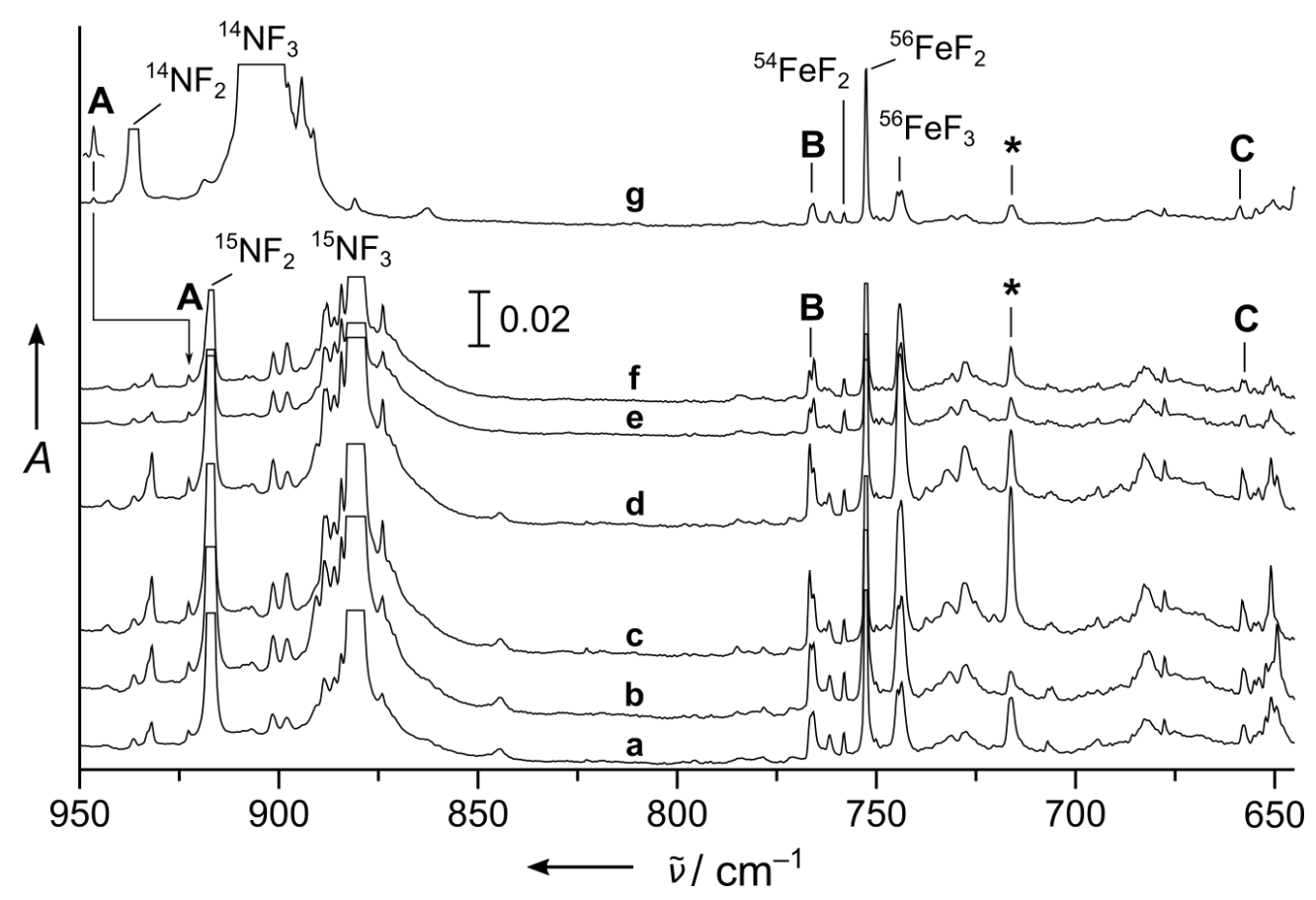

Figure S1. IR spectra of laser ablated iron co-deposited with $0.1 \%{ }^{15} \mathrm{NF}_{3}$ in $\mathrm{Ne}(\mathbf{a})$, after 10 min irradiation using LED light of $\lambda=656 \pm 10 \mathrm{~nm}$ (b), $470 \pm 10 \mathrm{~nm}$ (c), $273 \pm 10 \mathrm{~nm}$ (d), as well as a 193 $\mathrm{nm}$ excimer laser radiation (e), and successive annealing to $T=10 \mathrm{~K}(\mathbf{f})$. Experiment using $0.1 \%$ ${ }^{14} \mathrm{NF}_{3}$ in $\mathrm{Ne}(\mathrm{g})$. Bands labeled $\mathbf{A}, \mathbf{B}$ and $\mathbf{C}$ are assigned to $\mathrm{NFeF}_{3}$ (see Table S3). Band $\mathbf{A}$ is by a factor of five in spectrum $\mathbf{g}$. Known bands of binary iron fluorides ${ }^{[26]}$ are indicated, and an unassigned band showing no ${ }^{14 / 15} \mathrm{~N}$ isotopic shift is marked with an asterisk. Note that $\mathrm{NFeF}_{3}$ is unaffected by annealing to $10 \mathrm{~K}$ or the selective LED radiations, but this band slightly gains intensity upon irradiation with LED light with $\lambda=656 \mathrm{~nm}$ and lose intensity when irradiated with laser light of $\lambda=193 \mathrm{~nm}$. 


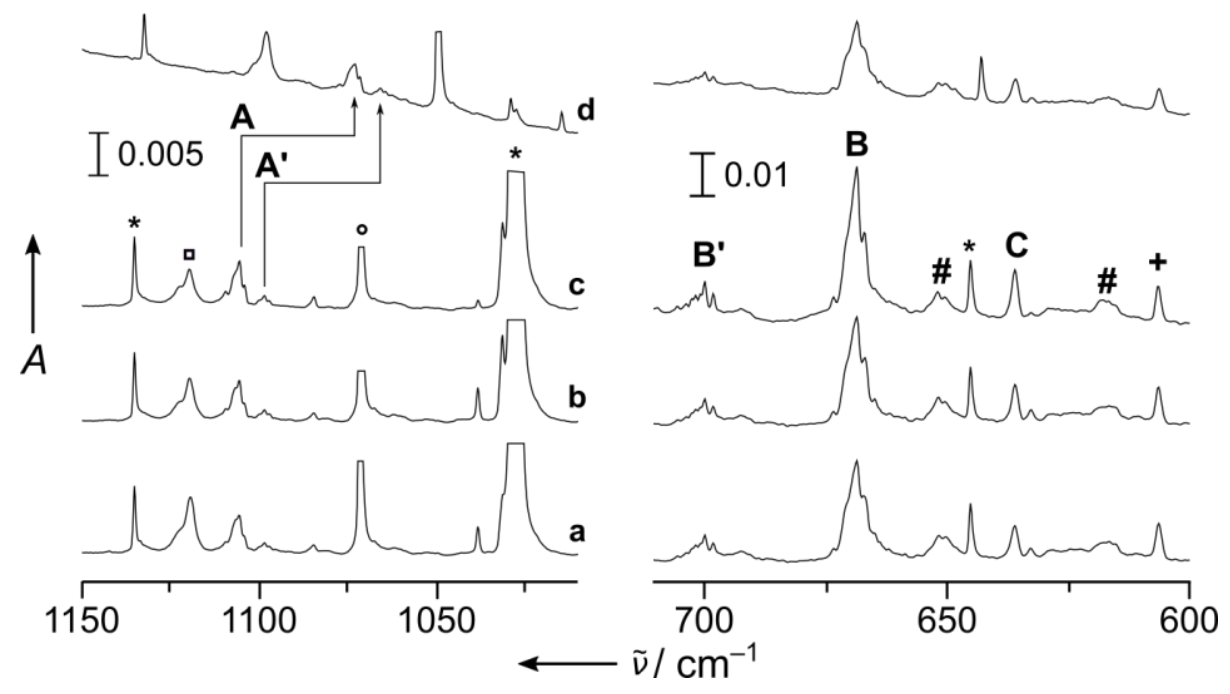

Figure S2. IR spectra of laser ablated ruthenium co-deposited with $0.1 \%{ }^{14} \mathrm{NF}_{3}$ in $\mathrm{Ne}(\mathbf{a})$, after annealing to $10 \mathrm{~K}(\mathbf{b})$, and broadband photolysis (c). Co-deposition of Ru with $0.1 \%{ }^{15} \mathrm{NF}_{3}$ in $\mathrm{Ne}(\mathbf{d})$. Bands labeled A - C are attributed to $\mathrm{NRuF}_{3}$ and $\mathbf{A}^{\prime}$ and $\mathbf{B}^{\prime}$ are due to $\mathrm{NRuF}_{4}$. Unknown product bands are labeled by a pound and plus sign, respectively. The bands associated with ${ }^{14} \mathrm{NF},{ }^{14} \mathrm{NF}_{2}$ and ${ }^{14} \mathrm{NF}_{3}$ are marked with squares, circles and asterisks, respectively. ${ }^{[33]}$

Note that the ${ }^{96 / 104} \mathrm{Ru}$ isotopic ratio of the band labeled by a plus sign at $651.9 \mathrm{~cm}^{-1}$ exhibits a characteristic ruthenium isotopic pattern expected for a mononuclear $\mathrm{Ru}$ complex, while the two bands labeled with a pound sign at 606.5 and $616.5 \mathrm{~cm}^{-1}$ show a different isotopic pattern, probably caused by a Ru dimer complex. 


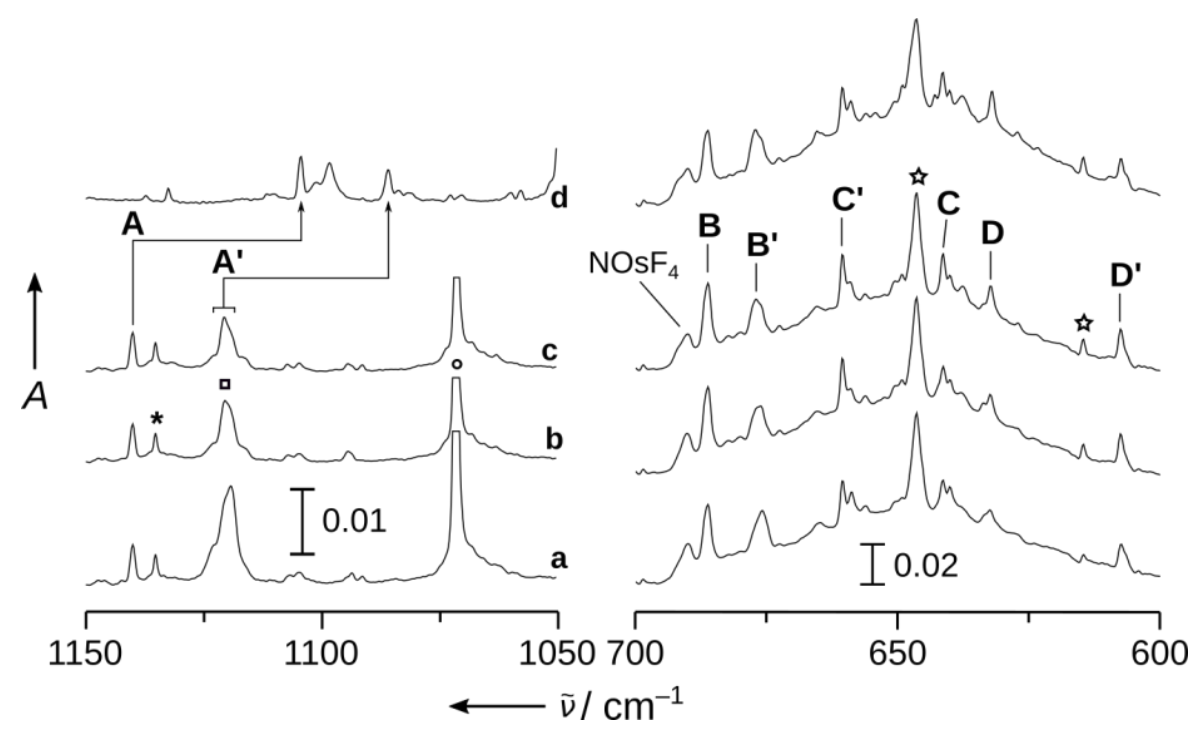

Figure S3. IR spectra of laser ablated osmium co-deposited with $0.1 \%{ }^{14} \mathrm{NF}_{3}$ in $\mathrm{Ne}(\mathbf{a})$, after annealing to $10 \mathrm{~K}(\mathbf{b})$, and broadband photolysis (c). Co-deposition of Os with $0.1 \%{ }^{15} \mathrm{NF}_{3}$ in $\mathrm{Ne}(\mathbf{d})$. Bands labeled A-D are attributed to $\mathrm{NOsF}_{3}$ and $\mathbf{A}^{\prime}-\mathbf{D}$ ' to $\mathrm{NOsF}_{3}\left({ }^{3} \mathrm{~A}\right.$ "). Bands of binary osmium fluorides are marked with star symbols. The bands associated with ${ }^{14} \mathrm{NF},{ }^{14} \mathrm{NF}_{2}$ and ${ }^{14} \mathrm{NF}_{3}$ are marked with squares, circles and asterisks, respectively. ${ }^{[33]}$ 


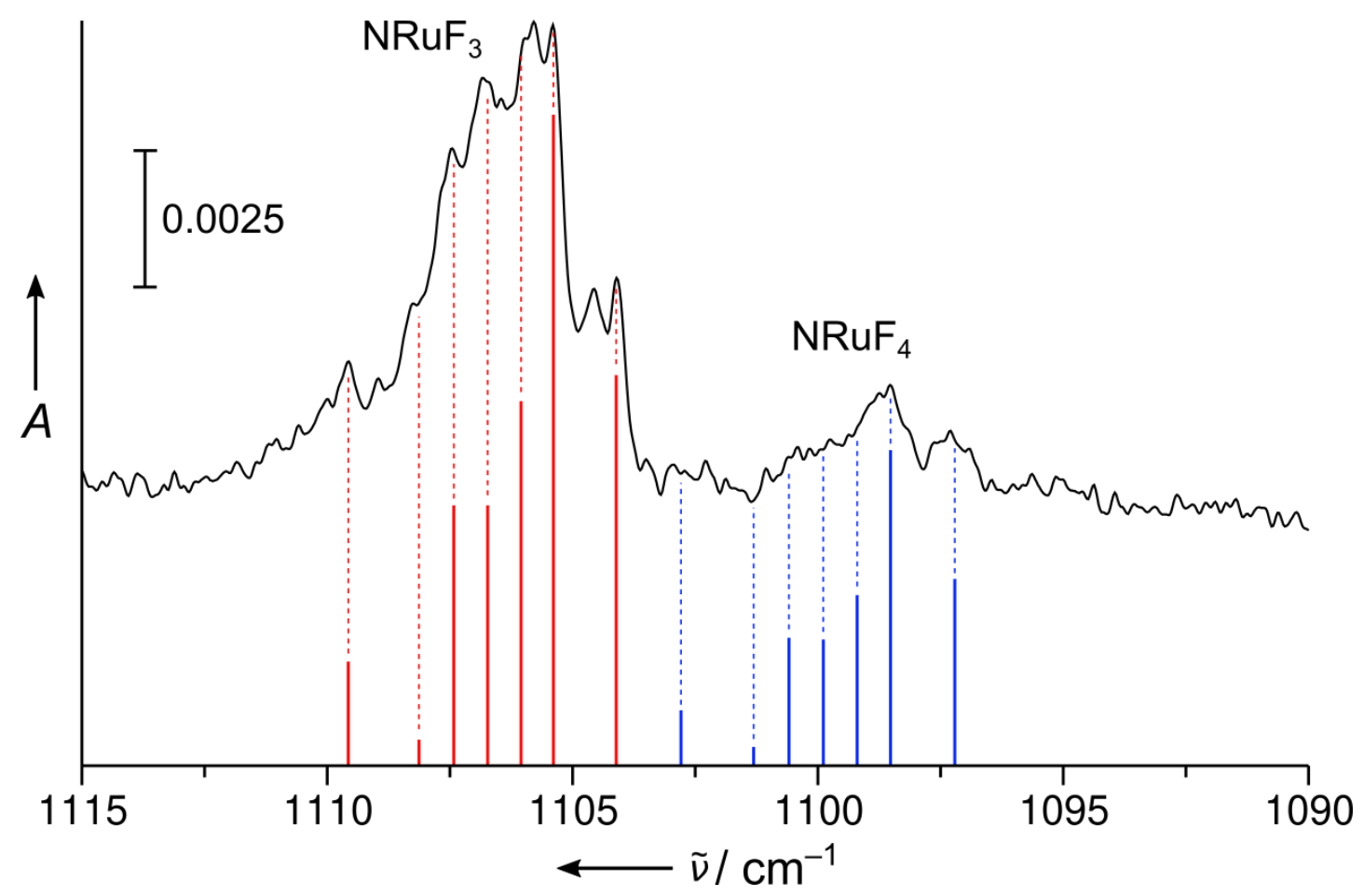

Figure S4. Infrared absorption spectrum of laser ablated ruthenium with $0.1 \% \mathrm{NF}_{3}$ displaying the $\mathrm{N}$ $\mathrm{Ru}$ stretching bands of $\mathrm{NRuF}_{3}$ and $\mathrm{NRuF}_{4}$ in a spectral resolution of $0.1 \mathrm{~cm}^{-1}$. The pattern is caused by the seven naturally occurring, stable ruthenium isotopes (see Table S4). 
A.1. High-Spin Iron(VI), Low-Spin Ruthenium(VI), and Magnetically Bistable of Osmium(VI): Molecular Group 8 Nitrido Trifluorides $\mathrm{NMF}_{3}$

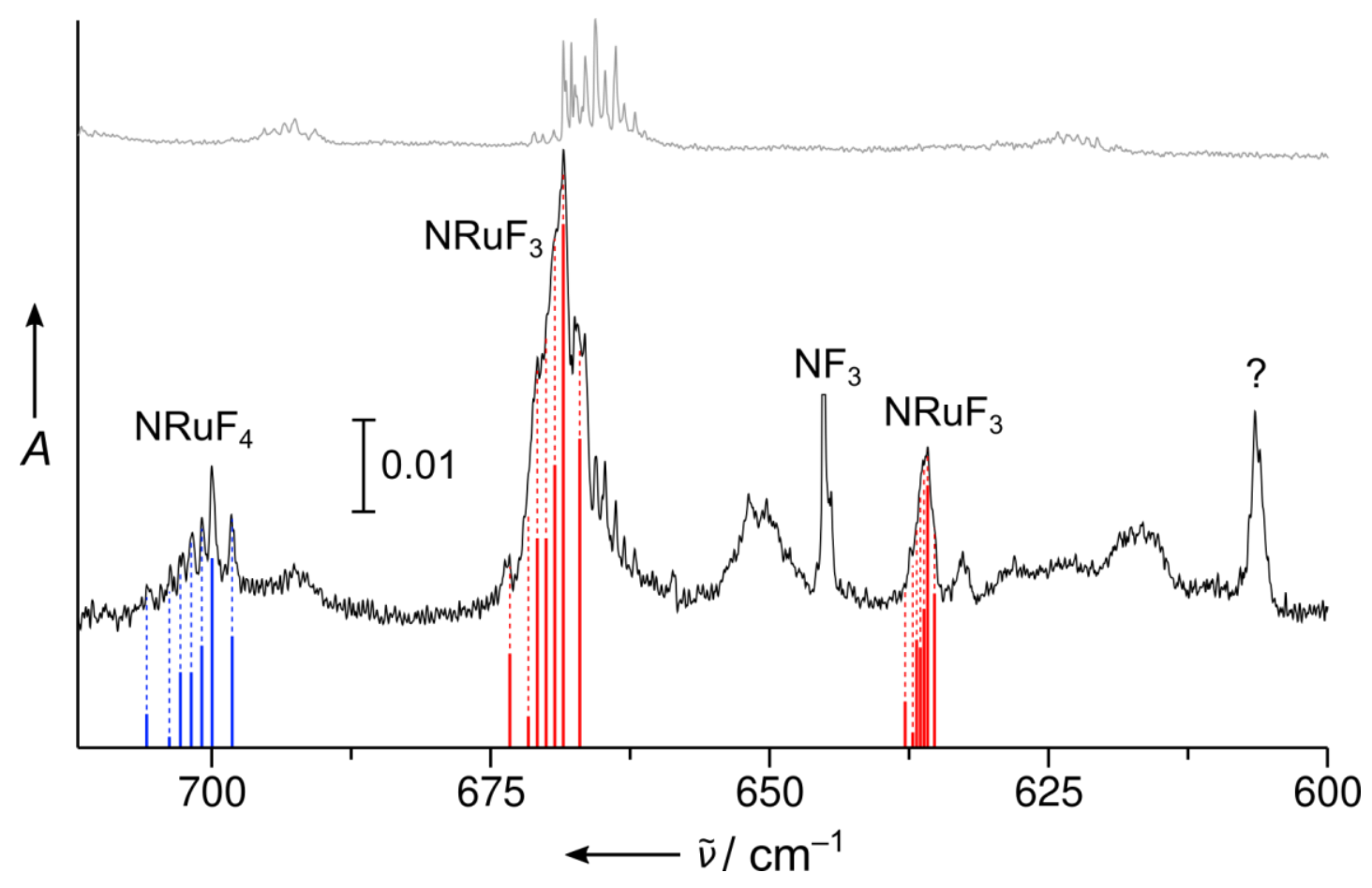

Figure S5. Infrared absorption spectrum of laser ablated ruthenium with $0.1 \% \mathrm{NF}_{3}$ displaying the RuF stretching bands of $\mathrm{NRuF}_{3}$ and $\mathrm{NRuF}_{4}$ in a spectral resolution of $0.1 \mathrm{~cm}^{-1}$. The pattern is caused by the seven naturally occurring, stable ruthenium isotopes (see Tables S5 and S6). 


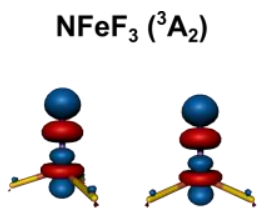

$13 \mathrm{a}_{1}$

0.20

0.0012

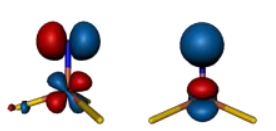

$10 \mathrm{e}$

0.30

$-0.1180$

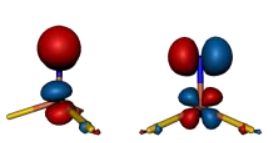

$10 \mathrm{e}$

0.30

$-0.1180$

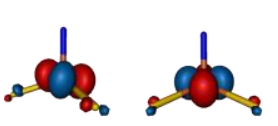

$9 \mathrm{e}$

1.00

$-0.3320$

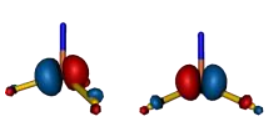

9 e

1.00

$-0.3320$

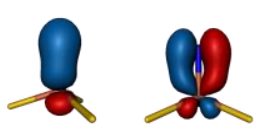

8 e

1.70

$-0.5989$

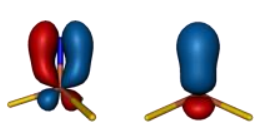

8 e

1.70

$-0.5989$

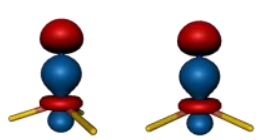

$12 \mathrm{a}_{1}$

1.80

$-0.6807$

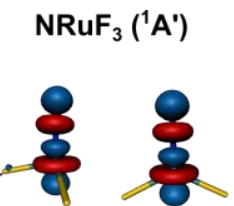

18a'

0.07

0.2004

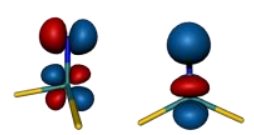

17a'

0.11

$-0.0020$

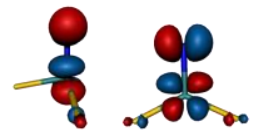

10a"

0.09

0.0517

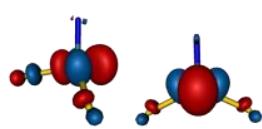

18a'

0.01

0.0313

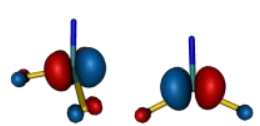

8a"

1.98

$-0.5464$

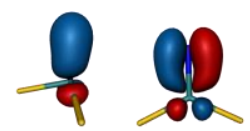

9a"

1.91

$-0.5872$

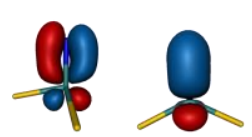

$16 a^{\prime}$

1.89

$-0.5996$

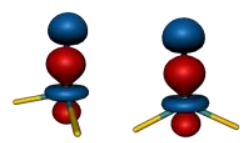

15a'

1.93

$-0.6636$
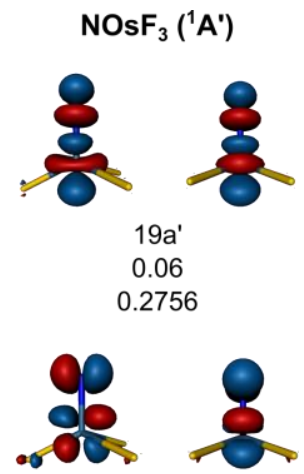

18a'

0.08

0.1084

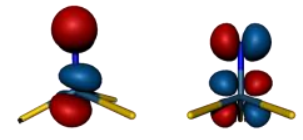

9a"

0.09

0.0456

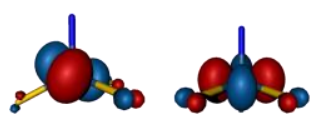

$17 a^{\prime}$

1.97

$-0.4871$

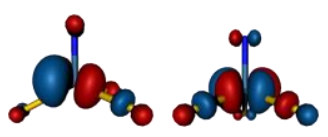

10a"

0.03

0.0580

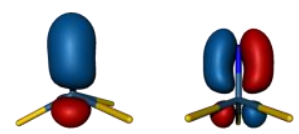

8 a"

1.91

$-0.5652$

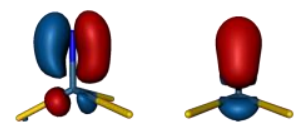

16a'

1.92

$-0.5496$

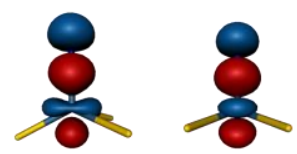

$15 a^{\prime}$

1.94

$-0.6308$
$\mathrm{NOsF}_{3}\left({ }^{3} \mathrm{~A}^{\prime \prime}\right)$
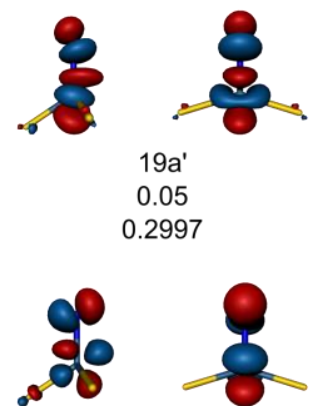

$18 a^{\prime}$

0.09

0.0941
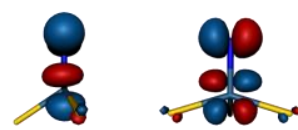

10a"

0.09

0.0697
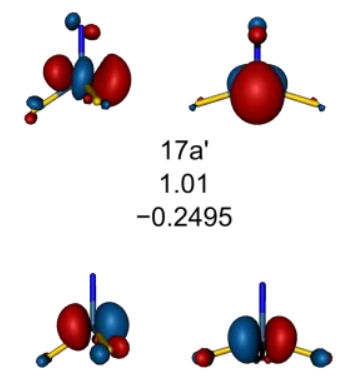

9a"

1.00

$-0.2623$
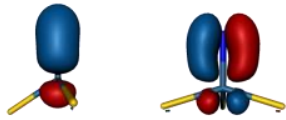

8a"

1.91

$-0.5619$
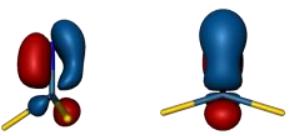

$16 a^{\prime}$

1.91

$-0.5768$
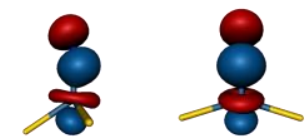

$15 a^{\prime}$

1.94

$-0.6450$

Figure S6. Active space natural molecular orbital plot at $\sigma=0.1 \mathrm{e} \mathrm{Bohr}^{-3}$, irreproducible representations, occupation numbers and orbital energies (hartree) of $\mathrm{NFeF}_{3}\left({ }^{3} \mathrm{~A}_{2}\right), \mathrm{NRuF}_{3}\left({ }^{1} A^{\prime}\right)$, $\mathrm{NOsF}_{3}\left({ }^{1} \mathrm{~A}^{\prime}\right)$ and $\mathrm{NOsF}_{3}\left({ }^{3} \mathrm{~A}^{\prime \prime}\right)$ calculated at the CASSCF $(8,8) /$ aug-cc-pVTZ(-PP) level of theory at the 
A.1. High-Spin Iron(VI), Low-Spin Ruthenium(VI), and Magnetically Bistable of Osmium(VI): Molecular Group 8 Nitrido Trifluorides $\mathrm{NMF}_{3}$

$\operatorname{CCSD}(T) /$ aug-cc-pVTZ-(-PP) ( $M=R u$, Os) or NEVPT2/aug-cc-pwCVTZ-DK (M = Fe) optimized ground state structures. For the singlet states of $\mathrm{NRhF}_{3}$ and $\mathrm{NOsF}_{3}$ a state-averaging procedure (Molpro: "states,2;weight,0.9,0.1") was applied to include the desired orbitals into the active space. Two columns are shown for each species: In the right column the molecules are shown in the $x z$ plane, whereas they are shown in the yz plane in the left column. The molecular orbitals for each species are ordered according to those of $\mathrm{NFeF}_{3}$ as reference.

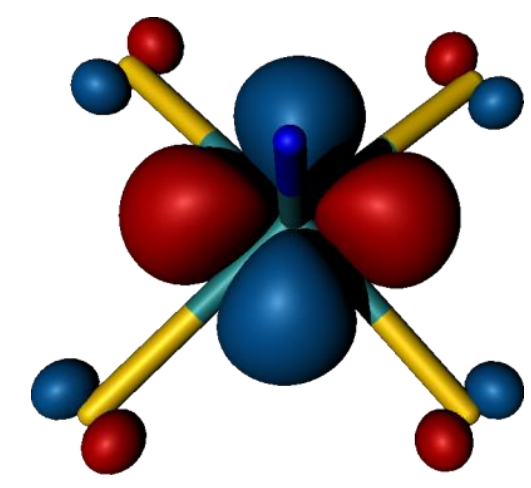

Figure S7. Singly occupied molecular orbital (SOMO) plot of $\mathrm{NRuF}_{4}$ at $\sigma=0.1 \mathrm{e} \mathrm{Bohr}^{-3}$ obtained at the ROHF/aug-cc-pVTZ(Ru: aug-cc-pVTZ-PP) level of theory. 


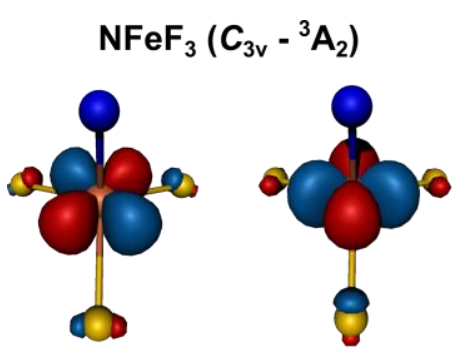

$9 \mathrm{e}$

1.00

$-0.3320$
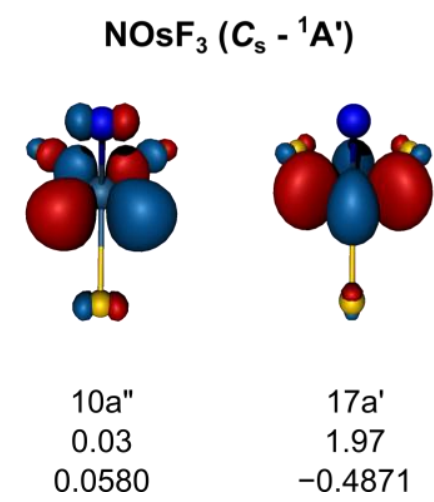

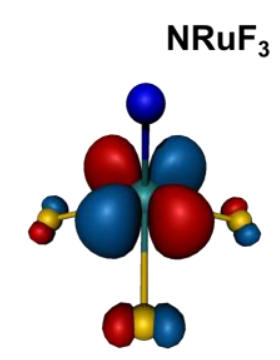

$8 a^{\prime \prime}$

1.98

$-0.5464$

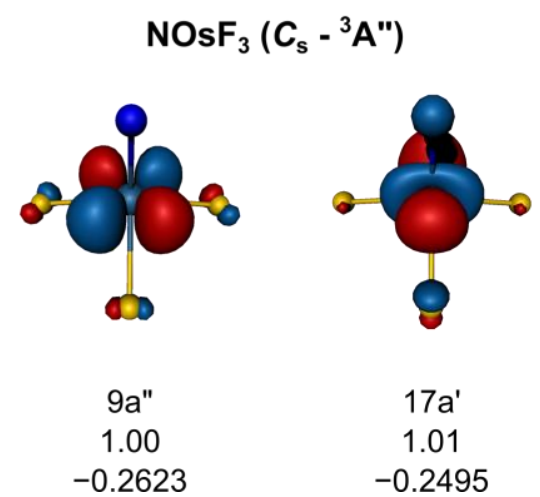

Figure S8. Plot of the metal centered e-type natural molecular orbitals of $\mathrm{NMF}_{3}$ at $\sigma=0.1$ e Bohr-3, irreproducible representations, occupation numbers and orbital energies (hartree) of $\mathrm{NFeF}_{3}\left({ }^{3} \mathrm{~A}_{2}\right)$, $\mathrm{NRuF}_{3}\left({ }^{1} \mathrm{~A}^{\prime}\right), \mathrm{NOsF}_{3}\left({ }^{1} \mathrm{~A}^{\prime}\right)$ and $\mathrm{NOsF}_{3}\left({ }^{3} \mathrm{~A}^{\prime}\right)$ calculated at the CASSCF $(8,8)$ /aug-cc-pVTZ(-PP) level of theory at the $\operatorname{CCSD}(T) /$ aug-cc-pVTZ-(-PP) (M = Ru, Os) or NEVPT2/aug-cc-pwCVTZ-DK ( $\mathrm{M}=\mathrm{Fe})$ optimized ground state structures. For the singlet states of $\mathrm{NRhF}_{3}$ and $\mathrm{NOsF}_{3}$ a state-averaging procedure (Molpro: "states,2;weight,0.9,0.1") was applied to include the desired orbitals into the active space. 
A.1. High-Spin Iron(VI), Low-Spin Ruthenium(VI), and Magnetically Bistable of Osmium(VI): Molecular Group 8 Nitrido Trifluorides $\mathrm{NMF}_{3}$

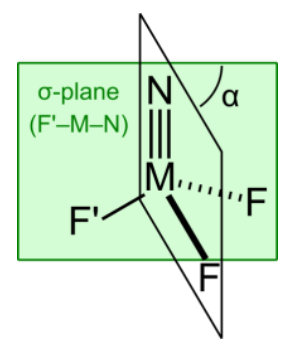

Figure S9. Dihedral angle $\alpha$ between the $\mathrm{F}^{\prime}-\mathrm{M}-\mathrm{N} \sigma-$ plane and a $\mathrm{F}-\mathrm{M}-\mathrm{N}$ plane. 


\section{Supplementary Tables}

Table S1. Experimental Fe-N distances $(\AA)$ and stretching fundamentals $\left(\mathrm{cm}^{-1}\right)$ of representative high-valent iron nitride complexes.

\begin{tabular}{|c|c|c|}
\hline Complex & Fe-N distances $(\AA ̊)$ & $\mathrm{Fe}-{ }^{-14} \mathrm{~N}$ stretch $\left(\mathrm{cm}^{-1}\right)$ \\
\hline$\left[\mathrm{Fe}^{\mathrm{V} N} \mathrm{~N}(\mathrm{OEP})\right]^{[\mathrm{a}]}$ & & $876(\mathrm{RR})$ \\
\hline$\left[\mathrm{Fe} e^{\mathrm{N}}(\mathrm{TPP})\right]^{[\mathrm{a}]}$ & & $876(\mathrm{RR})$ \\
\hline$\left[\mathrm{Fe}^{\mathrm{V} N} \mathrm{~N}(\mathrm{TTPPP})\right]^{[\mathrm{b}]}$ & & $876(\mathrm{RR})$ \\
\hline$\left[\mathrm{Fe}^{\vee}(\mathrm{N})\left(\mathrm{Me}_{2} \mathrm{Py}_{2} \mathrm{TACN}\right)\right]^{2+[c]}$ & & 866 (IRPD) \\
\hline$\left[\mathrm{Fe}^{\vee}(\mathrm{N})\left(\mathrm{MePy}_{2} \mathrm{TACN}\right)\right]\left(\mathrm{PF}_{6}\right)_{2}{ }^{[34]}$ & 1.64(1) (EXAFS) & 855 (IRPD) \\
\hline$\left[\mathrm{Fe}^{\vee}(\mathrm{N})(\mathrm{cyclam}-\mathrm{ac})\right]^{+}[\mathrm{d}]$ & 1.61(1) (EXAFS) & 864 (NRVS) \\
\hline$\left[\mathrm{Fe}^{\mathrm{VI}}(\mathrm{N})\left(\mathrm{Me}_{3} \mathrm{cyclam}-\mathrm{ac}\right)\right]^{2+[32]}$ & 1.57(2) (EXAFS) & \\
\hline$\left[\mathrm{Fe}^{\mathrm{IV}}(\mathrm{N})\left(\mathrm{PhB}\left(\mathrm{CH}_{2} \mathrm{P}^{\mathrm{i}} \mathrm{Pr}_{2}\right)_{3}\right]^{[35]}\right.$ & $1.51-1.55$ (EXAFS) & 1034 \\
\hline$\left[\mathrm{Fe}^{\mathrm{IV}}(\mathrm{N})\left(\mathrm{P}_{3} \mathrm{~B}\right)\right]^{+[\mathrm{e}]}$ & 1.54(2) (EXAFS) & \\
\hline$\left[\mathrm{Fe}^{\mathrm{IV}}(\mathrm{N})\left(\mathrm{PhB}\left({ }^{\mathrm{t} B u l m}\right)_{3}\right)\right]^{[36][f]}$ & $1.532(5)$ (X-Ray) & \\
\hline$\left[\mathrm{Fe}^{\mathrm{IV}}(\mathrm{N})\left(\mathrm{PhB}\left({ }^{(\mathrm{B} u l m}\right)_{3}\right)\right]^{[37]}$ & 1.512(1) (X-Ray) & $1028(\mathrm{RR})$ \\
\hline$\left[\mathrm{Fe} \vee(\mathrm{N})\left(\mathrm{PhB}\left({ }^{\mathrm{t}} \mathrm{Bulm}\right)_{3}\right)\right]^{+}[31]$ & 1.506(2)/1.502(2) (X-Ray) & \\
\hline$\left[\mathrm{Fe}^{\mathrm{IV}}(\mathrm{N})(\mathrm{TIMENMes})\right]^{+}[\mathrm{gg}[25]$ & 1.526(2) (X-Ray) & 1008 \\
\hline$\left[\mathrm{Fe}^{\mathrm{IV}}(\mathrm{N})\left(\mathrm{TIMMN}^{\mathrm{Mes}}\right)\right]^{+}[38]$ & 1.513(3) (X-Ray) & \\
\hline $\left.\mathrm{Fe}^{\mathrm{V}}(\mathrm{N})\left(\mathrm{TIMMNM}^{\mathrm{Mes}}\right)\right]^{2+[38]}$ & 1.529(1) (X-Ray) & \\
\hline
\end{tabular}

[a]: RR: Resonance Raman (OEP2-: octaethylporphinato dianion, TPP2-: tetraphenylporphinato dianion). ${ }^{[39]} v(\mathrm{M}=\mathrm{N})$ of stable nitridomanganese $(\mathrm{V})$ porphyrins and nitridochromium( $\left.\mathrm{V}\right)$ porphyrins were observed at $1049-1052 \mathrm{~cm}^{-1}$ for the former ${ }^{[40]}$ and at $1017 \mathrm{~cm}^{-1}$ for the latter. ${ }^{[41]}$

[b]: RR: Resonance Raman (TTPPP2- = tetrakis-(2,4,6-triphenylphenyl)porphyrinato dianion). ${ }^{[42]}$

[c]: ( $\left.\mathrm{Me}_{2} \mathrm{Py}_{2} \mathrm{tacn}\right)$ : 1-(di(pyridin-2-yl) methyl)-4,7-dimethyl-1,4,7-triazacyclononane, IRPD: infrared photodissociation; [34b]

[d]: NRVS: nuclear resonant vibrational spectroscopy. ${ }^{[43]}$

[e]: $\mathrm{P}_{3} \mathrm{~B}:=$ tris(o-diisopropylphosphinophenyl)borane. ${ }^{[44]}$

[f]: $\left.\mathrm{PhB}\left({ }^{(} \mathrm{Bulm}\right){ }_{3}\right)^{-}=$phenyltris(3-tert-butylimidazol-2-ylidene.

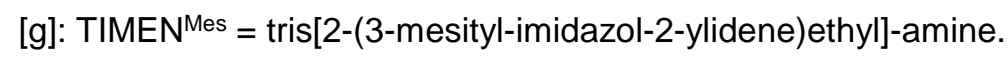

[h]: TIMMNMes $^{\text {= tris-[2-(3-mesityl-imidazol-2-ylidene) methyl]-amine. }}$ 
A.1. High-Spin Iron(VI), Low-Spin Ruthenium(VI), and Magnetically Bistable of Osmium(VI): Molecular Group 8 Nitrido Trifluorides $\mathrm{NMF}_{3}$

Table S2. Selected reaction enthalpies at $T=0$ for $M N F_{n}$ compounds $(n=1-3$ for $M=F e$ and $n=1-$ 4 for $\mathrm{M}=\mathrm{Ru}, \mathrm{Os}$ ) obtained at the B3LYP, BP86 and M06-L (Fe only) levels of theory. ${ }^{[a]}$

\begin{tabular}{|c|c|c|c|c|}
\hline \multirow{2}{*}{\multicolumn{2}{|c|}{ Reaction }} & \multicolumn{3}{|c|}{$\Delta H^{0}\left[\mathrm{~kJ} \mathrm{~mol}^{-1}\right]$} \\
\hline & & \multirow{2}{*}{$\begin{array}{c}\text { B3LYP } \\
-331\end{array}$} & \multirow{2}{*}{$\begin{array}{c}\text { BP86 } \\
-391\end{array}$} & \multirow{2}{*}{$\frac{\text { M06-L }}{-351}$} \\
\hline $\mathrm{Fe}+\mathrm{NF}_{3}$ & $\rightarrow \mathrm{F}_{2} \mathrm{NFeF}\left({ }^{3} \mathrm{~A}^{\prime}\right)$ & & & \\
\hline $\mathrm{F}_{2} \mathrm{NFeF}\left({ }^{3} \mathrm{~A}^{\prime}\right)$ & $\rightarrow \mathrm{FNFeF}_{2}\left({ }^{3} \mathrm{~A}^{\prime \prime}\right)$ & -239 & -246 & -267 \\
\hline $\mathrm{FNFeF}_{2}\left({ }^{2} \mathrm{~A} "\right)$ & $\rightarrow \mathrm{NFeF}_{3}\left(C_{3 \mathrm{v}},{ }^{3} \mathrm{~A}_{2}\right){ }^{[\mathrm{a}]}$ & -4 & -78 & -74 \\
\hline $\mathrm{NFeF}_{3}\left({ }^{3} \mathrm{~A}_{2}-\mathrm{C}_{3 \mathrm{v}}\right)$ & $\rightarrow \mathrm{NFeF}_{2}\left({ }^{2} \mathrm{~A}_{2}\right)+\mathrm{F}$ & 277 & 327 & 324 \\
\hline $\mathrm{NFeF}_{3}\left({ }^{3} \mathrm{~A}_{2}-\mathrm{C}_{3 \mathrm{v}}\right)$ & $\rightarrow \mathrm{NFeF}_{2}\left({ }^{2} \mathrm{~A}_{2}\right)+1 / 2 \mathrm{~F}_{2}$ & 204 & 224 & 250 \\
\hline $\mathrm{NFeF}_{3}\left({ }^{3} \mathrm{~A}_{2}-\mathrm{C}_{3 \mathrm{v}}\right)$ & $\rightarrow \mathrm{NFeF}\left({ }^{1} A^{\prime}\right)+\mathrm{F}_{2}$ & 597 & 592 & 604 \\
\hline $\mathrm{NFeF}_{3}\left({ }^{3} \mathrm{~A}_{2}-\mathrm{C}_{3 \mathrm{v}}\right)+\mathrm{F}$ & $\rightarrow \mathrm{NFeF}_{2}\left({ }^{2} \mathrm{~A}_{2}\right)+\mathrm{F}_{2}$ & 131 & 121 & 177 \\
\hline $\mathrm{Ru}+\mathrm{NF}_{3}$ & $\rightarrow \mathrm{F}_{2} \mathrm{NRuF}\left({ }^{3} \mathrm{~A} "\right)$ & -386 & -439 & - \\
\hline $\mathrm{F}_{2} \mathrm{NRuF}\left({ }^{3} \mathrm{~A} "\right)$ & $\rightarrow \mathrm{FNRuF}_{2}\left({ }^{3} \mathrm{~A}^{\prime \prime}\right)$ & -238 & -258 & - \\
\hline $\mathrm{FNRuF}_{2}\left({ }^{3} \mathrm{~A}{ }^{\prime \prime}\right)$ & $\rightarrow \mathrm{NRuF}_{3}\left(\mathrm{C}_{3 \mathrm{v}},{ }^{3} \mathrm{~A}_{2}\right)$ & -153 & -162 & - \\
\hline $\mathrm{FNRuF}_{2}\left({ }^{3} \mathrm{~A}^{\prime \prime}\right)$ & $\rightarrow \mathrm{NRuF}_{3}\left({ }^{1} \mathrm{~A}^{\prime}\right)$ & -143 & -146 & - \\
\hline $\mathrm{NRuF}_{3}\left({ }^{1} A^{\prime}\right)+F$ & $\rightarrow \mathrm{NRuF}_{4}\left(C_{4 v},{ }^{2} \mathrm{~B}_{2}\right)$ & -305 & -371 & - \\
\hline $\mathrm{NRuF}_{3}\left({ }^{3} \mathrm{~A}^{\prime \prime}\right)$ & $\rightarrow \mathrm{NRuF}_{2}\left(C_{2 v},{ }^{2} \mathrm{~A}_{2}\right)+\mathrm{F}$ & 286 & 332 & - \\
\hline $\mathrm{NRuF}_{3}\left({ }^{3} \mathrm{~A}^{\prime \prime}\right)$ & $\rightarrow \mathrm{NRuF}_{2}\left(C_{2 v},{ }^{2} \mathrm{~A}_{2}\right)+1 / 2 \mathrm{~F}$ & 213 & 232 & - \\
\hline $\mathrm{NRuF}_{3}\left({ }^{3} \mathrm{~A}^{\prime \prime}\right)$ & $\rightarrow \operatorname{NRuF}\left({ }^{1} A^{\prime}\right)+F_{2}$ & 535 & 577 & - \\
\hline $\mathrm{NRuF}_{3}\left({ }^{3} \mathrm{~A}^{\prime \prime}\right)+\mathrm{F}$ & $\rightarrow \mathrm{NRuF}_{2}\left(C_{2 v},{ }^{2} \mathrm{~A}_{2}\right)+\mathrm{F}_{2}$ & 140 & 129 & - \\
\hline $\mathrm{Os}+\mathrm{NF}_{3}$ & $\rightarrow \mathrm{F}_{2} \mathrm{NOsF}\left(\mathrm{C}_{2 \mathrm{v}},{ }^{3} \mathrm{~A}_{1}\right)$ & -413 & -474 & - \\
\hline $\mathrm{F}_{2} \mathrm{NOsF}\left({ }^{3} \mathrm{~A}_{1}-C_{2 \mathrm{v}}\right)$ & $\rightarrow \mathrm{FNOsF}_{2}\left({ }^{3} \mathrm{~A}^{\prime \prime}\right)$ & -295 & -299 & - \\
\hline $\mathrm{FNOsF}_{2}\left({ }^{3} \mathrm{~A}^{\prime \prime}\right)$ & $\rightarrow \mathrm{NOsF}_{3}\left({ }^{1} \mathrm{~A}^{\prime}\right)$ & -196 & -193 & - \\
\hline $\mathrm{FNOsF}_{2}\left({ }^{3} \mathrm{~A}^{\prime \prime}\right)$ & $\rightarrow \mathrm{NOsF}_{3}\left({ }^{3} \mathrm{~A}^{\prime \prime}\right)$ & -206 & -208 & - \\
\hline $\mathrm{NOsF}_{3}\left({ }^{3} \mathrm{~A}^{\prime \prime}\right)$ & $\rightarrow \mathrm{NOsF}_{2}\left({ }^{3} \mathrm{~A}^{\prime \prime}\right)+\mathrm{F}$ & 288 & 330 & - \\
\hline $\mathrm{NOsF}_{3}\left({ }^{3} \mathrm{~A}^{\prime \prime}\right)$ & $\rightarrow \mathrm{NOsF}_{2}\left({ }^{3} \mathrm{~A}^{\prime \prime}\right)+1 / 2 \mathrm{~F}$ & 215 & 227 & - \\
\hline $\mathrm{NOsF}_{3}\left({ }^{3} \mathrm{~A}^{\prime \prime}\right)$ & $\rightarrow \operatorname{NOsF}\left({ }^{1} A^{\prime}\right)+F_{2}$ & 674 & 686 & - \\
\hline $\mathrm{NOsF}_{3}\left({ }^{3} \mathrm{~A}^{\prime \prime}\right)+\mathrm{F}$ & $\rightarrow \mathrm{NOsF}_{2}\left(C_{2 v},{ }^{2} \mathrm{~A}_{1}\right)+\mathrm{F}_{2}$ & 142 & 124 & - \\
\hline
\end{tabular}

[a] Unless stated otherwise, complexes were optimized in $C$ s point group symmetry.

[b] ROB3LYP/def2-QZVP: $-31 \mathrm{~kJ} \mathrm{~mol}^{-1}$, CCSD(T)/aug-cc-pVTZ-DK: $-66 \mathrm{~kJ} \mathrm{~mol}$ 
Table S3. Comparison of the computed $\mathrm{N}-\mathrm{Fe}$ stretching frequency $\left(v(\mathrm{Fe}-\mathrm{N})\right.$ in $\left.\mathrm{cm}^{-1}\right)$ and bond length $(\mathrm{r}(\mathrm{Fe}-\mathrm{N})$ in $\mathrm{pm})$ in $\mathrm{NFeF}_{3}$ obtained at spin unrestricted and restricted open-shell DFT, $\operatorname{CCSD}(\mathrm{T})$ and NEVPT2 levels of theory.

\begin{tabular}{lccc}
\hline Method & $\mathbf{v}(\mathbf{F e}-\mathbf{N})$ & $\mathbf{r}(\mathbf{N}-\mathbf{F e})$ & $\mathbf{S C} / \boldsymbol{T}_{\mathbf{1}} / \mathbf{C}_{\mathbf{0}}{ }^{2}$ [a] \\
\hline UB3LYP & 421 & 163.8 & 1.343 \\
UM06-L & 785 & 154.5 & 0.556 \\
UBP86 & 1096 & 151.1 & 0.070 \\
ROB3LYP [b] & 1192 & 148.0 & - \\
CCSD(T) & 757 & 161.2 & 0.101 \\
NEVPT2 & 1028 & 153.3 & 0.599 \\
\hline
\end{tabular}

[a] Diagnostics of multi-reference character: SC (spin contamination) for unrestricted DFT methods UB3LYP, UM06-L and UBP86, $T_{1}$ diagnostic for $\operatorname{CCSD}(T)$ and the weight of the leading configuration $\mathrm{C}_{0}^{2}$ of the CASSCF wave function. [b] Calculated using Molpro 2019. 
Table S4. Calculated and experimental vibrational wavenumbers $\left(v\left({ }^{14} \mathrm{~N}\right)\right.$ in $\left.\mathrm{cm}^{-1}\right)$ and ${ }^{14 / 15} \mathrm{~N}$ isotopic shifts $(\Delta v$ in parentheses $)$ for $\mathrm{NFeF}_{3}, \mathrm{NRuF}_{3}, \mathrm{NRuF}_{4}, \mathrm{NOsF}_{3}$ and $\mathrm{NOsF}_{4}$.

\begin{tabular}{|c|c|c|c|c|}
\hline Exp. [a] & BP86 [b] & B3LYP [b] & $\operatorname{ccsD}(T)^{[b]}$ & Assignment \\
\hline \multicolumn{5}{|c|}{$\mathrm{NFeF}_{3}\left(C_{3 \mathrm{v}},{ }^{3} \mathrm{~A}_{2}\right)[\mathrm{cc}$} \\
\hline $946.4(-23.7)$ & $1096(-28)[34]$ & $421(-12)[21]$ & $1028(-26)[-]^{[d]}$ & NFe str., $a_{1}$ \\
\hline $658.8(-1.1)$ & $650(-1)[40]$ & $683(1)[33]$ & $689(-2)[-]^{[d]}$ & $\mathrm{FeF}_{3}$ str., $\mathrm{a}_{1}$ \\
\hline \multicolumn{5}{|c|}{$\mathrm{N}^{102} \mathrm{RuF}_{3}\left(C_{\mathrm{s}},{ }^{1} \mathrm{~A}^{\prime}\right)$} \\
\hline $1105.4(-32.7)$ & $1150(-34)[40]$ & $1202(-35)[43]$ & $1085(-32)[-]$ & NRu str., a' \\
\hline [e] & $651(0)[46]$ & $669(0)[54]$ & $682(0)[-]$ & F'-Ru str., a' \\
\hline $668.5(0)$ & $641(0)[150]$ & $661(0)[171]$ & $678(0)[-]$ & antisym. F-Ru-F str., a" \\
\hline $635.8(0)$ & $618(0)[48]$ & $634(0)[58]$ & $649(0)[-]$ & sym. F-Ru-F str., a' \\
\hline \multicolumn{5}{|c|}{$\mathrm{N}^{102} \mathrm{RuF}_{4}\left(C_{4 \mathrm{v}},{ }^{2} \mathrm{~B}_{1}\right)$} \\
\hline $1098.5(-32.5)$ & $1060(-31)[16]$ & $1175(-35)[15]$ & $1080(-32)[-]$ & NRu str., $a_{1}$ \\
\hline $700.1(0)$ & $675(0)[2 \times 162]$ & $694(0)[2 \times 196]$ & $711(0)[-]$ & $\mathrm{RuF}_{4}$ stretch, e \\
\hline$-[f]$ & $576(0)[0]$ & $588(0)[0]$ & $598(0)[-]]$ & $\mathrm{RuF}_{4}$ stretch, $\mathrm{b}_{2}$ \\
\hline \multicolumn{5}{|c|}{$\operatorname{NOsF}_{3}\left(C_{s},{ }^{1} A^{\prime}\right)$} \\
\hline $1140.1(-35.5)$ & $1148(-36)[23]$ & $1196(-38)[28]$ & $1152(-36)[-]$ & NOs str., a' \\
\hline 686.0 / $686.6(0)$ & $657(0)[98]$ & $671(0)[94]$ & $689(0)[-]$ & OsF 2 sym. str., a' \\
\hline 641.3 / $640.0(0)$ & $637(0)[45]$ & $647(0)[75]$ & $664(0)[-]$ & OsF' sym. str., a' \\
\hline $632.3(0)$ & $609(0)[51]$ & $629(0)[59]$ & $652(0)[-]$ & $\mathrm{OsF}_{2}$ antisym. str., a" \\
\hline \multicolumn{5}{|c|}{$\mathrm{NOsF}_{3}\left(C_{\mathrm{s}},{ }^{3} \mathrm{~A}^{\prime \prime}\right)$} \\
\hline
\end{tabular}




\begin{tabular}{|c|c|c|c|c|}
\hline $1086.0(-)^{[f]}$ & $1089(-35)$ [27] & $1130(-37)[31]$ & $1095(-36)[-]$ & ${ }^{15} \mathrm{NOs}$ str, a' \\
\hline $675.8 / 677.0$ & $646(0)[134]$ & $657(0)[153]$ & $675(0)[-]$ & $\mathrm{OsF}_{2}$ antisym. str., a" \\
\hline $660.5 / 658.9(0)$ & $637(0)[36]$ & $652(0)[50]$ & $668(0)[-]$ & OsF 2 sym. str., a' \\
\hline $607.4(0.0)$ & $581(0)[66]$ & $594(0)[75]$ & $614(0)[-]$ & OsF' sym. str., a' \\
\hline \multicolumn{5}{|c|}{$\operatorname{NOsF}_{4}\left(C_{4 v},{ }^{2} B_{1}\right)$} \\
\hline - [g] & $1140(-36)[13]$ & $1192(-37)[13]$ & $1145(-36)[-]$ & NOs str., a 1 \\
\hline - [g] & $664(0)[25]$ & $687(0)[31]$ & $706(0)[-]$ & $\mathrm{OsF}_{4}$ stretch, $\mathrm{a}_{1}$ \\
\hline $689.9(0)$ & $658(0)[2 \times 152]$ & $674(0)[2 \times 176]$ & $693(0)[-]$ & $\mathrm{OsF}_{4}$ stretch, e \\
\hline - [h] & $605(0)[0]$ & $617(0)[0]$ & $635(0)[-]$ & $\mathrm{OsF}_{4}$ stretch, $\mathrm{b}_{2}$ \\
\hline
\end{tabular}

[a] Neon matrix; matrix sites are separated by a slash. [b] Intensities in $\mathrm{km} \mathrm{mol}^{-1}$ in square brackets. [c] M06-L/def2-QZVP: 785 a 1 (-11) [12], 703 e (0) [200], $617 \mathrm{a}_{1}(-1)$ [40]. [d] NEVPT2/aug-cc-pwCVTZ-DK; [f] $v\left({ }^{15} \mathrm{~N}-\mathrm{Os}\right)$ in $\mathrm{cm}^{-1}$, see text. [e] Band is likely hidden by the stronger antisymmetric F-Ru-F stretching mode (a"). [g] Too weak or overlapped. [h] Not IR active. 
A.1. High-Spin Iron(VI), Low-Spin Ruthenium(VI), and Magnetically Bistable of Osmium(VI): Molecular Group 8 Nitrido Trifluorides $\mathrm{NMF}_{3}$

Table S5. The experimental isotopic pattern of the $\mathrm{N}-\mathrm{Ru}$ stretching band of $\mathrm{NRuF}_{3}$ caused by the seven naturally occurring, stable ruthenium isotopes.

\begin{tabular}{cccc}
\hline Isotopologue & $v(\mathbf{N R u}), \mathbf{a}^{\prime}$ & $\mathrm{v}(\mathbf{F R u F})$ antisym., a" & v(RuF'), a' \\
\hline $\mathrm{N}^{96} \mathrm{RuF}_{3}$ & 1109.57 & 673.32 & 637.93 \\
$\mathrm{~N}^{98} \mathrm{RuF}_{3}$ & 1108.25 & too weak & too weak \\
$\mathrm{N}^{99} \mathrm{RuF}_{3}$ & 1107.46 & 670.80 & 636.83 \\
$\mathrm{~N}^{100} \mathrm{RuF}_{3}$ & 1106.83 & 669.96 & 636.43 \\
$\mathrm{~N}^{101} \mathrm{RuF}_{3}$ & 1105.97 & 669.12 & 636.05 \\
$\mathrm{~N}^{102} \mathrm{RuF}_{3}$ & 1105.40 & 668.48 & 635.84 \\
$\mathrm{~N}^{104} \mathrm{RuF}_{3}$ & 1104.10 & 666.94 & 635.16 \\
\hline
\end{tabular}

Table 6. The experimental isotopic pattern of the N-Ru stretching band of $\mathrm{NRuF}_{4}$ caused by the seven naturally occurring, stable ruthenium isotopes.

\begin{tabular}{cc}
\hline Isotopologue & $v(\mathbf{N R u}), \mathbf{a}^{\prime}$ \\
\hline $\mathrm{N}^{96} \mathrm{RuF}_{4}$ & 705.85 \\
$\mathrm{~N}^{98} \mathrm{RuF}_{4}$ & 703.73 \\
$\mathrm{~N}^{99} \mathrm{RuF}_{4}$ & 702.87 \\
$\mathrm{~N}^{100} \mathrm{RuF}_{4}$ & 701.89 \\
$\mathrm{~N}^{101} \mathrm{RuF}_{4}$ & 700.89 \\
$\mathrm{~N}^{102} \mathrm{RuF}_{4}$ & 700.01 \\
$\mathrm{~N}^{104} \mathrm{RuF}_{4}$ & 698.25 \\
\hline
\end{tabular}


Table S7. Comparison of the experimental and calculated ${ }^{96 / 104} \mathrm{Ru}$ isotopic ratios of the bands assigned to $\mathrm{NRuF}_{3}$ and $\mathrm{NRuF}_{4}$.

\begin{tabular}{|c|c|c|c|c|}
\hline & \multirow{2}{*}{$\begin{array}{l}\text { Frequency }\left[\mathrm{cm}^{-1}\right]^{[\mathrm{a}]} \\
\text { Exp. }\end{array}$} & \multicolumn{3}{|c|}{${ }^{96 / 104} \mathrm{Ru}$ Isotopic Ratio } \\
\hline & & Exp. & B3LYP & $\operatorname{CCSD}(T)$ \\
\hline \multicolumn{5}{|l|}{$\mathrm{NRuF}_{3}$} \\
\hline$v(\mathrm{NRu}), \mathrm{a}^{\prime}$ & 1105.40 & 1.00495 & 1.00495 & 1.00497 \\
\hline$v(F R u F)$, antisym.a" & 668.48 & 1.00956 & 1.00940 & 1.00963 \\
\hline$v\left(\right.$ RuF'$\left.^{\prime}\right), a^{\prime}$ & 635.84 & 1.00361 & 1.00414 & 1.00378 \\
\hline \multicolumn{5}{|l|}{$\mathrm{NRuF}_{4}$} \\
\hline$v(\mathrm{NRu}), \mathrm{a}^{\prime}$ & 1098.53 & $-[b]$ & 1.00509 & 1.00507 \\
\hline$v(\mathrm{NRu}), \mathrm{a}^{\prime}$ & 700.01 & 1.01088 & 1.01097 & 1.01093 \\
\hline Unknown Product & 606.52 & 1.00289 & - & - \\
\hline \multicolumn{5}{|c|}{$\begin{array}{l}\text { [a] Band position of isotopologue containing the most abundant ruthenium isotope } \\
{ }^{102} \mathrm{Ru} \text {; [b] Intensity too low to safely assign the } \mathrm{NRu}^{96} \mathrm{~F}_{4} \text { band (see Figure S5) }\end{array}$} \\
\hline \multicolumn{5}{|c|}{$\begin{array}{l}\text { Table S8. CCSD }(T) \text { diagnostics to estimate the presence of multi-reference character of } \mathrm{NMF}_{3}(\mathrm{M}= \\
\mathrm{Fe}, \mathrm{Ru}, \mathrm{Os}) \text {. }\end{array}$} \\
\hline Compound & $T_{1}$ & $D_{1}$ & & TAE \\
\hline $\mathrm{NFeF}_{3}\left({ }^{3} \mathrm{~A}_{2}\right)$ & 0.1013 & 0.4353 & & 14.2 \\
\hline $\mathrm{NRuF}_{3}\left({ }^{1} \mathrm{~A}^{\prime}\right)$ & 0.0356 & 0.1166 & & 7.7 \\
\hline $\mathrm{NRuF}_{3}\left({ }^{3} \mathrm{~A}^{\prime \prime}\right)$ & 0.0296 & 0.0922 & & 7.8 \\
\hline $\mathrm{NOsF}_{3}\left({ }^{1} A^{\prime}\right)$ & 0.0280 & 0.0915 & & 6.8 \\
\hline $\mathrm{NOsF}_{3}\left({ }^{3} \mathrm{~A}^{\prime \prime}\right)$ & 0.0290 & 0.0839 & & 6.6 \\
\hline
\end{tabular}


A.1. High-Spin Iron(VI), Low-Spin Ruthenium(VI), and Magnetically Bistable of Osmium(VI): Molecular Group 8 Nitrido Trifluorides $\mathrm{NMF}_{3}$

Table S9. AIM charges, NPA charges, NLMO bond orders (totals by atom) and Wiberg bond indices (totals by atom) for all experimentally detected NMF 3 and $\mathrm{NMF}_{4}$ species calculated at the DFT (M06-L for $\mathrm{M}=\mathrm{Fe}$ and B3LYP for $\mathrm{M}=\mathrm{Ru}$, Os) levels of theory.

\begin{tabular}{|c|c|c|c|c|c|c|c|c|c|c|c|c|}
\hline & \multicolumn{2}{|c|}{$\mathrm{NFeF}_{3}\left({ }^{3} \mathrm{~A}_{2}\right)$} & \multicolumn{2}{|c|}{$\mathrm{NRuF}_{3}\left({ }^{1} \mathbf{A}_{1}\right)$} & \multicolumn{2}{|c|}{$\mathrm{NOsF}_{3}\left({ }^{1} \mathrm{~A}^{\prime}\right)$} & \multicolumn{2}{|c|}{$\mathrm{NOsF}_{3}\left({ }^{3} \mathrm{~A}^{\prime \prime}\right)$} & \multicolumn{2}{|c|}{$\mathrm{NRuF}_{4}\left({ }^{2} \mathrm{~B}_{2}\right)$} & \multicolumn{2}{|c|}{$\mathrm{NOsF}_{4}\left({ }^{2} \mathrm{~B}_{2}\right)$} \\
\hline & $\mathbf{N}$ & $\mathrm{Fe}$ & $\mathbf{N}$ & $\mathbf{R u}$ & $\mathbf{N}$ & Os & $\mathbf{N}$ & Os & $\mathbf{N}$ & $\mathbf{R u}$ & $\mathbf{N}$ & Os \\
\hline & \multicolumn{2}{|c|}{ M06-L } & \multicolumn{10}{|c|}{ B3LYP } \\
\hline AIM Charge & -0.25 & 1.90 & -0.35 & 2.04 & -0.49 & 2.21 & -0.51 & 2.25 & -0.25 & 2.38 & -0.40 & 2.66 \\
\hline $\begin{array}{l}\text { NPA } \\
\text { Charge }\end{array}$ & 0.05 & 1.41 & -0.03 & 1.55 & -0.21 & 1.72 & -0.26 & 1.80 & 0.08 & 1.69 & -0.11 & 1.99 \\
\hline NLMO B.O. & 2.30 & 3.21 & 2.62 & 3.64 & 2.77 & 3.84 & 2.80 & 3.80 & 2.28 & 4.30 & 2.54 & 4.48 \\
\hline Wiberg B.I. & 2.52 & 3.29 & 3.04 & 4.28 & 3.03 & 4.47 & 2.86 & 3.98 & 3.05 & 4.61 & 3.04 & 4.76 \\
\hline
\end{tabular}


Table S10. Electronic energies (hartree) and energy differences $\left(\mathrm{kJ} \mathrm{mol}^{-1}\right)$ of singlet and triplet $\mathrm{NRuF}_{3}$ calculated at the ROHF/UCCSD(T) level of theory with basis sets up to quintuple zeta quality, as well as CBS extrapolations. The single point energies were calculated at the minima obtained at the $\operatorname{CCSD}(\mathrm{T}) / \mathrm{aug}$ cc-pVTZ(-PP) levels.

\begin{tabular}{|c|c|c|c|c|c|c|c|}
\hline \multirow{2}{*}{ Basis set } & \multicolumn{3}{|c|}{$\mathrm{NRuF}_{3}\left(C_{\mathrm{s}},{ }^{1} \mathrm{~A}^{\prime}\right)$} & \multicolumn{3}{|c|}{$\mathrm{NRuF}_{3}\left(C_{3 \mathrm{v}},{ }^{3} \mathrm{~A}_{2}\right)$} & \multirow{2}{*}{$\Delta E_{\mathrm{T}-\mathrm{s}}$} \\
\hline & Reference E. & Correlation E. & Total Energy & Reference E. & Correlation E. & Total Energy & \\
\hline aVDZ(-PP) & -446.504523 & -1.181185 & -447.685709 & -446.507003 & -1.181062 & -447.688064 & -6.2 \\
\hline aVTZ(-PP) & -446.600941 & -1.422827 & -448.023769 & -446.602085 & -1.420950 & -448.023035 & 1.9 \\
\hline aQZ(-PP) & -446.627712 & -1.506839 & -448.134551 & -446.628722 & -1.504153 & -448.132875 & 4.4 \\
\hline aV5Z(-PP) & -446.634844 & -1.538137 & -448.172981 & -446.635786 & -1.534972 & -448.170758 & 5.8 \\
\hline CBS [a] & -446.634844 & -1.570975 & -448.205819 & -446.635786 & -1.567306 & -448.203092 & 7.2 \\
\hline CBS [b] & -445.634844 & -1.556720 & -447.191564 & -445.635786 & -1.553102 & -447.188889 & 7.0 \\
\hline apwCVDZ(-PP) & -446.511415 & -1.500142 & -448.011557 & -446.513189 & -1.501410 & -448.014598 & -8.0 \\
\hline apwCVTZ(-PP) & -446.603800 & -1.818958 & -448.422758 & -446.604814 & -1.818014 & -448.422827 & -0.2 \\
\hline apwCVQZ(-PP) & -446.628602 & -1.928322 & -448.556924 & -446.629599 & -1.926530 & -448.556129 & 2.1 \\
\hline apwCV5Z(-PP) & -446.635065 & -1.970985 & -448.606050 & -446.635995 & -1.968682 & -448.604677 & 3.6 \\
\hline CBS [a] & -446.635065 & -2.015746 & -448.650811 & -446.635995 & -2.012907 & -448.648902 & 5.0 \\
\hline CBS [b] & -445.635065 & -1.998272 & -447.633337 & -445.635995 & -1.995455 & -447.631450 & 5.0 \\
\hline
\end{tabular}

[a] Two-point extrapolation of the $\mathrm{QZ}$ and $5 Z \operatorname{CCSD}(\mathrm{T})$ correlation energies via $E_{n}=E_{\mathrm{CBS}}+\frac{A}{(n+1)^{3}}$, where $n$ is the cardinal number of the basis set $(4=\mathrm{QZ}$ and $5=5 Z$ ) and $A$ is a fitting parameter. ${ }^{[13 b, 45]}[\mathrm{b}]$ Exponential three point extrapolation of the $\mathrm{TZ}, \mathrm{QZ}$ and $5 Z \mathrm{CCSD}(\mathrm{T})$ correlation energies via $E_{n}=E_{C B S}+$ $B e^{-\alpha n}$, where $n$ is the cardinal number of the basis set $(3=\mathrm{TZ}, 4=\mathrm{QZ}$ and $5=5 \mathrm{Z})$, and $\alpha$ and $B$ are fitting parameters. ${ }^{[46]}$ 
Table S11. Electronic energies (hartree) and energy differences $\left(\mathrm{kJ} \mathrm{mol}^{-1}\right)$ of singlet and triplet $\mathrm{NOsF} \mathrm{F}_{3}$ calculated at the ROHF/ UCCSD(T) level of theory with basis sets up to quintuple zeta quality, as well as CBS extrapolations. The single point energies were calculated at the minima obtained at the $\operatorname{ccsD}(T) / a u g-c c-p V T Z(-P P)$ level of theory.

\begin{tabular}{|c|c|c|c|c|c|c|c|}
\hline \multirow{2}{*}{ Basis set } & \multicolumn{3}{|c|}{$\mathrm{NOsF}_{3}\left(C_{\mathrm{s}},{ }^{1} \mathrm{~A}^{\prime}\right)$} & \multicolumn{3}{|c|}{$\mathrm{NOsF}_{3}\left(C_{\mathrm{s}},{ }^{3} \mathrm{~A}^{\mathrm{c}}\right)$} & \multirow{2}{*}{$\Delta E_{\mathrm{T}-\mathrm{S}}$} \\
\hline & Reference E. & Correlation E. & Total Energy & Reference E. & Correlation E. & Total Energy & \\
\hline aVDZ(-PP) & -442.857904 & -1.147078 & -444.004982 & -442.871032 & -1.137832 & -444.008864 & -10.2 \\
\hline aVQZ(-PP) & -442.983445 & -1.466771 & -444.450217 & -442.995504 & -1.455350 & -444.450854 & -1.7 \\
\hline aV5Z(-PP) & -442.990207 & -1.497605 & -444.487811 & -443.002211 & -1.485787 & -444.487998 & -0.5 \\
\hline CBS [a] & -442.990207 & -1.529955 & -444.520161 & -443.002211 & -1.517720 & -444.519931 & 0.6 \\
\hline CBS [b] & -442.990207 & -1.515947 & -444.506153 & -443.002211 & -1.503757 & -444.505968 & 0.5 \\
\hline awCVDZ(-PP) & -442.864299 & -1.406781 & -444.271080 & -442.877117 & -1.398780 & -444.275898 & -12.6 \\
\hline apwCVTZ(-PP) & -442.959193 & -1.726200 & -444.685394 & -442.971236 & -1.716295 & -444.687530 & -5.6 \\
\hline apwCVQZ(-PP) & -442.983945 & -1.834221 & -444.818166 & -442.995976 & -1.823596 & -444.819572 & -3.7 \\
\hline apwCV5Z(-PP) & -442.990330 & -1.876415 & -444.866746 & -443.002320 & -1.865356 & -444.867676 & -2.4 \\
\hline CBS [a] & -442.990330 & -1.920685 & -444.911016 & -443.002320 & -1.909169 & -444.911490 & -1.2 \\
\hline
\end{tabular}

[a] Two-point extrapolation of the $\mathrm{QZ}$ and $5 Z \operatorname{CCSD}(\mathrm{T})$ correlation energies via $E_{n}=E_{\mathrm{CBS}}+\frac{A}{(n+1)^{3}}$, where $n$ is the cardinal number of the basis set $(4=\mathrm{QZ}$ and 5 $=5 Z$ ) and $A$ is a fitting parameter. ${ }^{[13 a, 45]} ;[\mathrm{b}]$ Exponential three point extrapolation of the TZ, $\mathrm{QZ}$ and $5 Z \operatorname{CCSD}(\mathrm{T}) \operatorname{correlation}$ energies via $E_{n}=E_{C B S}+B e^{-\alpha n}$, where $n$ is the cardinal number of the basis set $(3=T Z, 4=Q Z$ and $5=5 Z)$, and $\alpha$ and $B$ are fitting parameters. ${ }^{46]}$ 
Table S12. Total electronic energies $\left(E_{\mathrm{el}}\right)$ in hartree and electronic energy differences $\left(\Delta E_{\mathrm{el}}\right)$ in $\mathrm{kJ} \mathrm{mol}^{-1}$ of different points at the ${ }^{1} \mathrm{~A}$ ' and ${ }^{3} \mathrm{~A}$ " energy potential surfaces (PES) of NOsF 3 obtained at the B3LYP/def2-QZVP and UCCSD(T)/cc-pVTZ(-PP) level of theory.

\begin{tabular}{|c|c|c|c|c|}
\hline & \multicolumn{2}{|c|}{ B3LYP/def2-QZVP } & \multicolumn{2}{|c|}{$\operatorname{ccsD}(T) / c c-p V T Z(-P P)$} \\
\hline & $E_{\mathrm{el}}$ [hartree] & $\begin{array}{c}\Delta E_{\mathrm{el}} \\
{\left[\mathrm{kJ} \mathrm{mol}^{-1}\right]}\end{array}$ & Eel [hartree] & $\begin{array}{c}\Delta E_{\mathrm{el}} \\
{\left[\mathrm{kJ} \mathrm{mol}^{-1}\right]}\end{array}$ \\
\hline${ }^{1} A^{\prime}$ Minimum & -445.014761 & 0 & -444.559950 & 0 \\
\hline${ }^{1} A^{\prime}$ MECP & -445.009614 & 13.5 & -444.569336 & 24.6 \\
\hline${ }^{3} \mathrm{~A}$ " Minimum & -445.018544 & 0 & -444.559951 & 0 \\
\hline${ }^{3} \mathrm{~A} " \mathrm{MECP}$ & -445.009649 & 23.4 & -444.568806 & 23.2 \\
\hline
\end{tabular}

Table S13. AIM charges, NPA charges, NLMO bond orders (totals by atom) and Wiberg bond indices (totals by atom) for $\mathrm{NMF}_{2}$ species calculated the B3LYP $(M=R u$, Os) and M06-L $(M=F e)$ levels of theory.

\begin{tabular}{lcccccc}
\hline & \multicolumn{2}{c}{$\mathbf{N F e F}_{2}\left({ }^{2} \mathbf{A}_{2}\right)$} & \multicolumn{2}{c}{$\mathbf{N R u F}_{2}\left({ }^{2} \mathbf{A}_{2}\right)$} & \multicolumn{2}{c}{$\mathbf{N O s F}_{2}\left({ }^{2} \mathbf{A}_{2}\right)$} \\
& $\mathbf{N}$ & $\mathbf{F e}$ & $\mathbf{N}$ & $\mathbf{R u}$ & $\mathbf{N}$ & Os \\
\hline AIM Charge & -0.35 & 1.53 & -0.40 & 1.62 & -0.50 & 1.72 \\
NPA Charge & -0.03 & 1.10 & -0.12 & 1.25 & -0.22 & 1.28 \\
NLMO B.O. & 2.62 & 3.30 & 2.82 & 3.40 & 2.63 & 3.49 \\
Wiberg B.I. & 2.79 & 3.32 & 3.02 & 3.61 & 3.00 & 3.80 \\
\hline
\end{tabular}




\section{A.1. High-Spin Iron(VI), Low-Spin Ruthenium(VI), and Magnetically Bistable of Osmium(VI): Molecular Group 8 Nitrido Trifluorides $\mathrm{NMF}_{3}$}

Table S14. Adiabatic Potential Energy Surfaces of $\mathrm{NFeF}_{3}$ (Figure 6a) obtained at the SA-CASSCF(8,8)/NEVPT2/cc-pVTZ-DK,Fe=cc-pwCVTZ-DK level. RMN, RMF1, A1, RMF2, A2 and D1 are the MN bond length, MF' bond length, the NMF' bond angle, the MF bond length, the NMF angle and the F'MNF dihedral angle (see Figure 5). Energies in hartree, bond lengths in $\AA$ and angles in degree.

\begin{tabular}{|c|c|c|c|c|c|c|c|c|c|c|c|c|c|c|}
\hline RMN & RMF1 & A1 & RMF2 & A2 & D1 & $a^{1} A^{\prime}$ & $b^{1} A^{\prime}$ & $c^{1} A^{\prime}$ & $a^{1} A^{\prime \prime}$ & $b^{1} A^{\prime \prime}$ & $a^{3} A^{\prime}$ & $b^{3} A^{\prime}$ & $a^{3} A^{a}$ & $b^{3} A^{\prime \prime}$ \\
\hline 1.51107 & 68807 & & 1.69638 & 3.74074 & 3.66276 & 626.076795 & -1625.973598 & -1625.975589 & -1626.031556 & -1626.001221 & -1626.004367 & -1625.976403 & -1626.073821 & -1626.024558 \\
\hline 51269 & 1.69049 & 97.44400 & 69821 & 113.35754 & 95.54399 & 626.078618 & -1625.978474 & -1625.983043 & -1626.036292 & -1626.004008 & -1626.008436 & -1625.978687 & -1626.079081 & -1626.027246 \\
\hline 51430 & 69291 & 98.28493 & 1.70003 & 112.97435 & 97.42522 & -1626.079862 & -1625.984452 & -1625.988535 & -1626.040546 & -1626.006392 & -1626.012018 & -1625.980464 & -1626.083914 & -1626.029461 \\
\hline 1592 & 69533 & 99.12586 & 1.70186 & 112.59116 & 99.30645 & -1626.080560 & -1625.991012 & -1625.992605 & -1626.044352 & -1626.008383 & -1626.015114 & -1625.981835 & -1626.088341 & -1626.031225 \\
\hline 51753 & 1.69775 & 99.96678 & 1.70368 & 112.20797 & 101.18768 & -1626.080702 & -1625.997867 & -1625.995653 & -1626.047761 & -1626.009997 & -1626.017722 & -1625.982965 & -1626.092401 & -1626.032555 \\
\hline 51915 & 1.70017 & 100.80771 & 1.70551 & 111.82478 & 103.06891 & -1626.080297 & -1626.004749 & -1625.997961 & -1626.050816 & -1626.011264 & -1626.019926 & -1625.984398 & -1626.096105 & -1626.033523 \\
\hline 2076 & 0259 & 1.64864 & 0733 & 111.44159 & 4.95015 & -1626.079392 & -1626.011629 & -1625.999712 & 626.053544 & -1626.012290 & -1626.021798 & -1625.987494 & -1626.099465 & -1626.0 \\
\hline .52237 & 1.70501 & 102.48956 & 1.70916 & 111.05840 & 106.83138 & -1626.077985 & -1626.018207 & -1626.000773 & -1626.055843 & -1626.012819 & -1626.023110 & -1625.992245 & -1626.102384 & -1626.034436 \\
\hline 52399 & 1.70742 & 103.33049 & 1.71099 & 110.67520 & 108.71261 & -1626.076178 & -1626.024287 & -1626.001137 & -1626.057719 & -1626.012711 & -1626.023783 & -1625.996882 & -1626.104874 & -1626.034000 \\
\hline 2560 & 70984 & 4.17142 & 71281 & 110.29201 & 0.59384 & 626.074017 & -1626.029955 & -1626.000939 & 626.059241 & -1626.012092 & 26.023940 & 1113 & -1626.106989 & -1626.0 \\
\hline .52722 & 1.71226 & 105.01235 & 1.71464 & 109.90882 & 112.47507 & -1626.071530 & -1626.035239 & -1626.000206 & -1626.060441 & -1626.011023 & -1626.023614 & -1626.004951 & -1626.108748 & -1626.031693 \\
\hline 52883 & 1.71468 & 105.85327 & 1.71646 & 109.52563 & 114.35630 & -1626.068803 & -1626.040051 & -1625.998972 & -1626.061324 & -1626.009548 & -1626.022866 & -1626.008361 & -1626.110148 & -1626.029937 \\
\hline 53045 & 1710 & 106.69420 & 71829 & 09.14244 & 6.23754 & 626.066001 & 1626.044234 & -1625.997225 & 1626.061897 & -1626.007743 & -16 & 1267 & -1626. & -1626 \\
\hline 53206 & 1.71952 & 107.53513 & 1.72011 & 108.75925 & 118.11877 & -1626.063495 & -1626.047453 & -1625.994885 & -1626.062172 & -1626.005836 & -1626.020568 & -1626.013504 & -1626.111872 & -1626.025615 \\
\hline 53367 & 1.72194 & 108.37606 & 1.72194 & 108.37606 & 20.00000 & -1626.063184 & -1626.04 & -1625.993172 & -1626.062202 & -1626.005314 & -1626.01 & -1626.0 & -1626.112008 & -1626.025016 \\
\hline 53180 & 1.72030 & 109.58665 & 1943 & 7.88987 & 1.21794 & 626.063184 & -1626.048127 & 93172 & 1626.062202 & -1626.005314 & $-1626.0 \mathrm{>}$ & -1626.014059 & -1626.112008 & -1626.0 \\
\hline 52992 & 1.71866 & 110.79725 & 1.71692 & 107.40368 & 122.43588 & -1626.064964 & -1626.046198 & -1625.994284 & -1626.062023 & -1626.006522 & -1626.020447 & -1626.012793 & -1626.111608 & -1626.026343 \\
\hline .52804 & 1.71701 & 112.00784 & 1.71441 & 106.91749 & 123.65382 & -1626.067020 & -1626.043548 & -1625.995043 & -1626.061621 & -1626.007799 & -1626.020925 & -1626.011076 & -1626.110977 & -1626.027648 \\
\hline 52617 & 1.71537 & 113.21843 & 1.71190 & 106.43130 & 4.87176 & -1626.069094 & -1626.040372 & -1625.995496 & -1626.060971 & -1626.008905 & -1626.021288 & -1626.008945 & -1626.110096 & -1626.028748 \\
\hline 52429 & 1.71373 & 114.42903 & 1.70939 & 105.94511 & 6.08970 & -1626.071045 & -1626.036766 & -1625.995654 & -1626.060051 & -1626.009757 & -1626.021450 & -1626.006437 & -1626.108939 & -1626.029581 \\
\hline 52241 & 1.71209 & 115.63962 & 1.70688 & 105.45892 & 127.30764 & -1626.072790 & -1626.032777 & -1625.995507 & -1626.058841 & -1626.010306 & -1626.021357 & -1626.003568 & -1626.107486 & -1626.030108 \\
\hline .52054 & 1.71045 & 116.85022 & 1.70437 & 4.97273 & 3.52558 & -1626.074269 & -1626.028424 & -1625.995036 & -1626.057315 & -1626.010518 & -1626.020968 & -1626.000342 & -1626.105713 & -1626.030297 \\
\hline .51866 & 1.70881 & 118.06081 & 1.70186 & 104.48654 & 4352 & -1626.075427 & 3713 & -1625.994221 & -1626.055449 & 0353 & -1626.020251 & 96756 & 3592 & 0111 \\
\hline .51678 & 1.70717 & 119.27141 & 1.69936 & 104.00035 & 0.96146 & -1626.076212 & -1626.018620 & -1625.993024 & -1626.0 & -1626.009782 & -1626.019170 & -1625.992793 & -1626.101090 & -1626.029515 \\
\hline .51491 & 1.70552 & 120.48200 & 1.69685 & 103.51416 & 132.17940 & -1626.076600 & -1626.013096 & -1625.991389 & -1626.050558 & -1626.008762 & -1626.017676 & -1625.988424 & -1626.098169 & -1626.028465 \\
\hline & & & & & & & & & & & & 661 & & \\
\hline .51115 & 1.70224 & 122.90319 & 1.69183 & 102.54178 & 61528 & -1626.076028 & -1626.000483 & 25.986583 & -1626.043795 & -1626.005066 & 26.013258 & -1625.978619 & -1626.090828 & -1626.024733 \\
\hline 50928 & .70060 & 24.11378 & 1.68932 & 102.05560 & 135.83322 & -1626.074946 & -1625.993227 & -1625.983227 & -1626.039529 & -1626.002198 & -1626.010153 & -1625.973712 & -1626.086257 & -1626.021843 \\
\hline
\end{tabular}




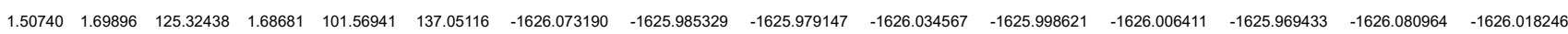

Table S15. Adiabatic Potential Energy Surfaces of $\mathrm{NRuF}_{3}$ (Figure 6b) obtained at the SA-CASSCF(8,8)/NEVPT2/cc-pVTZ-DK level. RMN, RMF1, A1, RMF2, A2 and D1 are the RuN bond length, the RuF' bond length, the NRuF' bond angle, the RuF bond length, the NRuF angle and the F'RuNF dihedral angle (see Figure 5). Energies in hartree, bond lengths in $\AA$ and angles in degree.

\begin{tabular}{|c|c|c|c|c|c|c|c|c|c|c|c|c|c|}
\hline RMN & RMF1 & A1 & RMF2 & A2 & D1 & $a^{1} A^{\prime}$ & $b^{1} A^{\prime}$ & $a^{1} A^{\prime \prime}$ & $a^{3} A^{\prime}$ & $b^{3} A^{\prime}$ & $a^{3} A^{4}$ & $b^{3} A^{4}$ & $c^{3} A^{\prime \prime}$ \\
\hline 1.59151 & 1.85257 & 95.41620 & 1.86341 & 115.28640 & 88.32920 & -4882.060830 & -4881.919104 & -4882.001768 & -4881.946690 & -4881.904183 & -4882.025083 & -4881.978223 & -4881.898661 \\
\hline .59184 & 1.85406 & 96.74090 & 1.86412 & 115.19180 & 90.59140 & -4882.063281 & -4881.927828 & -4882.007362 & -4881.950836 & -4881.907225 & -4882.030515 & -4881.980059 & -4881.902092 \\
\hline .59217 & 1.85554 & 98.06560 & 1.86483 & 115.09720 & 92.85360 & -4882.064930 & -4881.936563 & -4882.012431 & -4881.954416 & -4881.910018 & -4882.035459 & -4881.981343 & -4881.904791 \\
\hline 1.59250 & 1.85703 & 99.39030 & 1.86554 & 115.00260 & 95.11580 & -4882.065785 & -4881.945321 & -4882.017006 & -4881.957554 & -4881.913016 & -4882.039932 & -4881.982242 & -4881.906766 \\
\hline 1.59283 & 1.85851 & 100.71500 & 1.86625 & 114.90800 & 97.37800 & -4882.065948 & -4881.954229 & -4882.021143 & -4881.960331 & -4881.917505 & -4882.043993 & -4881.982894 & -4881.908147 \\
\hline .59316 & 1.86000 & 102.03970 & 1.86696 & 114.81340 & 99.64020 & -4882.065243 & -4881.962909 & -4882.024801 & -4881.962711 & -4881.923836 & -4882.047585 & -4881.983073 & -4881.909153 \\
\hline 1.59349 & 1.86148 & 103.36440 & 1.86767 & 114.71880 & 101.90240 & -4882.063576 & -4881.971538 & -4882.027830 & -4881.965039 & -4881.930240 & -4882.050568 & -4881.982740 & -4881.912829 \\
\hline 1.59382 & 1.86297 & 104.68910 & 1.86838 & 114.62420 & 104.16460 & -4882.061164 & -4881.979752 & -4882.030308 & -4881.965973 & -4881.935116 & -4882.053056 & -4881.981220 & -4881.919763 \\
\hline .59415 & 1.86445 & 106.01380 & 1.86909 & 114.52960 & 106.42680 & -4882.058350 & -4881.987697 & -4882.032477 & -4881.966045 & -4881.939294 & -4882.055282 & -4881.979006 & -4881.926101 \\
\hline 1.59448 & 1.86594 & 107.33850 & 1.86981 & 114.43500 & 108.68900 & -4882.055075 & -4881.995371 & -4882.034292 & -4881.965532 & -4881.943044 & -4882.057184 & -4881.976239 & -4881.932024 \\
\hline .59481 & 1.86742 & 108.66320 & 1.87052 & 114.34040 & 110.95120 & -4882.051400 & -4882.002705 & -4882.035754 & -4881.964493 & -4881.946352 & -4882.058757 & -4881.972942 & -4881.937513 \\
\hline .59514 & 1.86891 & 109.98790 & 1.87123 & 114.24580 & 113.21340 & -4882.047434 & -4882.009588 & -4882.036883 & -4881.962960 & -4881.949154 & -4882.060016 & -4881.969112 & -4881.942530 \\
\hline 1.59547 & 1.87039 & 111.31260 & 1.87194 & 114.15120 & 115.47560 & -4882.043341 & -4882.015751 & -4882.037643 & -4881.961051 & -4881.951376 & -4882.060916 & -4881.964789 & -4881.947065 \\
\hline 1.59580 & 1.87188 & 112.63730 & 1.87265 & 114.05660 & 117.73780 & -4882.039674 & -4882.020575 & -4882.038027 & -4881.958945 & -4881.952788 & -4882.061446 & -4881.960020 & -4881.950950 \\
\hline 1.59613 & 1.87336 & 113.96200 & 1.87336 & 113.96200 & 120.00000 & -4882.038031 & -4882.022576 & -4882.038031 & -4881.957291 & -4881.952738 & -4882.061597 & -4881.956156 & -4881.952738 \\
\hline 1.59616 & 1.87272 & 115.15450 & 1.87203 & 113.00220 & 121.52860 & -4882.039341 & -4882.021286 & -4882.037853 & -4881.958248 & -4881.953192 & -4882.061513 & -4881.959073 & -4881.951226 \\
\hline 1.59619 & 1.87209 & 116.34700 & 1.87071 & 112.04240 & 123.05720 & -4882.042154 & -4882.017919 & -4882.037346 & -4881.959443 & -4881.952792 & -4882.061118 & -4881.962961 & -4881.948019 \\
\hline 1.59622 & 1.87145 & 117.53950 & 1.86938 & 111.08260 & 124.58580 & -4882.045400 & -4882.013381 & -4882.036498 & -4881.960665 & -4881.951713 & -4882.060398 & -4881.966539 & -4881.944360 \\
\hline 1.59625 & 1.87082 & 118.73200 & 1.86805 & 110.12280 & 126.11440 & -4882.048579 & -4882.008109 & -4882.035288 & -4881.961729 & -4881.950112 & -4882.059325 & -4881.969743 & -4881.940369 \\
\hline 1.59629 & 1.87018 & 119.92450 & 1.86673 & 109.16300 & 127.64300 & -4882.051534 & -4882.002324 & -4882.033737 & -4881.962509 & -4881.948018 & -4882.057921 & -4881.972504 & -4881.936048 \\
\hline 1.59632 & 1.86954 & 121.11700 & 1.86540 & 108.20320 & 129.17160 & -4882.054152 & -4881.996096 & -4882.031811 & -4881.962954 & -4881.945474 & -4882.056146 & -4881.974817 & -4881.931403 \\
\hline 1.59635 & 1.86891 & 122.30950 & 1.86407 & 107.24340 & 130.70020 & -4882.056359 & -4881.989462 & -4882.029484 & -4881.963027 & -4881.942479 & -4882.053972 & -4881.976643 & -4881.926432 \\
\hline 1.59638 & 1.86827 & 123.50200 & 1.86274 & 106.28360 & 132.22880 & -4882.058091 & -4881.982418 & -4882.026722 & -4881.962686 & -4881.939021 & -4882.051360 & -4881.977949 & -4881.921111 \\
\hline 1.59641 & 1.86764 & 124.69450 & 1.86142 & 105.32380 & 133.75740 & -4882.059291 & -4881.974942 & -4882.023485 & -4881.961883 & -4881.935066 & -4882.048268 & -4881.978682 & -4881.915395 \\
\hline .59644 & 1.86700 & 125.88700 & 1.86009 & 104.36400 & 135.28600 & -4882.059890 & .967004 & 2.019724 & 1.960558 & 1.930556 & -4882.044647 & 81.978771 & -4881.909206 \\
\hline 1.59647 & 1.86636 & 127.07950 & 1.85876 & 103.40420 & 136.81460 & -4882.060206 & -4881.958638 & -4882.015695 & -4881.956846 & -4881.924397 & -4882.040850 & -4881.977388 & -4881.901885 \\
\hline
\end{tabular}


Table S16. Adiabatic Potential Energy Surfaces of NOsF 3 (Figure 6c) obtained at the SA-CASSCF(8,8)/NEVPT2/cc-pVTZ-DK level. RMN, RMF1, A1, RMF2, A2 and D1 are the OsN bond length, the OsF' bond length, the NOsF' bond angle, the OsF bond length, the NOsF angle and the F' OsNF dihedral angle (see Figure 5). Energies in hartree, bond lengths in $\AA$ and angles in degree.

$\begin{array}{cccccccc}\text { RMN } & \text { RMF1 } & \text { A1 } & \text { RMF2 } & \text { A2 } & \text { D1 } & \mathbf{a}^{1} \mathbf{A}^{\prime} & \mathbf{b}^{\mathbf{1}} \mathbf{A}^{\prime} \\ 1.62159 & 1.86334 & 96.09113 & 1.88474 & 116.01434 & 87.62533 & -17592.580260 & -17592.449170 \\ 1.62198 & 1.86548 & 97.45957 & 1.88536 & 115.95969 & 89.93780 & -17592.582700 & -17592.457310 \\ 1.62237 & 1.86763 & 98.82800 & 1.88597 & 115.90504 & 92.25028 & -17592.584250 & -17592.465260 \\ 1.62276 & 1.86977 & 100.19644 & 1.88659 & 115.85039 & 94.56276 & -17592.585000 & -17592.473110 \\ 1.62315 & 1.87192 & 101.56487 & 1.88721 & 115.79574 & 96.87523 & -17592.584910 & -17592.480770 \\ 1.62354 & 1.87406 & 102.93331 & 1.88782 & 115.74108 & 99.18771 & -17592.584080 & -17592.488190 \\ 1.62393 & 1.87621 & 104.30174 & 1.88844 & 115.68643 & 101.50019 & -17592.582430 & -17592.495450 \\ 1.62432 & 1.87835 & 105.67018 & 1.88905 & 115.63178 & 103.81266 & -17592.579870 & -17592.502660 \\ 1.62471 & 1.88050 & 107.03862 & 1.88967 & 115.57713 & 106.12514 & -17592.576830 & -17592.509450 \\ 1.62510 & 1.88264 & 108.40705 & 1.89029 & 115.52248 & 108.43762 & -17592.573390 & -17592.516010 \\ 1.62548 & 1.88479 & 109.77549 & 1.89090 & 115.46783 & 110.75009 & -17592.569640 & -17592.522400 \\ 1.62587 & 1.88693 & 111.14392 & 1.89152 & 115.41318 & 113.06257 & -17592.565580 & -17592.528480 \\ 1.62626 & 1.88908 & 112.51236 & 1.89213 & 115.35853 & 115.37505 & -17592.561460 & -17592.534090 \\ 1.62665 & 1.89122 & 113.88079 & 1.89275 & 115.30388 & 117.68752 & -17592.557830 & -17592.538600 \\ 1.62704 & 1.89337 & 115.24923 & 1.89337 & 115.24923 & 120.00000 & -17592.556225 & -17592.540465 \\ 1.62701 & 1.89019 & 115.49010 & 1.89204 & 114.22360 & 121.90130 & -17592.557870 & -17592.539180 \\ 1.62699 & 1.88702 & 115.73098 & 1.89072 & 113.19798 & 123.80260 & -17592.561240 & -17592.535720 \\ 1.62696 & 1.88384 & 115.97186 & 1.88939 & 112.17236 & 125.70390 & -17592.565200 & -17592.530960 \\ 1.62694 & 1.88067 & 116.21274 & 1.88807 & 111.14674 & 127.60520 & -17592.569270 & -17592.525430 \\ 1.62691 & 1.87749 & 116.45361 & 1.88674 & 110.12111 & 129.50650 & -17592.573230 & -17592.519290 \\ 1.62688 & 1.87432 & 116.69449 & 1.88542 & 109.09549 & 131.40780 & -17592.576930 & -17592.512540 \\ 1.62686 & 1.87114 & 116.93537 & 1.88409 & 108.06987 & 133.30910 & -17592.580230 & -17592.505170 \\ 1.62683 & 1.86797 & 117.17625 & 1.88277 & 107.04425 & 135.21040 & -17592.582950 & -17592.497110 \\ 1.62681 & 1.86479 & 117.41712 & 1.88144 & 106.01862 & 137.11170 & -17592.584940 & -17592.488290\end{array}$

\begin{tabular}{c}
$a^{1} \mathbf{A}^{“}$ \\
-17592.529650 \\
-17592.534790 \\
-17592.539280 \\
\hline-17592.543190 \\
\hline-17592.546470 \\
-17592.549220 \\
-17592.551460 \\
-17592.553130 \\
\hline-17592.554340 \\
\hline-17592.555250 \\
\hline-17592.555930 \\
\hline-17592.556340 \\
\hline-17592.556540 \\
\hline-17592.556500 \\
\hline-17592.556225 \\
\hline-17592.556030 \\
\hline-17592.555580 \\
\hline-17592.554810 \\
\hline-17592.553770 \\
\hline-17592.552400 \\
\hline-17592.550640 \\
\hline-17592.548400 \\
\hline-17592.545540 \\
\hline-17592.541950 \\
\hline
\end{tabular}

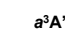

$-17592.449780$ $-17592.453820$ $-17592.457280$ $-17592.460220$ $-17592.462620$ $-17592.464530$ $-17592.465920$ $-17592.467470$ $-17592.467540$ $-17592.466890$ $-17592.465800$ $-17592.464240$ $-17592.462330$ $-17592.460230$ $-17592.458417$ $-17592.460830$ $-17592.463620$ $-17592.466440$ $-17592.469040$ $-17592.471300$ $-17592.473060$ $-17592.474250$ $-17592.474700$ $-17592.474270$

\begin{tabular}{|c|c|c|c|}
\hline$A^{\prime}$ & $A^{\prime \prime}$ & & \\
\hline 7592.41 & 17592.554670 & 17592.486310 & -17592.41399 \\
\hline 370 & & & \\
\hline 10 & 7592. & 9150 & \\
\hline 592.4 & -17592.5 & 17592. & -17592 \\
\hline 592 & -17592. & -17 & \\
\hline 592.4 & 7592.572480 & -17592.4 & 23240 \\
\hline 592.4 & 759 & & -175 \\
\hline 92.4 & -17592.5 & 10 & 75 \\
\hline 592.4 & -17592.577080 & -17592 & 1900 \\
\hline 592.4 & -17592. & 940 & \\
\hline 592.4508 & -17592.578670 & 17592. & -17592 \\
\hline 592. & -1759 & 40 & -17 \\
\hline 592.4 & 50 & 50 & \\
\hline 7592.454630 & -17592.5 & -17592 & -17592 \\
\hline 7592. & -1759 & & -175 \\
\hline 7592. & & & \\
\hline 7592.4 & -17592.5 & & -175 \\
\hline 592. & 7592.5 & & -17592 \\
\hline 7592.4 & & & 4620 \\
\hline 7592. & -17 & & -175 \\
\hline & & & \\
\hline & & & \\
\hline & & & 630 \\
\hline & & & \\
\hline
\end{tabular}




\section{A. Supporting Information of Publications}

\begin{tabular}{|c|c|c|c|c|c|c|c|c|c|c|c|c|c|}
\hline 1.62678 & 1.86162 & 117.65800 & 1.88012 & 104.99300 & 139.01300 & -17592.586340 & -17592.478320 & -17592.537570 & -17592.471120 & -17592.438100 & -17592.564610 & -17592.492080 & -17592.414940 \\
\hline 1.62675 & 1.85845 & 117.89888 & 1.87880 & 103.96738 & 140.91430 & -17592.585880 & -17592.466980 & -17592.531570 & -17592.467980 & -17592.431460 & -17592.558900 & -17592.490900 & -17592.412790 \\
\hline 1.62673 & 1.85527 & 118.13975 & 1.87747 & 102.94175 & 142.81560 & -17592.583560 & -17592.453830 & -17592.523750 & -17592.462960 & -17592.423070 & -17592.551350 & -17592.487710 & -17592.408990 \\
\hline 1.62670 & 1.85210 & 118.38063 & 1.87615 & 101.91613 & 144.71690 & -17592.578580 & -17592.438120 & -17592.513360 & -17592.455300 & -17592.412390 & -17592.541150 & -17592.481690 & -17592.402700 \\
\hline 1.62668 & 1.84892 & 118.62151 & 1.87482 & 100.89051 & 146.61820 & -17592.570020 & -17592.418830 & -17592.499410 & -17592.444100 & -17592.399110 & -17592.527350 & -17592.471860 & -17592.392960 \\
\hline
\end{tabular}

Table S17. Adiabatic Potential Energy Surfaces of $\mathrm{NOsF}_{3}$ (Figure 6d) obtained at the SA-CASSCF(8,8)/NEVPT2/cc-pVTZ-DK level. RMN, RMF1, A1, RMF2, A2 and D1 are the OsN bond length, the OsF' bond length, the NOsF' bond angle, the OsF bond length, the NOsF angle and the F'OsNF dihedral angle (see Figure 5). Energies in hartree, bond lengths in $\AA$ and angles in degree.

\begin{tabular}{|c|c|c|c|c|c|c|c|c|c|c|c|c|c|}
\hline RMN & RMF1 & A1 & RMF2 & A2 & D1 & $a^{1} A^{\prime}$ & $b^{1} A^{\prime}$ & $a^{1} A^{\prime \prime}$ & $a^{3} A^{\prime}$ & $b^{3} A^{\prime}$ & $a^{3} A^{\prime \prime}$ & $b^{3} A^{\prime \prime}$ & A“" \\
\hline 64110 & 1.89256 & 126.92771 & 1.86221 & 101.49391 & 93.35660 & -17592.559350 & -17592.525640 & -17592.559190 & -17592.471240 & -17592.438640 & -17592.583180 & -17592.468440 & -17592.450060 \\
\hline 64009 & 1.89262 & 126.09353 & 1.86443 & 102.47643 & 95.25970 & -17592.561810 & -17592.527380 & -17592.561130 & -17592.473220 & -17592.439580 & -17592.584840 & -17592.470890 & -17592.451570 \\
\hline 63909 & 1.89267 & 125.25935 & 1.86666 & 103.45895 & 97.16280 & -17592.563550 & -17592.528950 & -17592.562500 & -17592.474700 & -17592.440770 & -17592.585940 & -17592.472820 & -17592.453000 \\
\hline 63808 & 1.89273 & 124.42518 & 1.86888 & 104.44148 & 99.06590 & -17592.564670 & -17592.530360 & -17592.563340 & -17592.475760 & -17592.443380 & -17592.586520 & -17592.474360 & -17592.454430 \\
\hline 63708 & 1.89279 & 123.59100 & 1.87111 & 105.42400 & 100.96900 & -17592.565210 & -17592.531570 & -17592.563670 & -17592.476250 & -17592.446500 & -17592.586620 & -17592.475240 & -17592.455550 \\
\hline 1.63608 & 1.89285 & 122.75682 & 1.87334 & 106.40652 & 102.87210 & -17592.565150 & -17592.532530 & -17592.563490 & -17592.476020 & -17592.448600 & -17592.586220 & -17592.475280 & -17592.456190 \\
\hline 63507 & 1.89291 & 121.92265 & 1.87556 & 107.38905 & 104.77520 & -17592.564620 & -17592.533390 & -17592.562930 & -17592.475230 & -17592.450090 & -17592.585470 & -17592.474640 & -17592.456530 \\
\hline 1.63407 & 1.89296 & 121.08847 & 1.87779 & 108.37157 & 106.67830 & -17592.563790 & -17592.534170 & -17592.562140 & -17592.474020 & -17592.451170 & -17592.584540 & -17592.473470 & -17592.456610 \\
\hline 1.63306 & 1.89302 & 120.25429 & 1.88001 & 109.35409 & 108.58140 & -17592.562710 & -17592.534890 & -17592.561130 & -17592.472380 & -17592.451980 & -17592.583460 & -17592.471800 & -17592.456480 \\
\hline 63206 & 1.89308 & 119.42011 & 1.88224 & 110.33661 & 110.48450 & -17592.561490 & -17592.535780 & -17592.560100 & -17592.470460 & -17592.452730 & -17592.582440 & -17592.469800 & -17592.456310 \\
\hline 1.63106 & 1.89314 & 118.58594 & 1.88446 & 111.31914 & 112.38760 & -17592.560100 & -17592.536780 & -17592.559060 & -17592.468220 & -17592.453370 & -17592.581480 & -17592.467410 & -17592.456080 \\
\hline .63005 & 1.89319 & 117.75176 & 1.88669 & 112.30166 & 114.29070 & -17592.558720 & -17592.537980 & -17592.558160 & -17592.465780 & -17592.453990 & -17592.580750 & -17592.464760 & -17592.455880 \\
\hline .62905 & 1.89325 & 116.91758 & 1.88891 & 113.28418 & 116.19380 & -17592.557410 & -17592.539170 & -17592.557360 & -17592.463140 & -17592.454480 & -17592.580200 & -17592.461850 & -17592.455650 \\
\hline 1.62804 & 1.89331 & 116.08340 & 1.89114 & 114.26670 & 118.09690 & -17592.556500 & -17592.540170 & -17592.556760 & -17592.460550 & -17592.454770 & -17592.579910 & -17592.458850 & -17592.455360 \\
\hline 1.62704 & 1.89337 & 115.24923 & 1.89337 & 115.24923 & 120.00000 & -17592.556225 & -17592.540465 & -17592.556225 & -17592.458417 & -17592.454196 & -17592.579724 & -17592.456442 & -17592.454196 \\
\hline 1.62701 & 1.89019 & 115.49010 & 1.89204 & 114.22360 & 121.90130 & -17592.557870 & -17592.539180 & -17592.556030 & -17592.460830 & -17592.456170 & -17592.579760 & -17592.461280 & -17592.453320 \\
\hline 62699 & 1.88702 & 115.73098 & 1.89072 & 113.19798 & 123.80260 & -17592.561240 & -17592.535720 & -17592.555580 & -17592.463620 & -17592.457110 & -17592.579600 & -17592.466790 & -17592.450920 \\
\hline 1.62696 & 1.88384 & 115.97186 & 1.88939 & 112.17236 & 125.70390 & -17592.565200 & -17592.530960 & -17592.554810 & -17592.466440 & -17592.457210 & -17592.579160 & -17592.471930 & -17592.448000 \\
\hline 1.62694 & 1.88067 & 116.21274 & 1.88807 & 111.14674 & 127.60520 & -17592.569270 & -17592.525430 & -17592.553770 & -17592.469040 & -17592.456690 & -17592.578470 & -17592.476700 & -17592.444620 \\
\hline 62691 & 1.87749 & 116.45361 & 1.88674 & 110.12111 & 129.50650 & -17592.573230 & -17592.519290 & -17592.552400 & -17592.471300 & -17592.455610 & -17592.577490 & -17592.481060 & -17592.440770 \\
\hline 1.62688 & 1.87432 & 116.69449 & 1.88542 & 109.09549 & 131.40780 & -17592.576930 & -17592.512540 & -17592.550640 & -17592.473060 & -17592.453910 & -17592.576130 & -17592.484920 & -17592.436360 \\
\hline 1.62686 & 1.87114 & 116.93537 & 1.88409 & 108.06987 & 133.30910 & -17592.580230 & -17592.505170 & -17592.548400 & -17592.474250 & -17592.451530 & -17592.574280 & -17592.488190 & -17592.431350 \\
\hline
\end{tabular}


A.1. High-Spin Iron(VI), Low-Spin Ruthenium(VI), and Magnetically Bistable of Osmium(VI): Molecular Group 8 Nitrido Trifluorides $\mathrm{NMF}_{3}$

\begin{tabular}{|c|c|c|c|c|c|c|c|c|c|c|c|c|c|}
\hline 1.62683 & 1.86797 & 117.17625 & 1.88277 & 107.04425 & 135.21040 & -17592.582950 & -17592.497110 & -17592.545540 & -17592.474700 & -17592.448370 & -17592.571810 & -17592.490690 & -17592.425630 \\
\hline 1.62681 & 1.86479 & 117.41712 & 1.88144 & 106.01862 & 137.11170 & -17592.584940 & -17592.488290 & -17592.541950 & -17592.474270 & -17592.444290 & -17592.568570 & -17592.492270 & -17592.419080 \\
\hline 1.62678 & 1.86162 & 117.65800 & 1.88012 & 104.99300 & 139.01300 & -17592.586340 & -17592.478320 & -17592.537570 & -17592.471120 & -17592.438100 & -17592.564610 & -17592.492080 & -17592.414940 \\
\hline 1.62675 & 1.85845 & 117.89888 & 1.87880 & 103.96738 & 140.91430 & -17592.585880 & -17592.466980 & -17592.531570 & -17592.467980 & -17592.431460 & -17592.558900 & -17592.490900 & -17592.412790 \\
\hline 1.62673 & 1.85527 & 118.13975 & 1.87747 & 102.94175 & 142.81560 & -17592.583560 & -17592.453830 & -17592.523750 & -17592.462960 & -17592.423070 & -17592.551350 & -17592.487710 & -17592.408990 \\
\hline 1.62670 & 1.85210 & 118.38063 & 1.87615 & 101.91613 & 144.71690 & -17592.578580 & -17592.438120 & -17592.513360 & -17592.455300 & -17592.412390 & -17592.541150 & -17592.481690 & -17592.402700 \\
\hline 1.62668 & 1.84892 & 118.62151 & 1.87482 & 100.89051 & 146.61820 & -17592.570020 & -17592.418830 & -17592.499410 & -17592.444100 & -17592.399110 & -17592.527350 & -17592.471860 & -17592.392960 \\
\hline
\end{tabular}




\section{Calculated molecular structures and vibrational data}

The following table list computed z-matrices (structures), total energies, and vibrational data of optimized structures in $C_{\mathrm{s}}$ point group symmetry (unless stated otherwise) and with positive HOMO-LUMO (closed shell) or SOMO-LUMO (open shell) gap.

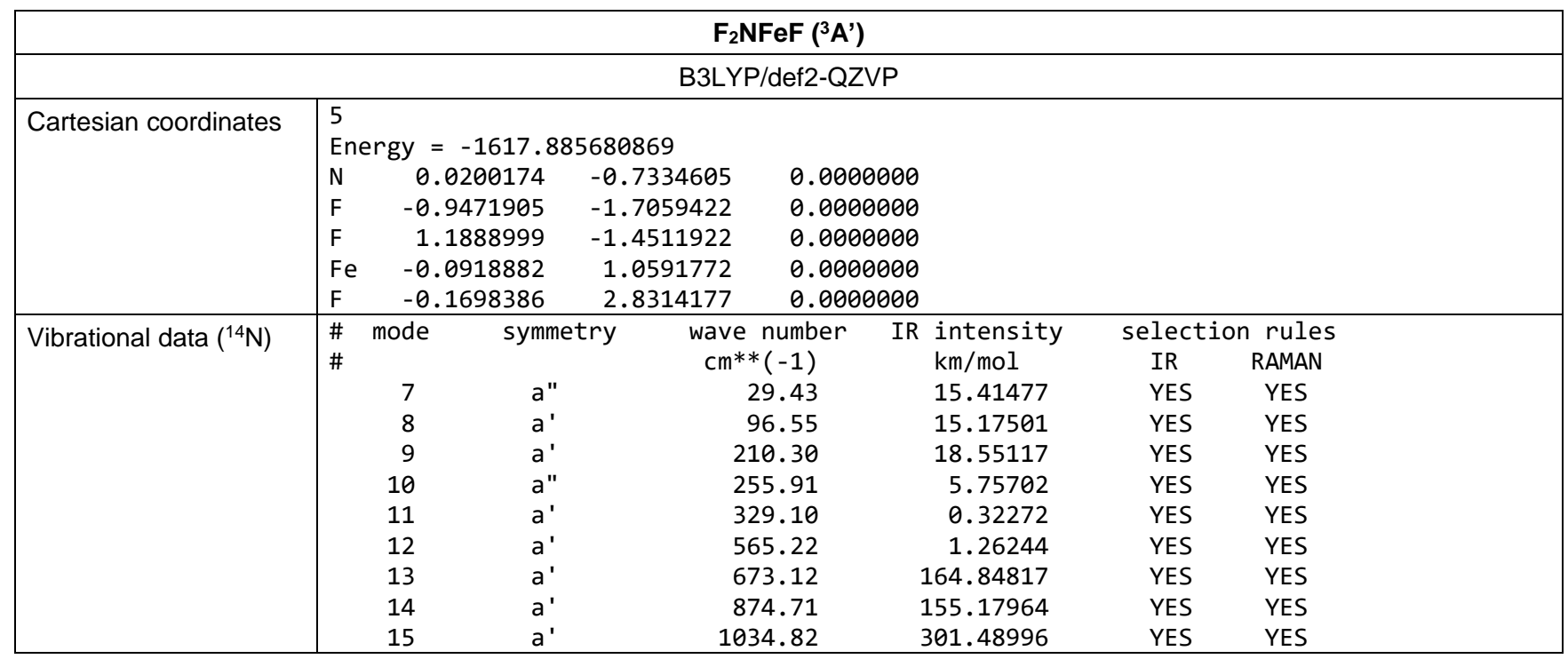


A.1. High-Spin Iron(VI), Low-Spin Ruthenium(VI), and Magnetically Bistable of Osmium(VI): Molecular Group 8 Nitrido Trifluorides $\mathrm{NMF}_{3}$

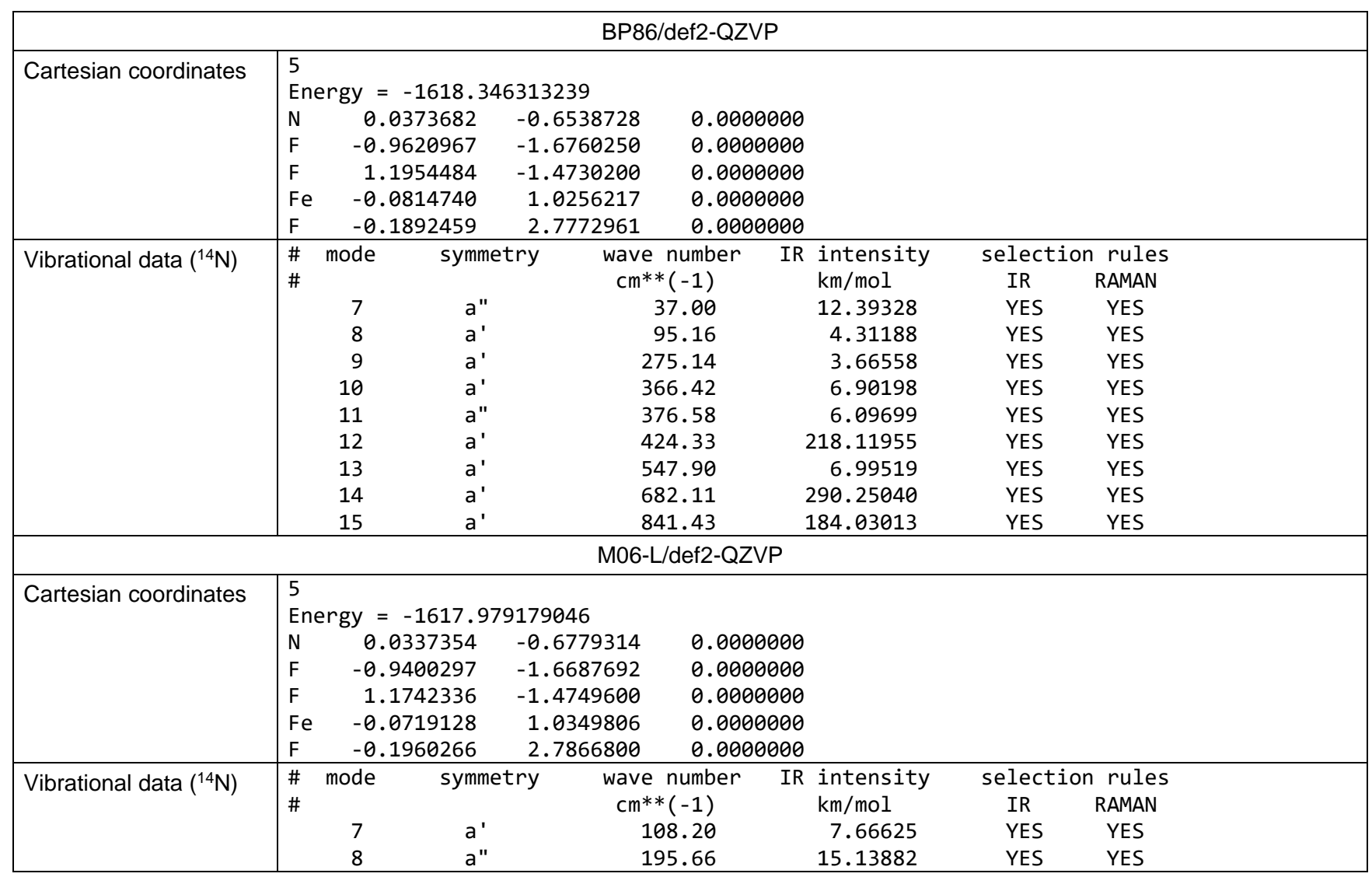




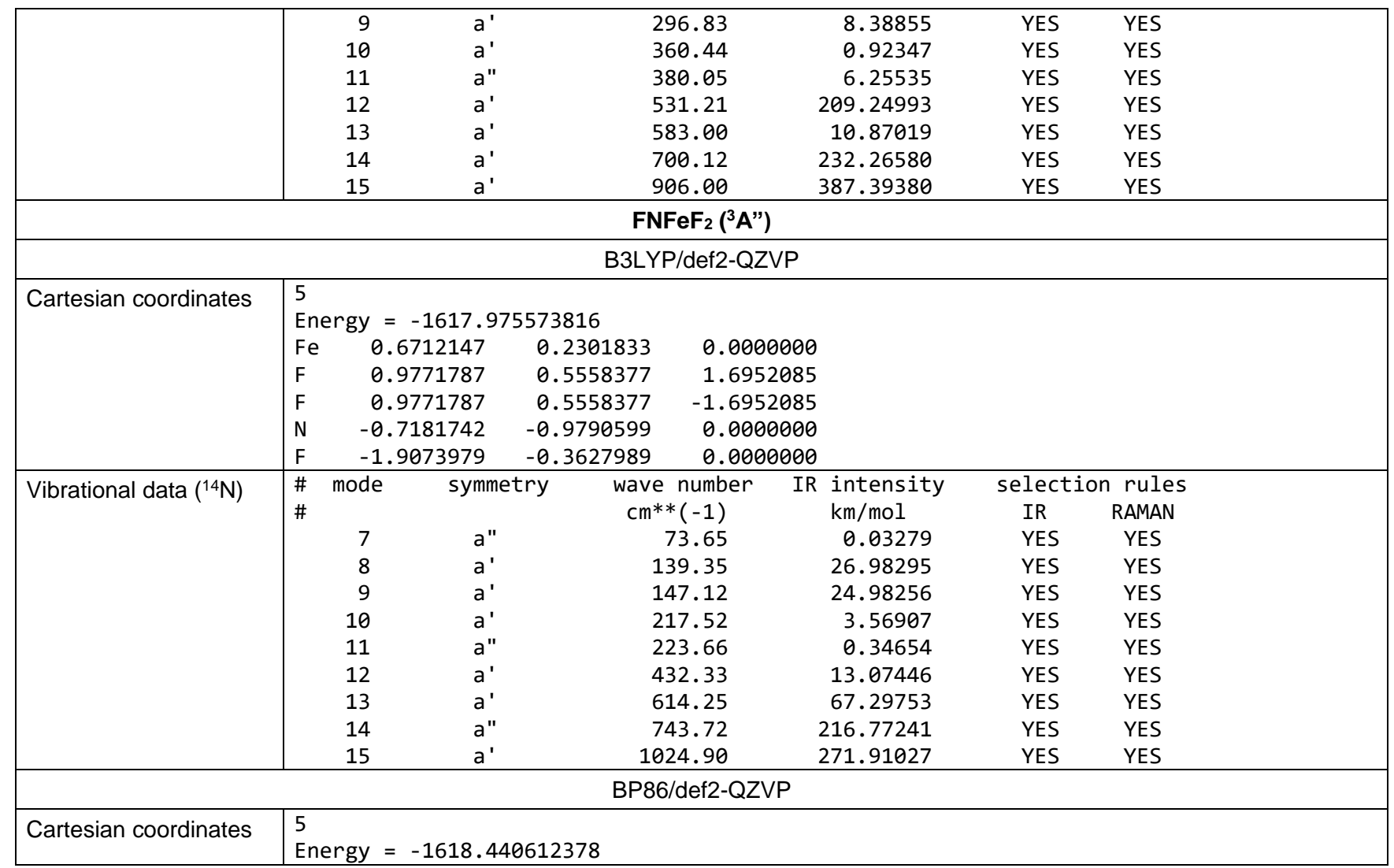


A.1. High-Spin Iron(VI), Low-Spin Ruthenium(VI), and Magnetically Bistable of Osmium(VI): Molecular Group 8 Nitrido Trifluorides $\mathrm{NMF}_{3}$

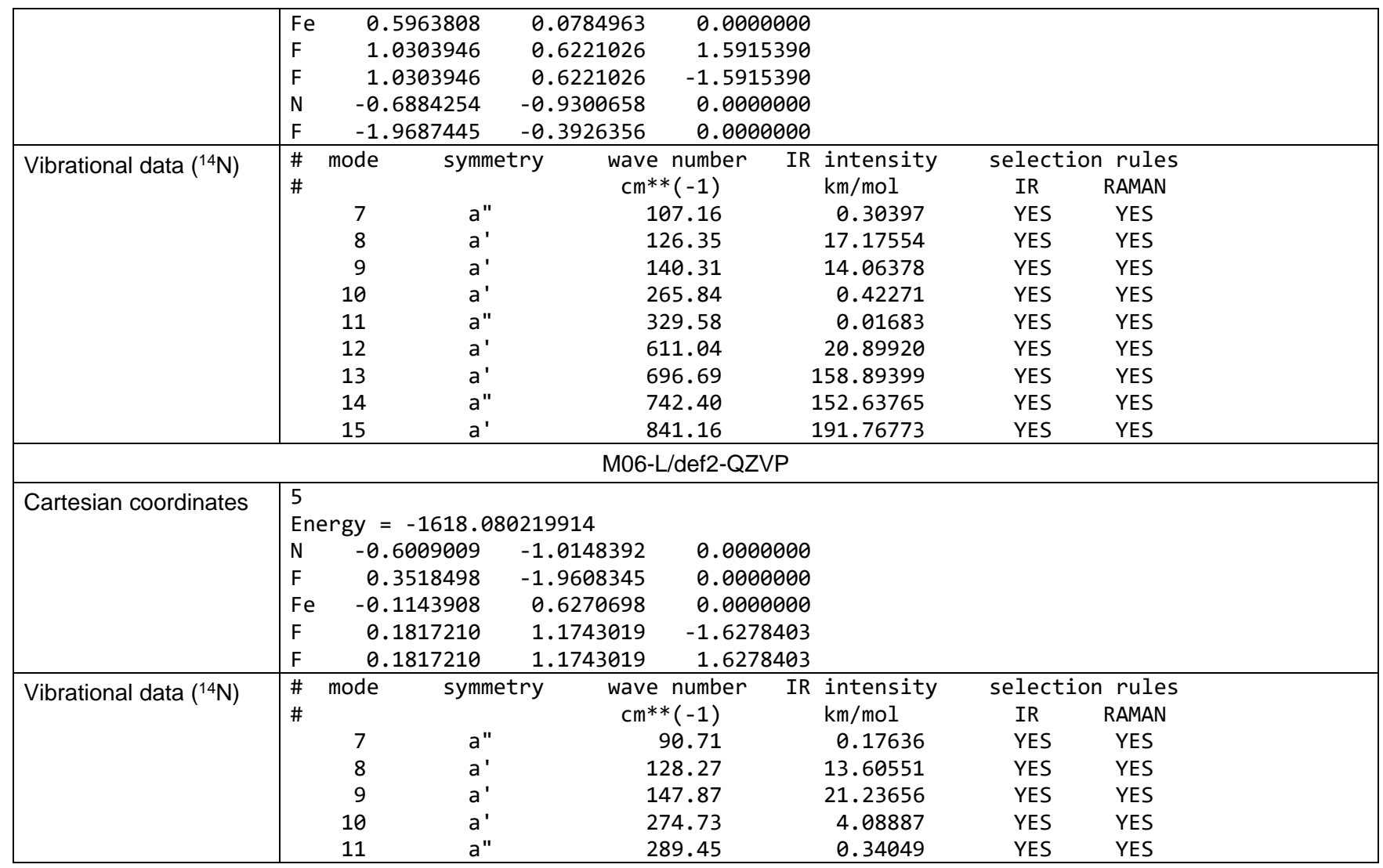




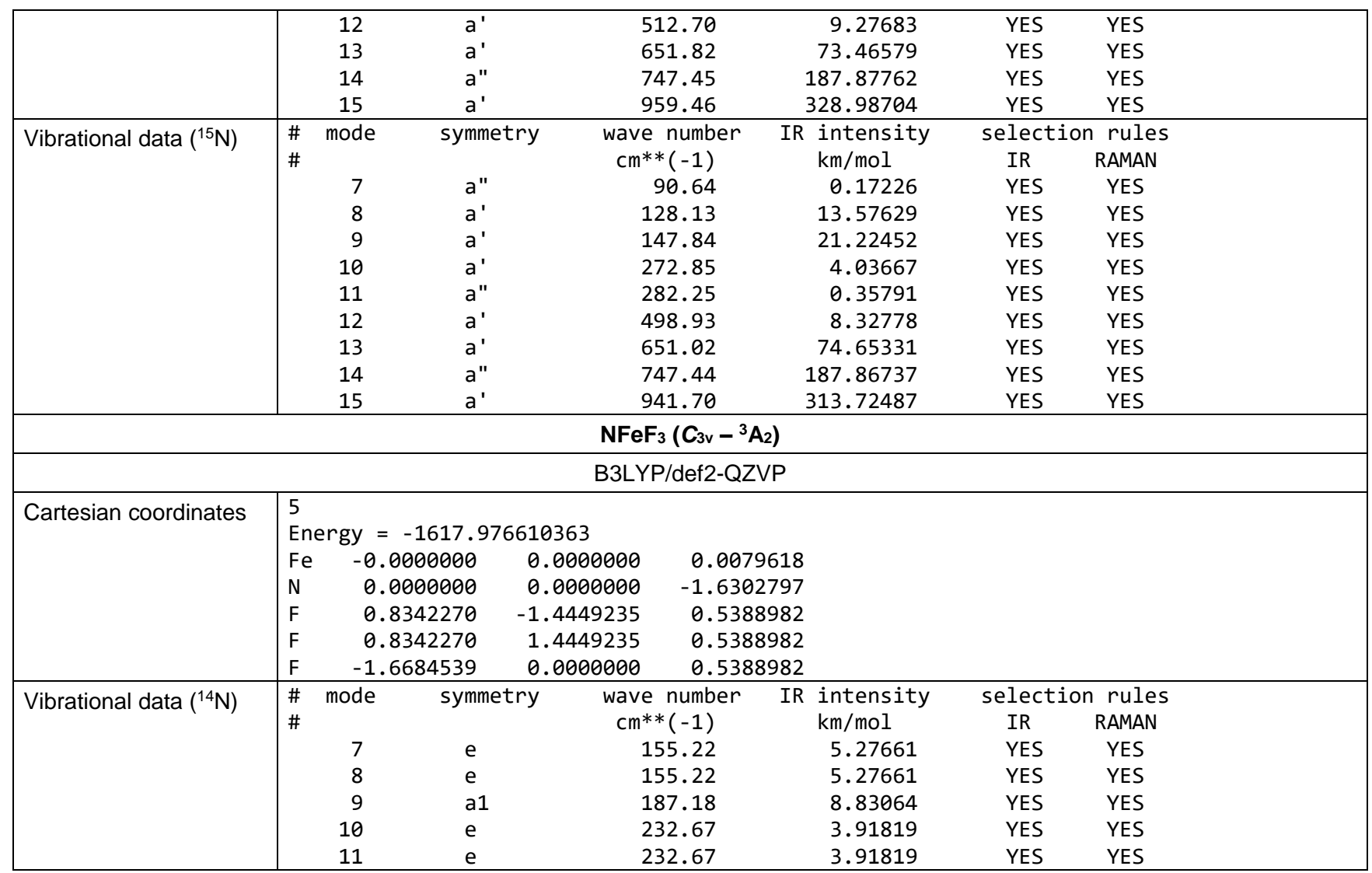

39 
A.1. High-Spin Iron(VI), Low-Spin Ruthenium(VI), and Magnetically Bistable of Osmium(VI): Molecular Group 8 Nitrido Trifluorides $\mathrm{NMF}_{3}$

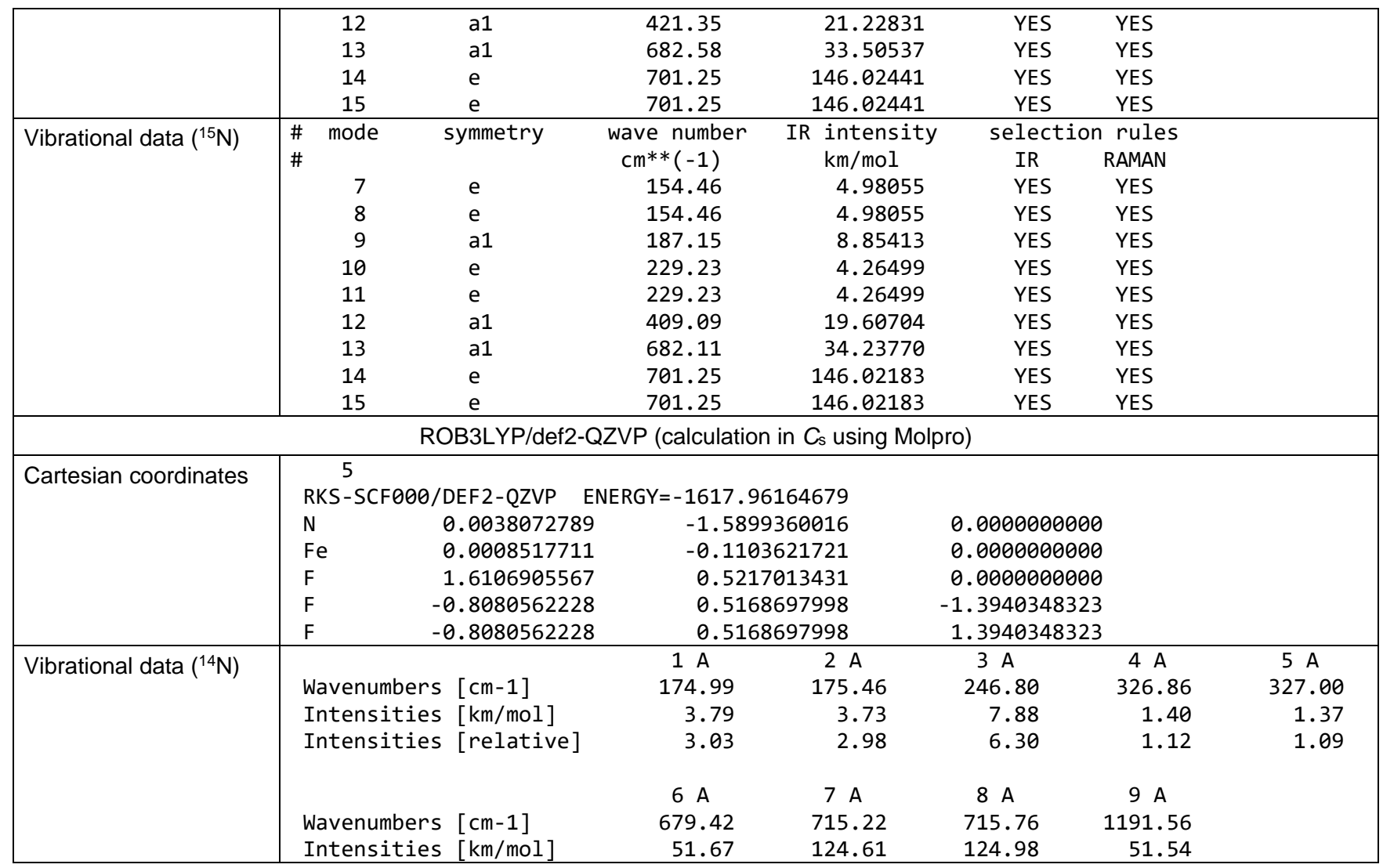

40 


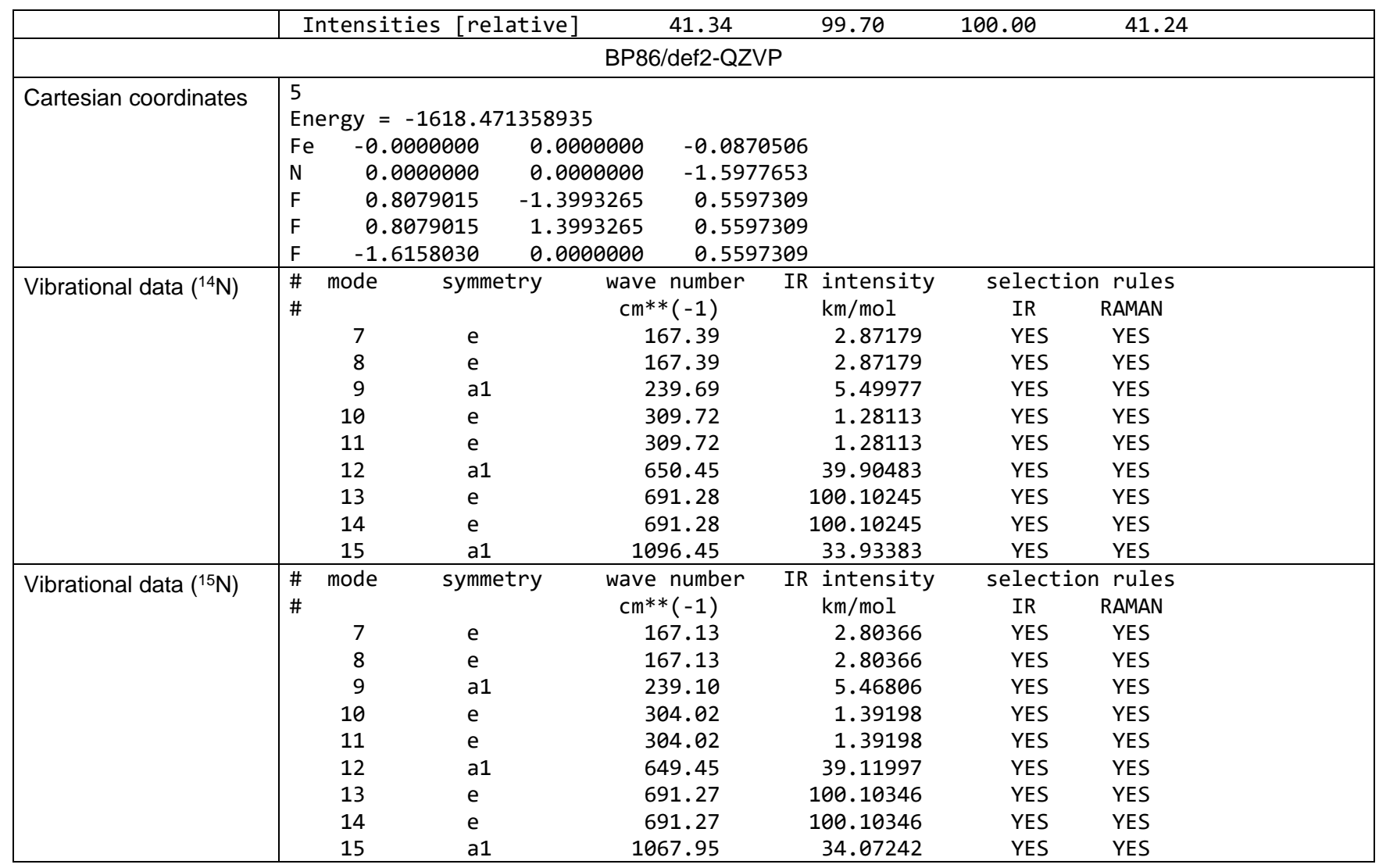


A.1. High-Spin Iron(VI), Low-Spin Ruthenium(VI), and Magnetically Bistable of Osmium(VI): Molecular Group 8 Nitrido Trifluorides $\mathrm{NMF}_{3}$

M06-L/def2-QZVP

\begin{tabular}{|l|lrrr}
\hline Cartesian coordinates & \multicolumn{4}{l}{ 5 } \\
& Energy $=-1618.108613779$ & \\
& N & -0.0000000 & 0.0000000 & -1.6162454 \\
& Fe & 0.0000000 & 0.0000000 & -0.0709558 \\
& F & -0.8100550 & 1.4030564 & 0.5625015 \\
& F & -0.8100550 & -1.4030564 & 0.5625015 \\
& F & 1.6201100 & 0.0000000 & 0.5625015
\end{tabular}

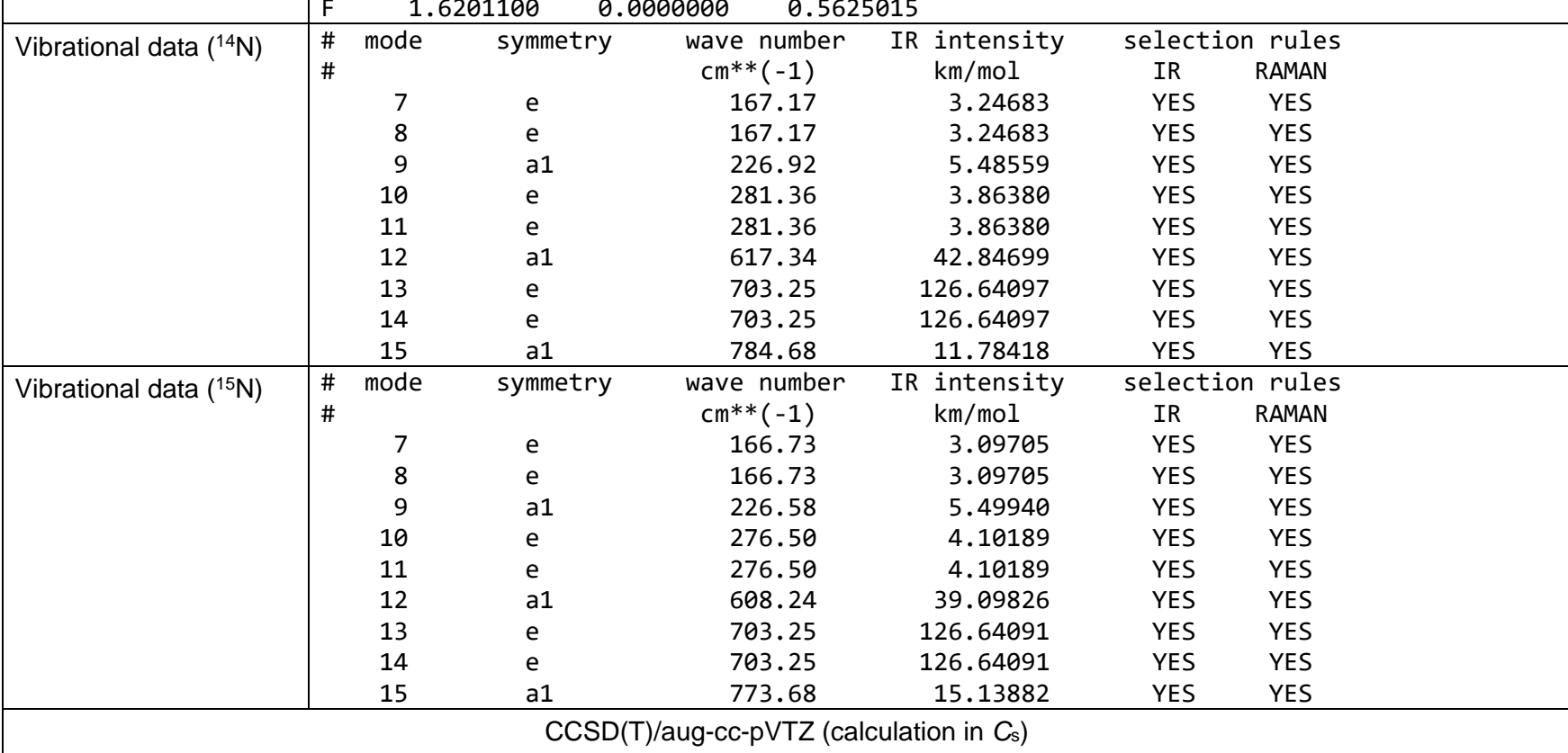

42 


\begin{tabular}{|c|c|c|c|c|c|c|}
\hline \multirow[t]{6}{*}{ Cartesian coordinates } & \multicolumn{6}{|c|}{$\begin{array}{l}5 \\
\operatorname{UCCSD}(T) / A U G-C C-P V T Z\end{array}$} \\
\hline & \multicolumn{3}{|c|}{$\begin{array}{lll}\mathrm{N} & -0.0000000000 & -1.6558196996\end{array}$} & \multicolumn{3}{|c|}{0.0000000000} \\
\hline & Fe $\quad-0.0000000000$ & \multicolumn{2}{|c|}{-0.0441039939} & \multicolumn{3}{|c|}{0.0000000000} \\
\hline & 1.6861214269 & \multicolumn{2}{|c|}{0.4501368796} & \multicolumn{3}{|c|}{0.0000000000} \\
\hline & -0.8430607134 & \multicolumn{2}{|c|}{0.4501368796} & \multicolumn{3}{|c|}{-1.4602239896} \\
\hline & -0.8430607134 & \multicolumn{2}{|c|}{0.4501368796} & \multicolumn{2}{|c|}{1.4602239896} & \\
\hline \multirow{8}{*}{ Vibrational data $\left({ }^{14} \mathrm{~N}\right)$} & & $1 A^{\prime}$ & $2 A$ & $3 A$ & $4 A^{\prime}$ & $5 A^{\prime}$ \\
\hline & Wavenumbers [cm-1] & 87.62 & 132.56 & 184.09 & 225.79 & 231.05 \\
\hline & Intensities $[\mathrm{km} / \mathrm{mol}]$ & 0.00 & 0.00 & 0.00 & 0.00 & 0.00 \\
\hline & Intensities [relative] & 0.00 & 0.00 & 0.00 & 0.00 & 0.00 \\
\hline & & $6 A^{\prime}$ & $7 A^{\cdots}$ & $8 A^{\prime}$ & $9 A^{-}$ & \\
\hline & Wavenumbers $[\mathrm{cm}-1]$ & 537.56 & 718.94 & 720.08 & 757.29 & \\
\hline & Intensities [ $\mathrm{km} / \mathrm{mol}]$ & 0.00 & 0.00 & 0.00 & 0.00 & \\
\hline & Intensities [relative] & 0.00 & 0.00 & 0.00 & 0.00 & \\
\hline \multirow[t]{8}{*}{ Vibrational data $\left({ }^{15} \mathrm{~N}\right)$} & & $1 A^{\prime}$ & $2 A^{\prime}$ & $3 A$ & $4 A^{\prime}$ & $5 A^{\prime}$ \\
\hline & Wavenumbers $[\mathrm{cm}-1]$ & 87.66 & 132.40 & 183.78 & 221.65 & 226.62 \\
\hline & Intensities [km/mol] & 0.00 & 0.00 & 0.00 & 0.00 & 0.00 \\
\hline & Intensities [relative] & 0.00 & 0.00 & 0.00 & 0.00 & 0.00 \\
\hline & & $6 \mathrm{~A}^{-}$ & $7 A^{\cdots}$ & $8 A^{\prime}$ & $9 A^{-}$ & \\
\hline & Wavenumbers [cm-1] & 528.75 & 718.93 & 720.03 & 747.74 & \\
\hline & Intensities [ $\mathrm{km} / \mathrm{mol}]$ & 0.00 & 0.00 & 0.00 & 0.00 & \\
\hline & Intensities [relative] & 0.00 & 0.00 & 0.00 & 0.00 & \\
\hline \multicolumn{7}{|c|}{ CCSD(T)/aug-cc-pVTZ(Fe: aug-cc-pVTZ-PP) (calculation in $C_{\mathrm{s}}$ ) } \\
\hline \multirow[t]{4}{*}{ Cartesian coordinates } & \multicolumn{6}{|c|}{$\operatorname{UCCSD}(T) /$ USERDEF $\quad$ ENERGY $=-1625.76907210$} \\
\hline & $\mathrm{Fe} \quad 0.0000327714$ & \multicolumn{2}{|c|}{0.0000000000} & \multicolumn{3}{|c|}{0.0052274647} \\
\hline & 0.0000103441 & \multicolumn{2}{|c|}{0.0000000000} & \multicolumn{3}{|c|}{-1.5776279214} \\
\hline & 0.8343780343 & \multicolumn{2}{|c|}{-1.4450891256} & \multicolumn{2}{|c|}{0.5222495883} & \\
\hline
\end{tabular}


A.1. High-Spin Iron(VI), Low-Spin Ruthenium(VI), and Magnetically Bistable of Osmium(VI): Molecular Group 8 Nitrido Trifluorides $\mathrm{NMF}_{3}$

\begin{tabular}{|c|c|c|c|c|c|c|}
\hline & $\begin{array}{r}0.8343780343 \\
-1.6687991842 \\
\end{array}$ & $\begin{array}{l}1.44 \\
0.06\end{array}$ & $\begin{array}{l}1256 \\
0000\end{array}$ & $\begin{array}{l}0.522248 \\
0.52227 \varepsilon\end{array}$ & & \\
\hline Vibrational data $\left({ }^{14} \mathrm{~N}\right)$ & & $1 \mathrm{~A}$ & $2 A$ & $3 \mathrm{~A}$ & $4 \mathrm{~A}$ & $5 \mathrm{~A}$ \\
\hline & Wavenumbers [cm-1] & 60.63 & 67.35 & 185.20 & 242.61 & 253.84 \\
\hline & Intensities [km/mol] & 0.00 & 0.00 & 0.00 & 0.00 & 0.00 \\
\hline & Intensities [relative] & 0.00 & 0.00 & 0.00 & 0.00 & 0.00 \\
\hline & & $6 \mathrm{~A}$ & $7 \mathrm{~A}$ & $8 \mathrm{~A}$ & $9 \mathrm{~A}$ & \\
\hline & Wavenumbers [cm-1] & 563.67 & 751.03 & 752.58 & 791.12 & \\
\hline & Intensities [km/mol] & 0.00 & 0.00 & 0.00 & 0.00 & \\
\hline & Intensities [relative] & 0.00 & 0.00 & 0.00 & 0.00 & \\
\hline Vibrational data $\left({ }^{15} \mathrm{~N}\right)$ & & $1 \mathrm{~A}$ & $2 \mathrm{~A}$ & $3 \mathrm{~A}$ & $4 \mathrm{~A}$ & $5 \mathrm{~A}$ \\
\hline & Wavenumbers [cm-1] & 61.02 & 67.00 & 185.01 & 238.71 & 249.60 \\
\hline & Intensities [km/mol] & 0.00 & 0.00 & 0.00 & 0.00 & 0.00 \\
\hline & Intensities [relative] & 0.00 & 0.00 & 0.00 & 0.00 & 0.00 \\
\hline & & $6 \mathrm{~A}$ & $7 \mathrm{~A}$ & $8 \mathrm{~A}$ & $9 \mathrm{~A}$ & \\
\hline & Wavenumbers [cm-1] & 555.79 & 751.01 & 752.58 & 779.51 & \\
\hline & Intensities [km/mol] & 0.00 & 0.00 & 0.00 & 0.00 & \\
\hline & Intensities [relative] & 0.00 & 0.00 & 0.00 & 0.00 & \\
\hline & NEVPT2/aug-cc- & Z-DK(Fe: & c-pwCVT & & & \\
\hline Cartesian coordinates & $\begin{array}{l}5 \\
\text { NEVPT2/AUG-CC-PVTZ-DK, FE }\end{array}$ & 5-CC-PWC & DK ENEF & -1626.144 & & \\
\hline & $\begin{array}{ll}N & -0.0000000000\end{array}$ & -1.55 & 6515 & 0.000000 & & \\
\hline & -0.0000000000 & -0.06 & 7671 & 0.000006 & & \\
\hline & 1.6341336229 & 0.47 & 7965 & -0.000000 & & \\
\hline & -0.8170668115 & 0.47 & 7965 & -1.415201 & & \\
\hline & -0.8170668115 & 0.47 & 7965 & 1.415201 & & \\
\hline Vibrational data $\left({ }^{14} \mathrm{~N}\right)$ & & $1 A^{\prime}$ & $2 A^{\prime}$ & $3 A^{\prime}$ & $4 A^{\prime}$ & $5 A^{\prime}$ \\
\hline & Wavenumbers [cm-1] & 185.48 & 198.28 & 235.04 & 287.16 & 288.62 \\
\hline & Intensities $[\mathrm{km} / \mathrm{mol}]$ & 0.00 & 0.00 & 0.00 & 0.00 & 0.00 \\
\hline
\end{tabular}




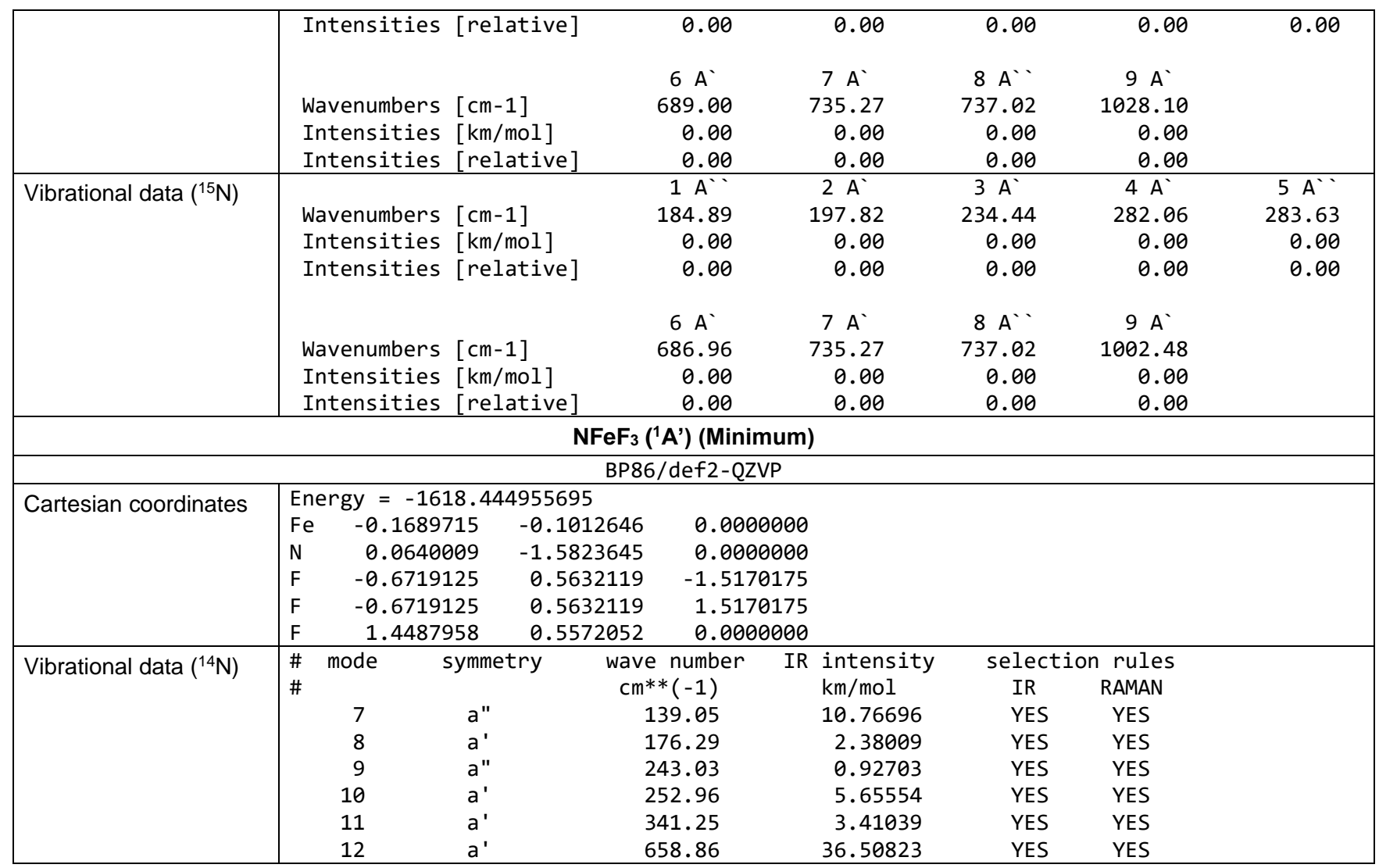


A.1. High-Spin Iron(VI), Low-Spin Ruthenium(VI), and Magnetically Bistable of Osmium(VI): Molecular Group 8 Nitrido Trifluorides $\mathrm{NMF}_{3}$

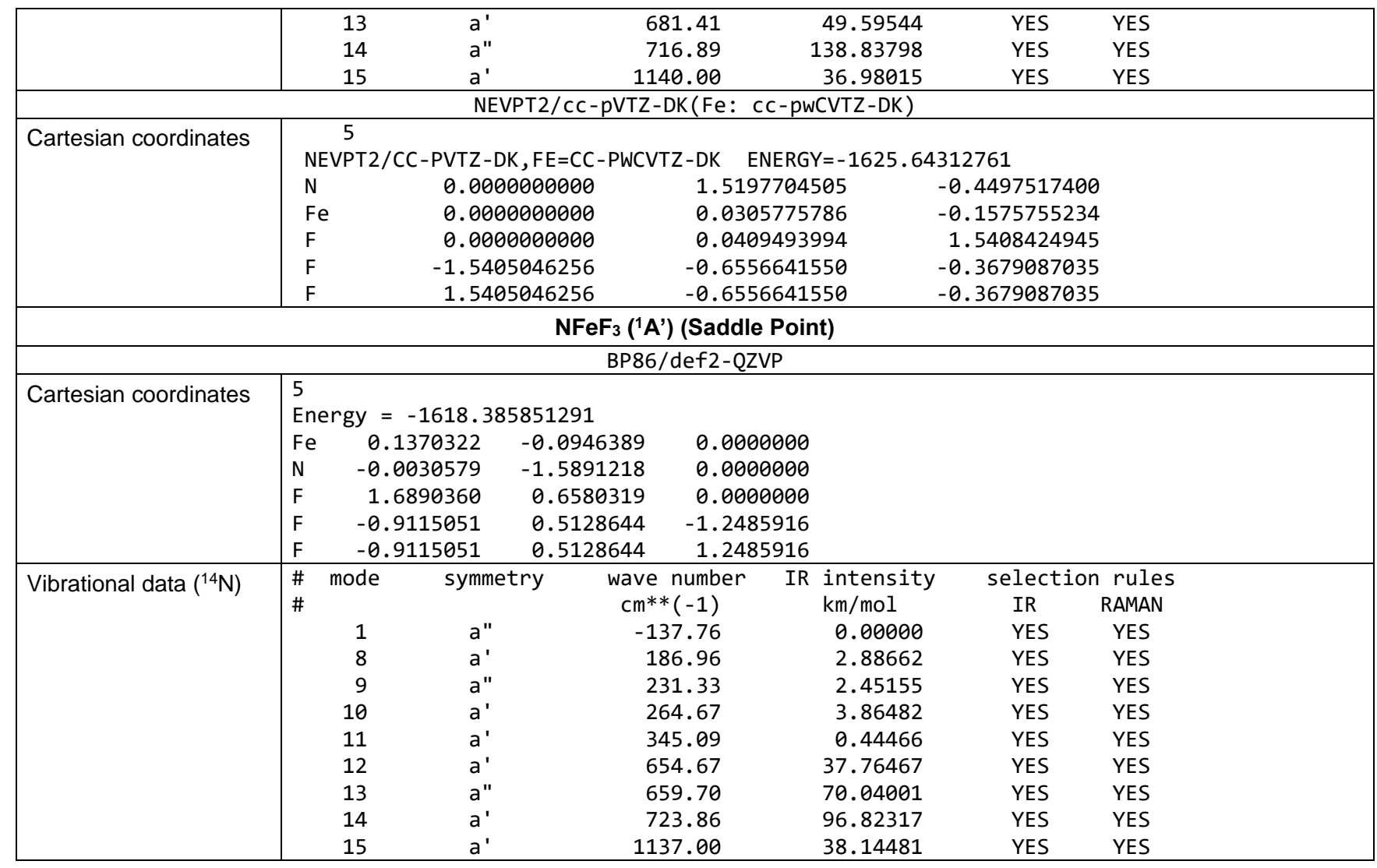




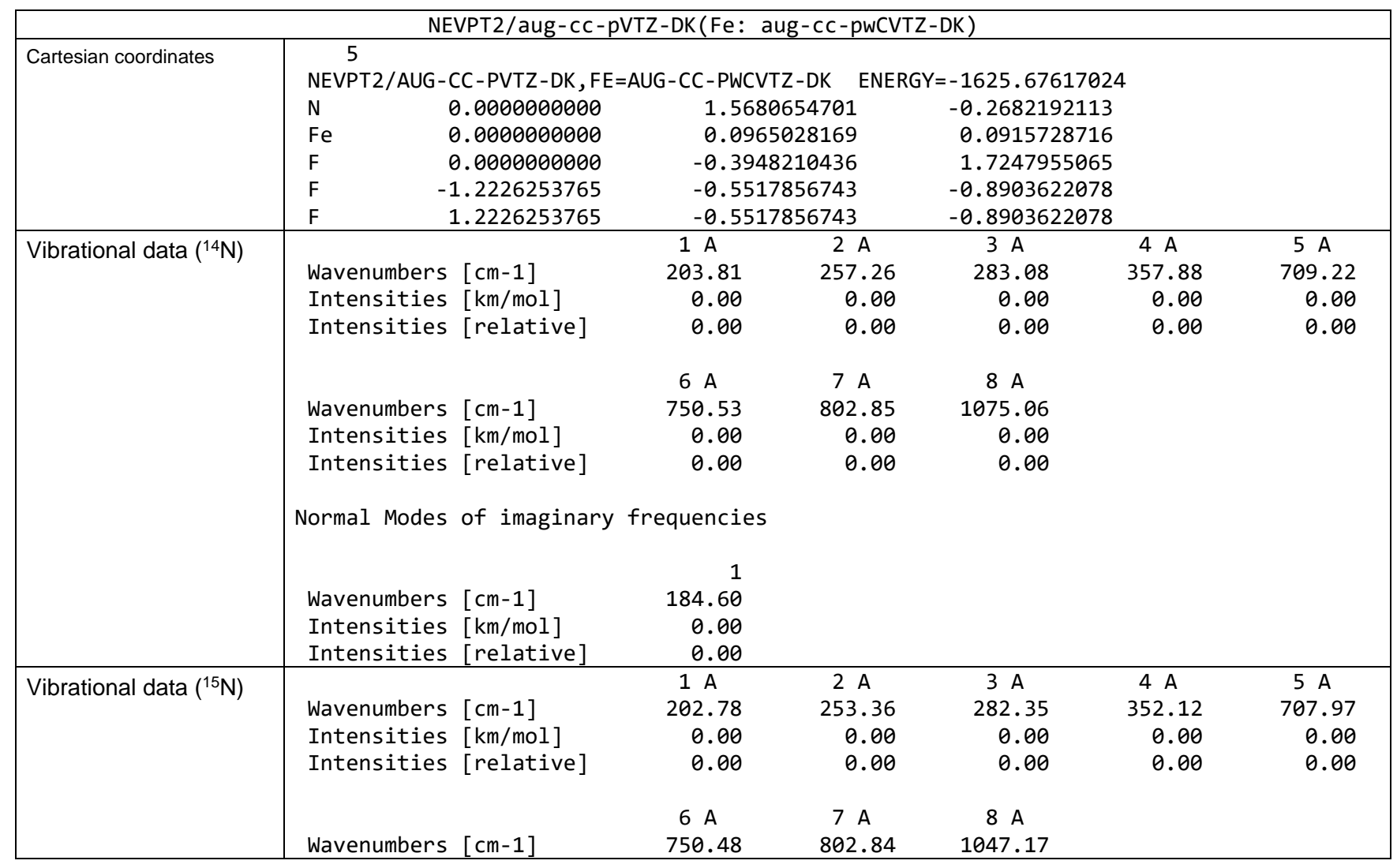


A.1. High-Spin Iron(VI), Low-Spin Ruthenium(VI), and Magnetically Bistable of Osmium(VI): Molecular Group 8 Nitrido Trifluorides $\mathrm{NMF}_{3}$

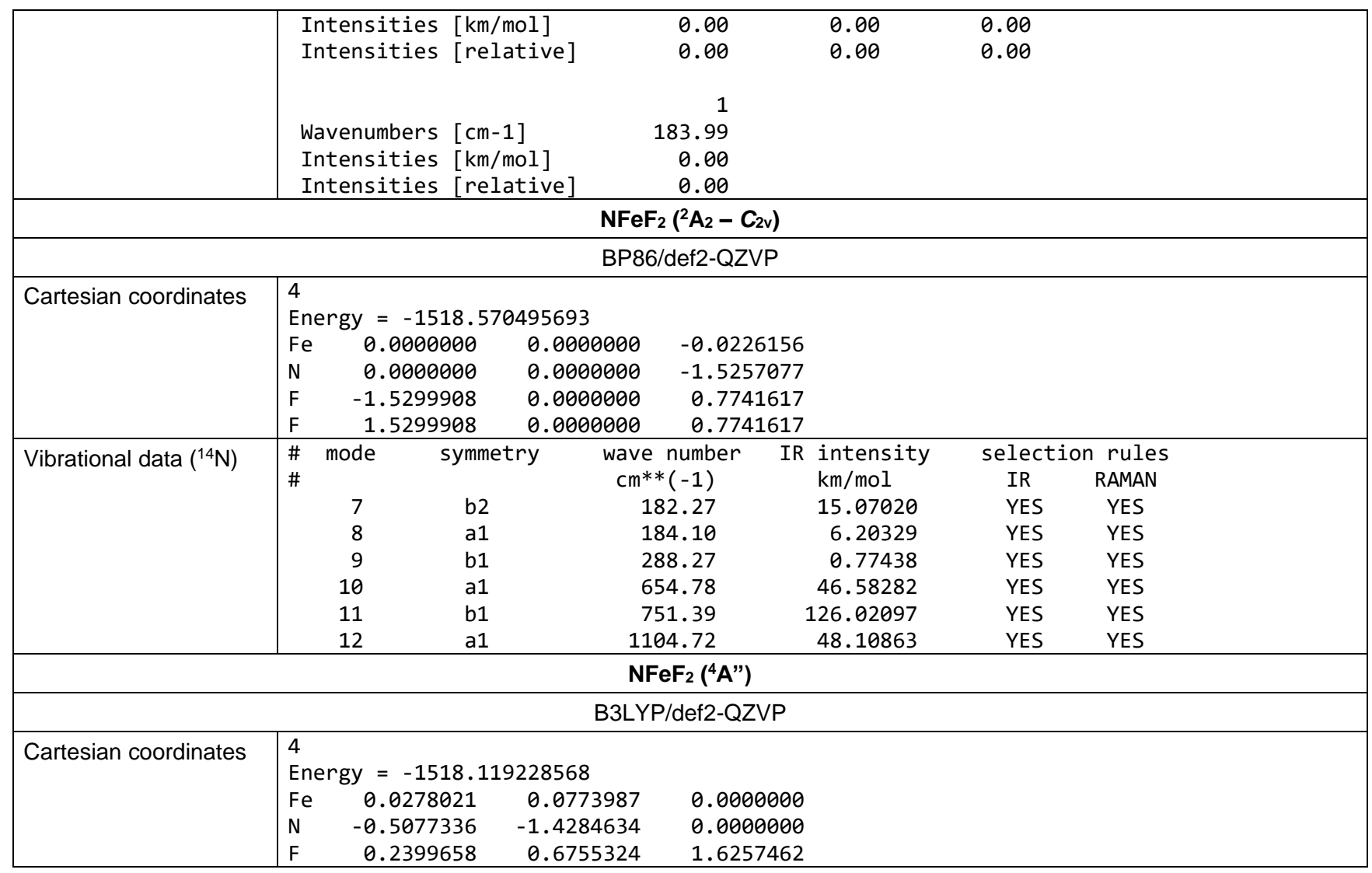




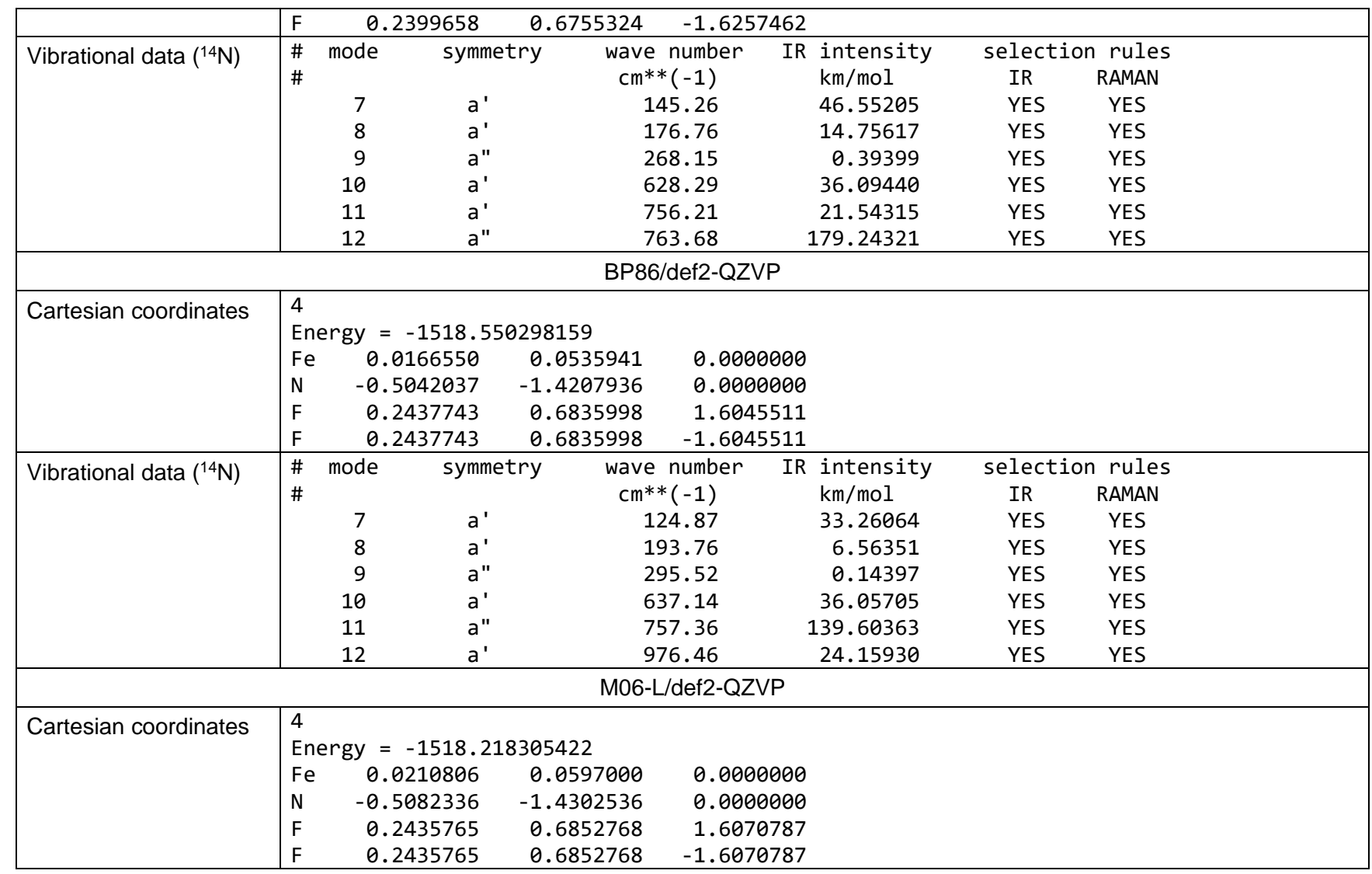


A.1. High-Spin Iron(VI), Low-Spin Ruthenium(VI), and Magnetically Bistable of Osmium(VI): Molecular Group 8 Nitrido Trifluorides $\mathrm{NMF}_{3}$

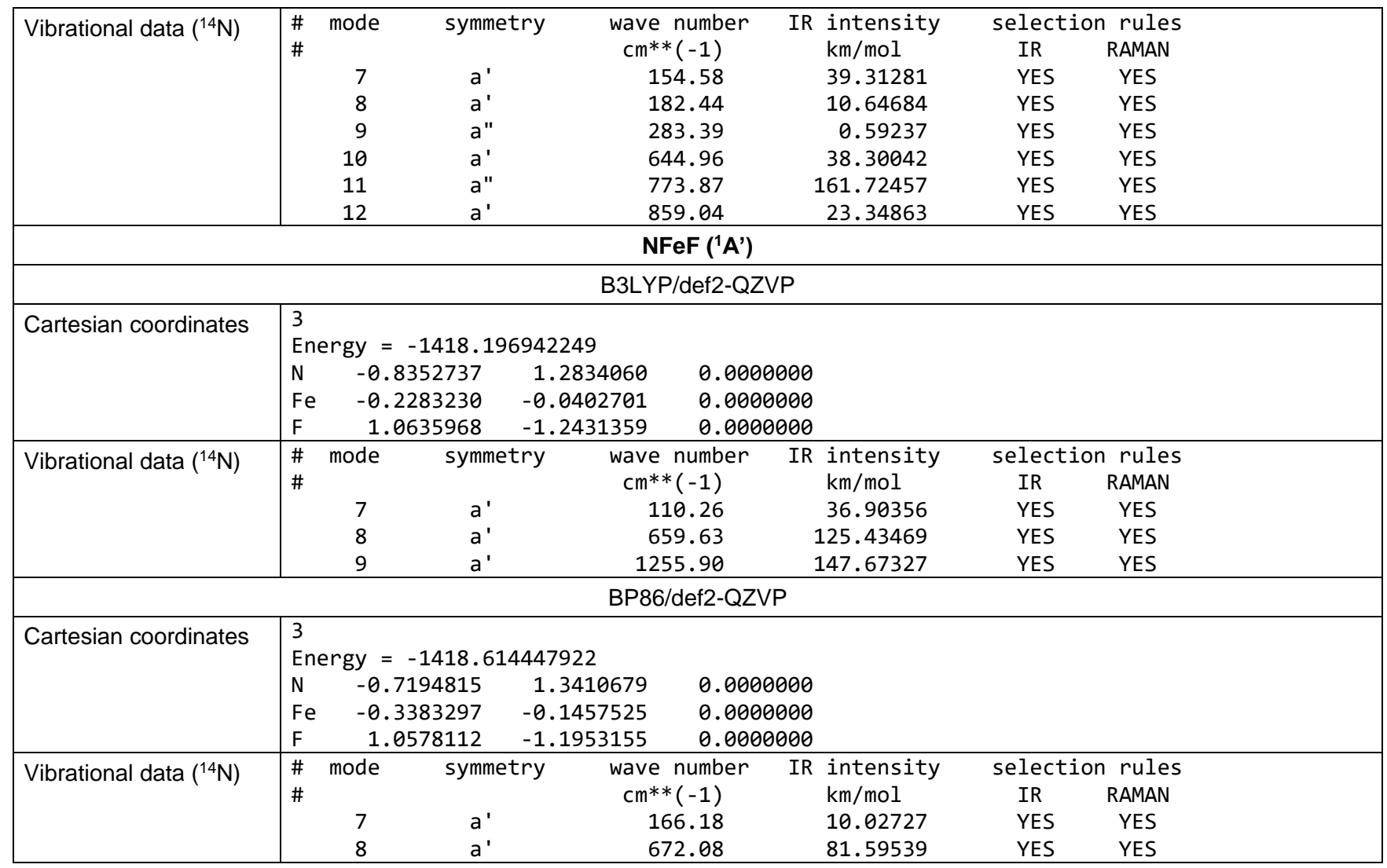




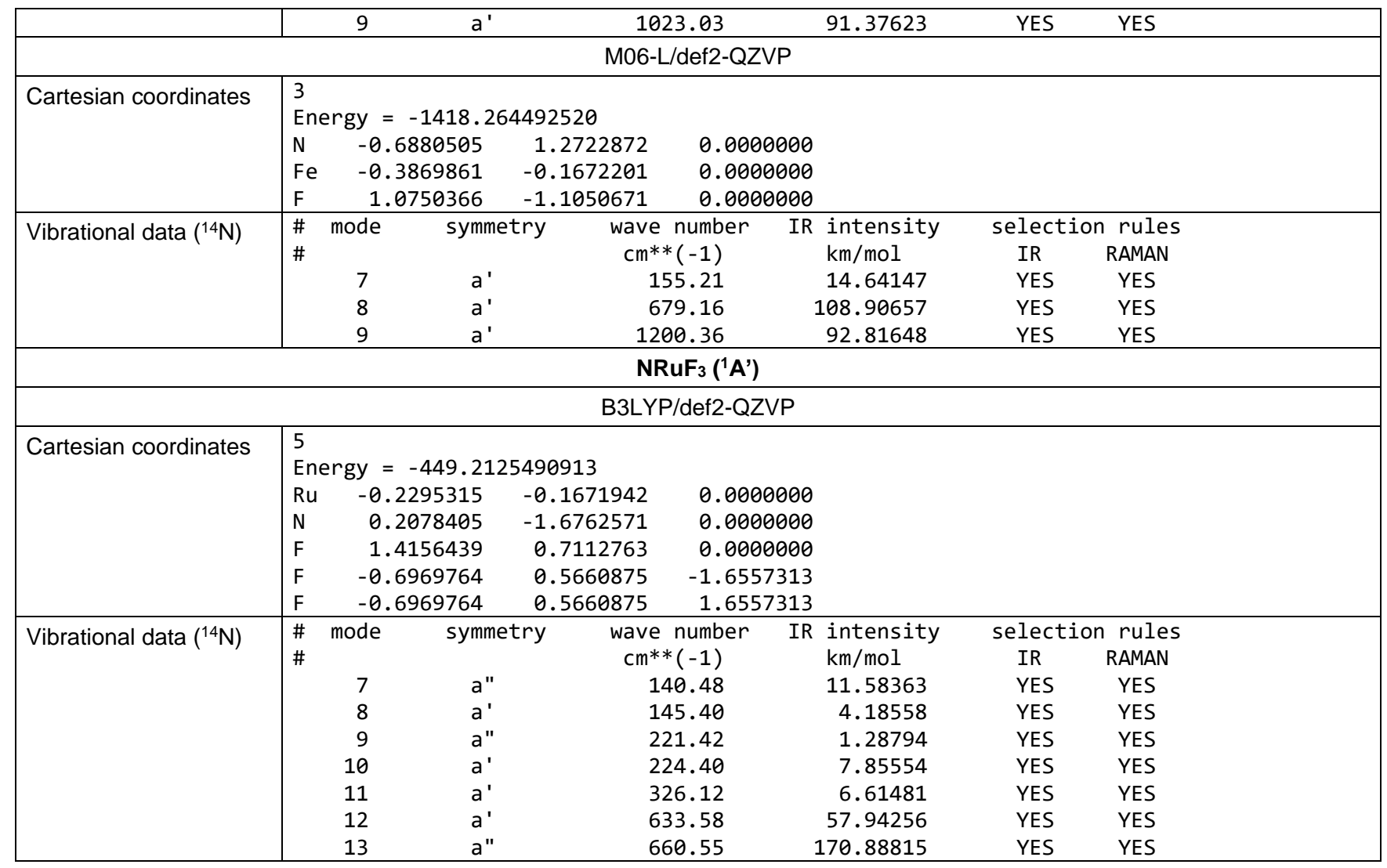


A.1. High-Spin Iron(VI), Low-Spin Ruthenium(VI), and Magnetically Bistable of Osmium(VI): Molecular Group 8 Nitrido Trifluorides $\mathrm{NMF}_{3}$

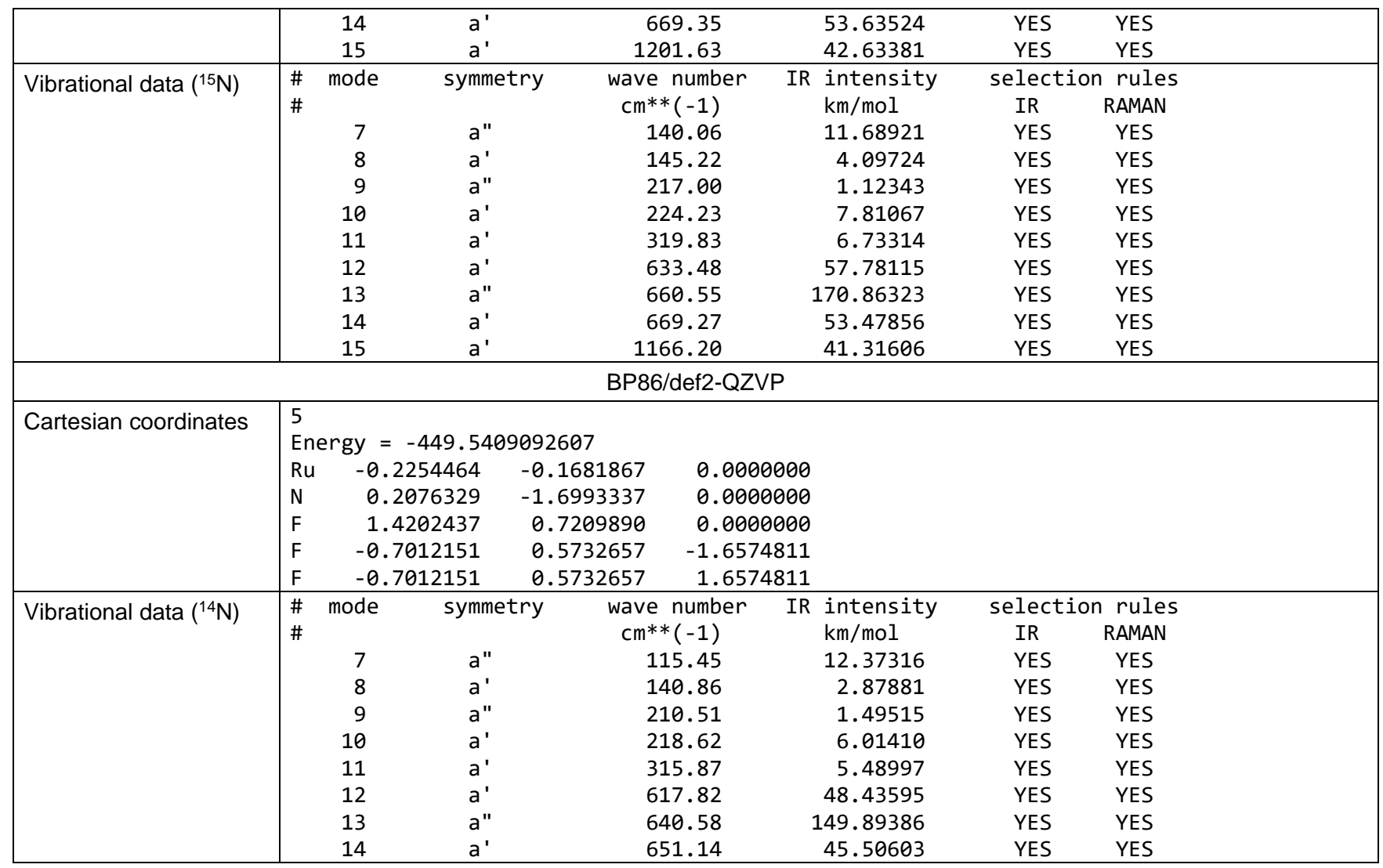




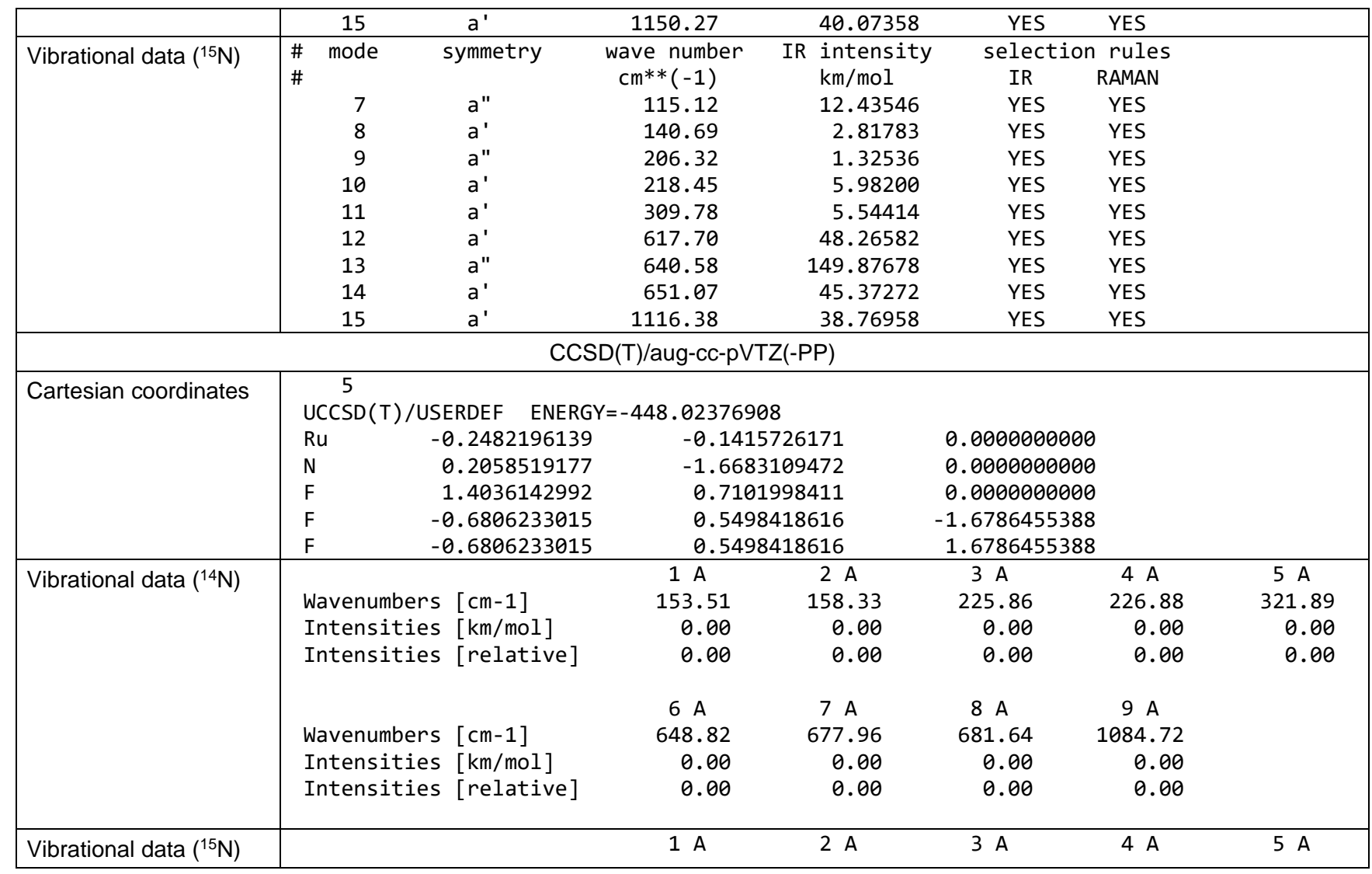


A.1. High-Spin Iron(VI), Low-Spin Ruthenium(VI), and Magnetically Bistable of Osmium(VI): Molecular Group 8 Nitrido Trifluorides $\mathrm{NMF}_{3}$

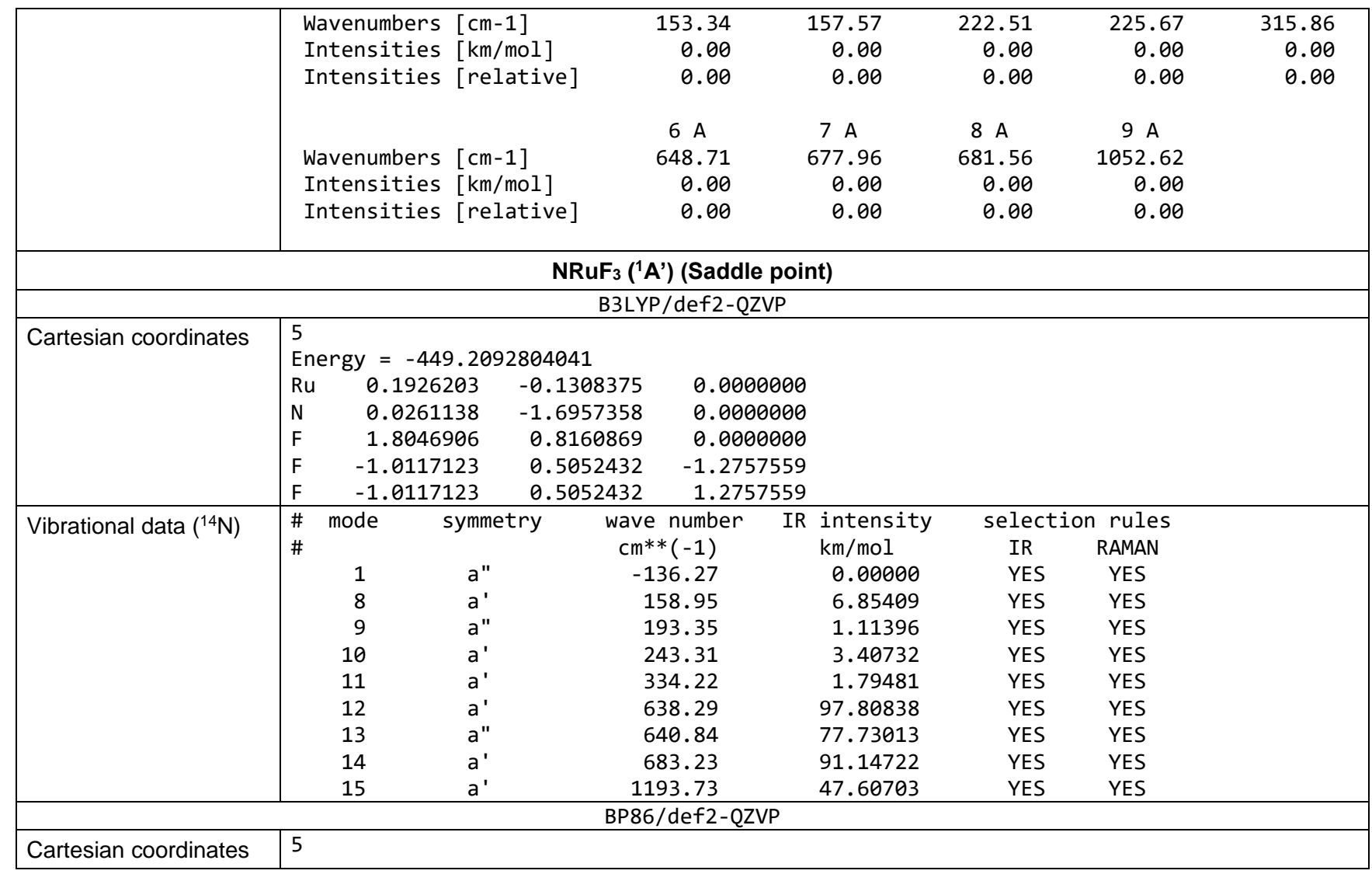




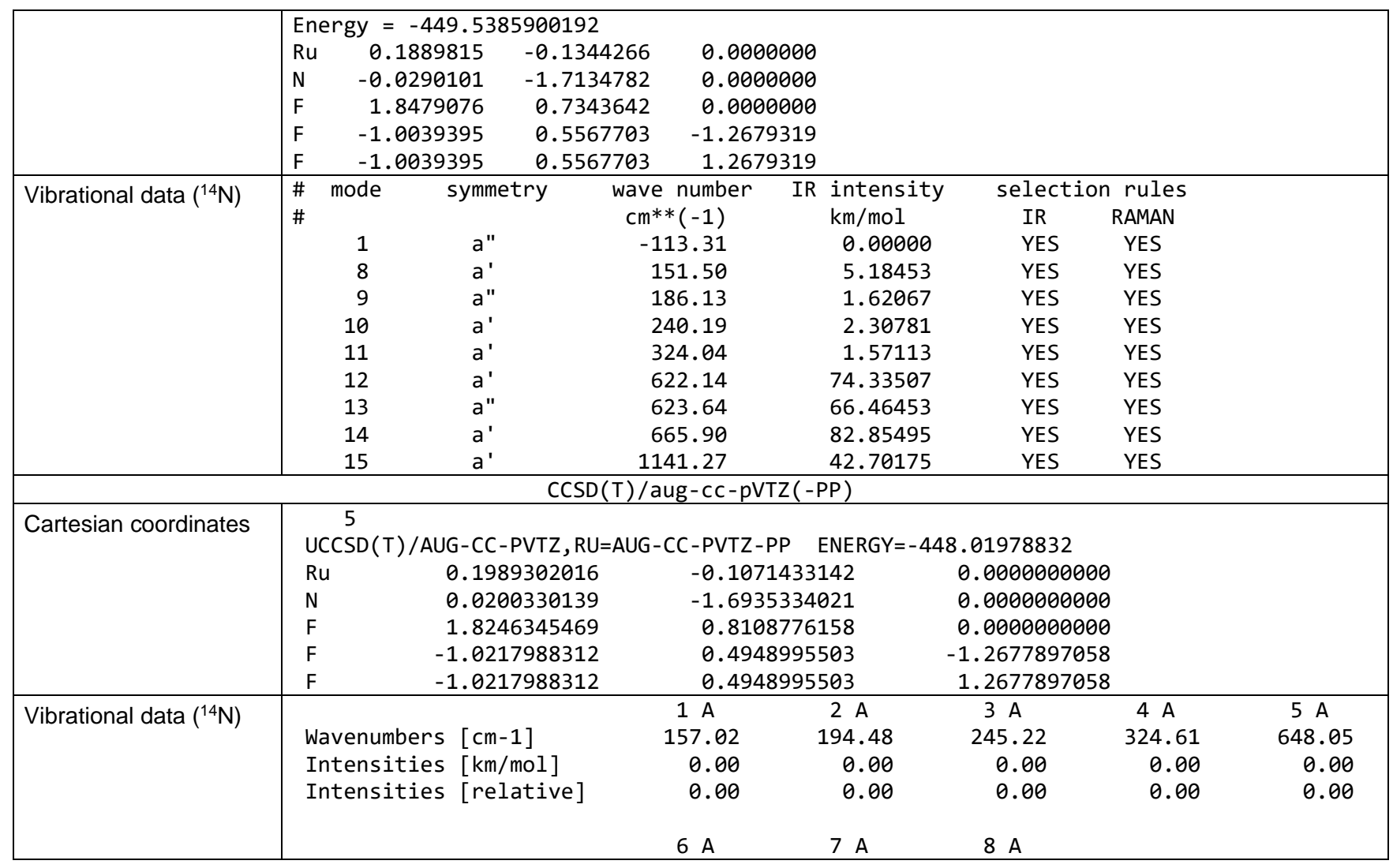


A.1. High-Spin Iron(VI), Low-Spin Ruthenium(VI), and Magnetically Bistable of Osmium(VI): Molecular Group 8 Nitrido Trifluorides $\mathrm{NMF}_{3}$

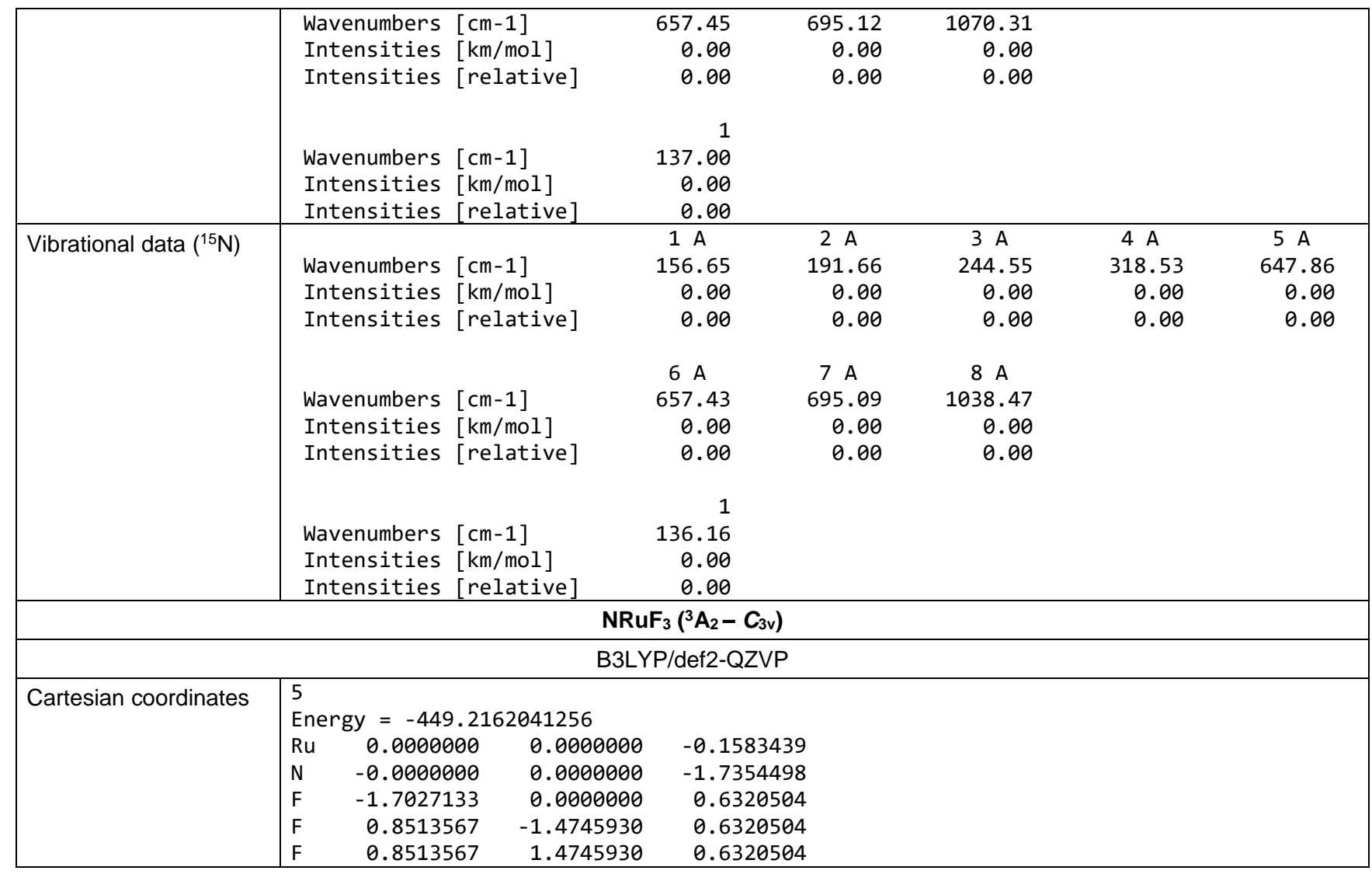




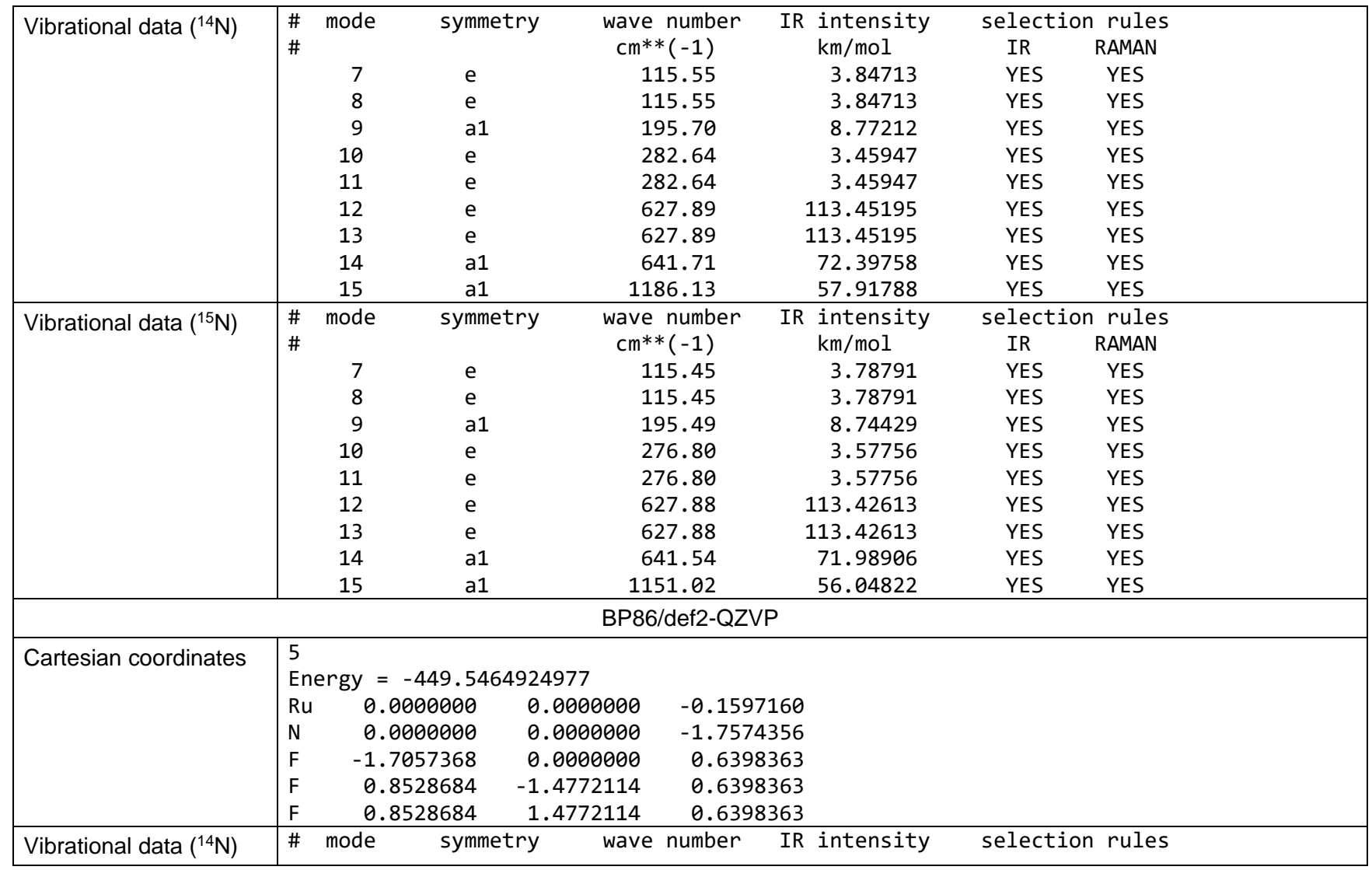


A.1. High-Spin Iron(VI), Low-Spin Ruthenium(VI), and Magnetically Bistable of Osmium(VI): Molecular Group 8 Nitrido Trifluorides $\mathrm{NMF}_{3}$

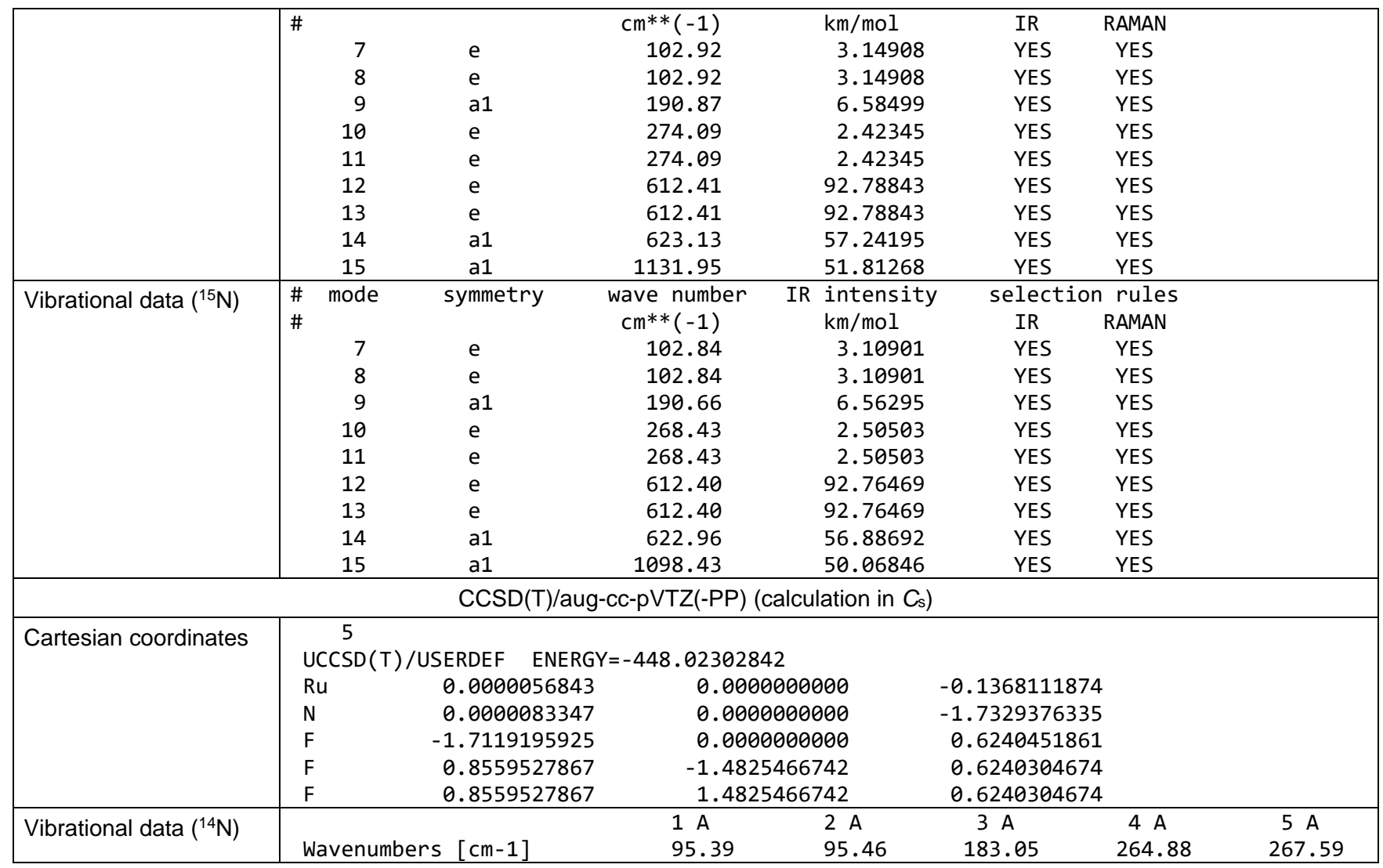

58 


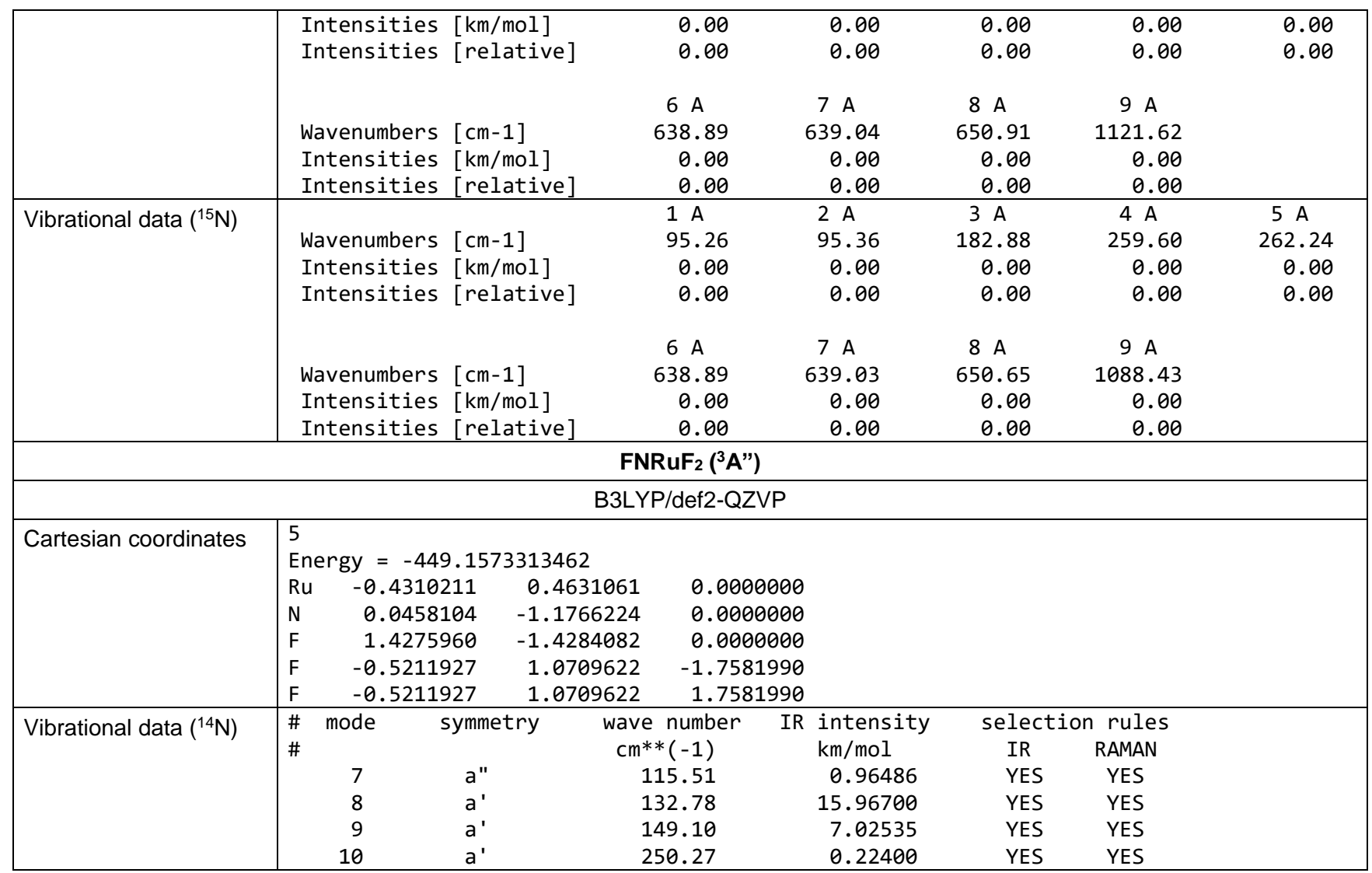


A.1. High-Spin Iron(VI), Low-Spin Ruthenium(VI), and Magnetically Bistable of Osmium(VI): Molecular Group 8 Nitrido Trifluorides $\mathrm{NMF}_{3}$

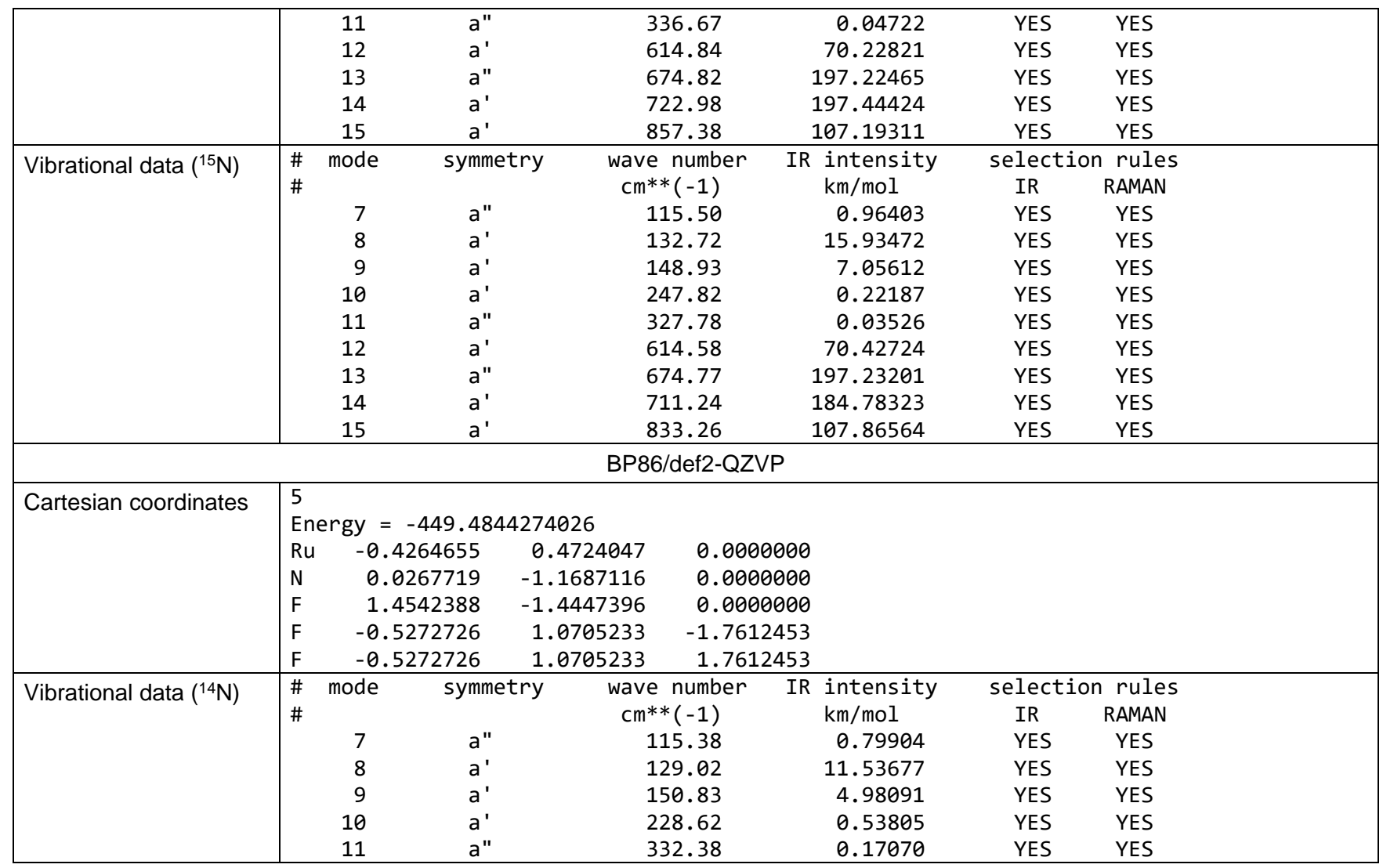

60 


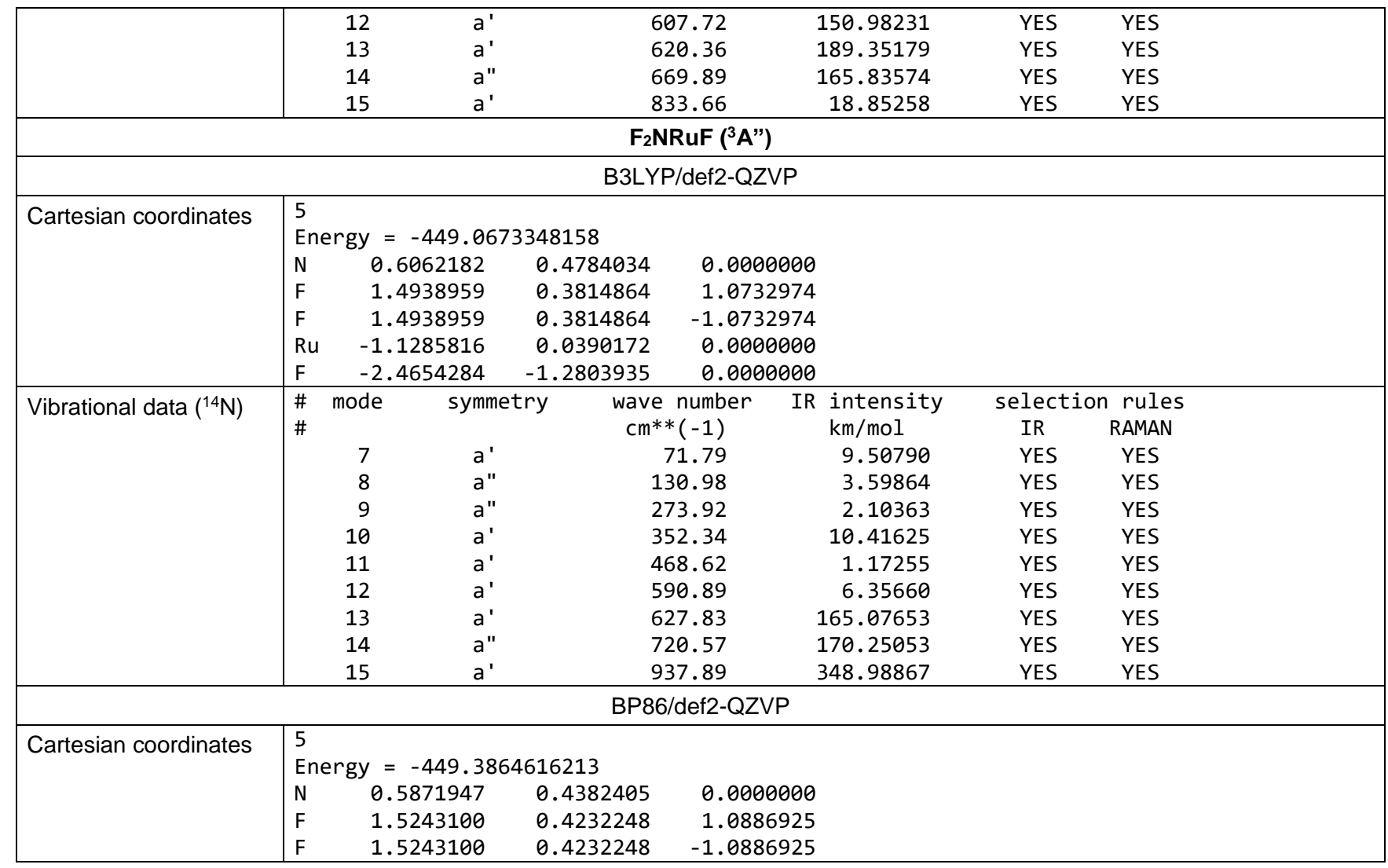


A.1. High-Spin Iron(VI), Low-Spin Ruthenium(VI), and Magnetically Bistable of Osmium(VI): Molecular Group 8 Nitrido Trifluorides $\mathrm{NMF}_{3}$

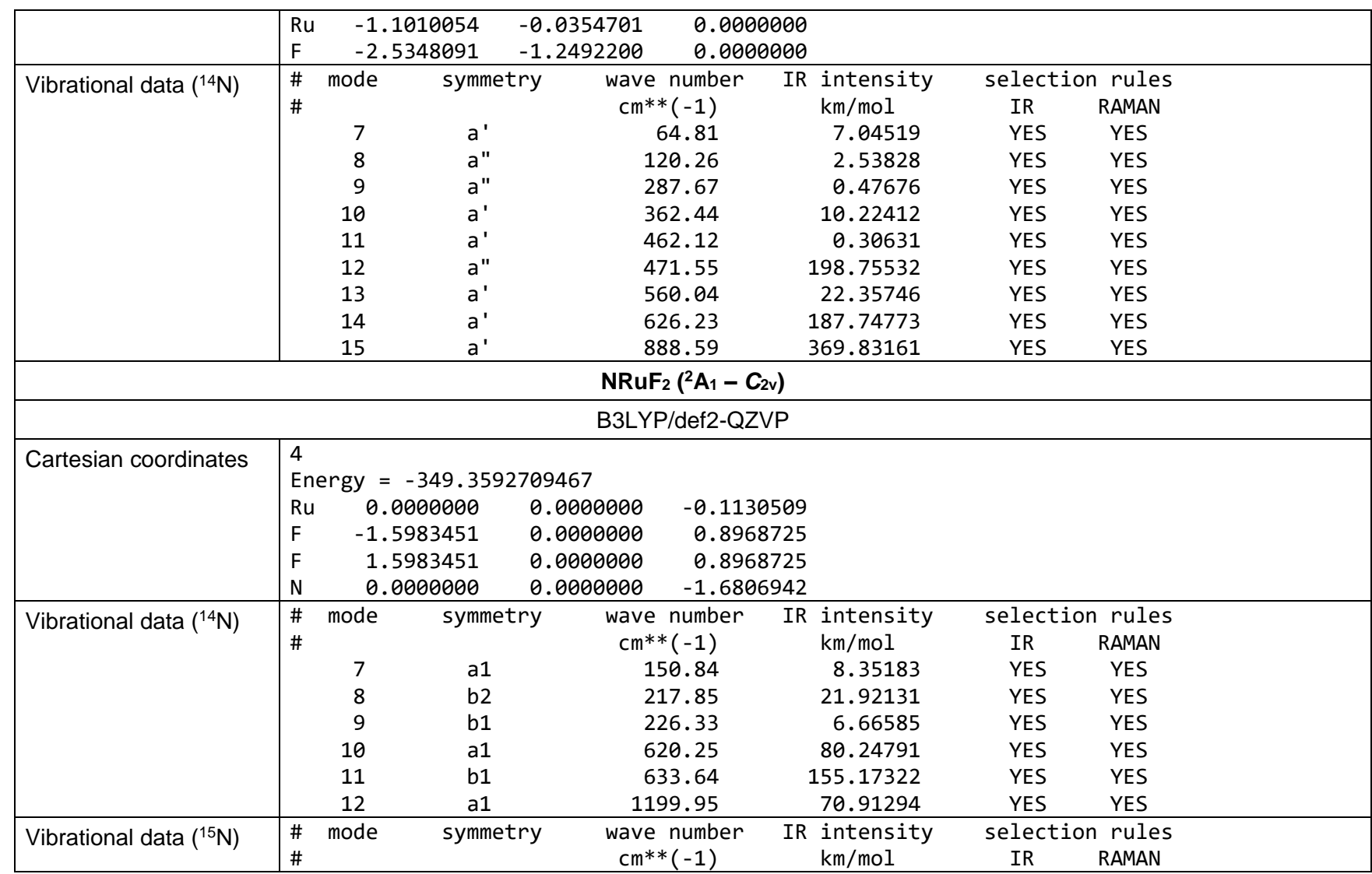

62 


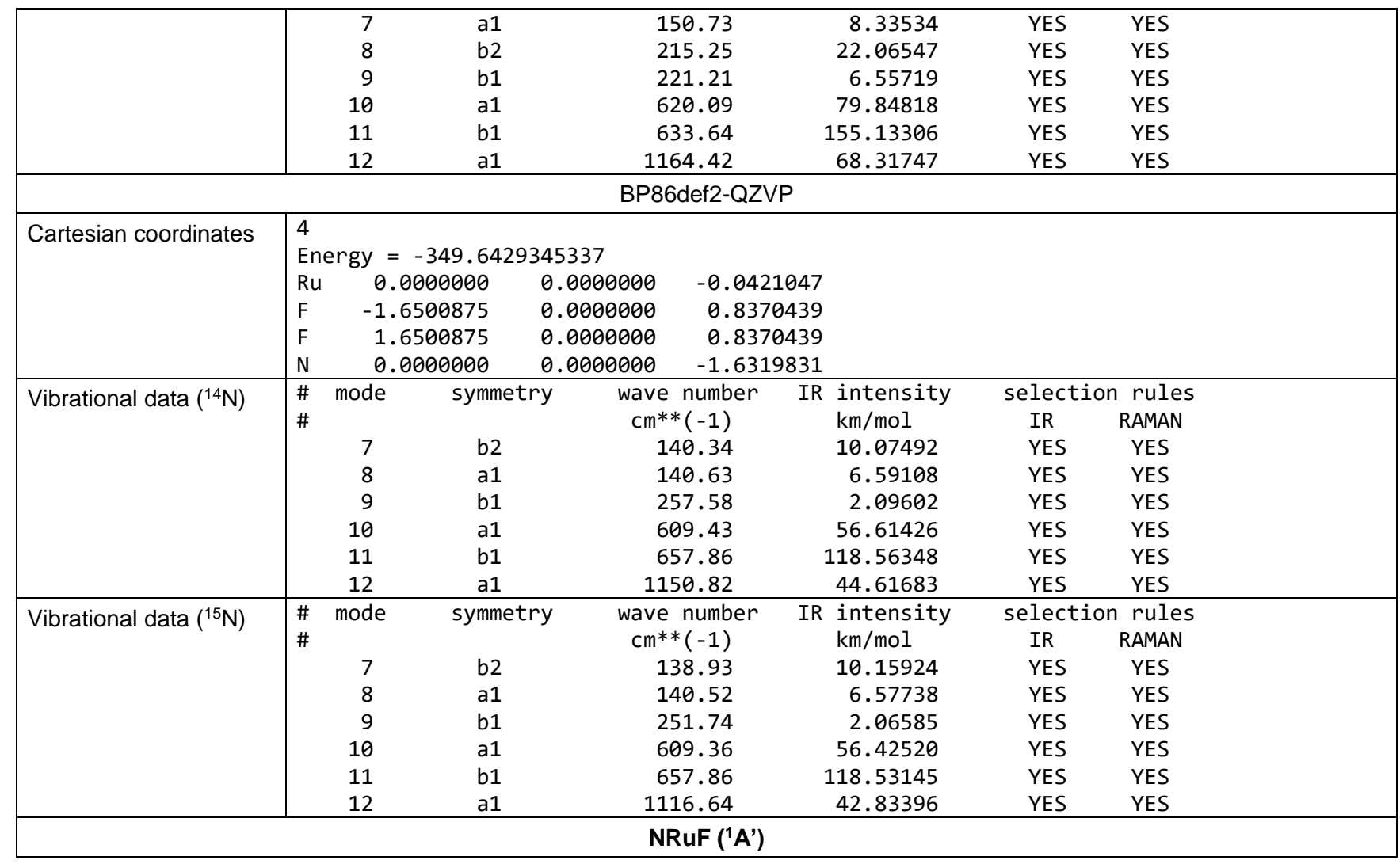


A.1. High-Spin Iron(VI), Low-Spin Ruthenium(VI), and Magnetically Bistable of Osmium(VI): Molecular Group 8 Nitrido Trifluorides $\mathrm{NMF}_{3}$

B3LYP/def2-QZVP

\begin{tabular}{|l|lrrr}
\hline Cartesian coordinates & \multicolumn{4}{l}{ 3 } \\
& Energy $=-249.4681749998$ & \\
& $\mathrm{~N}$ & -0.7636745 & 1.4649454 & 0.0000000 \\
& Ru & -0.2472823 & -0.0038843 & 0.0000000 \\
& $\mathrm{~F}$ & 1.0109568 & -1.4610611 & 0.0000000
\end{tabular}

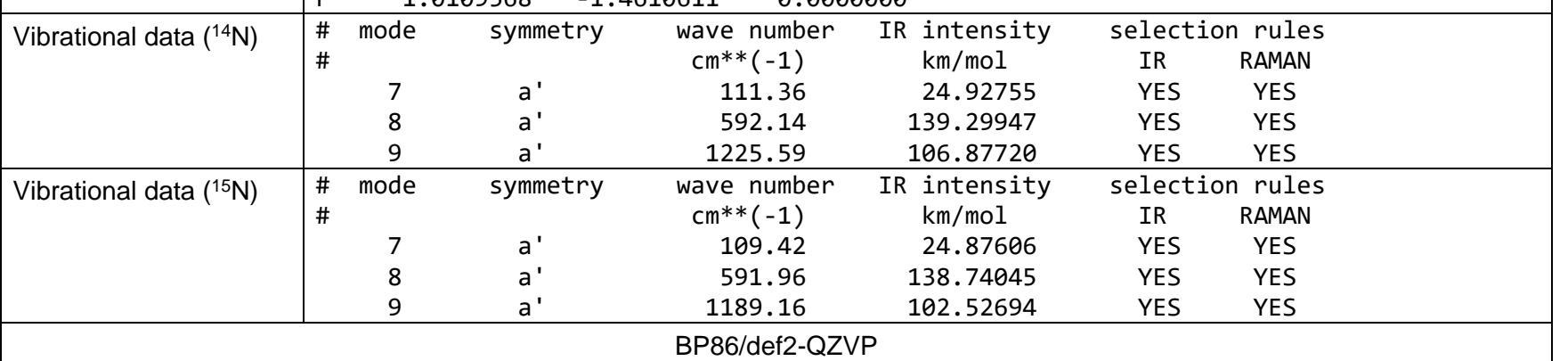

\begin{tabular}{|l|lrrr}
\hline Cartesian coordinates & \multicolumn{4}{l}{3} \\
& Energy $=-249.6962748053$ & \\
& N & -0.7416205 & 1.4724700 & 0.0000000 \\
& Ru & -0.2775501 & -0.0310340 & 0.0000000 \\
& F & 1.0191706 & -1.4414360 & 0.0000000
\end{tabular}

\begin{tabular}{|l|ccccccc|}
\hline Vibrational data $\left({ }^{14} \mathrm{~N}\right)$ & $\#$ & mode & symmetry & wave number & IR intensity & selection rules \\
& $\#$ & & & $\mathrm{~cm} * *(-1)$ & $\mathrm{km} / \mathrm{mol}$ & IR & RAMAN \\
& & 7 & $\mathrm{a}^{\prime}$ & 119.54 & 21.68419 & YES & YES \\
& & 8 & $\mathrm{a}^{\prime}$ & 591.60 & 121.27984 & YES & YES \\
& & 9 & $\mathrm{a}^{\prime}$ & 1180.20 & 93.30420 & YES & YES \\
\hline Vibrational data $\left({ }^{15} \mathrm{~N}\right)$ & $\#$ & mode & symmetry & wave number & IR intensity & selection rules \\
& $\#$ & & & $\mathrm{~cm} * *(-1)$ & $\mathrm{km} / \mathrm{mol}$ & IR & RAMAN \\
& & 7 & $\mathrm{a}^{\prime}$ & 117.46 & 21.59550 & YES & YES \\
\hline
\end{tabular}




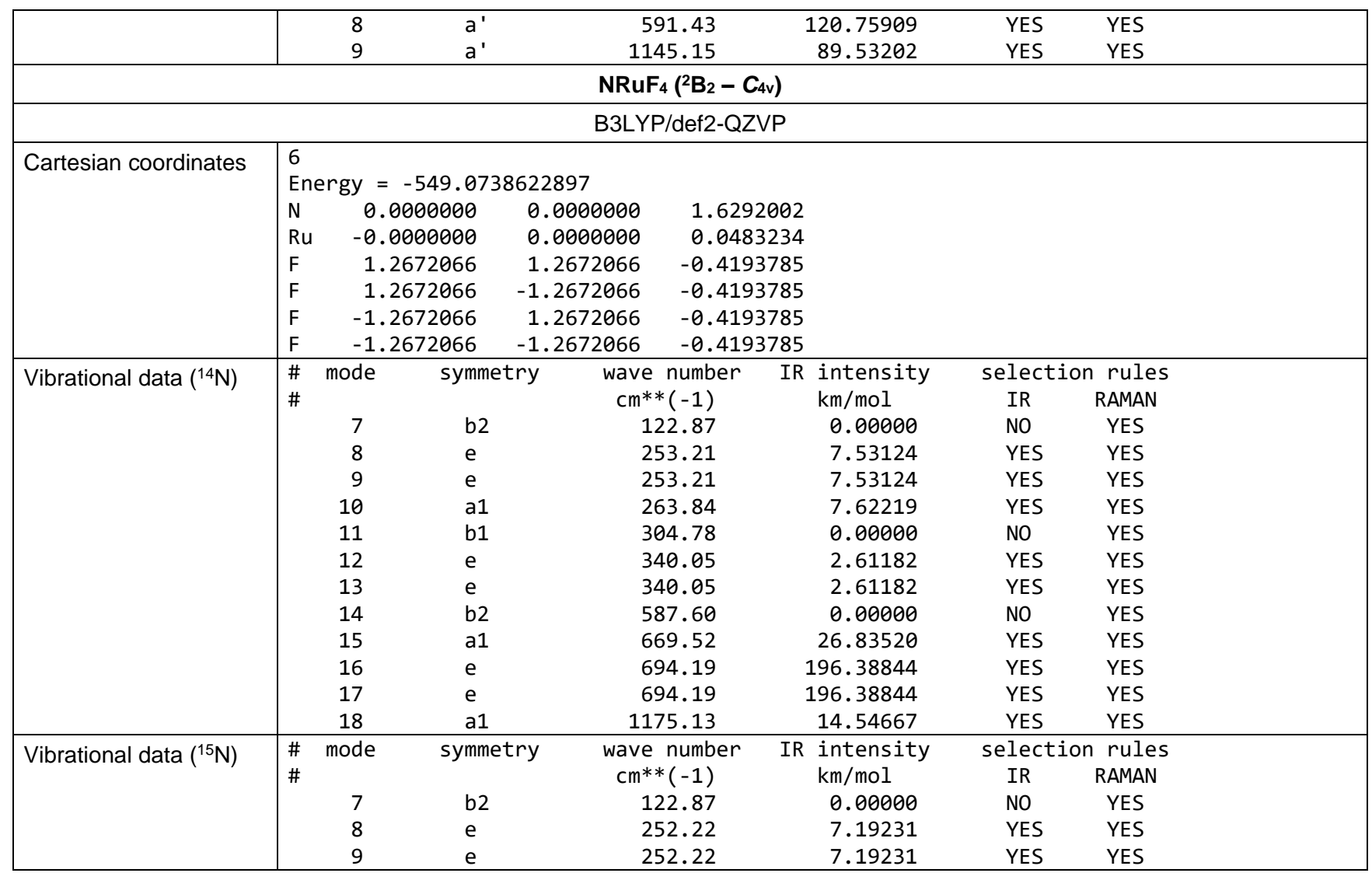

65 
A.1. High-Spin Iron(VI), Low-Spin Ruthenium(VI), and Magnetically Bistable of Osmium(VI): Molecular Group 8 Nitrido Trifluorides $\mathrm{NMF}_{3}$

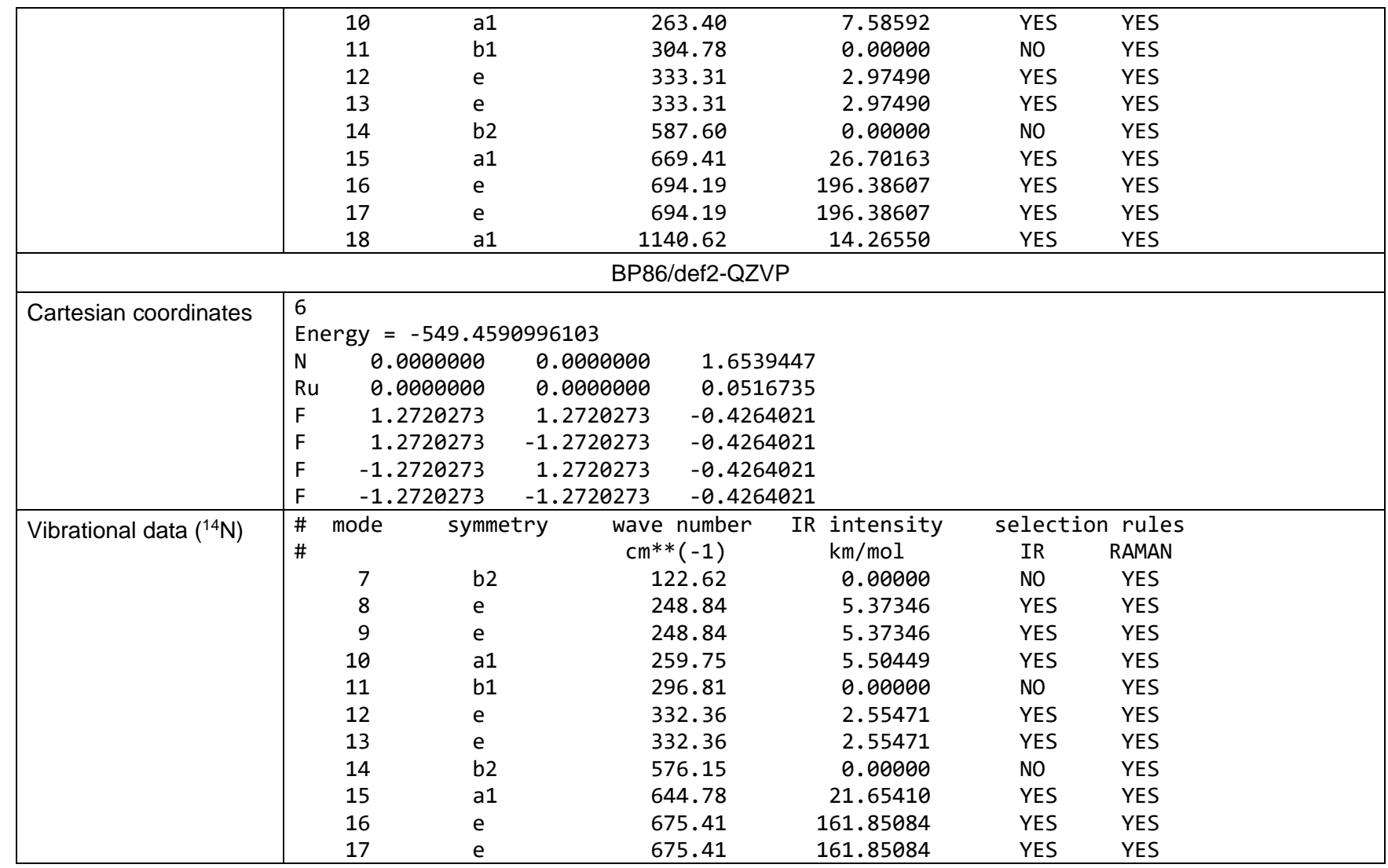




\begin{tabular}{|c|c|c|c|c|c|c|c|}
\hline \multirow{15}{*}{ Vibrational data $\left({ }^{15} \mathrm{~N}\right)$} & 18 & a1 & 1125.73 & 16.00755 & YES & YES & \\
\hline & mode & symmetry & wave number & IR intensity & selection & rules & \\
\hline & \# & & $\mathrm{cm} * *(-1)$ & $\mathrm{km} / \mathrm{mol}$ & IR $\quad R$ & RAMAN & \\
\hline & 7 & b2 & 122.62 & 0.00000 & NO & YES & \\
\hline & 8 & e & 247.73 & 5.08819 & YES & YES & \\
\hline & 9 & e & 247.73 & 5.08819 & YES & YES & \\
\hline & 10 & a1 & 259.31 & 5.47530 & YES & YES & \\
\hline & 11 & b1 & 296.81 & 0.00000 & NO & YES & \\
\hline & 12 & e & 325.99 & 2.85933 & YES & YES & \\
\hline & 13 & e & 325.99 & 2.85933 & YES & YES & \\
\hline & 14 & b2 & 576.15 & 0.00000 & NO & YES & \\
\hline & 15 & a1 & 644.68 & 21.53607 & YES & YES & \\
\hline & 16 & e & 675.40 & 161.84468 & YES & YES & \\
\hline & 17 & e & 675.40 & 161.84468 & YES & YES & \\
\hline & 18 & a1 & 1092.65 & 15.59090 & YES & YES & \\
\hline \multicolumn{8}{|c|}{$\operatorname{CCSD}(T) /$ aug-cc-pVTZ(-PP) (Calculation in $C_{2 v}$ ) } \\
\hline \multirow[t]{7}{*}{ Cartesian coordinates } & \multicolumn{7}{|c|}{$\operatorname{UCCSD}(T) / A U G-C C-P V T Z, R U=A U G-C C-P V T Z-P P \quad E N E R G Y=-547.76517712$} \\
\hline & \multicolumn{7}{|c|}{ 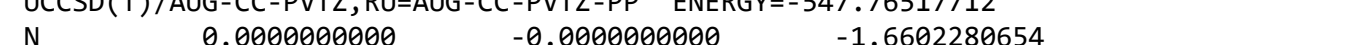 } \\
\hline & Ru & 0.0000000000 & \multicolumn{2}{|c|}{-0.0000000000} & \multicolumn{2}{|l|}{-0.0536568805} & \\
\hline & $\mathrm{F}$ & 1.7941816843 & \multicolumn{2}{|c|}{0.0000000000} & \multicolumn{2}{|l|}{0.3773661575} & \\
\hline & $\mathrm{F}$ & 0.0000000000 & \multicolumn{2}{|c|}{1.7941816843} & \multicolumn{2}{|l|}{0.3773661575} & \\
\hline & $\mathrm{F}$ & 0.0000000000 & \multicolumn{2}{|c|}{-1.7941816843} & \multicolumn{2}{|l|}{0.3773661575} & \\
\hline & $\mathrm{F}$ & -1.7941816843 & \multicolumn{2}{|c|}{0.0000000000} & 0.3773661575 & & \\
\hline \multirow[t]{5}{*}{ Vibrational data $\left({ }^{14} \mathrm{~N}\right)$} & \multirow{2}{*}{\multicolumn{2}{|c|}{ Wavenumbers [cm-1] }} & $1 \mathrm{~A} 1$ & $2 B 2$ & 3 B1 & 4 A1 & 5 A2 \\
\hline & & $\mathrm{s}[\mathrm{cm}-1]$ & 112.61 & 248.28 & 248.28 & 254.69 & 296.69 \\
\hline & \multirow{2}{*}{\multicolumn{2}{|c|}{$\begin{array}{l}\text { Intensities [ } \mathrm{km} / \mathrm{mol}] \\
\text { Intensities [relative] }\end{array}$}} & 0.00 & 0.00 & 0.00 & 0.00 & 0.00 \\
\hline & & & 0.00 & 0.00 & 0.00 & 0.00 & 0.00 \\
\hline & \multicolumn{2}{|c|}{ Wavenumbers $[\mathrm{cm}-1]$} & $\begin{array}{c}6 \text { B1 } \\
325.44\end{array}$ & $\begin{array}{c}7 \text { B2 } \\
325.44\end{array}$ & $\begin{array}{c}8 \text { A1 } \\
597.59\end{array}$ & $\begin{array}{c}9 \text { A1 } \\
680.82\end{array}$ & $\begin{array}{l}10 \text { B1 } \\
710.95\end{array}$ \\
\hline
\end{tabular}


A.1. High-Spin Iron(VI), Low-Spin Ruthenium(VI), and Magnetically Bistable of Osmium(VI): Molecular Group 8 Nitrido Trifluorides $\mathrm{NMF}_{3}$

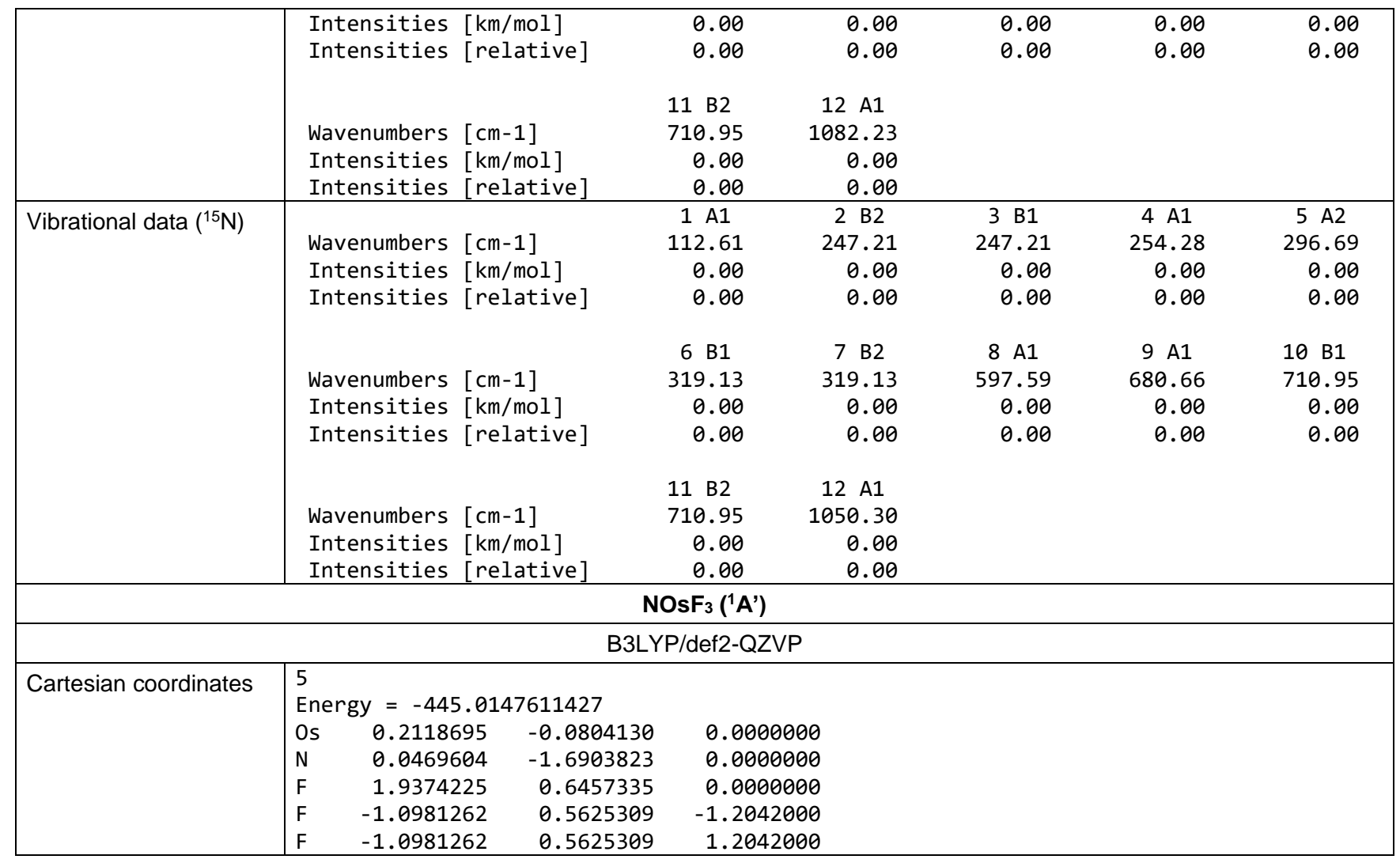




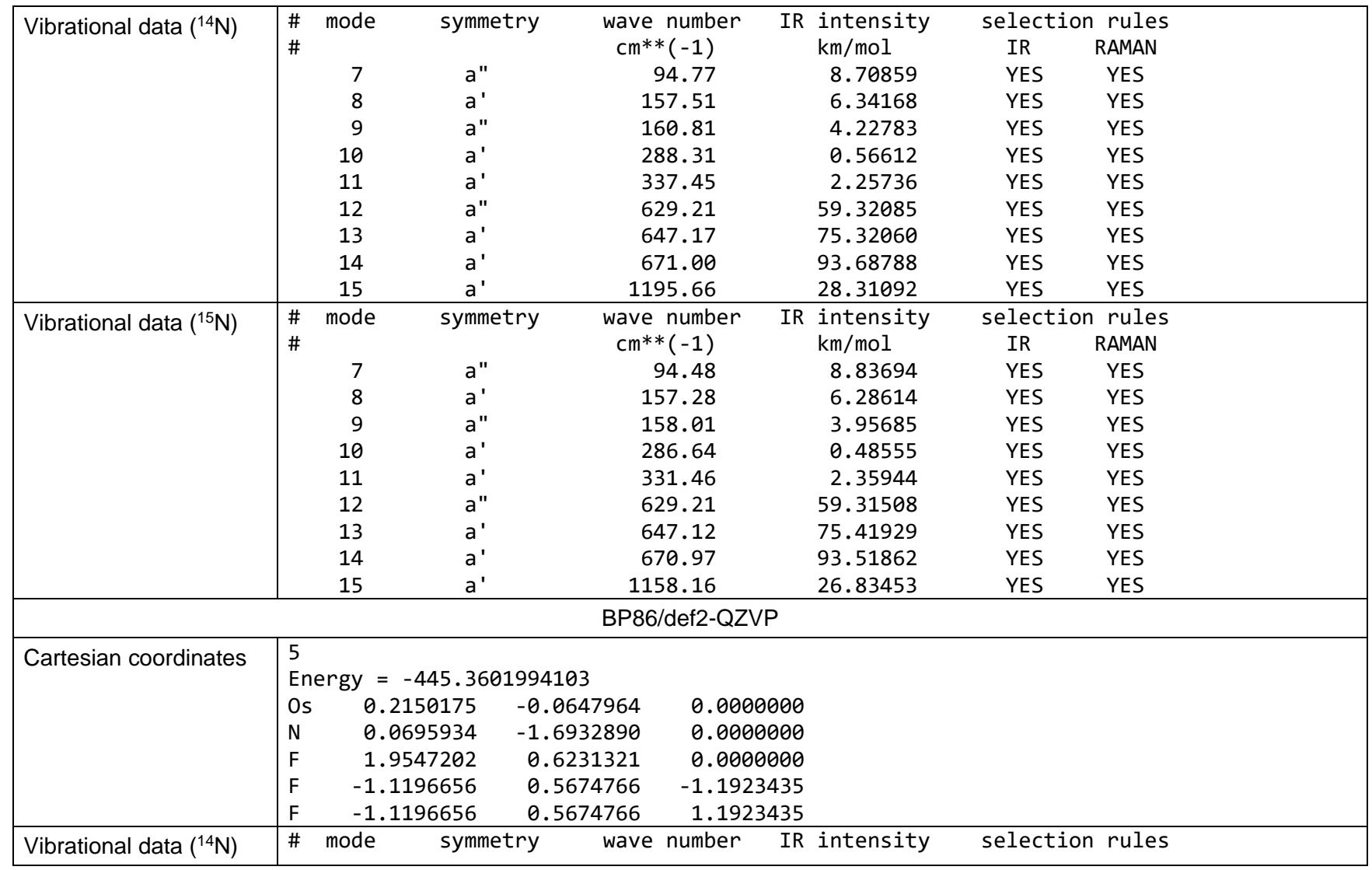


A.1. High-Spin Iron(VI), Low-Spin Ruthenium(VI), and Magnetically Bistable of Osmium(VI): Molecular Group 8 Nitrido Trifluorides $\mathrm{NMF}_{3}$

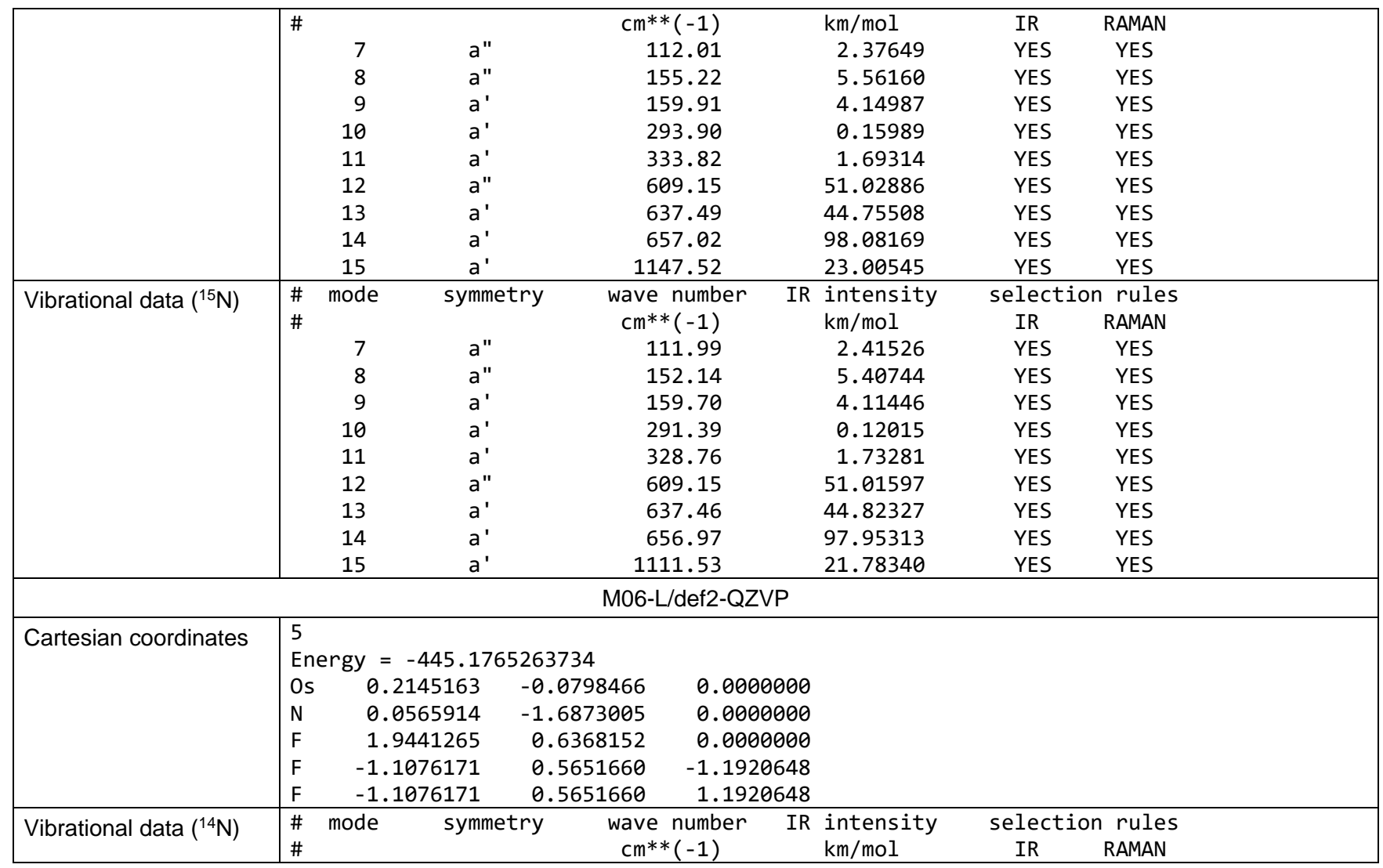




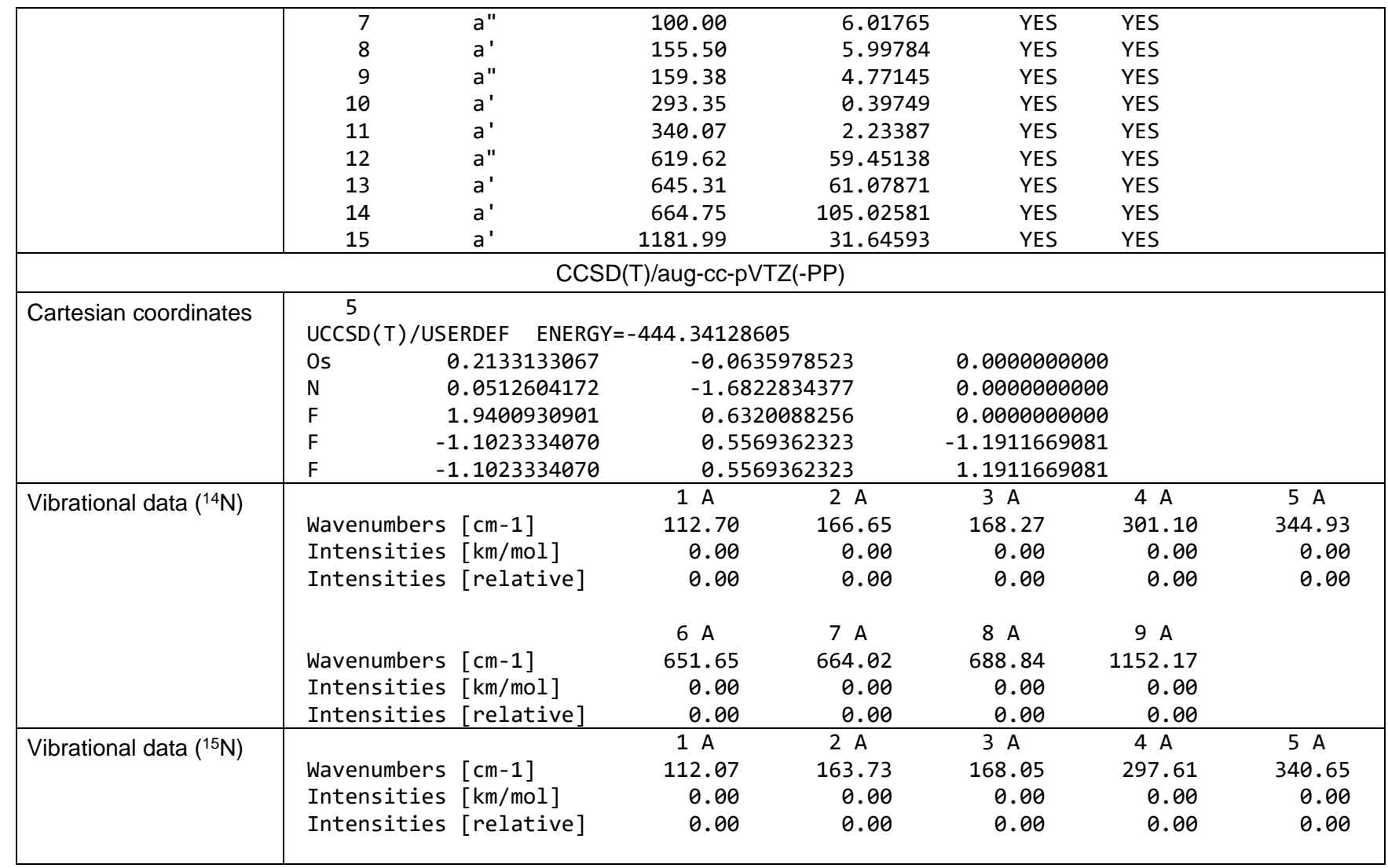


A.1. High-Spin Iron(VI), Low-Spin Ruthenium(VI), and Magnetically Bistable of Osmium(VI): Molecular Group 8 Nitrido Trifluorides $\mathrm{NMF}_{3}$

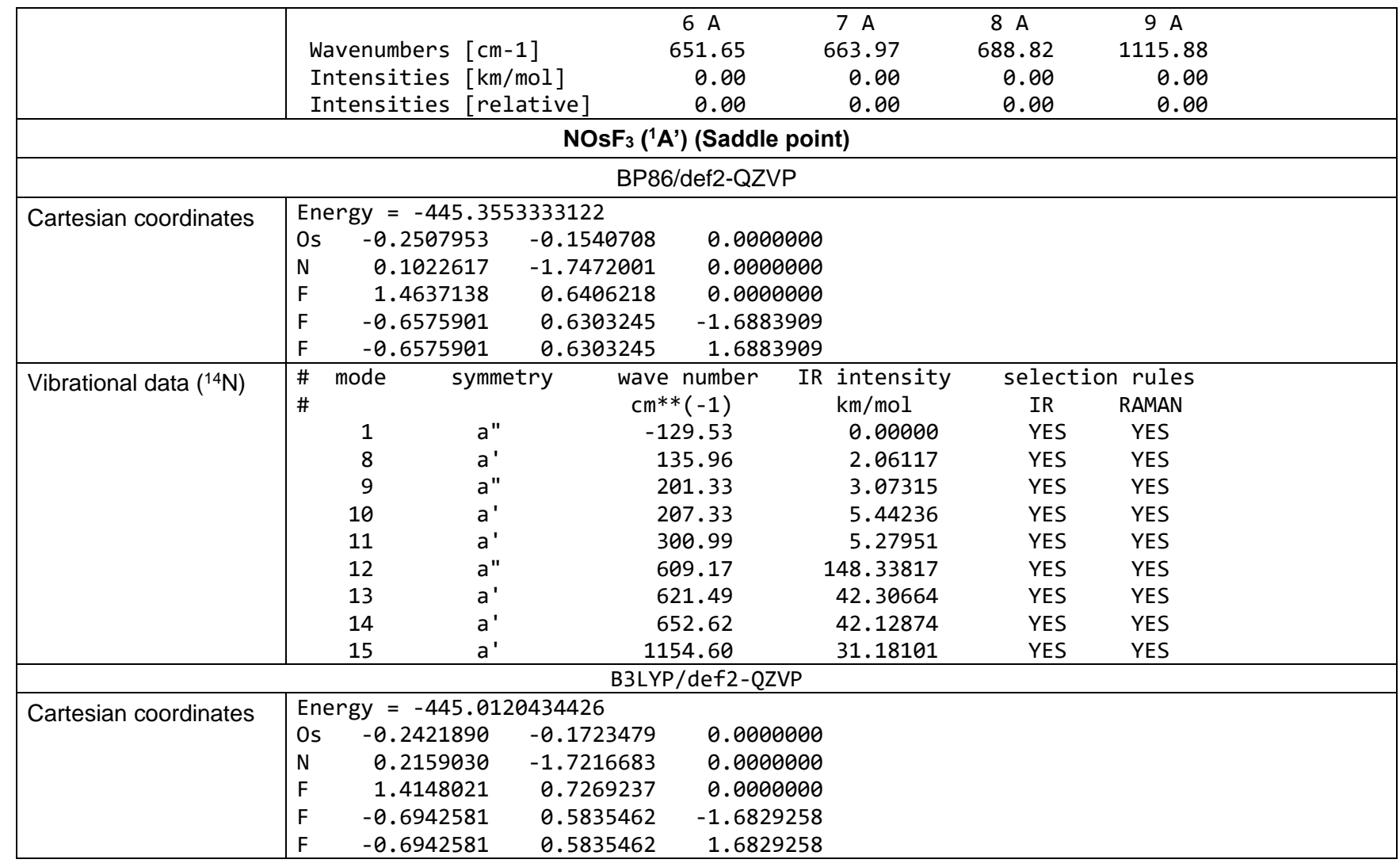




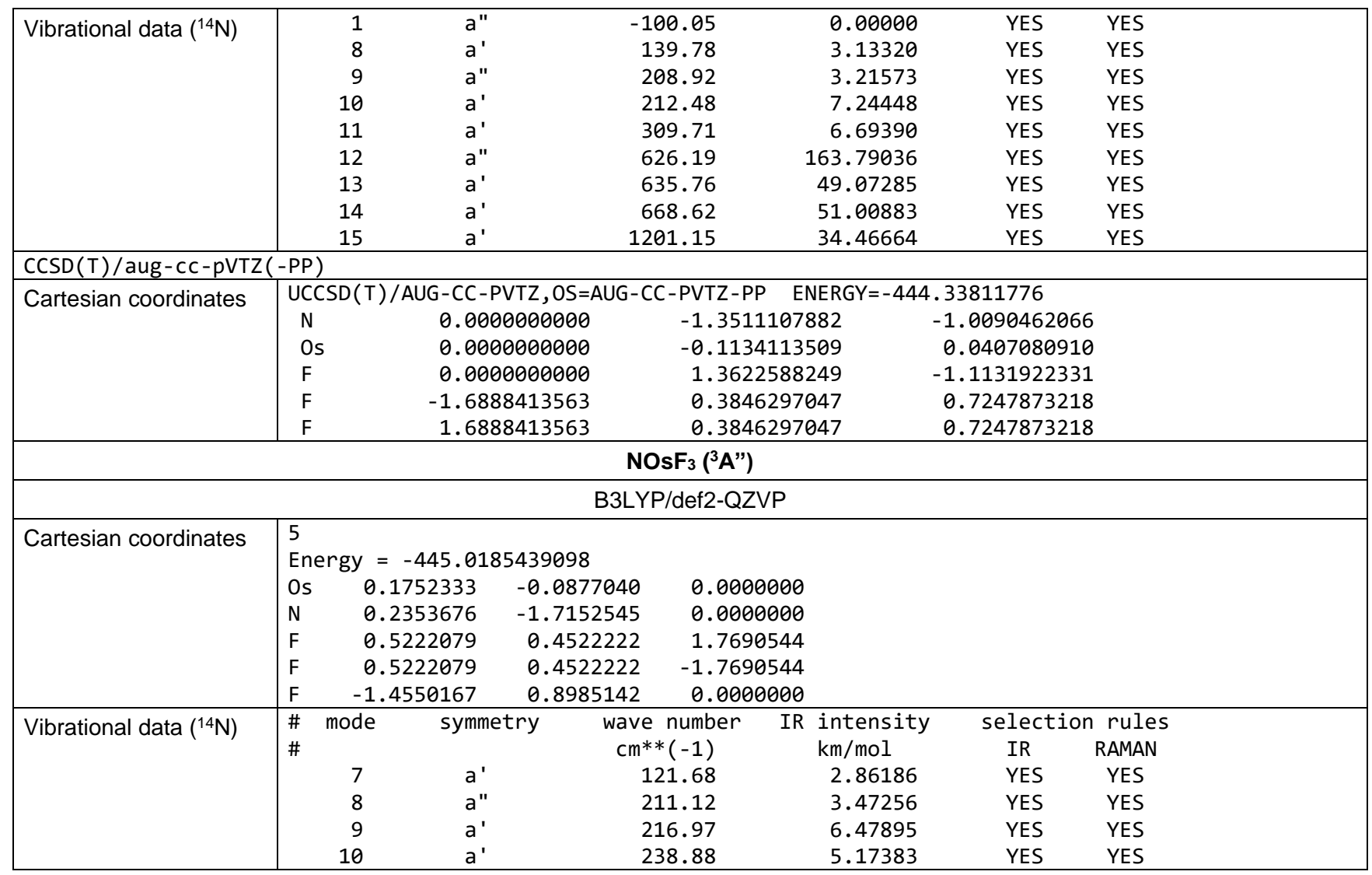


A.1. High-Spin Iron(VI), Low-Spin Ruthenium(VI), and Magnetically Bistable of Osmium(VI): Molecular Group 8 Nitrido Trifluorides $\mathrm{NMF}_{3}$

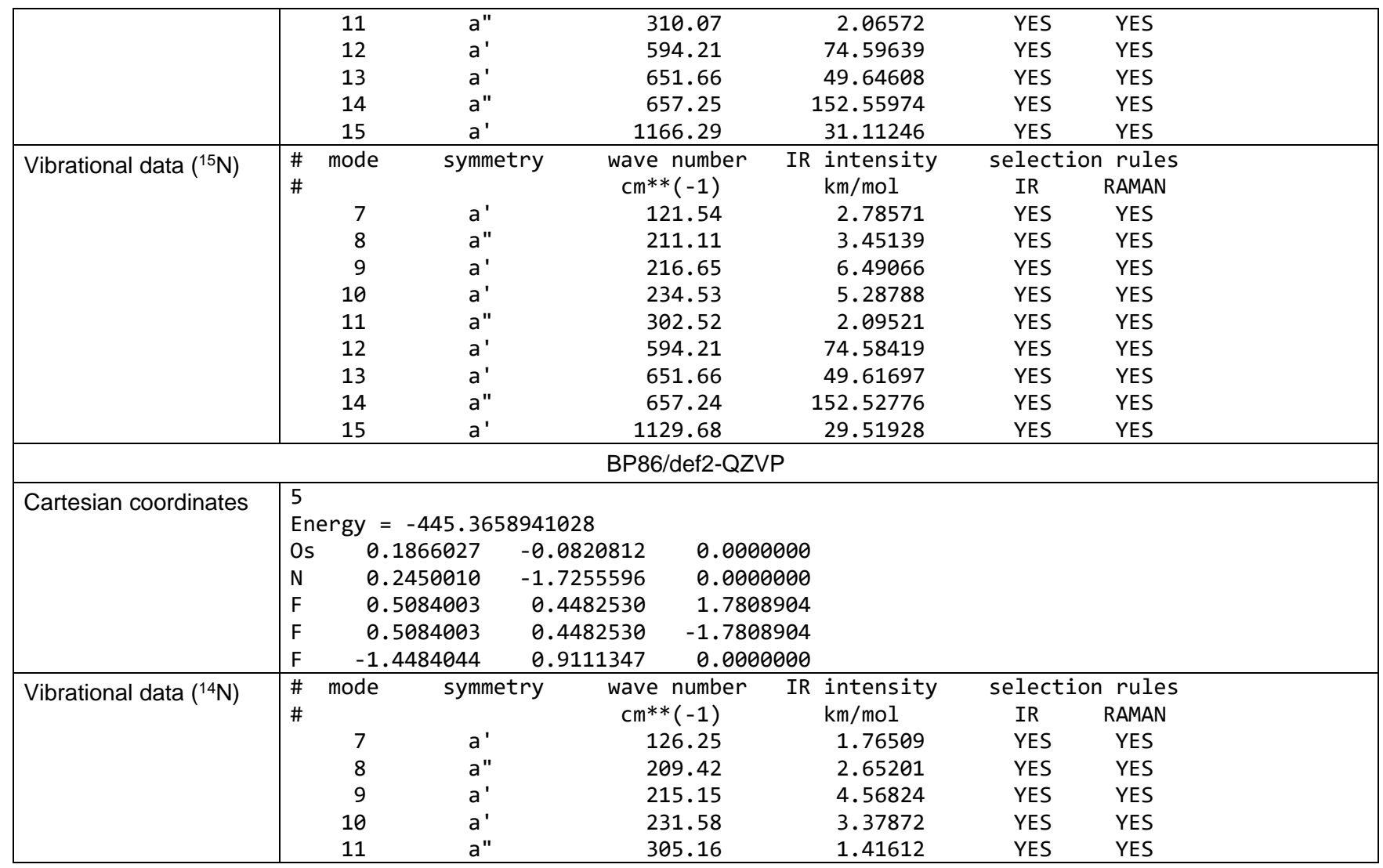




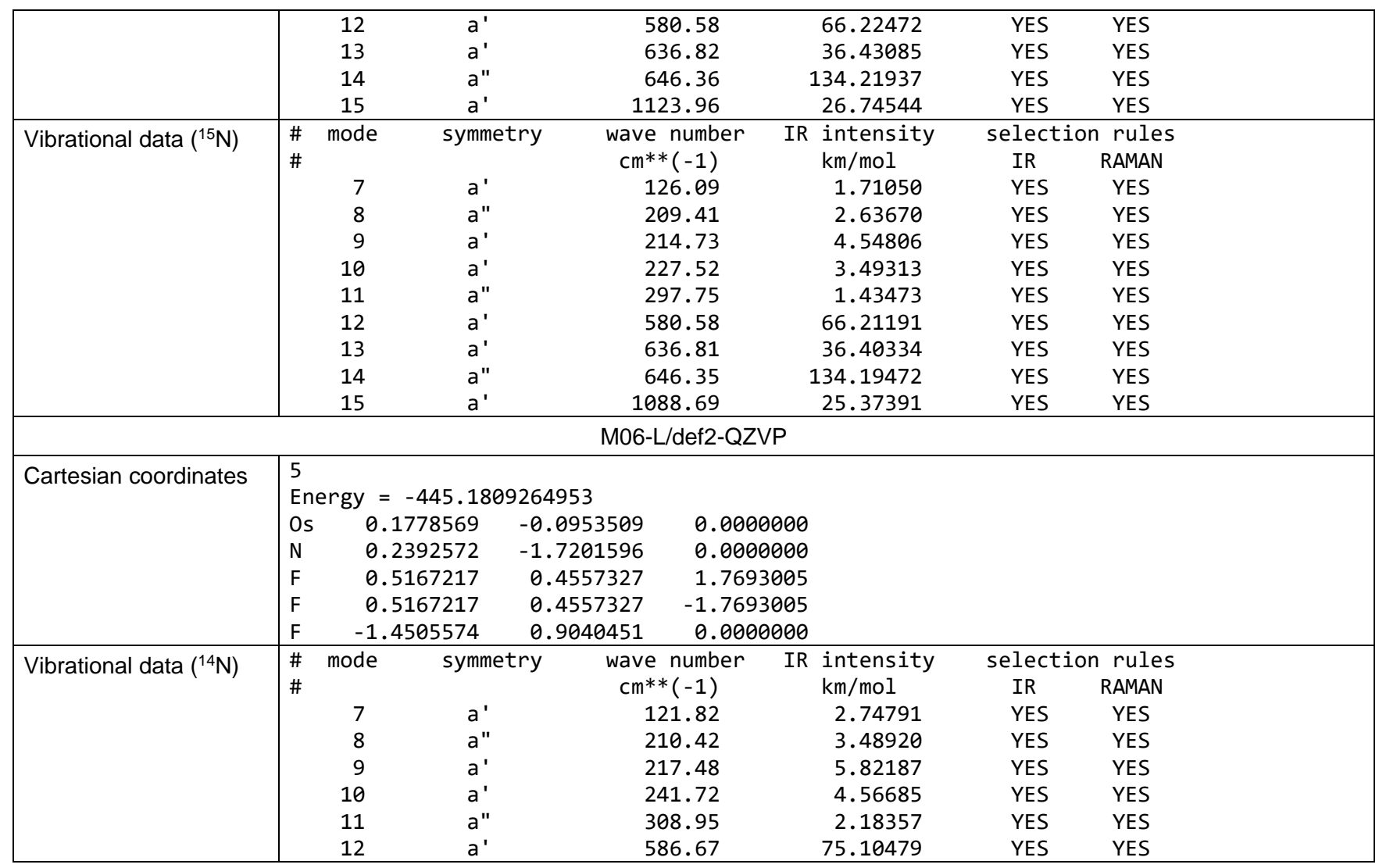


A.1. High-Spin Iron(VI), Low-Spin Ruthenium(VI), and Magnetically Bistable of Osmium(VI): Molecular Group 8 Nitrido Trifluorides $\mathrm{NMF}_{3}$

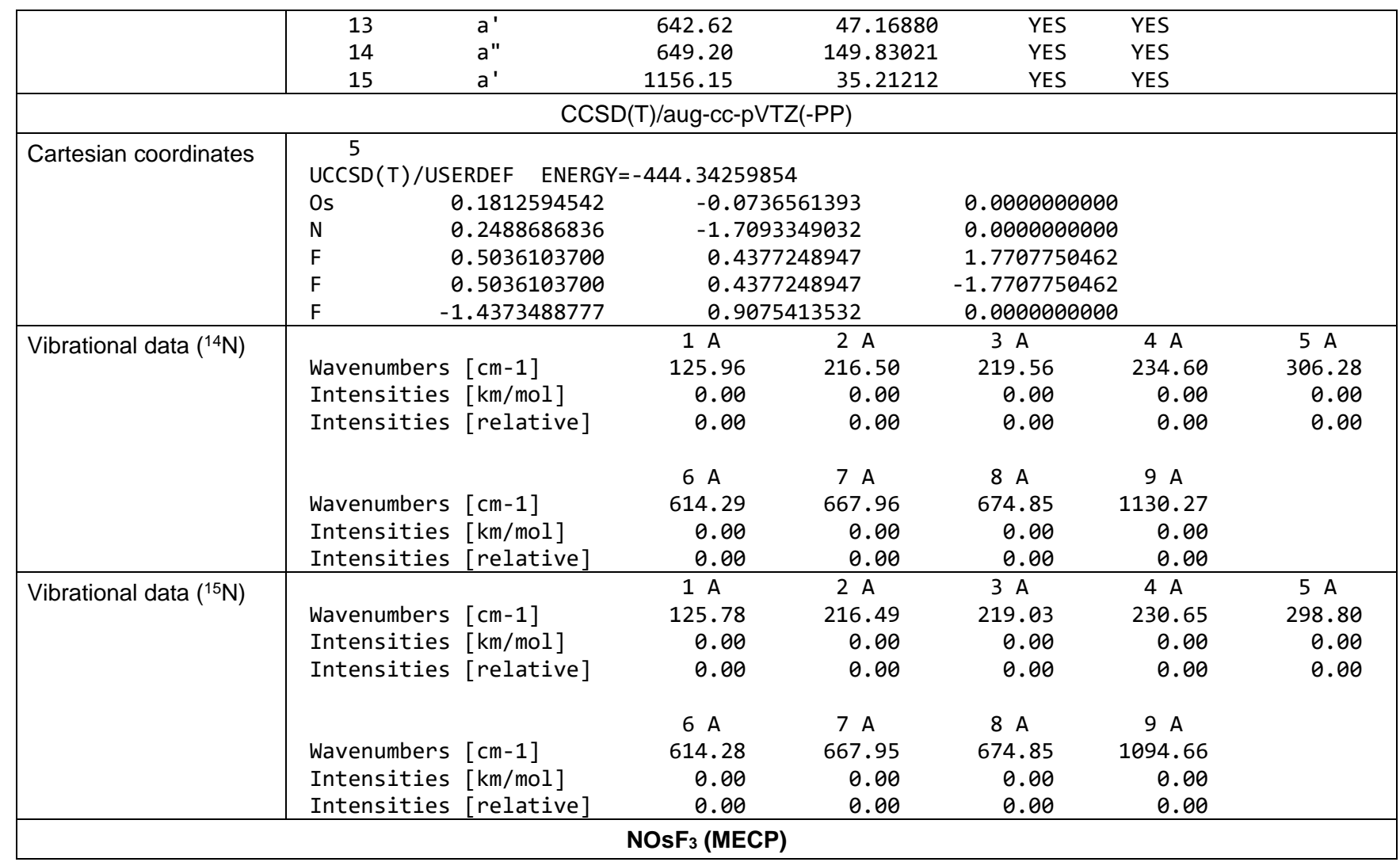


B3LYP/def2-QZVP (ORCA)

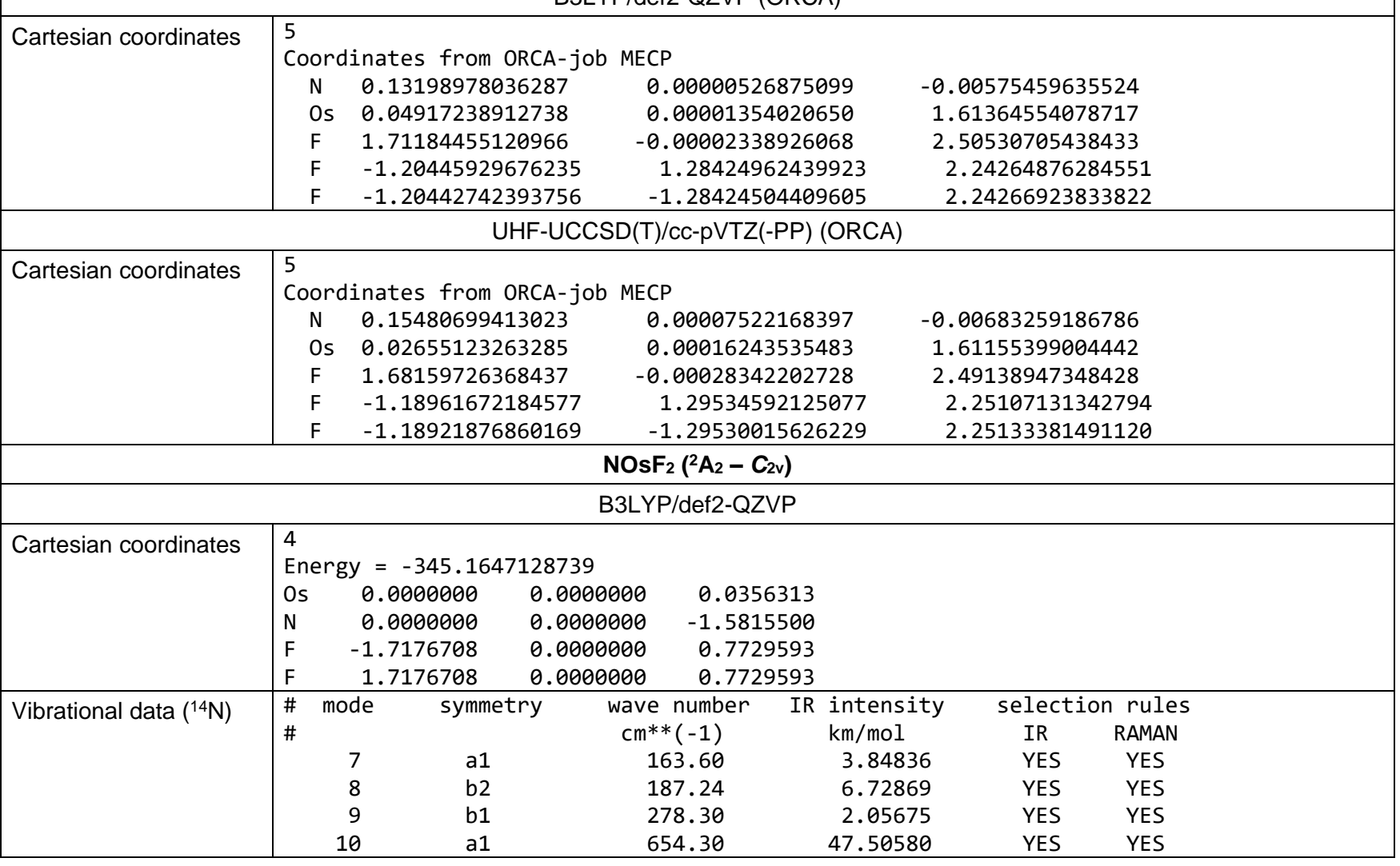


A.1. High-Spin Iron(VI), Low-Spin Ruthenium(VI), and Magnetically Bistable of Osmium(VI): Molecular Group 8 Nitrido Trifluorides $\mathrm{NMF}_{3}$

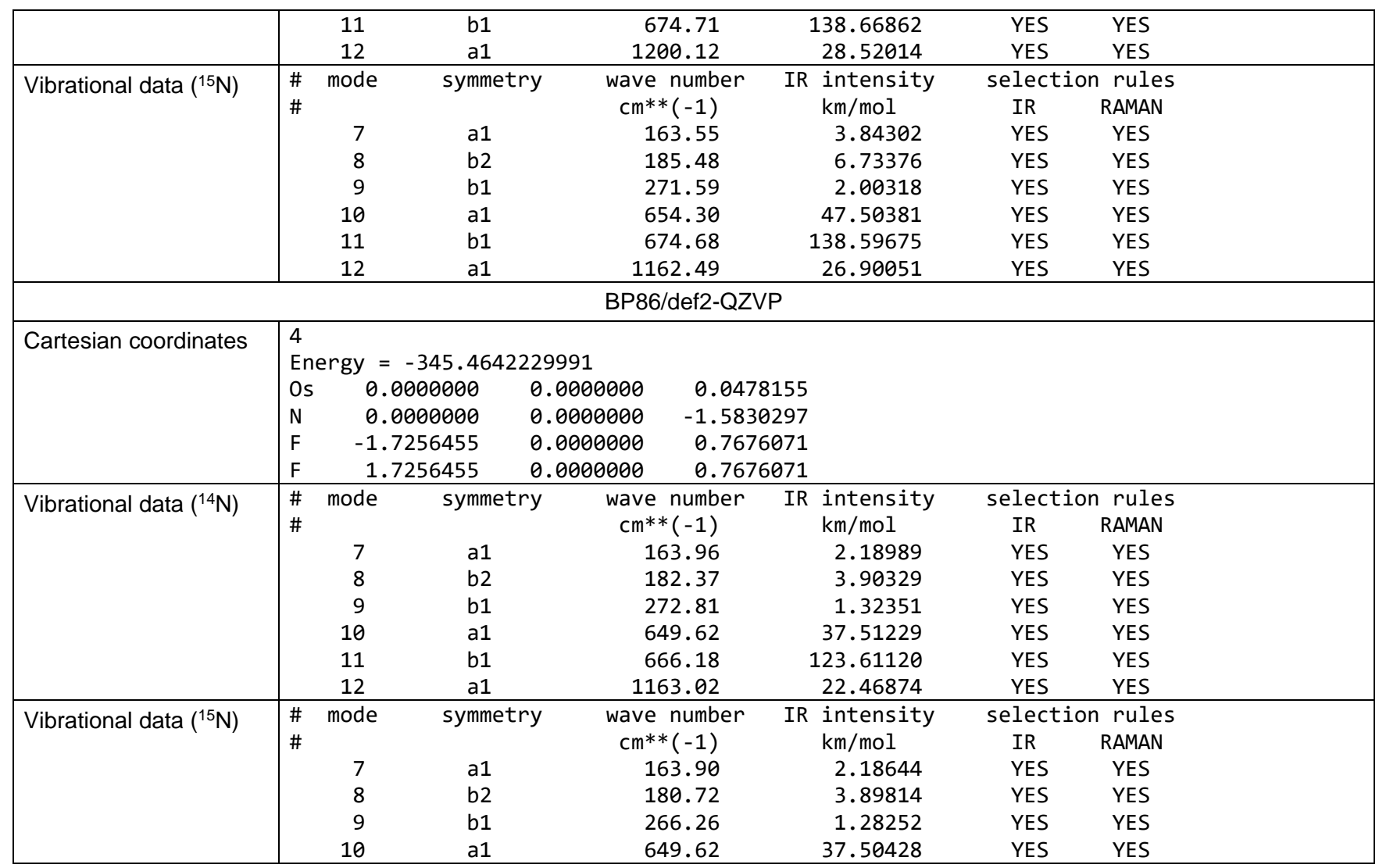




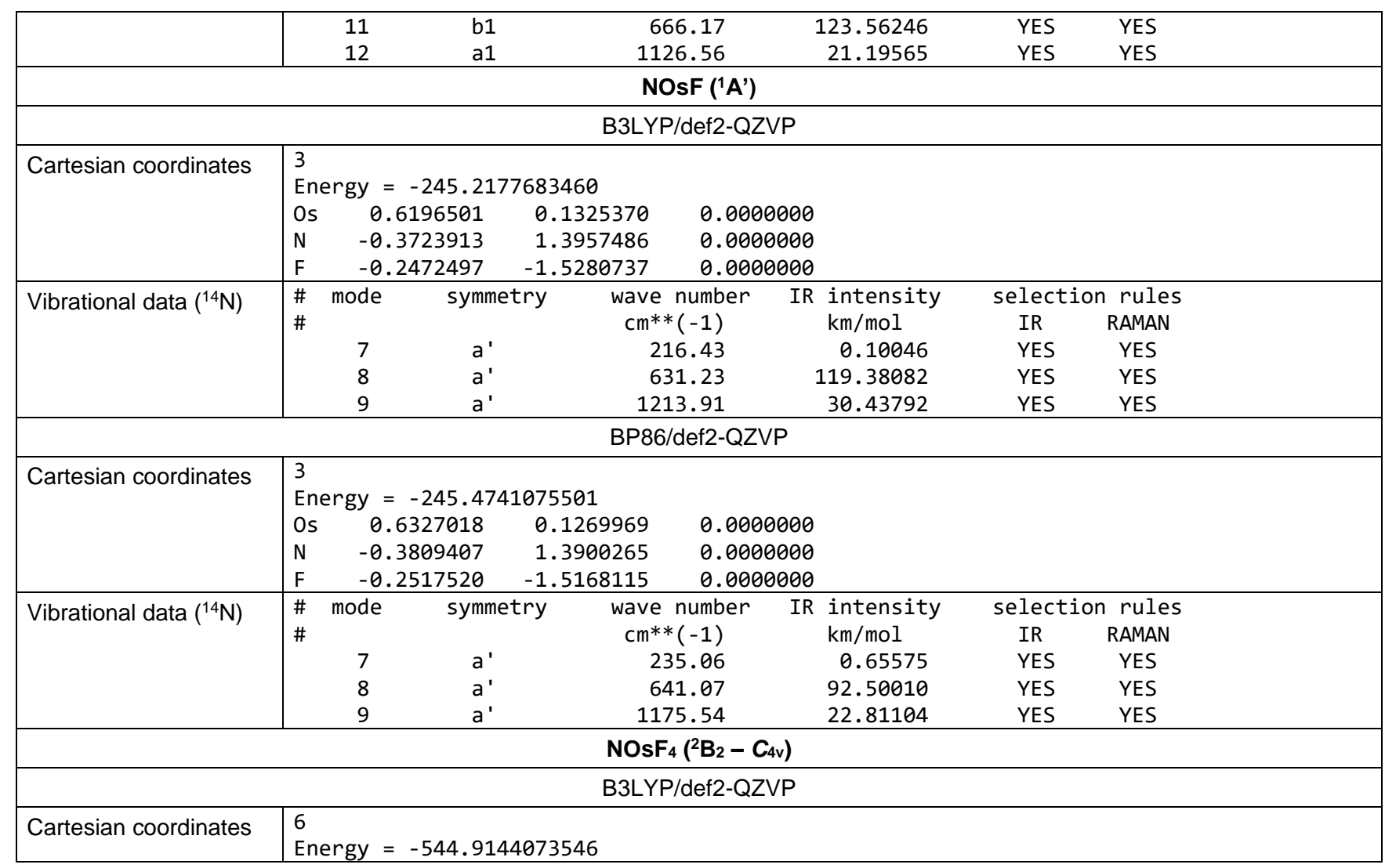


A.1. High-Spin Iron(VI), Low-Spin Ruthenium(VI), and Magnetically Bistable of Osmium(VI): Molecular Group 8 Nitrido Trifluorides $\mathrm{NMF}_{3}$

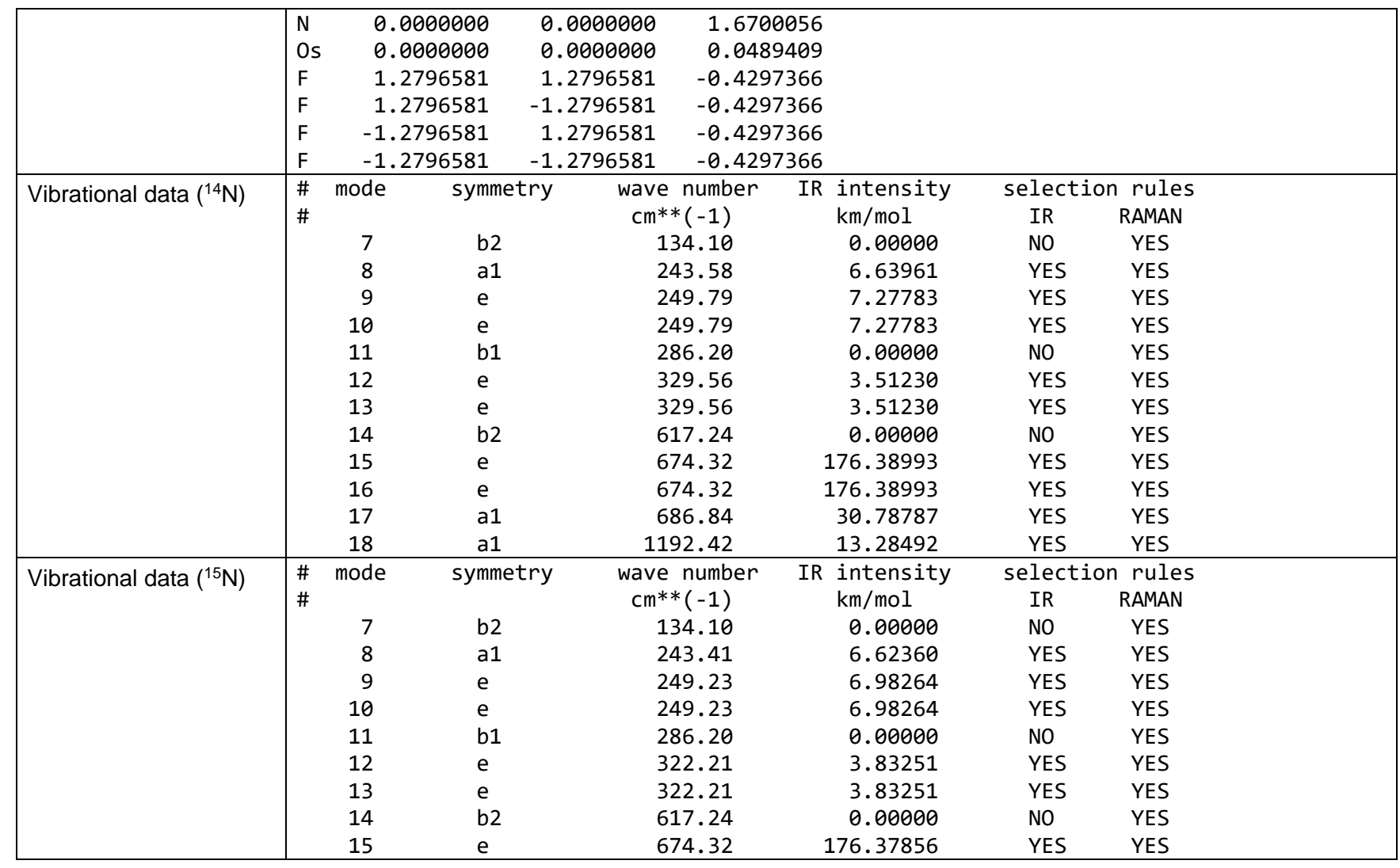




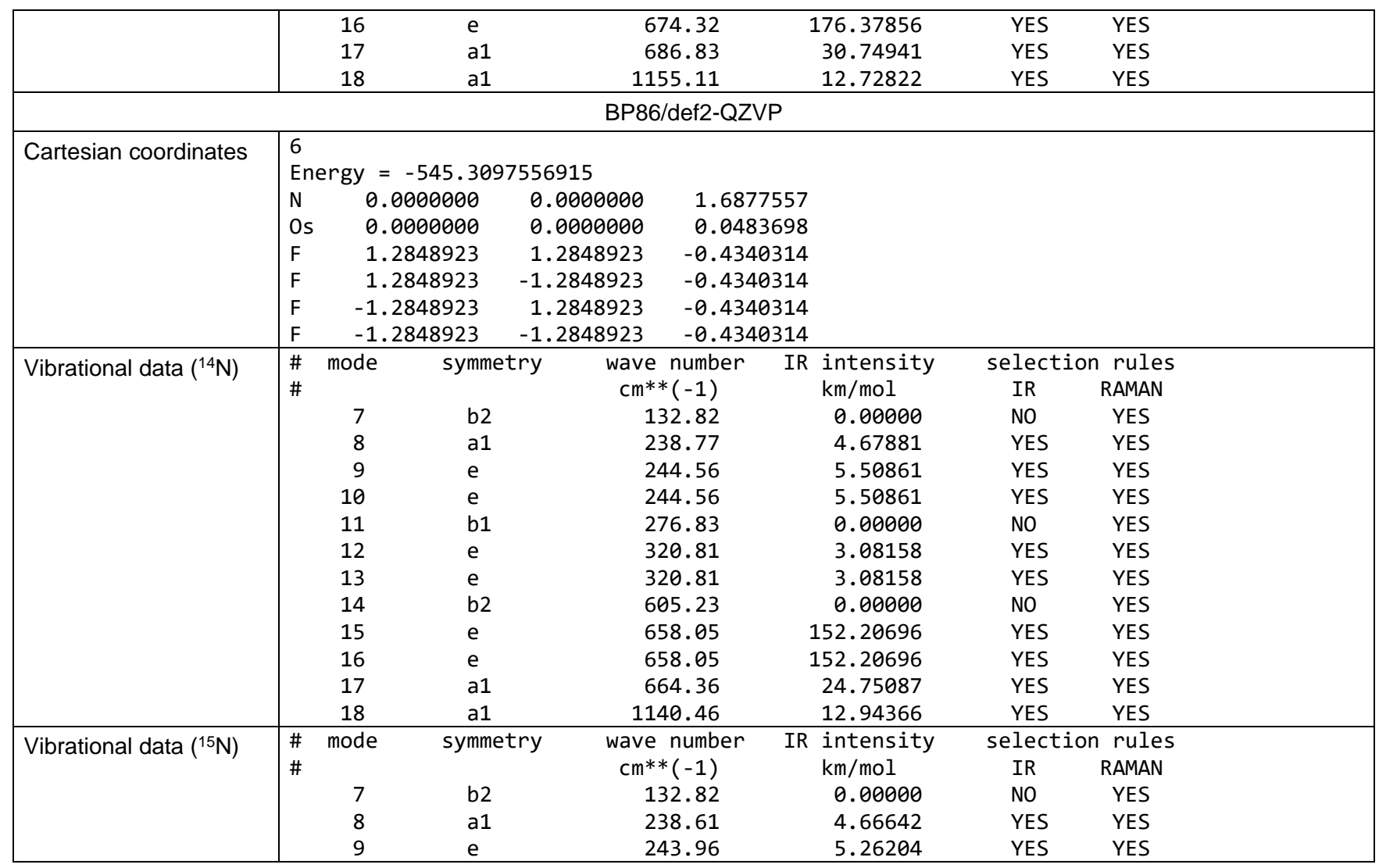


A.1. High-Spin Iron(VI), Low-Spin Ruthenium(VI), and Magnetically Bistable of Osmium(VI): Molecular Group 8 Nitrido Trifluorides $\mathrm{NMF}_{3}$

\begin{tabular}{|c|c|c|c|c|c|c|c|}
\hline & 10 & e & 243.96 & 5.26204 & YES & YES & \\
\hline & 11 & b1 & 276.83 & 0.00000 & NO & YES & \\
\hline & 12 & e & 313.74 & 3.33965 & YES & YES & \\
\hline & 13 & e & 313.74 & 3.33965 & YES & YES & \\
\hline & 14 & b2 & 605.23 & 0.00000 & NO & YES & \\
\hline & 15 & e & 658.05 & 152.19752 & YES & YES & \\
\hline & 16 & e & 658.05 & 152.19752 & YES & YES & \\
\hline & 17 & a1 & 664.35 & 24.72035 & YES & YES & \\
\hline & 18 & a1 & 1104.76 & 12.35962 & YES & YES & \\
\hline \multicolumn{8}{|c|}{ CCSD(T)/aug-cc-pVTZ(-PP) } \\
\hline \multirow[t]{7}{*}{ Cartesian coordinates } & \multicolumn{7}{|c|}{ UCCSD (T)/AUG-CC-PVTZ, OS=AUG-CC-PVTZ-PP ENERGY=-544.12920372 } \\
\hline & $\mathrm{N}$ & -0.0000000000 & \multicolumn{5}{|c|}{ UCCSD (T) /AUG-CC-PVTZ, OS=AUG-CC-PVTZ-PP ENERGY=-544.12920372 } \\
\hline & Os & -0.0000000000 & \multicolumn{2}{|c|}{-0.0000000000} & \multicolumn{2}{|c|}{-0.0422087884} & \\
\hline & $\mathrm{F}$ & 1.8021400214 & \multicolumn{2}{|c|}{0.0000000000} & \multicolumn{2}{|c|}{0.4139846943} & \\
\hline & $\mathrm{F}$ & 0.0000000000 & \multicolumn{2}{|c|}{1.8021400214} & \multicolumn{2}{|c|}{0.4139846943} & \\
\hline & $\mathrm{F}$ & 0.0000000000 & \multicolumn{2}{|c|}{-1.8021400214} & \multicolumn{2}{|c|}{0.4139846943} & \\
\hline & $\mathrm{F}$ & -1.8021400214 & \multicolumn{2}{|c|}{0.0000000000} & \multicolumn{2}{|c|}{0.4139846943} & \\
\hline \multirow{11}{*}{ Vibrational data $\left({ }^{14} \mathrm{~N}\right)$} & \multirow{2}{*}{\multicolumn{2}{|c|}{ Wavenumbers $[\mathrm{cm}-1]$}} & $1 \mathrm{~A} 1$ & $2 \mathrm{~A} 1$ & \multirow{2}{*}{$\begin{array}{c}3 \text { B1 } \\
249.87\end{array}$} & $4 \mathrm{~B} 2$ & 5 A2 \\
\hline & & & 136.22 & 241.61 & & 249.87 & 283.34 \\
\hline & Intensitie & s $[\mathrm{km} / \mathrm{mol}]$ & 0.00 & 0.00 & 0.00 & 0.00 & 0.00 \\
\hline & \multicolumn{2}{|c|}{ Intensities [relative] } & 0.00 & 0.00 & 0.00 & 0.00 & 0.00 \\
\hline & & & 6 B2 & 7 B1 & \multirow{2}{*}{$\begin{array}{c}8 \text { A1 } \\
635.02\end{array}$} & 9 B1 & $10 \mathrm{~B} 2$ \\
\hline & \multirow{3}{*}{\multicolumn{2}{|c|}{$\begin{array}{l}\text { Wavenumbers }[\mathrm{cm}-1] \\
\text { Intensities }[\mathrm{km} / \mathrm{mol}] \\
\text { Intensities }\end{array}$}} & 323.23 & 323.23 & & 693.20 & 693.20 \\
\hline & & & 0.00 & 0.00 & \multirow{2}{*}{$\begin{array}{l}0.00 \\
0.00\end{array}$} & 0.00 & 0.00 \\
\hline & & & 0.00 & 0.00 & & 0.00 & 0.00 \\
\hline & & & $11 \mathrm{~A} 1$ & $12 \mathrm{~A} 1$ & & & \\
\hline & \multirow{2}{*}{\multicolumn{2}{|c|}{$\begin{array}{l}\text { Wavenumbers }[\mathrm{cm}-1] \\
\text { Intensities }[\mathrm{km} / \mathrm{mol}]\end{array}$}} & 705.63 & 1145.42 & & & \\
\hline & & & 0.00 & 0.00 & & & \\
\hline
\end{tabular}




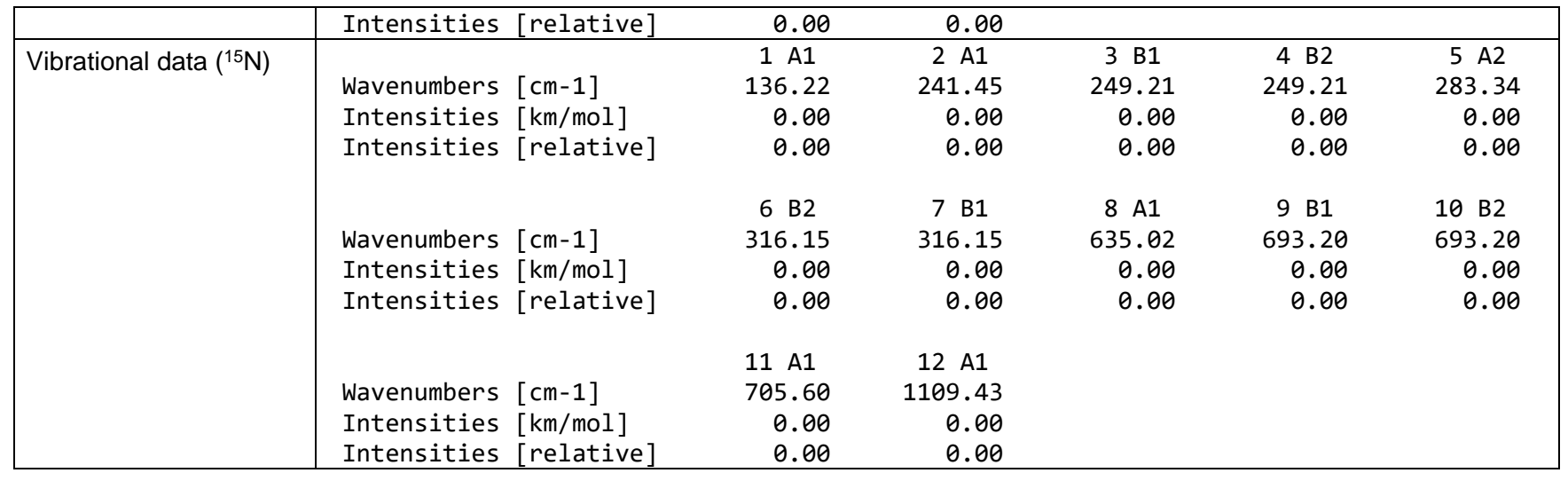




\section{Supporting Information References}

[1] T. Stüker, T. Hohmann, H. Beckers, S. Riedel, Angew. Chem. Int. Ed. 2020, 59, 23174-23179.

[2] TURBOMOLE GmbH, TURBOMOLE V7.3: a development of University of Karlsruhe and Forschungszentrum Karlsruhe GmbH, 2018.

[3] a) A. D. Becke, Phys. Rev. A 1988, 38, 3098-3100; b) J. P. Perdew, Phys. Rev. B 1986, 33, 8822-8824;

[4] Y. Zhao, D. G. Truhlar, Theor. Chem. Acc. 2008, 120, 215-241.

[5] a) A. D. Becke, J. Chem. Phys. 1993, 98, 5648-5652; b) C. Lee, W. Yang, R. G. Parr, Phys. Rev. B 1988, 37, 785-789; c) P. J. Stephens, F. J. Devlin, C. F. Chabalowski, M. J. Frisch, J. Phys. Chem. 1994, 98, 11623-11627; d) S. H. Vosko, L. Wilk, M. Nusair, Can. J. Phys. 1980, 58, 1200-1211;

[6] a) F. Weigend, F. Furche, R. Ahlrichs, J. Chem. Phys. 2003, 119, 12753-12762;

b) F. Weigend, R. Ahlrichs, Phys. Chem. Chem. Phys. 2005, 7, 3297-3305;

[7] D. Andrae, U. Huermann, M. Dolg, H. Stoll, H. Preu, Theor. Chim. Acta 1990, $77,123-141$.

[8] P. J. Knowles, C. Hampel, H.-J. Werner, J. Chem. Phys. 1993, 99, 5219-5227.

[9] H.-J. Werner, P. J. Knowles, G. Knizia, F. R. Manby, M. Schütz, P. Celani, W. Györffy, D. Kats, T. Korona, R. Lindh, A. Mitrushenkov, G. Rauhut, K. R. Shamasundar, T. B. Adler, R. D. Amos, S. J. Bennie, A. Bernhardsson, A. Berning, D. L. Cooper, M. J. O. Deegan, A. J. Dobbyn, F. Eckert, E. Goll, C. Hampel, A. Hesselmann, G. Hetzer, T. Hrenar, G. Jansen, C. Köppl, S. J. R. Lee, 
Y. Liu, A. W. Lloyd, Q. Ma, R. A. Mata, A. J. May, S. J. McNicholas, W. Meyer, T.

F. Miller III, M. E. Mura, A. Nicklass, D. P. O’Neill, P. Palmieri, D. Peng, K.

Pflüger, R. Pitzer, M. Reiher, T. Shiozaki, H. Stoll, A. J. Stone, R. Tarroni, T.

Thorsteinsson, M. Wang, M. Welborn, MOLPRO, version 2019.2, a package of ab initio programs.

[10] a) P. J. Knowles, H.-J. Werner, Chem. Phys. Lett. 1985, 115, 259-267; b) D. A. Kreplin, P. J. Knowles, H.-J. Werner, The Journal of chemical physics 2019, 150, 194106; c) H.-J. Werner, P. J. Knowles, J. Chem. Phys. 1985, 82, 5053-5063;

[11] a) C. Angeli, R. Cimiraglia, S. Evangelisti, T. Leininger, J.-P. Malrieu, J. Chem. Phys. 2001, 114, 10252-10264; b) C. Angeli, R. Cimiraglia, J.-P. Malrieu, J. Chem. Phys. 2002, 117, 9138-9153; c) C. Angeli, M. Pastore, R. Cimiraglia, Theor Chem Acc 2007, 117, 743-754;

[12] a) N. B. Balabanov, K. A. Peterson, J. Chem. Phys. 2005, 123, 64107; b) R. A. Kendall, T. H. Dunning, R. J. Harrison, J. Chem. Phys. 1992, 96, 6796-6806; c) T. H. Dunning, J. Chem. Phys. 1989, 90, 1007-1023;

[13] a) D. Figgen, K. A. Peterson, M. Dolg, H. Stoll, J. Chem. Phys. 2009, 130, 164108; b) K. A. Peterson, D. Figgen, M. Dolg, H. Stoll, J. Chem. Phys. 2007, 126,124101

[14] A. Wolf, M. Reiher, B. A. Hess, J. Chem. Phys. 2002, 117, 9215-9226.

[15] W. Jiang, N. J. DeYonker, A. K. Wilson, J. Chem. Theory Comput. 2012, 8, 460-468.

[16] J. Wang, S. Manivasagam, A. K. Wilson, J. Chem. Theory Comput. 2015, 11, $5865-5872$. 
A.1. High-Spin Iron(VI), Low-Spin Ruthenium(VI), and Magnetically Bistable of Osmium(VI): Molecular Group 8 Nitrido Trifluorides $\mathrm{NMF}_{3}$

[17] a) F. Neese, WIREs Comput. Mol. Sci. 2012, 2, 73-78; b) F. Neese, WIREs Comput. Mol. Sci. 2017, 2, e1327; c) J. N. Harvey, M. Aschi, H. Schwarz, W. Koch, Theor Chem Acc 1998, 99, 95-99;

[18] R. F. W. Bader, Atoms in Molecules: A Quantum Theory; Clarendon Press, 1994.

[19] T. Lu, F. Chen, J. Comput. Chem. 2012, 33, 580-592.

[20] A. E. Reed, Schleyer, Paul v. R, J. Am. Chem. Soc. 1990, 112, 1434-1445.

[21] K. B. Wiberg, Tetrahedron 1968, 24, 1083-1096.

[22] E. D. Glendening, J. K. Badenhoop, A. E. Reed, J. E. Carpenter, J. A. Bohmann, C. M. Morales, P. Karafiloglou, C. R. Landis, F. Weinhold, NBO 7.0; Theoretical Chemistry Institute, University of Wisconsin, Madison, WI, 2018.

[23] W. Humphrey, A. Dalke, K. Schulten, Journal of Molecular Graphics 1996, 14, 33-8, 27-8.

[24] X. Wang, L. Andrews, R. Lindh, V. Veryazov, B. O. Roos, J. Phys. Chem. A 2008, 112, 8030-8037.

[25] C. Vogel, F. W. Heinemann, J. Sutter, C. Anthon, K. Meyer, Angew. Chem. Int. Ed. 2008, 47, 2681-2684.

[26] T. Schlöder, T. Vent-Schmidt, S. Riedel, Angew. Chem. Int. Ed. 2012, 51, 12063-12067.

[27] A. K. Brisdon, E. G. Hope, J. H. Holloway, W. Levason, J. S. Ogden, J. Fluorine Chem. 1993, 64, 117-123.

[28] M. R. Sundberg, R. Ponec, Inorg. Chim. Acta FIELD Full Journal Title:Inorganica Chimica Acta 2006, 359, 899-906. 
[29] M. Kaupp, J. Comput. Chem. 2007, 28, 320-325.

[30] B. O. Roos, A. C. Borin, L. Gagliardi, Angew. Chem. Int. Ed. 2007, 46, 14691472.

[31] J. J. Scepaniak, C. S. Vogel, M. M. Khusniyarov, F. W. Heinemann, K. Meyer, J. M. Smith, Science 2011, 331, 1049-1052.

[32] J. F. Berry, E. Bill, E. Bothe, S. D. George, B. Mienert, F. Neese, K. Wieghardt, Science 2006, 312, 1937-1941.

[33] a) M. E. Jacox, J. Phys. Chem. Ref. Data 1998, 27, 115-393; b) D. E. Milligan, M. E. Jacox, J. Chem. Phys. 1964, 40, 2461-2466;

[34] a) G. Sabenya, L. Lázaro, I. Gamba, V. Martin-Diaconescu, E. Andris, T. Weyhermüller, F. Neese, J. Roithova, E. Bill, J. Lloret-Fillol, M. Costas, J. Am. Chem. Soc. 2017, 139, 9168-9177; b) E. Andris, R. Navrátil, J. Jašík, G. Sabenya, M. Costas, M. Srnec, J. Roithová, Chemistry - A European Journal 2018, 24, 5078-5081;

[35] a) T. A. Betley, J. C. Peters, J. Am. Chem. Soc. 2004, 126, 6252-6254; b) J.U. Rohde, T. A. Betley, T. A. Jackson, C. T. Saouma, J. C. Peters, Que, Lawrence, Jr, Inorganic Chemistry (Washington, DC, United States) 2007, 46, 5720-5726;

[36] L. Bucinsky, M. Breza, W.-T. Lee, A. K. Hickey, D. A. Dickie, I. Nieto, J. A. DeGayner, T. D. Harris, K. Meyer, J. Krzystek, A. Ozarowski, J. Nehrkorn, A. Schnegg, K. Holldack, R. H. Herber, J. Telser, J. M. Smith, Inorg. Chem. 2017, 56, 4752-4769.

[37] J. J. Scepaniak, M. D. Fulton, R. P. Bontchev, E. N. Duesler, M. L. Kirk, J. M. Smith, J. Am. Chem. Soc. 2008, 130, 10515-10517. 
A.1. High-Spin Iron(VI), Low-Spin Ruthenium(VI), and Magnetically Bistable of Osmium(VI): Molecular Group 8 Nitrido Trifluorides $\mathrm{NMF}_{3}$

[38] M. Keilwerth, L. Grunwald, W. Mao, F. W. Heinemann, J. Sutter, E. Bill, K. Meyer, J. Am. Chem. Soc. 2021, 143, 1458-1465.

[39] W. D. Wagner, K. Nakamoto, J. Am. Chem. Soc. 1989, 111, 1590-1598.

[40] a) J. W. Buchler, C. Dreher, K. L. Lay, Z. Naturforsch, B: Chem. Sci. 1982, 37, 1155-1162; b) J. W. Buchler, C. Dreher, K.-L. Lay, A. Raap, K. Gersonde, Inorg. Chem. 1983, 22, 879-884; c) C. Campochiaro, J. A. Hofmann, D. F. Bocian, Inorg. Chem. 1985, 24, 449-450;

[41] J. T. Groves, T. Takahashi, W. M. Butler, Inorg. Chem. 1983, 22, 884-887.

[42] H.-X. Wang, L. Wu, B. Zheng, L. Du, W.-P. To, C.-H. Ko, D. L. Phillips, C.-M. Che, Angewandte Chemie International Edition 2020.

[43] a) T. Petrenko, S. DeBeer George, N. Aliaga-Alcalde, E. Bill, B. Mienert, Y. Xiao, Y. Guo, W. Sturhahn, S. P. Cramer, K. Wieghardt, F. Neese, J. Am. Chem. Soc. 2007, 129, 11053-11060; b) N. Aliaga-Alcalde, S. DeBeer George, B. Mienert, E. Bill, K. Wieghardt, F. Neese, Angew. Chem. Int. Ed. 2005, 44, 29082912;

[44] N. B. Thompson, M. T. Green, J. C. Peters, J. Am. Chem. Soc. 2017, 139, $15312-15315$.

[45] a) A. Halkier, T. Helgaker, P. Jorgensen, W. Klopper, H. Koch, J. Olsen, A. K. Wilson, Chem. Phys. Lett. 1998, 286, 243-252; b) T. Helgaker, W. Klopper, H. Koch, J. Noga, J. Chem. Phys. 1997, 106, 9639-9646;

[46] A. Halkier, T. Helgaker, P. Jørgensen, W. Klopper, J. Olsen, Chem. Phys. Lett. 1999, 302, 437-446. 
A.2 Fluoro Nitrenoid Complexes $F N=M_{2}(M=C o, R h, I r)$ : Electronic Structure Dichotomy and Formation of Nitrido Fluorides $\mathrm{N} \equiv \mathrm{MF}_{3}$ 


\section{Angewandte

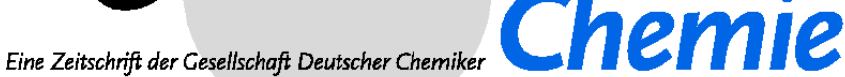

Supporting Information

Fluoro Nitrenoid Complexes $\mathbf{F N}=\mathrm{MF}_{2}(\mathbf{M}=\mathrm{Co}, \mathbf{R h}, \mathbf{I r})$ : Electronic Structure Dichotomy and Formation of Nitrido Fluorides $\mathbf{N} \equiv \mathbf{M F}_{\mathbf{3}}$

Tony Stüker, Thomas Hohmann, Helmut Beckers, and Sebastian Riedel*

ange_202010950_sm_miscellaneous_information.pdf 


\section{Contents}

Contents

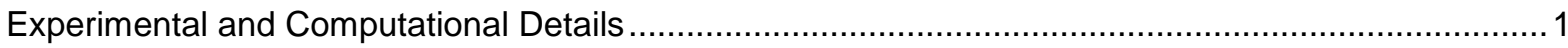

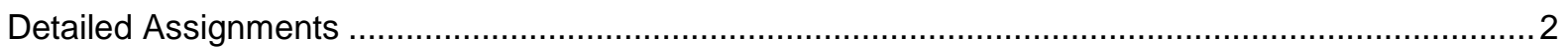

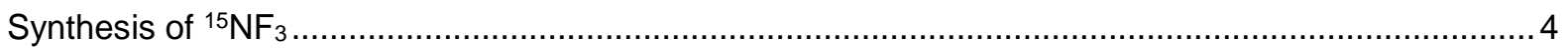

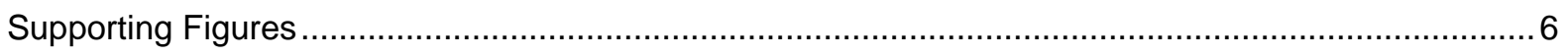

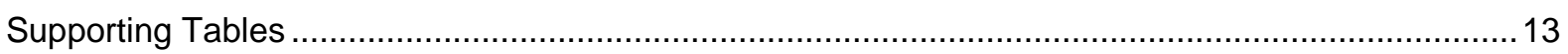

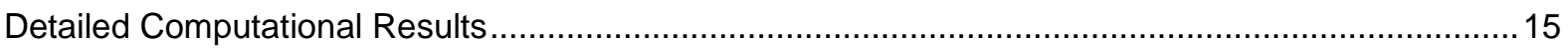

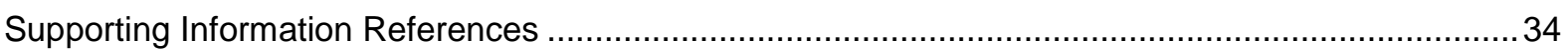

\section{Experimental and Computational Details}

\section{Computational Details}

Density functional theory (DFT) calculations were performed using the TURBOMOLE 7.0.1 program package ${ }^{[1]}$ employing the GGA and hybrid exchange-correlation density functionals BP86 ${ }^{[2]}$ and B3LYP[${ }^{[3]}$ with the polarized quadruple- $\xi$ basis set def2-QZVP[4] which applies the Stuttgart-Dresden effective core potential for rhodium and iridium ${ }^{[5]}$. The Coupled Cluster Single Double and perturbative Triple excitations $(\operatorname{CCSD}(T))$ calculations were carried out in the spin unrestricted ROHF-UCCSD $(T)$ open-shell coupled cluster formalism using default frozen core settings as implemented in the Molpro 2019 software package. ${ }^{[6]}$ The same software was used for all Complete Active Space Self Consistent Field (CASSCF) and Complete Active Space Perturbation Theory Second Order (CASPT2) calculations. Unless stated otherwise, all $\operatorname{CCSD}(T)$ calculations were combined with the augmented triple- $\xi$ basis sets aug-cc-pVTZ for nitrogen and fluorine, and aug-cc-pVTZ-PP for rhodium and iridium. .7-9] CASPT2 calculations for $\mathrm{FNRhF}_{2}$ and $\mathrm{FNCoF}_{2}$ were carried out with relativistic corrections using the second order Douglas-Kroll-Hess Hamiltonian combined with the Dunning's correlation consistent polarized triple- $\xi$ basis sets cc-pVTZ-DK[7,8,10]. The active space for the state-specific complete active-space (SS-CASSCF) reference wavefunction was chosen to consist of the M-N $\sigma$ and $\pi$ binding and anti-binding and the metal centered d-type molecular orbitals formed by the $2 p(N), 3 d\left(C_{0}\right)$ and $4 \mathrm{~d}(\mathrm{Rh})$ atomic orbitals, yielding 9 electrons in 7 molecular orbitals $(9,7)$ for $\mathrm{FNCoF}_{2}$ and $\mathrm{FNRhF}_{2}$. Single point SS-CASSCF calculations carried out for $\mathrm{NRhF}_{3}$ and $\mathrm{N}_{\mathrm{rrF}}$ consisted of an active space of of 9 electrons in 8 orbitals covering the $\mathrm{M}-\mathrm{N}$ three bonding, three antibonding and the singly and doubly occupied metal centered molecular orbitals. The lowest 9 molecular orbitals for $\mathrm{FNCoF} / \mathrm{NCoF}_{3}$ and the lowest 18 molecular orbitals for $\mathrm{FNRhF}_{2} / \mathrm{NRhF}_{3}$ were frozen in the subsequent CASPT2 dynamic 
correlation treatment. Harmonic vibrational frequency calculations were carried out for optimized structures analytically (BP86, B3LYP) or numerically (CCSD(T) and CASPT2).Matrix-isolation Experiments

${ }^{14} \mathrm{NF}_{3}$ and ${ }^{15} \mathrm{NF}_{3}$ (vide infra) were premixed with neon or argon (both $99.999 \%$, Linde) in a stainlesssteel cylinder. The mixing vessel was connected to a stainless-steel vacuum line connected to a selfmade matrix chamber by a stainless-steel capillary. The gas mixture was then co-deposited for $100 \mathrm{~min}$ with laser-ablated cobalt, rhodium or iridium atoms onto a CsI window (argon matrices) or onto a gold plated copper mirror (neon matrices) and cooled to $4 \mathrm{~K}$ by using a closed-cycle helium cryostat (Sumitomo Heavy Industries, RDK-205D) inside the vacuum chamber. For the laser-ablation, the 1064 $\mathrm{nm}$ fundamental of a Nd:YAG laser (Continuum, Minilite II, $10 \mathrm{~Hz}$ repetition rate, 35-50 mJ pulse ${ }^{-1}$ ) was focused onto a rotating iridium metal target through a hole in the cold window. Infrared spectra were recorded on a Bruker Vertex 70 spectrometer purged with dry air (argon matrices) or a Bruker Vertex $80 \mathrm{v}$ with evacuated optical path (neon matrices) at $0.5 \mathrm{~cm}^{-1}$ resolution in the region $4000-430 \mathrm{~cm}^{-1}$ by using a liquid-nitrogen-cooled mercury cadmium telluride (MCT) detector. The matrix samples were irradiated by a mercury arc streetlamp (Osram HQL 250) with the outer globe removed.

\section{Detailed Assignments}

Laser-ablated iridium, rhodium and cobalt atoms were reacted with ${ }^{14} \mathrm{NF}_{3}$ and ${ }^{15} \mathrm{NF}_{3}$ in a 1:1000 excess of neon or argon and deposited on a gold-plated copper mirror cooled to 5 and $12 \mathrm{~K}$, respectively. The IR spectra in excess neon are shown in Figures 2-4 for iridium, rhodium and cobalt. The complementary argon spectra for iridium and rhodium are shown in Figures S1-S3. By comparing spectra of the reaction products of one metal with those of another metal, the metal dependent bands were identified. Further simplification was achieved by neglecting bands belonging to $\mathrm{MF}_{\mathrm{n}}$ obtained by recording complementary spectra of metal fluorine reaction products under the same conditions. It is worth pointing out that the IR spectra obtained in neon are generally of better quality in terms of intensity and line broadening. This is because neon is being considered the least interacting and most inert cryogenic matrix available. ${ }^{[11]}$

\section{$\mathrm{FNCOF}_{2}$}

After co-depositing laser-ablated $\mathrm{Co}$ and $\mathrm{NF}_{3}$ diluted in $\mathrm{Ne}$, the IR spectra shown in Figure $\mathrm{S} 11$ and $\mathrm{S} 12$ were recorded. The $1100-725 \mathrm{~cm}^{-1}$ region in Figure $\mathrm{S} 11$ contains two bands. A weak band at $1056.8 \mathrm{~cm}^{-1}$ which exhibits an ${ }^{14 / 15} \mathrm{~N}$ isotopic shift of $-21.4 \mathrm{~cm}^{-1}$ and at $751.7 \mathrm{~cm}^{-1}$ without isotopic shift. In the spectral region of $725-525 \mathrm{~cm}^{-1}$ shown in Figure $\mathrm{S} 12$ two bands with an isotopic shift are located at 629.6 and $586.1 \mathrm{~cm}^{-1}$ with isotopic shifts of -3.5 and $-12.1 \mathrm{~cm}^{-1}$, respectively. The isotopic shift of the band at $1056.8 \mathrm{~cm}^{-1}$ is considereably less than expected for a terminal bond nitrogen atom and consistent with an assignment to to the F-N stretching mode of $\mathrm{FNCoF}_{2}$. The remaining bands at 751.7, 629.6 and $586.1 \mathrm{~cm}^{-1}$ are assigned to the antisymmetric F-Co-F, symmetric F-Co-F and to the N-Co stretching mode. Attempts to use single reference correlation methods to calculate the geometry and frequencies of this species failed. They did not converge $(\operatorname{CCSD}(T))$, or did not yield qualitatively 
consistent results (B3LYP and BP86). To account for the strong non-dynamical correlation, $\operatorname{CASSCF}(9,7)$ with subsquent CASPT2 dynamical correlation treatment was employed. The values calculated at the CASPT2/cc-pVTZ-DK level of theory are in good agreement with the experiment (Table 1). The assignment of $\mathrm{FNCoF}_{2}$ is further supported by the fact that the lowest energy structural isomer based on the reaction enthalpies summarized in Table S1.

\section{$\mathrm{NRhF}_{3}$}

The IR spectra obtained after co-depositing evaporated rhodium and diluted $\mathrm{NF}_{3}$ in neon shown in Figures $\mathrm{S} 13$ and $\mathrm{S} 14$ contain three bands with significant isotopic shifts. The position of the band at $1116.1 \mathrm{~cm}^{-1}$ (Figure 3, A) and the isotopic shift of $-33 \mathrm{~cm}^{-1}$ are indicative for a terminally bond nitrogen with a triple bond. This band, as well as three additional bands in the M-F stretching region were assigned to $\mathrm{NRhF}_{3}$. The bands located at 626.2 and $622.8 \mathrm{~cm}^{-1}$ loose intensity upon broadband irradiation and annealing to $12 \mathrm{~K}$ with their initially weaker matrix sites at 624.8 and $622.2 \mathrm{~cm}^{-1}$ gaining intensity. These bands were assigned to the antisymmetric and symmetric F-Rh-F stretching mode, respectively. The last band is located at $542.5 \mathrm{~cm}^{-1}$ shows a small isotopic shift of $-0.5 \mathrm{~cm}^{-1}$ and was assigned to the Rh-F' stretching mode. The assignments are supported by quantum chemical calculations, which yield 1087 (1113), 625 (603), 618 (601) and 581 (562) cm-1 at the BP86 (B3LYP) levels of theory. The calculated isotopic shift of the $\mathrm{N}$-Rh stretching mode is $-32(-33)$ at the BP86 (B3LYP) level of theory, respectively, and in very good agreement with the experimentally observed values in neon and in argon (both $-33 \mathrm{~cm}^{-1}$ ). The small observed isotopic shift of $-0.4(-0.5) \mathrm{cm}^{-1}$ of the Rh-F' stretching mode observed in neon (argon) was not predicted by both DFT methods but is also observed in $\mathrm{NIrF}_{3}$ as well. Unfortunately, calculations at the $\operatorname{CCSD}(\mathrm{T})$ level of theory yield two imaginary frequencies probably caused by a low-laying excited electronic state which interferes with the calculation of displaced steps during the numerical hessian calculation where the symmetry is lowered to $C_{1}$. However, the structure obtained at the B3LYP level of theory is very close to the one obtained at the $\operatorname{CCSD}(T)$ level (Figures 5 and S5) and the good match of the B3LYP results for $\mathrm{NlrF}_{3}$ with the experimental values suggest a good performance of $B 3 L Y P$ for the $\mathrm{NMF}_{3}$ species.

\section{FNRhF 2}

The two remaining bands with significant isotopic shifts of -18.9 and $-18.0 \mathrm{~cm}^{-1}$ (labeled $\mathbf{B}$ and $\mathbf{C}$ in Figure S13) centered at 872.6 and $761.4 \mathrm{~cm}^{-1}$ are indicative for absorptions of two modes exhibiting significant displacements of a nitrogen atom which is not terminally bonded. The assignment to the two modes involving the $\mathrm{F}-\mathrm{N}-\mathrm{Rh}$ moiety of $\mathrm{FNRhF}_{2}$ suggests itself, however, while quantum chemical calculations at the DFT BP86 (B3LYP) level of theory yield acceptable band positions of 850 (935) and $721(786) \mathrm{cm}^{-1}$, the isotopic shifts of $-24(-24)$ and $-12(-16) \mathrm{cm}^{-1}$ do not match the observed ones. More sophisticated calculations at the $\operatorname{CSSD}(\mathrm{T})$ (CASPT2) levels of theory yield isotopic shifts of -16 $(-19)$ and $-19(-20)$ (Table S5) which are in better agreement with the observed values. However, the deviations between the calculated and observed band positions at 899 (981) and $720(756) \mathrm{cm}^{-1}$ indicates the presence of vibronic coupling effects which are not taken into account in the harmonic approximation. The band centered at $872.6 \mathrm{~cm}^{-1}$ was assigned to the $\mathrm{F}-\mathrm{N}$ stretching mode, while the band at $761.4 \mathrm{~cm}^{-1}$ was assigned to the $\mathrm{N}-\mathrm{Rh}$ stretching mode. Along with vibrations related to the $\mathrm{F}$ - 
$\mathrm{N}$-Rh moiety, the bands belonging to the antisymmetric and symmetric F-Rh-F stretching modes were assigned to bands at 638.6 and $596.7 \mathrm{~cm}^{-1}$ (labeled $\mathbf{A}$ and $\mathbf{D}$ in Figure S14) in an overall very good agreement with the calculated values summarized in Table 1. The antisymmetric F-N-Rh stretching mode could not be identified in the corresponding argon spectrum. Additional bands are much weaker. They are tentatively assigned in Figures $\mathrm{S} 1$ and $\mathrm{S} 2$ and summarized in Table 1. The presence of both species, $\mathrm{NRhF}_{3}$ and $\mathrm{FNRhF}_{2}$, is reasonably justified considering the small energy difference of 7 [12] $\mathrm{kJ} \mathrm{mol}^{-1}$ calculated at the B3LYP $[\operatorname{CCSD}(\mathrm{T})]$ level of theory (see Table S1 and Figure 1).

\section{$\mathrm{NIrF}_{3}$}

After depositing iridium and $\mathrm{NF}_{3}$ diluted in neon, bands immune to annealing and broadband irradiation centered at 1150.4, 659.8, 651.6, 648.9 and $562.1 \mathrm{~cm}^{-1}$ shown in Figure $\mathrm{S} 15$ were singled out and assigned to $\mathrm{NlrF}_{3}$ with a point group symmetry of $C_{\mathrm{s}}$. The position of the band centered at $1150.4 \mathrm{~cm}^{-1}$ (Figure $\mathrm{S} 15, \mathrm{~A}$ ), the isotopic shift of $-36 \mathrm{~cm}^{-1}$ and the ${ }^{14 / 15} \mathrm{~N}$ isotopic ratio of 1.0323 are indicative for a vibration of a strongly bond single nitrogen atom attached to a heavy element. Theoretical calculations support the assignment to the $\mathrm{I}=\mathrm{N}$ stretching mode, with calculated isotopic shifts of $-35,-36$, and -36 and ${ }^{14 / 15} \mathrm{~N}$ isotopic ratios of $1.0325,1.0325$ and 1.0326 obtained the BP86/def2-QZVP, B3LYP/def2QZVP and ROHF-UCCSD(T)/aug-cc-pVTZ(-PP) levels of theory, respectively. However, the absolute values of 1121,1158 and $1126 \mathrm{~cm}^{-1}$ (BP86, B3LYP and $\operatorname{CCSD}(\mathrm{T})$ ) deviate by $-29,8$ and $-24 \mathrm{~cm}^{-1}$, respectively. The assignment of the absorption at $659.8 \mathrm{~cm}^{-1}$ (Figure S15, B) to the symmetric F-Ir-F stretching mode is backed by calculated values of 618,635 and $653 \mathrm{~cm}^{-1}$ (BP86, B3LYP and CCSD(T)). Isotopic shifts were not observed and were calculated to be 0 for the ${ }^{14 / 15} \mathrm{~N}$ substituted isotopologue. The more intense antisymmetric F-Ir-F stretching mode and its matrix site are located at 651.6 and $648.9 \mathrm{~cm}^{-1}$ (Figure S15, C) and do not show any matrix shift either. The calculated values of 618,634 , and $650 \mathrm{~cm}^{-1}$ (BP86, B3LYP, CCSD(T)) confirm the proximity of the symmetric and antisymmetric F-Ir$F$ stretching frequencies. Finally, the band showing a very small isotopic shift of $-0.2 \mathrm{~cm}^{-1}$ centered at $562.1 \mathrm{~cm}^{-1}$ (Figure S15, D) was assigned to the F'-Ir stretching mode involving the fluorine atom residing the mirror plane of the molecule. The IR spectra obtained in argon (Figure S3) are not as comprehensive as in neon. The Ir- $\mathrm{N}$ stretching mode and the $\mathrm{F}^{\prime}$-Ir stretching mode were tentatively assigned to very weak bands centered at 1144.6 and $560.1 \mathrm{~cm}^{-1}$, respectively. The bands belonging to the symmetric and antisymmetric F-Ir-F stretching modes are probably overlapped by the bands belonging to the strong and broad symmetric deformation mode of $\mathrm{NF}_{3}$ and its matrix sites.

\section{Synthesis of ${ }^{15} \mathrm{NF}_{3}$}

The synthesis of ${ }^{15} \mathrm{NF}_{3}$ was carried out in an electric discharge cell described by Ruff and Menze[ [12] following the procedure described by Maya ${ }^{[13]}$. A 1:4 mixture of ${ }^{15} \mathrm{~N}_{2}$ and $\mathrm{F}_{2}$ was slowly allowed to enter an electric discharge cell submerged in liquid nitrogen $\left(\mathrm{LN}_{2}\right)$ shown in Figure S9. The electronic discharge arc was generated by a current of $7.0 \mathrm{kV}$, while the flow was adjusted to maintain a constant pressure of $30-35$ mbar inside the reactor. After $1.5 \mathrm{~h}$ a volume of $113 \mathrm{~mL}$ of the ${ }^{15} \mathrm{~N}_{2} / \mathrm{F}_{2}$ mixture was admitted to the reactor. The condensed, crude reaction product at the bottom of the reactor was 
recondensed into a glass cylinder. The volatile gas phase of the LN2 cooled crude phase contained $F_{2}$ (identified through the presence of $\mathrm{SiF}_{4}$ ). To remove all remaining $\mathrm{F}_{2}$ from the crude product, the glass cylinder was cooled using a $\mathrm{N}_{2}$ slurry and pumping off all volatile components for $5 \mathrm{~min}$ at $10^{-3} \mathrm{mbar}$. The purification process was followed by gas phase IR spectra shown in Figure S0. The purified product did not show any IR active impurities in a matrix-isolation spectrum in $99.9 \%$ excess neon shown in Figure S4. In addition to the assignments by Allan et al. ${ }^{[14]}$, six more combination- and overtone bands were identified and listed in Table S2. The overall yield was $73 \%$ with respect to ${ }^{15} \mathrm{~N}_{2}$, significantly higher than the reported yield of $30 \%{ }^{14} \mathrm{NF}_{3} .{ }^{[13]}$ 


\section{Supporting Figures}

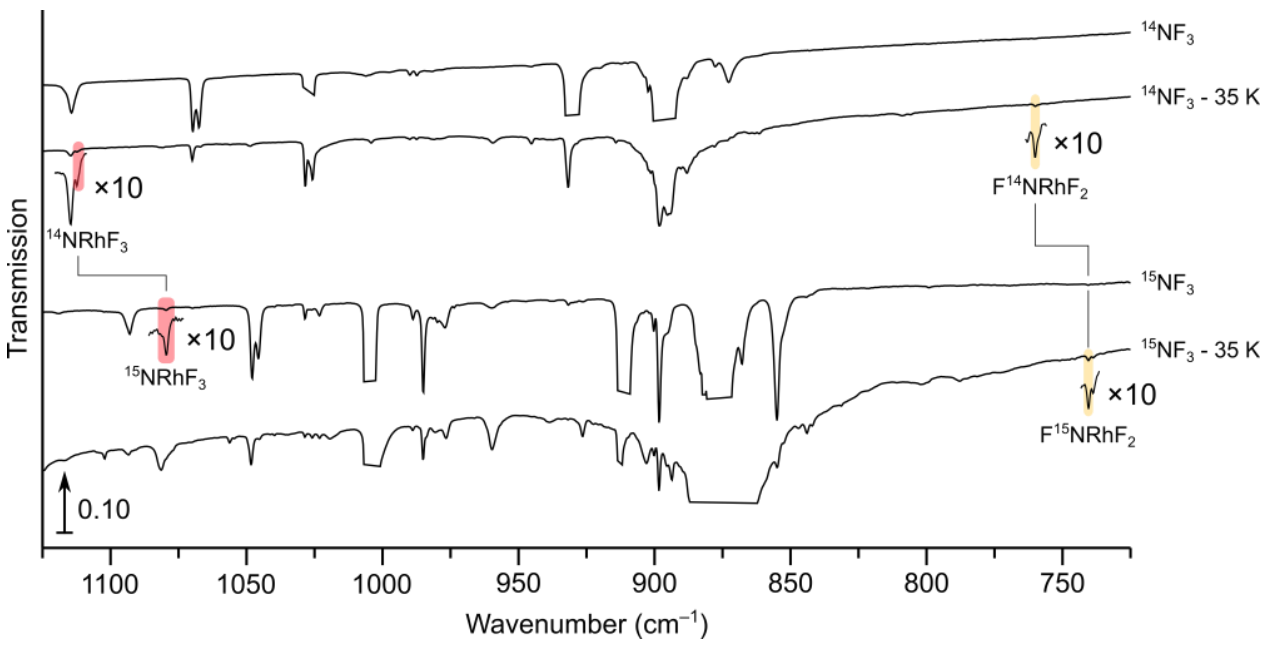

Figure S1. Infrared transmission spectra in the $1125-725 \mathrm{~cm}^{-1}$ region of laser ablated rhodium co-deposited with $0.5 \%{ }^{14} \mathrm{NF}_{3}$ and ${ }^{15} \mathrm{NF}_{3}$ diluted in argon and treated according to the labels.

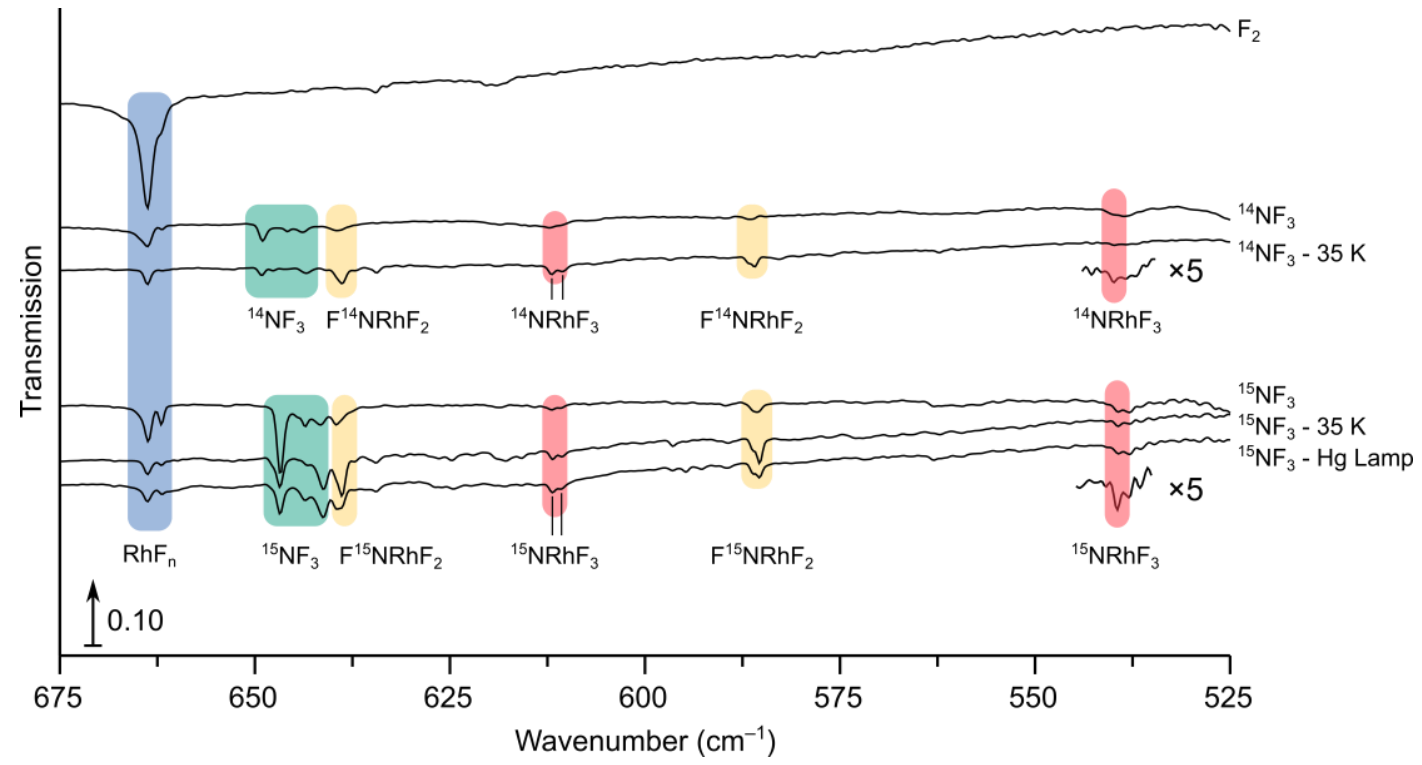

Figure S2. Infrared transmission spectra in the $675-525 \mathrm{~cm}^{-1}$ region of laser ablated rhodium co-deposited with $0.5 \%$ of $F_{2}$, ${ }^{14} \mathrm{NF}_{3}$ and ${ }^{15} \mathrm{NF}_{3}$ diluted in argon and treated according to the labels. 

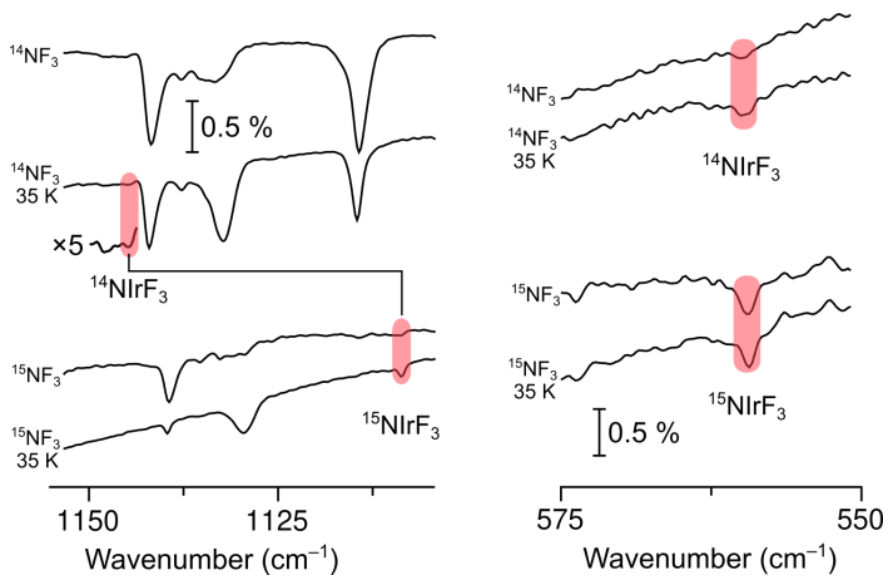

Figure S3. Infrared transmission spectra in the $1155-1100$ and $575-550 \mathrm{~cm}^{-1}$ regions of laser ablated iridium co-deposited with $0.5 \%{ }^{14} \mathrm{NF}_{3}$ and ${ }^{15} \mathrm{NF}_{3}$ diluted in argon and treated according to the labels.

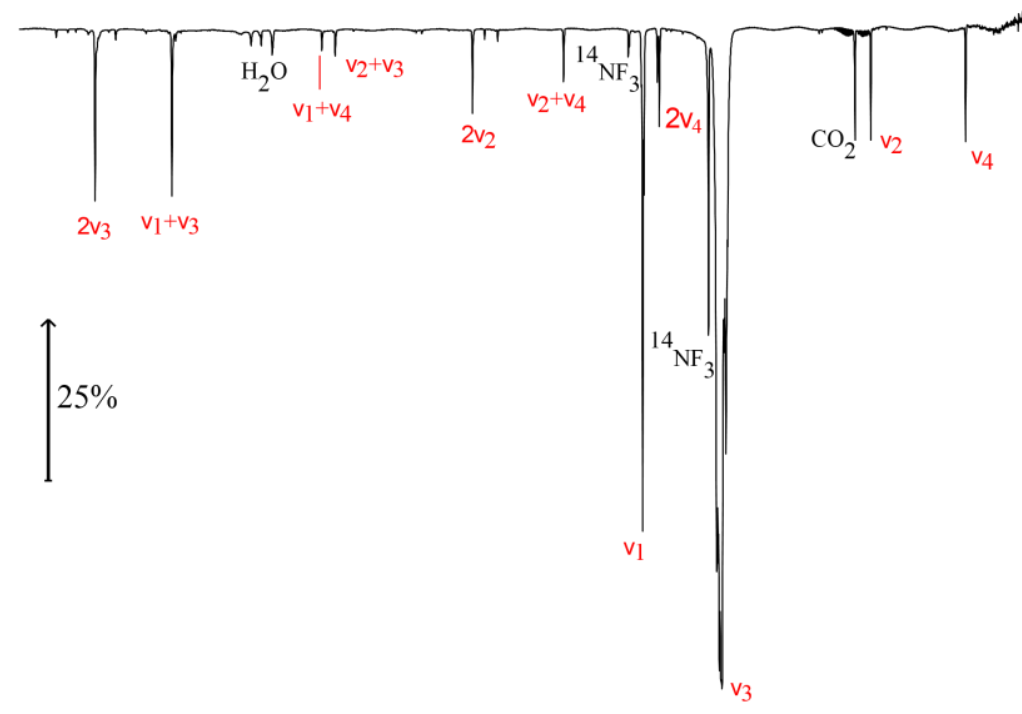

\begin{tabular}{ccccccc}
\hline 2000 & 1750 & 1500 & 1250 & 1000 & 750 & 500 \\
& & & \\
& & &
\end{tabular}

Figure S4. IR spectrum of ${ }^{15} \mathrm{NF}_{3}$ in excess neon $(0.1 \%)$ at $4.2 \mathrm{~K}$. 

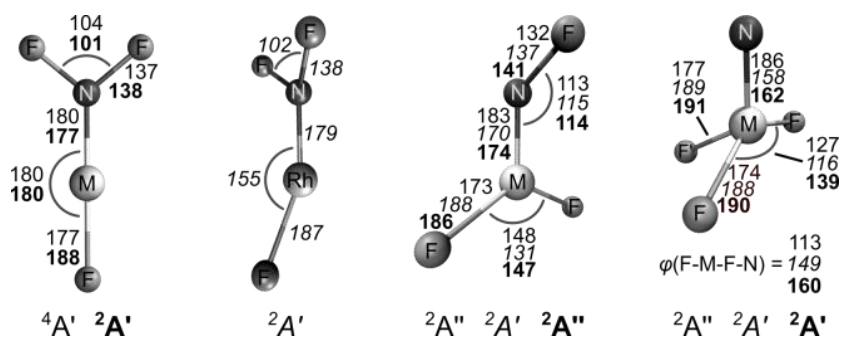

Figure S5. Molecular structures and electronic ground state symbols calculated at the B3LYP level of theory. Bond lengths in pm and angles in degree ( $\varphi$ denotes the dihedral angle of F-M-F-N). Values for M = Co (normal), Rh (italic) and Ir (bold).

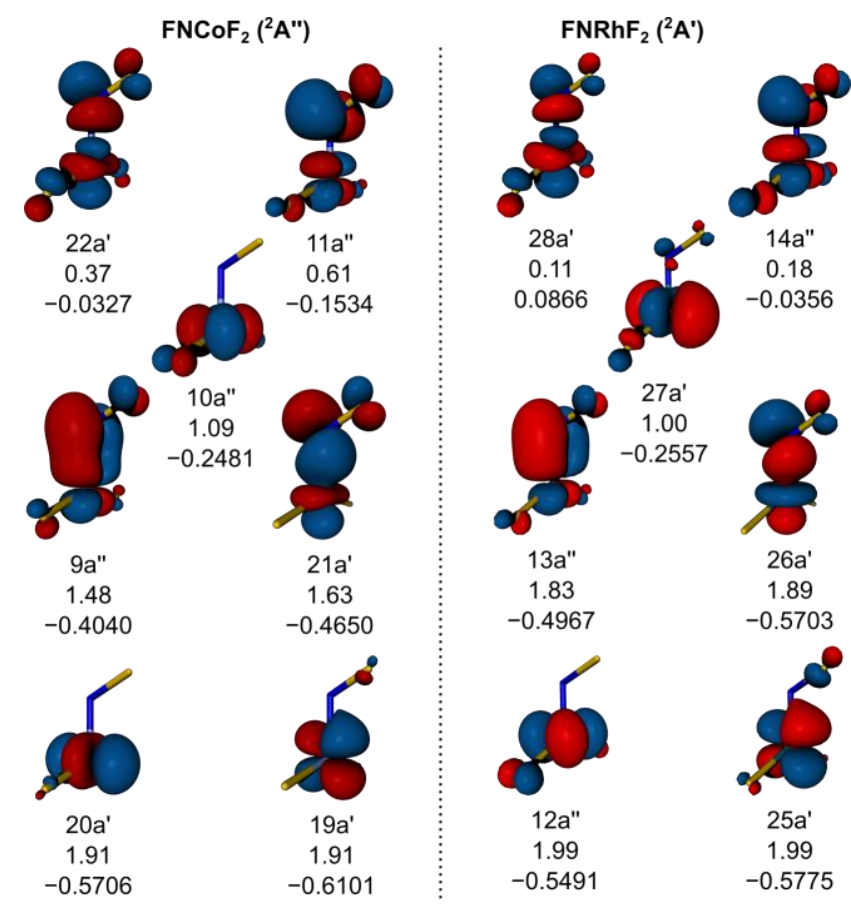

Figure S6. Natural frontier molecular orbitals (isovalue 0.05 a.u.) of $\mathrm{FNCoF}_{2}$ (left) and $\mathrm{FNRhF}_{2}$ (right) calculated at the CASSCF $(9,7) / c c-p V T Z-D K$ level of theory, including irreps, occupation numbers and orbital energies.

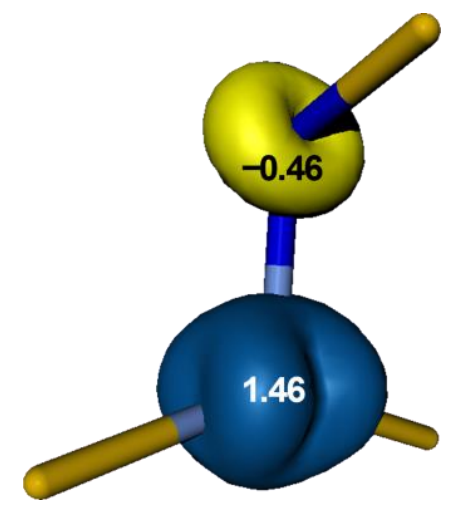

Figure S7. Spin density plot (isovalue 0.03 a.u.) of $\mathrm{FNCoF}_{2}$ calculated at the CASSCF(9,7)/cc-pVTZ-DK level of theory. 

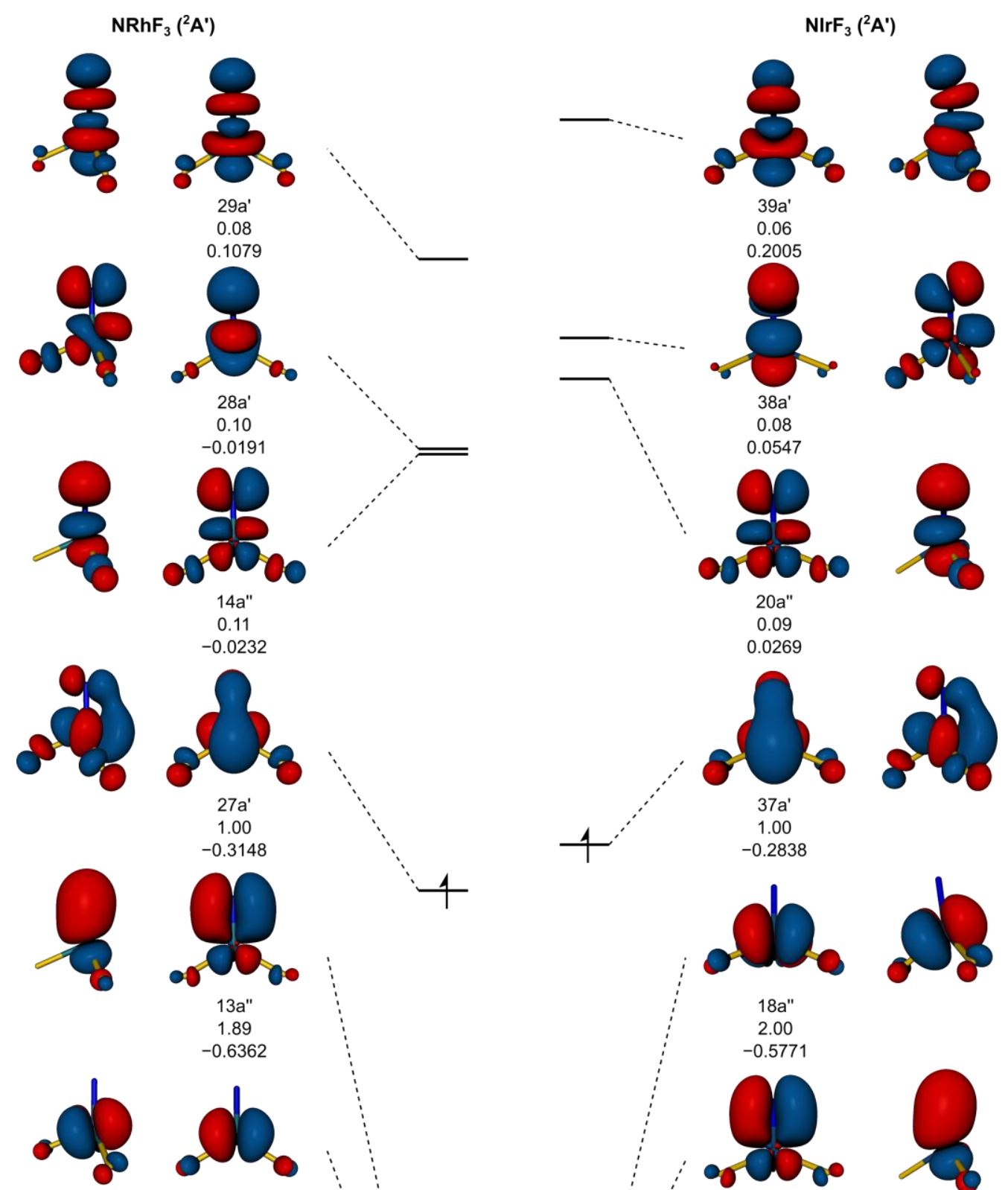

12a"

2.00

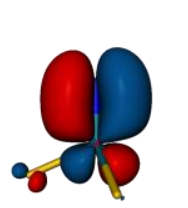

$$
-0.6573
$$
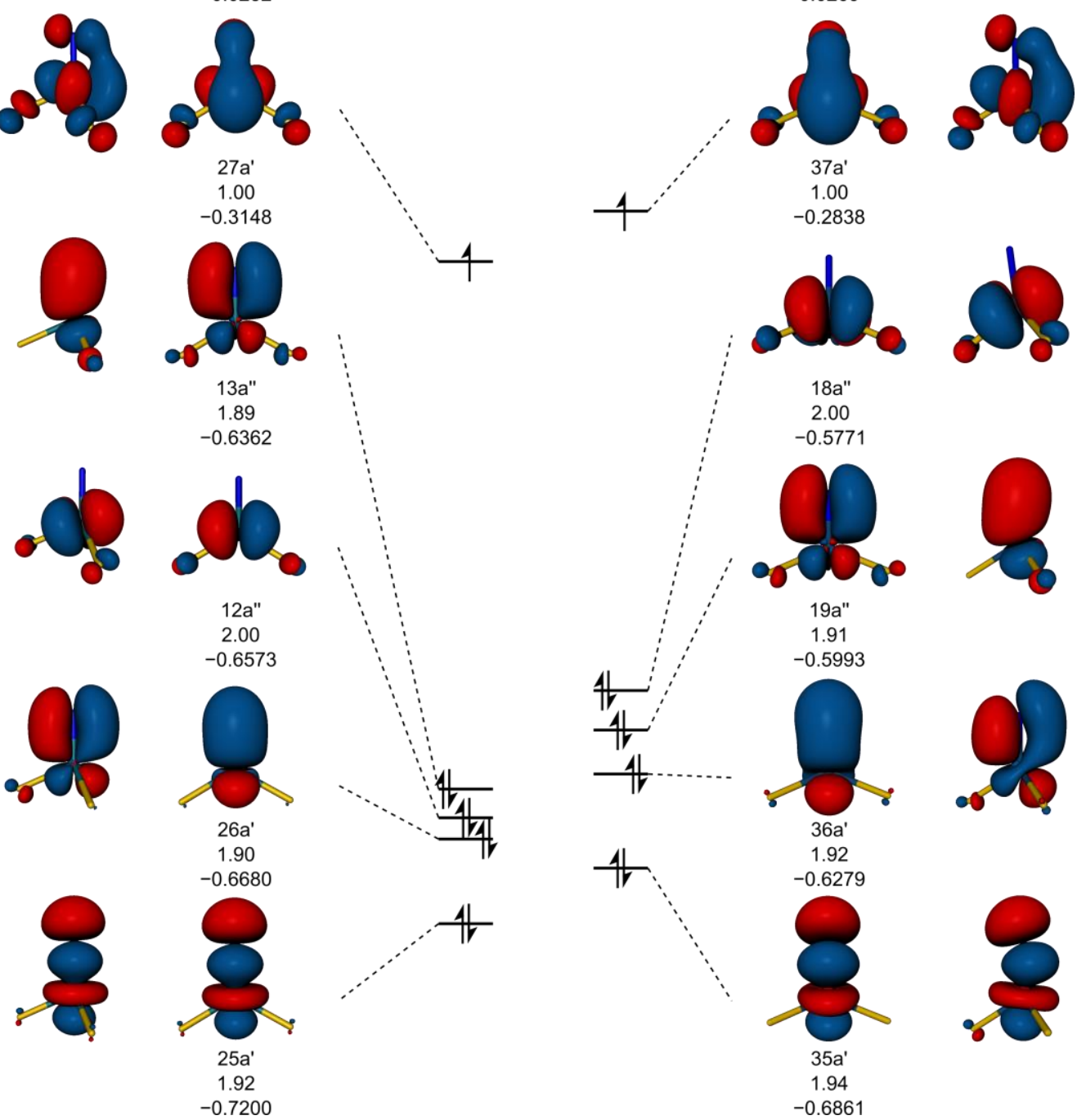

18a"

2.00
-0.5771
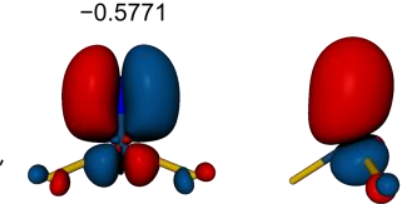

19a"

1.91

$-0.5993$
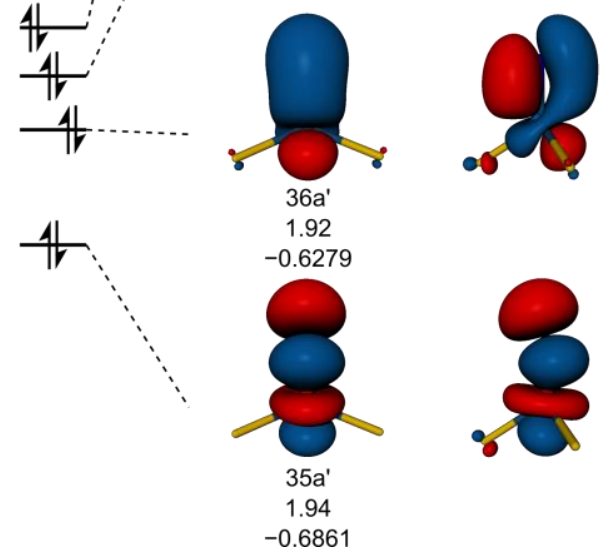

Figure S8. MO diagram of the active space natural molecular orbitals, irreproducible representations, occupation numbers and orbital energies of $\mathrm{NRhF}_{3}$ (left) and $\mathrm{NlrF}_{3}$ (right) calculated at the CASSCF $(9,8) / \mathrm{cc}$-pVTZ-DK level of theory at the B3LYP/def2-QZVP optimized ground state structures. 


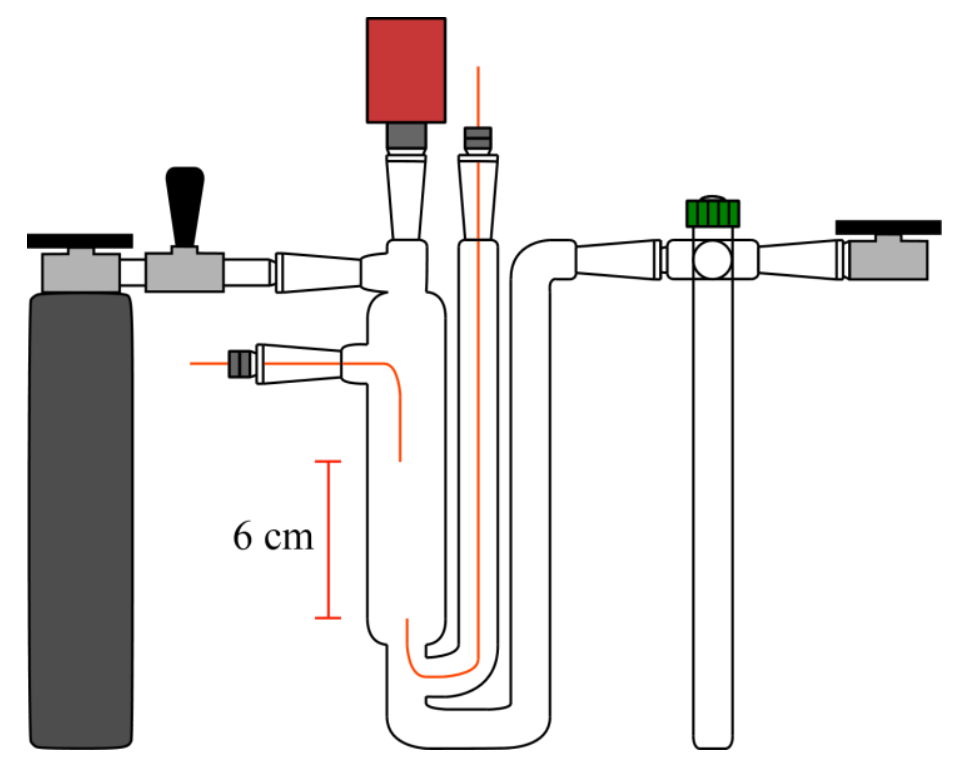

Figure S9. Electric discharge cell attached with a stainless-steel cylinder containing premixed ${ }^{15} \mathrm{~N}_{2}$ and $\mathrm{F}_{2}$ (left) and a dried glass for the final product (right).

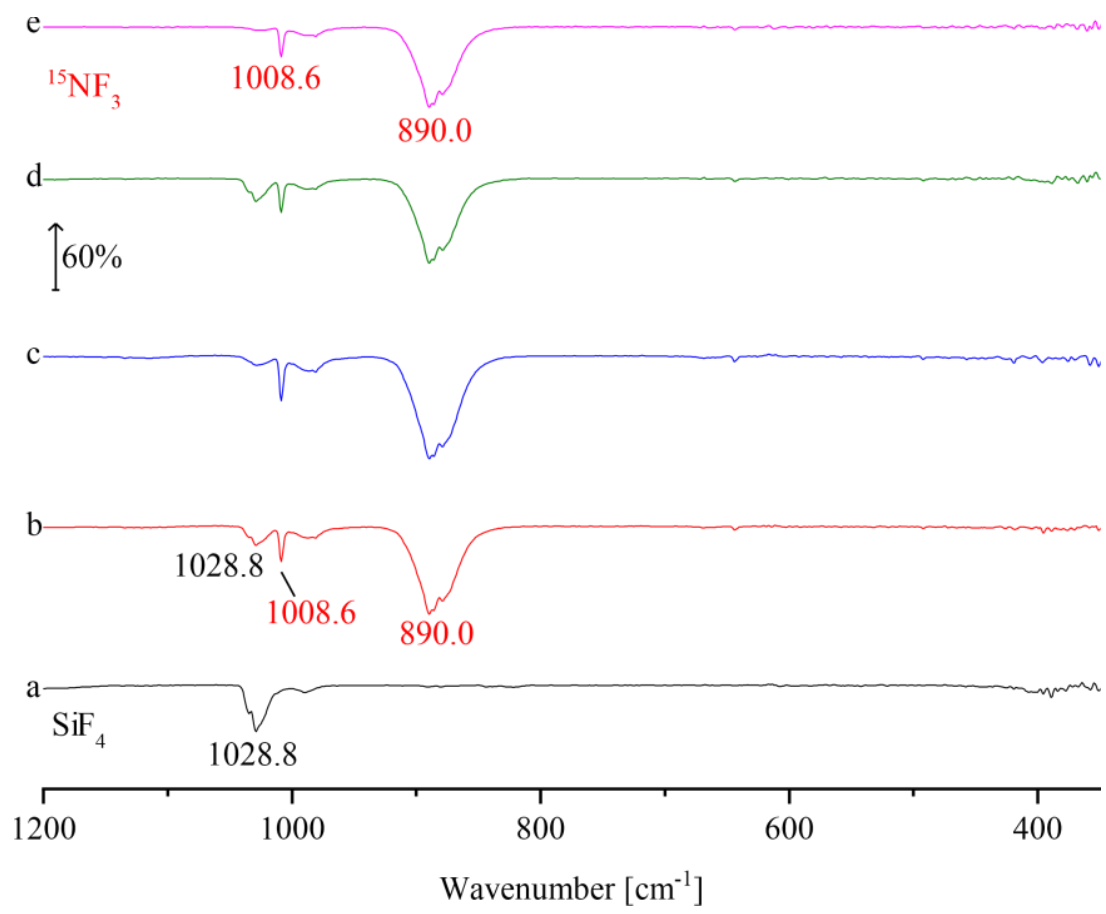

Figure S10. Gas phase IR spectra of the most volatile components of crude product during the purification process of ${ }^{15} \mathrm{NF}_{3}$ by gradually reducing the pressure to $10^{-3} \mathrm{mbar}(\mathrm{e})$. 


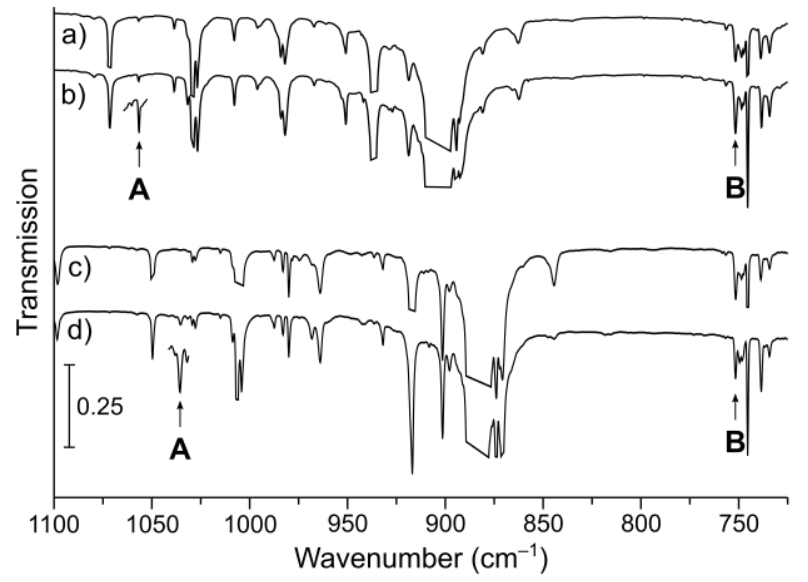

Figure S11. Infrared transmission spectra in the $1100-725 \mathrm{~cm}^{-1}$ region after co-depositing laser-ablated cobalt atoms with $0.1 \%{ }^{14} \mathrm{NF}_{3}(\mathrm{a})$, with ${ }^{14} \mathrm{NF}_{3}$ after annealing to $10 \mathrm{~K}$ (b) as well as with ${ }^{15} \mathrm{NF}_{3}$ (c), with subsequent annealing to $10 \mathrm{~K}$ (d). The absorption bands belonging to the F-N stretching mode and antisymmetric F-Co-F stretching mode are labeled $\mathbf{A}$ and $\mathbf{B}$, respectively.

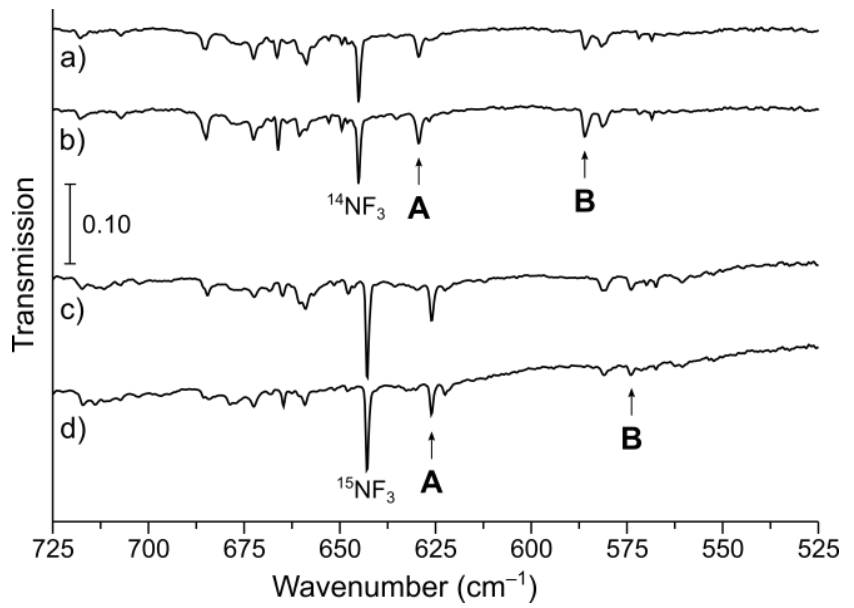

Figure S12. Infrared transmission spectra in the $725-525 \mathrm{~cm}^{-1}$ region after co-depositing laser-ablated cobalt atoms with $0.1 \%{ }^{14} \mathrm{NF}_{3}(\mathrm{a})$, with ${ }^{14} \mathrm{NF}_{3}$ after annealing to $10 \mathrm{~K}$ (b) as well as with ${ }^{15} \mathrm{NF}_{3}$ (c), with subsequent annealing to $10 \mathrm{~K}$ (d). The absorption bands belonging to the symmetric F-Co-F stretching mode and Co-N stretching mode are labeled $\mathbf{A}$ and $\mathbf{B}$, respectively. 


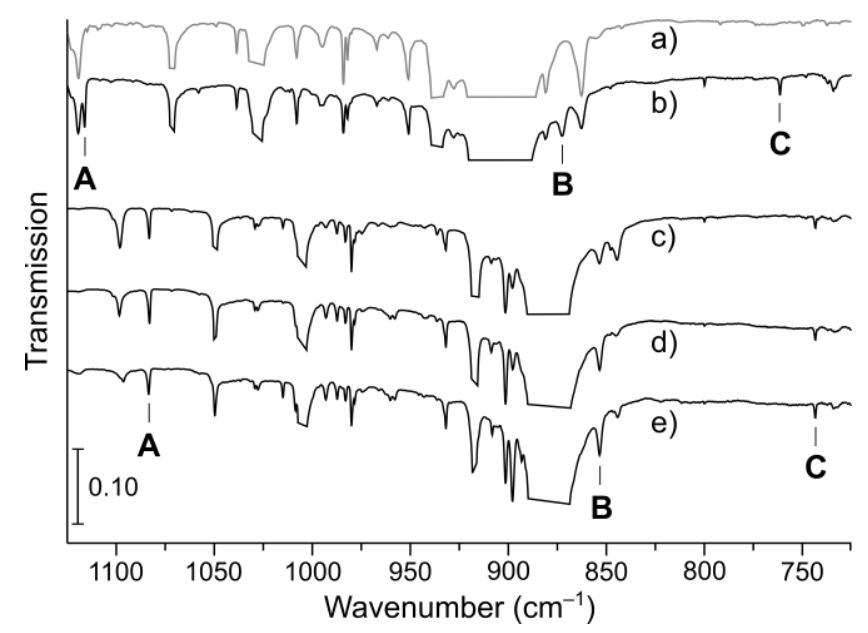

Figure S13. Infrared transmission spectra in the $1125-725 \mathrm{~cm}^{-1}$ region after co-depositing laser-ablated iridium atoms with $0.1 \%{ }^{14} \mathrm{NF}_{3}$ (a), co-depositing rhodium with ${ }^{14} \mathrm{NF}_{3}$ (b) as well as ${ }^{15} \mathrm{NF}_{3}$ (c), with subsequent full-arc photolysis (d) and annealing to $12 \mathrm{~K}(\mathrm{e})$. The absorption bands belonging to the $\mathrm{N}-\mathrm{Rh}$ stretching mode of $\mathrm{NRhF}_{3}, \mathrm{Rh}-\mathrm{N}-\mathrm{F}$ stretching mode and to the symmetric Rh-N-F stretching mode are labeled $\mathbf{A}, \mathbf{B}$ and $\mathbf{C}$. For the sake of clearity, some very strong $\mathrm{NF}_{3}$ absorption bands were cropped.

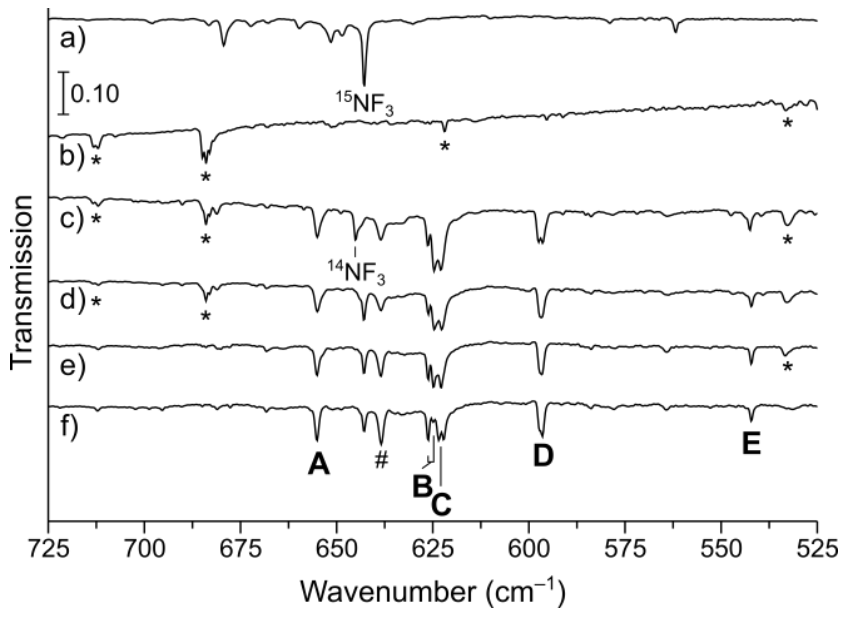

Figure S14. Infrared transmission spectra in the $725-525 \mathrm{~cm}^{-1}$ region after co-depositing laser-ablated iridium atoms with $0.1 \%{ }^{15} \mathrm{NF}_{3}(\mathrm{a})$, co-depositing rhodium with $0.1 \% \mathrm{~F}_{2}(\mathrm{~b})$, with $0.1 \%{ }^{14} \mathrm{NF}_{3}(\mathrm{c})$, with $0.1 \%{ }^{15} \mathrm{NF}_{3}$ (d), after full arc photolysis (e) and annealing to $12 \mathrm{~K}(\mathrm{f})$. The absorption bands belonging to the antisymmetric and symmetric F-Rh-F stretching mode of $\mathrm{FNRhF}_{2}$ are labeled with $\mathbf{A}$ and $\mathbf{D}$. The absorption bands stemming from the antisymmetric and symmetric $\mathrm{F}-\mathrm{Rh}-\mathrm{F}$ stretching, as well as the $\mathrm{F}^{\prime}-\mathrm{Rh}$ stretching mode of $\mathrm{NRhF}_{3}$ are labeled with $\mathbf{B}, \mathbf{C}$ and $\mathbf{E}$, respectively. Bands marked with asterisks are assigned to rhodium fluorides. 

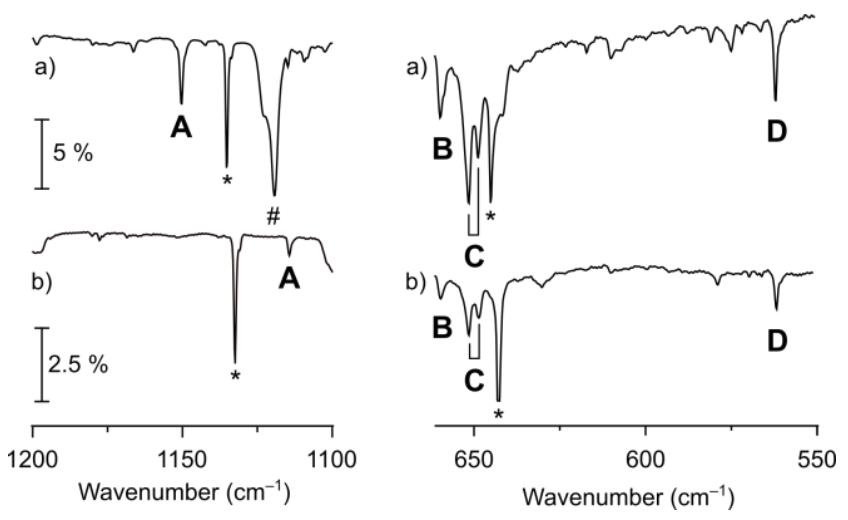

Figure S15. Infrared transmission spectra in the $1200-1100 \mathrm{~cm}^{-1}$ (left) and $660-550 \mathrm{~cm}^{-1}$ (right) region from co-deposition of laser-ablated iridium atoms with $0.1 \%{ }^{14} \mathrm{NF}_{3}$ (a) and $0.1 \%{ }^{15} \mathrm{NF}_{3}$ in neon. Bands highlighted. Labels $\mathbf{A}, \mathbf{B}, \mathbf{C}$ and $\mathbf{D}$ denote the absorption bands of $\mathrm{NIrF}_{3}$. Namely, the Ir-N stretching mode, the symmetric F-Ir-F stretching mode, the antisymmetric F-Ir-F stretching mode and the Ir-F' stretching mode, respectively. Labels * and \# denote absorptions bands from $\mathrm{NF}_{3}$ and $\mathrm{NF}$, respectively.

\section{Supporting Tables}

Table S1. Reaction enthalpies at $T=0$ for reactions of formation and selected decomposition reactions obtained at the B3LYP and BP86 level of theory. All complexes in Cs point group symmetry, unless stated otherwise.

\begin{tabular}{|c|c|c|c|}
\hline \multirow{2}{*}{ Reaction } & & \multicolumn{2}{|c|}{$\Delta H^{0}\left[\mathrm{~kJ} \mathrm{~mol}{ }^{-1}\right]$} \\
\hline & & B3LYP & BP86 \\
\hline $\mathrm{Co}+\mathrm{NF}_{3}\left({ }^{1} \mathrm{~A}_{1}\right)$ & $\rightarrow \mathrm{F}_{2} \mathrm{NCoF}\left({ }^{4} \mathrm{~A}_{2}-\mathrm{C}_{2 \mathrm{v}}\right)$ & -470 & -441 \\
\hline $\mathrm{F}_{2} \mathrm{NCoF}\left({ }^{4} \mathrm{~A}_{2}-\mathrm{C}_{2 \mathrm{v}}\right)$ & $\rightarrow \mathrm{FNCoF}_{2}\left({ }^{2} \mathrm{~A} "\right)$ & -92 & -158 \\
\hline $\mathrm{FNCoF}_{2}\left({ }^{2} \mathrm{~A} "\right)$ & $\rightarrow \mathrm{NCoF}_{3}\left({ }^{2} \mathrm{~A}^{\prime \prime}\right)$ & 77 & 47 \\
\hline $\mathrm{FNCoF}_{2}\left({ }^{2} \mathrm{~A} "\right)$ & $\rightarrow \mathrm{NCoF}_{2}\left({ }^{1} \mathrm{~A}_{1}-\mathrm{C}_{2 \mathrm{v}}\right)+\mathrm{F}$ & 331 & 290 \\
\hline $\mathrm{FNCoF}_{2}\left({ }^{2} \mathrm{~A} "\right)$ & $\rightarrow \mathrm{NCoF}_{2}\left({ }^{3} \mathrm{~B}_{1}-\mathrm{C}_{2 \mathrm{v}}\right)+\mathrm{F}$ & 311 & 315 \\
\hline $\mathrm{FNCoF}_{2}\left({ }^{2} \mathrm{~A} "\right)$ & $\rightarrow \mathrm{NCoF}_{2}\left({ }^{1} \mathrm{~A}_{1}-\mathrm{C}_{2 \mathrm{v}}\right)+1 / 2 \mathrm{~F}_{2}$ & 258 & 187 \\
\hline $\mathrm{FNCoF}_{2}\left({ }^{2} \mathrm{~A} "\right)$ & $\rightarrow \mathrm{NCoF}_{2}\left({ }^{3} \mathrm{~B}_{1}-\mathrm{C}_{2 \mathrm{v}}\right)+1 / 2 \mathrm{~F}_{2}$ & 238 & 212 \\
\hline $\mathrm{FNCoF}_{2}\left({ }^{2} \mathrm{~A} "\right)$ & $\rightarrow \mathrm{NCoF}\left({ }^{4} \mathrm{~A}^{\prime \prime}\right)+\mathrm{F}_{2}$ & 522 & 533 \\
\hline $\mathrm{FNCoF}_{2}\left({ }^{2} \mathrm{~A} "\right)$ & $\rightarrow \mathrm{NCoF}\left({ }^{2} \mathrm{~A}^{\prime}\right)+\mathrm{F}_{2}$ & 522 & 493 \\
\hline $\mathrm{Rh}+\mathrm{NF}_{3}\left({ }^{1} \mathrm{~A}_{1}\right)$ & $\rightarrow \mathrm{F}_{2} \mathrm{NRhF}\left({ }^{2} \mathrm{~A}^{\prime}\right)$ & -356 & -413 \\
\hline $\mathrm{F}_{2} \mathrm{NRhF}\left({ }^{2} \mathrm{~A}^{\prime}\right)$ & $\rightarrow \mathrm{FNRhF}_{2}\left({ }^{2} \mathrm{~A}^{\prime}\right)$ & -136 & -155 \\
\hline $\mathrm{FNRhF}_{2}\left({ }^{2} \mathrm{~A}^{\prime}\right)$ & $\rightarrow \mathrm{NRhF}_{3}\left({ }^{2} \mathrm{~A}^{\prime}\right)^{\text {a) }}$ & -7 & -26 \\
\hline $\mathrm{NRhF}_{3}\left({ }^{2} \mathrm{~A}^{\prime}\right)$ & $\rightarrow \mathrm{NRhF}_{2}\left({ }^{1} \mathrm{~A}_{1}-\mathrm{C}_{2 \mathrm{v}}\right)+\mathrm{F}$ & 168 & 221 \\
\hline $\mathrm{NRhF}_{3}\left({ }^{2} \mathrm{~A}^{\prime}\right)$ & $\rightarrow \mathrm{NRhF}_{2}\left({ }^{1} \mathrm{~A}_{1}-\mathrm{C}_{2 \mathrm{v}}\right)+1 / 2 \mathrm{~F}$ & 95 & 118 \\
\hline $\mathrm{NRhF}_{3}\left({ }^{2} \mathrm{~A}^{\prime}\right)$ & $\rightarrow \mathrm{NRhF}\left({ }^{2} \mathrm{~A}^{\prime}\right)+\mathrm{F}_{2}$ & 386 & 423 \\
\hline $\mathrm{Ir}+\mathrm{NF}_{3}\left({ }^{1} \mathrm{~A}_{1}\right)$ & $\rightarrow \mathrm{F}_{2} \mathrm{NIrF}\left({ }^{2} A^{\prime}\right)$ & -460 & -509 \\
\hline $\mathrm{F}_{2} \mathrm{NlrF}\left({ }^{2} \mathrm{~A}^{\prime}\right)$ & $\rightarrow \mathrm{FNIrF}_{2}\left({ }^{2} \mathrm{~A}^{\prime \prime}\right)$ & -186 & -201 \\
\hline $\mathrm{FNIrF}_{2}\left({ }^{2} \mathrm{~A}^{\prime \prime}\right)$ & $\rightarrow \mathrm{NIrF}_{3}\left({ }^{2} A^{\prime}\right)^{\mathrm{b})}$ & -81 & -77 \\
\hline $\mathrm{NlrF}_{3}\left({ }^{2} \mathrm{~A}^{\prime}\right)$ & $\rightarrow \mathrm{NlrF}_{2}\left({ }^{1} \mathrm{~A}_{1}\right)+\mathrm{F}$ & 197 & 240 \\
\hline $\mathrm{NlrF}_{3}\left({ }^{2} A^{\prime}\right)$ & $\rightarrow \mathrm{NlrF}_{2}\left({ }^{1} \mathrm{~A}_{1}\right)+1 / 2 \mathrm{~F}$ & 248 & 274 \\
\hline $\mathrm{NlrF}_{3}\left({ }^{2} A^{\prime}\right)$ & $\rightarrow \operatorname{NIrF}\left({ }^{2} A^{\prime}\right)+F_{2}$ & 444 & 468 \\
\hline
\end{tabular}

a): $\operatorname{CCSD}(\mathrm{T})$ at $\mathrm{B} 3 \mathrm{LYP}$ minimum: $\Delta H^{0}=-12 \mathrm{~kJ} \mathrm{~mol}^{-1}$; b): $\operatorname{CCSD}(\mathrm{T})$ at $\mathrm{B} 3 \mathrm{LYP}$ minimum: $\Delta H^{0}=$ $-98 \mathrm{~kJ} \mathrm{~mol}^{-1}$ 


\begin{tabular}{lcccc}
\multicolumn{5}{c}{ Table S2. Assignments of IR absorptions of $0.1 \%{ }^{15} \mathrm{NF}_{3}$ isolated in solid neon (Figure S2). } \\
\hline Assignment & Frequency [cm $\left.{ }^{-1}\right]$ & Intensity & Isotopic Shift [cm $\left.{ }^{-1}\right]$ & Lit. $^{[14]}$ \\
\hline $\mathrm{V}_{1}+\mathrm{V}_{3}$ & 1879.1 & $\mathrm{~m}$ & - \\
$2 \mathrm{v}_{3}$ & 1756.7 & $\mathrm{~m}$ & - \\
$\mathrm{V}_{2}+\mathrm{V}_{3}$ & 1517.5 & $\mathrm{~W}$ & - \\
$\mathrm{V}_{1}+\mathrm{V}_{4}$ & 1496.3 & $\mathrm{~W}$ & - \\
$2 \mathrm{~V}_{2}$ & 1277.4 & $\mathrm{~m}$ & & - \\
$\mathrm{V}_{2}+\mathrm{V}_{4}$ & 1132.3 & $\mathrm{~m}$ & -22.9 & - \\
$\mathrm{V}_{1}$ & 1006.2 & $\mathrm{~S}$ & & 1008.9 \\
$2 \mathrm{v}_{4}$ & 979.7 & $\mathrm{~m}$ & 981.9 \\
$\mathrm{~V}_{3}$ & 879.9 & $\mathrm{vs}$ & -21.5 & 886.3 \\
$\mathrm{~V}_{2}$ & 642.7 & $\mathrm{~m}$ & & 644.8 \\
$\mathrm{~V}_{4}$ & 491.6 & $\mathrm{~m}$ & 492.0 \\
\hline
\end{tabular}

Table S3. Selected structural parameters calculated at various levels of theory for $F N M N F_{2}(M=C o, R h)$ species. Bond lengths in pm, angles in degrees.

\begin{tabular}{|c|c|c|c|c|c|c|c|c|c|c|}
\hline \multirow[b]{2}{*}{ Method } & \multicolumn{2}{|c|}{$r(F N)$} & \multicolumn{2}{|c|}{$r(N M)$} & \multicolumn{2}{|c|}{$r(M F)$} & \multicolumn{2}{|c|}{$a(F N M)$} & \multicolumn{2}{|c|}{$a(F M F)$} \\
\hline & $\mathrm{FNCoF}_{2}$ & $\mathrm{FNRhF}_{2}$ & $\mathrm{FNCoF}_{2}$ & $\mathrm{FNRhF}_{2}$ & $\mathrm{FNCoF}_{2}$ & $\mathrm{FNRhF}_{2}$ & $\mathrm{FNCoF}_{2}$ & $\mathrm{FNRhF}_{2}$ & $\mathrm{FNCoF}_{2}$ & $\mathrm{FNRhF}_{2}$ \\
\hline CASPT2 & 131 & 135 & 177 & 174 & 171 & 186 & 113 & 113 & 148 & 135 \\
\hline B3LYP & 132 & 137 & 183 & 170 & 173 & 188 & 113 & 115 & 148 & 131 \\
\hline BP86 a) & 138 & 142 & 162 & 172 & 172 & $186 / 191$ & 115 & 117 & 133 & 131 \\
\hline
\end{tabular}

[a]: BP86 converged to a structure with $C_{1}$ point group symmetry for $\mathrm{FNRhF}_{2}$.

Table S4. Weights of the main configurations of the electronic ground states of FNCoF $2\left({ }^{2} A^{\prime \prime}, C s\right)$ and $\mathrm{FNRhF}_{2}\left({ }^{2} \mathrm{~A}^{\prime}, \mathrm{C}_{\mathrm{s}}\right)$ obtained at the CASSCF $(9,7) / \mathrm{CC}-$ pVTZ-DK level of theory.

\begin{tabular}{lc}
\hline Configurationa) & Weight [\%] \\
\hline & FNCoF $_{2}\left({ }^{2} \mathbf{A}^{\prime \prime}, \boldsymbol{C}_{\mathbf{s}}\right)$ \\
$\sigma^{2} \pi^{2} \delta^{1} \pi^{\star 0} \sigma^{\star 0}$ & 48 \\
$\sigma^{2} \pi^{0} \delta^{1} \pi^{\star 2} \sigma^{* 0}$ & 10 \\
$\sigma^{2} \pi^{1} \delta^{1} \pi^{\star 1} \sigma^{\star 2}$ & 6 \\
$\sigma^{0} \pi^{2} \delta^{1} \pi^{\star 0} \sigma^{\star 2}$ & 5 \\
$\sigma^{0} \pi^{0} \delta^{1} \pi^{\star 2} \sigma^{* 2}$ & 4 \\
$\sigma^{2} \pi^{2} \delta^{1} \pi^{* 0} \sigma^{* 0}$ & FNRhF $_{2}\left({ }^{2} \mathbf{A}^{\prime}, \boldsymbol{C}_{\mathbf{s}}\right)$ \\
$\sigma^{2} \pi^{0} \delta^{1} \pi^{\star 2} \sigma^{* 0}$ & 81 \\
\hline
\end{tabular}

[a] Approximate local symmetries are used for an ostensive description the frontier molecular orbitals along the M-N bond axis. $\sigma, \pi, \delta, \sigma^{*}, \pi^{*}$ and $\delta^{*}$ correspond to 21a', 9a", 10a", 11a" and 22a' (FNCoF ${ }_{2}$ ) and 26a', 13a", 27a', $14 a^{\prime \prime}$ and 28a' (FNRhF 2 ) (see Figure S6). 
Table S5. Comparison of infrared band positions $\left(\mathrm{cm}^{-1}\right)$ and isotopic shifts $\left(\mathrm{cm}^{-1}\right.$, in parenthesis) of FNRhF $\left.2{ }^{2} \mathrm{~A}^{\prime}-C_{\mathrm{s}}\right)$ observed in solid neon with values calculated using $\operatorname{CCSD}(\mathrm{T})$ with different basis set qualities, and CASPT2.

\begin{tabular}{|c|c|c|c|c|c|}
\hline Assignment & Neon & cc-pVDZ(-PP)a) & aug-cc-pVTZ(-PP)a) & cc-pVTZ-DKb) & CASPT2 \\
\hline F-N str. [a'] & $872.6(-18.9)$ & $893(-16)$ & $872(-16)$ & $899(-17)$ & $981(-19)$ \\
\hline N-Rh str. [a'] & $761.4(-18.0)$ & $536(-15)$ & $707(-19)$ & $720(-18)$ & $756(-20)$ \\
\hline antisym. F-Rh-F str. [a"] & $655.1(0)$ & $665(0)$ & $652(0)$ & $663(0)$ & $672(0)$ \\
\hline sym. F-Rh-F str. [a'] & $596.7(0)$ & $620(-2)$ & $580(-2)$ & $603(-2)$ & $623(-0.5)$ \\
\hline
\end{tabular}

[a]: RHF/UCCSD(T) using ECP28MDF. [b]: RHF/UCCSD(T) using DKH2 relativistic approximation.

\section{Detailed Computational Results}

All structures in $C_{\text {s }}$ point group symmetry (unless stated otherwise) and with positive HOMO-LUMO or SOMO-LUMO gap.

\section{$\mathrm{NCoF}_{3}$}

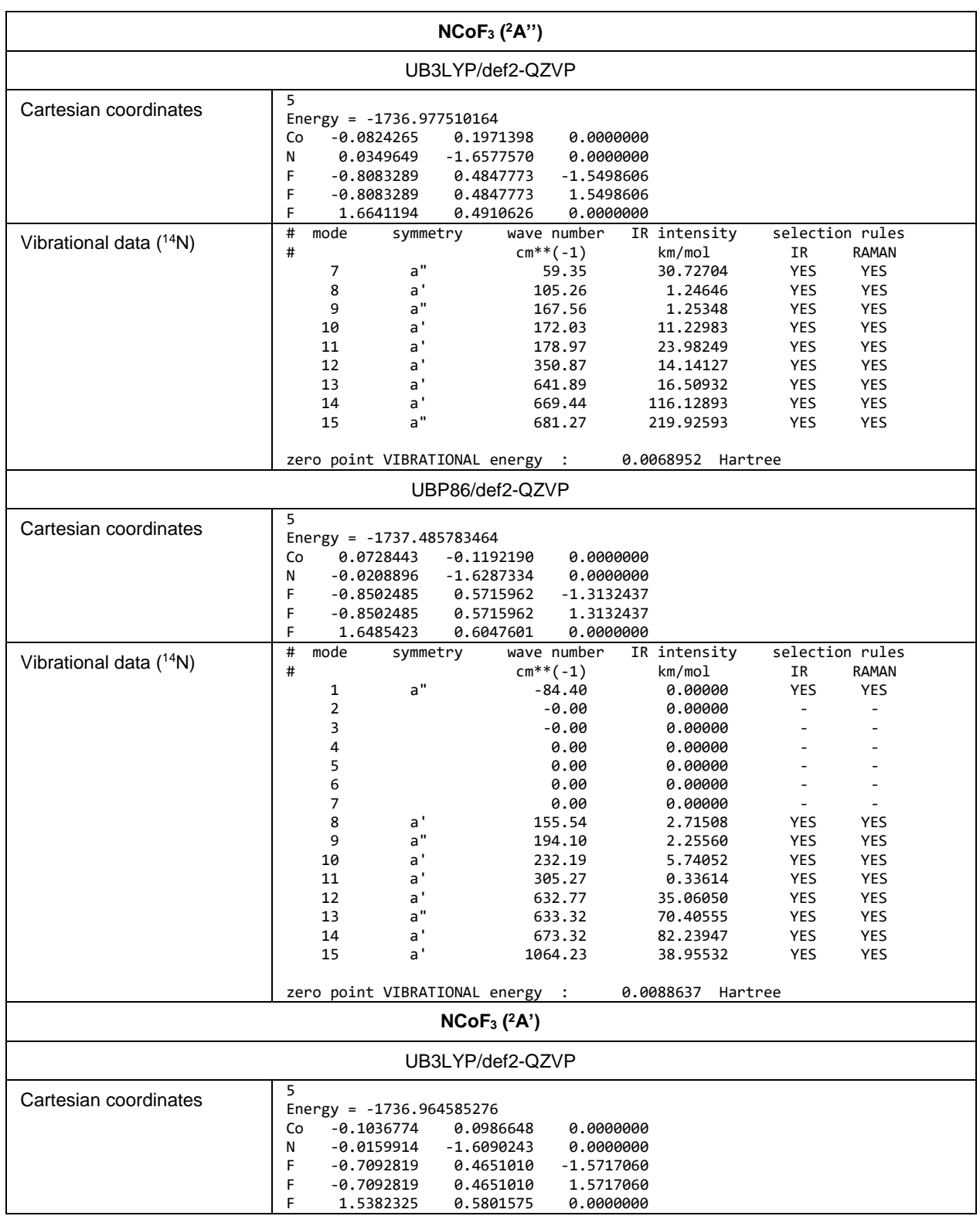


A.2. Fluoro Nitrenoid Complexes $F N=M F_{2}(M=C o, R h, I r)$ : Electronic Structure Dichotomy and Formation of Nitrido Fluorides $N \equiv \mathrm{MF}_{3}$

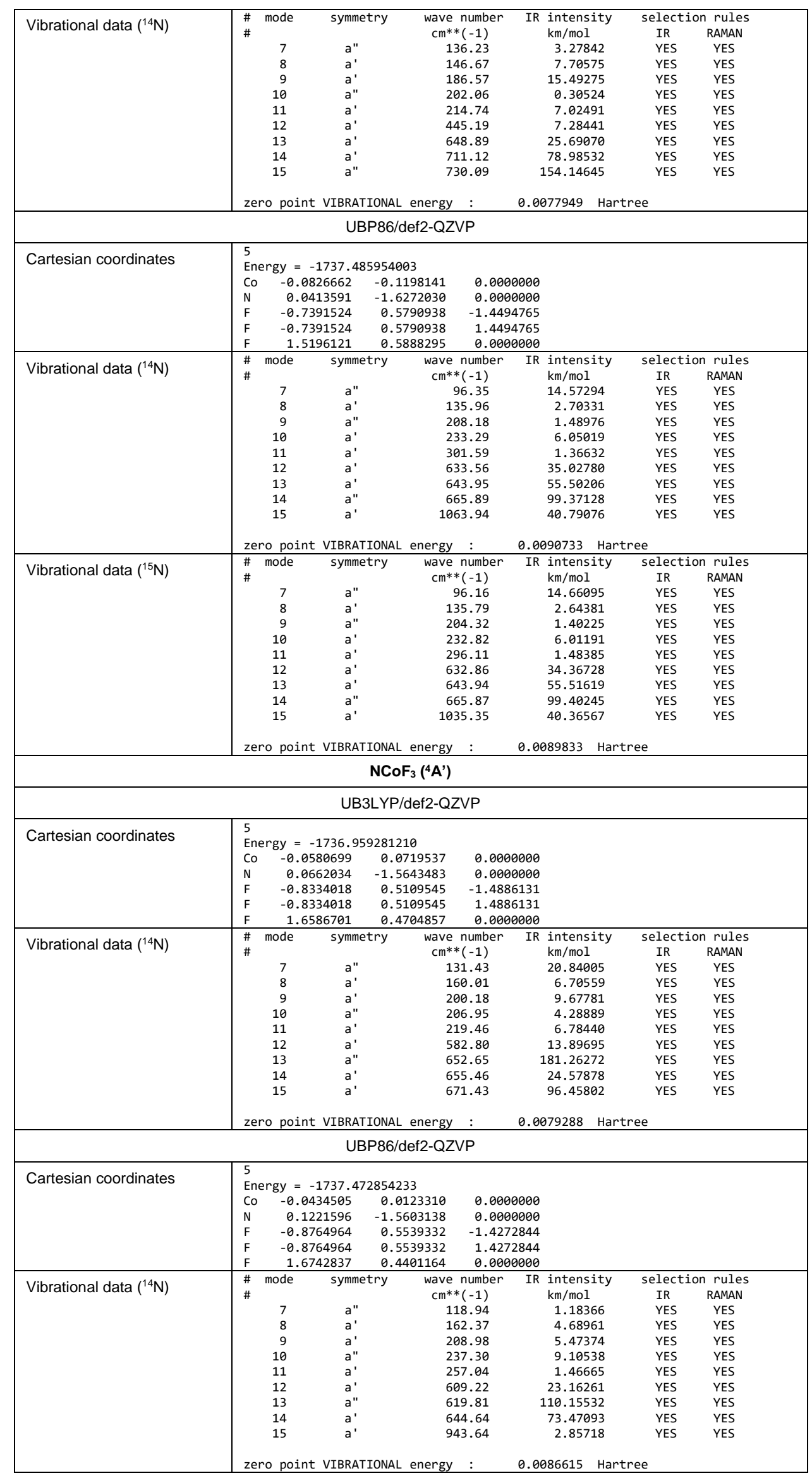


$\mathrm{FNCoF}_{\mathbf{2}}$

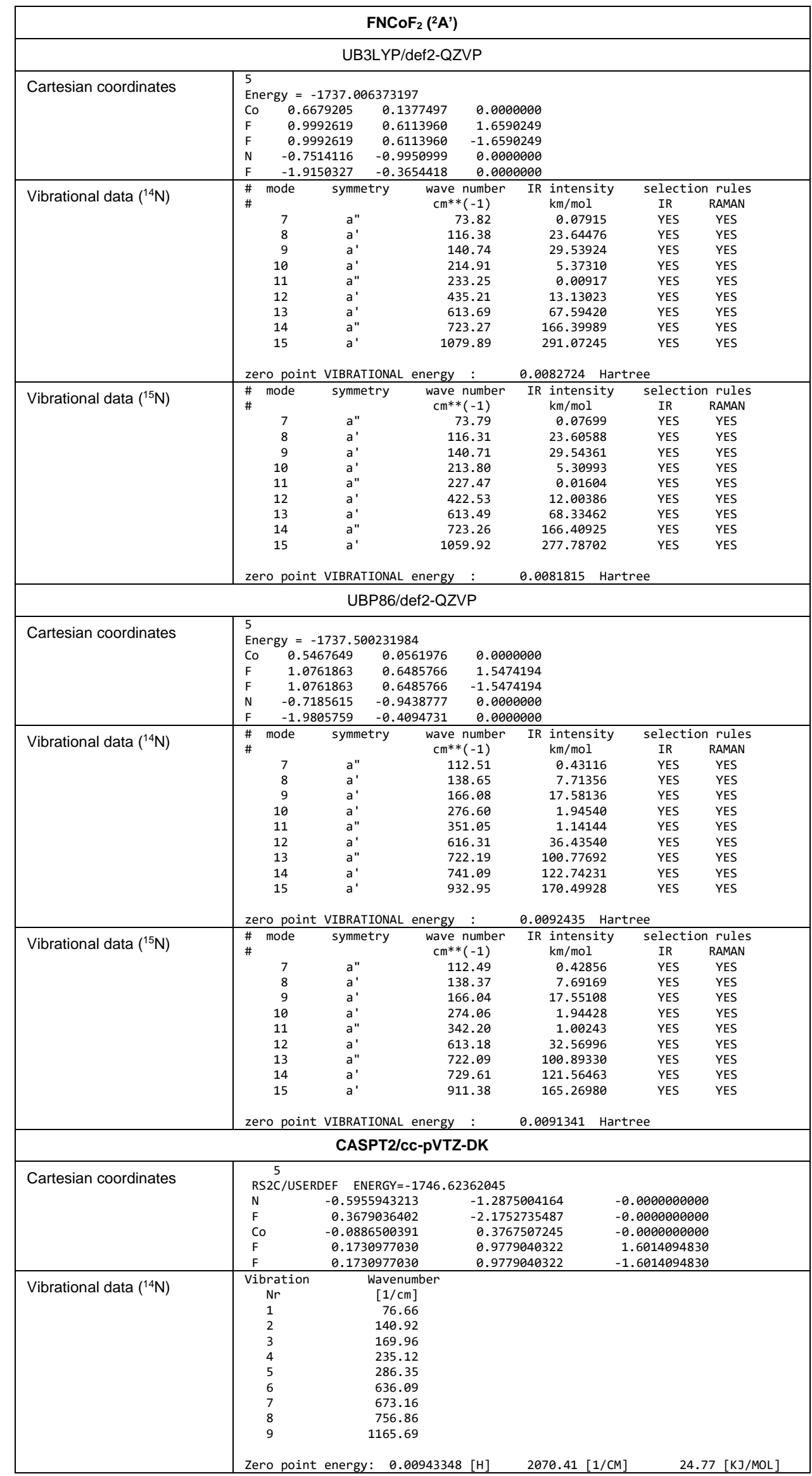


A.2. Fluoro Nitrenoid Complexes $F N=M_{2}(M=C o, R h, I r)$ : Electronic Structure Dichotomy and Formation of Nitrido Fluorides $N \equiv \mathrm{MF}_{3}$

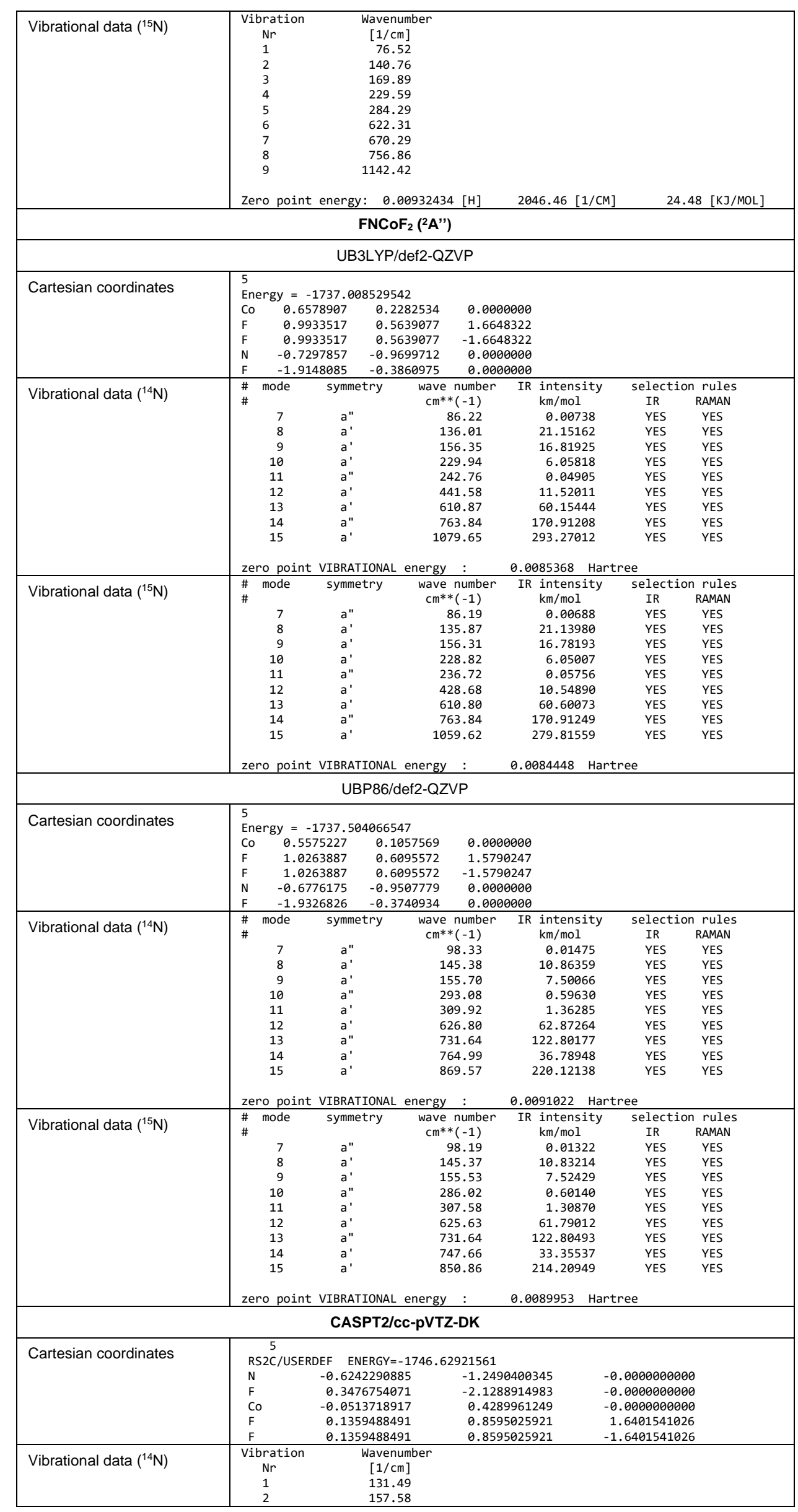




\section{A. Supporting Information of Publications}

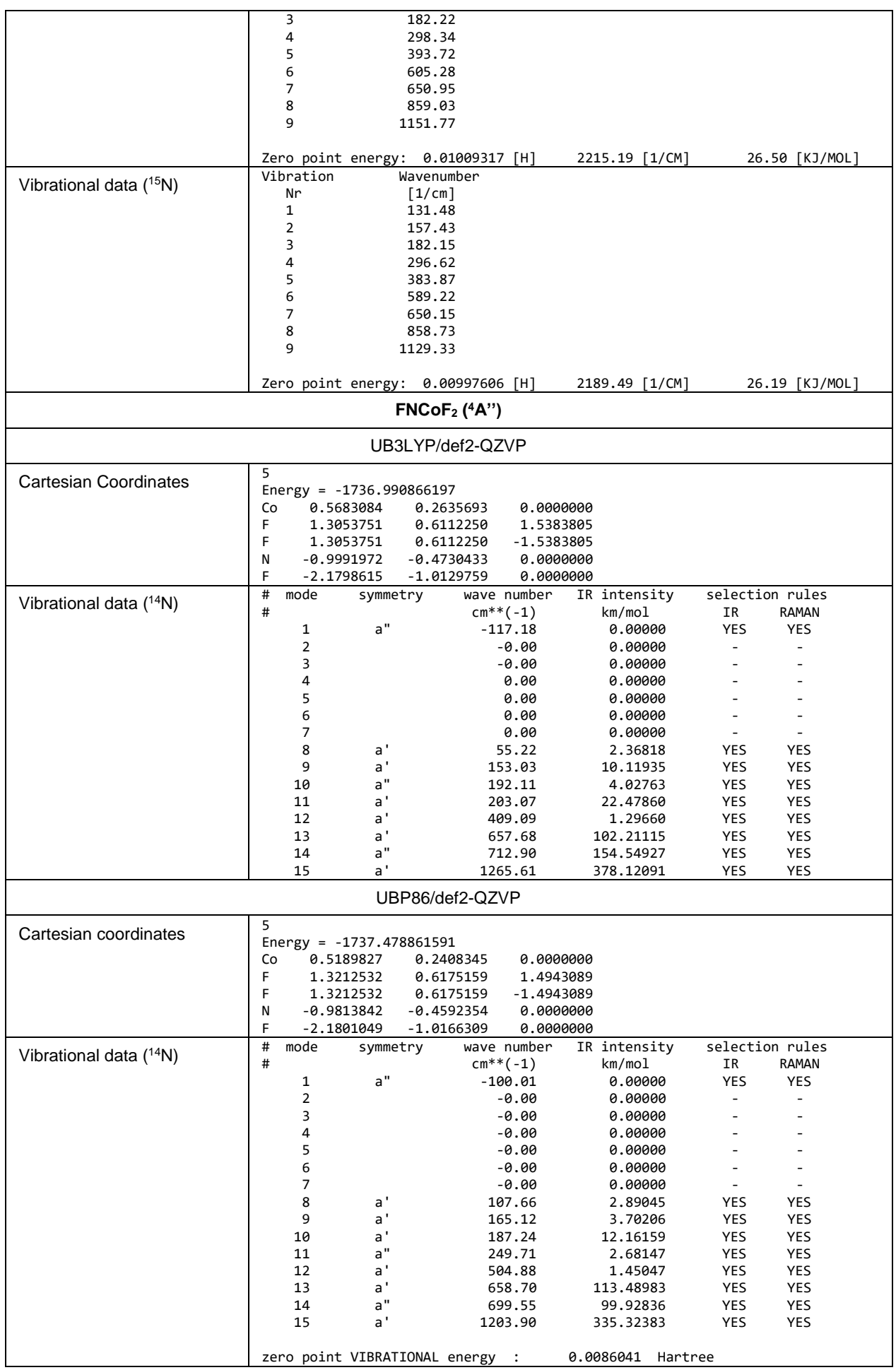

$\mathrm{F}_{2} \mathrm{NCoF}$

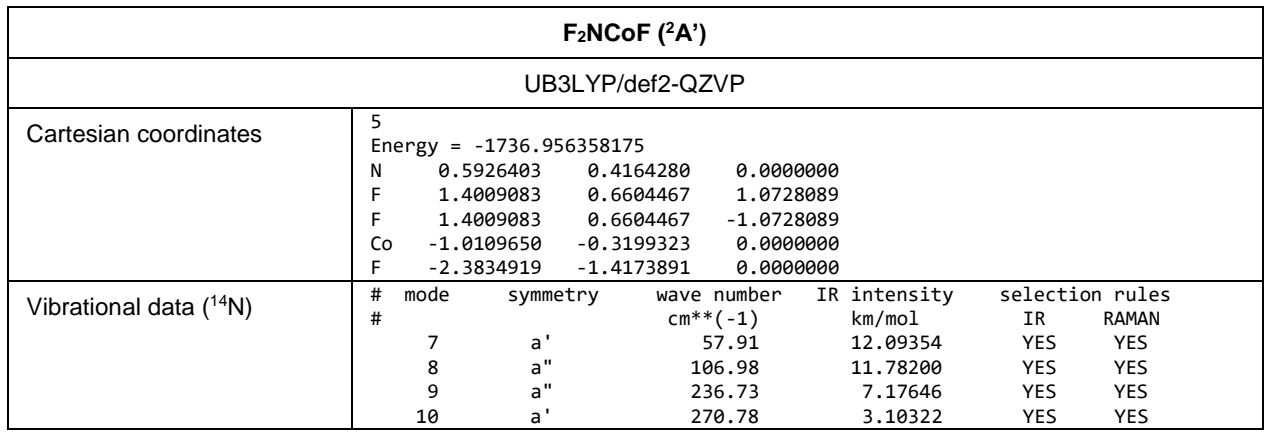


A.2. Fluoro Nitrenoid Complexes $F N=M F_{2}(M=C o, R h, I r)$ : Electronic Structure Dichotomy and Formation of Nitrido Fluorides $N \equiv \mathrm{MF}_{3}$

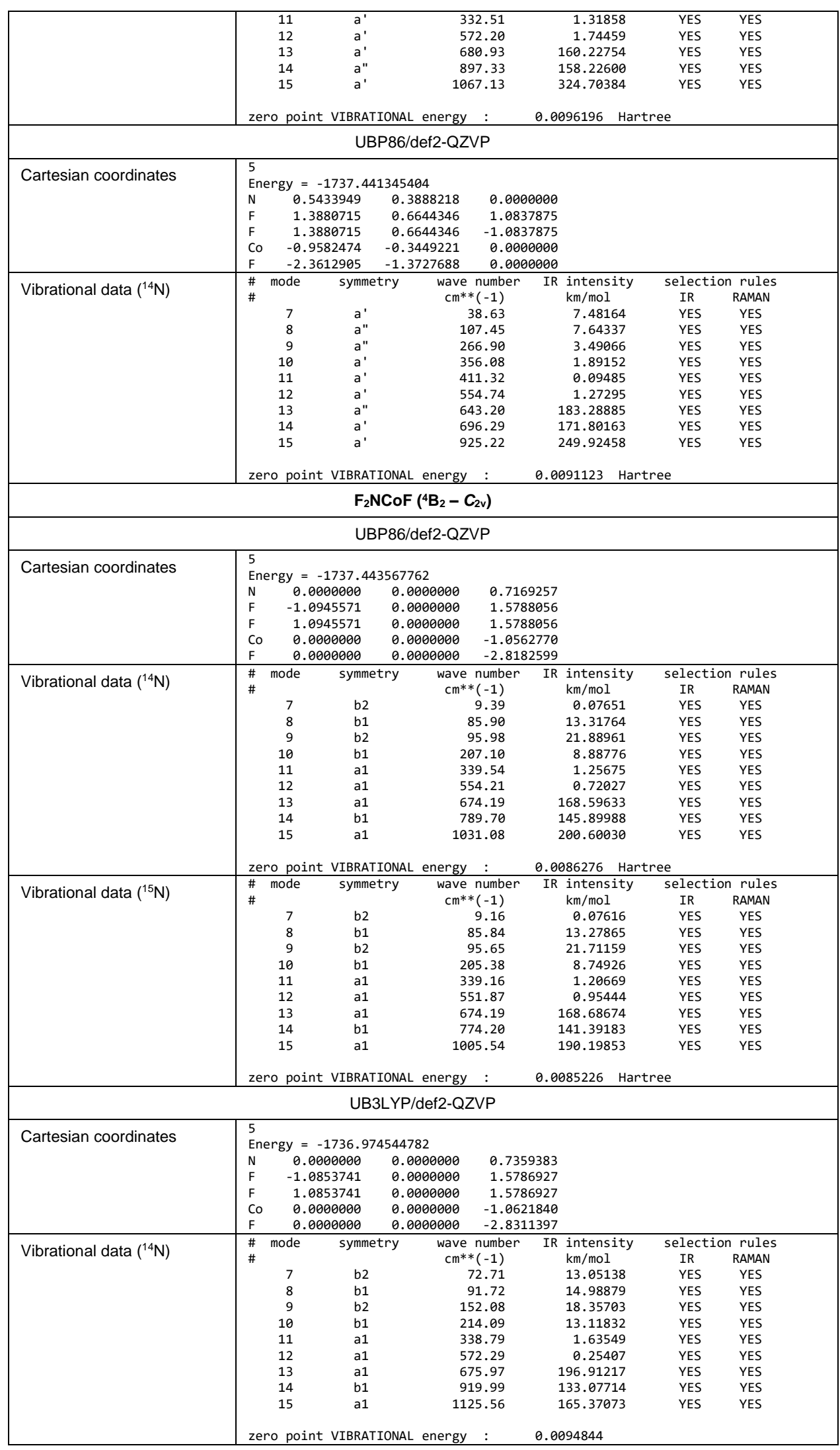

$\mathrm{NCoF}_{2}$

\begin{tabular}{|l|l|}
\hline \multicolumn{2}{|c|}{$\mathrm{NCoF}_{2}\left({ }^{1} \mathrm{~A}_{1}-\mathrm{C}_{2 \mathrm{v}}\right)$} \\
\hline \multicolumn{1}{|c|}{ UBP86/def2-QZVP } \\
\hline Cartesian coordinates & $\begin{array}{l}4 \\
\text { Energy }=-1637.617920216\end{array}$ \\
\hline
\end{tabular}




\section{A. Supporting Information of Publications}

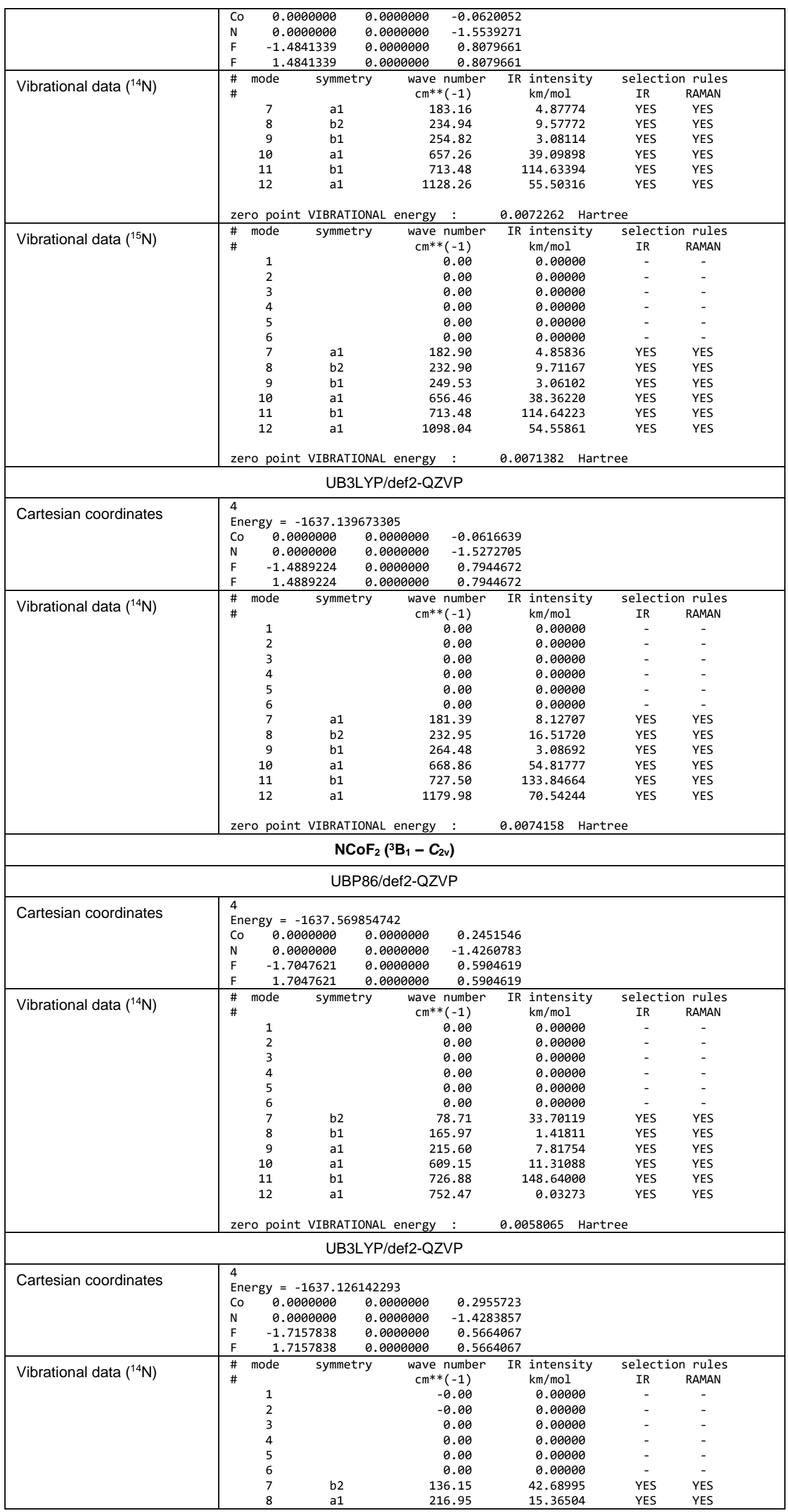


A.2. Fluoro Nitrenoid Complexes $F N=M_{2}(M=C o, R h, I r)$ : Electronic Structure Dichotomy and Formation of Nitrido Fluorides $N \equiv M_{3}$

\begin{tabular}{|l|rrrrrr|}
\hline & 9 & b1 & 238.75 & 0.00124 & YES & YES \\
& 10 & a1 & 605.58 & 7.60221 & YES & YES \\
& 11 & a 1 & 630.09 & 9.20571 & YES & YES \\
& 12 & b1 & 761.68 & 197.35444 & YES & YES \\
& & & & & \\
& zero point VIBRATIONAL energy & $:$ & 0.0058986 & Hartree & & \\
\hline
\end{tabular}

\section{NCoF}

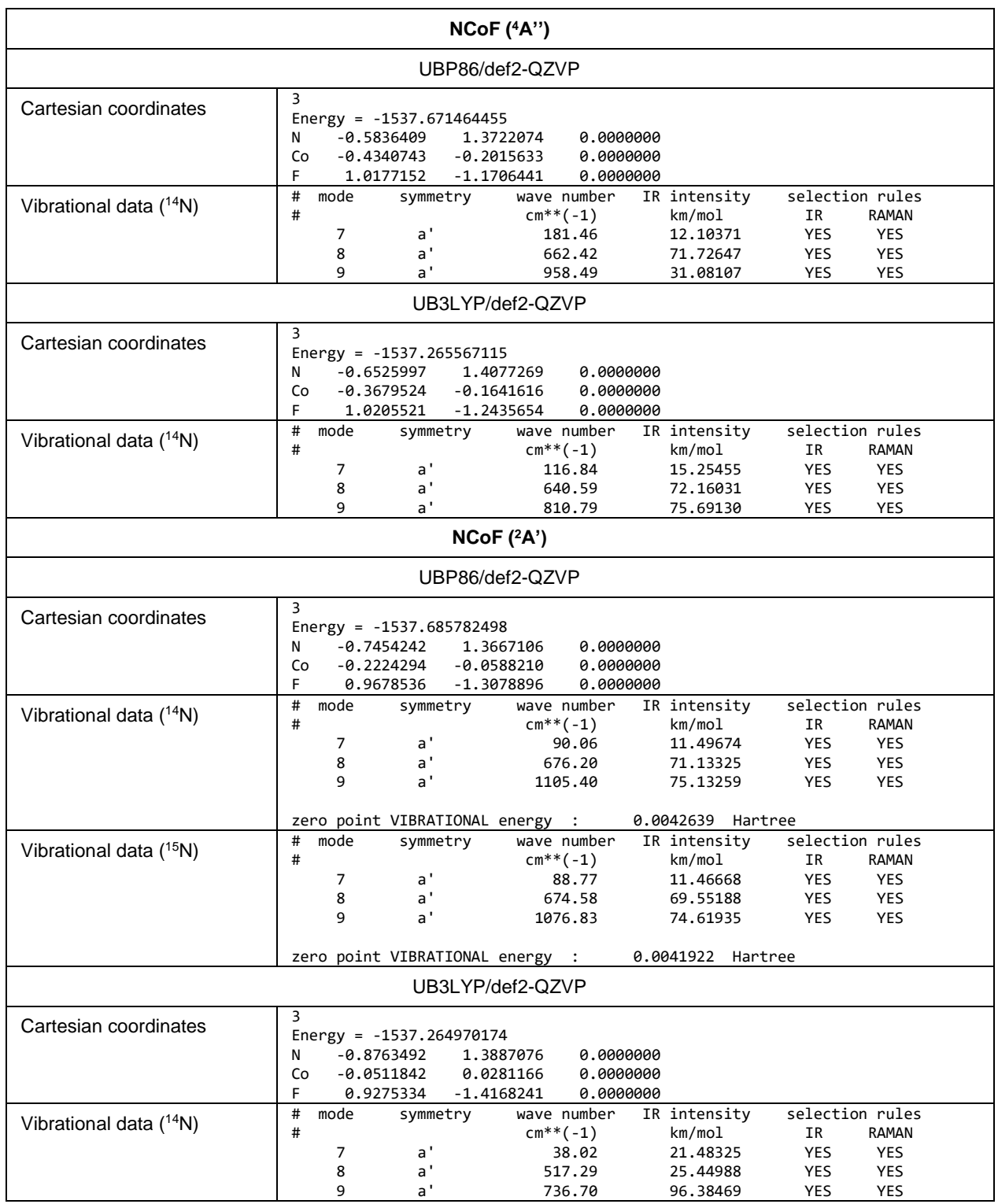

\section{$\mathbf{N R h F}_{\mathbf{3}}$}

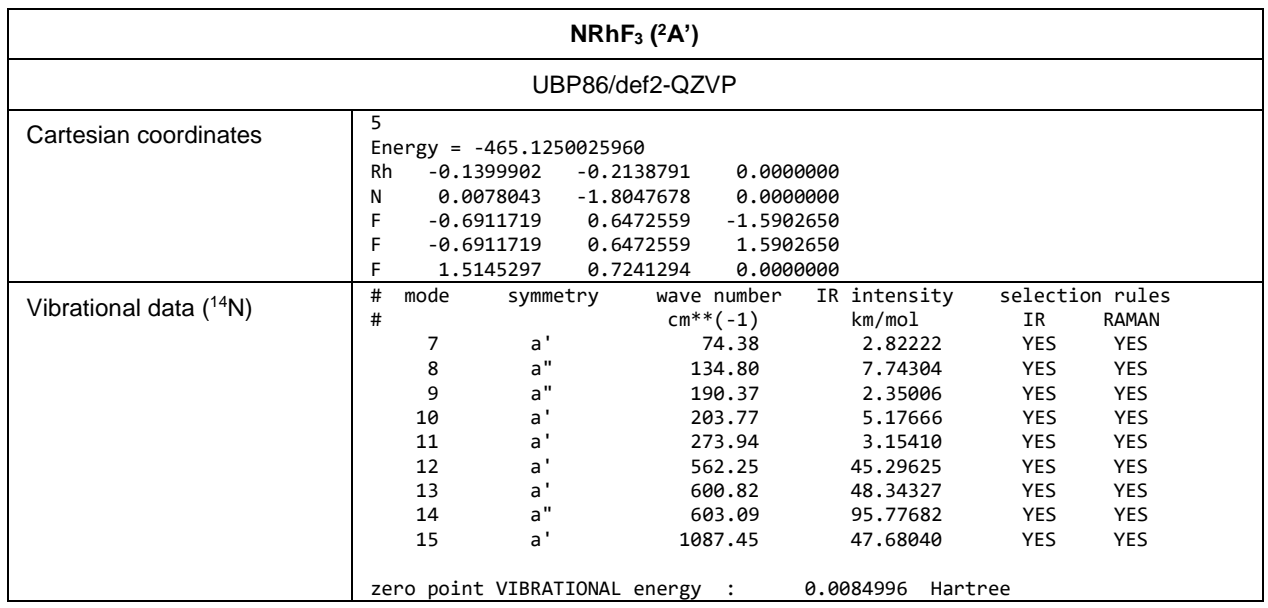




\section{A. Supporting Information of Publications}

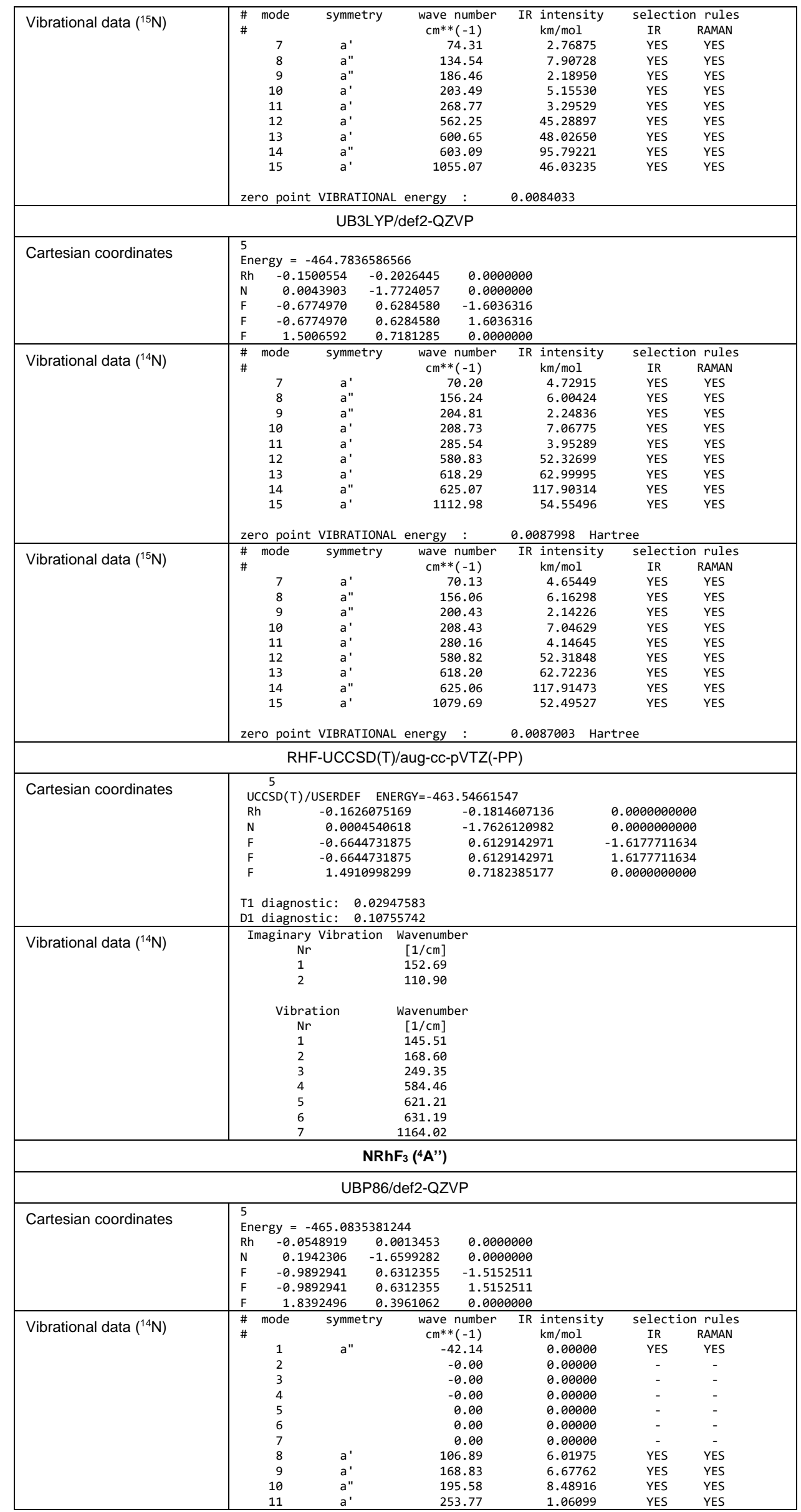


A.2. Fluoro Nitrenoid Complexes $F N=M F_{2}(M=C o, R h, I r)$ : Electronic Structure Dichotomy and Formation of Nitrido Fluorides $N \equiv M_{3}$

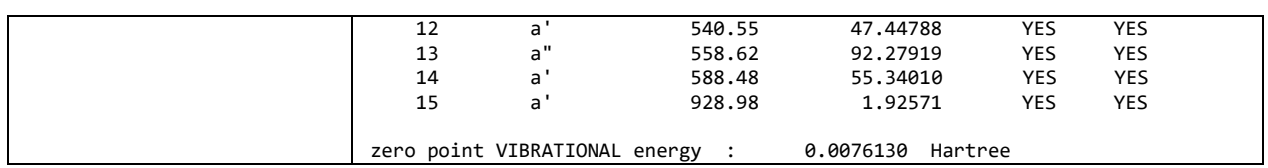

$\mathrm{FNRhF}_{2}$

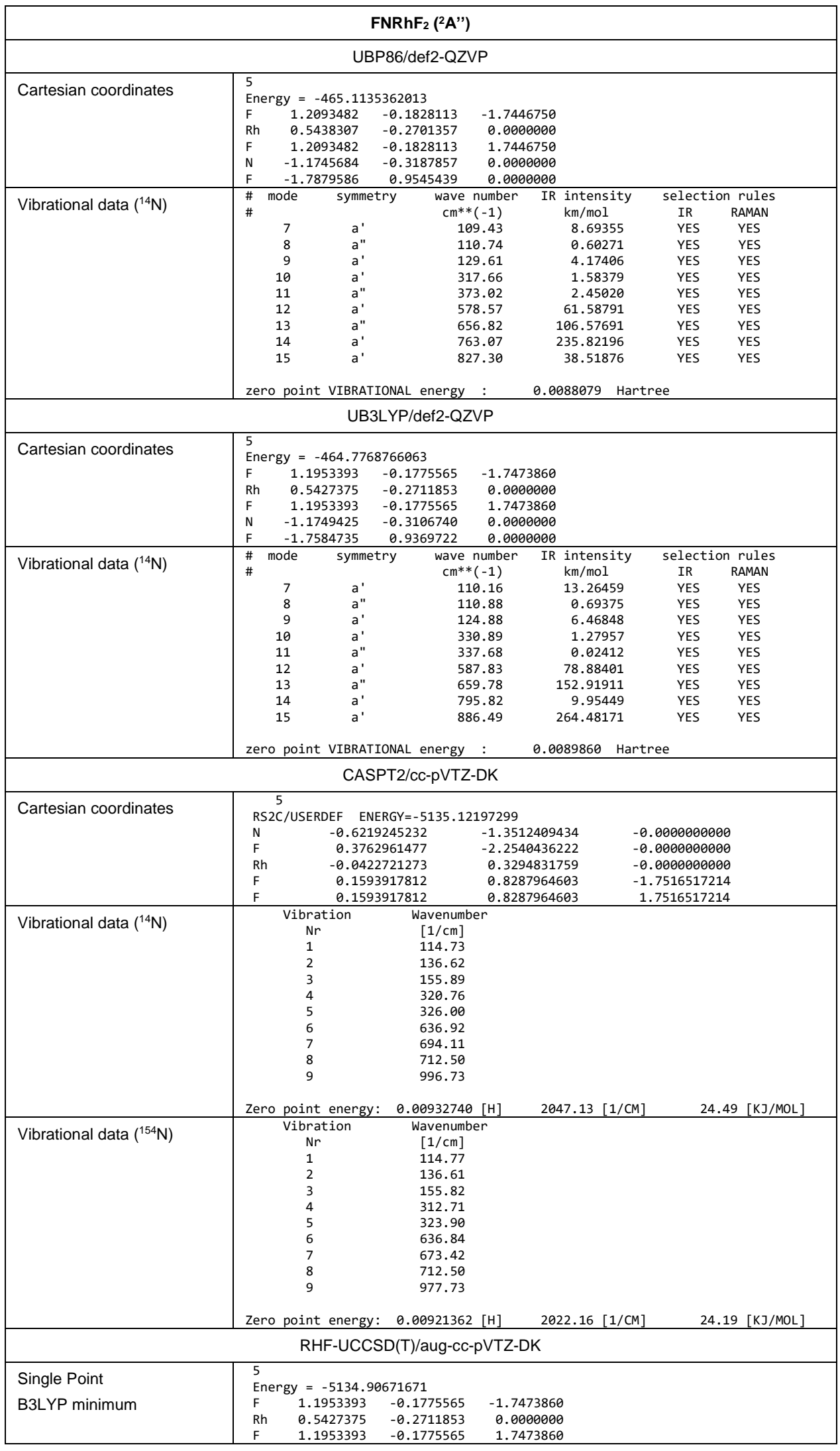




\section{A. Supporting Information of Publications}

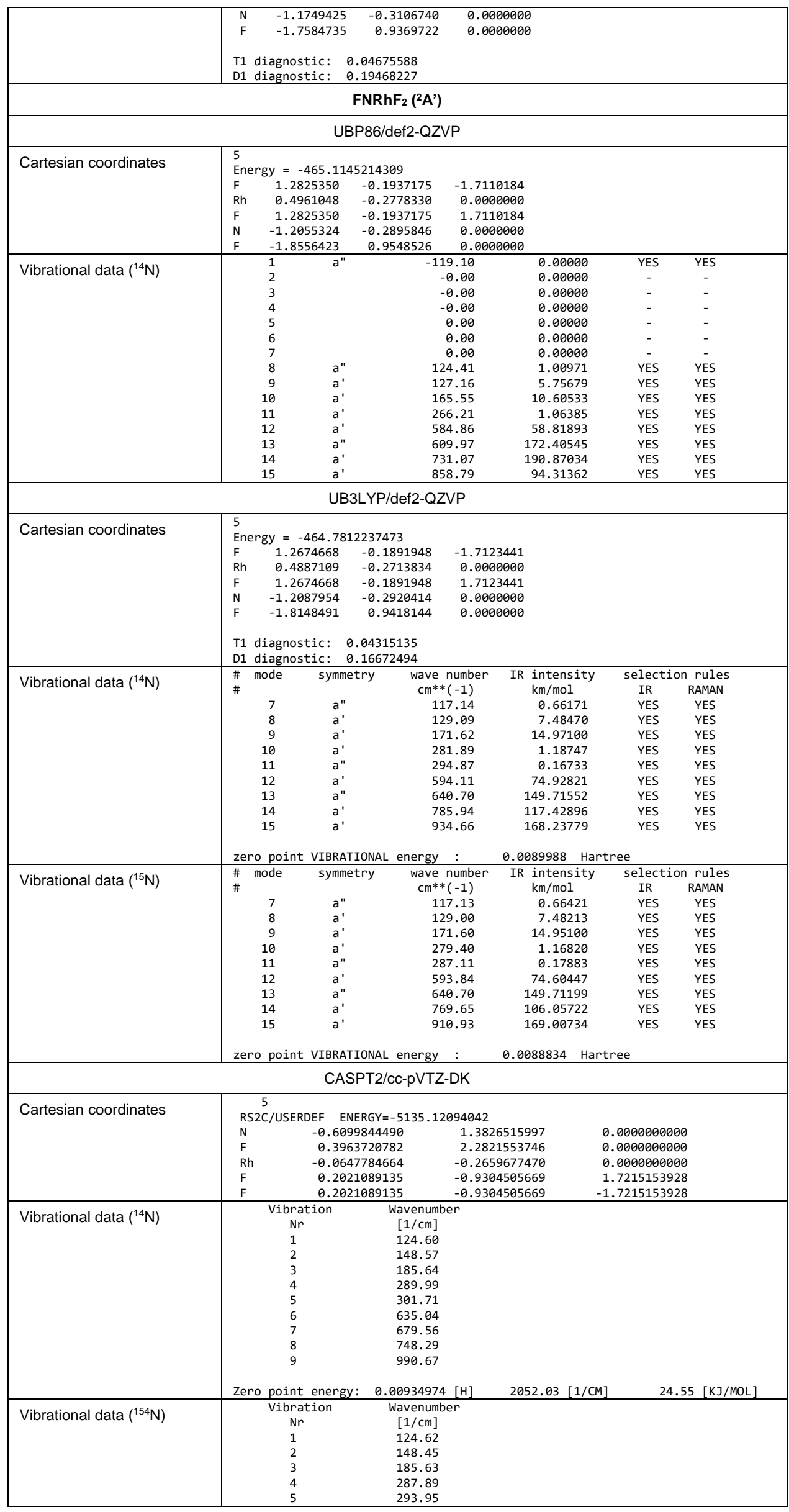


A.2. Fluoro Nitrenoid Complexes $F N=M F_{2}(M=C o, R h, I r)$ : Electronic Structure Dichotomy and Formation of Nitrido Fluorides $N \equiv \mathrm{MF}_{3}$

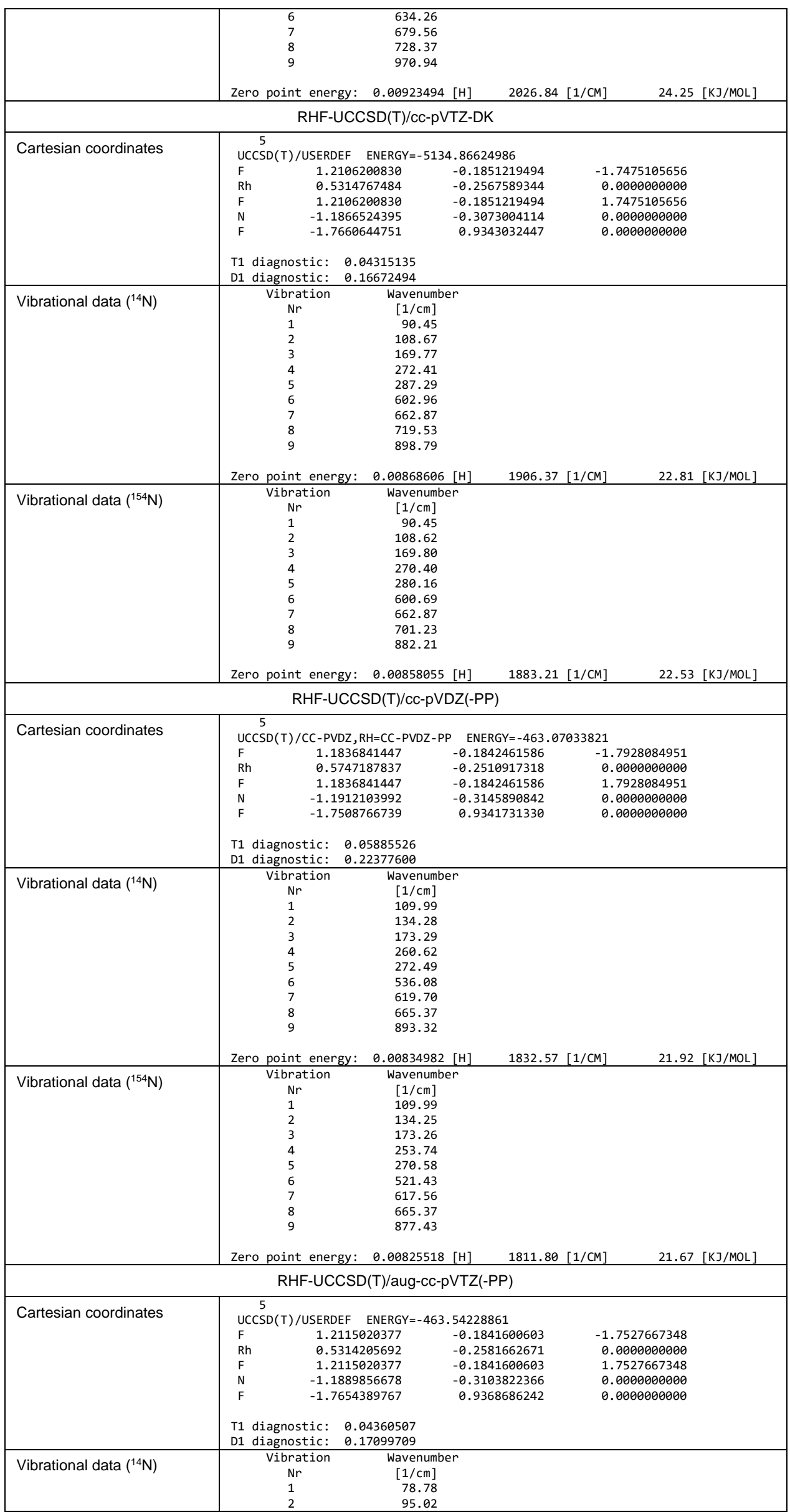




\section{A. Supporting Information of Publications}

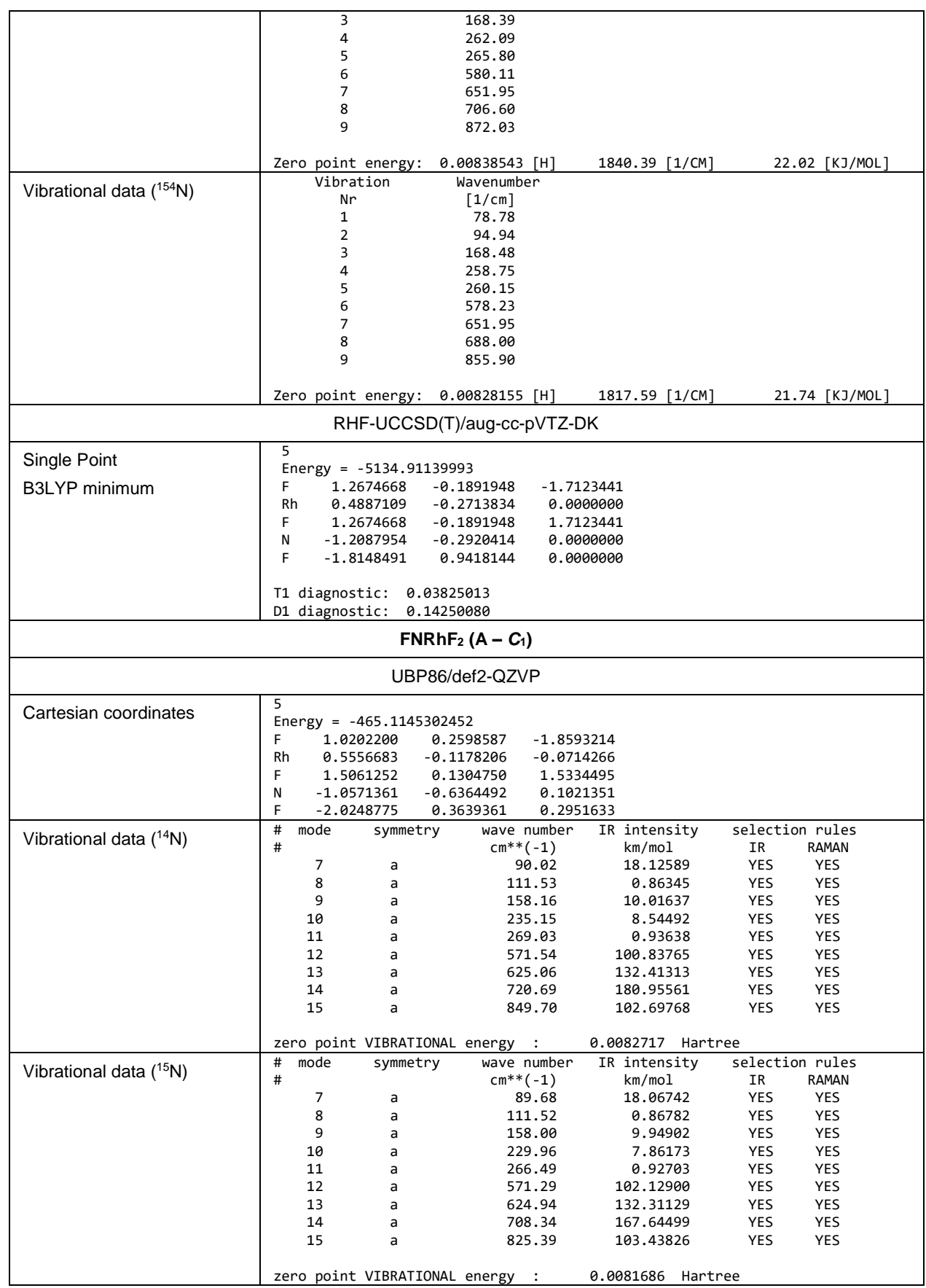

F NRhF

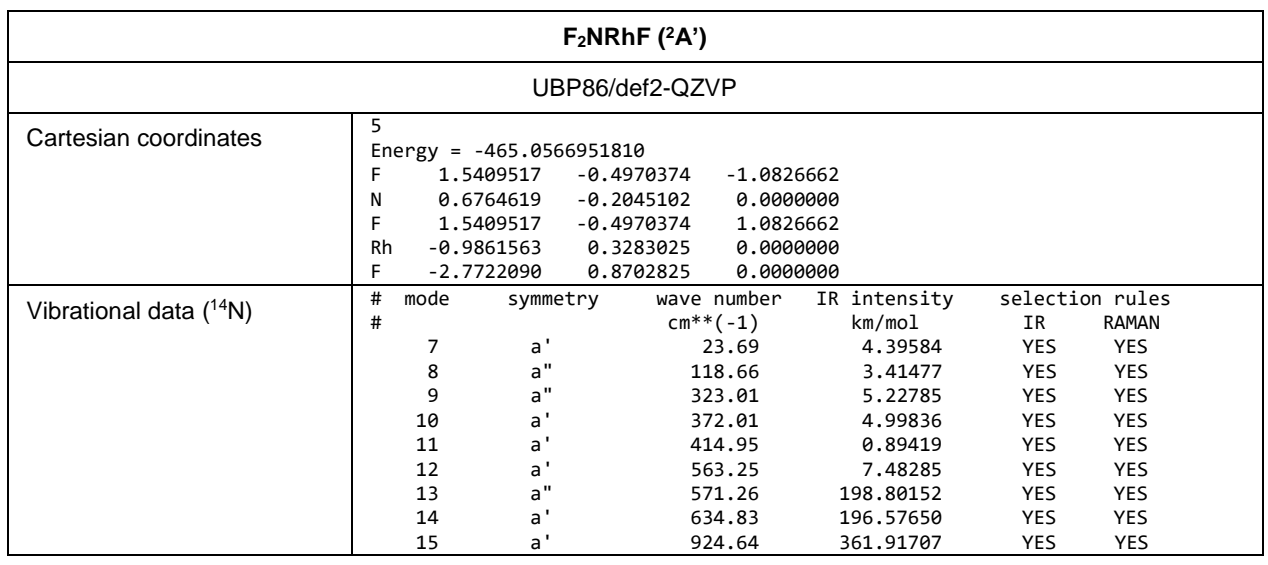


A.2. Fluoro Nitrenoid Complexes $F N=M_{2}(M=C o, R h, I r)$ : Electronic Structure Dichotomy and Formation of Nitrido Fluorides $N \equiv \mathrm{MF}_{3}$

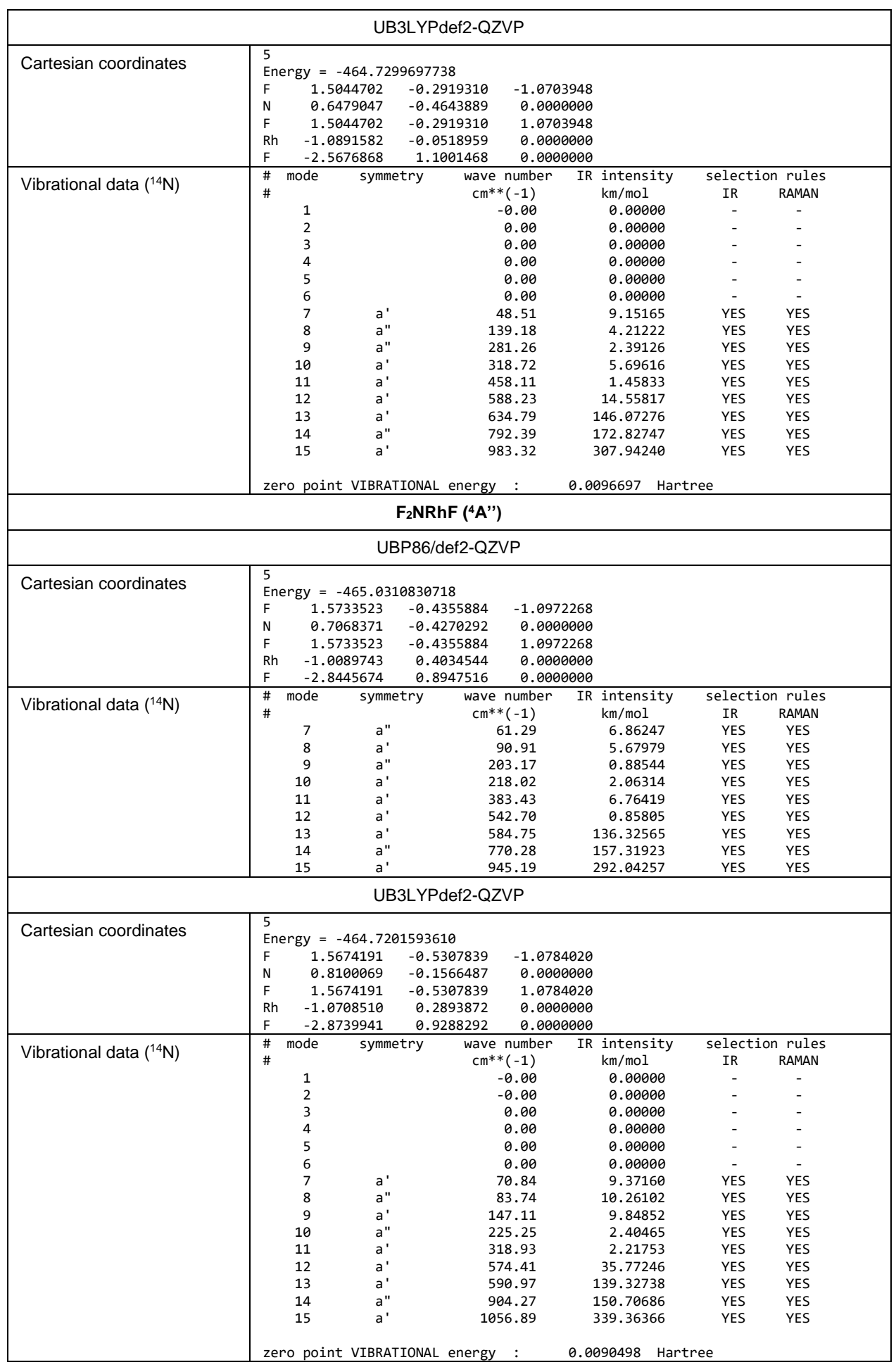

$\mathrm{NRhF}_{\mathbf{2}}$

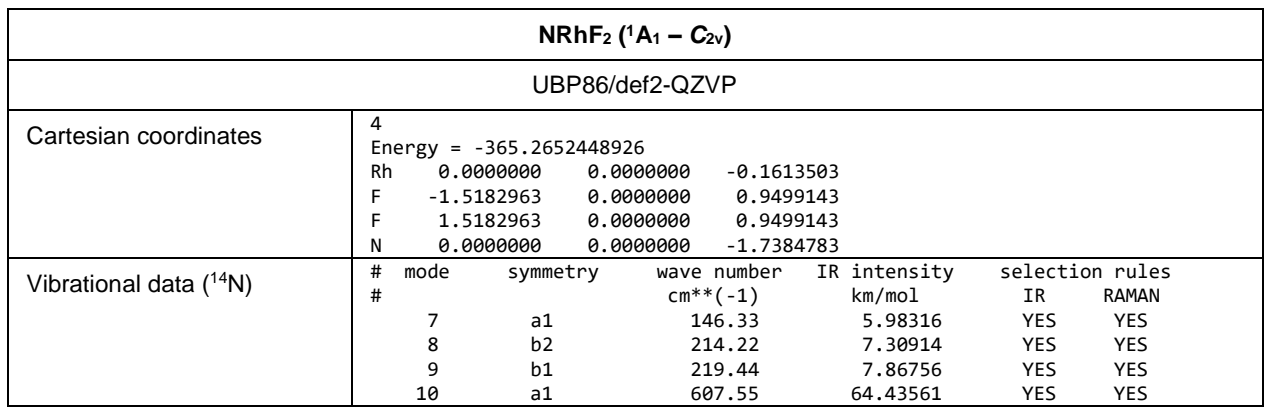




\section{A. Supporting Information of Publications}

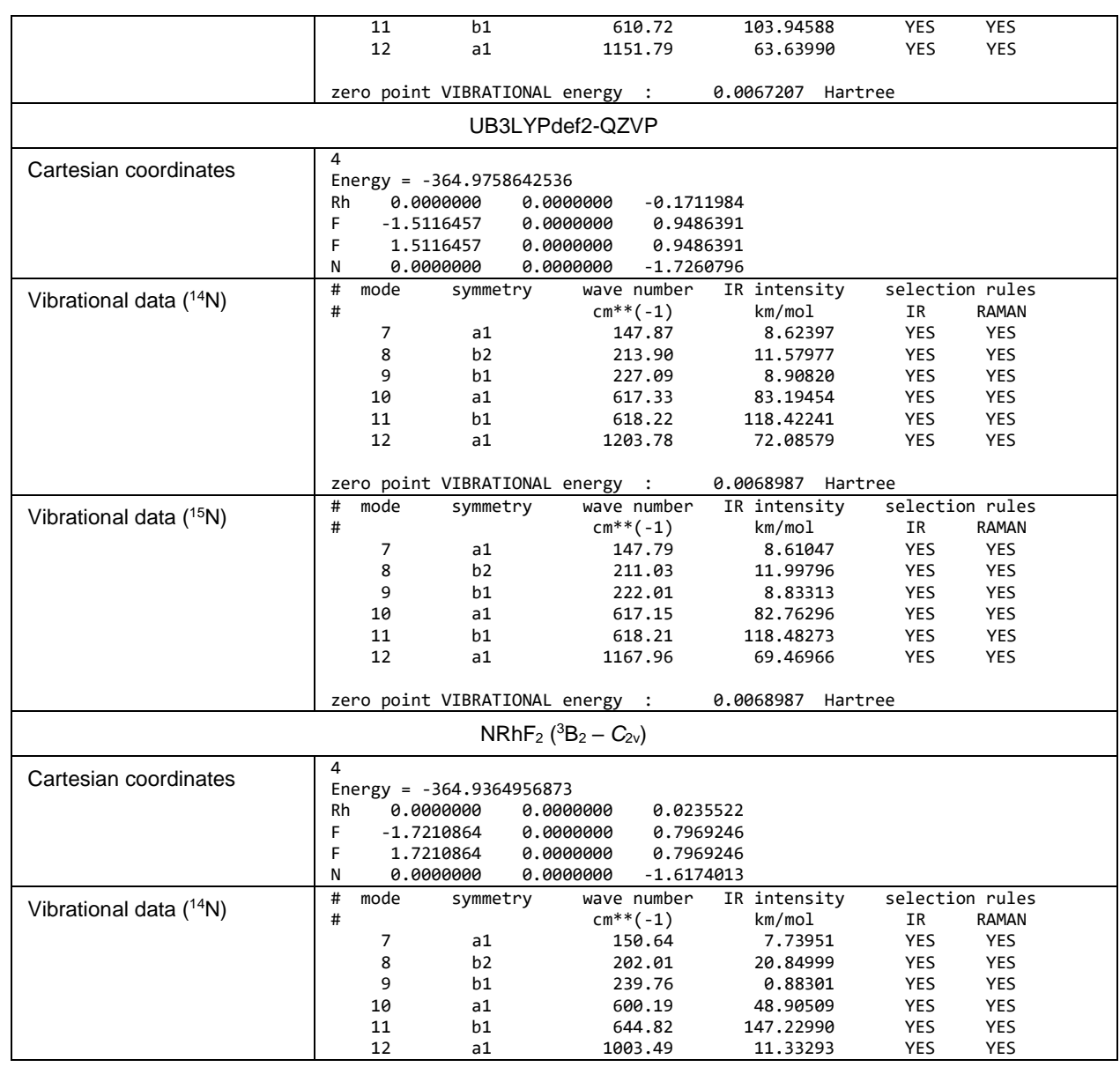

\section{NRhF}

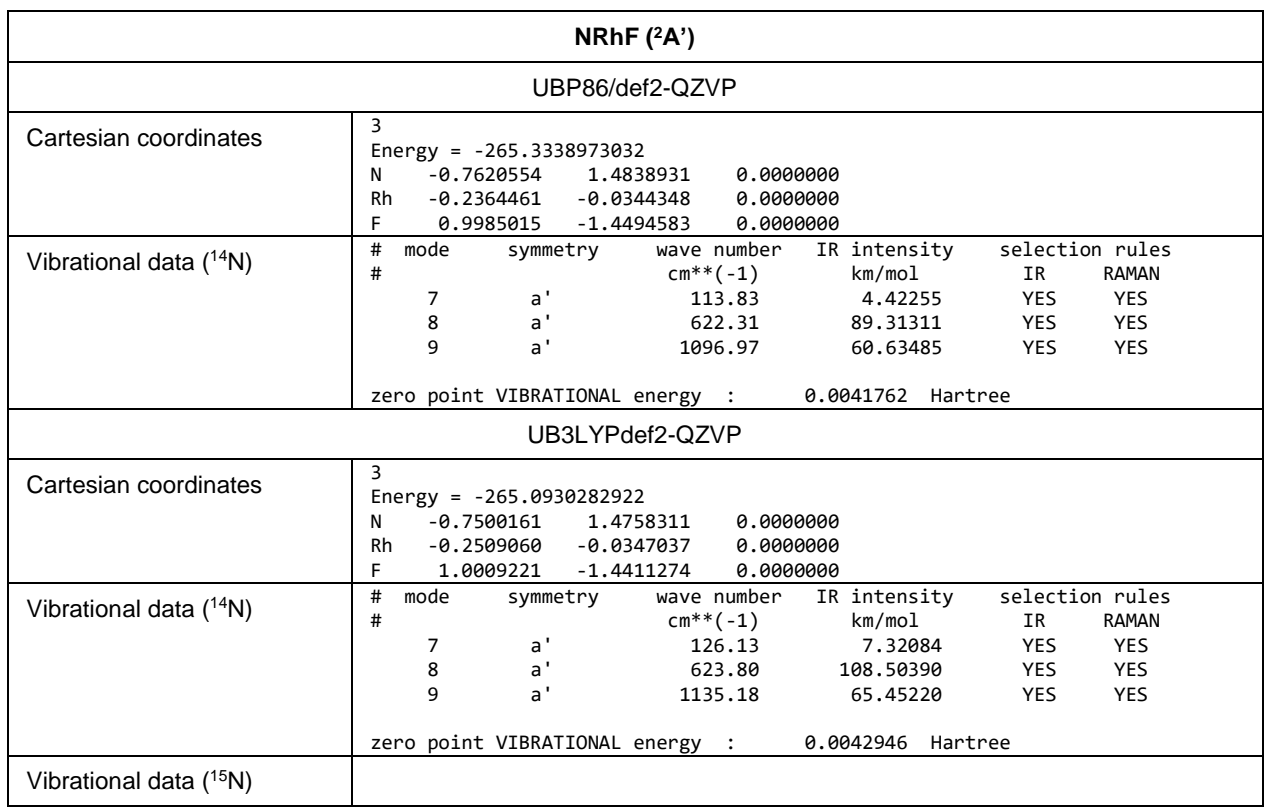

\section{$\mathrm{NIrF}_{3}$}

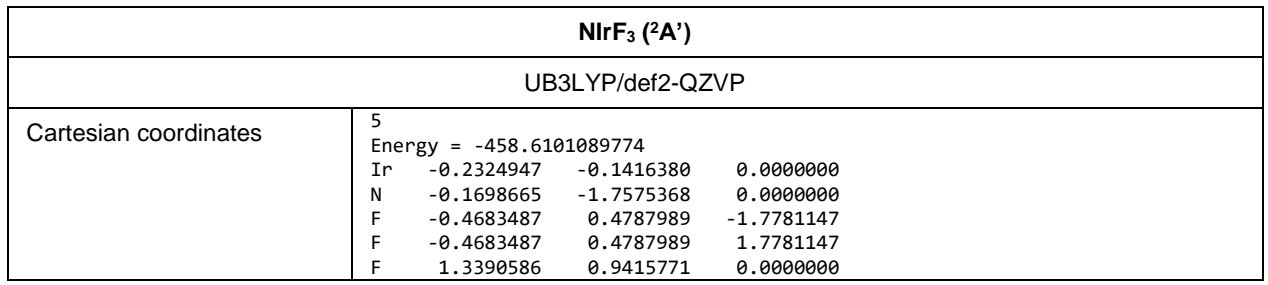


A.2. Fluoro Nitrenoid Complexes $F N=M_{2}(M=C o, R h, I r)$ : Electronic Structure Dichotomy and Formation of Nitrido Fluorides $\mathrm{N} \equiv \mathrm{MF}_{3}$

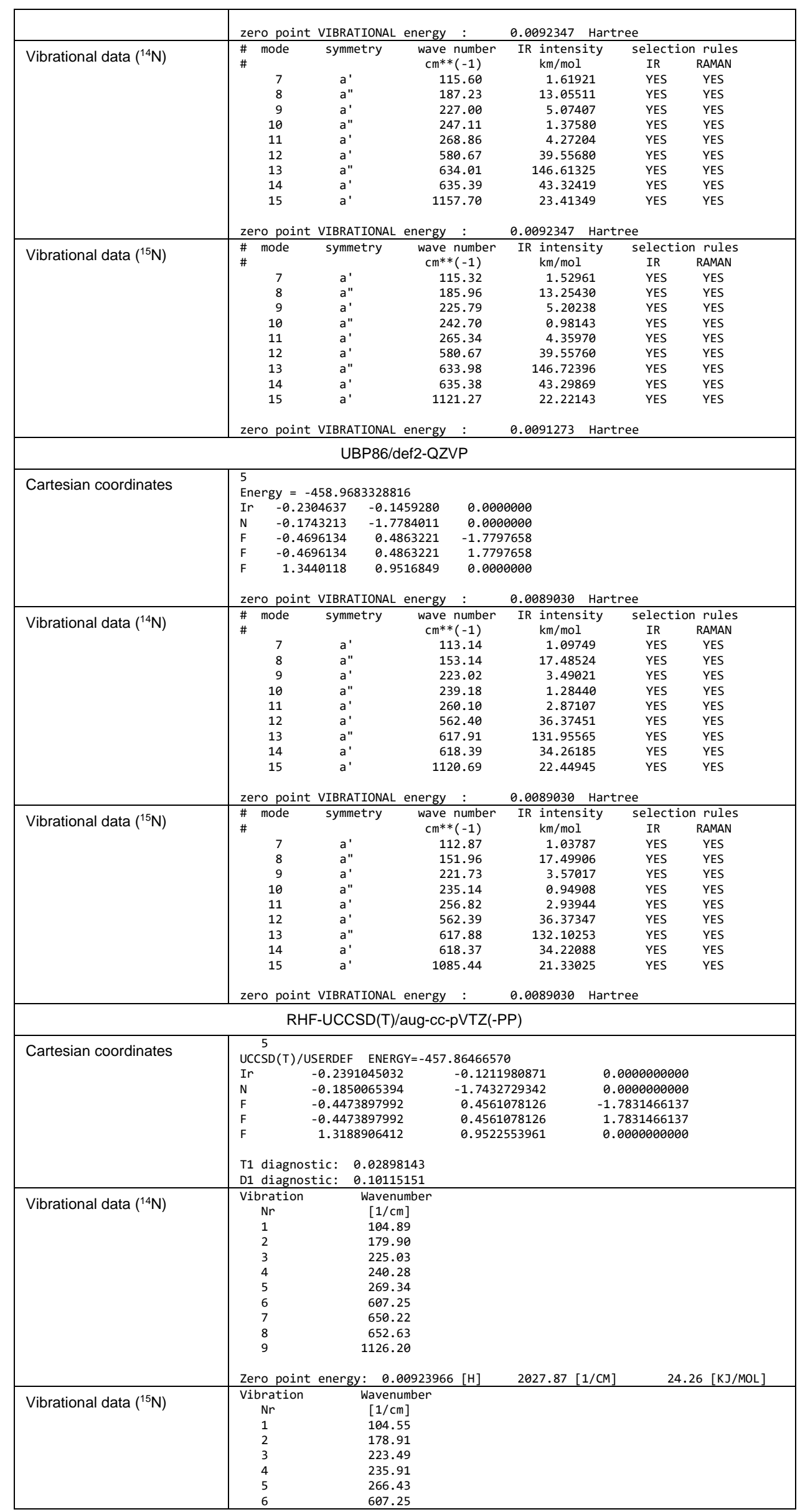




\section{A. Supporting Information of Publications}

\begin{tabular}{|l|cccc|}
\hline & 7 & 650.20 & & \\
& 8 & 652.60 & & \\
9 & 1090.65 & & & \\
& & & & \\
& Zero point energy : & $0.00913544[\mathrm{H}]$ & $2005.00[1 / \mathrm{CM}]$ & $23.99[\mathrm{KJ} / \mathrm{MOL}]$ \\
\hline
\end{tabular}

FNIrF 2

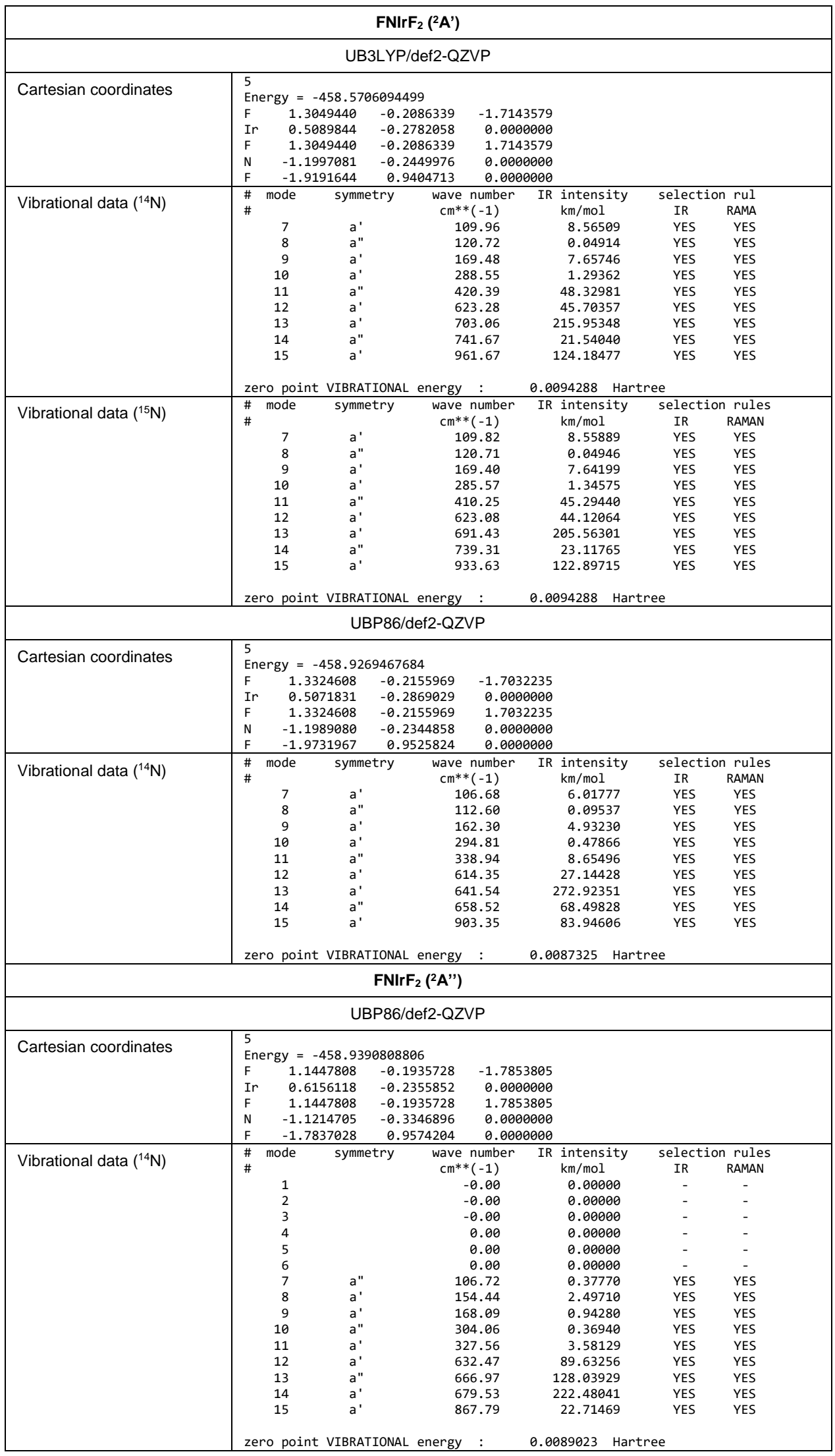


A.2. Fluoro Nitrenoid Complexes $F N=M F_{2}(M=C o, R h, I r)$ : Electronic Structure Dichotomy and Formation of Nitrido Fluorides $N \equiv \mathrm{MF}_{3}$

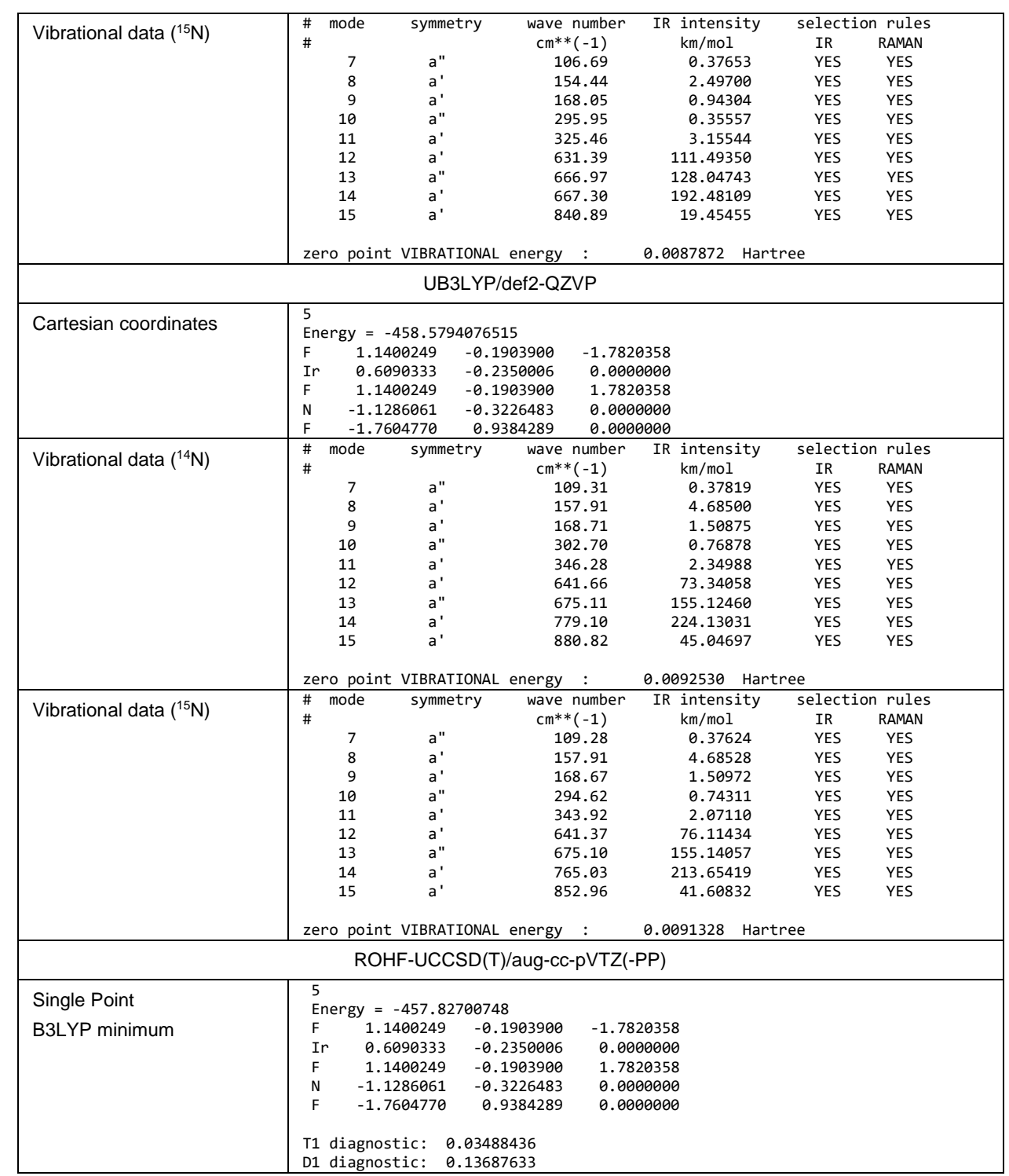

\section{$F_{2}$ NIrF}

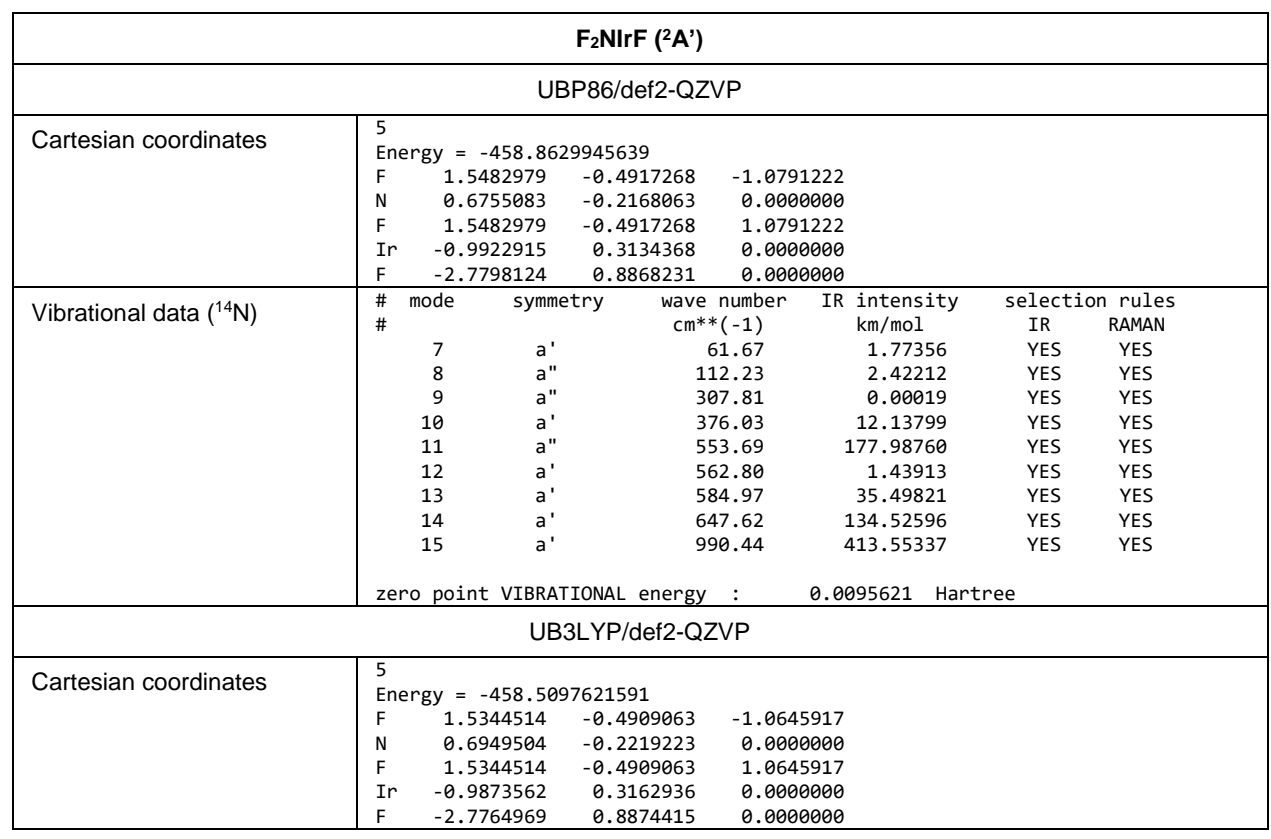




\section{A. Supporting Information of Publications}

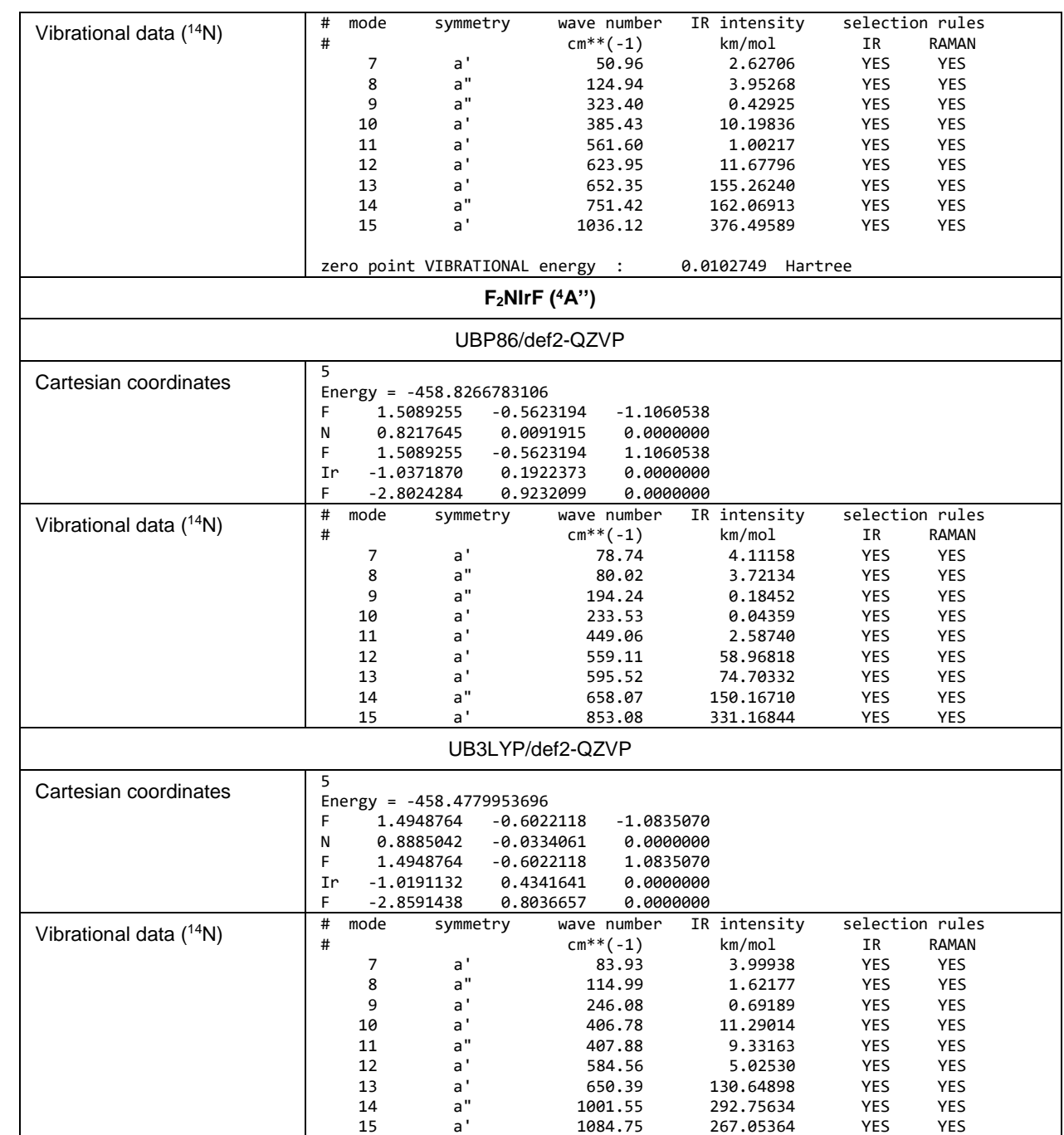

\section{$\mathrm{NIrF}_{2}$}

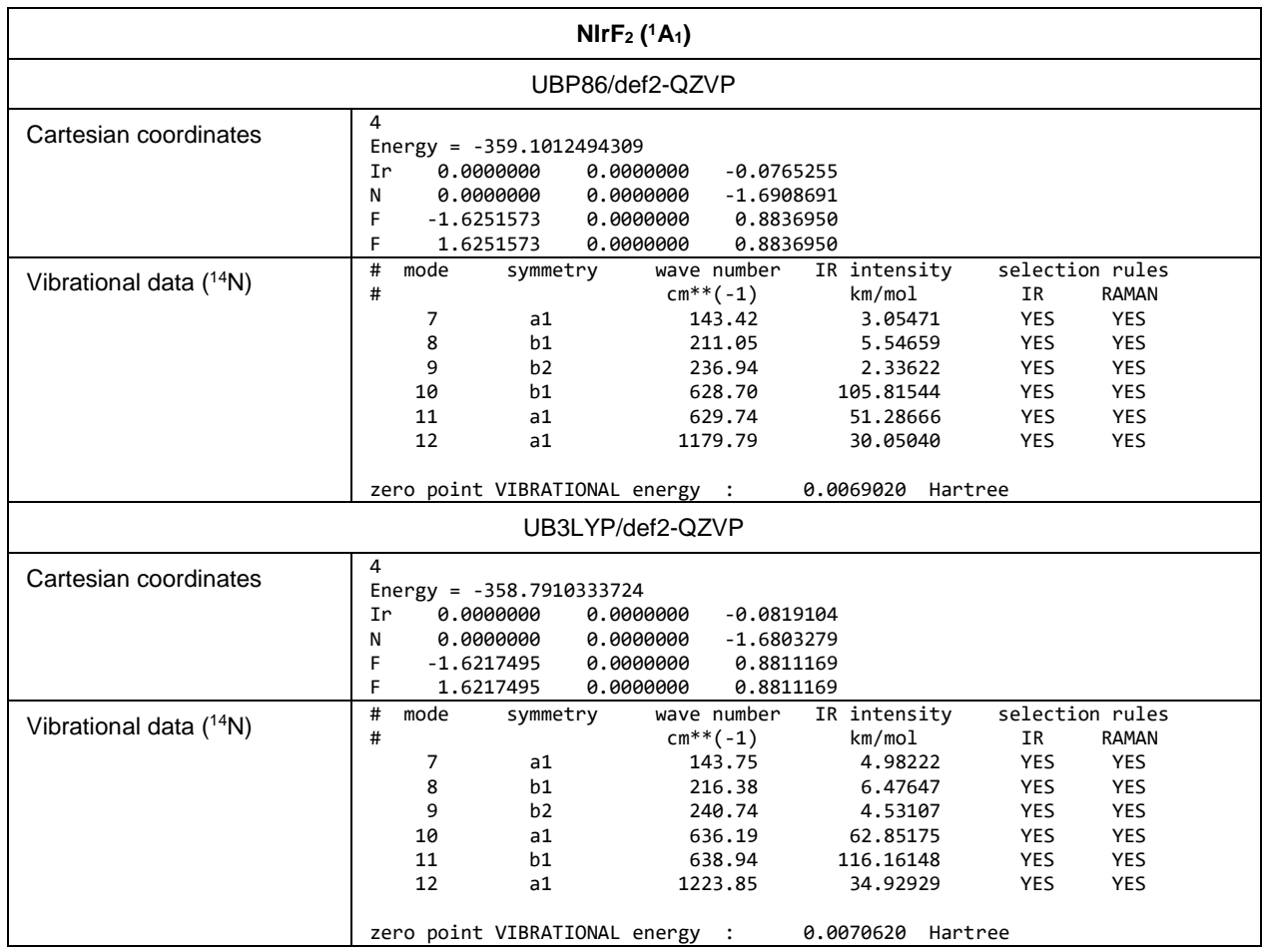


A.2. Fluoro Nitrenoid Complexes $F N=M F_{2}(M=C o, R h, I r)$ : Electronic Structure Dichotomy and Formation of Nitrido Fluorides $N \equiv \mathrm{MF}_{3}$

NIrF

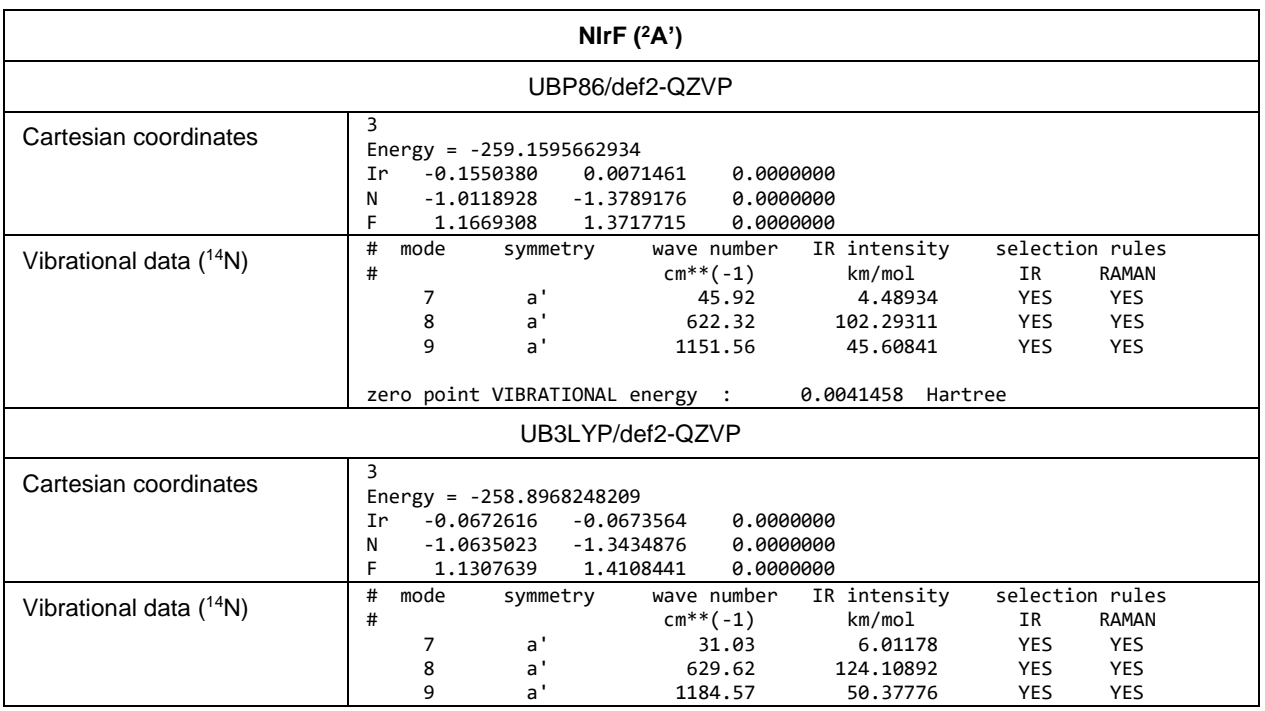

\section{Supporting Information References}

[1] TURBOMOLE GmbH, TURBOMOLE V7.0.1, 2015.

[2] a) A. D. Becke, Phys. Rev. A 1988, 38, 3098; b) J. P. Perdew, Phys. Rev. B 1986, 33, 8822.

[3] a) S. H. Vosko, L. Wilk, M. Nusair, Can. J. Phys. 1980, 58, 1200; b) C. Lee, W. Yang, R. G. Parr, Phys. Rev. B 1988, 37, 785; c) A. D. Becke, J. Chem. Phys. 1993, 98, 5648; d) P. J. Stephens, F. J. Devlin, C. F. Chabalowski, M. J. Frisch, J. Phys. Chem. 1994, 98, 11623.

[4] a) F. Weigend, F. Furche, R. Ahlrichs, J. Chem. Phys. 2003, 119, 12753; b) F. Weigend, R. Ahlrichs, Phys. Chem. Chem. Phys. 2005, 7, 3297.

[5] D. Andrae, U. Huermann, M. Dolg, H. Stoll, H. Preu, Theor. Chim. Acta 1990, 77, 123.

[6] H.-J. Werner, P. J. Knowles, G. Knizia, F. R. Manby, M. Schütz, P. Celani, W. Györffy, D. Kats, T. Korona, R. Lindh, A. Mitrushenkov, G. Rauhut, K. R. Shamasundar, T. B. Adler, R. D. Amos, S. J. Bennie, A. Bernhardsson, A. Berning, D. L. Cooper, M. J. O. Deegan, A. J. Dobbyn, F. Eckert, E. Goll, C. Hampel, A. Hesselmann, G. Hetzer, T. Hrenar, G. Jansen, C. Köppl, S. J. R. Lee, Y. Liu, A. W. Lloyd, Q. Ma, R. A. Mata, A. J. May, S. J. McNicholas, W. Meyer, T. F. Miller III, M. E. Mura, A. Nicklass, D. P. O’Neill, P. Palmieri, D. Peng, K. Pflüger, R. Pitzer, M. Reiher, T. Shiozaki, H. Stoll, A. J. Stone, R. Tarroni, T. Thorsteinsson, M. Wang, M. Welborn, MOLPRO, version 2019.2, a package of ab initio programs.

[7] K. A. Peterson, D. Figgen, M. Dolg, H. Stoll, J. Chem. Phys. 2007, 126, 124101.

[8] D. Figgen, K. A. Peterson, M. Dolg, H. Stoll, J. Chem. Phys. 2009, 130, 164108.

[9] R. A. Kendall, T. H. Dunning, R. J. Harrison, J. Chem. Phys. 1992, 96, 6796. 
[10] a) T. H. Dunning, J. Chem. Phys. 1989, 90, 1007; b) W. A. de Jong, R. J. Harrison, D. A. Dixon, J. Chem. Phys. 2001, 114, 48; c) N. B. Balabanov, K. A. Peterson, J. Chem. Phys. 2005, 123, 64107.

[11] O. M. Wilkin, N. Harris, J. F. Rooms, E. L. Dixon, A. J. Bridgeman, N. A. Young, J. Phys. Chem. A 2018, 122, 1994.

[12] O. Ruff, W. Menzel, Z. Anorg. Allg. Chem. 1934, 217, 85.

[13] W. Maya, Inorg. Chem. 1964, 3, 1063.

[14] A. Allan, J.L. Duncan, J.H. Holloway, D.C. McKean, J. Mol. Spectrosc. 1969, 31, 368. 
A.3. A Cornucopia of Iridium Nitrogen Compounds Produced from Laser-Ablated Iridium Atoms and Dinitrogen

A.3 A Cornucopia of Iridium Nitrogen Compounds Produced from Laser-Ablated Iridium Atoms and Dinitrogen 


\section{Chemistry-A European Journal Supporting Information}

A Cornucopia of Iridium Nitrogen Compounds Produced from Laser-Ablated Iridium Atoms and Dinitrogen

Tony Stüker, Helmut Beckers, and Sebastian Riedel*[a] 


\section{A Cornucopia of Iridium Nitrogen Compounds Produced from Laser-Ablated Iridium Atoms and Dinitrogen}

Table of Contents




\section{Supplemental Tables}

Table S1. Low-energy electronic state configuration (sorted by increasing energy) and vibrational frequencies (in $\mathrm{cm}^{-1}$ ) of selected nitrogen containing molecules.

\begin{tabular}{|c|c|c|c|c|c|}
\hline \multirow{2}{*}{$\begin{array}{l}\text { Molecule } \\
\mathrm{N}_{2}\end{array}$} & \multirow{2}{*}{$\begin{array}{l}\text { Point Group } \\
D_{\infty h}\end{array}$} & \multicolumn{2}{|c|}{ Electronic state and HOMOs } & \multirow[t]{2}{*}{$\Delta E$} & \multirow{2}{*}{$\begin{array}{l}\text { Vibrational frequencies (Intensities) [Symmetry] } \tilde{v}^{\mathrm{c}} \\
2348(0)\left[\sigma_{g}\right]\end{array}$} \\
\hline & & ${ }^{1} \Sigma^{+}$ & $\left(1 \sigma_{g}^{2} 1 \sigma^{2} 1 \pi_{g}{ }^{4} 2 \sigma_{g}{ }^{2}\right)$ & & \\
\hline $\mathrm{N}_{3}$ & & ${ }^{2} \Pi_{g}$ & $\left(1 \pi_{u}^{4} 3 \sigma_{u^{2}}^{2} 4 \sigma_{g}^{2} 1 \pi_{g}^{4}\right)$ & 0 & $479(9)\left[\pi_{u}\right], 1716(142)\left[\sigma_{u}\right]$ \\
\hline $\mathrm{N}_{3}^{-}$ & & ${ }^{1} \Sigma_{\mathrm{g}}^{+}$ & $\left(1 \pi_{u^{4}} 3 \sigma_{u^{2}}^{2} 4 \sigma_{g}^{2} 1 \pi_{g}^{4}\right)$ & -263 & $2042(894)\left[\sigma_{u}\right]$ \\
\hline \multirow[t]{3}{*}{ IrN } & $C_{\infty V}$ & ${ }^{1} \Sigma$ & $\left(5 \sigma^{2} 2 \pi^{4} 1 \delta^{4} 6 \sigma^{2}\right)$ & 0 & $1209(36)[\sigma]$ \\
\hline & & & & & $1195(38)[\sigma]$ \\
\hline & $C_{\infty V}$ & ${ }^{3} \Pi$ & $\left(2 \pi^{4} 1 \delta^{4} 6 \sigma^{1} 3 \pi^{1}\right)$ & +95 & $1039(15)[\sigma]$ \\
\hline \multirow[t]{4}{*}{$\operatorname{lr}(\mathrm{N})_{2}$} & $C_{2 v}$ & ${ }^{2} \mathrm{~B}_{1}$ & $\left(2 b_{1}^{2} 6 a_{1}^{2} 5 b_{2}^{2} 7 a_{1}^{2} 3 b_{1}^{1}\right)$ & 0 & $869(41)\left[b_{2}\right]$ \\
\hline & $C_{2 v}$ & ${ }^{2} \mathrm{~B}_{2}$ & $\left(2 b_{1}^{2} 6 a_{1}^{2} 7 a_{1}^{2} 5 b_{2}^{1} 3 b_{1}^{2}\right)$ & +103 & $1119(595)\left[b_{2}\right]$ \\
\hline & & ${ }^{2} A_{1}$ & $\left(2 b_{1}^{2} 6 a_{1}^{2} 5 b_{2}^{2} 7 a_{1}^{1} 3 b_{1}^{2}\right)$ & +111 & $1005(3)\left[b_{2}\right], 990(1)\left[a_{1}\right]$ \\
\hline & & ${ }^{4} \mathrm{~A}_{2}$ & $\left(6 a_{1}^{2} 7 a_{1}^{2} 5 b_{2}^{1} 3 b_{1}^{1} 8 a_{1}^{1}\right)$ & +59 & $958(11)\left[a_{1}\right], 466(595)\left[b_{2}\right]$ \\
\hline $\operatorname{Ir}(\mathrm{N})_{3}$ & $D_{3 \mathrm{~h}}$ & ${ }^{1} A_{1}$ & & & $968(0)\left[a 1^{\prime}\right], 770(2 \times 0.7)\left[e^{\prime}\right]$ \\
\hline \multirow[t]{3}{*}{$\mathrm{IrN}_{2}$} & $C_{\infty V}$ & ${ }^{2} \Delta$ & $\left(7 \sigma^{2} 3 \pi^{4} 1 \delta^{3} 8 \sigma^{2}\right)$ & 0 & $382(3)[\pi], 382(3)[\pi], 584(10)\left[\sigma^{+}\right], 2119(283)\left[\sigma^{+}\right]$ \\
\hline & & & & & $377(3)[\pi], 377(3)[\pi], 549(29)\left[\sigma^{+}\right], 2140(463)\left[\sigma^{+}\right]$ \\
\hline & $C_{s}$ & ${ }^{4} A^{\prime}$ & $\left(4 a^{\prime \prime 2} 11 a^{\prime 1} 12 a^{\prime 1} 13 a^{\prime 1}\right)$ & +104 & $143(20)$ [a'] 332 (0) [a'], 2119 (312) [a'] \\
\hline \multirow[t]{2}{*}{$\operatorname{lr}\left(\mathrm{N}_{2}\right)^{-}$} & $C_{\infty v}$ & ${ }^{1} \Sigma^{+}$ & $\left(7 \sigma^{2} 3 \pi^{4} 1 \delta^{4} 8 \sigma^{2}\right)$ & -182 & $429(3)[\pi], 429(3)[\pi], 654(5)\left[\sigma^{+}\right], 1955(675)\left[\sigma^{+}\right]$ \\
\hline & & & & & $434(3)[\pi], 434(3)[\pi], 648(12)\left[\sigma^{+}\right], 1963(1018)\left[\sigma^{+}\right]$ \\
\hline \multirow[t]{2}{*}{$\operatorname{lr}\left(\mathrm{N}_{2}\right)^{+}$} & $C_{\infty v}$ & ${ }^{3} \Delta$ & $\left(7 \sigma^{2} 3 \pi^{4} 1 \delta^{3} 8 \sigma^{1}\right)$ & +848 & $341(1)[\pi], 341(1)[\pi], 488(15), 2212(48)$ \\
\hline & & & & & $313(1)[\pi], 313(1)[\pi], 401(14)\left[\sigma^{+}\right], 2286(24)\left[\sigma^{+}\right]$ \\
\hline \multirow[t]{2}{*}{$\operatorname{Ir}\left(\mathrm{N}_{2}\right)_{2}$} & $D_{\infty h}$ & ${ }^{2} \Delta g$ & $\left(2 \pi_{g}{ }^{4} 7 \sigma_{g}{ }^{2} 1 \delta_{g}^{3}\right)$ & 0 & 439 (99), 2149 (1001) \\
\hline & $D_{\infty h}$ & ${ }^{4} \Pi_{u}$ & $\left(2 \pi_{\mathrm{g}}{ }^{4} 1 \delta_{\mathrm{g}}{ }^{2} 7 \sigma_{\mathrm{g}}^{2} 2 \pi_{\mathrm{u}}{ }^{1}\right)$ & +246 & 276 (30), 1964 (1793) \\
\hline \multirow[t]{3}{*}[\operatorname{lr}(\mathrm{N}_{2})_{2}]{$^{+}$} & $D_{\infty h}$ & ${ }^{3} \Delta g$ & $\left(2 \pi_{g}{ }^{4} 7 \sigma_{g}^{2} 1 \delta_{g}^{2}\right)$ & +846 & $383(48)\left[\sigma_{u}\right], 2269(173)\left[\sigma_{u}\right]$ \\
\hline & $D_{\infty h}$ & ${ }^{1} \Sigma_{\mathrm{g}}^{+}$ & $\left(2 \pi_{g}{ }^{4} 7 \sigma_{g}{ }^{2} 1 \delta_{g}^{2}\right)$ & +866 & $383(48)\left[\sigma_{u}\right], 2239(174)\left[\sigma_{u}\right]$ \\
\hline & $D_{\infty h}$ & ${ }^{1} \Sigma_{\mathrm{g}}{ }^{+}$ & $\left(2 \pi_{g}{ }^{4} 7 \sigma_{g}{ }^{0} 1 \delta_{g}{ }^{4}\right)$ & +944 & $379(46)\left[\sigma_{u}\right], 2209(211)\left[\sigma_{u}\right]$ \\
\hline$\left[\operatorname{lr}\left(\mathrm{N}_{2}\right)_{2}\right]^{-}$ & $C_{2 v}$ & ${ }^{1} \mathrm{~A}_{1}$ & $\left(\left(2 a_{2}^{2} 8 b_{1}^{2}\right) 9 a_{1}^{2}\left(3 b_{2}^{2} 10 a_{1}^{2}\right)\right)$ & -224 & $486(69)\left[b_{1}\right], 1988(1926)\left[b_{1}\right], 2052(38)\left[a_{1}\right]$ \\
\hline $\operatorname{Ir}\left(\mathrm{N}_{3}\right)$ & $C_{\mathrm{s}}$ & ${ }^{3} A "$ & $\left(13 a^{\prime 2} 4 a^{\prime 2} 14 a^{\prime 2} 15 a^{\prime 1} 5 a^{\prime \prime 1}\right)$ & & 2020 (407) [a'], 1153 (53) [a'] \\
\hline \multirow[t]{2}{*}{ IrNNIr } & $D_{\infty h}$ & ${ }^{3} \Sigma_{\mathrm{u}^{+}}^{+}$ & $6 \sigma_{\mathrm{g}}^{2} 2 \pi_{\mathrm{u}}^{4} 1 \delta_{\mathrm{g}}^{3} 1 \delta \mathrm{u}^{3}$ & & $2081(0)\left[\sigma_{g}\right], 781(162)\left[\sigma_{u}\right]$ \\
\hline & & & & & $2103(0)\left[\sigma_{g}\right], 729(361)\left[\sigma_{u}\right]$ \\
\hline $\operatorname{NIr}\left(\mathrm{N}_{2}\right)$ & $C_{\mathrm{s}}$ & ${ }^{1} A^{\prime}$ & & & 2110 (388) [a'], 1085 (27) [a'] \\
\hline IrlrN & $C_{\mathrm{s}}$ & ${ }^{2} A^{\prime}$ & $\left(13 a^{\prime 2} 14 a^{\prime 2} 5 a^{\prime \prime 2} 6 a^{\prime 2} 15 a^{\prime 1}\right)$ & & $1054(60)\left[a^{\prime}\right]$ \\
\hline
\end{tabular}

cSelected vibrational absorptions with intensities greater than 0 and wavenumbers in observable range. See detailed computational results for all data. 
TableTable S2. Overview of IR bands (in $\mathrm{cm}^{-1}$ ) of dinitrogen complexes of the platinum group metals obtained in solid argon matrices.

\begin{tabular}{|c|c|c|c|c|c|c|c|c|c|}
\hline Metal & $M\left({ }^{14} N_{2}\right)$ & $M\left({ }^{15} N_{2}\right)$ & $\left.\Delta v_{N_{2}} c\right)$ & $\mathrm{M}\left({ }^{14} \mathrm{~N}_{2}\right)_{2}$ & $M\left({ }^{15} N_{2}\right)_{2}$ & $\left.\Delta w_{N_{2}}{ }^{c}\right)$ & $\mathrm{M}\left({ }^{14} \mathrm{~N}_{2}\right)_{2}^{-}$ & $\mathrm{M}\left({ }^{15} \mathrm{~N}_{2}\right)_{2}^{-}$ & $\left.\Delta w_{N_{2}}{ }^{c}\right)$ \\
\hline $\mathrm{Ru}^{[1]}$ & 2034.6 & 1967.1 & 293 & 2077.6 & 2008.6 & 250 & & & \\
\hline $\mathrm{Rh}^{[2]}$ & 2153.3 & 2081.7 & 175 & 2185.9 & 2112.8 & 142 & 1958.9 & 1893.4 & 369 \\
\hline $\mathrm{Pd}^{[3]}$ & 2213.0 & 2138.7 & 115 & 2234.0 & 2159.5 & 94 & & & \\
\hline $\mathrm{Os}^{[1]}$ & 2044.2 & 1976.2 & 283 & 2083.2 & 2013.9 & 245 & & & \\
\hline Ir & 2087.6 & 2018.2 & 240 & 2144.7 & 2073.7 & 183 & $1956.4^{a}$ & $1890.3^{a}$ & $371^{a}$ \\
\hline $\mathrm{Pt}^{[4]}$ & 2168.5 & 2096.2 & 159 & 2195.4 & 2122.2 & 133 & $1862.5^{b}$ & $1803.5^{b}$ & $465^{b}$ \\
\hline
\end{tabular}

${ }^{a}$ Recorded in neon matrix. ${ }^{b}$ Recorded in pure dinitrogen matrix. ${ }^{c}$ Red shift relative to uncoordinated $\mathrm{N}_{2}$.

Table S3. NPA- and QTAIM results, bond lengths of selected iridium nitrogen molecules obtained by analyzing the BP86/def2-QZVP wavefunctions..

\begin{tabular}{|c|c|c|c|c|c|c|c|c|c|c|c|}
\hline Property & & NN & $\left(\mathrm{NH}_{2}\right)_{2}$ & $\operatorname{Ir}\left(\mathrm{NN}^{\prime}\right)$ & $\operatorname{Ir}\left(\mathrm{NN}^{\prime}\right)_{2}$ & IrNNIr & $\operatorname{lr}\left(\mathrm{N}_{2}\right)^{+}$ & $\operatorname{Ir}\left(\mathrm{N}_{2}\right)_{2}^{-}$ & IrN & $\operatorname{Ir}(\mathrm{N})_{2}$ & $\operatorname{Ir}(\mathrm{N})_{3}$ \\
\hline \multirow{3}{*}{$\begin{array}{l}\text { Bond } \\
\text { length }\end{array}$} & Ir-N & - & - & 179 & 190 & 180 & 187 & 185 & 160 & 170 & 176 \\
\hline & $\mathrm{N}-\mathrm{N}$ & 110 & 144 & 113 & 112 & 115 & 112 & 114 & - & - & - \\
\hline & Ir & - & - & 0.227 & 1.611 & 0.227 & 0.954 & -0.018 & 0.278 & 0.896 & 1.250 \\
\hline \multirow[t]{3}{*}{$\begin{array}{l}\text { QTAIM } \\
\text { Charge }\end{array}$} & $\mathrm{N}$ & 0.000 & -0.667 & -0.264 & -0.499 & -0.227 & -0.191 & -0.154 & -0.278 & -0.448 & $-0.417^{a}$ \\
\hline & $\mathrm{N}^{\prime}$ & - & - & 0.037 & -0.307 & - & 0.237 & -0.337 & - & - & - \\
\hline & Ir-N & - & - & 0.209 & 0.111 & 0.205 & 0.171 & 0.178 & 0.378 & 0.290 & 0.260 \\
\hline \multicolumn{12}{|l|}{ AIM $\rho_{\mathrm{b}}$} \\
\hline & $\mathrm{N}-\mathrm{N}$ & 0.700 & 0.298 & 0.622 & 0.592 & 0.579 & 0.648 & 0.613 & - & - & \\
\hline & Ir & - & - & 0.069 & 0.087 & 0.087 & 0.926 & -0.46 & -0.032 & 0.588 & 0.847 \\
\hline \multirow[t]{3}{*}{$\begin{array}{l}\text { NPA } \\
\text { Charge }\end{array}$} & $\mathrm{N}$ & 0.000 & -0.678 & -0.032 & -0.070 & -0.087 & -0.122 & -0.08 & 0.032 & -0.294 & -0.282 \\
\hline & $\mathrm{N}^{\prime}$ & - & - & -0.037 & 0.027 & & 0.196 & -0.19 & - & - & - \\
\hline & Ir-N & - & - & 0.65 & $0.38 / 0.43$ & 0.62 & 0.50 & 0.55 & 2.82 & 2.06 & $1.74^{\mathrm{a}}$ \\
\hline \multicolumn{12}{|l|}{ NPA B.O } \\
\hline & $\mathrm{N}-\mathrm{N}$ & 3.01 & 1.02 & 2.56 & 2.64 & 2.51 & 2.55 & 2.61 & - & - & \\
\hline
\end{tabular}

${ }^{\text {aA }}$ veraged values. 


\section{A. Supporting Information of Publications}

Table S4. Absolute and relative energies of the two lowest electronic states of all irreproducible representation of doublet, quartet, and sextet spin states of molecular iridium dinitride $\operatorname{Ir}(\mathrm{N})_{2}$.

\begin{tabular}{|c|c|c|c|c|c|c|}
\hline & \multicolumn{2}{|c|}{ Doublet } & \multicolumn{2}{|c|}{ Quartet } & \multicolumn{2}{|c|}{ Sextet } \\
\hline Irrep. & $E$ (hartree) & $\Delta E\left(\mathrm{~kJ} \mathrm{~mol}^{-1}\right)$ & $E$ (hartree) & $\Delta E\left(\mathrm{~kJ} \mathrm{~mol}^{-1}\right)$ & $E$ (hartree) & $\Delta E\left(\mathrm{~kJ} \mathrm{~mol}^{-1}\right)$ \\
\hline$A_{1}$ & -212.5839098 & 50 & -212.5115669 & 240 & -212.5067341 & 252 \\
\hline$A_{1}$ & -212.5572517 & 120 & -212.4780023 & 328 & -212.4098773 & 507 \\
\hline $\mathrm{B}_{1}$ & -212.6029061 & 0 & -212.5594627 & 114 & -212.4358756 & 439 \\
\hline $\mathrm{B}_{1}$ & -212.5285217 & 195 & -212.5050720 & 257 & -212.4212219 & 477 \\
\hline $\mathrm{B}_{2}$ & -212.5565516 & 122 & -212.5285079 & 195 & -212.4148392 & 494 \\
\hline $\mathrm{B}_{2}$ & -212.5190630 & 220 & -212.5074391 & 251 & -212.3828112 & 578 \\
\hline $\mathrm{A}_{2}$ & -212.5479788 & 144 & -212.5709677 & 84 & -212.4102628 & 506 \\
\hline$A_{2}$ & -212.5377015 & 171 & -212.4960646 & 281 & -212.3931535 & 551 \\
\hline
\end{tabular}

\section{Supplemental Figures}

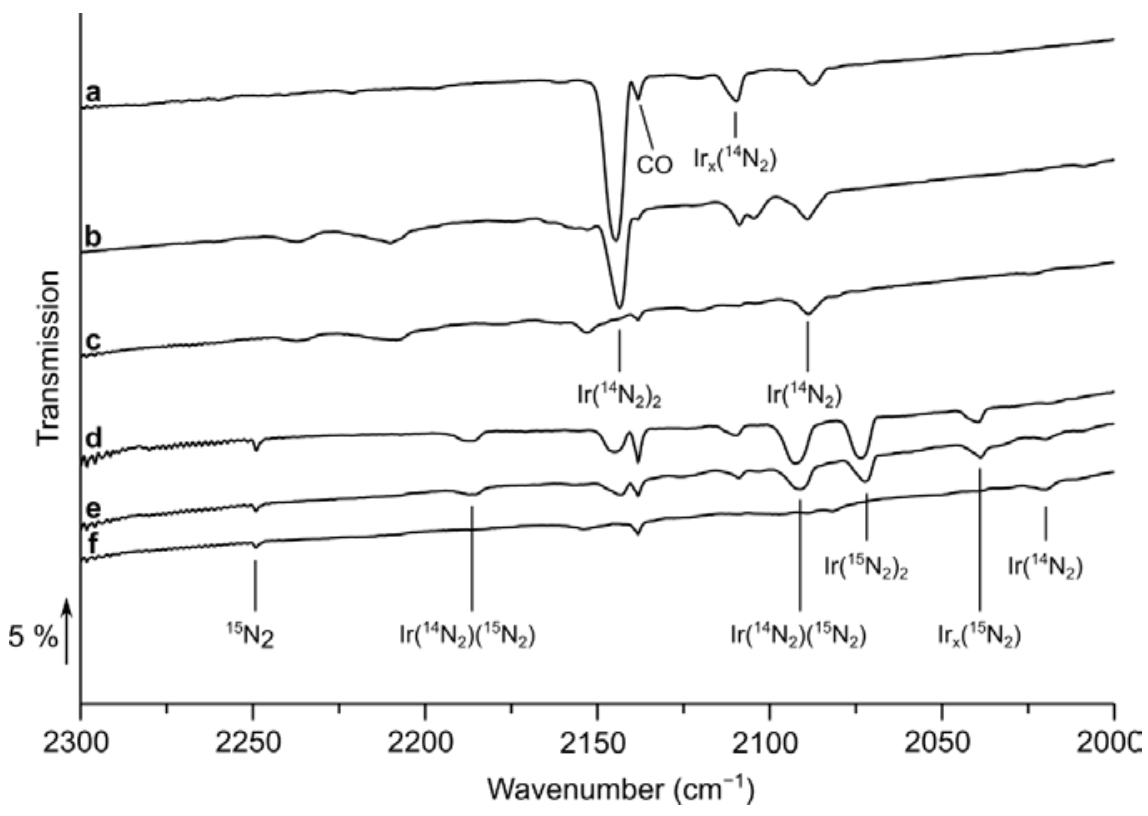

Figure S1. Infrared transmission spectra in the $2000-2350 \mathrm{~cm}^{-1}$ region of the reaction products of laser-ablated iridium atoms with $10 \%{ }^{14} \mathrm{~N}_{2}$ (a, b and $\mathbf{c}$ ) or a 1:1 mixture of ${ }^{14} \mathrm{~N}_{2}$ and ${ }^{15} \mathrm{~N}_{2}$ (d, e and $\left.\mathbf{f}\right)$. Spectrum $\mathbf{a}$ and $\mathbf{d}$ were recorded after 90 min deposition, $\mathbf{b}$ and $\mathbf{e}$ after annealing to $25 \mathrm{~K}$, and $\mathbf{c}$ and $\mathbf{f}$ were taken after irradiation with an LED light of $455 \mathrm{~nm}$ wavelength for $10 \mathrm{~min}$. 


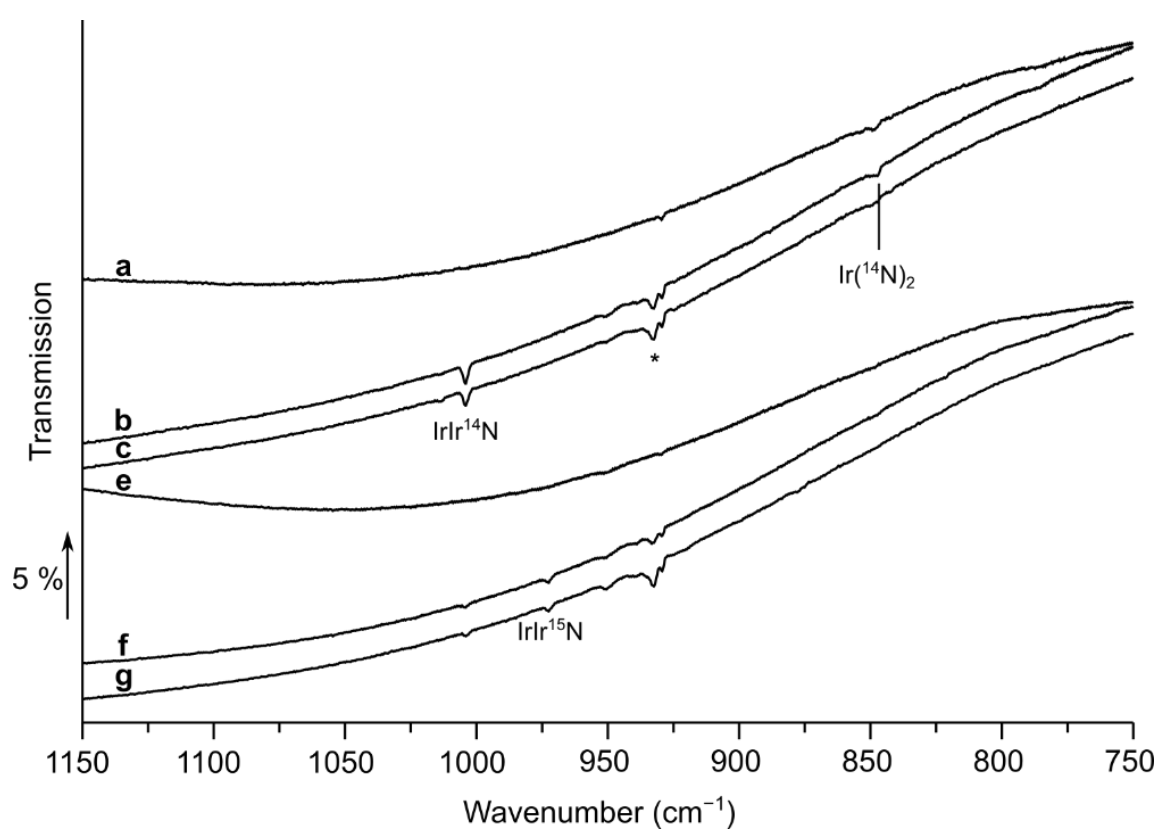

Figure S2. Infrared transmission spectra in the $750-1150 \mathrm{~cm}^{-1}$ region of the reaction products of laser-ablated iridium atoms with $10 \%{ }^{14} \mathrm{~N}_{2}(\mathbf{a}$, b and $\mathbf{c}$ ) or a 1:1 mixture of ${ }^{14} \mathrm{~N}_{2}$ and ${ }^{15} \mathrm{~N}_{2}$ (d, e and $\mathbf{f}$ ). Spectrum $\mathbf{a}$ and $\mathbf{d}$ were recorded after 90 min deposition, $\mathbf{b}$ and $\mathbf{e}$ after annealing to $25 \mathrm{~K}$, and $\mathbf{c}$ and $\mathbf{f}$ were taken after irradiation with an LED light of $455 \mathrm{~nm}$ wavelength for $10 \mathrm{~min}$. Signal group highlighted with the asterisk belongs to nitrogen-less impurities which do not exhibit an isotopic shift.

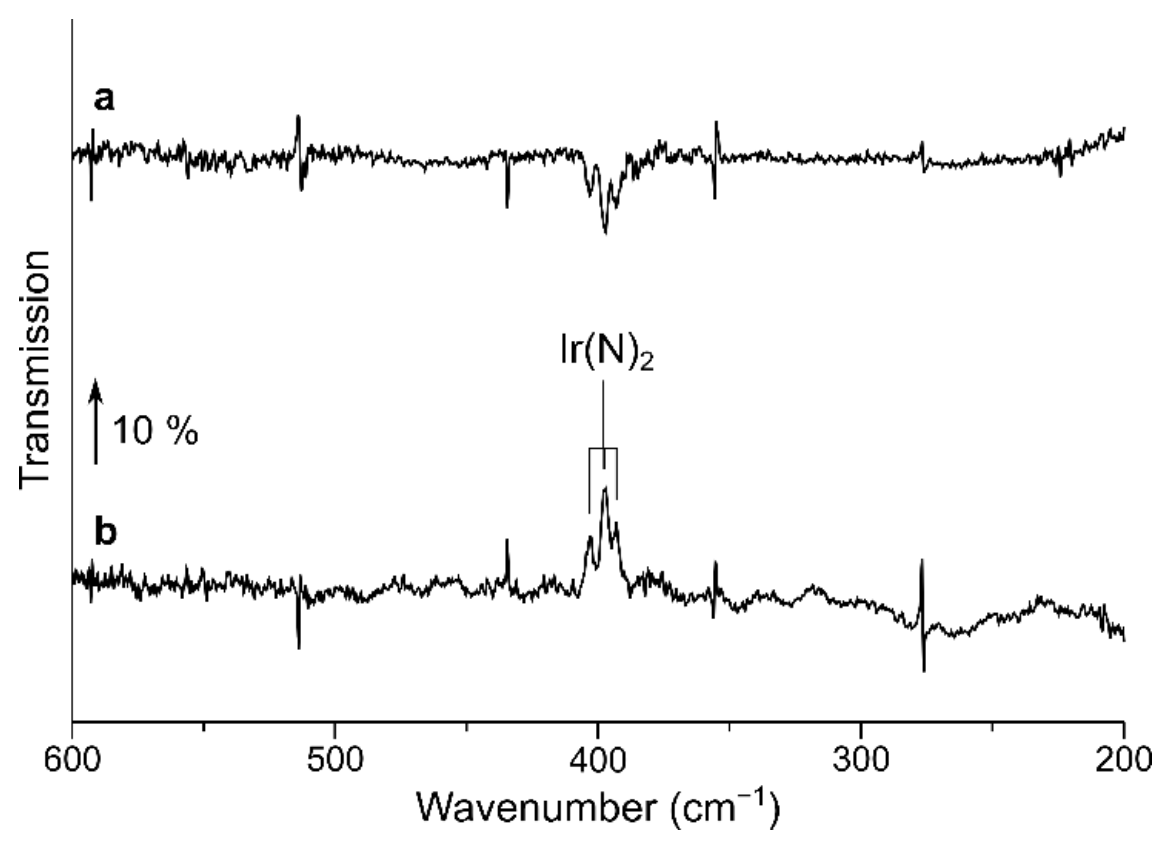

Figure S3. Infrared transmission spectrum in the $200-600 \mathrm{~cm}^{-1}$ region of the reaction products of laser-ablated iridium atoms with $10 \%$ of a 1:1 mixture of ${ }^{14} \mathrm{~N}_{2}$ and ${ }^{15} \mathrm{~N}_{2}$ diluted in neon. Spectrum a was taken after 90 min of deposition, difference spectrum $\mathbf{b}$ was recorded after irradiating the matrix with LED light of $455 \mathrm{~nm}$ wavelength for $10 \mathrm{~min}$. 


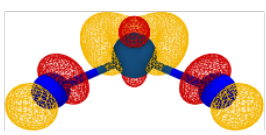

$9 \mathrm{a}_{1}$

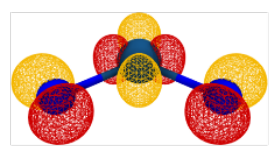

$8 a_{1}$
0.21

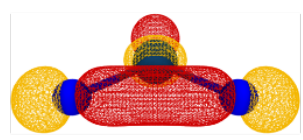

$7 \mathrm{a}_{1}$

1.89

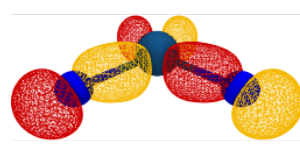

$4 b_{2}$
1.94

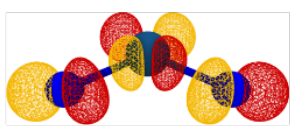

$6 b_{2}$

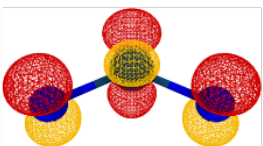

$3 b_{1}$
1.02

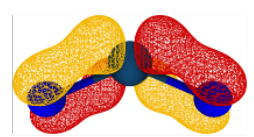

$1 a_{2}$

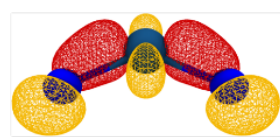

$6 a_{1}$

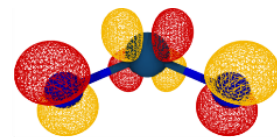

$2 \mathrm{a}_{2}$

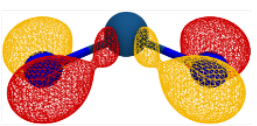

$5 \mathrm{~b}_{2}$

1.85

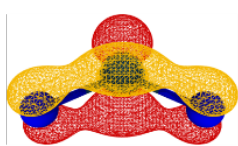

$2 \mathrm{~b}_{1}$

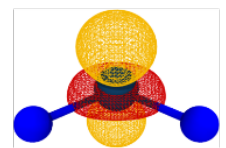

$5 a_{1}$

Figure S4. Valence natural molecular orbitals with an isosurface value of $0.04 \AA^{-1}$ at the CASSCF(15,12)/cc-pVTZ(-PP) level of theory with occupation numbers and orbital wavefunction symmetry.

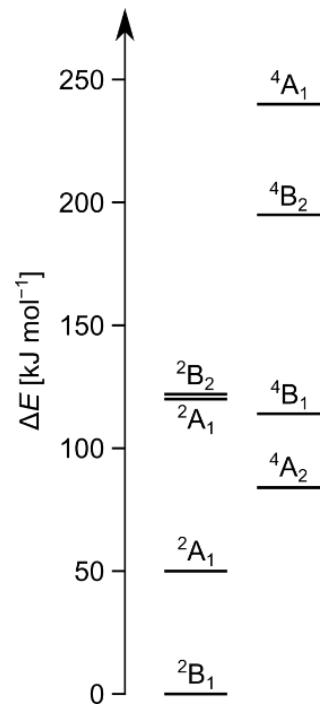

Figure S5. The four lowest electronic doublet and quartet states of $\operatorname{Ir}(\mathrm{N})_{2}$ calculated using SA-CASSCF $(15,12) / \mathrm{cc}-\mathrm{pVTZ}$ at the minimum geometry obtained at the BP86/def2-QZVP level of theory. 


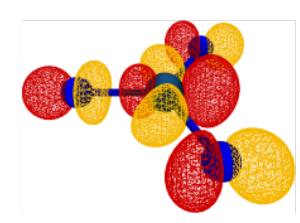

$6 e^{\prime}$

$-2.4$

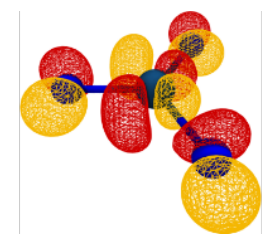

$6 e^{\prime}$

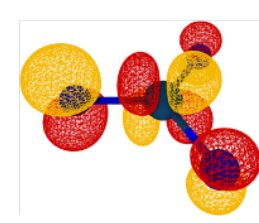

$2 e^{\prime \prime}$

$-5.1$

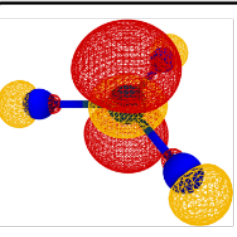

$5 a_{1}{ }^{2}$

$-7.8$

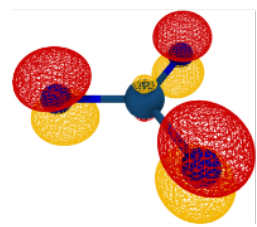

$2 \mathrm{a}_{2}{ }^{\prime 2}$

$-8.4$

$1 \mathrm{e}^{\prime 2}$

$-113$

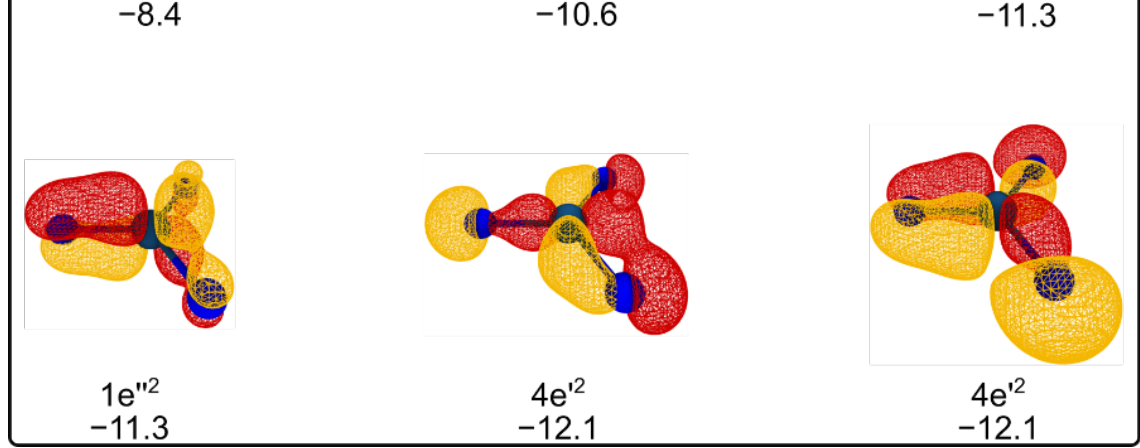

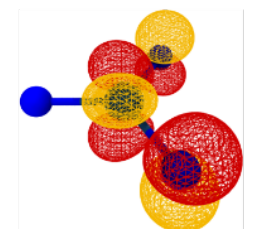

$2 e^{\prime \prime}$
-5.1

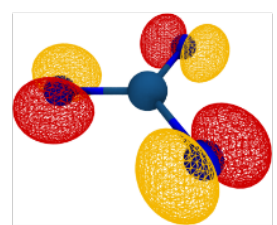

$1 \mathrm{a}_{2}{ }^{\prime}$

Figure 6. Molecular orbitals arising from the $5 d(\operatorname{Ir})$ and $2 p(N)$ atomic orbitals of $\operatorname{Ir}(N)_{3}$ calculated at the R-BP86/ZORA-def2-TZVPP(N)/SARCZORA-TZVPP(Ir) level of theory with corresponding symmetries and energies (eV). Occupation numbers of orbitals inside the box 2 , outside 0. 


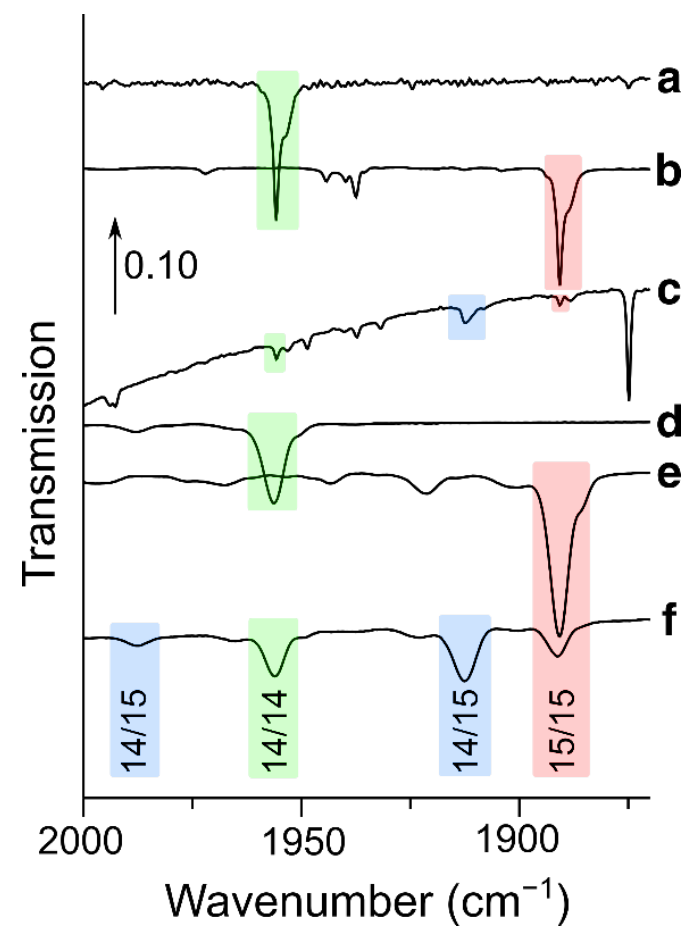

Figure S7. Infrared transmission spectrum of $\operatorname{tr}\left(\mathrm{N}_{2}\right)^{-}$in the $1870-2000 \mathrm{~cm}^{-1}$ region obtained by reacting laser-ablated iridium atoms with neat ${ }^{14} \mathrm{~N}_{2}(\mathbf{a})$, neat ${ }^{15} \mathrm{~N}_{2}$ (b), a neat $1: 1$ mixture of ${ }^{14} \mathrm{~N}_{2}$ and ${ }^{15} \mathrm{~N}_{2}$ (c), $10 \%$ of ${ }^{14} \mathrm{~N}_{2}$ in $\mathrm{Ne}(\mathbf{d}), 10 \%$ of ${ }^{15} \mathrm{~N}_{2}$ in $\mathrm{Ne}(\mathbf{e})$ and $10 \%$ of a $1: 1$ mixture of ${ }^{14} \mathrm{~N}_{2}$ and ${ }^{15} \mathrm{~N}_{2}$ in $\mathrm{Ne}(\mathbf{f})$. Trace $\mathbf{c}$ is enhanced by a factor of 6 . The highlighted bands are assigned to the isotopologues $\operatorname{Ir}\left({ }^{14} \mathrm{~N}\right)_{2}\left({ }^{14} \mathrm{~N}_{2}\right)(\mathrm{green})$, $\operatorname{Ir}\left({ }^{14} \mathrm{~N}\right)_{2}\left({ }^{15} \mathrm{~N}_{2}\right)$ (blue), and $\operatorname{Ir}\left({ }^{15} \mathrm{~N}\right){ }_{2}\left({ }^{15} \mathrm{~N}_{2}\right)$ (red). 


\section{Supplemental computational results}

The vibrational data were calculated with the mass of the most abundant isotope, unless indicated otherwise. Vibrational modes with wavenumbers equal to zero (rotations and translations) are omitted. Point groups and electronic states given here are the ones used in the calculations. The electronic energy is given in hartree, $x y z$ coordinates in Angstroem. Unless otherwise indicated, all BP86 and M06-L DFT calculations were carried out using the unrestricted Kohn-Sham (UKS) formalism.

\section{BP86/def2-QZVP}

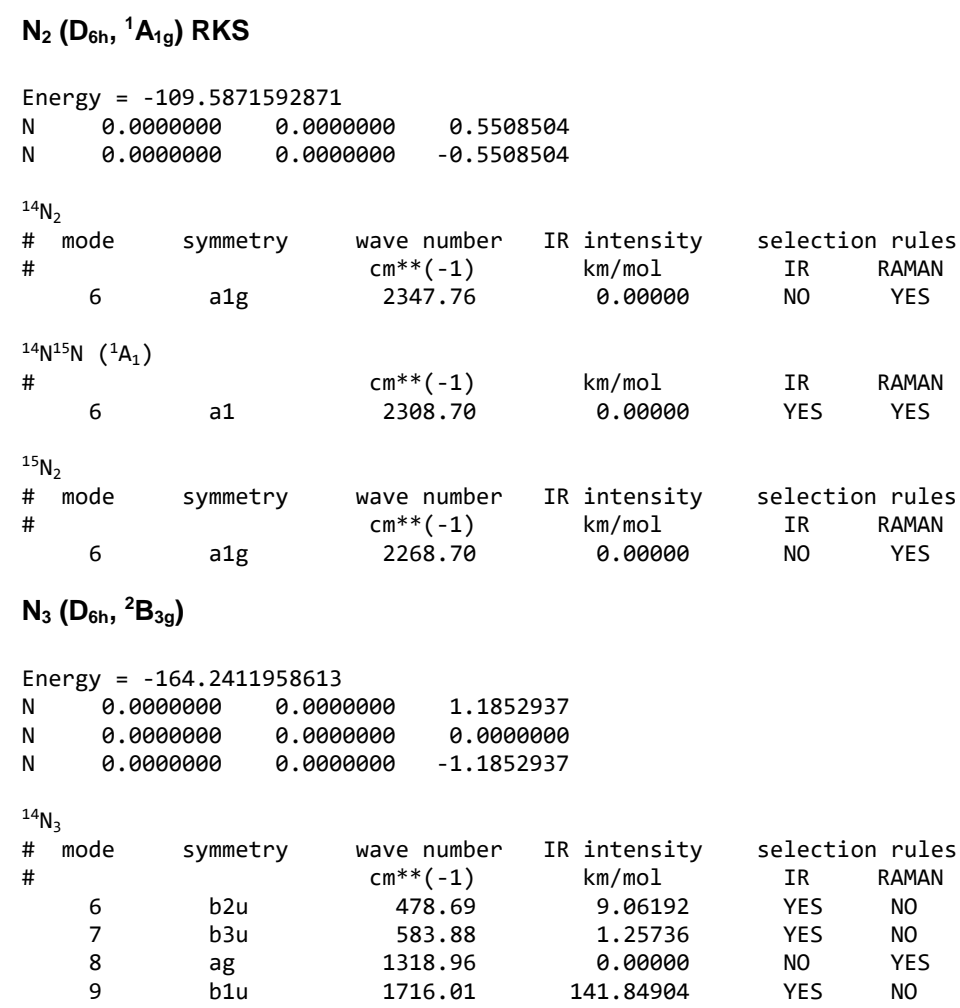

$\mathrm{N}_{3}{ }^{-}\left(D_{6 h},{ }^{1} A_{1 g}\right)$ RKS

\begin{tabular}{|c|c|c|c|c|c|c|c|c|c|}
\hline \multicolumn{10}{|c|}{ Energy $=-164.3423630893$} \\
\hline $\mathrm{N}$ & \multicolumn{2}{|c|}{0.0000000} & \multicolumn{2}{|c|}{0.0000000} & \multicolumn{2}{|c|}{1.1914452} & & & \\
\hline $\mathrm{N}$ & \multicolumn{2}{|c|}{0.0000000} & \multicolumn{2}{|c|}{0.0000000} & \multicolumn{2}{|c|}{-0.0000000} & & & \\
\hline $\mathrm{N}$ & \multicolumn{2}{|c|}{0.0000000} & \multicolumn{2}{|c|}{0.0000000} & \multicolumn{3}{|c|}{-1.1914452} & & \\
\hline \multicolumn{10}{|c|}{${ }^{14} \mathrm{~N}_{3}^{-}$} \\
\hline \# & \multirow[t]{2}{*}{ mode } & \multicolumn{2}{|c|}{ symmetry } & \multirow{2}{*}{\multicolumn{2}{|c|}{$\begin{array}{l}\text { wave number } \\
\mathrm{cm}^{* *}(-1)\end{array}$}} & \multirow[t]{2}{*}{ IR } & intensity & \multicolumn{2}{|c|}{ selection rules } \\
\hline \multirow[t]{5}{*}{ \# } & & & & & & & $\mathrm{km} / \mathrm{mol}$ & \multicolumn{2}{|c|}{ IR RAMAN } \\
\hline & 6 & \multicolumn{2}{|c|}{ e1u } & \multicolumn{2}{|c|}{630.52} & & 1.45779 & YES & NO \\
\hline & 7 & e1u & & & 0.52 & & 1.45779 & YES & NO \\
\hline & 8 & a1g & & & 6.02 & & 0.00000 & NO & YES \\
\hline & 9 & $a 2 u$ & & & 2.07 & & 893.58204 & YES & NO \\
\hline \multicolumn{10}{|c|}{${ }^{15} \mathrm{~N}_{3}^{-}$} \\
\hline \# & \multirow[t]{2}{*}{ mode } & \multirow{2}{*}{\multicolumn{2}{|c|}{ symmetry }} & \multirow{2}{*}{\multicolumn{2}{|c|}{$\begin{array}{c}\text { wave number } \\
\mathrm{cm}^{* *}(-1)\end{array}$}} & \multirow[t]{2}{*}{ IR } & intensity & \multicolumn{2}{|c|}{ selection rules } \\
\hline \multirow[t]{5}{*}{ \# } & & & & & & & $\mathrm{km} / \mathrm{mol}$ & IR & RAMAN \\
\hline & 6 & \multicolumn{2}{|c|}{ e1u } & \multicolumn{2}{|c|}{609.28} & & 1.36125 & YES & NO \\
\hline & 7 & \multicolumn{2}{|c|}{ e1u } & \multicolumn{2}{|c|}{609.28} & & 1.36125 & YES & NO \\
\hline & 8 & a1g & & & 2.37 & & 0.00000 & NO & YES \\
\hline & 9 & $a 2 u$ & & & 3.30 & & 834.40904 & YES & NO \\
\hline & ${ }^{15} \mathrm{~N}^{15} \mathrm{~N}^{-}$ & $\left.v,{ }^{1} A_{1}\right)$ & & & & & & & \\
\hline \# & mode & symme & & wave & number & IR & intensity & select & n rules \\
\hline & & & & $\mathrm{cm} *$ & $(-1)$ & & $\mathrm{km} / \mathrm{mol}$ & IR & RAMAN \\
\hline & 6 & e1 & & & 2.87 & & 1.56487 & YES & YES \\
\hline & 7 & e1 & & & 2.87 & & 1.56487 & YES & YES \\
\hline & 8 & a1 & & 12 & 3.95 & & 0.07689 & YES & YES \\
\hline & 9 & a1 & & & 35.20 & & 848.71210 & YES & YES \\
\hline
\end{tabular}




\begin{tabular}{ccccccc}
${ }^{15} \mathrm{~N}^{14} \mathrm{~N}^{14} \mathrm{~N}^{-}$ & $\left(\mathrm{C}_{6 \mathrm{v}},{ }^{1} \mathrm{~A}_{1}\right)$ & & & & \\
$\#$ & mode & symmetry & wave number & IR intensity & \multicolumn{2}{c}{ selection rules } \\
$\#$ & & & $\mathrm{Cm} * *(-1)$ & $\mathrm{km} / \mathrm{mol}$ & IR & RAMAN \\
& & e1 & 627.03 & 1.26587 & YES & YES \\
& 6 & e1 & 627.03 & 1.26587 & YES & YES \\
& a1 & 1273.98 & 0.05871 & YES & YES \\
& a1 & a1 & 2031.02 & 879.19016 & YES & YES
\end{tabular}

$\operatorname{IrN}\left(\mathrm{C}_{6 \mathrm{6v}},{ }^{1} \mathrm{~A}_{1}\right)$

Energy $=-159.2161562580$

$\begin{array}{llll}\text { Ir } & 0.0000000 & 0.0000000 & -0.7990476\end{array}$

$\begin{array}{llll}\mathrm{N} & 0.0000000 & 0.0000000 & 0.7990476\end{array}$

$\operatorname{Ir}^{14} \mathrm{~N}$

\begin{tabular}{|c|c|c|c|c|c|c|c|}
\hline \# & mode & symmetry & wave number & IR & intensity & selec & rules \\
\hline \# & & & $\mathrm{cm} * *(-1)$ & & $\mathrm{km} / \mathrm{mol}$ & IR & RAMAN \\
\hline & 6 & a1 & 1208.95 & & 36.14598 & YES & YES \\
\hline & & & & & & & \\
\hline & mode & symmetry & wave number & IR & intensity & selec & rules \\
\hline & & & $\mathrm{cm} * *(-1)$ & & km/mol & IR & RAMAN \\
\hline & 6 & a1 & 1171.04 & & 33.91496 & YES & YES \\
\hline
\end{tabular}

$\operatorname{Ir}(\mathrm{N})_{2}\left(\mathrm{C}_{2 \mathrm{v},}{ }^{2} \mathrm{~B}_{1}\right)$

\begin{tabular}{|c|c|c|c|c|c|c|c|c|c|}
\hline \multicolumn{10}{|c|}{ Energy $=-213.9559837886$} \\
\hline $\mathrm{N}$ & \multicolumn{2}{|c|}{1.4123939} & \multicolumn{2}{|c|}{0.0000000} & \multicolumn{2}{|c|}{0.3160590} & & & \\
\hline Ir & \multicolumn{2}{|c|}{0.0000000} & \multicolumn{2}{|c|}{0.0000000} & \multicolumn{2}{|c|}{-0.6321178} & & & \\
\hline $\mathrm{N}$ & \multicolumn{2}{|c|}{-1.4123939} & \multicolumn{2}{|c|}{0.0000000} & \multicolumn{2}{|c|}{0.3160590} & & & \\
\hline \multicolumn{10}{|c|}{$\operatorname{Ir}\left({ }^{14} \mathrm{~N}\right)_{2}$} \\
\hline \multirow[t]{4}{*}{ \# } & & \multicolumn{2}{|c|}{ symmetry } & \multicolumn{2}{|c|}{$\begin{array}{l}\text { wave number } \\
\mathrm{cm}^{* *}(-1)\end{array}$} & IR & $\begin{array}{l}\text { intensity } \\
\mathrm{km} / \mathrm{mol}\end{array}$ & $\begin{array}{l}\text { select } \\
\text { IR }\end{array}$ & $\begin{array}{l}\text { rules } \\
\text { RAMAN }\end{array}$ \\
\hline & 7 & a1 & & & 2.69 & & 0.02446 & YES & YES \\
\hline & 8 & b1 & & & 8.62 & & 41.44662 & YES & YES \\
\hline & 9 & a1 & & 102 & 7.06 & & 1.51089 & YES & YES \\
\hline \multicolumn{10}{|c|}{$\operatorname{Ir}\left({ }^{15} \mathrm{~N}\right)_{2}$} \\
\hline \multirow{5}{*}{ \# } & mode & \multicolumn{2}{|c|}{ symmetry } & \multirow{2}{*}{\multicolumn{2}{|c|}{$\begin{array}{l}\text { wave number } \\
\mathrm{cm} * *(-1)\end{array}$}} & \multirow[t]{2}{*}{ IR } & intensity & \multicolumn{2}{|c|}{ selection rules } \\
\hline & & & & & & & km/mol & IR & RAMAN \\
\hline & 7 & a1 & & & 0.51 & & 0.02324 & YES & YES \\
\hline & 8 & b1 & & & 2.08 & & 39.04173 & YES & YES \\
\hline & 9 & a1 & & & 4.21 & & 1.41392 & YES & YES \\
\hline \multicolumn{10}{|c|}{$\operatorname{Ir}\left({ }^{15} \mathrm{~N}\right)\left({ }^{14} \mathrm{~N}\right)\left(\mathrm{C}_{5}, \mathrm{~A}^{\prime \prime}\right)$} \\
\hline \# & mode & symme & & wave & number & IR & intensity & $\begin{array}{l}\text { select } \\
\text { IR }\end{array}$ & $\begin{array}{l}7 \text { rules } \\
\text { RAMAN }\end{array}$ \\
\hline & 7 & $a^{\prime}$ & & & 7.40 & & 0.03082 & YES & YES \\
\hline & 8 & $a^{\prime}$ & & & 2.88 & & 39.69499 & YES & YES \\
\hline & 9 & $a^{\prime}$ & & 101 & 1.80 & & 1.91496 & YES & YES \\
\hline
\end{tabular}

$\operatorname{Ir}(\mathrm{N})_{2}\left(\mathrm{C}_{2 \mathrm{v}},{ }^{2} \mathrm{~B}_{2}\right)$

Energy $=-213.9168489215$

$\begin{array}{lllr}\mathrm{N} & 1.4829328 & 0.0000000 & 0.2901401 \\ \text { Ir } & 0.0000000 & 0.0000000 & -0.5802799\end{array}$

.0000000 -0.5802799

\# mode symmetry wave number IR in

\# symmetry wave numb

$\begin{array}{lll}7 & \text { a1 } & 276.66 \\ 8 & \text { a1 } & 983.51\end{array}$

9 b1 1119.44

IR intensity $\mathrm{km} / \mathrm{mol}$

IR RAMAN

YES YES

$\begin{array}{lll}595.71207 & \text { YES } & \text { YES } \\ & \text { YES } & \text { YES }\end{array}$

$\operatorname{Ir}(\mathrm{N})_{2}\left(\mathrm{C}_{2 \mathrm{v},}{ }^{2} \mathrm{~A}_{1}\right)$

\begin{tabular}{lrrr}
\multicolumn{4}{l}{ Energy $=-213.9140155669$} \\
$\mathrm{~N}$ & 1.4875439 & 0.0000000 & 0.2814508 \\
Ir & 0.0000000 & 0.0000000 & -0.5629013 \\
$\mathrm{~N}$ & -1.4875439 & 0.0000000 & 0.2814508
\end{tabular}

\begin{tabular}{rrrrrr}
$\#$ mode & symmetry & wave number & IR intensity & \multicolumn{2}{c}{ selection rules } \\
$\#$ & & cm**(-1) & $\mathrm{km} / \mathrm{mol}$ & IR & RAMAN \\
& a1 & 346.49 & 0.80753 & YES & YES \\
8 & a1 & 990.22 & 1.15859 & YES & YES \\
9 & b1 & 1004.94 & 3.37700 & YES & YES
\end{tabular}


$\operatorname{Ir}(\mathrm{N})_{2}\left(\mathrm{C}_{2 \mathrm{v}},{ }^{4} \mathrm{~A}_{2}\right)$

\begin{tabular}{|c|c|c|c|c|c|c|c|c|c|}
\hline \multicolumn{10}{|c|}{ Energy $=-213.9321859773$} \\
\hline $\mathrm{N}$ & \multicolumn{2}{|c|}{1.5245185} & \multicolumn{2}{|c|}{0.0000000} & \multicolumn{2}{|c|}{0.2729119} & & & \\
\hline Ir & \multicolumn{2}{|c|}{0.0000000} & \multicolumn{2}{|c|}{0.0000000} & \multicolumn{2}{|c|}{-0.5458234} & & & \\
\hline $\mathrm{N}$ & \multicolumn{2}{|c|}{-1.5245185} & & 3000 & \multicolumn{3}{|c|}{0.2729119} & & \\
\hline \# & \multirow[t]{2}{*}{ mode } & \multirow{2}{*}{\multicolumn{2}{|c|}{ symmetry }} & \multirow{2}{*}{\multicolumn{2}{|c|}{$\begin{array}{l}\text { wave number } \\
\mathrm{cm} * *(-1)\end{array}$}} & \multirow[t]{2}{*}{ IR } & \multirow{2}{*}{$\begin{array}{l}\text { intensity } \\
\mathrm{km} / \mathrm{mol}\end{array}$} & \multicolumn{2}{|c|}{ selection rules } \\
\hline \# & & & & & & & & IR & RAMAN \\
\hline & 7 & a1 & & & 54.36 & & 1.92459 & YES & YES \\
\hline & 8 & b1 & & & 66.21 & & 33.49477 & YES & YES \\
\hline & 9 & a1 & & & 57.58 & & 11.11216 & YES & YES \\
\hline
\end{tabular}

$\operatorname{Ir}(\mathrm{N})_{3}\left(\mathrm{D}_{3 \mathrm{~h}},{ }^{1} \mathrm{~A}_{1}{ }^{\prime}\right)$

Energy $=-268.6541880303$

\begin{tabular}{|c|c|c|c|c|c|c|c|c|c|}
\hline$r$ & 0 & 3000 & & 0000 & 0.006 & 300 & & & \\
\hline J & & 5308 & -1 & 1241 & 0.006 & 800 & & & \\
\hline v & & 5308 & & 1241 & 0.006 & 900 & & & \\
\hline & -1 & 3616 & & 0000 & 0.006 & 300 & & & \\
\hline \# & mode & symme & try & wave & number & IR & intensity & selec & $n$ rules \\
\hline \# & & & & $\mathrm{cm}^{*}$ & $(-1)$ & & km/mol & IR & RAMAN \\
\hline & 7 & a2" & & & 4.71 & & 0.98897 & YES & NO \\
\hline & 8 & $e^{\prime}$ & & & 5.11 & & 0.61870 & YES & YES \\
\hline & 9 & $e^{\prime}$ & & & 5.11 & & 0.61870 & YES & YES \\
\hline & 10 & $e^{\prime}$ & & & 0.49 & & 0.69120 & YES & YES \\
\hline & 11 & $e^{\prime}$ & & & 0.49 & & 0.69120 & YES & YES \\
\hline & 12 & a1 & & & 8.10 & & 0.00000 & NO & YES \\
\hline
\end{tabular}

$\operatorname{Ir}\left(\mathrm{N}_{2}\right)\left(\mathrm{C}_{6 \mathrm{v}},{ }^{2} \mathrm{~A}_{2}\right)$

Energy $=-214.0303648898$

$\begin{array}{lllr}\text { Ir } & 0.0000000 & 0.0000000 & -1.5731627 \\ \mathrm{~N} & 0.0000000 & 0.0000000 & 0.2208581\end{array}$

$N \quad 0.0000000 \quad 0.0000000-1.3523046$

$\operatorname{Ir}\left({ }^{14} \mathrm{~N}_{2}\right)$

\# mode symmetry wave number

$\#$

$\mathrm{cm} * *(-1)$

IR intensity

selection rules

$\mathrm{km} / \mathrm{mol}$

2.82388

2.82388

$\begin{array}{ll}\text { YES } & \text { YES } \\ \text { YES } & \text { YES }\end{array}$

$\begin{array}{ll}\text { b1 } & 381.97 \\ \text { b2 } & 381.97\end{array}$

a1 584.12

$584.12 \quad 9.63272$

YES YES

$\operatorname{Ir}\left({ }^{15} \mathrm{~N}_{2}\right)$

\# mode

symmetry

wave number

IR intensity

selection rules

$\mathrm{cm}^{* *}(-1)$

368.85

368.85

566.85

$\mathrm{km} / \mathrm{mol}$

2.63819

2.63819

9.07778

264.17935

$\begin{array}{lc}\text { IR } & \text { RAMAN } \\ \text { YES } & \text { YES } \\ \text { YES } & \text { YES } \\ \text { YES } & \text { YES } \\ \text { YES } & \text { YES }\end{array}$

$\operatorname{Ir}\left(\mathrm{N}_{2}\right)\left(\mathrm{C}_{\mathrm{s}},{ }^{4} \mathrm{~A}^{\prime}\right)$

Energy $=-213.9887166667$

$\begin{array}{lrrr}\mathrm{N} & -0.1306671 & -0.3041779 & 0.0000000 \\ \mathrm{~N} & 0.1114863 & -1.4013518 & 0.0000000 \\ \mathrm{Ir} & 0.0191808 & 1.7055297 & 0.0000000\end{array}$

\# mode symmetry wave number

\#

7
8
9

$\begin{array}{rr} & \mathrm{cm} * *(-1) \\ \text { a }^{\prime} & 142.43 \\ \text { a }^{\prime} & 332.09 \\ \text { a }^{\prime} & 2118.96\end{array}$

IR intensity

$\mathrm{km} / \mathrm{mol}$

19.57173

0.12137

311.72410

selection rules

IR RAMAN

YES YES

YES YES

$\operatorname{Ir}\left(\mathrm{N}_{2}\right)^{-}\left(\mathrm{C}_{2 \mathrm{v}},{ }^{1} \mathrm{~A}_{1}\right)$

Energy $=-214.0996310483$ 


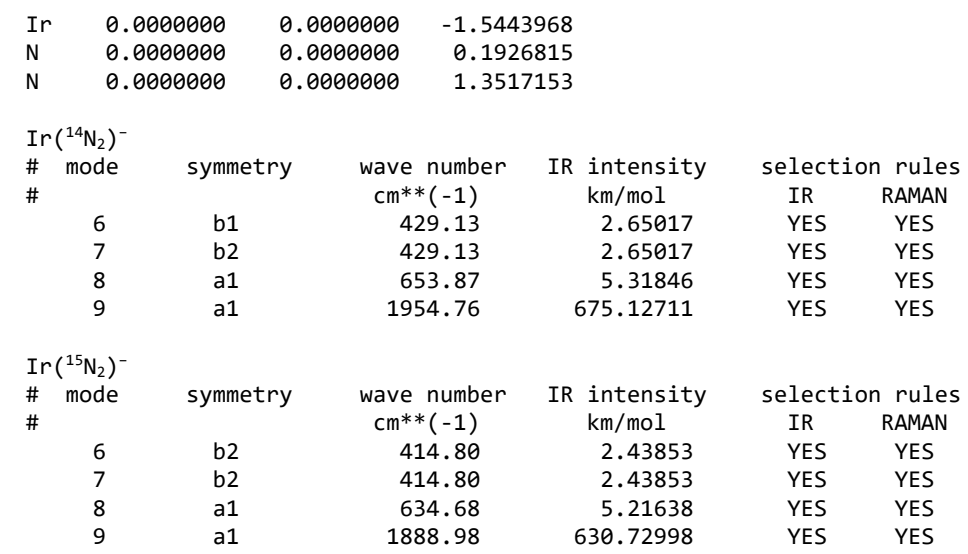

$\operatorname{Ir}\left(\mathrm{N}_{2}\right)^{+}\left(\mathrm{C}_{\mathrm{s}},{ }^{4} \mathrm{~A}^{\prime}\right)$

\begin{tabular}{|c|c|c|c|c|c|c|c|c|c|}
\hline \multicolumn{10}{|c|}{ Energy $=-213.7070345445$} \\
\hline Ir & \multicolumn{2}{|c|}{0.0000000} & \multicolumn{2}{|c|}{0.0000000} & \multicolumn{3}{|c|}{-1.6178553} & & \\
\hline $\mathrm{N}$ & \multicolumn{2}{|c|}{0.0000000} & \multicolumn{2}{|c|}{0.0000000} & \multicolumn{3}{|c|}{0.2509589} & & \\
\hline$N$ & \multicolumn{2}{|c|}{0.0000000} & & 2000 & \multicolumn{3}{|c|}{1.3668964} & & \\
\hline \multicolumn{10}{|c|}{$\operatorname{Ir}\left({ }^{14} \mathrm{~N}_{2}\right)^{+}$} \\
\hline \multirow{6}{*}{$\begin{array}{l}\text { \# } \\
\text { \# }\end{array}$} & node & \multirow{2}{*}{\multicolumn{2}{|c|}{ symmetry }} & \multirow{2}{*}{\multicolumn{2}{|c|}{$\begin{array}{l}\text { wave number } \\
\mathrm{cm} * *(-1)\end{array}$}} & \multirow[t]{2}{*}{ IR } & intensity & \multicolumn{2}{|c|}{ selection rules } \\
\hline & & & & & & & km/mol & IR & RAMAN \\
\hline & 6 & \multicolumn{2}{|c|}{ b2 } & \multicolumn{2}{|c|}{341.18} & & 0.90551 & YES & YES \\
\hline & 7 & b2 & & \multicolumn{2}{|c|}{341.18} & & 0.90551 & YES & YES \\
\hline & 8 & a1 & & \multicolumn{2}{|c|}{487.91} & & 15.23200 & YES & YES \\
\hline & 9 & a1 & & \multicolumn{2}{|c|}{2211.96} & & 48.49148 & YES & YES \\
\hline \multicolumn{10}{|c|}{$\operatorname{Ir}\left({ }^{15} \mathrm{~N}_{2}\right)^{+}$} \\
\hline \multirow{6}{*}{$\begin{array}{l}\# \\
\# \\
\#\end{array}$} & node & \multirow{2}{*}{\multicolumn{2}{|c|}{ symmetry }} & \multirow{2}{*}{\multicolumn{2}{|c|}{$\begin{array}{l}\text { wave number } \\
\mathrm{cm} * *(-1)\end{array}$}} & \multirow[t]{2}{*}{ IR } & intensity & \multicolumn{2}{|c|}{ selection rules } \\
\hline & & & & & & & km/mol & IR & RAMAN \\
\hline & 6 & b2 & & & 9.77 & & 0.86805 & YES & YES \\
\hline & 7 & b2 & & & 9.77 & & 0.86805 & YES & YES \\
\hline & 8 & a1 & & & 3.60 & & 13.99107 & YES & YES \\
\hline & 9 & a1 & & 213 & 7.47 & & 45.27682 & YES & YES \\
\hline
\end{tabular}

$\operatorname{Ir}\left(\mathrm{N}_{2}\right)_{2}\left(\mathrm{D}_{2 \mathrm{~h}}{ }^{2} \mathrm{~A}_{\mathrm{g}}\right)$

\begin{tabular}{lllr}
\multicolumn{4}{l}{ Energy $=-323.6864664802$} \\
Ir & 0.0000000 & 0.0000000 & 0.0000000 \\
N & 0.0000000 & 0.0000000 & 1.8991645 \\
N & 0.0000000 & 0.0000000 & 3.0198683 \\
N & 0.0000000 & 0.0000000 & -1.8991645 \\
N & 0.0000000 & 0.0000000 & -3.0198683
\end{tabular}

$\operatorname{Ir}\left({ }^{14} \mathrm{~N}_{2}\right)_{2}$

$\begin{array}{cccc}\# \text { mode } & \text { symmetry } & \begin{array}{c}\text { wave number } \\ \mathrm{cm} * *(-1)\end{array} \\ \# & & \text { b3u } & 75.49 \\ & 6 & \text { b2u } & 75.50 \\ 7 & \text { b3g } & 326.53 \\ 8 & \text { b2g } & 326.54 \\ 9 & \text { b1u } & 439.41 \\ 10 & \text { b3u } & 463.30 \\ 11 & \text { b2u } & 463.35 \\ 12 & \text { ag } & 490.52 \\ 13 & \text { b1u } & 2148.81 \\ 14 & \text { ag } & 2200.37 \\ 15 & & \end{array}$

$\operatorname{Ir}\left({ }^{15} \mathrm{~N}_{2}\right)_{2}$

\# mode

\#

$\begin{array}{rl}6 & \mathrm{~b} 3 \\ 7 & \mathrm{~b} 2 \\ 8 & \mathrm{~b} 3 \\ 9 & \mathrm{~b} 2 \\ 10 & \mathrm{~b} 1 \\ 11 & \mathrm{~b} 3 \\ 12 & \mathrm{~b} 2 \\ 13 & \mathrm{ag} \\ 14 & \mathrm{~b} 1 \\ 15 & \mathrm{ag}\end{array}$

symmetry

b3u
b2u
b3g
b2g
b1u
b3u
b2u
ag
b1u
ag

$\operatorname{Ir}\left({ }^{15} \mathrm{~N}_{2}\right)\left({ }^{14} \mathrm{~N}_{2}\right)\left(\mathrm{C}_{2 \mathrm{v}},{ }^{2} \mathrm{~A}_{1}\right)$

\# mode symmetry

$6 \quad$ b1 wave number $\mathrm{cm} * *(-1)$

73.42

73.43

315.54

315.55

428.00

448.36

448.40

474.00

2076.44

2126.27

$\mathrm{cm} * *(-1)$ wave number
IR intensity $\mathrm{km} / \mathrm{mol}$

0.27235

0.27235

0.00000

0.00000

99.53577

0.03105

0.03085

0.00000

1001.24580

0.00000

IR intensity $\mathrm{km} / \mathrm{mol}$

0.25760

0.25760

0.00000

0.00000

94.43042

0.03018

0.03000

0.00000

934.98223

0.00000

IR intensity $\mathrm{km} / \mathrm{mol}$

0.26496

\begin{tabular}{ll}
\multicolumn{2}{c}{ selection } \\
IR & rules \\
YES & NO \\
YES & NO \\
NO & YES \\
NO & YES \\
YES & NO \\
YES & NO \\
YES & NO \\
NO & YES \\
YES & NO \\
NO & YES
\end{tabular}

selection rules

$\begin{array}{ll}\text { IR } & \text { RAMAN } \\ \text { YES } & \text { NO } \\ \text { YES } & \text { NO } \\ \text { NO } & \text { YES } \\ \text { NO } & \text { YES } \\ \text { YES } & \text { NO } \\ \text { YES } & \text { NO } \\ \text { YES } & \text { NO } \\ \text { NO } & \text { YES } \\ \text { YES } & \text { NO } \\ \text { NO } & \text { YES }\end{array}$

selection rules

IR RAMAN 


$\begin{array}{rrrrrr}7 & \text { b2 } & 74.47 & 0.26495 & \text { YES } & \text { YES } \\ 8 & \text { b2 } & 320.74 & 0.00010 & \text { YES } & \text { YES } \\ 9 & \text { b1 } & 320.75 & 0.00010 & \text { YES } & \text { YES } \\ 10 & \text { a1 } & 432.74 & 94.71981 & \text { YES } & \text { YES } \\ 11 & \text { b1 } & 456.14 & 0.03053 & \text { YES } & \text { YES } \\ 12 & \text { b2 } & 456.18 & 0.03034 & \text { YES } & \text { YES } \\ 13 & \text { a1 } & 483.23 & 2.26519 & \text { YES } & \text { YES } \\ 14 & \text { a1 } & 2093.45 & 745.54068 & \text { YES } & \text { YES } \\ 15 & \text { a1 } & 2182.49 & 222.57143 & \text { YES } & \text { YES }\end{array}$

$\operatorname{Ir}\left(\mathrm{N}_{2}\right)_{2}\left(\mathrm{D}_{2 \mathrm{~h}},{ }^{4} \mathrm{~B}_{2 \mathrm{u}}\right)$

\begin{tabular}{llrr}
\multicolumn{5}{c}{ Energy $=-323.5917128454$} & \\
Ir & 0.0000000 & 0.0000000 & 0.0000000 \\
N & 0.0000000 & 0.0000000 & 1.9197455 \\
N & 0.0000000 & 0.0000000 & 3.0595303 \\
N & 0.0000000 & 0.0000000 & -1.9197455 \\
N & 0.0000000 & 0.0000000 & -3.0595303
\end{tabular}

\begin{tabular}{rcrrrr}
$\#$ mode & symmetry & wave number & IR intensity & \multicolumn{2}{c}{ selection rules } \\
\# & & cm**(-1) & $\mathrm{km} / \mathrm{mol}$ & IR & RAMAN \\
6 & b2u & 87.71 & 2.25204 & YES & NO \\
7 & b3u & 95.54 & 1.80407 & YES & NO \\
8 & b3u & 276.08 & 29.91069 & YES & NO \\
9 & b3g & 315.71 & 0.00000 & NO & YES \\
10 & b2g & 368.99 & 0.00000 & NO & YES \\
11 & b1u & 443.80 & 0.04404 & YES & NO \\
12 & ag & 475.61 & 0.00000 & NO & YES \\
13 & b2u & 493.01 & 0.12332 & YES & NO \\
14 & b1u & 1963.81 & 1793.21471 & YES & NO \\
15 & ag & 2055.51 & 0.00000 & NO & YES
\end{tabular}

$\operatorname{Ir}\left(\mathrm{N}_{2}\right)_{2}{ }^{+}\left(D_{2 h},{ }^{3} A_{g}\right)$

$\begin{array}{lllr}\text { Energy }=-323.3643926816 & \\ \text { Ir } & 0.0000000 & 0.0000000 & 0.0000000 \\ N & 0.0000000 & 0.0000000 & 1.9555958 \\ N & 0.0000000 & 0.0000000 & 3.0659497 \\ N & 0.0000000 & 0.0000000 & -1.9555958 \\ N & 0.0000000 & 0.0000000 & -3.0659497\end{array}$

\begin{tabular}{rcrrrl} 
\# & mode & symmetry & $\begin{array}{c}\text { wave number } \\
\text { \# } \text { I }^{*}(-1)\end{array}$ & $\begin{array}{c}\text { IR intensity } \\
\mathrm{km} / \mathrm{mol}\end{array}$ & \multicolumn{2}{c}{ selection rules } \\
& & IR & RAMAN \\
6 & b2u & 85.52 & 0.10171 & YES & NO \\
7 & b3u & 85.52 & 0.10171 & YES & NO \\
8 & b2g & 304.51 & 0.00000 & NO & YES \\
9 & b3g & 304.51 & 0.00000 & NO & YES \\
10 & b1u & 383.06 & 48.38707 & YES & NO \\
11 & ag & 430.73 & 0.00000 & NO & YES \\
12 & b2u & 470.20 & 0.61928 & YES & NO \\
13 & b3u & 470.20 & 0.61928 & YES & NO \\
14 & b1u & 2242.64 & 173.28622 & YES & NO \\
15 & ag & 2269.64 & 0.00000 & NO & YES
\end{tabular}

$\operatorname{Ir}\left(\mathrm{N}_{2}\right)_{2}{ }^{+}\left(\mathrm{D}_{2 \mathrm{~h}},{ }^{1} \mathrm{~A}_{\mathrm{g}}\right)$

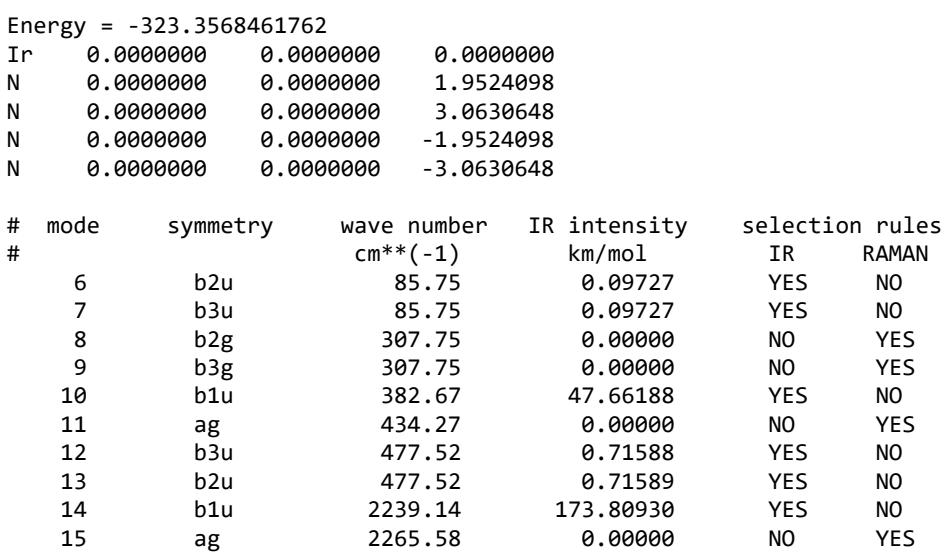

$\operatorname{Ir}\left(\mathrm{N}_{2}\right)_{2}{ }^{+}\left(\mathrm{D}_{2 \mathrm{~h}},{ }^{1} \mathrm{~A}_{\mathrm{g}}\right)$

Energy $=-323.3272925494$

$\begin{array}{lrrr}\text { Ir } & 0.0000000 & 0.0000000 & 0.0000000 \\ \text { N } & 0.0000000 & 0.0000000 & 1.9378028 \\ \text { N } & 0.0000000 & 0.0000000 & 3.0506974 \\ \text { N } & 0.0000000 & 0.0000000 & -1.9378028\end{array}$




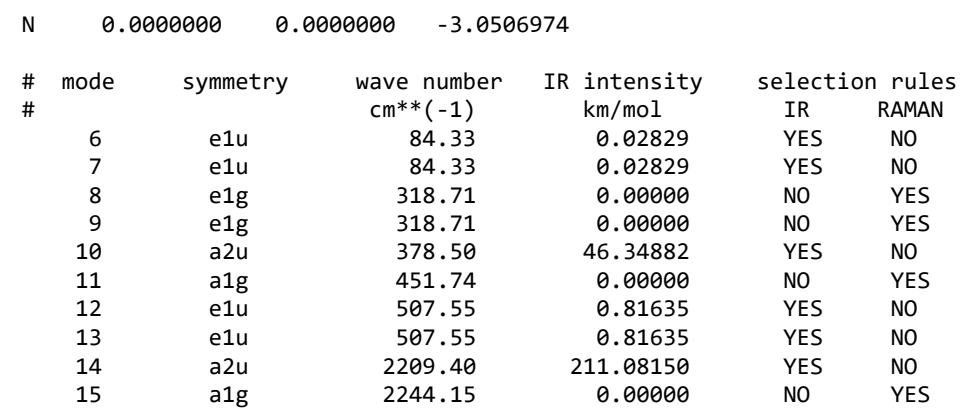

$\operatorname{Ir}\left(\mathrm{N}_{2}\right)_{2}{ }^{-}\left(\mathrm{C}_{2 \mathrm{v},}{ }^{1} \mathrm{~A}_{1}\right)$

\begin{tabular}{lrrr}
\multicolumn{4}{l}{ Energy $=-323.7712152965$} \\
$\mathrm{~N}$ & -1.8251145 & 0.0000000 & 0.0646127 \\
$\mathrm{~N}$ & -2.9215603 & 0.0000000 & -0.259736 \\
$\mathrm{Ir}$ & 0.0000000 & 0.0000000 & 0.3902468 \\
$\mathrm{~N}$ & 1.8251145 & 0.0000000 & 0.0646127 \\
$\mathrm{~N}$ & 2.9215603 & 0.0000000 & -0.259736
\end{tabular}

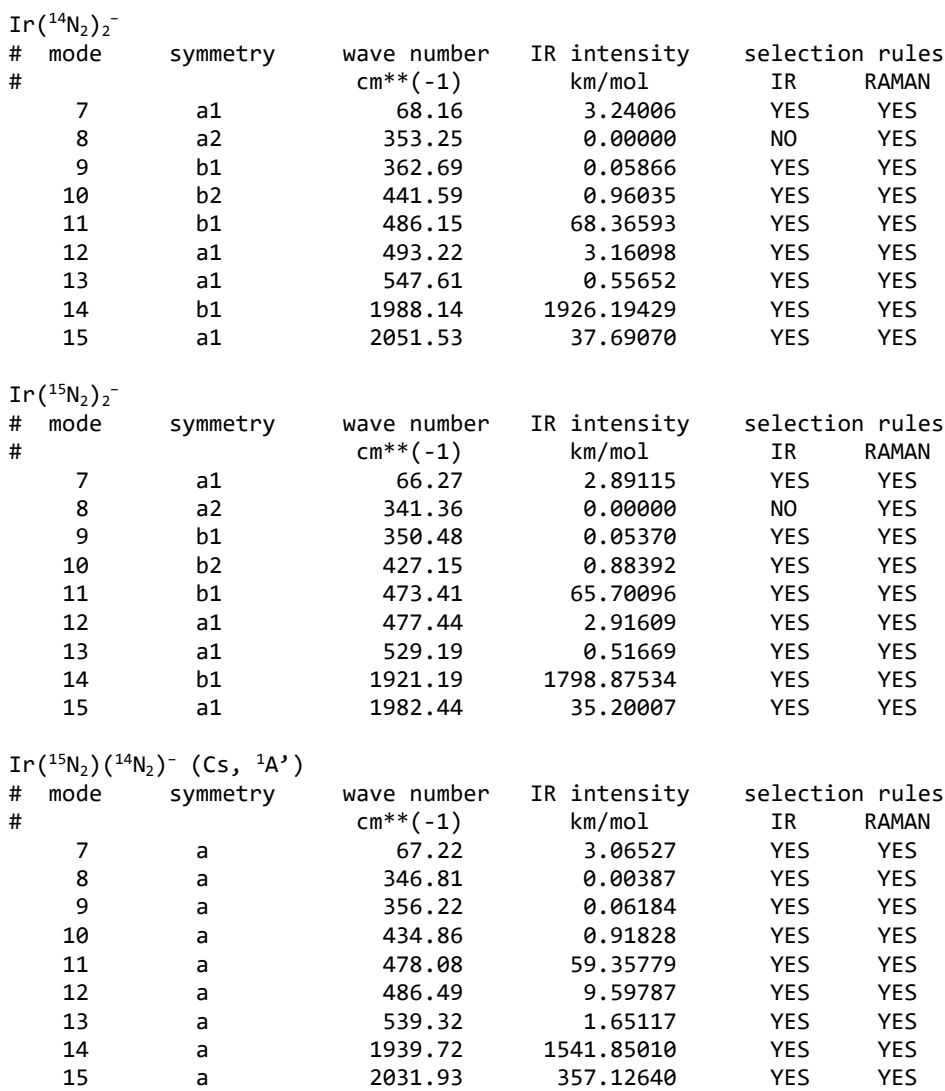

$\operatorname{Ir}\left(\mathrm{N}_{3}\right)\left(\mathrm{C}_{\mathrm{s}},{ }^{3} \mathrm{~A}^{\prime \prime}\right)$

Energy $=-268.7297430506$

$\begin{array}{lrrr}\text { Ir } & -0.8727706 & 1.8857263 & 0.0000000 \\ \mathrm{~N} & -0.7277581 & 0.0225820 & 0.0000000 \\ \mathrm{~N} & 0.3642280 & -0.5803123 & 0.0000000 \\ \mathrm{~N} & 1.2363008 & -1.3279960 & 0.0000000\end{array}$

\begin{tabular}{rrrrrr}
$\#$ mode & symmetry & wave number & IR intensity & \multicolumn{2}{c}{ selection rules } \\
\# & & cm** $(-1)$ & $\mathrm{km} / \mathrm{mol}$ & IR & RAMAN \\
7 & $a^{\prime}$ & 143.79 & 3.56380 & YES & YES \\
8 & $a^{\prime}$ & 430.61 & 3.54809 & YES & YES \\
9 & $a^{\prime \prime}$ & 443.15 & 1.37139 & YES & YES \\
10 & $a^{\prime}$ & 671.92 & 5.10472 & YES & YES \\
11 & $a^{\prime}$ & 1152.81 & 53.23297 & YES & YES \\
12 & $a^{\prime}$ & 2019.81 & 407.41122 & YES & YES
\end{tabular}

$\operatorname{IrNNIr}\left(D_{2 h},{ }^{3} B_{1 u}\right)$

Energy $=-318.4719683227$ 


\begin{tabular}{|c|c|c|c|c|c|c|c|c|c|}
\hline Ir & \multicolumn{2}{|c|}{0.0000000} & \multicolumn{2}{|c|}{0.0000000} & \multicolumn{3}{|c|}{-2.3766401} & & \\
\hline $\mathrm{N}$ & \multicolumn{2}{|c|}{0.0000000} & \multicolumn{2}{|c|}{0.0000000} & \multicolumn{3}{|c|}{-0.5754674} & & \\
\hline $\mathrm{N}$ & \multicolumn{2}{|c|}{0.0000000} & \multicolumn{2}{|c|}{0.0000000} & \multicolumn{3}{|c|}{0.5754674} & & \\
\hline Ir & \multicolumn{2}{|c|}{0.0000000} & \multicolumn{2}{|c|}{0.0000000} & \multicolumn{3}{|c|}{2.3766401} & & \\
\hline \multicolumn{10}{|c|}{$\mathrm{Ir}^{14} \mathrm{~N}^{14} \mathrm{NIr}$} \\
\hline \multirow{7}{*}{$\begin{array}{l}\# \\
\#\end{array}$} & & \multirow{2}{*}{\multicolumn{2}{|c|}{ symmetry }} & \multirow{2}{*}{\multicolumn{2}{|c|}{$\begin{array}{l}\text { wave number } \\
\mathrm{cm}^{* *}(-1)\end{array}$}} & \multirow[t]{2}{*}{ IR } & \multirow{2}{*}{$\begin{array}{l}\text { intensity } \\
\mathrm{km} / \mathrm{mol}\end{array}$} & \multicolumn{2}{|c|}{ selection rules } \\
\hline & & & & & & & & IR & RAMAN \\
\hline & 6 & b2u & & & 1.33 & & 6.24364 & YES & NO \\
\hline & 7 & b3c & & & 1.33 & & 6.24364 & YES & NO \\
\hline & 8 & ag & & & 3.20 & & 0.00000 & NO & YES \\
\hline & 9 & b3g & & & 6.80 & & 0.00000 & NO & YES \\
\hline & 10 & $b 2 \xi$ & & & 6.80 & & 0.00000 & NO & YES \\
\hline & 11 & b1c & & & 31.81 & & 161.57713 & YES & NO \\
\hline & 12 & ag & & & 30.71 & & 0.00000 & NO & YES \\
\hline \multicolumn{10}{|c|}{$\operatorname{Ir}{ }^{15} \mathrm{~N}^{15} \mathrm{NIr}$} \\
\hline \# & node & \multirow{2}{*}{\multicolumn{2}{|c|}{ symmetry }} & \multirow{2}{*}{\multicolumn{2}{|c|}{$\begin{array}{c}\text { wave number } \\
\mathrm{cm}^{* *}(-1)\end{array}$}} & \multirow[t]{2}{*}{ IR } & intensity & \multicolumn{2}{|c|}{ selection rules } \\
\hline & & & & & & & $\mathrm{km} / \mathrm{mol}$ & IR & RAMAN \\
\hline \multirow{7}{*}{ \# } & 6 & b2u & & & 7.84 & & 5.85827 & YES & NO \\
\hline & 7 & b3c & & & 7.84 & & 5.85827 & YES & NO \\
\hline & 8 & ag & & & 3.20 & & 0.00000 & NO & YES \\
\hline & 9 & b3g & & & 18.19 & & 0.00000 & NO & YES \\
\hline & 10 & $b 2 \xi$ & & & 18.19 & & 0.00000 & NO & YES \\
\hline & 11 & b1u & & & 7.29 & & 151.60420 & YES & NO \\
\hline & 12 & ag & & & 0.69 & & 0.00000 & NO & YES \\
\hline \multicolumn{10}{|c|}{$\operatorname{Ir}{ }^{14} N^{15} \mathrm{NIr}\left(C_{2 v},{ }^{3} A_{1}\right)$} \\
\hline \# & mode & symme & & wave & number & IR & intensity & select & n rules \\
\hline \# & & & & $\mathrm{cm} *$ & $(-1)$ & & $\mathrm{km} / \mathrm{mol}$ & IR & RAMAN \\
\hline & 6 & b2 & & & 9.52 & & 6.04099 & YES & YES \\
\hline & 7 & b1 & & & 9.52 & & 6.04099 & YES & YES \\
\hline & 8 & a1 & & & 3.20 & & 0.00000 & YES & YES \\
\hline & 9 & b2 & & & 2.57 & & 0.00997 & YES & YES \\
\hline & 10 & b1 & & & 2.57 & & 0.00997 & YES & YES \\
\hline & 11 & a1 & & & 99.16 & & 156.35928 & YES & YES \\
\hline & 12 & a1 & & 20 & 16.18 & & 0.23139 & YES & YES \\
\hline
\end{tabular}

$\operatorname{NIr}\left(\mathrm{N}_{2}\right)\left(\mathrm{C}_{\mathrm{s}},{ }^{1} \mathrm{~A}^{\prime}\right)$

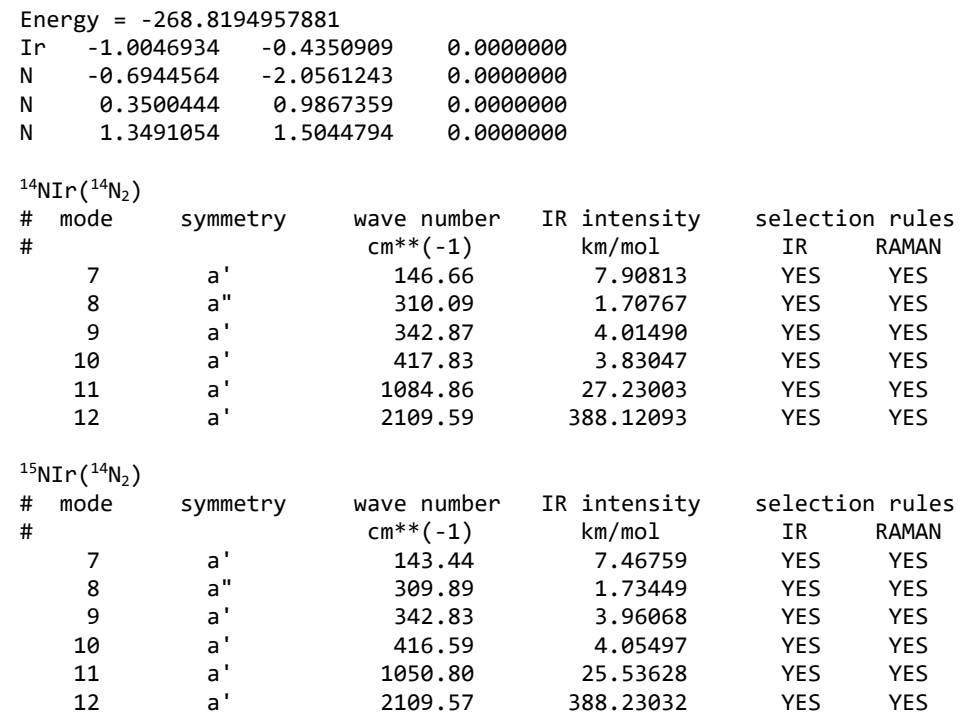

$\operatorname{IrIrN}\left(\mathrm{C}_{\mathrm{s},}{ }^{2} \mathrm{~A}^{\prime}\right)$

\begin{tabular}{|c|c|c|c|c|c|c|c|c|c|}
\hline \multicolumn{10}{|c|}{ Energy $=-263.7144182651$} \\
\hline Ir & \multicolumn{2}{|c|}{-0.5963376} & \multicolumn{2}{|c|}{1.8879672} & \multicolumn{3}{|c|}{0.0000000} & & \\
\hline Ir & \multicolumn{2}{|c|}{-0.3190028} & \multicolumn{2}{|c|}{-0.3927475} & \multicolumn{3}{|c|}{0.0000000} & & \\
\hline $\mathrm{N}$ & \multicolumn{2}{|c|}{0.9153404} & -1 & 2197 & \multicolumn{3}{|c|}{0.0000000} & & \\
\hline \multicolumn{10}{|c|}{$\operatorname{Ir} \operatorname{Ir}^{14} \mathrm{~N}$} \\
\hline & mode & \multicolumn{2}{|c|}{ symmetry } & \multicolumn{2}{|c|}{ wave number } & \multirow[t]{2}{*}{ IR } & intensity & \multicolumn{2}{|c|}{ selection rules } \\
\hline \multirow{4}{*}{ \# } & & & & \multicolumn{2}{|c|}{$\mathrm{cm} * *(-1)$} & & $\mathrm{km} / \mathrm{mol}$ & IR & RAMAN \\
\hline & 7 & \multicolumn{2}{|c|}{$a^{\prime}$} & & 5.80 & & 5.85343 & YES & YES \\
\hline & 8 & $a^{\prime}$ & & & 1.76 & & 0.95737 & YES & YES \\
\hline & 9 & $a^{\prime}$ & & & 4.29 & & 60.02501 & YES & YES \\
\hline \multicolumn{10}{|c|}{$\operatorname{IrIr}^{15} \mathrm{~N}$} \\
\hline \multirow{3}{*}{$\begin{array}{l}\# \\
\#\end{array}$} & mode & \multirow{2}{*}{\multicolumn{2}{|c|}{ symmetry }} & \multirow{2}{*}{\multicolumn{2}{|c|}{$\begin{array}{l}\text { wave number } \\
\mathrm{cm} * *(-1)\end{array}$}} & \multirow{3}{*}{ IR } & intensity & \multicolumn{2}{|c|}{ selection rules } \\
\hline & & & & & & & $\mathrm{km} / \mathrm{mol}$ & IR & RAMAN \\
\hline & 7 & $a^{\prime}$ & & & 2.86 & & 5.46297 & YES & YES \\
\hline
\end{tabular}




$\begin{array}{rlrrrr}8 & a^{\prime} & 221.66 & 0.95186 & \text { YES } & \text { YES } \\ 9 & a^{\prime} & 1021.00 & 56.40977 & \text { YES } & \text { YES }\end{array}$

\section{BP86/ZORA-def2-TZVPP(N)/SARC-ZORA-TZVPP(Ir)}

\begin{tabular}{|c|c|c|c|c|c|c|}
\hline \multicolumn{7}{|c|}{$\operatorname{Ir}(\mathrm{N})_{2}\left(\mathrm{C}_{1},{ }^{2} \mathrm{~A}\right)$} \\
\hline \multicolumn{7}{|c|}{ Energy $=-18527.459076532468$} \\
\hline Ir & \multicolumn{2}{|c|}{-0.00000005284280} & \multicolumn{2}{|c|}{0.00000000000000} & \multicolumn{2}{|c|}{-0.63128496123684} \\
\hline $\mathrm{N}$ & \multicolumn{2}{|c|}{-1.41022715939508} & \multicolumn{2}{|c|}{0.00000000000000} & \multicolumn{2}{|c|}{0.31564266296423} \\
\hline $\mathrm{N}$ & \multicolumn{2}{|c|}{1.41022721223788} & \multicolumn{2}{|c|}{0.00000000000000} & \multicolumn{2}{|c|}{0.31564269827261} \\
\hline \multicolumn{2}{|c|}{ Mode } & freq $(\mathrm{cm} * *-1)$ & $\mathrm{T} * * 2$ & TX & TY & $T Z$ \\
\hline & & & & & & \\
\hline & : & 392.86 & 0.015350 & $(-0.000000$ & 0.000000 & $-0.123897)$ \\
\hline & : & 878.80 & 37.913039 & $(-6.157356$ & -0.000000 & $0.000007)$ \\
\hline & 8: & 1035.26 & 1.480248 & $(-0.000023$ & 0.000000 & $1.216654)$ \\
\hline
\end{tabular}

$\operatorname{Ir}(\mathrm{N})_{2}$ TS $\left(\mathrm{C}_{1},{ }^{2} \mathrm{~A}\right)$

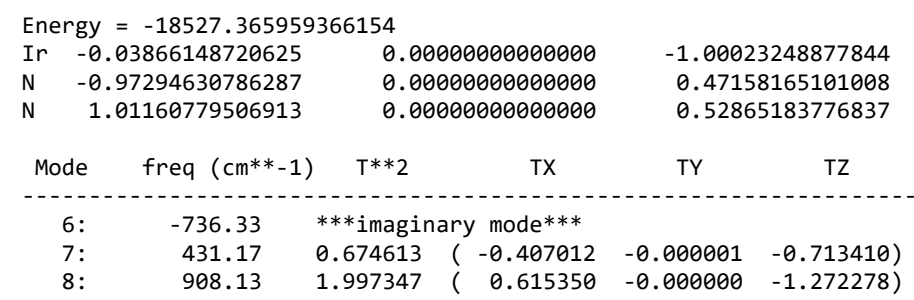

$\operatorname{Ir}(\mathrm{N})_{2}$ TS $\left(\mathrm{C}_{1},{ }^{4} \mathrm{~A}\right)$

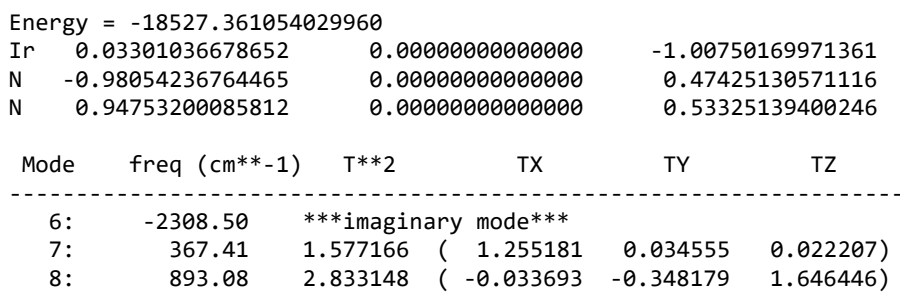

$\operatorname{Ir}\left(\mathrm{N}_{2}\right)\left(\mathrm{C}_{1},{ }^{2} \mathrm{~A}\right)$

Energy $=-18527.508956688940$

\begin{tabular}{|c|c|c|c|c|c|}
\hline Ir & -0.00000000066953 & \multicolumn{2}{|c|}{-0.00000000031987} & \multicolumn{2}{|c|}{-1.56484112101323} \\
\hline$e$ & 0.00000000133903 & \multicolumn{2}{|c|}{0.00000000063987} & \multicolumn{2}{|c|}{0.21341197152127} \\
\hline & -0.00000000066950 & \multicolumn{2}{|c|}{-0.00000000031999} & \multicolumn{2}{|c|}{1.35142914949195} \\
\hline Mode & freq $\left(\mathrm{cm}^{* *-1}\right)$ & $\mathrm{T} * * 2$ & TX & TY & $T Z$ \\
\hline & & & & & \\
\hline 6 & $5:$ & 1.514508 & & & 0.0000 \\
\hline 7 & .92 & 11.39339 & 0.000 & 0.000 & $-3.375410)$ \\
\hline 8 & 2074.84 & 27.932089 & $(-0.000000$ & -0.000000 & 18.108895) \\
\hline
\end{tabular}

$\operatorname{Ir}(\mathrm{N})_{3}\left(\mathrm{C}_{1},{ }^{1} \mathrm{~A}\right) \mathrm{RKS}$

\begin{tabular}{|c|c|c|c|c|c|}
\hline \multicolumn{6}{|c|}{ Energy $=-18582.208568531445$} \\
\hline $\mathrm{N}$ & 0.877993 & 1.520731 & -0.000000 & & \\
\hline Ir & -0.000001 & 0.000000 & 0.000000 & & \\
\hline $\mathrm{N}$ & 0.877993 & -1.520731 & -0.000000 & & \\
\hline $\mathrm{N}$ & -1.755985 & 0.000000 & -0.000000 & & \\
\hline Mode & freq $\left(\mathrm{cm}^{* *-1}\right.$ & $\mathrm{T} * * 2$ & TX & TY & TZ \\
\hline 6: & 142.84 & 0.795457 & 0.000000 & 0.000000 & $0.891884)$ \\
\hline 7: & 189.97 & 0.508095 & $(-0.712808$ & 0.000045 & $-0.000000)$ \\
\hline 8: & 190.14 & 0.507954 & 0.000045 & 0.712709 & $-0.000000)$ \\
\hline 9: & 788.71 & 0.688991 & 0.830055 & 0.000374 & $-0.000000)$ \\
\hline 10: & 788.72 & 0.688937 & -0.000374 & 0.830022 & $-0.000000)$ \\
\hline 11: & 976.94 & 0.000000 & 0.000059 & 0.000000 & $0.000000)$ \\
\hline
\end{tabular}

$\operatorname{Ir}(\mathrm{N})_{3}\left(\mathrm{C}_{1},{ }^{1} \mathrm{~A}\right)$

$\begin{array}{lrrr}\text { Energy } & = & -18582.208568533388 & \\ \mathrm{~N} & 0.877996 & 1.520736 & 0.000000 \\ \text { Ir } & -0.000002 & 0.000000 & -0.000000\end{array}$




\begin{tabular}{|c|c|c|c|c|c|}
\hline $\mathrm{N}$ & 0.877996 & -1.520736 & 0.000000 & & \\
\hline N & -1.755990 & 0.000000 & 0.000000 & & \\
\hline Mode & freq $\left(\mathrm{cm}^{* *}-1\right)$ & $\mathrm{T} * * 2$ & TX & TY & $\mathrm{TZ}$ \\
\hline 6: & 142.86 & 0.795777 & -0.000000 & 0.000000 & $-0.892063)$ \\
\hline 7: & 189.98 & 0.508199 & 0.712881 & 0.000024 & $0.000000)$ \\
\hline 8: & 190.15 & 0.507974 & -0.000029 & 0.712723 & $-0.000000)$ \\
\hline 9: & 788.70 & 0.689450 & 0.830266 & -0.010414 & $-0.000000)$ \\
\hline 10: & 788.70 & 0.689159 & 0.010430 & 0.830091 & $-0.000000)$ \\
\hline 11: & 976.93 & 0.000000 & 0.000075 & -0.000010 & $0.000000)$ \\
\hline
\end{tabular}

$\operatorname{Ir}(\mathrm{N})_{3}$ TS $\left(\mathrm{C}_{1},{ }^{1} \mathrm{~A}\right)$ RKS

Energy $=-18582 \cdot 191698412571$

\begin{tabular}{|c|c|c|c|c|c|}
\hline $\mathrm{N}$ & 0.98504117841954 & \multicolumn{2}{|c|}{1.70618191713348} & \multicolumn{2}{|c|}{-0.01726953128539} \\
\hline Ir & 0.13626371759078 & \multicolumn{2}{|c|}{0.23596137442520} & \multicolumn{2}{|c|}{-0.00256235402343} \\
\hline $\mathrm{N}$ & 0.41847717313611 & \multicolumn{2}{|c|}{-1.53641771301031} & \multicolumn{2}{|c|}{0.00986257570181} \\
\hline-3 & -1.53978106914643 & \multicolumn{2}{|c|}{-0.40572557854836} & \multicolumn{2}{|c|}{0.00996930960701} \\
\hline Mode & freq $\left(\mathrm{cm}^{* *-1}\right)$ & $\mathrm{T} * * 2$ & $\mathrm{TX}$ & TY & $T Z$ \\
\hline 6: & -315.28 & $* * *$ imagi & ary mode*** & & \\
\hline 7: & 123.26 & 1.381596 & $(-0.001127$ & -0.010960 & $-1.175362)$ \\
\hline 8: & 189.88 & 5.598902 & $(-2.049855$ & 1.181945 & $-0.002140)$ \\
\hline 9: & 799.34 & 0.086670 & $(-0.255809$ & 0.145710 & $0.000010)$ \\
\hline 10: & 857.65 & 28.574006 & ( 2.672182 & 4.629386 & $-0.047255)$ \\
\hline 11: & 1000.79 & 14.419617 & $(-1.898642$ & -3.288417 & $0.032987)$ \\
\hline
\end{tabular}

$\operatorname{Ir}(\mathrm{N})_{3} \operatorname{TS}\left(\mathrm{C}_{1},{ }^{3} \mathrm{~A}\right)$

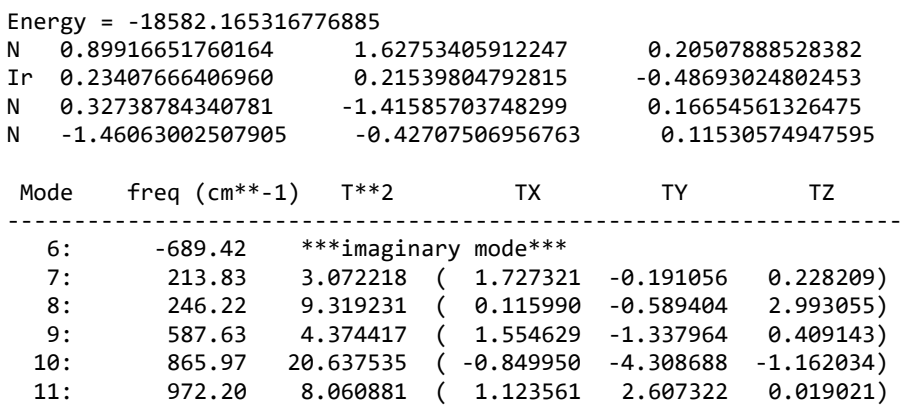

\section{$\operatorname{Ir}(\mathrm{N})\left(\mathrm{N}_{2}\right)\left(\mathrm{C}_{1},{ }^{3} \mathrm{~A}\right) \mathrm{RKS}$}

\begin{tabular}{|c|c|c|c|c|c|c|c|}
\hline \multicolumn{8}{|c|}{ Energy = } \\
\hline Ir & \multicolumn{3}{|c|}{-0.99843601031668} & \multicolumn{2}{|c|}{-0.43465654378306} & \multicolumn{2}{|c|}{0.00001460729074} \\
\hline $\mathrm{N}$ & \multicolumn{3}{|c|}{-0.69857605006467} & \multicolumn{2}{|c|}{-2.05566281879788} & \multicolumn{2}{|c|}{-0.00000414845203} \\
\hline $\mathrm{N}$ & \multicolumn{3}{|c|}{0.35043497938319} & \multicolumn{2}{|c|}{0.98244325687028} & \multicolumn{2}{|c|}{-0.00002586909360} \\
\hline $\mathrm{N}$ & \multicolumn{3}{|c|}{1.34657708099816} & \multicolumn{2}{|c|}{1.50787610571065} & \multicolumn{2}{|c|}{0.00001541025489} \\
\hline \multicolumn{2}{|c|}{ Mode } & \multicolumn{2}{|l|}{ freq $(\mathrm{cm} * *-1)$} & $\mathrm{T} * * 2$ & $T X$ & TY & TZ \\
\hline & 6: & 149.71 & & 640629 & 2.542583 & 1.084390 & $-0.000051)$ \\
\hline & 7: & 315.22 & & 726735 & 0.000292 & 0.000128 & $-1.314053)$ \\
\hline & 8: & 349.88 & & 848438 & 1.712748 & 0.956521 & $0.000004)$ \\
\hline & 9: & 422.49 & & 003985 & $(-1.792344$ & -0.889656 & $0.000145)$ \\
\hline 10 & 0: & 1095.70 & 25 . & 572155 & ( 4.370009 & -2.544636 & $-0.000227)$ \\
\hline 11 & 1: & 2109.71 & 378. & 724859 & ( 14.037302 & 13.478836 & $-0.000371)$ \\
\hline
\end{tabular}

\section{M06-L/ZORA-def2-TZVPP(N)/SARC-ZORA-TZVPP(Ir)}

\begin{tabular}{|c|c|c|c|c|c|c|}
\hline \multicolumn{7}{|c|}{$\operatorname{Ir}(\mathrm{N})_{2}\left(\mathrm{C}_{1},{ }^{2} \mathrm{~A}\right)$} \\
\hline \multicolumn{7}{|c|}{ Energy $=-18525.467056933678$} \\
\hline Ir & \multicolumn{2}{|c|}{-0.00000009045772} & \multicolumn{2}{|c|}{0.00000000000000} & \multicolumn{2}{|c|}{-0.62823498277550} \\
\hline $\mathrm{N}$ & \multicolumn{2}{|c|}{-1.40069500576939} & \multicolumn{2}{|c|}{0.00000000000000} & \multicolumn{2}{|c|}{0.31411766236377} \\
\hline $\mathrm{N}$ & \multicolumn{2}{|c|}{1.40069509622710} & \multicolumn{2}{|c|}{0.00000000000000} & \multicolumn{2}{|c|}{0.31411772041173} \\
\hline Mo & & freq $\left(\mathrm{cm}^{* *}-1\right)$ & $\mathrm{T} * * 2$ & $\mathrm{TX}$ & TY & $\mathrm{TZ}$ \\
\hline & 6: & 406.40 & 0.119210 & 0.005129 & -0.000348 & $-0.345230)$ \\
\hline & 7: & 875.66 & 48.032941 & $(-6.930580$ & -0.000055 & $0.000232)$ \\
\hline & 8: & 1058.48 & 3.434843 & $(0.002007$ & -0.000050 & $1.853332)$ \\
\hline
\end{tabular}

$\operatorname{Ir}(\mathrm{N})_{2}$ TS $\left(\mathrm{C}_{1},{ }^{2} \mathrm{~A}\right)$

Energy $=-18525 \cdot 372866912498$ 


\section{A. Supporting Information of Publications}

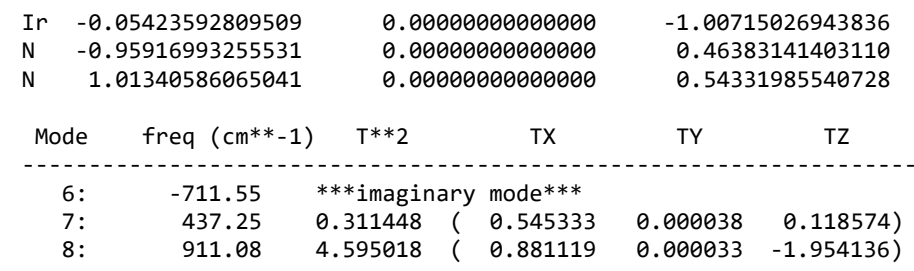

$\operatorname{Ir}(\mathrm{N})_{3}\left(\mathrm{C}_{1},{ }^{1} \mathrm{~A}\right) \mathrm{RKS}$

\begin{tabular}{|c|c|c|c|c|c|}
\hline \multicolumn{6}{|c|}{ Energy $=-18580.193789971730$} \\
\hline $\mathrm{N}$ & 7443135203633 & 1.5 & 461844965352 & 0.000 & 0094120495 \\
\hline Ir & 0003416411595 & -0.0 & 300030039386 & -0.0006 & 0282342226 \\
\hline $\mathrm{N}$ & 7443065827745 & -1.5 & 461784888252 & 0.0000 & 0094120706 \\
\hline- & 4882784619783 & -0.0 & 000030037713 & 0.000 & 0094101025 \\
\hline Mode & freq $\left(\mathrm{cm}^{* *}-1\right)$ & $T^{* * 2}$ & $T X$ & TY & $T Z$ \\
\hline 6: $1-1+(-1)(-1)$ & 126.46 & 1.535762 & $(-0.0105 t)$ & 0.007064 & $-1.239194)$ \\
\hline 7: & 193.03 & 1.102940 & -0.799239 & 0.681121 & $0.015210)$ \\
\hline 8: & 195.47 & 1.122133 & $(-0.655602$ & -0.832056 & $0.001262)$ \\
\hline 9: & 773.87 & 0.054071 & $(-0.232480$ & 0.004928 & $-0.000142)$ \\
\hline 10: & 776.07 & 0.086261 & $(-0.007649$ & -0.293597 & $0.001649)$ \\
\hline 11: & 1003.90 & 0.000467 & $(-0.020525$ & 0.006719 & $0.000341)$ \\
\hline
\end{tabular}

$\operatorname{Ir}(\mathrm{N})_{3}$ TS $\left(\mathrm{C}_{1},{ }^{1} \mathrm{~A}\right) \mathrm{RKS}$

\begin{tabular}{|c|c|c|c|c|c|}
\hline \multicolumn{6}{|c|}{ Energy $=-18580.178264754060$} \\
\hline $\mathrm{N} \quad \mathrm{e}$ & 0.97490410868930 & \multicolumn{2}{|c|}{1.68881126151210} & \multicolumn{2}{|c|}{-0.01770995567920} \\
\hline Ir & 0.13030719215327 & \multicolumn{2}{|c|}{0.22545450004475} & \multicolumn{2}{|c|}{0.00043654942375} \\
\hline e & 0.44375596989281 & \multicolumn{2}{|c|}{-1.53243636509665} & \multicolumn{2}{|c|}{0.00856198738820} \\
\hline & -1.54896627073538 & \multicolumn{2}{|c|}{-0.38182939646019} & \multicolumn{2}{|c|}{0.00871141886726} \\
\hline Mode & freq $(\mathrm{cm} * *-1)$ & $T^{* * 2} 2$ & TX & TY & $T Z$ \\
\hline 6 & -306.08 & $* * *$ imagi & ary mode*** & & \\
\hline 7 & 105.94 & 2.400416 & $(-0.082091$ & -0.019473 & $-1.547029)$ \\
\hline 8 & 184.62 & 8.962498 & $(-2.605275$ & 1.474798 & $-0.003351)$ \\
\hline 9 & 819.45 & 0.035455 & $(-0.030187$ & 0.185858 & $-0.000671)$ \\
\hline 10 & 869.51 & 38.409588 & ( 3.103273 & 5.364424 & $-0.047283)$ \\
\hline 11 & 1023.99 & 13.526293 & $(-1.835324$ & -3.186866 & $0.041968)$ \\
\hline
\end{tabular}

\section{$\operatorname{ccSD}(T) /$ aug-cc-pVTZ(-PP)}

\section{$\operatorname{IrN}\left(\mathrm{C}_{2 \mathrm{v}},{ }^{1} \mathrm{~A}_{1}\right)$}

$\begin{array}{lccr}\text { Energy } & = & -158.596318228943 & \\ \text { Ir } & 0.00000 & 0.00000 & 0.10821 \\ \mathrm{~N} & 0.00000 & 0.00000 & -1.49116\end{array}$

\begin{tabular}{|c|c|c|c|}
\hline $\begin{array}{l}\text { Irreducible } \\
\text { Representation }\end{array}$ & $\begin{array}{l}\text { Harmonic } \\
\text { Frequency }\end{array}$ & $\begin{array}{l}\text { Infrared } \\
\text { Intensity }\end{array}$ & Type \\
\hline-- & $(\mathrm{cm}-1)$ & $(\mathrm{km} / \mathrm{mol})$ & \\
\hline SG+ & 1195.3928 & 37.7081 & VIBRATION \\
\hline
\end{tabular}

$\operatorname{Ir}\left(\mathrm{N}_{2}\right)\left(\mathrm{C}_{2 \mathrm{v}},{ }^{2} \mathrm{~A}_{2}\right)$

$\begin{array}{llrr}\text { Energy } & =-213.296141642281 & \\ \text { Ir } & 0.000000 & 0.000000 & 0.300969 \\ \mathrm{~N} & 0.000000 & 0.000000 & -1.511567 \\ \mathrm{~N} & 0.000000 & 0.000000 & -2.635797\end{array}$

$\operatorname{Ir}\left({ }^{14} \mathrm{~N}_{2}\right)$

Normal Coordinate Analysis

$\begin{array}{cccc}\begin{array}{c}\text { Irreducible } \\ \text { Representation }\end{array} & \begin{array}{l}\text { Harmonic } \\ \text { Frequency }\end{array} & \begin{array}{l}\text { Infrared } \\ \text { Intensity }\end{array} & \text { Type } \\ & (\mathrm{cm}-1) & (\mathrm{km} / \mathrm{mol}) & \\ \text { PI } & 377.1830 & 2.7636 & \text { VIBRATION } \\ \text { PI } & 377.1830 & 2.7636 & \text { VIBRATION } \\ \text { SG+ } & 548.5365 & 29.0796 & \text { VIBRATION } \\ \text { SG+ } & 2140.2401 & 462.6555 & \text { VIBRATION }\end{array}$




\begin{tabular}{|c|c|c|c|}
\hline \multicolumn{4}{|c|}{ Normal Coordinate Analysis } \\
\hline $\begin{array}{l}\text { Irreducible } \\
\text { Representation }\end{array}$ & $\begin{array}{l}\text { Harmonic } \\
\text { Frequency }\end{array}$ & $\begin{array}{l}\text { Infrared } \\
\text { Intensity }\end{array}$ & Type \\
\hline & $(\mathrm{cm}-1)$ & $(\mathrm{km} / \mathrm{mol})$ & \\
\hline PI & 364.5371 & 2.5891 & VIBRATION \\
\hline PI & 364.5371 & 2.5891 & VIBRATION \\
\hline SG+ & 532.5155 & 27.4014 & VIBRATION \\
\hline SG+ & 2067.8968 & 431.9740 & VIBRATION \\
\hline
\end{tabular}

$\operatorname{Ir}\left(\mathbf{N}_{2}\right)^{-}\left(\mathrm{C}_{2 \mathrm{v}},{ }^{1} \mathrm{~A}_{1}\right)$

$\begin{array}{cccr}\text { Energy } & =-213.357526833504 & \\ \text { Ir } & 0.000000 & 0.000000 & -0.294152 \\ \mathrm{~N} & 0.000000 & 0.000000 & 1.449982 \\ \mathrm{~N} & 0.000000 & 0.000000 & 2.603441\end{array}$

$\operatorname{Ir}\left({ }^{14} \mathrm{~N}_{2}\right)$

Normal Coordinate Analysis

$\begin{array}{cccc}\begin{array}{c}\text { Irreducible } \\ \text { Representation }\end{array} & \begin{array}{l}\text { Harmonic } \\ \text { Frequency }\end{array} & \begin{array}{l}\text { Infrared } \\ \text { Intensity }\end{array} & \text { Type } \\ & (\mathrm{cm}-1) & (\mathrm{km} / \mathrm{mol}) & \\ \mathrm{PI} & 434.0213 & 3.3179 & \text { VIBRATION } \\ \mathrm{PI} & 434.0213 & 3.3179 & \text { VIBRATION } \\ \text { SG+ } & 648.4311 & 11.7478 & \text { VIBRATION } \\ \text { SG+ } & 1962.7107 & 1017.9657 & \text { VIBRATION } \\ & & & \end{array}$

\begin{tabular}{|c|c|c|c|}
\hline \multicolumn{4}{|c|}{ Normal Coordinate Analysis } \\
\hline $\begin{array}{l}\text { Irreducible } \\
\text { Representation }\end{array}$ & $\begin{array}{l}\text { Harmonic } \\
\text { Frequency }\end{array}$ & $\begin{array}{l}\text { Infrared } \\
\text { Intensity }\end{array}$ & Type \\
\hline & $(\mathrm{cm}-1)$ & $(\mathrm{km} / \mathrm{mol})$ & \\
\hline PI & 419.4812 & 3.1143 & VIBRATION \\
\hline PI & 419.4812 & 3.1143 & VIBRATION \\
\hline SG+ & 629.4805 & 11.0542 & VIBRATION \\
\hline SG+ & 1896.4047 & 950.5014 & VIBRATION \\
\hline
\end{tabular}

$\operatorname{Ir}\left(\mathrm{N}_{2}\right)^{+}\left(\mathrm{C}_{2 \mathrm{v}},{ }^{3} \mathrm{~A}_{1}\right)$

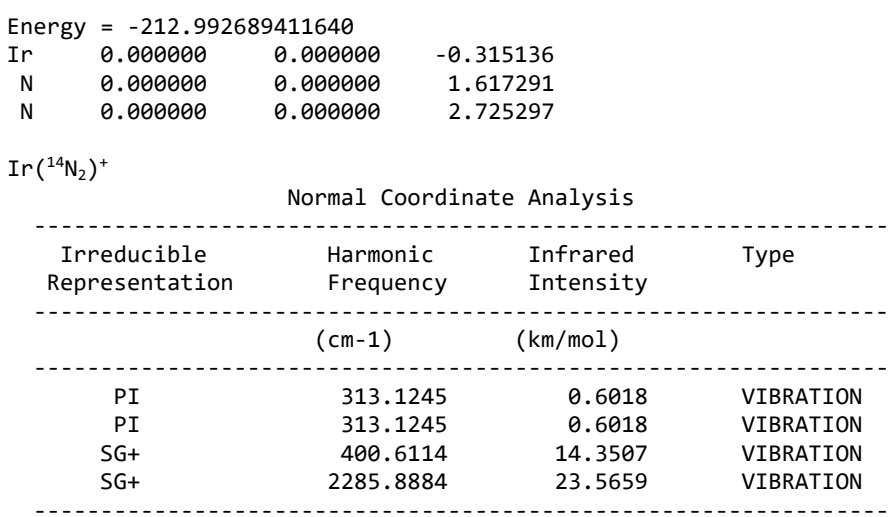

$\operatorname{Ir}\left({ }^{15} \mathrm{~N}_{2}\right)^{+}$

Normal Coordinate Analysis

$\begin{array}{cccc}\begin{array}{c}\text { Irreducible } \\ \text { Representation }\end{array} & \begin{array}{l}\text { Harmonic } \\ \text { Frequency }\end{array} & \begin{array}{l}\text { Infrared } \\ \text { Intensity }\end{array} & \text { Type } \\ & (\mathrm{cm}-1) & (\mathrm{km} / \mathrm{mol}) & \\ \text { PI } & 302.6168 & 0.5625 & \text { VIBRATION } \\ \text { PI } & 302.6168 & 0.5625 & \text { VIBRATION } \\ \text { SG+ } & 388.9122 & 13.5247 & \text { VIBRATION } \\ \text { SG+ } & 2208.6143 & 22.0039 & \text { VIBRATION }\end{array}$


$\operatorname{IrNNIr}\left(\mathrm{D}_{2 \mathrm{~h},}{ }^{3} \mathrm{~B}_{1 \mathrm{u}}\right)$

$\begin{array}{ccrr}\text { Energy } & =-317.213761825221 & \\ \mathrm{~N} & 0.000000 & 0.000000 & 0.569367 \\ \mathrm{~N} & 0.000000 & 0.000000 & -0.569367 \\ \text { Ir } & 0.000000 & 0.000000 & -2.385426 \\ \text { Ir } & 0.000000 & 0.000000 & 2.385426\end{array}$

$\operatorname{Ir}^{14} \mathrm{~N}^{14} \mathrm{NIr}$

Normal Coordinate Analysis

\begin{tabular}{|c|c|c|c|}
\hline $\begin{array}{l}\text { Irreducible } \\
\text { Representation }\end{array}$ & $\begin{array}{l}\text { Harmonic } \\
\text { Frequency }\end{array}$ & $\begin{array}{l}\text { Infrared } \\
\text { Intensity }\end{array}$ & Type \\
\hline & $(\mathrm{cm}-1)$ & $(\mathrm{km} / \mathrm{mol})$ & \\
\hline PIu & 115.1277 & 5.7702 & VIBRATION \\
\hline PIu & 115.1277 & 5.7702 & VIBRATION \\
\hline SGg+ & 194.6052 & 0.0000 & VIBRATION \\
\hline PIg & 345.5060 & 0.0000 & VIBRATION \\
\hline PIg & 345.5060 & 0.0000 & VIBRATION \\
\hline SGu- & 729.1069 & 361.6940 & VIBRATION \\
\hline SGg+ & 2102.6390 & 0.0000 & VIBRATION \\
\hline
\end{tabular}

$\mathrm{Ir}^{15} \mathrm{~N}^{15} \mathrm{NIr}$

Normal Coordinate Analysis

\begin{tabular}{|c|c|c|c|}
\hline $\begin{array}{l}\text { Irreducible } \\
\text { Representation }\end{array}$ & $\begin{array}{l}\text { Harmonic } \\
\text { Frequency }\end{array}$ & $\begin{array}{l}\text { Infrared } \\
\text { Intensity }\end{array}$ & Type \\
\hline & $(\mathrm{cm}-1)$ & $(\mathrm{km} / \mathrm{mol})$ & \\
\hline PIu & 111.5034 & 5.4126 & VIBRATION \\
\hline PIu & 111.5034 & 5.4126 & VIBRATION \\
\hline SGg+ & 194.6019 & 0.0000 & VIBRATION \\
\hline PIg & 333.8749 & 0.0000 & VIBRATION \\
\hline PIg & 333.8749 & 0.0000 & VIBRATION \\
\hline SGu- & 706.1538 & 339.2793 & VIBRATION \\
\hline SGg+ & 2031.5923 & 0.0000 & VIBRATION \\
\hline
\end{tabular}

$\operatorname{Ir}^{14} \mathrm{~N}^{15} \mathrm{NIr}\left(\mathrm{C}_{2 \mathrm{v}},{ }^{3} \mathrm{~A}_{1}\right)$

Normal Coordinate Analysis

$\begin{array}{cccc}\begin{array}{c}\text { Irreducible } \\ \text { Representation }\end{array} & \begin{array}{c}\text { Harmonic } \\ \text { Frequency }\end{array} & \begin{array}{l}\text { Infrared } \\ \text { Intensity }\end{array} & \text { Type } \\ & (\mathrm{cm}-1) & (\mathrm{km} / \mathrm{mol}) & \\ \text { PI } & 113.2602 & 5.5836 & \text { VIBRATION } \\ \text { PI } & 113.2602 & 5.5836 & \text { VIBRATION } \\ \text { SG+ } & 194.6035 & 0.0000 & \text { VIBRATION } \\ \text { PI } & 339.7635 & 0.0077 & \text { VIBRATION } \\ \text { PI } & 339.7635 & 0.0077 & \text { VIBRATION } \\ \text { SG+ } & 717.2738 & 349.9890 & \text { VIBRATION } \\ \text { SG+ } & 2067.5765 & 0.4977 & \text { VIBRATION } \\ & & & \end{array}$


A.3. A Cornucopia of Iridium Nitrogen Compounds Produced from Laser-Ablated Iridium Atoms and Dinitrogen

\section{References}

[1] A. Citra, L. Andrews, J. Phys. Chem. A 2000, 104, 1152-1161.

[2] X. Wang, L. Andrews, J. Phys. Chem. A 2002, 106, 2457-2464.

[3] W. Klotzbuecher, G. A. Ozin, J. Am. Chem. Soc. 1975, 97, 2672-2675.

[4] A. Citra, X. Wang, W. D. Bare, L. Andrews, J. Phys. Chem. A 2001, 105, 7799-7811. 